
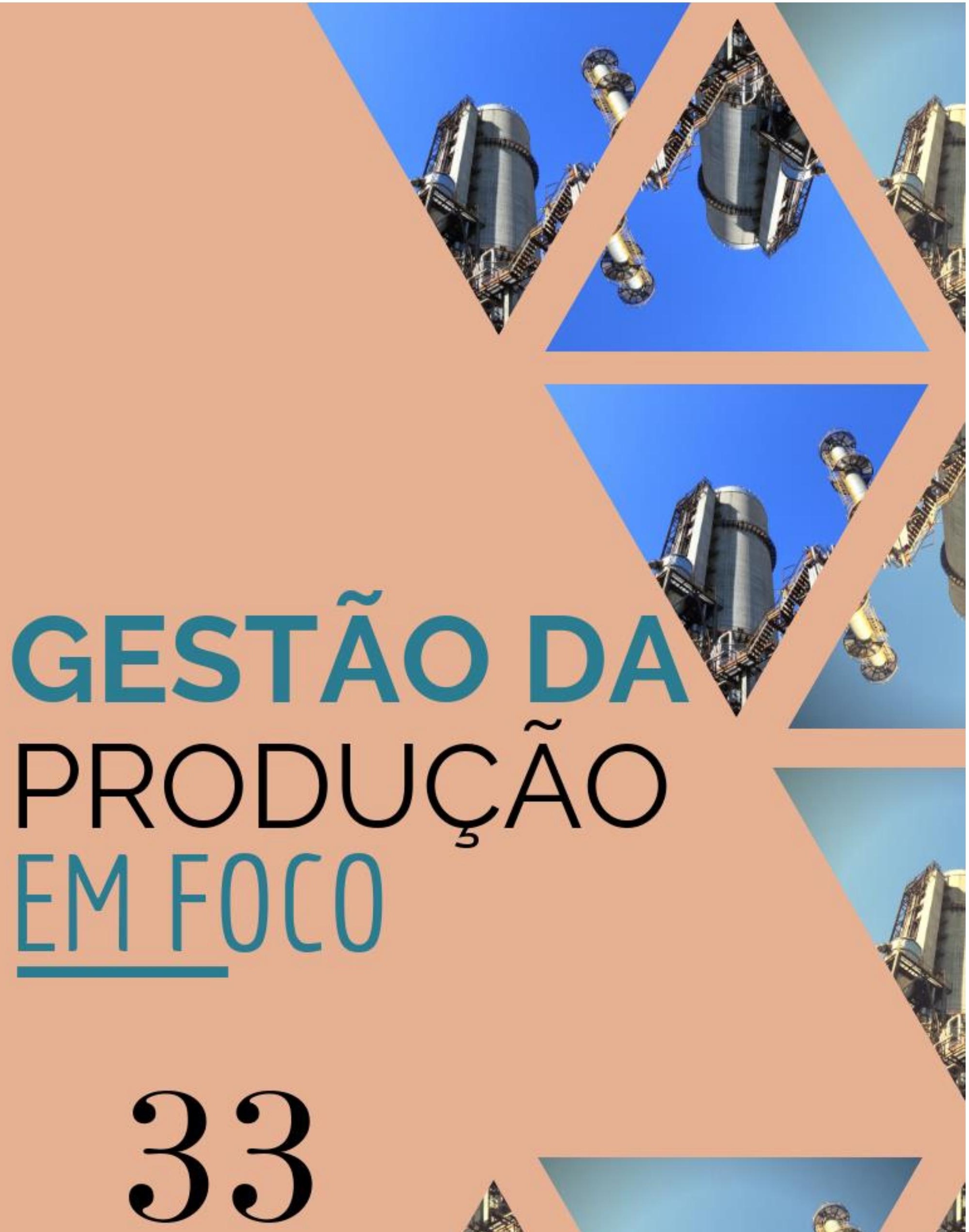

$\prec$ Editora Poisson

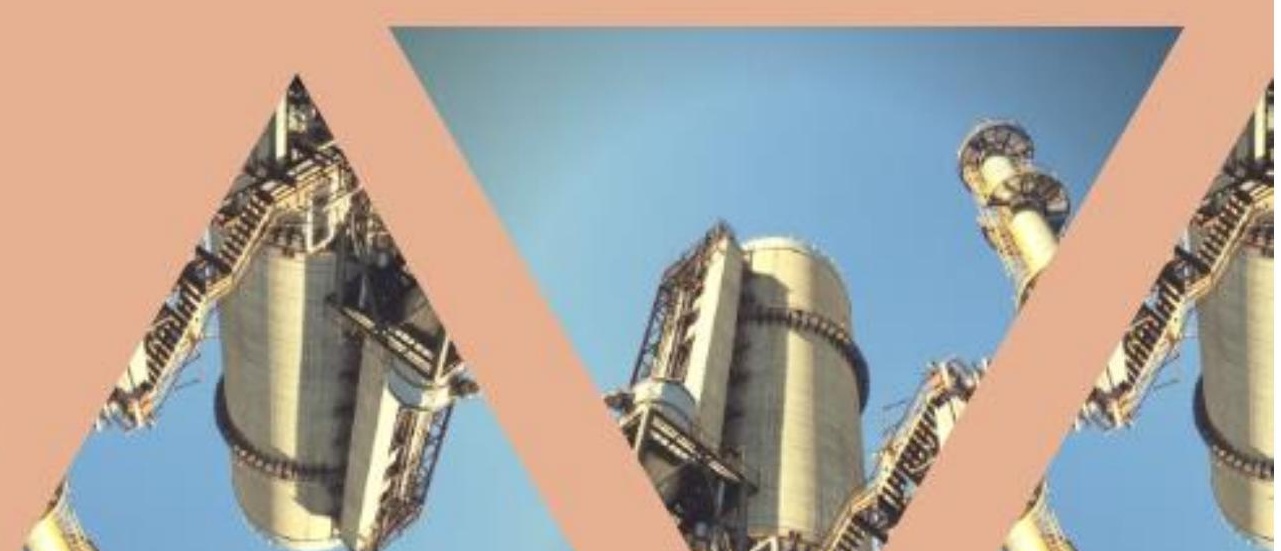


Editora Poisson

\title{
Gestão da Produção em Foco Volume 33
}

\author{
1a Edição
}

Belo Horizonte

Poisson

2019 
Editor Chefe: Dr. Darly Fernando Andrade

\section{Conselho Editorial}

Dr. Antônio Artur de Souza - Universidade Federal de Minas Gerais

Ms. Davilson Eduardo Andrade

Dr. José Eduardo Ferreira Lopes - Universidade Federal de Uberlândia

Dr. Otaviano Francisco Neves - Pontifícia Universidade Católica de Minas Gerais

Dr. Luiz Cláudio de Lima - Universidade FUMEC

Dr. Nelson Ferreira Filho - Faculdades Kennedy

Ms. Valdiney Alves de Oliveira - Universidade Federal de Uberlândia

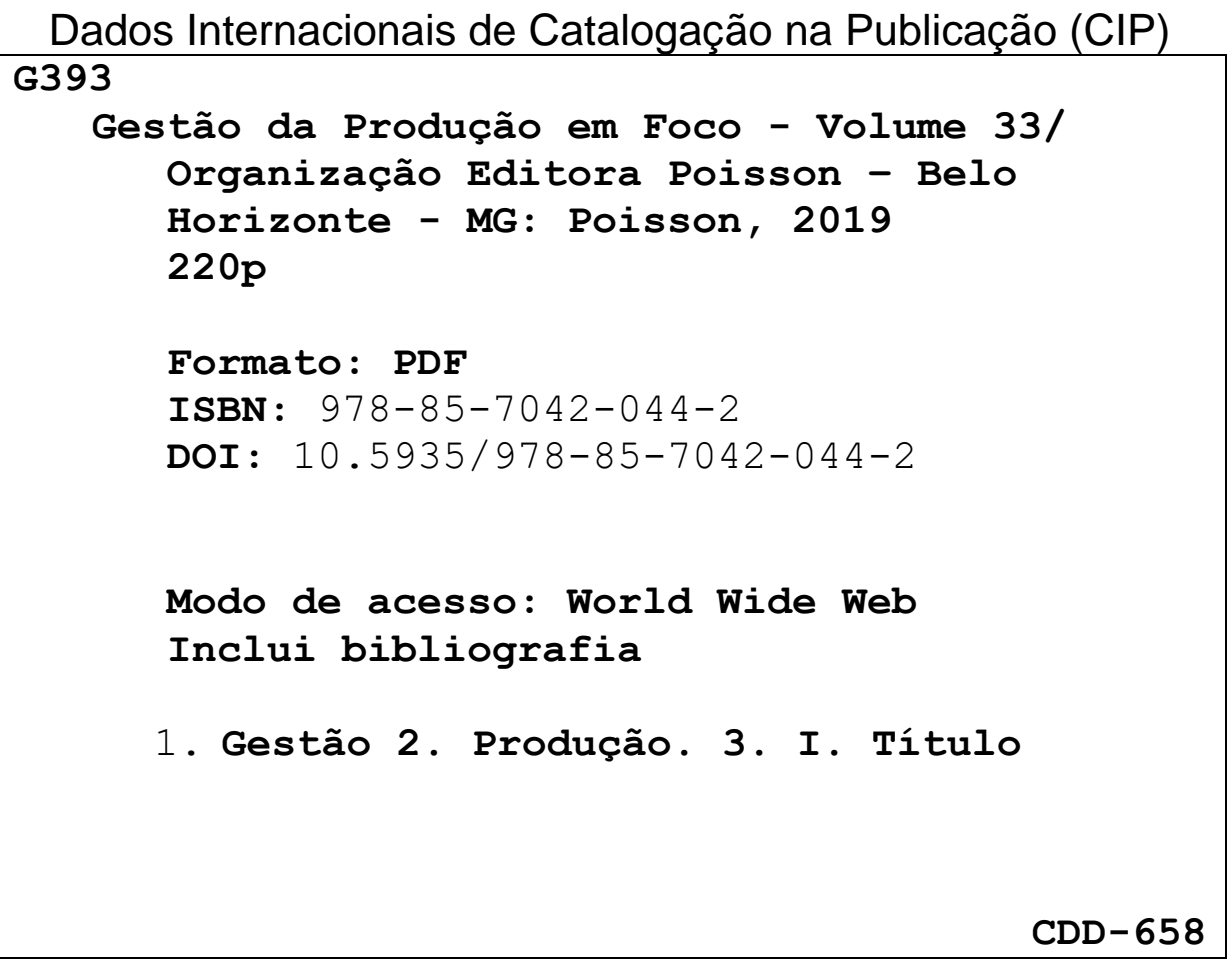

O conteúdo dos artigos e seus dados em sua forma, correção e confiabilidade são de responsabilidade exclusiva dos seus respectivos autores.

Baixe outros títulos gratuitamente em www.poisson.com.br

contato@poisson.com.br 


\section{SUMÁRIO}

Capítulo 1: Estudo de implantação de um sistema de gerenciamento de transporte em uma empresa privada de distribuição de energia .

André Cristiano Silva Melo, Bernardo Moreira Vergara, Kauê Jucá Jardim de Oliveira, Rafaela Francisca Moreira Barbosa, Stefanie Brabo Dantas

Capítulo 2: Influência do transporte público na educação: Um estudo em uma instituição de ensino no município de São João da Barra 16

Fabiana Nunes Cabral Monteiro, Fernando Cerutti Aguiar , Bruno Rabbi, Denise Cristina de Oliveira Nascimento, Geórgia Regina Rodrigues Gomes

Capítulo 3: A importância do controle de estoque no comércio varejista: Estudo de caso no supermercado Vida Nova em Aliança-PE 24

Bruno Cezar de Farias, Michele Bezerra Saito

Capítulo 4: Localização estratégica de um centro de distribuição para redução dos custos operacionais: Uma aplicação do Método do Centro de Gravidade ......... 33

Thayane Nascimento de Azevedo, Deborah Porto de Almeida Cardoso, Cássia Cristina Costa do Carmo, Ruy Gomes da Silva

Capítulo 5: O problema de localização de máxima cobertura: Abordagem multiobjetivo clássica

Helton Cristiano Gomes, Cristiano Luís Turbino de França e Silva, Ruan Carlos Silva Menezes Pinheiro

Capítulo 6: Análise da confiabilidade na pontualidade de voos de algumas empresas brasileiras utilizando Cadeias de Markov.

Elyelton Cesar de Souza Lima, Amanda Ribeiro Ganske, Christiane Wenck Nogueira Fernandes, Luisa Mafra de Oliveira, Silvia Lopes de Sena Taglialenha

Capítulo 7: A produção científica mundial sobre cadeias de suprimentos ágeis publicada em periódicos indexados pela Scopus e Web of Science: Um estudo bibliométrico.

Thales Botelho de Sousa, Carlos Eduardo Pinto, Weidy Luana Rocha Gervaz, Willian Victor Silva Borba Cordeiro, Cássio Germano Lara de Souza, Igor Fonseca da Rocha

Capítulo 8: O resultado no planejamento da produção devido à associação das camadas de controle avançado e de Scheduling na indústria 


\section{SUMÁRIO}

Capítulo 9: Reestruturação do controle de estoque através dos princípios do Lean Thinking 80

Pablo Costa, Andrei Bonamigo

Capítulo 10: PCM - Planejamento e controle de manutenção, estudo de melhoria em uma empresa do ramo agropecuário.

Isabela Muckenberger Saddi, Juliana Pardinho dos Santos, Rogério Francisco de Oliveira, Luiz Felipe Cougo

Capítulo 11: Aplicação do RCM (Realibility Centred in Maintenance) na redução de falhas: Estudo de caso em uma fábrica de pregos 104

Márcio Iscold Dutra

Capítulo 12: Análise do desperdício em um canteiro de obras na cidade de Araguaína-TO. 121

Jhony Carlos Lucena Cardoso, Denes de Paula Alves Sousa, Mariana Matos Arantes

Capítulo 13: Elaboração de reator aeróbio em escala laboratorial como póstratamento de efluente sanitário de restaurante universitário.

Beatriz Fernanda Crotti, Amanda Silva Nunes, Dioni Fraisoli, Micheli Maria de Oliveira, Isabela Bruna de Tavares Machado Bolonhesi

Capítulo 14: Utilização da Soft Systems Methodology em uma indústria de bebidas no Maranhão 138

Eduardo Mendonça Pinheiro, Ruan Carlos Corrêa Mendes, Herbeth Sandro Malheiros Bezerra, Clemilton Oliveira de Sousa, Elon Vieira Lima, Ana Célia Silva Vieira

Capítulo 15: Execução do projeto da construção de uma ponte de palitos de picolés utilizando o gerenciamento de projeto e o guia PMBOK

Rudson Lourival Oliveira da Silva, Priscila de Oliveira Serafini, Deborah Deah Assis Carneiro

Capítulo 16: Análise Preliminar de Risco - APR - no ambiente laboral do setor de marmoraria: Estudo de caso no município de João Pessoa - PB 155

Marcella Renata Silva de Araújo Sales, Denise Dantas Muniz, Eduardo Braga Costa Santos, Renata Dantas Muniz de Queiroz 


\section{SUMÁRIO}

Capítulo 17: Projeto do trabalho em um torno CNC: Da análise à sugestão de adequações das condições de saúde e segurança.

Joele dos Santos Marques, Antônio Felipe Alves Machado, Juliana Machion Gonçalves, Fábio Morais Borges

Capítulo 18: Gerenciamento compacto de riscos em projetos: Priorização do gerenciamento de riscos centrado nas atividades críticas

Luciano Azevedo de Souza, Celso Souza de Moraes Junior

Capítulo 19: Uma visão geral da internet de veículos

Thales Botelho de Sousa, Ernani José Fortunato Lisbôa Enke, Daiane Ferreira Kogiski, Larissa

Carvalho Ferreira Reverte, Raphany Cordeiro Hahn, Marcos Vinícius de Freitas Santos

Capítulo 20: Análise da gamificação no ensino em engenharia de produção: Um estudo sobre a aplicação do Lean Board Game

Luís Henrique Rodrigues, Carlos Roberto Franzini Filho, Thays Aparecida Vendramin Delecrodio, Alexandre Tavares Soares, Jane Luchtenberg Vieira

Autores 


\section{Capítulo 1}

\section{ESTUDO DE IMPLANTACÃO DE UM SISTEMA DE GERENCIAMENTO DE TRANSPORTE EM UMA EMPRESA PRIVADA DE DISTRIBUIÇÃO DE ENERGIA}

\section{André Cristiano Silva Melo}

Bernardo Moreira Vergara

Kauê Jucá Jardim de Oliveira

Rafaela Francisca Moreira Barbosa

Stefanie Brabo Dantas

Resumo: Este artigo analisou o aumento no desempenho logístico de uma distribuidora de energia a partir da implantação de um sistema de gerenciamento de transporte. Atualmente a empresa apresenta pouca consistência no fluxo de informações com o transportador, por consequência tendo pouco controle dos fretes contratados por conta da demora do feedback na realização dos mesmos. Além do mais, a utilização de conhecimentos empíricos na consolidação de carga causa baixa performance nos seus transportes. A metodologia utilizada foi uma pesquisa exploratória, tendo os dados necessários para a pesquisa sendo coletados in loco, a partir da análise do cenário atual de monitoramento de transportes da empresa, verificando quais os requisitos para a implantação do TMS e qual sua viabilidade operacional. Dentre os resultados obtidos pelo estudo, destacam-se as principais vantagens oferecidas pela utilização desse sistema, como maior controle da frota, fornecimento de relatórios de performance, programação de entregas e planejamento de cargas.

Palavras-chave: sistema de gerenciamento de transporte, indústria de eletricidade, componentes logísticos. 


\section{INTRODUÇÃO}

O termo "indústria" representa o conjunto de atividades que visam à manipulação de matérias-primas para a produção de bens de consumo. No caso da indústria de eletricidade, produz-se energia elétrica, um bem impalpável utilizado de forma indireta, seja para produzir luz, movimento, calor ou qualquer outra transformação energética (ABRADEE, 2017). Este setor da indústria é dividido em três segmentos: geração, transmissão e distribuição. A geração, gera a energia elétrica, a partir de outras formas de energia, a transmissão promove a transferência dessa energia desde as geradoras e as entrega às distribuidoras (distribuição) que, por sua vez, transfere a energia elétrica ao usuário final (ANEEL, 2017). No contexto apresentado neste estudo, tratou-se apenas do setor de distribuição que abastece, de forma fracionada, consumidores de pequeno e médio porte, incluindo residências, pequenos comércios e pequenas indústrias.

Atualmente, o setor elétrico pode ser caracterizado por um crescente e novo paradigma de operação dos sistemas elétricos, chamado Geração Distribuidora, que vem descentralizando a geração de energia elétrica em diversos países no mundo ao possibilitar o surgimento de pequenos geradores elétricos, dentre eles os geradores de fontes renováveis. As redes de distribuição passaram a ter o papel de protagonista na operação do sistema, contrabalanceando os efeitos intermitentes de pequenos geradores elétricos e aumentando a qualidade do fornecimento de energia (ABRADEE, 2017). Quando a conta chega ao consumidor, ele precisa pagar pela compra da energia (custos do gerador), pela sua transmissão (custos da transmissora) e distribuição (serviços prestados pela distribuidora), além de encargos setoriais e tributos (ANEEL, 2017).

No Brasil, o segmento de distribuição é composto por 63 concessionárias, responsáveis pela administração e operação de linhas abaixo de 230 mil Volts, que têm nas redes de média e baixa tensão os seus principais pontos de atuação. Já o estado do Pará, com mais de 1,2 milhão de Km2, representando quase $15 \%$ do território nacional, concentra cerca de $34 \%$ de toda a extensão da bacia amazônica, o que cria grandes entraves e peculiaridades logísticas, dificultando também o seu controle. Seu potencial hidrelétrico é avaliado em mais de
61 mil MW, estando distribuído em nove grandes bacias, destacando-se a do Rio Tocantins, onde implantou-se a Usina Hidrelétrica de Tucuruí, inaugurada em 1984. No Pará, há em torno de 2 milhões de unidades consumidoras, sendo atendidas pela concessionária que possui a concessão de distribuição dentro do estado.

A partir de 1995, a tarifa de energia elétrica deixou de ser única no país e passou a ser fixada por concessionária, dando início à regulação por incentivos, onde as distribuidoras são incentivadas a se tornarem continuamente eficientes. As revisões tarifárias e reajustes tarifários passaram, então, a considerar as características de cada área de concessão, tais como o número de consumidores, a densidade do mercado (quantidade de energia distribuída a partir de uma determinada infraestrutura), os quilômetros da rede de distribuição de cada empresa, o custo da energia comprada pelas distribuidoras, dentre outras. O segmento de distribuição de energia elétrica precisa de investimentos em soluções tecnológicas que otimizem os seus serviços e que possibilitem à concessionária a busca por mais incentivos.

Este artigo teve por objetivo propor a implantação de um Sistema de Gerenciamento de Transporte (TMS Transportation Management System) para o transporte de materiais utilizados nas obras de expansão da rede de distribuição, que atualmente é executado por empresas terceirizadas. Após análise da situação atual da empresa, pode-se indicar as melhorias que seriam possíveis graças a implantação da tecnologia TMS tanto no nível operacional, quanto na gestão de toda a cadeia de distribuição de seus insumos.

Dessa maneira, o artigo foi segmentado em 5 partes, incluindo essa introdução. Em sequência, foi proposta uma revisão bibliográfica, que oferece todo o suporte teórico necessário para embasar e entender este estudo, posteriormente foi apresentado o método empregado ao desenvolvimento dessa pesquisa para, então, na seção a seguir caracterizar o fluxo logístico dentro da empresa, indicando como funciona atualmente a gestão dos transportes, e propor a implantação da tecnologia TMS, evidenciando as potenciais vantagens logísticas advindas da sua implantação. Por último, conclui-se a pesquisa com sugestões à empresa e proposta de pesquisas futuras. 


\section{REVISÃO DA LITERATURA}

\subsection{COMPONENTES OPERACIONAIS}

LOGÍSTICOS

Logística é o processo de planejamento, implementação e controle do fluxo eficiente e economicamente eficaz de matérias-primas, estoques em processo, produtos acabados e informações relativas desde o ponto de origem até o ponto de consumo, com 0 propósito de atender às exigências dos clientes (NOVAES, 2007).

Segundo Bowersox et al. (2014), é responsabilidade da logística projetar e administrar sistemas para o controle, transporte e localização geográfica dos estoques de insumos, produtos ainda nas fases de processo, além de produtos acabados, objetivando o custo mínimo total. Esta finalidade atinge segmentos financeiros e humanos participantes da logística.

Para geração de valor agregado, a logística necessita funcionar buscando a eficiência e a eficácia. Sendo assim, pode ser caracterizada a partir dos seus componentes logísticos, sendo divididos em operacionais e estratégicos.

Segundo Ballou (2006), os componentes operacionais se caracterizam em instalações, estoques, transportes, informações. De acordo com Novaes (2007) as instalações oferecem espaços destinados a manter mercadorias, até a sua transferência para o atender o próximo "elo" da cadeia, provendo facilidades para descarga dos produtos, transporte interno e carregamento dos veículos de distribuição.

Para Corrêa (2004), os estoques são formados pelo acúmulo de recursos materiais entre etapas de um processo de transformação, entre eles apresentando: estoques de matérias-primas e suprimentos, estoques em processo, estoque de bens acabados e estoque de materiais para manutenção, reparo, consumo e movimentação. $O$ transporte permite o melhor fluxo de insumo, bens em processo e bens acabados (estoques) entre as instalações, conseguindo, com isso, uma agregação de valor a partir da localização e distribuição eficiente eficaz dos estoques.

A informação sempre foi um elemento de vital importância na logística, no entanto, seu papel atualmente tem sido muito mais evidente na melhoria da estratégia competitiva das empresas. A transferência e o tratamento das informações, hoje em dia, permitem melhor gerenciamento das organizações, além da prestação de um serviço de maior qualidade (SALLES, 2016).

\subsection{A TECNOLOGIA DE INFORMAÇÃO NA LOGÍSTICA}

O transporte de matérias-primas e/ou bens acabados representa a maior parcela dos custos logísticos na maioria das empresas. A atividade de transporte representam, em média, $60 \%$ das despesas logísticas da empresa, significando de $4 \%$ a $25 \%$ de seu faturamento bruto, dependendo de seu ramo de atuação (BALLOU, 2001). O avanço nas tecnologias de equipamentos de transporte e iniciativas, tais como a intermodalidade, a multimodalidade (integração de vários modais de transporte) e a terceirização desta atividade por operadores logísticos (prestadores de serviços logísticos), têm sido importantes para a redução de custos (FESTA, 2012).

No Brasil, uma das principais barreiras ao desenvolvimento da logística e da multimodalidade está relacionada às deficiências na infraestrutura de transportes. Com a expressiva participação, próxima a $60 \%$, na matriz dos transportes de cargas do Brasil, seguida por cerca de $14 \%$ da ferrovia, o transporte rodoviário é o maior responsável pela movimentação brasileira de cargas (FERREIRA, 2005).

O uso de Tecnologias de Informação e Comunicação (TICs) na gestão de atividades logísticas provoca mudanças nos processos, com melhoria na utilização dos ativos, gerando maior produtividade e consistência nas operações, reduzindo desperdícios e tempos de entrega. Além da inovação em processos, o uso de TICs muda a forma de gerenciamento dos negócios, facilitando planejamentos e programações de abastecimento de componentes produtivos e na distribuição dos produtos, para atender às necessidades de produção e vendas. Tal coordenação é sempre procurada no gerenciamento da cadeia de suprimentos.

\subsection{SISTEMA DE GERENCIAMENTO DE TRANSPORTES (TRANSPORTATION MANAGEMENT SYSTEM)}


Segundo Festa e Assumpção (2012), no momento em que dados ou informações são avaliados em nível estratégico, usando como base de análise o apoio de um sistema para gerenciamento da cadeia de suprimento, este abrangendo todos os processos que compõem atividades de produção e distribuição. Enquanto isso, em um nível tático, a Tecnologia da Informação (TI) deve fornecer dados e informações que apoiem as decisões de projeto, programação de rede de instalações e controle das operações, sejam logísticas ou produtivas.

O TMS pode ser considerado um módulo de um sistema de gerenciamento da cadeia de suprimento, servindo às decisões no nível operacional/transacional, além de subsidiar as decisões para negociação de contratos e controle gerencial e de capacidade das instalações e de projeto de rede (SILVA, 2009). Deste modo, o TMS apoia o gerenciamento da cadeia de suprimentos, em seus níveis tático e operacional.

No mercado, há várias soluções comerciais de TMS, podendo apresentar módulos específicos para cada situação. Segundo Marques (2002), as principais funcionalidades de um TMS podem ser classificadas da seguinte forma: planejamento e execução; monitoramento e controle; apoio à negociação e auditoria de frete, como mostrado no Quadro

QUADRO 1: Funcionalidades de um TMS

\begin{tabular}{|c|c|}
\hline Categoria & Funcionalidade \\
\hline \multirow{3}{*}{ Monitoramento e Controle } & Monitoramento de custos (valor orçado vs. valor gasto) e serviço \\
\hline & Rastreamento das cargas \\
\hline & Controle e nível de utilização da frota \\
\hline \multirow{4}{*}{ Planejamento e Execução } & Dimensionamento da frota \\
\hline & $\begin{array}{l}\text { Roteirização (Programação dos veículos e determinação de rotas em } \\
\text { um ambiente dinâmico) }\end{array}$ \\
\hline & Alocação automática de carga por transportadora \\
\hline & Consolidação de carga \\
\hline \multirow{2}{*}{ Planejamento e Execução } & Frete retorno \\
\hline & Emissão de documentos de embarque \\
\hline \multirow{2}{*}{$\begin{array}{l}\text { Apoio à Negociação e Auditoria de } \\
\text { Frete }\end{array}$} & $\begin{array}{l}\text { Checagem dos valores cobrados e pagos pelos serviços de } \\
\text { transportes }\end{array}$ \\
\hline & Gerar relatórios para auxiliar nas negociações \\
\hline
\end{tabular}

Fonte: Marques (2002).

Os módulos operacionais auxiliam às tomadas de decisões que são baseadas em informações transacionais, com elevado nível de detalhamento, oferecendo um bom suporte ao controle gerencial das operações. O TMS pode ser considerado um desses módulos operacionais dentro de um sistema de gerenciamento da cadeia de suprimentos, participando das decisões no nível operacional e tático, além de subsidiar a determinação de contratos e controle gerencial.

\section{MÉTODO DE PESQUISA}

Este estudo apresenta os impactos da implantação de um sistema de gerenciamento de transportes de materiais em uma empresa privada de distribuição de energia, a partir de pesquisas que exponham a situação atual da concessionária de energia considerada, quais tecnologias a empresa poderia implantar, quais suas vantagens e seus requisitos para que funcione adequadamente.

A metodologia utilizada no referido trabalho foi uma pesquisa Exploratória, pela necessidade de assinalar os elementos teóricos necessários que favorecem a compreensão de todos os conceitos integrantes do estudo. Além do que, utilizou-se como procedimento 
técnico um Estudo de caso, tendo em vista o caráter qualitativo.

Para tal, realizou-se uma identificação na literatura de conceitos utilizados neste artigo, tendo assim o apoio teórico sobre todos os aspectos envolvidos. Além disso, procurou-se obter dados sobre a atual gestão de transportes dentro da empresa, a partir de observações in loco, sendo acompanhado pelo gestor do departamento, definindo como funciona a administração dos fretes contratados para o transporte de materiais, além do fluxo de informações tanto internamente, quanto entre a empresa e seu transportador contratado.

Com os dados recolhidos, foram analisados os recursos empregados para essa gestão e como estes são alocados aos componentes logísticos. Assim, primeiramente foi analisada e apresentado um diagnóstico da situação atual na qual a empresa se encontra, sendo proposta a implantação de um TMS para a possíveis melhorias na gestão de transporte, indicando os benefícios sobre os componentes logísticos que isso acarretaria.

\section{RESULTADOS E DISCUSSÕES}

\subsection{CARACTERIZAÇÃO DA EMPRESA}

No setor de distribuição de energia do estado do Pará, a empresa em estudo atua desde 1962, surgindo com o objetivo de eletrificar todo o estado. É constituída por 5 regionais dentro do território do Pará, com sua sede administrativa e centro de distribuição (CD) localizados na cidade de Belém. É na sede administrativa que ocorre o gerenciamento de todos os pontos de obras e realização dos projetos de expansão e manutenção da rede elétrica. Estas obras são realizadas, em sua maioria, por empresas terceirizadas, arcando com o custo da mão de obra para o andamento dos projetos, que utilizam os materiais (transformadores, cabos, postes etc.) pertencentes à distribuidora para tal. O controle do almoxarifado e o transporte dos materiais é realizado por empresas terceirizadas especializadas no ramo.

Com isso, o setor de logística da empresa é responsável pelo controle dos estoques desses materiais, pela análise de necessidade de materiais nas obras e nas regionais, pelo gerenciamento dos transportes realizados por meio de fretes, além do fluxo de informações sobre a expedição e distribuição dos materiais entre a empresa e os terceirizados.

\subsection{O PROCESSO ATUAL DA GESTÃO DE TRANSPORTES}

A empresa objeto desta pesquisa trabalha em regime de contratos anuais com as terceirizadas, tendo definido os veículos denominados: Fracionado (mais leve entre todos), Toco, Truck e Carreta.

O processo começa a partir de uma solicitação de transporte, que pode vir do CD, das Regionais ou dos Pontos de Obra. Esta solicitação é enviada para o setor de logística, o qual aciona os transportadores, repassando informações de tipo e quantidade de veículos necessários. Cada um dos possíveis solicitantes é responsável pela correta execução dos procedimentos listados e detalhados a seguir.

Centro de Distribuição: Os colaboradores do almoxarifado tratam do recebimento, armazenagem, separação e expedição dos materiais. Com isso, quando há carga separada na expedição para uma ou mais localidades (que podem ser as regionais ou os pontos de obra), sendo estas suficientes para carregar um ou mais veículos, O CD solicita o quantitativo necessário conforme as dimensões e pesos dos materiais;

Regional: Quando uma das regionais verifica excesso de material, pouco utilizado ou que não será mais utilizado, solicita um frete de retorno, para que o material seja levado ao CD. Esse processo também ocorre quando há materiais avariados, que retornarão ao CD para que o setor de logística promova a tratativa necessária;

Pontos de obra: Executa o mesmo processo das regionais. Quando há excesso de material, ou material avariado, o ponto solicita o transporte para o retorno destes ao CD.

A partir dessas solicitações, o setor de logística é responsável por analisar o que foi requisitado, verificando se o dimensionamento dos veículos está em conformidade com o que será transportado, se há alguma outra especificação necessária, entre outros. A solicitação é então enviada para as transportadoras para que façam as tratativas necessárias, movimentando os veículos para a coleta dos materiais. Na Figura 1, o fluxo do processo acima descrito é ilustrado, para melhor entendimento. 
Vale ressaltar que a consolidação de cargas nos veículos é realizada com base nos conhecimentos empíricos dos solicitantes, prevendo a partir da sua experiência, o tipo de veículo necessário para o transporte do material separado, não sendo utilizados métodos quantitativos para essa decisão.

FIGURA 1 - Fluxo das solicitações de transporte.

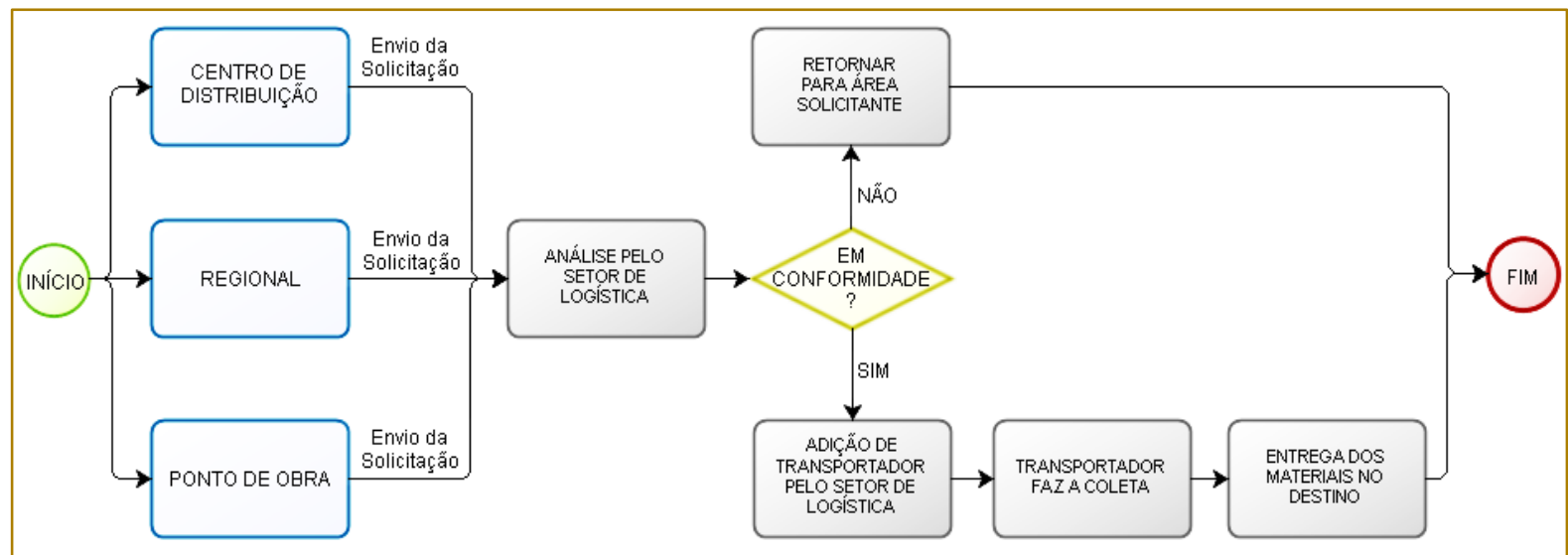

Fonte: Autores (2017).

Ao observar o fluxo, percebe-se que o setor de logística não recebe o feedback do transportador sobre a entrega dos materiais. Ou seja, não há comprovantes de entrega em tempo real como demonstrativo de que determinada carga foi recebida no destino programado. Esses comprovantes são recebidos somente quando o transportador entrega as Notas Fiscais à sede para o pagamento dos fretes, os quais têm um prazo de até 90 dias para o envio das mesmas. Com esse intervalo de tempo considerável, ocorre elevado atraso no recebimento de informações, além do grande risco de perdas das mesmas dentro do processo.

Além disso, todas as solicitações e o fluxo de informações são realizados a partir de e-mails e, por conta disso, não há registros em bancos de dados das requisições realizadas, das entregas de materiais, dos veículos solicitados, previsões de custo dos fretes ou qualquer outra informação que possa dar suporte às tomadas de decisões ou facilitar a gestão dos transportes.

\subsection{MELHORIAS COM O USO DO TMS}

O setor de transporte possui alta dinamicidade e o TMS é uma tecnologia que possui a capacidade de acompanhar em tempo real os processos e operações realizadas durante a movimentação de cargas e veículos dentro da cadeia de suprimentos. Em relação aos componentes logísticos operacionais, o sistema é capaz de trazer variados benefícios, como listado a seguir:

Transportes: É o componente que terá maiores benefícios. O TMS permite a execução de operações de distribuição consolidada (Peddling), nas quais um único veículo realiza entregas em vários pontos (clientes) diferentes. Para isso, dispõe também da função roteirização, que propõe rotas, por exemplo, com os caminhos mais curtos para a realização dessas entregas. Além disso, com o TMS, a arrumação mais equilibrada, em termos de peso das cargas, nos veículos, é facilitada, potencializando menos riscos de acidentes e de avarias nas cargas, e menos manutenções aos veículos. Estas características potencializam significativa redução de custos nos transportes, além de aumento no nível de serviço;

Instalações: O TMS permite o melhor posicionamento e distribuição do peso das cargas dentro dos veículos, auxiliando o processo de consolidação das cargas, reduzindo riscos de acidentes por falta de estabilidade do veículo e de avarias nas cargas, durante o transporte. Com isso, reduz-se também o retorno de cargas e a consequente insatisfação de clientes que não têm suas demandas plenamente atendidas por causa dessas avarias. Além disso, com menos cargas de retorno haveria menos necessidade de espaço para rearmazená-las, assim reduzindo-se as necessidades de 
ampliações das instalações atuais ou de aquisições de novas instalações para armazenagem;

Estoques: Com o menor retorno de cargas avariadas, menores serão os estoques de cargas com tal status e menores serão os montantes financeiros associados a tais estoques, ou seja, custos de manutenção, capital imobilizado, oportunidades, depreciação etc., diminuindo assim os custos operacionais decorrentes desse importante componente logístico;

Informação: O TMS registra em um banco de dados todas as informações pertinentes em cada viagem, além de conseguir gerar, com essa base de dados, relatórios gerenciais que auxiliam nas tomadas de decisão em relação a transportadores, equipamentos utilizados, seus custos, entre outros. Essa TI também possibilita uma comunicação via EDI (Electronic Data Interchange) com os transportadores, rastreando veículos e informações mais próximas do tempo real, permitindo que o fluxo de informações entre transportador e empresa seja mais intenso.

\subsection{PROCESSO DE IMPLANTAÇÃO DO TMS}

Segundo Morettin et al. (2012), para a implantação do TMS são necessários certos subprocessos para que a ferramenta seja inserida de forma efetiva na cadeia logística da empresa. Primeiramente, a escolha de um fornecedor para a ferramenta deve ser feita de modo minucioso, verificando se o software disponível é compatível com as tecnologias já existentes na empresa, o que ajudará na integração dos softwares e resultará ainda na diminuição do tempo de implantação. Morettin et al. (2012) aponta que a busca por referências sobre o prestador de serviço também é importante, pois a troca de fornecedor é um risco que pode gerar altos custos, e com isso sugerealguns pontospara essa pesquisa, tais como:

- Rapidez no tempo de atendimento à ocorrências;

- Envolvimento do prestador de serviços com as necessidades da empresa;

- Análise custo-benefício.

A definição de gerentes e consultores do projeto é parte importante do processo, visto que essas pessoas serão as responsáveis por definir toda a estrutura a ser seguida após a escolha do fornecedor e, também, por absorver e repassar por meio de treinamentos os conhecimentos adquiridos. O consultor deve ter a capacidade técnica de lidar com erros, oportunidades e criar medidas que possam moldar o TMS de forma que a ferramenta se encaixe de maneira eficaz aos processos já existentes da organização. Esta moldagem se dará a partir de conversas com os potenciais usuários do sistema, objetivando entender as principais rotinas da empresa e sugerir customizações necessárias para atender as mesmas.

Deve ser elaborado também o cadastro de transportadores, produtos, rotas, fretes, veículos, cidades, entre outras variáveis. Este cadastro pode ser realizado de forma manual ou automática, por meio de um banco de dados pré-estabelecido.

O treinamento dos usuários passa não só por questões técnicas do software, mas também por questões comportamentais, pois a mudança da cultura organizacional e a implantação de uma nova ferramenta podem causar impressões negativas aos colaboradores. É importante, então, desenvolvê-los com o propósito de tornar a utilização do TMS mais simples, para que o software não se torne subutilizado.

Nos procedimentos atuais da empresa, a consolidação das cargas nos veículos é realizada a partir dos conhecimentos empíricos dos operadores que solicitam os transportes. Um fator para isso é que a empresa não possui registro de dimensões ou pesos de todos os materiais estocados. Com isso, como o software utiliza a ferramenta de consolidação e planejamento de carga, para que esse módulo do sistema não fique sujeito à subutilização, a empresa precisará realizar a medição das dimensões dos materiais que transporta, principalmente daqueles que, por observação, ocupam o maior volume em um veículo, como os transformadores e bobinas de cabos. Será necessário exigir dos fornecedores o peso unitário dos produtos que são adquiridos durante o processo de compra. A partir dessas informações, será possível alimentar o banco de dados do sistema, permitindo a utilização do módulo de consolidação de cargas de forma otimizada.

Os procedimentos de utilização do novo modelo de gestão devem ser divulgados para todos os solicitantes de transportes, fazendo campanhas para conhecimento do sistema implantado e divulgação sobre os benefícios que trará à empresa. 
É imprescindível o monitoramento contínuo do desempenho do TMS durante os meses iniciais da implantação, afim de sugerir melhorias e elaborar planos para melhor desenvolvimento da ferramenta, além de sanar dúvidas pontuais de usuários que devem ocorrer durante o período inicial de operação.

\section{CONSIDERAÇÕES FINAIS}

O presente estudo teve a missão de expor os benefícios da integração e transmissão de informação a partir da implantação de um software para a gestão de um dos componentes logísticos mais importantes: o transporte.

A partir da análise do funcionamento da empresa estudada em relação ao fluxo de solicitações de transporte, foi possível observar falhas relacionadas à execução e monitoramento dos serviços. A proposta do artigo envolveu a implantação do TMS (Transportation Management System), com vistas a conscientizar a empresa sobre a importância da geração de relatórios com informações gerenciais capazes de suportar tomadas de decisões mais rápidas, potencializando a minimização dos custos de transporte e a simplificação do controle financeiro da empresa, assim como a qualidade dos serviços realizados. O cadastro de informações pode permitir o controle de fretes e rotas, além do rastreamento, por satélite, de cargas e veículos, possibilitando que imprevistos sejam identificados e solucionados de forma rápida e efetiva.

A implantação do TMS, em geral, ocorre em um processo relativamente longo, considerando a quantidade de informações

\section{REFERÊNCIAS}

[1] ABRADEE - Associação Brasileira de Distribuidoras de Energia Elétrica. Disponível em: <http://www.abradee.com.br/setor-eletrico/visaogeral-do-setor>. Acesso em: 17/10/2017

[2] ANEEL - Agência Nacional de Energia Elétrica. Disponível em: $<$ http://www.aneel.gov.br/conteudo-ducativo/-/ asset_publisher/vE6xsWH/content/composicao-datarifa/65480?inheritRedirect=false $>$. Acesso em: $17 / 10 / 2017$ necessárias a serem coletadas para garantir o correto funcionamento do sistema. Este processo é crucial para que a empresa possa gerenciar todos os seus recursos de forma eficiente, pois está fundamentada em dados quantitativos da própria empresa. Nenhuma das atividades necessárias para a implantação é complexa, porém se faz necessário elaborar estratégias para que os colaboradores aprendam a usar a ferramenta e conscientizem-se sobre a sua necessidade, evitando que esta seja subutilizada.

Por fim, é ressaltada a necessidade de manter um monitoramento do desempenho do sistema durante o período de implantação do TMS, considerando as necessidades de adaptação tanto da nova tecnologia implantada ao sistema quanto da cultura da empresa ao novo modelo de gestão, muitas vezes imposto pela tecnologia implantada.

Como uma oportunidade de pesquisa futura, propõe-se a quantificação das vantagens financeiras que a implantação de um sistema TMS pode trazer de retorno para a empresa, necessitando de uma análise detalhada dos custos envolvidos tanto na implantação do sistema TMS quanto nos processos atuais de planejamento de carga e o seu transporte. Dessa forma, pode-se calcular o período de retorno do investimento e a margem de contribuição do sistema às operações logísticas da empresa.

Além do mais, é necessário um estudo dos KPI's que devem ser implementados a partir da utilização do novo sistema, procurando o ajuste dos mesmos às necessidades da empresa. Com esses indicadores bem ajustados, pode-se conseguir uma maior eficiência logística, tornando a empresa mais competitiva.

[3] BALLOU, R. H. Gerenciamento da cadeia de suprimentos: planejamento, organização e logística empresarial. Porto Alegre: Bookman, 2001

[4] BALLOU, R. H. Gerenciamento da cadeia de suprimentos: planejamento, organização e logística empresarial. Porto Alegre: Bookman, 2006

[5] CORRÊA, H.L. - CORRÊA, C.A. Administração de Produção e Operações: manufatura e serviços: uma abordagem estratégica. São Paulo: Atlas, 2004. 
[6] FERREIRA, K. A. Impactos da tecnologia de informação no desempenho de operações na cadeia de suprimentos da indústria alimentícia. 2005. 192 f. Dissertação (Mestrado em Engenharia de Produção) - Universidade Federal de São Carlos, São Carlos.

[7] FESTA, Eduardo; ASSUMPÇÃO, Maria Rita Pontes. Uso da tecnologia de informação e desempenho logístico na cadeia produtiva de eletroeletrônicos. Revista de Ciência \& Tecnologia, v. 17, n. 33, p 7-23, 2012.

[8] MARQUES, V. Utilizando o TMS (Transportation Management System) para uma Gestão eficaz de Transportes. Disponível em: $<$ http://www.ilos.com.br/web/utilizando-o-tmstransportation-management-system-para-umagestao-eficaz-de-transportes/>. Acesso em: 15/10/2017

[9] MORETTIN, Ana, P.; LOTIERSO, Angelo; VASCONCELOS, William, F. Identificação do processo de im-plantação de um sistema de gerenciamento de transporte. Simpósio de Excelência em Gestão e Tecnologia, 2012.

[10] NOVAES, Antonio Galvão. Logística e Gerenciamento da Cadeia de Distribuição: Estratégia, Operação e Avaliação. - Rio de Janeiro: Elsevier, 2007.

[11] SALLES, Cristiano; HERMOSILLA, José L. G.; SILVA, Ethel C. C. A influência da informação (telemetria) na gestão de frota: um estudo de caso em uma empresa de transportes de médio porte do interior do Estado de São Paulo. ABEPRO, 2016.

[12] SILVA, R. A. TMS como ferramenta de gestão de transporte: um estudo de caso no segmento do comércio eletrônico. 2009. 67 f. Monografia (Graduação) - Faculdade de Tecnologia Zona Leste, São Paulo. Disponível em: <http://docplayer.com.br/7268673-Tms-comoferramenta-no-gerenciamento-de-transporte-umestudo-de-caso-no-segmento-de-comercioeletronico.html>. Acesso em: 06/12/2017. 


\section{Capítulo 2}

\section{INFLUENCIA DO TRANSPORTE PÚBLICO NA EDUCAÇÃO: UM ESTUDO EM UMA INSTITUICÃO DE ENSINO NO MUNICÍPIO DE SÃO JOÃO DA BARRA}

\section{Fabiana Nunes Cabral Monteiro}

\section{Fernando Cerutti Aguiar}

\section{Bruno Rabbi}

\section{Denise Cristina de Oliveira Nascimento \\ Geórgia Regina Rodrigues Gomes}

Resumo: Uma logística de transportes eficiente é considerado de vital importância para instituições de ensino. Este artigo foi elaborado com o objetivo de identificar como o transporte público pode influenciar na vida da comunidade frequentadora dee uma instituição localizada no norte fluminense. Para isto foi realizada uma pesquisa com 141 alunos e servidores desta unidade de forma a apontar os principais problemas de transporte na região. Os resultados indicaram que o transporte público na região é ineficiente e a má qualidade do serviço influencia consideravelmente na vida destes usuários, inclusive, podendo ser apontado como um dos motivos para evasão escolar dos alunos desta instituição.

Palavras-chaves: educação; logística; transporte; são joão da barra. 


\section{INTRODUÇÃO}

O transporte público vem sendo cada vez mais utilizado por vários fatores, e um deles está relacionado a segurança e economicidade. Sabe-se também que o transporte coletivo no Brasil é um dos modais de transporte mais utilizados por estudantes, pois muitos não possuem meios de transporte particular para se locomover até à escola. Neste sentido, este artigo visa ressaltar a grande importância que o transporte público exerce na educação, assim como a sua influência.

Para melhor entendimento sobre o assunto, uma pesquisa sobre a percepção do transporte público foi realizada em uma Instituição de Ensino que atualmente oferece 3 tipos de cursos presenciais, a saber: curso técnico concomitante em Eletromecânica, curso técnico integrado ao ensino médio em Construção Naval e curso técnico integrado ao ensino médio em Petróleo e Gás. Ao todo, no ano de 2017, a instituição de ensino dispõe de 155 alunos regularmente matriculados e frequentando nestes 3 cursos que são presenciais, porém 122 responderam à pesquisa, tornando a pesquisa extremamente fidedigna. Além disso, a pesquisa também foi realizada com servidores que utilizam do transporte público para trabalhar. Ao final da pesquisa pode-se contar com 141 respostas.

O trabalho está dividido em 05 partes. Para um melhor entendimento, no capítulo dois será apresentada a revisão bibliográfica, onde será tratado tópicos específicos sobre o tema deste artigo. No capítulo três, será apresentada a metodologia escolhida. No capítulo 4 poderá ser visto o estudo de caso e por fim, no capítulo 5 , as considerações finais.

\section{REVISÃO BIBLIOGRÁFICA}

\subsection{BIBLIOMETRIA}

Inicialmente, para desenvolver este trabalho, foi feita uma pesquisa na literatura para mapear e selecionar modelos de artigo. Esta pesquisa foi realizada nas bases Google Acadêmico, sciencedirect.com e Scopus, acessadas por meio do portal de periódicos da CAPES. Tais periódicos são amplamente utilizados por acadêmicos, pesquisadores e profissionais para disseminar novos conhecimentos e conceitos, o que auxilia para melhor aprofundamento dos itens correlacionados ao tema do trabalho.

A palavra-chave inicialmente utilizada para o desenvolvimento da pesquisa foi: "Influência do transporte público na educação", foram encontrados registros de 91 artigos na Base Scopus (Elsevier), 40 artigos na Base Web of Science e 14.100 no Google Acadêmico; Já no site sciencedirect.com foram encontrados 12 referências.

Após a pesquisa com a palavra-chave em português foi utilizada para o desenvolvimento da pesquisa o mesmo termo em inglês. Notase que os resultados são significativos: "Influence of public transport on education", foram encontrados registros de

11.298 artigos na Base Scopus (Elsevier), 36.833 artigos na Base Web of Science e 142.000 no Google Acadêmico; Já no site sciencedirect.com foram encontrados 3.635 referências.

\subsection{TRANSPORTE PÚBLICO}

De acordo com Rodrigues (2009), o transporte público é deveras muito importante, pois é capaz de atender a pessoas de baixa renda e também contribui para a questão ambiental, diminuindo a poluição, congestionamento e acidentes de trânsito ao passo que reduz o número de automóveis circulando por conseguir assistir a um quantitativo maior de indivíduos em um único transporte. Segundo Pires (2008), o transporte público é um serviço imprescindível e fundamental para a mobilidade urbana.

\subsection{MODAIS DE TRANSPORTE}

Segundo Bowersox e Closs (2007), os mais básicos tipos de modais de transportes são: aéreo, aquaviário, dutoviário, ferroviário e rodoviário. Cada tipo de modal tèm sua importância e sua utilização varia de acordo com a necessidade, custo, tamanho e rapidez. Abaixo será possível conhecer um pouco de cada um deles:

- $\quad$ Aéreo - Segundo Faria e Costa (2010), a principal vantagem do modal aéreo é a velocidade com que a carga pode ser transportada. Devido aos altos custos, o modal é utilizado principalmente no transporte de produtos de alto valor agregado para médias e longas distâncias. Além de ser o 
mais rápido, também possui níveis de avarias e extravios mais baixos, resultando em maior segurança e confiabilidade.

- Aquaviário - O modal aquaviário ou hidroviário apresenta vantagens significativas nos transportes de cargas de proporções maiores em longas distâncias. Possui custos de transporte e níveis de perdas e danos consideravelmente baixos. Entre as desvantagens, segundo Ballou (1993), o modal é considerado limitado, pois está confinado a hidrovias o que exige ao usuário que esteja as suas margens ou utilize outro modal como complemento. Além disso, é um dos mais lentos e sua disponibilidade depende de condições meteorológicas.

- Dutoviário - Também de acordo com Faria e Costa (2010), este modal refere-se aos transportes de produtos por meios de dutos subterrâneos e sua utilização é muito limitada, restrita a produtos em estado gasoso, líquido ou pastoso. Funcionam 24 horas por dia, sete dias por semana e só são interrompidos por operações de troca de mercadoria ou manutenção. Está entre os mais confiáveis pois não sofrem interrupções, nem influência de fatores meteorológicos, o que proporciona uma excelente precisão no tempo de entrega.

- Ferroviário - Segundo Martins, Biasi e Junior (s.d.), o transporte sobre trilhos é o mais eficiente para transportar grandes cargas de baixo valor agregado a distâncias relativamente longas. É considerado um dos mais econômicos e ambientalmente correto, pois utiliza pouco combustível em relação a quantidade de carga transportada. No Brasil, é utilizado para transportar principalmente minério, carvão mineral e cereais em grãos.

- Rodoviário - De acordo com Ribeiro e Ferreira (2002), este é o modal indicado para o transporte de curta e média distâncias. Suas principais vantagens estão na abrangência (disponível em quase todo território nacional) e na possibilidade de fazer a entrega porta a porta. Por apresentar preços mais elevados que os modais ferroviário e aquaviário, é mais indicado para mercadorias de alto valor e perecíveis. Portanto, não é recomendado para produtos agrícolas a granel, cujo custo é muito baixo para este modal.

\subsection{TRANSPORTE PÚBLICO X EDUCAÇÃO}

O transporte público ou também conhecido como transporte coletivo pode ser considerado como público ou privado e sua principal característica é a de transportar diversas pessoas ao mesmo tempo (WILHEIM, 2013). O transporte público e a educação estão completamente ligadas simplesmente pelo fato de as duas possuírem uma característica em comum: poder atender muitas pessoas ao mesmo tempo. Um transporte público que não é eficaz, eficiente e de boa qualidade acarreta vários problemas ao cidadão, pois ele não prejudica apenas em uma área, mas sim, várias, como por exemplo: saúde, cultura, lazer e principalmente a educação (PEDUZZI, 2013). Em se tratando do transporte público na educação, cabe ressaltar a sua importância para os que dependem do transporte público para chegarem às escolas e conseguirem se qualificar para se inserirem no mercado de trabalho. Há de destacar-se que a dificuldade em utilizar o transporte coletivo, seja pela falta de qualidade, infraestrutura, de passagens caras ou até mesmo pela ausência do transporte coletivo, afeta diretamente 0 rendimento escolar do estudante. Muitos alunos que sofrem com os diversos problemas (passagens caras, atrasos de ônibus, entre outras) do transporte público podem ser considerados nos altos índices de desistência e evasão escolar. Às vezes deixam de frequentar à escola por não conseguirem pagar passagens, pois tem os valores muito elevados ou então levam horas dentro do transporte coletivo chegando cansados nas escolas. Outro fator que prejudica o rendimento do aluno são os poucos horários disponíveis do transporte, muitas das vezes o estudante precisa acordar muito cedo para pegar o transporte, pois o próximo horário não é compatível com o horário que ele precisa chegar à escola. Após todos esses fatores apresentados, é notório que quando se tem um bom transporte público é possível ter uma educação com qualidade. A seguir será apresentado um estudo sobre a percepção do transporte público por alunos de uma instituição de ensino.

\section{METODOLOGIA}

Com o objetivo de identificar a percepção do serviço logístico do transporte público no município de São João da Barra, mais especificamente para o IFFluminense campus Avançado São João da Barra, e como o transporte público pode influenciar em uma instituição de ensino, este estudo utilizou-se da pesquisa de caráter quantitativo e 
exploratório como metodologia. Segundo Fonseca (2002), a pesquisa quantitativa é objetiva pelo fato de se poder quantificar e gerar resultados bastante precisos. Já a pesquisa de caráter exploratório pode ser compreendida por ser mais clara, tornando o problema ou o que está sendo investigado mais familiar e de fácil entendimento. Geralmente é realizada através de estudo de caso ou pesquisa bibliográfica (GIL, 2007).

\subsection{COLETA E ANÁLISE DE DADOS}

No mês de setembro e outubro de 2017 foram realizadas a coleta e análise de dados com 141 alunos e servidores de uma instituição de ensino do município de São João da Barra. A pesquisa foi elaborada levando em consideração a grande dificuldade que a comunidade acadêmica possui com o transporte público coletivo no município. Esta dificuldade foi constatada por um dos autores deste artigo que utiliza o transporte na cidade em estudo, o que estimulou a pesquisa da influência do transporte público especificamente em uma unidade de ensino. Um formulário foi criado com o objetivo de entender a percepção do serviço prestado justamente nas pessoas que utilizam e dependem do transporte público seja para estudar e/ou trabalhar.

\section{ESTUDO DE CASO}

A escolha pelo estudo do transporte público no município de São João da Barra se deu pelo fato de a cidade está em acelerado desenvolvimento e crescimento devido ao grande complexo portuário logístico que foi instalado no Açu. Com o Porto do Açu, a cidade começou a ficar mais movimentada e por consequência a utilização do transporte público também, pois pessoas de cidades vizinhas começaram a trabalhar ou até mesmo se mudarem para a cidade devido à enorme geração de emprego que foi ocasionada pelo novo empreendimento.

No ano de 2015, o Instituto Federal Fluminense campus Avançado São João da Barra iniciou sua trajetória no município ofertando cursos diretamente relacionados à indústria com o objetivo de formar profissionais para atender a nova demanda do mercado. Vale ressaltar que vários estudantes das cidades ao redor do município começaram a procurar o IFFluminense campus Avançado São João da Barra a fim de obter uma qualificação profissional e se tornar competitivo no mercado de trabalho, o que pode ter sido um dos fatores que contribuiu com o aumento exacerbado no transporte público do município. Mesmo diante dessa acentuada procura no transporte público, as autoridades competentes devem oferecer um serviço seguro, de qualidade e que consiga atender a toda população que carece desse serviço.

Com o objetivo de avaliar a logística do transporte público no município de São João da Barra através da percepção da comunidade acadêmica do Instituto Federal Fluminense campus Avançado São João da Barra que utiliza do serviço em questão, será possível visualizar o panorama geral através dos resultados da pesquisa, onde um questionário foi formulado com doze perguntas. 


\subsection{RESULTADOS DA PESQUISA}

Figura 1 - Gráficos do questionário sobre a percepção do transporte público

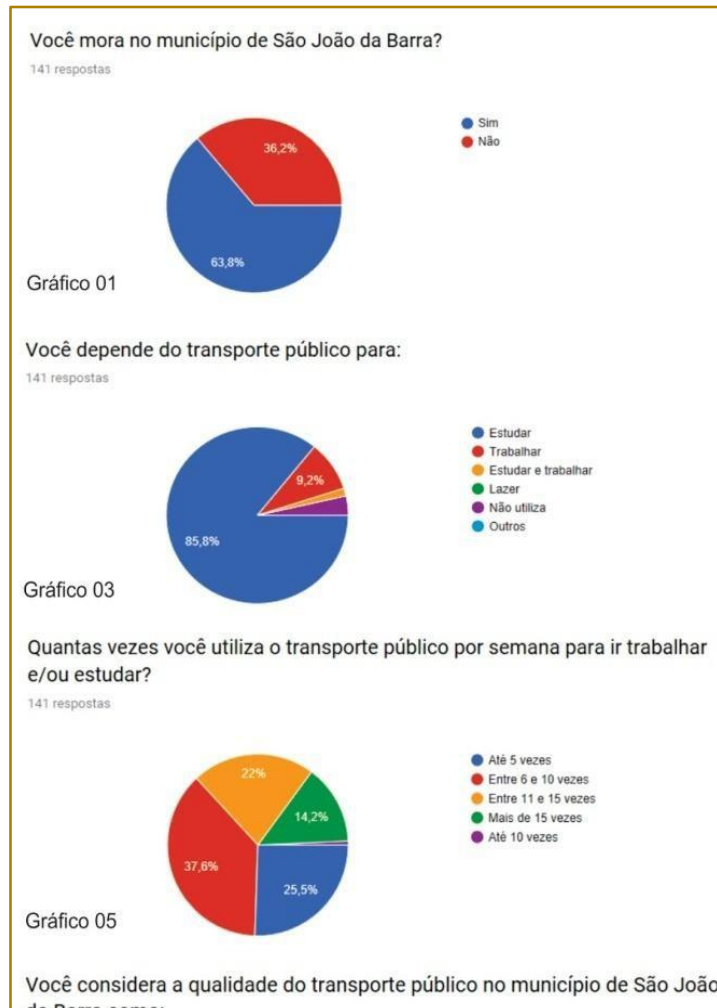
da Barra como:

141 respostas

Gráfico 07
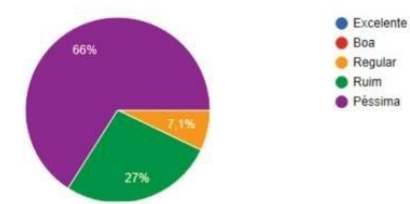

Qual problema no transporte público mais atrapalha sua frequência à escola ou trabalho?

141 respostas

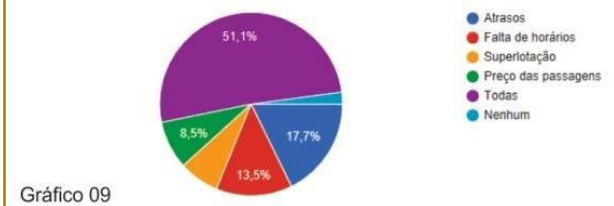

Quando o transporte público regular está indisponivel, você utiliza para ir à escola ou trabalho:

141 respostas

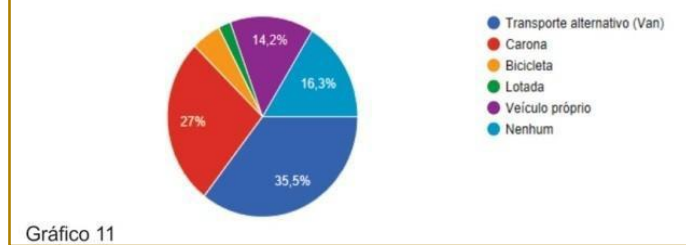

- Gráfico 01 da figura 1
Qual o seu vínculo com o IFFluminense campus Avançado São João da Barra?

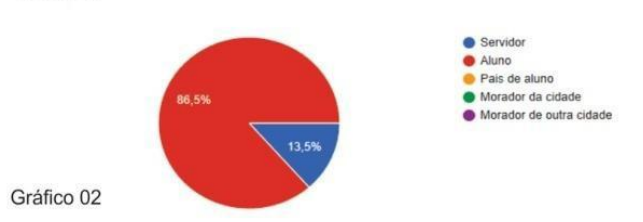

Você já deixou de embarcar no ônibus porque não tinha como entrar? 141 respostas

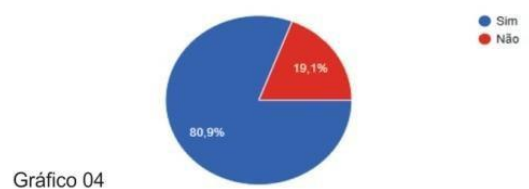

Quanto tempo vocē demora para chegar da sua casa ao IFFluminense campus Avançado São João da Barra quando depende do transporte público?

141 respostas

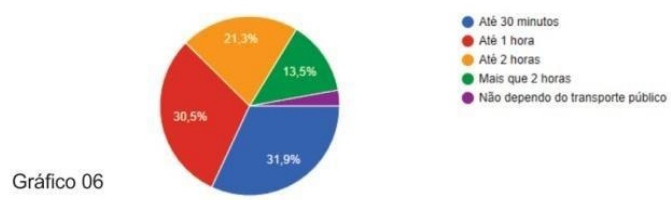

Você já deixou de ir à escola ou trabalhar por falta do transporte público? 141 respostas

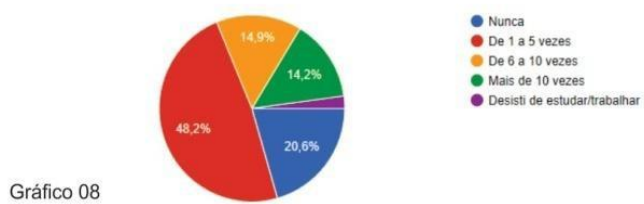

Quanto a segurança dos coletivos, você considera: 141 respostas

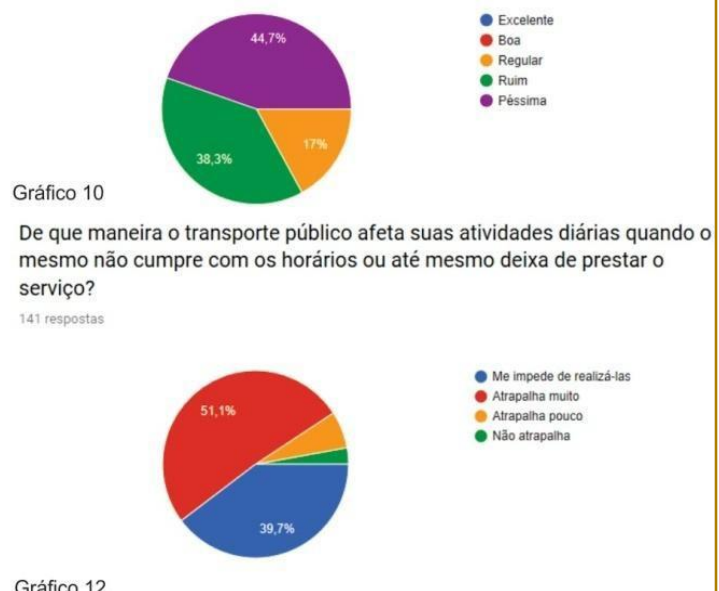

Gráfico 12

Você mora no município de São João da Barra? 
63,2\% (90 Respostas) das pessoas entrevistadas moram no local e 36,8\% (51 Respostas) vêm de outros locais, nesse caso predominam as pessoas que moram no local.

- Gráfico 02 da figura 1

Qual o seu vínculo com o IFFluminense campus Avançado São João da Barra?

86,5\%(122 Respostas) das pessoas entrevistadas são alunos e 13,5\% (19 Respostas) servidores. Os alunos predominam, pois são eles a grande clientela atendida.

\section{- Gráfico 03 da figura 1}

Você depende do transporte público para: Estudar, Trabalhar, Estudar e Trabalhar, Lazer, não utiliza ou outros

85,8\%(121 Respostas) das pessoas entrevistadas utilizam para estudar 9,2\%(13 Respostas) para trabalhar 3,5\%(5 Respostas) não utilizam 1,4\%(2 Respostas) Trabalhar e estudar. Neste item predomina o uso por parte dos alunos.

\section{- Gráfico 04 da figura 1}

Você já deixou de embarcar no ônibus porque não tinha como entrar?

80,9\%(114 Respostas) das pessoas entrevistadas deixaram de utilizar o ônibus e 19,1\%(27 Respostas) não deixaram de utilizar.

\section{- Gráfico 05 da figura 1}

Quantas vezes você utiliza o transporte público por semana para ir trabalhar e/ou estudar?

Utilizam entre 6 e 10 vezes $37,6 \%$ (53 Respostas), até 5 vezes 25,5\% (36 Respostas), entre 11 e 15 vezes 22\% (31 Respostas), mais de 15 vezes $14,2 \%$ (20 Respostas), até 10 vezes 0,7\%(1 Resposta). 0 uso do transporte público acontece pelas respostas acima dentro dos dias úteis semanais justamente nos dias letivos de aula.

\section{- Gráfico 06 da figura 1}

Quanto tempo você demora para chegar da sua casa ao IFFluminense campus Avançado São João da Barra quando depende do transporte público?
31,9\% (45 Respostas) leva até 30 minutos, 30,5\% (43 Respostas) leva até 1(uma) hora, 21,3\% (30 Respostas), leva até 2(duas) horas, $13,5 \%$ (19 Respostas) mais de 2(duas) horas, 2,8\% (4 Resposta) Não depende do transporte público.

\section{- Gráfico 07 da figura 1}

Você considera a qualidade do transporte público no município de São João da Barra como: 66\% (93 Respostas) como péssimo, 27\% (38 Respostas) como ruim, 7,1\% (10 Respostas) como regular. A qualidade do transporte público pelas respostas mostra o quanto é falho e necessita de ajustes e melhorias para atender o mínimo de qualidade, haja visto que a maior clientela é predominantemente de alunos e os parâmetros de qualidade podem ser diferentes para outros segmentos de público que usa o transporte no dia-a-dia.

\section{- Gráfico 08 da figura 1}

Você já deixou de ir à escola ou trabalhar por falta do transporte público?

48,2\% (68 Respostas) de 1 a 5 vezes, 20,6\% (29 Respostas) Nunca deixaram de ir, $14,9 \%$ (21 Respostas) de 6 a 10 vezes, 14,2\% (20 Respostas) Mais de 10 vezes, 2,1\% (3 Respostas) Desistiu de estudar ou trabalhar. Ou seja, a falta do transporte público impossibilita o usuário de ir à escola ou trabalhar pelo menos de uma a cinco vezes.

\section{- Gráfico 09 da figura 1}

Qual problema no transporte público mais atrapalha sua frequência à escola ou trabalho? $51,1 \%$ (72 Respostas) todas as alternativas, 17,7\%(25 Respostas) Atrasos, 13,5\%(19 Respostas) pela falta de horários, 8,5\%(12 Respostas) preço das passagens, 7,1\%(10 Respostas) superlotação de ônibus. A maioria das pessoas retratam que não é só apenas um fator que atrapalha a frequência à escola ou trabalho e sim vários, como por exemplo: atrasos, falta de horários compatíveis com a realidade que o município necessita, altos preços das passagens e principalmente superlotação dos ônibus.

\section{- Gráfico 10 da figura 1}

Quanto a segurança dos coletivos, você considera: 
44,7\%(63 Respostas) como péssima, 38,3\%(54 Respostas) como ruim, 17\%(24 Respostas) como regular.

- Gráfico 11 da figura 1

Quando o transporte público regular está indisponível, você utiliza para ir à escola ou trabalho:

35,5\% (50 Respostas) transporte alternativo(Van), 27\% (38 Respostas) carona, 16,3\% (23 Respostas) nenhum, 14,2\% (20 Respostas) veículo próprio, 5\% (7 Respostas) bicicleta, 2,1\% (3 Respostas) lotada.

\section{- Gráfico 12 da figura 1}

De que maneira o transporte público afeta suas atividades diárias quando o mesmo não cumpre com os horários ou até mesmo deixar de prestar o serviço?

$51,1 \%$ (72 Respostas) atrapalham muito, 39,7 \%(56 Respostas) me impede realizá-las, 6,4\% (9 Respostas) atrapalha pouco, 4\% (8 Respostas) não atrapalha.

A partir desta pesquisa, fica evidente a falta de eficiência do transporte público local. Dos 141 entrevistados, 95\% dependem do transporte para estudar ou trabalhar, sendo que $80,9 \%$ já deixaram de embarcar porque não tinham como entrar no ônibus. Além disso $66 \%$ classificou o transporte coletivo como péssimo e aproximadamente $77 \%$ já deixou de ir trabalhar ou estudar uma ou mais vezes por falta de transporte público. Ficou também clara a relação do transporte com a produtividade dos usuários nos estudos ou no trabalho, quando $90,8 \%$ das pessoas responderam que quando o serviço é prestado fora dos horários ou não é prestado (gráfico 12), suas atividades diárias são prejudicadas ou não realizadas.

\section{CONSIDERAÇÕES FINAIS}

A partir do estudo de caso, fica notório que o transporte público exerce uma função consideravelmente importante na vida escolar de um indivíduo.

A pesquisa pôde mostrar através dos seus resultados que atualmente 0 transporte público não atende de maneira eficiente, eficaz e satisfatória a necessidade da comunidade acadêmica do IFFluminense campus Avançado São João da Barra, trazendo assim consequências para o aluno e também para o trabalhador da educação. vale ressaltar que o modal rodoviário geralmente é utilizado pelo seu alto poder de facilidade e também de economicidade, todavia neste estudo pôde-se constatar uma grande dificuldade em sua utilização, devido ao difícil acesso pela falta do mesmo e pelo alto valor das passagens, superlotação, atrasos, falta de horários demonstrando assim um serviço totalmente precário e ineficiente para os que utilizam do transporte público no município de São João da Barra.

Outro fator relevante que os entrevistados relataram é que a falta do transporte público atrapalham muito o desenvolvimento de suas atividades ou então os impede de realizá-las. Este ponto deve ser considerado, pois influencia diretamente na vida do estudante que não consegue chegar à Instituição de Ensino. Deve-se levar em consideração que atrasos, muitas das vezes ocasionadas pelo transporte que vive superlotado ou até mesmo porque não cumpre seus horários pode afetar a qualidade de ensino, pois o aluno que chega atrasado em uma sala de aula pode acabar perdendo conteúdos importantes.

Como trabalho futuro sugere-se que seja feita uma pesquisa mais a fundo sobre os bairros mais afetados pela falta do transporte público ou até mesmo pela pouca disponibilidade de horário que as empresas oferecem para os mesmos. Também é sugerido um estudo para analisar o impacto que a falta do transporte público gera na formação do aluno e o quanto ele pode estar interligado a questão da evasão escolar. 


\section{REFERÊNCIAS}

[1] BALLOU, Ronald H. Logística empresarial. São Paulo: Atlas, 1993.

[2] BOWERSOX, D. J., CLOSS, D. J. Logística Empresarial - O Processo de Integração da Cadeia de Suprimento. São Paulo: Atlas, 2007.

[3] FARIA, A. C.; COSTA, M. F. G. Gestão de custos logísticos. São Paulo: Atlas, 2010. FONSECA, J. J. S. Metodologia da pesquisa científica. Fortaleza: UEC, 2002. Apostila. GIL, A. C. Como elaborar projetos de pesquisa. 4. ed. São Paulo: Atlas, 2007.

[4] MARTINS, A. L., BIASI, M., JÚNIOR, L. M. A importância da logística no desenvolvimento de sociedades e os benefícios possibilitados pela ferrovia como modal de transportes. Faculdade Prof. Antônio Seabra - Fatec de Lins - Lins-SP, s.d.

[5] PEDUZZI, P. Transporte público ruim afeta saúde, educação e cultura da população, dizem especialistas. 2013. Disponível em: <http://www.ebc.com.br/noticias/brasil/2013/07/tran sporte-publico-ruim-afeta-saude-educacao- e- cultura-da-populacao-dizem>. Acesso em: 29 set. 2017.

[6] PIRES, F.L. Mobilidade Urbana e Princípios de Justiça. Letras Livres, Série Anis, Ano VIII, n.63, p.1-11, 2008.

[7] RIBEIRO, P. C. C., FERREIRA, K. A. Logística e Transportes: Uma discussão sobre modais de transporte e o panorama brasileiro. XXII Encontro Nacional de Engenharia de Produção, Curitiba-PR, 2002.

[8] RODRIGUES, M. A., SORRATINI, J. A. A Qualidade no transporte coletivo. Universidade Federal de Uberlândia, Uberlândia 2009. Disponível em:

<http://www.anpet.org.br/ssat/interface/content/aut or/trabalhos/publicacao/2008/163_AC.pdf>. Acesso em: 24 set. 2017.

[9] WILHEIM, J. Mobilidade urbana: um desafio paulistano. 2013. Disponível em: <http://www.scielo.br/pdf/ea/v27n79/v27n79a02.pd f>. Acesso em: 25 set 2017. 


\section{Capítulo 3}

\section{A IMPORTÂNCIA DO CONTROLE DE ESTOQUE NO COMERCIO VAREJISTA: ESTUDO DE CASO NO SUPERMERCADO VIDA NOVA EM ALIANÇA-PE.}

\section{Bruno Cezar de Farias}

Michele Bezerra Saito

Resumo: Essa pesquisa tem como objetivo, analisar o processo de controle de estoques no supermercado vida nova, mencionando as práticas adotadas, de forma a verificar se a organização consegue obter como benefício a redução de custos. A metodologia de pesquisa aplicada foi a qualitativa-descritiva, através do estudo de caso, ao qual a coleta dos dados foi feita por meio de entrevista com aplicação de questionário estruturado com o gestor da empresa, com dezoito perguntas divididas em três blocos que buscavam compreender o processo de aquisição das mercadorias e saídas dos produtos, o comportamento do controle dos estoques e as práticas adotadas juntamente com os benefícios obtidos pelo supermercado.o resultado principal é que o controle é feito manualmente pelo próprio gestor, favorecendo o descontrole. Podendo-se concluir que as dificuldades enfrentadas pelo supermercado vida nova, reside no gerenciamento dos estoques, onde o problema com maior ocorrência é a ausência de alguns itens procurados pelos clientes. O que só reforça a necessidade de uma ferramenta de monitoramento, associado à um gerenciamento melhor de sua demanda prevista, de modo à minimizar falta dos produtos e ao mesmo atender às exigências dos clientes. 


\section{INTRODUÇÃO}

A busca constante das empresas pela obtenção de melhores resultados, faz com que seja necessário, na grande maioria das vezes, um mapeamento dentro da organização com o objetivo de encontrar possíveis gargalos nos processos, tornandose imprescindível um maior controle no gerenciamento das perdas, quer sejam estas ocorridas por furtos, avarias e até mesmo falhas gerenciais e operacionais.

Conforme Martelli; Dandaro (2015), empresas dos diversos segmentos devem prestar atenção nas particularidades que envolvem a gestão de estoque e seu controle, consideradas de imensa relevância para obtenção de melhores resultados na administração de uma empresa.

O estoque é considerado o núcleo principal do varejo, necessitando de um controle mais rígido, devido à alta variedade e perecibilidade da maioria dos itens armazenados. Por isso é tão importante empenhar-se na utilização de ferramentas que auxiliem no gerenciamento dos mesmos. Para que se tenha um bom gerenciamento do estoque, é essencial o registro de todas as movimentações ocorridas - tanto de entrada como de saída - evitando dessa forma, compras em desacordo com a necessidade, contribuindo assim, para a redução dos desperdícios de recursos e consequentemente redução de custos.

Diante do exposto, esse trabalho visa analisar o processo de controle de estoques no supermercado vida nova em Aliança - PE, mencionando as práticas adotadas, de forma a verificar se a organização consegue obter como benefício a redução de custo. Para tanto, será verificado o processo de aquisição de mercadorias e de controle de estoques.

\section{GESTÃO DE ESTOQUE}

O estoque é um item de bastante importância para a empresa, quando o estoque não é atualizado em relação às entradas ou saídas de mercadorias, implicará em possíveis perdas, tanto nas vendas, pelo fato de algum ou maior parte dos itens acabarem estragando e até mesmo nas compras, abastecendo em excesso os almoxarifados, resultando dessa forma, numa grande perda financeira.
Apesar de sua relevância, o gerenciamento dos estoques é um grande problema dentro das organizações, pelo simples fato de poder gerar prejuízos para organização, como: perda da produtividade, perda de investimento, retrabalho, entre outros. Em compensação, quando bem gerenciado pode proporcionar para as organizações um diferencial competitivo.

De acordo com Ramos (2006), a concorrência é um fator que gera grande preocupação por parte das empresas, pois para conquistar uma maior parcela de mercado, as empresas têm que estar atentas ao preço, qualidade dos produtos e disponibilidade no ponto de venda. Por isso, o excesso ou ausência de produtos no estoque, afetam diretamente a lucratividade das empresas.

Outro ponto crucial é a negociação com os fornecedores. Ao qual a empresa a partir do preço estabelecido nessa negociação, poderá reduzir ou não seus custos.

Para Ballou (1993), a atividade básica dos estoques é armazenar os itens que serão necessários ao processo produtivo, e no caso de produtos acabados, armazenar os destinados à venda. Cabendo ao gestor a responsabilidade de gerenciá-los da melhor forma, principalmente por estar diretamente relacionado ao nível de serviço prestado, pois a margem de venda da empresa está em boa parte relacionada a boa imagem que a empresa terá junto aos seus clientes no mercado, atendendo no momento certo, na quantidade adequada e com o melhor preço possível.

A gestão de estoques tem o papel crucial de determinar "o que" deverá manter em estoque, "quando" deverá reabastecer e "quanto" deverá requisitar de cada item. (OLIVEIRA; SILVA, 2014). A importância da gestão de estoque se dá devido a necessidade de esquilíbrio entre compra e venda desses produtos, buscando reduzir custo e aumentar o capital de giro da empresa.

\subsection{A IMPORTÂNCIA DO CONTROLE DE ESTOQUE}

De acordo com o Portal de Educação (2013) O controle de estoque é importante por representar para empresa um alto investimento, devendo a mesma observar e se adequar aos tipos de estoques: mínimo e máximo, pois estes serão fundamentais para 
que não se adquira produto em excesso ou ocorra falta do produto quando o cliente solicitar. O controle tem essa função, analisar se está sendo efetuado de acordo com o que foi planejado: quanto mais íntegros, determinados e administrados forem as ações, mais fácil será o controle.

Segundo Dantas (2015, p.23):

O estoque é um item indispensável para a composição de uma empresa, seja ela industrial ou comercial. O modo como ele é armazenado e controlado pode aumentar a lucratividade da entidade ou causar transtornos para a mesma. Para isso, é indispensável que o gestor participe fielmente na administração da empresa.

No controle do estoque outro ponto importante a ser tratado é a acuracidade, permitindo ao gestor comparar o estoque físico com o virtual, de forma que sejam verificados se o número de produtos existentes no estoque da empresa, é o mesmo que está sendo informado pelo sistema. A acuracidade fornecerá ao gestor o percentual correspondente a assertividade do estoque. Ou seja, a acuracidade informará o quão próximo o estoque virtual está do real.

Para Nunes et al. (2014), a acuracidade do estoque é um indicador ao qual emite uma confiabilidade das informações existentes no sistema de acordo com a existência física dos itens controlados. Ainda segundo o autor, no momento que esta acuracidade não existir, pode vir a ocorrer alguns problemas como: sobra e ausência de produtos. Sendo esta última um problema que pode trazer fortes consequências econômicas, como a extinção da essência da organização.

\subsection{SISTEMAS DE GERENCIAMENTO DE ESTOQUE}

A gestão de estoques pode ser feita através de dois tipos: periódico ou permanente. Conforme Rosa; Mayerle; Gonçalves (2010) o modelo de revisão periódica consiste em definir um intervalo ótimo entre cada solicitação, onde a quantidade solicitada varia a cada novo pedido, de acordo com o consumo no período anterior. Por isso Dias (1993, p.126) afirma que "todas as formas de registro de estoque objetivam controlar a quantidade de materiais em estoque, tanto o volume físico quanto o financeiro."

A figura 1, retrata o lote de ressuprimento no sistema de revisão periódica, onde os lotes são adequados ao consumo de modo que possa suprir alguma situação, como: alto consumo ou possíveis atrasos por parte dos responsáveis pelo abastecimento.

FIGURA 1- Gráfico dente de serra na revisão periódica

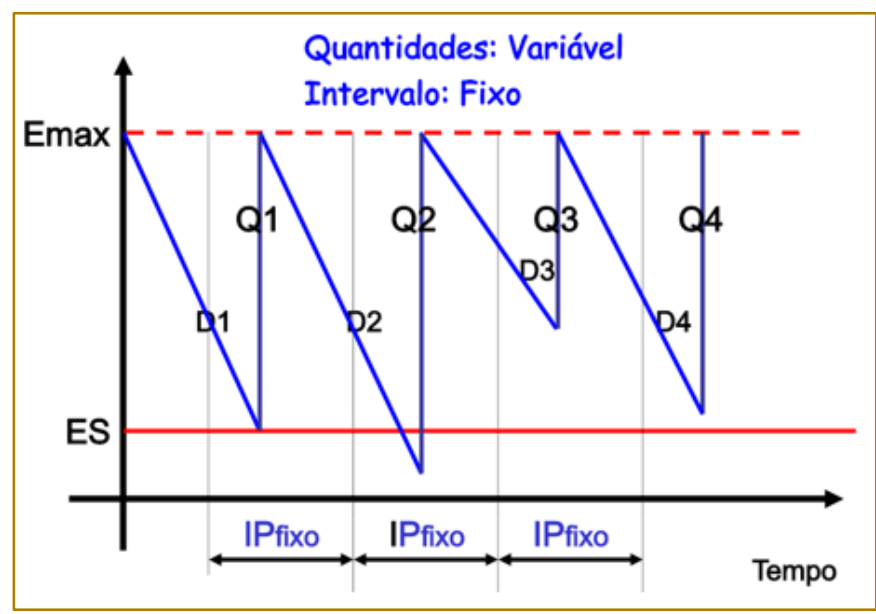

Fonte: TSestoque (2017).

Conforme Silva (2003), o inventário periódico é geralmente apropriado para empresas que tem uma elevada rotação em seus estoques, como por exemplo: supermercados ou farmácias, porém algumas dessas empresas já possuem sistemas de controle totalmente eficientes e integrados com seus fornecedores, almoxarifados entre outros.

Em relação ao sistema de revisão contínua, Rosa; Mayerle; Gonçalves (2010), comenta 
que este modelo consiste em estabelecer um nível fixo de reposição, onde ao ser atingido, dispara a emissão de um novo pedido de tamanho pré-estabelecido. A figura 2, mostra o volume de reabastecimento constante, onde não existe uma data fixa para realização dos pedidos, o intervalo de ressuprimento é variável.

FIGURA 2 - Gráfico dente de serra na revisão contínua

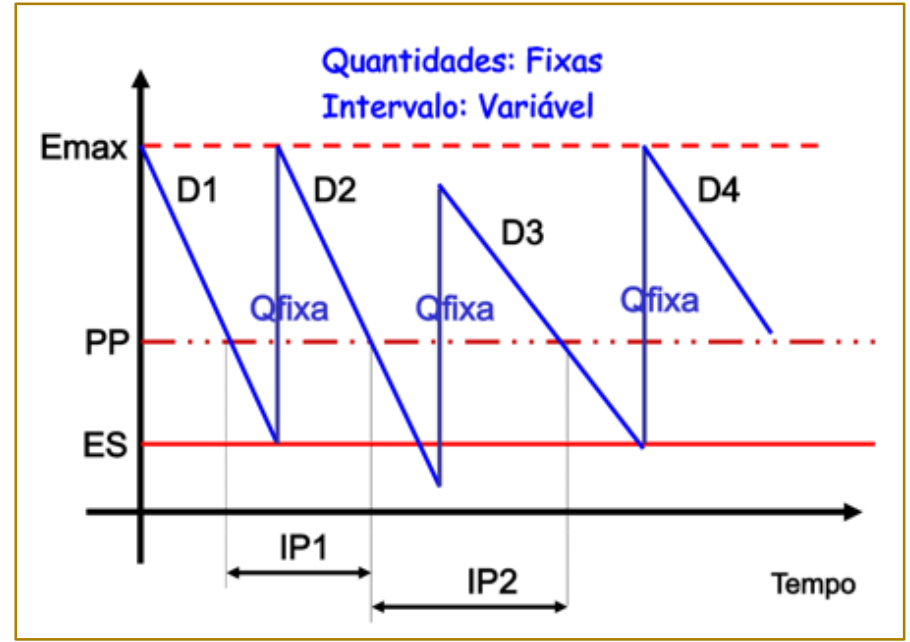

Fonte: TSestoque (2017).

Os sistemas de gerenciamento dos estoques são importantes por definir se a organização adotará a revisão periódica ou contínua e isso facilita na utilização da curva $A B C$, já que a mesma classifica os produtos de acordo com a maior relevância que esses possuem.

\subsubsection{CURVA ABC}

A Curva ABC também conhecida como curva de Pareto ou curva 80-20, é considerada uma das principais ferramentas de controle de estoque, que classifica as informações sobre os produtos, separando os materiais de alta, média e pequena relevância para empresa. A curva $A B C$ propicia ao gestor um critério de seleção dos produtos em seu estoque, onde os que possuem um alto valor agregado, geralmente estão em menores quantidades, exigindo da gestão um cuidado maior, principalmente por ter uma alta representatividade na lucratividade da empresa.

Segundo Amaral (2013), a curva ABC é usada para identificar a importância de cada item no estoque, seja em relação à lucratividade, faturamento ou até mesmo em relação ao giro de cada item no estoque. Para um controle mais rígido, os itens são divididos em três grupos:
Classe A: São os produtos fundamentais em estoque e com alto privilégio ou seja $20 \%$ dos produtos condizem relativamente a $80 \%$ do valor.

Classe B: São os produtos que ainda são vistos economicamente preciosos. $30 \%$ dos produtos condizem relativamente a $15 \%$ do valor.

Classe C: São os produtos de baixo valor ou de baixa movimentação. $50 \%$ dos produtos condizem relativamente a $5 \%$ do valor.

A representação gráfica da curva $A B C$ pode ser visualizada na figura 3 , onde para ser elaborar a curva, deve-se levar em consideração algumas etapas que são necessárias na obtenção do cálculo. Na 1ำ etapa lista-se todos os itens, ou seja, deve ser identificado todos os produtos presentes nos estoques, determinando o preço por unidade, quantidade, valor total e sua descrição; na $2^{\circ}$ etapa: é feito a reorganização do valor total, organizando de modo que seja formulada uma lista dos valores em ordem decrescente; na $3^{\circ}$ etapa deve ser calculado o valor acumulado e na última etapa: deve-se calcular a frequência acumulada, de modo que se defina as categorias segundo as classificações A,B ou C. 
FIGURA 3 - Curva ABC para produtos em estoque

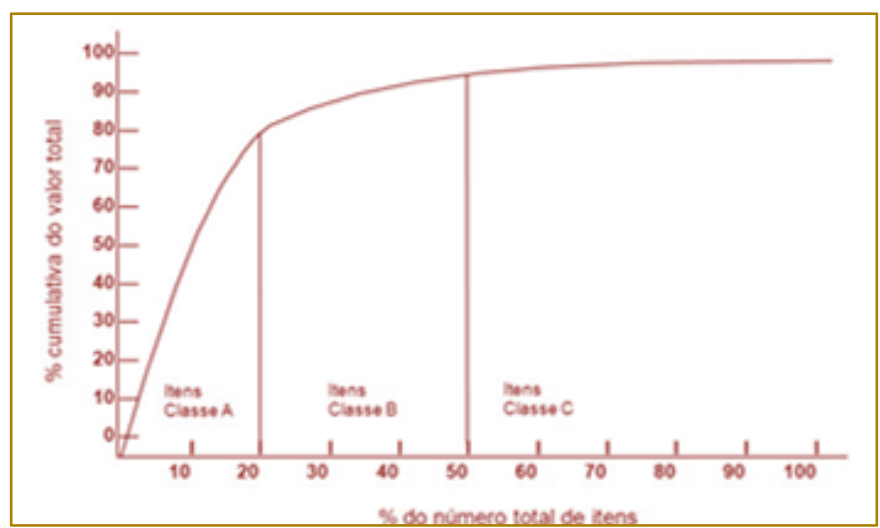

Fonte: Slack et al. (2009, p. 379).

A curva $A B C$ proporciona benefícios para as empresas, como redução dos desperdícios e aumento da lucratividade, auxiliando a empresa na elaboração de estratégias facilitando o processo de tomada de decisão.

\subsection{COMÉRCIO VAREJISTA}

Varejo é o local designado para os setores de comércio ao qual realizam suas vendas diretamente aos seus clientes finais, as atividades feitas no comércio varejista são importantes pelo fato de que é gerador de grandes quantidades de emprego no Brasil.

Segundo Nunes; Sousa (2013, p.7) "É no ambiente varejista que, regularmente, as demandas dos consumidores finais são supridas através da pulverização de itens em pequena quantidade para um grande número de pessoas", ou seja, afirma-se que todos os recursos de grande parte da população são realizados nas compras em pequenas quantidades nos comércios varejistas.

Os itens primordiais do setor varejista são: supermercados, lojas de vestuários, farmácias, posto de gasolina, lojas de móveis e decoração, lojas de eletroeletrônicos, e livrarias. Sendo de extrema importância nesse segmento, a utilização de ferramentas de gerenciamento dos estoques, principalmente pelo alto volume e variedade existente em seus estoques.

\section{METODOLOGIA}

No presente trabalho, a pesquisa utilizada foi do tipo qualitativa-descritiva. Que de acordo com Silva; Menezes (2005, p.20) "A pesquisa qualitativa considera que há uma relação dinâmica entre o mundo real e o sujeito, isto é, um vínculo indissociável entre o mundo objetivo e a subjetividade do sujeito que não pode ser traduzido em números". Também foi feito uma pesquisa bibliográfica ao qual consiste na etapa inicial que é reunir o maior número de informações possíveis, pois esses servirão de base para a construção da investigação. Tendo como ponto principal da pesquisa o estudo de caso no supermercado vida nova em Aliança - PE, onde para o processo de coleta dos dados, foi feita uma entrevista com o gestor da empresa por meio de um questionário estruturado, com 18 perguntas, ao qual foram divididas em três blocos, o primeiro bloco abordou o processo de aquisição de mercadorias e saídas de produtos, o segundo bloco analisou 0 comportamento do controle de estoques e o último apresentou as práticas adotadas e os benefícios obtidos pelo Supermercado.

\section{ESTUDO DE CASO: RESULTADO DA PESQUISA}

\subsection{DESCRIÇÃO DA EMPRESA ESTUDADA}

A empresa estudada tem como razão social Supermercado Vida Nova, fundada em 1989, atuando no mercado há 29 anos, localizada no centro da cidade de Aliança- PE, é uma empresa de pequeno porte e possui atuação no segmento varejista de produtos alimentícios, nos anos iniciais essa organização iniciou-se como um ponto de venda e com o decorrer do tempo foi se ajustando ao mercado e focalizando seus 
esforços pra se tornar então o supermercado que é nos dias atuais com grande referência na cidade.

\subsection{ANÁLISE DO RESULTADO DA PESQUISA}

\subsubsection{PROCESSO DE AQUISIÇÃO DE} MERCADORIAS E SAÍDAS DE PRODUTOS

Nesse bloco foram atribuídas algumas questões dando ênfase à parte de compras e comercialização dos produtos, assim como as principais atividades referentes ao estoque da organização, abordando se o estoque é centralizado ou descentralizado. O entrevistado afirmou possuir estoques descentralizados, sendo no total 5 estoques que abastecem apenas a sua empresa.

Quanto à aquisição de mercadorias e saídas de produtos, a figura 4 demonstra como ocorre esse ciclo dentro da empresa em estudo. Primeiro, o fornecedor comparece à empresa para negociação, a partir desse momento o gestor solicita as compras necessárias para o suprimento dos seus clientes, compreendido com o que tem em seus estoques, e ao receber a mercadoria solicitada, faz a conferência da mesma, com base na nota fiscal. Em seguida a mercadoria é armazenada nos estoques, sendo feita a reposição das prateleiras do supermercado, de acordo com a necessidade.

FIGURA 4 - Ciclo do Processo de Aquisição de Mercadorias e Saída dos Produtos

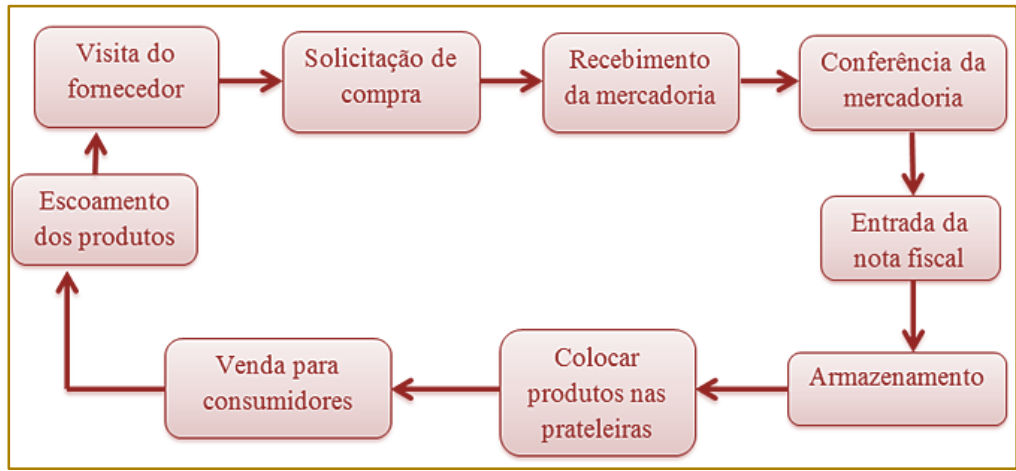

Fonte: Elaborado pelo autor. (2018).

Após a visualização do ciclo de aquisição de mercadorias dentro da empresa, será retratado alguns pontos importantes acerca do produtos adquiridos e da forma como eles são monitorados.

\section{a) Aquisição dos produtos e monitoramento do fluxo}

Em relação à aquisição dos produtos e ao monitoramento do fluxo desse material, foi questionado se era utilizado alguma ferramenta para efetuar o controle de estoques, e o gestor respondeu que possui um funcionário que fica responsável pelo recebimento da mercadoria, e afirma que essa mesma pessoa confere manualmente toda a movimentação das entradas e saídas de seus produtos. A empresa não utiliza nenhuma ferramenta para controlar seus estoques. E quando há necessidade de nova aquisição, um funcionário confere a quantidade existente e se for necessário, adquire-se a quantidade necessária. Esse procedimento é feito com o fornecedor na empresa, esperando o pedido com os produtos e as quantidades desejadas.

\section{b) Prazo de Validade dos produtos}

No que se diz respeito aos produtos que venceram ou que já estão próximo do prazo de validade, foi questionado se é executada algum contrato com o fornecedor, tipo consignação, para retirada desses produtos vencidos do estoque ou se a empresa possui alguma ação que tenha o intuito de retirar esses produtos. E o mesmo afirma, que em situações como esta, a empresa promove promoção, baixando o preço de forma a estimular a aquisição por parte dos consumidores, e aqueles produtos que mesmo com essa ação, permanecem em seus estoques, a empresa devolve para o fornecedor. Este procedimento é feito com a nota de devolução, sendo recebido outro produto na mesma quantidade devolvida e com novo prazo de validade, e se o produto fornecido não obtiver saída, mesmo estando com o prazo de validade ainda distante, é 
feito a troca por outro item que tenha mais saída.

\section{c) Arranjo Físico dos Estoques}

Referente ao arranjo dos seus estoques, é verificado se é feito de acordo com a característica do produto, e o gestor afirma que até tenta realizar a arrumação conforme as características dos materiais, mas que não obtêm êxito. Ainda em relação ao arranjo físico dos estoques, o gestor afirma que os produtos de maiores movimentações estão localizados perto das portas, ficando o mais acessível possível, de modo a otimizar tempo e espaço.

Referente aos produtos refrigerados que são comercializados na organização, questionou se esses produtos possuíam estoques próprios e se outros fatores como estrutura e temperatura são favoráveis a esses produtos. O mesmo afirmou que os estoques dos produtos refrigerados são feitos nos próprios freezers, localizados dentro do supermercado, não havendo necessidade de estocar maiores quantidades em seus estoques, sendo a quantidade adquirida suficiente para atender seu público.

\section{d) Determinação do Estoque Mínimo e/ou Máximo}

Quanto ao modo como é estabelecido o estoque mínimo e/ou máximo, o gestor informou que ambos são utilizados, e que a quantidade mínima é estabelecida com base no giro de estoque e no fornecedor, onde os produtos em maiores quantidades são solicitados, quando o fornecedor comparece a empresa uma vez ao mês.

Em relação aos produtos que agregam maiores valores aos estoques, e ao modo como eles são tratados, o gestor respondeu que os produtos que mais agregam à sua empresa, são a charque (Carne salgada) e o leite. Esses produtos são tratados de forma diferenciada, porém o mesmo não faz uso da curva $A B C$. A curva poderia facilitar 0 gerenciamento desses produtos e de algum outro que também agregue valor e que eles desconheçam.

\subsubsection{COMPORTAMENTO DO CONTROLE DE ESTOQUES}

Nesse bloco referente ao controle de estoques, foram tratadas algumas questões que envolviam essa temática, na qual foram verificados alguns atributos como: confiança nos fornecedores, demanda, produtos, poder de barganha, planejamento das compras, periodicidade entre outros a serem abordados nos tópicos.

\section{a) Credibilidade dos fornecedores}

Quanto à confiança nos fornecedores, o gestor comentou que para sua empresa é essencial ter fornecedores íntegros e comprometidos. E como suas compras são feitas com certa periodicidade, esse aspecto torna-se imprescindível.

Também foi questionado se existiam fornecedores alternativos para os produtos comercializados em seu negócio, ele afirmou que existem produtos que possuem cinco fornecedores, por exemplo, visando obter o maior número de cotações para que adquira o produto com o preço mais acessível.

\section{b) Demanda}

Em relação à forma como a demanda era estipulada e se alguma ferramenta era utilizada, o mesmo respondeu que não existe uma certa previsibilidade na demanda, o estoque é conferido praticamente no mesmo momento que o fornecedor comparece à empresa. Ou seja, não existe um planejamento em relação à aquisição dos produtos, ocasionando em alguns momentos ausência de alguns itens, por não haver esse planejamento e nenhuma ferramenta que o auxilie nesse controle. $\mathrm{Na}$ realidade, a demanda é calculada de acordo com o fornecedor e através do estoque, sendo feita nessa consulta uma média pelo que foi vendido em todo o mês. Este é o parâmetro para a realização de novas compras.

\section{c) Produtos e Poder de barganha}

Referente ao preço dos seus produtos foi questionado se ocorriam alterações, sendo respondido que o preço dos produtos vendidos em seus supermercados são estáveis na maior parte do tempo, mas que o aumento de preço pode ocorrer em determinados momentos, de acordo com a necessidade, mas numa proporção muito menor. Inclusive o grande motivo de seus produtos terem preços tão estáveis, está na aquisição de grandes quantidades, onde a empresa consegue obter preços mais baixos. Não são descontos extraordinários, mas são agradáveis e que de acordo com a quantidade adquirida.

d) Planejamento da compras e Periodicidade dos produtos 
Quanto ao planejamento, já foi visto na figura 4, no tópico 4.2.1, que não existe um planejamento, as compras são feitas no exato momento em que o fornecedor comparece à empresa. Já quanto à periodicidade dos produtos que não obtiveram saídas, o gestor comentou que essa questão é verificada a cada 30 dias e que a partir disso, faz-se uma atuação maior sobre esses produtos para que escoem com mais facilidade. Também foi questionado quais fatores contribuíam para que esses produtos encalhassem, e o mesmo respondeu que percebeu que alguns produtos possuem questões regionais, citando como exemplo, que determinadas

marcas de café que não são conhecidas naquela região, se não forem ofertadas para degustação, os clientes não irão adquirir por não ter conhecimento daquele produto.

A respeito dos produtos sazonais, questionouse quais procedimentos eram adotados, e o gestor informou que toma por base o ano anterior tendo em vista o mercado atual, E complementa, que se o mercado atual está em baixa a empresa obtêm uma quantidade menor, já quando o mercado está em alta, é verificado o que foi adquirido no ano anterior e se houver necessidade aumenta as vendas.

Com relação a ausência de produtos, o gestor respondeu que todo dia é verificado se está faltando produtos, pelo simples fato de todos os dias ter um fornecedor diferente visitando a empresa. Também foi informado que as faltas dos produtos ocorrem, devido à imprevisibilidade do mercado, o mesmo ainda citou que existem casos em que um único cliente adquire todos os produtos de determinada marca, zerando a prateleira. E em situações como essa, o reabastecimento ocorre imediatamente, mas caso não tenha aquele determinado produto em estoque, naquele momento, o mesmo ficará ausente das prateleiras por muitos dias, até ser reabastecido novamente pelo fornecedor.

\subsubsection{PRÁTICAS ADOTADAS E OS BENEFÍCIOS OBTIDOS}

Nesse bloco buscou-se compreender quais práticas eram adotadas para o controle de estoques no supermercado vida nova e, o gestor afirmou que em cada sessão do supermercado, existe uma pessoa específica, responsável pela organização e conferência de todos os produtos, inclusive dos prazos de validade. Afirma também, que para isso, é bastante rígido com todos os funcionários para que cumpram com suas responsabilidades. Essa cobrança ocorre, por saber que essa prática adotada resultará em benefícios para a desenvolvimento da empresa, minimizando os prejuízos e gerando resultados positivos em termos de lucratividade.

Em relação aos problemas enfrentados pela organização e as maiores dificuldades no gerenciamento dos estoques, o gestor comentou que a ausência de alguns itens procurados pelos clientes, ainda é um problema que persiste.

A respeito do que deveria ser melhorado nos estoques da empresa, o mesmo reconhece que deveria existir um maior controle de seus estoques, onde fosse verificado a cada 3 meses quais itens constam em seus estoques, e não como é realizado hoje, uma vez ao ano.

\section{CONSIDERAÇÕES FINAIS}

No controle de estoques é fundamental ter o propósito de atender suas necessidades/expectativas aos seus respectivos clientes, ou seja, a demanda máxima que pode existir em sua organização e para isso o gestor deve se programar tendo em vista que deve haver uma eficiência em seu controle.

Relacionada ao atendimento, a demanda é fundamental até mesmo para que não falte o produto, pois a ausência do mesmo implicará em uma busca do cliente em outro estabelecimento, podendo ocorrer uma possível perda, relacionada à rentabilidade da empresa.

O controle de estoques deve ser visto de maneira estratégica, de forma que se integre aos diversos setores da empresa, indo desde a produção até o financeiro. A ausência do controle de estoque associado à falta de alguns produtos, pode afetar diretamente as vendas, gerando para a empresa em estudo grandes prejuízos.

Segundo a pesquisa realizada no Supermercado Vida Nova, pode-se perceber que os maiores problemas enfrentados pelo gestor em relação aos estoques consiste na ausência de uma ferramenta de monitoramento e no modo como o estoque é posicionado, de forma descentralizada, o que contribui para a falta de alguns produtos procurados pelos clientes, associados à 
necessidade de ter uma previsibilidade de demanda. De acordo com as informações obtidas a partir da pesquisa feita no Supermercado Vida Nova, recomenda-se centralizar seu estoque, o que proporcionará para o mesmo um controle bem melhor em relação ao modo como vem sendo trabalhado. Ou caso não exista possibilidade em centralizar, sugere-se que sejam alocadas porcentagens de itens distribuídos igualmente para todos os cinco estoques, não ocorrendo excesso de alguns produtos e falta em outros.

Relacionado a demanda, a forma como ela é prevista deve ser alterada urgentemente, deve-se haver um planejamento, a demanda é algo que tem que ser vista com antecedência, até mesmo antes da chegada do fornecedor para não perder tempo conferindo a quantidade existente nos estoques. Pois a forma como vem sendo determinada,

\section{REFERÊNCIAS}

[1] AMARAL, J. L. S. Gestão de Estoques na Indústria Têxtil: Malhas D'estefano em estudo de caso. 2013. 59f. Monografia (Graduação em Engenharia de Produção). - Universidade Federal de Juiz de Fora, MG.

[2] BALLOU, Ronald H. Logística Empresarial: transportes, administração de materiais e distribuição física. 1.ed. São Paulo: Atlas, 1993.

[3] DANTAS, J. C. A. A Importância do Controle de Estoque: estudo realizado em um supermercado na cidade de Caicó /RN. 2015. 55f. Monografia (Bacharel em Ciências Contábeis). Universidade Federal do Rio Grande do Norte, RN.

[4] MARTELLI, L. L.; DANDARO, F. Planejamento e Controle de Estoque nas Organizações. In: Revista Gestão Industrial, Ponta Grossa, v. 11, n. 2, p.170-185, jan./mai. 2015.

[5] NUNES, F. R. M ; SOUSA, E. C. A influência do centro de distribuição no desempenho logístico de empresas varejistas de supermercado no município de fortaleza: estudo de multicascos. Revista Ciência Administrativa, Fortaleza, v. 19, n. 1, p.353-379, jan./jun. 2013.

[6] NUNES, R. V. et al. A relevância do estudo da acuracidade de estoques em um comércio atacadista. X Congresso nacional de excelência em gestão - CNEG. Ceará/CE - 8 e 9 de agosto de 2014.

[7] PORTAL DA EDUCAÇÃO. A importância dos estoques. Logística empresarial. Disponível favorece a não solicitação de algum item, fazendo com que o mesmo falte nas prateleiras, comprometendo dessa forma o nível de serviço prestado. Outro fator a ser revisto, é em relação aos produtos que não obtiveram saída, sugere-se reduzir o prazo trabalhado, que atualmente é de 30 dias, realizando inventários com periodicidade quinzenal, por exemplo, em uma semana fazse o inventário de massas, em outra semana, de latas e assim sucessivamente, fazendo com que o gestor conheça melhor o valor do seu estoque.

Em empresas que não possuem um rigoroso controle do estoque, o inventário torna-se imprescindível, por evitar divergências entre o estoque físico e contábil, fornecendo informações acerca das perdas e desperdícios que estão ocorrendo no estoque.

em:<https://www.portaleducacao.com.br/conteudo/ artigos/educacao/a-importancia-dos estoqueslogistica-empresarial/31350> Acesso em: 02/12/2017.

[8] RAMOS, S. A. Proposta de implantação de um sistema de controle de estoque.2006. 62f. Monografia (Bacharel em Administração). Universidade do Vale do Itajaí - CE.

[9] ROSA, H.; MAYERLE, S. F.; GONÇALVES, M. B. Controle de Estoque por Revisão Contínua e Revisão Periódica: uma análise comparativa utilizando simulação. In: Revista Produção, v.20, n.4, Out/Dez-2010.

[10] SILVA, E. L.; MENEZES, E. M. Metodologia da pesquisa e elaboração de dissertação. 4. ed. Florianópolis, 2005.

[11] SILVA, R. B. A avaliação e Controle de Estoques e suas influências no resultado de empresas. 2003. 60f. Trabalho de Conclusão de Curso (Graduação em Ciências Contábeis). Universidade Federal de Santa Catarina, SC.

[12] SLACK, N et al. Administração da produção. 3. ed. São Paulo: Atlas, 2009.

[13] TSESTOQUE. O que é gestão de estoques?- Parte 3 (Ponto de Ressuprimento). Disponível em: $<$ http://universidadeestoque.com.br/blog/index.php /o-que-e-gestao-de-estoques-parte-3-ponto-deressuprimento/>.Acesso em: 16/05/2018. 


\section{Capítulo 4}

\section{LOCALIZACÃO ESTRATÉGICA DE UM CENTRO DE DISTRIBUIÇÃO PARA REDUCCÃO DOS CUSTOS OPERACIONAIS: UMA APLICAÇÃO DO METTODO DO CENTRO DE GRAVIDADE}

\section{Thayane Nascimento de Azevedo}

Deborah Porto de Almeida Cardoso

Cássia Cristina Costa do Carmo

Ruy Gomes da Silva

Resumo: A decisão em se instalar um centro de distribuição vai não somente na escolha de um local com menor custo de aluguel ou compra, devem-se levar em consideração outras variáveis como a demanda da região, os custos com o transporte, bem como a localização geográfica em relação às demais lojas da franquia. Com essa perspectiva este artigo trata de um estudo de caso, no qual se aplicou o método do Centro de Gravidade em uma empresa do setor farmacêutico, a fim de identificar o local mais estratégico para mudar a instalação de seu centro de distribuição, de modo que todos os clientes sejam atendidos e a mesma tenha uma redução de custos operacionais. O método utilizado mostrou-se satisfatório, a localidade sugerida proporcionará uma redução de $R \$ 1.391 .397 .072,01$ nos custos de transporte e melhor posicionamento em relação aos seus clientes. Dessa forma, aumentará a qualidade de atendimento e proporcionará uma maior competitividade no mercado para empresa estudada.

Palavras-chaves: Método do Centro de Gravidade, Centro de Distribuição, Redução de custos, Competitividade, Logística. 


\section{INTRODUÇÃO}

A localização estratégica adequada de um centro de distribuição é fundamental para a eficiência no nível de serviço de toda organização. Tal critério é ainda mais crucial para as empresas transportadoras, pois exercem um papel fundamental no sistema de integração entre pontos da cadeia de suprimentos, onde há escoamento dos produtos e fluxo de insumos no mercado (SOUZA et al., 2015).

Ramos (2015) complementa que a localização ideal de um centro de distribuição de qualquer segmento de negócio é justificada principalmente pela redução dos custos operacionais, envolvendo diretamente os custos de transporte, já que os tempos de espera com veículo parado nos engarrafamentos impactam de forma acentuada o componente de custo.

Atualmente, com o aumento das transações comerciais, Souza et al. (2015) afirmam que há uma tendência das empresas em atingir mercados em diferentes localidades. Porém, os autores ressaltam que, em determinadas situações percebe-se que a instalação física da empresa torna-se inviável em relação aos custos e acesso aos clientes e, que um dos fatores críticos para o sucesso é a busca pelo melhor local geográfico onde a instalação deve ser implantada, pois há altos investimentos envolvidos para a sua decisão.

Este artigo se insere nesta temática com o objetivo identificar o melhor ponto de instalação para um centro de distribuição e compará-lo com a posição atual, tendo em vista minimizar os tempos e custos operacionais ao atender a demanda de uma empresa do comércio varejista. O estudo foi elaborado através da aplicação do método do centro de gravidade, com análise de variáveis como: tempo, custo de transporte, demanda e coordenadas geográficas das lojas dependentes do centro de distribuição para reposição de seus estoques.

Mediante a apresentação do objetivo do trabalho, surge a seguinte pergunta de pesquisa: A aplicação do método do Centro de Gravidade para localização estratégica de um Centro de Distribuição pode auxiliar em uma redução significativa nos custos logísticos, sem deixar de atender a demanda por seus produtos? E como sua implementação auxiliará no aumento dos lucros empresariais, bem como uma maior competitividade no mercado?

\section{REFERENCIAL TEÓRICO}

Nesta seção apresenta-se o embasamento teórico necessário para desenvolver o presente estudo, no qual são levantados os principais conceitos de Logística, Centro de Distribuição, localização e método do Centro de Gravidade.

\section{1. LOGÍSTICA}

Pires (2004), esclarecer que a logística inclui o processo de planejamento, implementação e controle da eficiência, custos efetivos de fluxos e estoque de matéria-prima, estoque circulante, mercadorias acabadas e informações relacionadas do ponto de origem ao ponto de consumo com a finalidade de atender aos requisitos do cliente.

Novaes (2007), afirma que a logística se refere a agregar valor de lugar, tempo, qualidade e informação e explica que as atividades logísticas, geralmente, são confundidas apenas com transporte e armazenagem. Desta forma, a logística empresarial que, atualmente, é exercida nas empresas implica na melhoria dos recursos, eliminando processos que provoquem custos altos e não geram valor ao consumidor final.

Diante disso, em uma época de muita competitividade, devem-se encontrar outras formas de se destacar no mercado. As operações logísticas têm tudo a ver com os aspectos apresentados, pois é ela que ajudará a empresa a ser cada vez mais eficiente, eficaz e competitiva.

\section{2. CENTRO DE DISTRIBUIÇÃO}

A distribuição física é entendida como processos operacionais e de controle que permitem transferir os produtos desde o ponto de fabricação, até o local em que a mercadoria é finalmente entregue ao consumidor final (NOVAES, 2015). O Centro de Distribuição (CD) tem a função de dar suporte às empresas para que tenham o produto disponível no momento em que realizar o pedido, assim facilitando a entrega mais rápida ao cliente, satisfazendo às suas necessidades.

Os centros de distribuição utilizam armazéns que realizam a gestão do estoque e a sua distribuição física surgem como uma alternativa para as empresas quando o objetivo é encurtar as distâncias entre os 
parques fabris e seus clientes (CARVALHO E MACEDO, 2010). Calazans (2011) enumera as principais funções do $C D$, tais quais são: recebimento, movimentação, armazenagem, separação de pedidos e expedição (figura 01):

Figura 1 - Funções básicas do CD

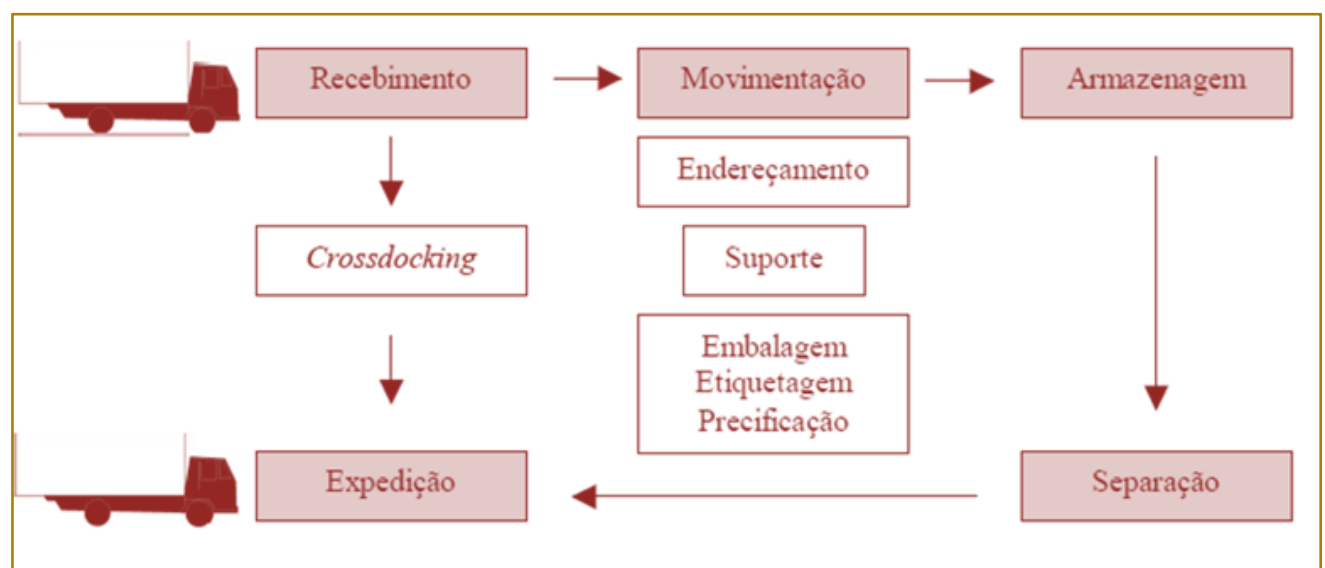

Fonte: Adaptado de Calazans (2011)

Os custos de armazenagem em CDs são justificáveis, uma vez que podem ser compensados com a redução dos custos produtivos, pois seus estoques absorvem as variações dos níveis de produção. Os estoques em CDs podem reduzir custos de transporte, pois permitem o uso de quantidades maiores e mais econômicas nos lotes de carregamento (BALLOU, 2007).

De acordo com Vieira et al. (2011), para a instalação de um centro de distribuição é necessário que se levante o montante que será investido e a localização que melhor atenderá o mercado consumidor.

Pode-se notar que um CD é extremamente estratégico dentro das atividades empresariais, por que essas atividades estão diretamente ligadas ao controle de estoques e mercadorias. A localização do CD precisa ser bem planejada para que atenda as necessidades da empresa.

\section{3. LOCALIZAÇÃO}

Cada empreendimento possui características que devem ser respeitadas durante a escolha da localização. O tipo de cada operação realizada e os produtos ofertados contribui para essa tomada de decisão. A localização de instalações tem como objetivo a escolha do melhor local para uma ou diversas instalações dado um conjunto de locais possíveis, a fim de se obter o menor custo possível e/ou a maximização dos lucros (BALLOU, 2001).

A escolha por uma localização pode envolver variados fatores, como custos de transporte; impostos e incentivos; potencial de mercado; qualidade de vida; acesso à infraestrutura de transporte; infraestrutura local de serviços; custo de espaço e disponibilidade para expansão (FERREIRA et al., 2013; CORRÊA e CORRÊA, 2005).

Saber onde melhor localizar uma instalação envolve uma questão estratégica de longo prazo. O seu investimento econômico pode influenciar em todas as demais decisões da cadeia de suprimentos de uma empresa, ou seja, a decisão não se torna apenas uma questão econômica, mas também de sobrevivência da empresa (PAMPLONA et al., 2014)

Os estudos de localização buscam determinar as melhores alternativas para a escolha do local de instalação de uma unidade, dentro de um conjunto geográfico possível. Assim, diversos fatores locacionais são analisados, comparados e combinados, o que orienta as decisões de localização (MACEDO; ALMEIDA; BARBOSA, 2008).

Melachrinoudis e Min (2000) afirmam que os problemas de decisão sobre a localização de facilidades envolvem diversos fatores, quantitativos e qualitativos. Diante disso, é muito importante o uso de ferramentas e métodos de auxílio na decisão da nova instalação. Diante do apresentado, atribuiu-se 
a necessidade para este trabalho de se utilizar um método quantitativo.

\subsection{CENTRO DE GRAVIDADE}

O método do centro de gravidade é um método quantitativo. Também conhecido como p-gravidade ou método de centroide, esse método é um pouco mais complexo, mas também é o mais realista diante da real situação que as empresas enfrentam na localização de facilidades (Slack et al., 2002).

O método do centro de gravidade é baseado no fato de que todas as localizações possíveis têm um "valor" que é a soma de todos os custos de transporte para aquela localização. A melhor localização, a que minimiza custos, é representada pelo que, em uma analogia física, seria o centro de gravidade ponderado de todos os pontos para onde as mercadorias são transportadas.

Segundo Bowersox e Closs (2001), uma alternativa para buscar a melhor localização geográfica é através do método Centro de Gravidade. Este centro pode ser relacionado a vários tipos de taxas, como peso, volume e distância para selecionar a alternativa de menor custo. Segundo Ballou (2009) o centro de gravidade exato possui uma abordagem simples, dada uma série de pontos representando fontes e demanda, o objetivo deste método é minimizar a o custo total do transporte. Para isso utiliza-se a equação 1 a seguir:

$$
\operatorname{Min} \mathrm{TC}=\sum \mathrm{Vi} \times \mathrm{Ri} \times \mathrm{di}
$$

A localização da instalação é encontrada pela resolução de duas equações para as coordenadas da localização. Para o calculo da coordenada $\times$ no plano cartesiano utiliza a equação 2:

$$
X=\frac{\sum V_{i x} R i x \times i / d i}{\sum V i x R i / d i}
$$

E para determinar a coordenada y do novo ponto, utiliza-se a equação 3 a seguir:

$$
Y=\frac{\sum V i \times R i x Y i / d i}{\sum V i \times R i / d i}
$$

Em que:

$\mathrm{TC}=$ custo total do transporte;

$\mathrm{Vi}=$ volume no ponto $\mathrm{i}$;

$\mathrm{Ri}=$ taxa de transporte até o ponto i;

di = distância até o ponto i da instalação a ser localizada;

$\mathrm{Xi}=$ coordenada na direção $\mathrm{x}$ do local $\mathrm{i}$;

$Y \mathrm{i}=$ coordenada na direção y do local $\mathrm{i}$.

O di da distância é estimado pela equação 4 seguinte

$$
\mathrm{d} i=\mathrm{K} \sqrt{(\mathrm{Xi}-\mathrm{X})^{2}+(\mathrm{Yi}-\mathrm{Y})^{2}}
$$

Em que $\mathrm{K}$ representa um fator de escala para converter uma unidade de uma coordenada em uma medida mais comum de distancia, por exemplo, milhas ou quilômetros. 
Hoover (1957) apud Ballou (2006) mostrou que as taxas de transporte decrescem com o aumento das distâncias. Ao buscar a minimização das taxas de transporte, uma instalação localizada entre uma fonte de matérias-primas e um ponto de mercado obterá um custo mínimo de transporte em um destes dois pontos. Desse modo a técnica do centro de gravidade é mais vantajosa quando os custos de transporte são substanciais no custo total do produto (SLACK et al., 2009).

\section{METODOLOGIA}

A metodologia aplicada neste trabalho baseia-se em uma revisão de literatura e um posterior estudo de caso. Segundo Boaventura (2004), o estudo de caso possui uma metodologia de pesquisa classificada como aplicada, na qual se busca a aplicação prática de conhecimentos para a solução de problemas sociais. Yin (2001) complementa tal afirmação ao dizer que o estudo de caso é uma investigação empírica que investiga um fenômeno contemporâneo dentro de seu contexto da vida real. Prodanov e Freitas (2013) ressaltam que tal estudo é classificado com um tipo de pesquisa qualitativa e/ou quantitativa. Diante do exposto, apresenta-se a seguir a empresa escolhida como objeto de estudo.

\section{OBJETO DE ESTUDO}

\subsection{APRESENTAÇÃO DA EMPRESA}

O estudo foi realizado em uma empresa varejista, denominada "grupo N", com localização no Estado do Pará, a empresa começou com a comercialização apenas de produtos farmacêuticos, conforme foi ganhando espaço no mercado adotou o conceito de drugstore e, dessa maneira, passou a realizar vendas de produtos de beleza, higiene pessoal e conveniência. Hoje, além dessas vendas, a empresa também conta com a produção de medicamentos e cosméticos manipulados.

O processo de distribuição de seus produtos ocorre diariamente, de acordo com os requisitos de abastecimento de cada uma das suas 14 lojas dependentes. Atualmente a empresa tem um custo de $\mathrm{R} \$$ 1.650.261.300,70 com o transporte das mercadorias e possui um eficiente esquema de planejamento das atividades de compras, armazenagem e gerenciamento de produtos em estoque.

\subsection{PROBLEMÁTICA}

Devido aos altos custos com transporte e consequentemente diminuição de sua receita, surge à necessidade da empresa instalar seu CD em um local mais estratégico, possibilitando a redução de seus custos operacionais, sem deixar de atender as necessidades de suas lojas na cidade de Belém. Para o gestor do grupo "N", a distância entre os pontos de origem e destino é indicador de relevância para o bom atendimento de seus clientes, em razão dos prazos a serem atendidos e qualidade na entrega. Dessa forma, torna-se necessário avaliar a possibilidade de instalar seu CD mais próximo de suas lojas.

Porém devido as grandes variáveis para a tomada de decisão, as possibilidades são várias. Além dos custos fixos, tem-se o destaque para as seguintes variáveis que influenciam nos custos operacionais: as distancias que serão percorridas, seus respectivos custos de transporte bem como a demanda de cada loja. É importante destacar que o grupo "N" tem como único modal de transporte o rodoviário e, que o tempo de distribuição depende dos congestionamentos e mobilidade das vias de cada bairro onde as lojas estão situadas.

Sabe-se que quanto maior a distância do CD até a loja maior será o tempo de transporte de mercadorias, consequentemente maior será seu custo, já que aumentará o uso de combustíveis nos caminhões. Por esta razão também é necessário analisar o volume que será transportado para cada loja, de forma a equilibrar a distância que será percorrida com a demanda necessária. Para isso foi analisado a demanda de produtos de cada loja nos últimos 12 meses, conforme figura 02 a seguir. 
Figura 02 - Gráfico da demanda dos produtos por loja

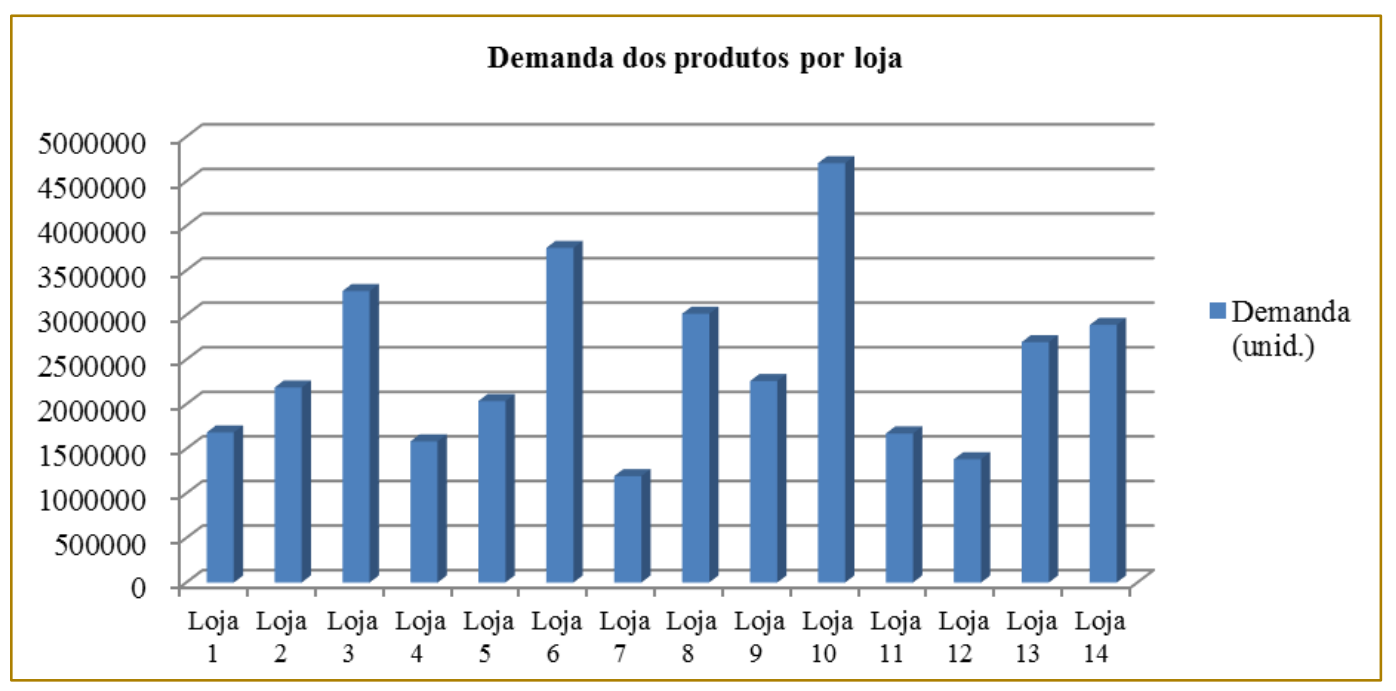

Fonte: Autores, 2018.

Para a construção do gráfico da figura 02 , utilizaram-se os dados apresentados pelas lojas. A partir do mesmo é possível observar, que a loja 10 é o que possui maior demanda, com 47.038 unidades e a loja 7 tem menor demanda, com 11.932 unidades. Tal fato influenciará na combinação das variáveis para o encontro da nova localização. Dessa maneira inicia-se a aplicação do Método do CG para resolver o presente problema, em razão do mesmo possibilitar que tais variáveis sejam ponderadas de forma a encontrar um ponto que apresente menor custo de transporte para a empresa instalar o seu CD.

\section{APLICAÇÃO DO MÉTODO CENTRO DE GRAVIDADE}

Após a coleta de dados como: demanda dos produtos por loja e o custo de transporte, disponibilizados pela empresa, realizou-se o levantamento da localização do Centro de distribuição e das 14 lojas, para isso foi preciso identificar no mapa (figura 03) onde as mesmas estão situadas:

Figura 03 - Mapa com a localização das lojas

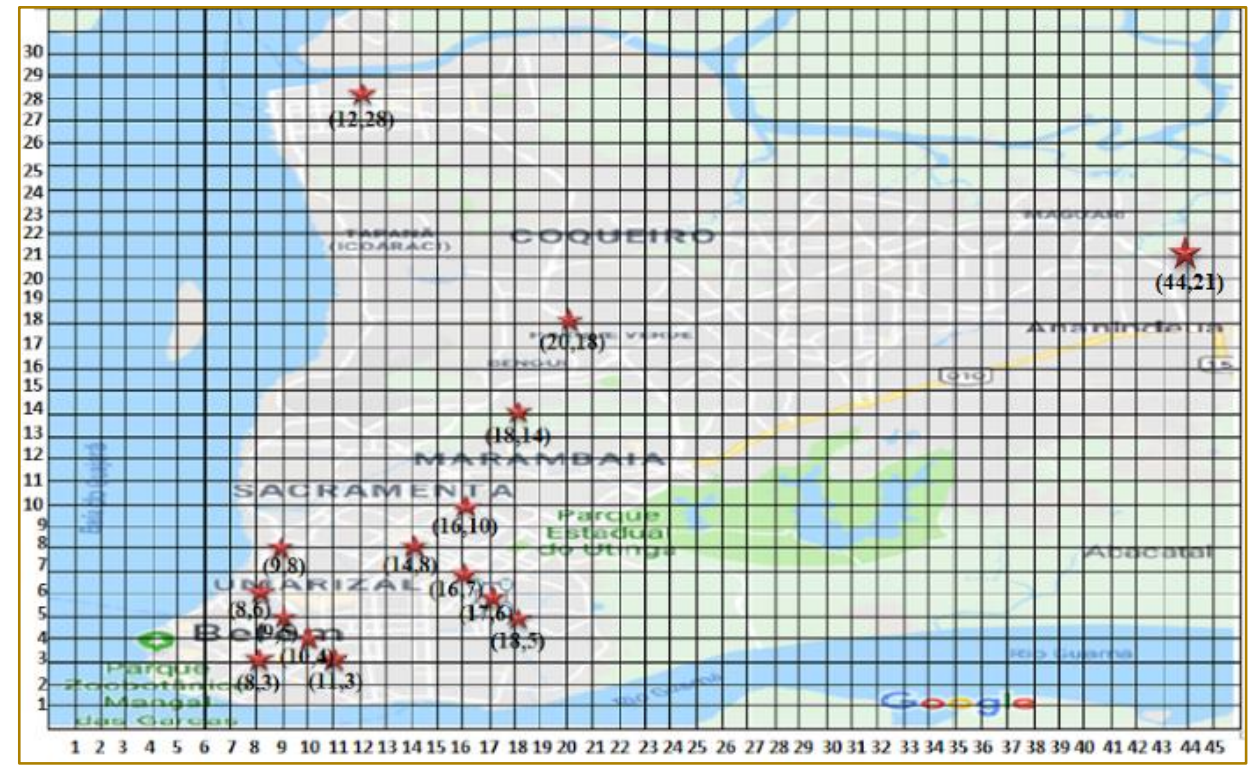

Fonte: Autores, 2018 
Diante do mapa com os pontos do CD atual (latitude: 44 e longitude: 21) e das 14 lojas identificados, construiu-se a tabela 01 (abaixo) com a coordenada de localização no eixo $\mathrm{X}$ e $\mathrm{Y}$, considerando o volume que será transportado do centro de distribuição para cada loja do grupo "N", tal tabela servirá de base para a realização do primeiro passo do Método de Centro de Gravidade.

Tabela 01 - Coordenadas de localização das lojas

\begin{tabular}{|cccc|}
\hline Ponto (i) & $\begin{array}{c}\text { Volume } \\
\text { Transportado } \\
\text { (unid) }\end{array}$ & X & Y \\
\hline 1 & 16824 & 12 & 28 \\
2 & 21875 & 20 & 18 \\
3 & 32696 & 18 & 14 \\
4 & 15835 & 16 & 10 \\
5 & 20347 & 9 & 8 \\
6 & 37535 & 14 & 8 \\
7 & 11932 & 8 & 6 \\
8 & 30153 & 16 & 7 \\
9 & 22604 & 17 & 6 \\
10 & 47038 & 9 & 5 \\
11 & 16717 & 10 & 4 \\
12 & 13829 & 18 & 5 \\
13 & 26967 & 8 & 3 \\
14 & 28897 & 11 & 3 \\
\hline
\end{tabular}

Fonte: Autores, 2018

Com as informações da tabela 01, juntamente com o valor da tarifa de transporte é possível relacioná-los entre si e, então compor a segunda etapa do Método. Nesta etapa os valores das distancias não são considerados.
A empresa informou que o custo de transporte é de $\mathrm{R} \$ 3,21$ por $\mathrm{km}$ percorrido, Na tabela 02 apresentam-se as relações obtidas entre o volume, tarifa de transporte e coordenada cartesiana.

Tabela 02 - Relação de Volume, Tarifa e Coordenada Cartesiana

\begin{tabular}{|cccrrr|}
\hline $\mathrm{Vi}$ & \multicolumn{1}{c}{ Coordenadas de Localização } & \multicolumn{1}{c}{$\mathrm{V}{ }^{*} \mathrm{Ci}$} & \multicolumn{1}{c|}{$\mathrm{V}^{*}{ }^{*} \mathrm{Ci}{ }^{*} \mathrm{X}$} & \multicolumn{1}{c|}{$\mathrm{Vi}^{*} \mathrm{Ci}^{*} \mathrm{Y}$} \\
\hline 16824 & 12 & 28 & $54.005,04$ & $648.060,48$ & $1.512 .141,12$ \\
21875 & 20 & 18 & $70.218,75$ & $1.404 .375,00$ & $1.263 .937,50$ \\
32696 & 18 & 14 & $104.954,16$ & $1.889 .174,88$ & $1.469 .358,24$ \\
15835 & 16 & 10 & $50.830,35$ & $813.285,60$ & $508.303,50$ \\
20347 & 9 & 8 & $65.313,87$ & $587.824,83$ & $522.510,96$ \\
37535 & 14 & 8 & $120.487,35$ & $1.686 .822,90$ & $963.898,80$ \\
11932 & 8 & 6 & $38.301,72$ & $306.413,76$ & $229.810,32$ \\
30153 & 16 & 7 & $96.791,13$ & $1.548 .658,08$ & $677.537,91$ \\
22604 & 17 & 6 & $72.558,84$ & $1.233 .500,28$ & $435.353,04$ \\
47038 & 9 & 5 & $150.991,98$ & $1.358 .927,82$ & $754.959,90$ \\
16717 & 10 & 4 & $53.661,57$ & $536.615,70$ & $214.646,28$ \\
13829 & 18 & 5 & $44.391,09$ & $799.039,62$ & $221.955,45$ \\
26967 & 8 & 3 & $86.564,07$ & $692.512,56$ & $259.692,21$ \\
28897 & 11 & 3 & $92.759,37$ & $1.020 .353,07$ & $278.278,11$ \\
& & Somatório & $\mathbf{1 . 1 0 1 . 8 2 9 , 2 9}$ & $\mathbf{1 4 . 5 2 5 . 5 6 4 , 5 8}$ & $\mathbf{9 . 3 1 2 . 3 8 3 , 3 4}$ \\
\hline
\end{tabular}

Fonte: Autores, 2018 
Com os resultados dos somatórios da tabela 02, juntamente com o uso da equação 2 e 3 , descrita no referencial teórico, calcula-se o primeiro valor da coordenada $X$ e $Y$ proposta pelo método de Centro de Gravidade. É

$$
X=\frac{14 \cdot 525 \cdot 564,58}{1 \cdot 101 \cdot 829,29}=13,18
$$

Tais resultados serão utilizados para o cálculo das distâncias, na qual irá considerar o valor de $X$ e $Y$ do mapa (latitude e longitude), como também, o valor de $X$ e $Y$ obtido na equação 2 e $3(13,18$ e 8,45$)$. O valor do fator de escala $\mathrm{K}$ utilizado neste estudo foi definido por meio da subtração do ponto de cada loja em relação ao ponto do centro de distribuição, em módulo. Conforme a aplicação da fórmula importante ressaltar que nessa etapa não são consideradas as distâncias. Os valores de X e Y são: 13,18 e 8,45, respectivamente, conforme a resolução da fórmula apresentada a seguir:

$Y=\frac{9.312 \cdot 383,34}{1 \cdot 101 \cdot 829,29}=8,45$

4 supracitada, obtivemos os valores das distâncias de cada ponto do mapa. A partir desses resultados é possível reunir todas as informações necessárias para a realização da etapa 4 do método CG, na qual possibilitará o encontro da coordenada ideal do problema em questão. Os dados estão dispostos na tabela 3 (a seguir) a fim de facilitar a demonstração dos resultados:

Tabela 03 - Dados para cálculo do eixo X e Y

\begin{tabular}{|c|c|c|c|c|c|c|c|c|c|c|}
\hline \multirow[b]{2}{*}{$\mathrm{i}$} & \multirow[b]{2}{*}{$\mathrm{K}$} & \multirow[b]{2}{*}{$\mathrm{Vi}$} & \multicolumn{2}{|c|}{ Coordenadas de Localização } & \multirow[b]{2}{*}{ di } & \multirow[b]{2}{*}{$\mathrm{Vi} * \mathrm{Ri}^{*} \mathrm{X} / \mathrm{d}$} & \multirow[b]{2}{*}{$\mathrm{Vi}^{*} \mathrm{Ri}^{*} \mathrm{Y} / \mathrm{d}$} & \multirow[b]{2}{*}{$\mathrm{Vi} * \mathrm{Ri} / \mathrm{d}$} & \multirow{2}{*}{\multicolumn{2}{|c|}{$\begin{array}{c}\text { Custos Transporte } \\
\text { (R\$) }\end{array}$}} \\
\hline & & & X & $\mathrm{Y}$ & & & & & & \\
\hline 1 & 25 & 16824 & 12 & 28 & 509,92 & $1.270,91$ & $2.965,47$ & 105,91 & $\mathrm{R} \$$ & $27.538 .075,57$ \\
\hline 2 & 27 & 21875 & 20 & 18 & 325,25 & $4.317,84$ & $3.886,06$ & 215,89 & $\mathrm{R} \$$ & $22.838 .590,23$ \\
\hline 3 & 33 & 32696 & 18 & 14 & 250,67 & $7.536,53$ & $5.861,74$ & 418,70 & $\mathrm{R} \$$ & $26.308 .763,05$ \\
\hline 4 & 39 & 15835 & 16 & 10 & 125,09 & $6.501,83$ & $4.063,65$ & 406,36 & $\mathrm{R} \$$ & $6.358 .142,71$ \\
\hline 5 & 48 & 20347 & 9 & 8 & 230,13 & $2.554,29$ & $2.270,48$ & 283,81 & $\mathrm{R} \$$ & $15.030 .838,45$ \\
\hline 6 & 43 & 37535 & 14 & 8 & 16,55 & $101.907,21$ & $58.232,69$ & $7.279,09$ & $\mathrm{R} \$$ & $1.994 .371,43$ \\
\hline 7 & 51 & 11932 & 8 & 6 & 307,19 & 997,48 & 748,11 & 124,68 & $\mathrm{R} \$$ & $11.765 .835,48$ \\
\hline 8 & 42 & 30153 & 16 & 7 & 97,38 & $15.903,19$ & $6.957,64$ & 993,95 & $\mathrm{R} \$$ & $9.425 .556,28$ \\
\hline 9 & 42 & 22604 & 17 & 6 & 152,43 & $8.092,43$ & $2.856,15$ & 476,03 & $\mathrm{R} \$$ & $11.059 .892,06$ \\
\hline 10 & 51 & 47038 & 9 & 5 & 279,69 & $4.858,70$ & $2.699,28$ & 539,86 & $\mathrm{R} \$$ & $42.230 .853,69$ \\
\hline 11 & 51 & 16717 & 10 & 4 & 269,24 & $1.993,05$ & 797,22 & 199,31 & $\mathrm{R} \$$ & $14.447 .995,47$ \\
\hline 12 & 42 & 13829 & 18 & 5 & 209,86 & $3.807,51$ & $1.057,64$ & 211,53 & $\mathrm{R} \$$ & $9.315 .865,11$ \\
\hline 13 & 54 & 26967 & 8 & 3 & 401,82 & $1.723,46$ & 646,30 & 215,43 & $\mathrm{R} \$$ & $34.782 .822,50$ \\
\hline 14 & 51 & 28897 & 11 & 3 & 277,78 & $3.673,25$ & $1.001,80$ & 333,93 & $\mathrm{R} \$$ & $25.766 .626,67$ \\
\hline \multicolumn{2}{|c|}{ Somatório } & 343249 & & Somatório & $3.452,99$ & $165.137,68$ & $94.044,22$ & $11.804,47$ & RS & $258.864 .228,69$ \\
\hline
\end{tabular}

Fonte: Autores, 2018

Com o uso da fórmula 1 supracitada, obtiveram-se o custo de transporte apresentado na tabela 03 (acima) que corresponde a multiplicação do volume transportado, tarifa e distancia de cada ponto. Como pode-se observar os custos totais envolvidos no transporte foi igual a $R \$ 258.864 .228,69$. A partir dos somatórios obtido na tabela 03, aplicam-se as fórmulas 2 e 3 descritas no referencial teórico, na qual apresentará o valor de $X$ e $Y$ da segunda interação. Desta forma o valor de $X$ foi igual a 13,9894 e $Y$ igual a 7,9668, conforme mostra as resoluções a seguir:

$$
X=\frac{165.137,68}{11.804,47}=13,9894 \quad \text { (2) } ; \quad Y=\frac{94.044,22}{11.804,47}=7,9668
$$


Após o encontro das coordenadas $X$ e $Y$, repete-se a etapa 4 até que as coordenadas $X$ e $Y$ não mudem por sucessivas interações, ou até que alterem minimamente, de forma que não seja proveitoso continuar o cálculo. A partir deste resultado, sugere-se nova coordenada de localização que auxiliará na tomada de decisão de mudar a instalação do $\mathrm{CD}$ do grupo "N".

\section{RESULTADOS OBTIDOS}

A aplicação do método possibilitou identificar a seguinte coordenada como localização mais estratégica: 13,9894; 7,9668. A partir desta solução pode-se realizar a identificação no mapa do local proposto para o novo Centro de Distribuição. Segue abaixo a figura 04 de sua localização:

Figura 04 - Mapa da localização do novo Centro de Distribuição

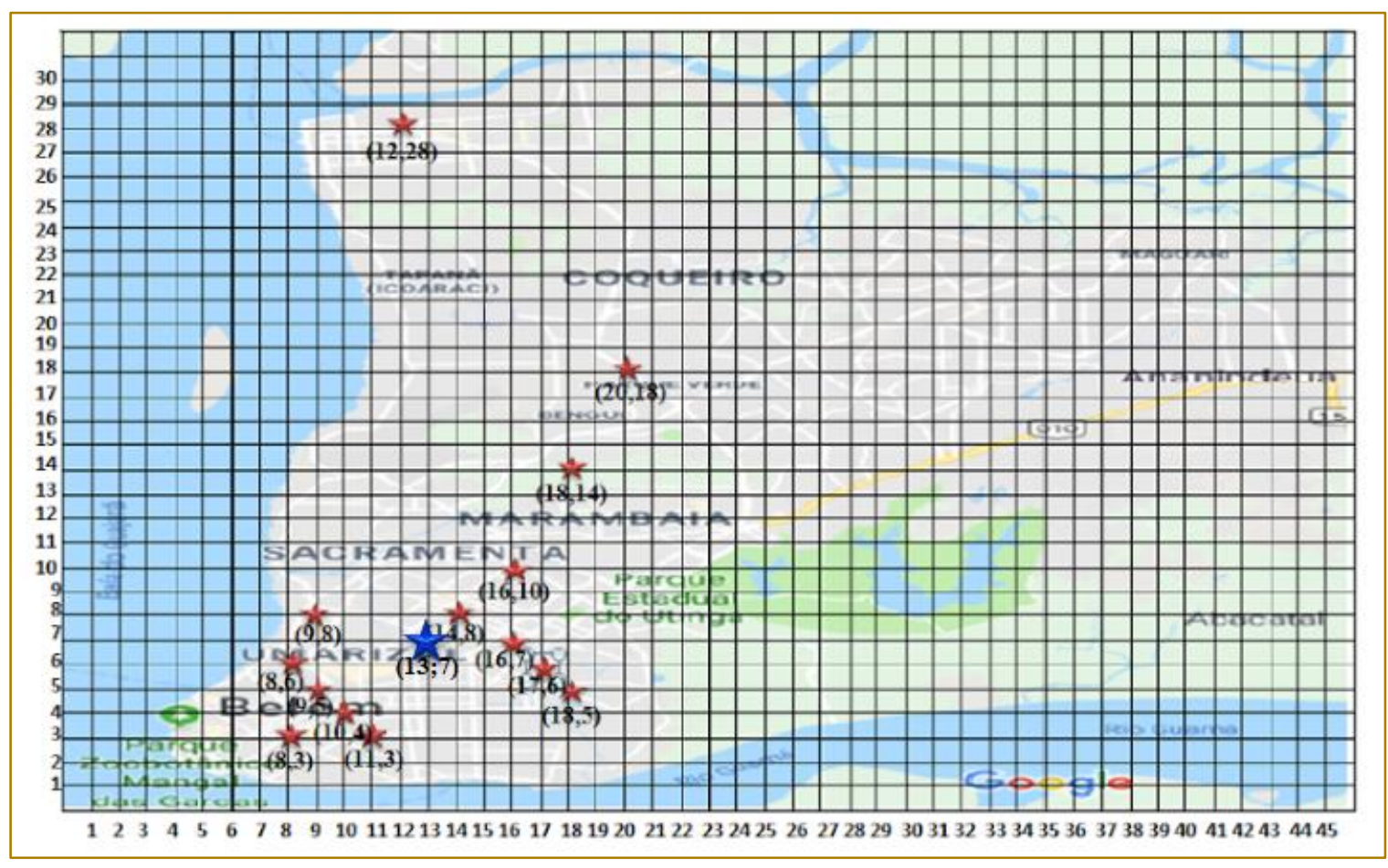

Fonte: Autores, 2018

A leitura da figura 04 mostra que a localização proposta pelo Método CG encontra-se bem próxima da maioria das lojas do grupo "N", tal cenário possibilitará um menor custo de transporte para a empresa, como pode ser comprovado com os cálculos realizados no estudo em questão. Após a identificação dos pontos sugeridos para a instalação do CD da empresa, realizou-se uma comparação de custos de transporte do cenário atual e proposto, conforme a figura 05 abaixo: 
Figura 05 - Gráfico comparativo do custo de transporte atual e proposto

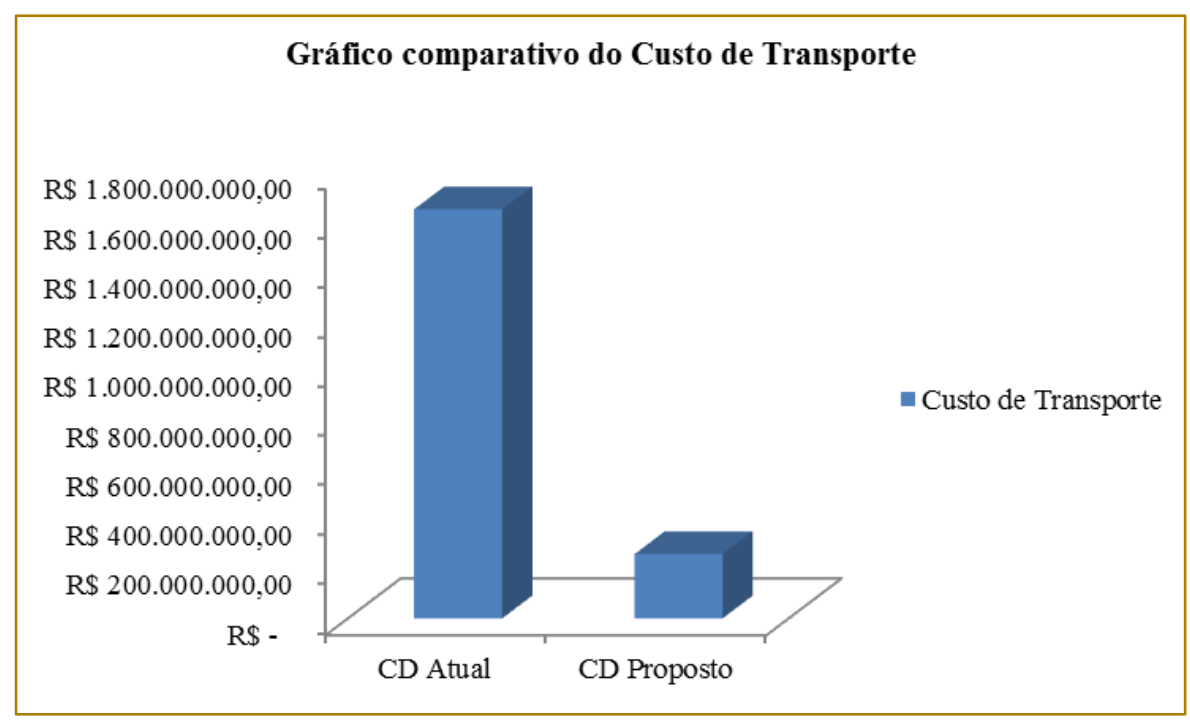

Fonte: Autores, 2018

A leitura da figura 05 permite comparar os custos de transporte do CD atual e o proposto pelo método do CG que apresentaram um total de $R \$ R \$ 1.650 .261 .300,70$ e $\mathrm{R} \$ 258.864 .228,69$, respectivamente. Dessa forma, pode-se quantificar uma redução de $\mathrm{R} \$$ 1.391.397.072,01 que a empresa terá nos seus custos operacionais. Tal valor é bastante significativo para o gestor da empresa, uma vez poderá influenciar no tempo de retorno do investimento de mudança de seu CD.

\section{CONSIDERAÇÕES FINAIS}

No âmbito logístico, equilibrar o nível de serviço ideal com o menor custo operacional tem sido um desafio para as organizações, uma vez que o amplo atendimento ao cliente é fator de competitividade no mercado. Tal fato tem impulsionado a aplicação de métodos e técnicas que auxiliem na eficiência dos seus processos. Neste trabalho o foco do estudo foi o cálculo de uma nova coordenada de localização para um CD, de forma a encontrar um ponto que auxilie na redução dos custos de transporte, sem deixar de atender as exigências dos clientes.

\section{REFERÊNCIAS}

[1] AAKER, D. A. Administração estratégica de mercado. 9 ed. Porto Alegre: Bookman, 2012.

[2] BALLOU, R. H. Gerenciamento da cadeia de suprimentos - Logística empresarial. 5 ed. Bookman, 2009.
Diante dessa perspectiva a aplicação do Método do Centro de Gravidade se mostrou satisfatório, uma vez que sugeriu um ponto estratégico no mapa que se encontrará mais próximos de suas lojas dependentes para reposição de seus produtos, bem como apresentará menor custo operacional para o grupo "N". Tal método levou em considerações variáveis relevantes para o gestor da empresa, tais como a demanda dos pontos, taxa de transporte e as distâncias de cada loja.

Com a localização atual do seu CD (ponto 44; 21) a empresa tem um custo de $\mathrm{R} \$ 1.650 .261 .300,70 \mathrm{com}$ a distribuição das mercadorias, ao mudar a instalação do seu CD para o ponto 13; 7 a empresa passará a ter um custo de transporte igual a $\mathrm{R} \$ 258.864 .228,69$, tal fato proporcionará uma redução de $R \$ 1.391 .397 .072,01$ nos seus custos operacionais. Dessa forma, a empresa terá aumento nos seus lucros, melhor posicionamento no mercado para atender seus clientes e consequentemente vantagens competitivas.

[3] BALLOU, R. H. Gerenciamento da cadeia de suprimentos planejamento, organização e logística empresarial. $4^{\underline{a}}$ ed. Porto Alegre: Bookman, 2001. 
[4] BOAVENTURA, E. M. Metodologia da Pesquisa: monografia, dissertação e tese. São Paulo: Atlas, 2004.

[5] BOWERSOX, D. J.; CLOSS D. J. Logística Empresarial. São Paulo: Atlas, 2001.

[6] CALAZANS, F. Centros de distribuição. Gazeta Mercantil: Agosto, 2011.

[7] CORRÊA, H. L.; CORRÊA, C. A. Administração de produção e operações: manufatura e serviços: uma abordagem estratégica. Edição compacta. São Paulo: Atlas, 2005.

[8] COSTA, E. A. Gestão estratégica. 6 ed. São Paulo: Saraiva, 2006.

[9] FERREIRA. J. B.; RAMOS, N. M; NETO, O. J. O; SILVA, P. A. P. Estudo de localização para as usinas sucroalcooleiras da região do pontal do triângulo mineiro. Encontro Nacional de Engenharia de Produção. Salvador, BA, Brasil, 08 a 11 de outubro de 2013.

[10] PAMPLONA, D. A.; FORTES, J.L.C.; ALVES, C. J. P. Consolidação de instalações de manutenção aeronáutica pela utilização do Método do Centro de Gravidade. Revista Scientia Plena. Vol. 10, num. 09. 2014.

[11] MACEDO, A. S. M.; ALMEIDA K.; BARBOSA, C. T. A. M. Análise envoltória em decisões de localização. 2008.

[12] MELACHRINOUDIS, E.; Min, H. "The Dynamic Relocation and Phase-out of a Hybrid, Two-echelon Plant/Warehousing Facility: A Multiple Objective Approach", European Journal of perational Research, vol. 123, no. 1, pp. 1-15. 2000 .
[13] NOVAES, A. G. Logística e gerenciamento da cadeia de distribuição. 13ํㅡㄹ Reimpressão. Rio de Janeiro: Elsevier, 2007.

[14] OLIVEIRA, D. de P. R. Planejamento estratégico: conceitos, metodologias e práticas. 23 ed. São Paulo: Atlas, 2007.

[15] PAMPLONA, E. de O.; MONTEVECHI, J. A. B. Apostila de engenharia econômica I. UNIFEI, Itajubá, MG, 1999.

[16] PIRES, S. R. I. Gestão da cadeia de suprimentos: conceitos, estratégias, práticas e casos. São Paulo: Atlas, 2004

[17] PRODANOV, C. C.; FREITAS, E. C. Metodologia do Trabalho Científico: Métodos e Técnicas da Pesquisa e do Trabalho Acadêmico. 2. ed. Novo Hamburgo: Feevale, 2013.

[18] RAMOS, P. de T. R. Implantação de centros de distribuição de produtos farmacêuticos na cidade de Uberlândia (MG). Dissertação de mestrado. Uberlândia, 2015.

[19] SLACK, N.; CHAMBERS, S.; JOHNSTON, R. Administração da Produção. 2ed. São Paulo: Atlas, 2002.

[20] SOUZA, F. J. S.; PEREIRA N. de S.; PONTES, H. L. J. Aplicação do método do centro de gravidade para decisão de localização de uma transportadora rodoviária de cargas. XXXV Encontro Nacional de Engenharia de Produção. Fortaleza, 2015.

[21] YIN, R. K. Estudo de caso: planejamento e métodos. 2. ed. Porto Alegre: Bookman, 2001. 


\section{Capítulo 5}

\section{O PROBLEMA DE LOCALIZACCÃO DE MÁXIMA COBERTURA: ABORDAGEM MULTIOBJETIVO CLÁSSICA}

\section{Helton Cristiano Gomes}

Cristiano Luís Turbino de França e Silva

Ruan Carlos Silva Menezes Pinheiro

Resumo: A tomada de decisão relacionada à localização de instalações é uma tarefa importante do planejamento estratégico de organizações, vistos os inúmeros benefícios que uma decisão acertada pode gerar. Uma determinação correta para a localização de instalações pode proporcionar vantagens competitivas, além de reduzir custos operacionais e logísticos e melhorar o atendimento da demanda dos clientes. A decisão de localização requer inúmeros estudos específicos e necessita da utilização de algum tipo de ferramenta para auxiliar na análise das alternativas. Visando auxiliar os gestores das organizações na determinação da localização de instalações, tornando a tomada de decisão mais acertada, foram propostos nesse trabalho dois métodos multiobjetivo clássicos para gerar soluções para o problema de localização de máxima cobertura (PLMC). Os métodos propostos foram o de ponderação dos objetivos e o do critério global. Foram considerados como objetivos a maximização do atendimento da demanda dos clientes e a minimização do custo de instalação das facilidades. Para exemplificar a aplicação dos métodos foi utilizada uma instância gerada conforme a literatura. Devido ao PLMC ser de difícil resolução, os métodos podem não ser eficientes computacionalmente para problemas com dimensões elevadas. 


\section{INTRODUÇÃO}

A tomada de decisão relacionada à localização de instalações é uma tarefa importante do planejamento estratégico de organizações públicas e privadas, vistos os inúmeros benefícios que uma decisão acertada pode gerar. Uma determinação correta para a localização de instalações pode proporcionar vantagens competitivas através da proximidade com clientes/fornecedores e de fontes de recursos, bem como com a redução de custos operacionais e logísticos. Tal decisão implica, também, no melhor atendimento da demanda dos clientes.

$\mathrm{Na}$ determinação da melhor localização para uma ou mais instalações, diversos fatores devem ser levados e consideração, dentre os quais destacam-se: disponibilidade de matéria prima e mão de obra, proximidade de clientes e fornecedores, infraestrutura de transporte, impostos e leis, custos operacionais, etc. O maior número possível de dados sobre os locais candidatos deve ser coletado e estudado, gerando informações confiáveis para o tomador de decisão. Com base nessas informações, ele consegue diminuir o grau de incertezas da sua escolha. Entretanto, essa decisão requer estudos específicos, com base nas informações coletadas, onde o auxílio de algum tipo de ferramenta é de extrema importância. Dentre as ferramentas disponíveis, utilizou-se nesse trabalho a otimização, o qual apresenta um problema clássico de programação linear inteira referente à localização de facilidades.

O problema de localização de facilidades (PLF) trata de decisões sobre a obtenção da melhor configuração para a instalação de uma ou mais facilidades, visando atender a demanda de uma população. No setor público, as facilidades podem ser classificadas em duas categorias: serviços não-emergenciais e serviços de emergência. Na primeira categoria estão incluídas escolas, bibliotecas, agências de correio, alguns serviços de saúde pública, pontos de ônibus e mesmo serviços relacionados ao meioambiente, como suprimento de água e instalações para o depósito de lixo. A categoria de serviços emergenciais inclui, por exemplo, hospitais, serviços de atendimento de emergência por ambulâncias e estações do corpo de bombeiros. No setor privado, o termo facilidade refere-se a fábricas, depósitos, antenas de telecomunicações, etc. O PLF apresenta algumas variantes, sendo uma das principais o problema de localização de máxima cobertura (PLMC). O PLMC consiste em definir a localização de facilidades com o objetivo de maximizar o atendimento da demanda dos clientes.

Problemas de localização podem, também, ser escritos como problemas de otimização multiobjetivo (OM), devido às organizações buscarem atender a demanda do maior número de clientes com o menor custo possível. Tal abordagem é particularmente importante quando os objetivos são conflitantes e, apresenta vantagens em relação à otimização mono-objetivo pois pode gerar soluções com diferentes contrapartidas entre distintos objetivos. Entretanto, é necessário que o tomador de decisões escolha a solução que melhor atenda às necessidades da organização. Sendo assim, é fundamental a escolha de uma técnica que determine o conjunto de soluções mais adequado para auxiliar os gestores.

A resolução de um problema de OM é, em geral, associada à construção de um diagrama de Pareto, onde cada ponto do diagrama representa uma solução. A construção do diagrama pode ser muito complexa, às vezes impossível, dependendo da natureza do problema a ser resolvido. Segundo Gomes et al. (2014), dentre as principais técnicas, tem-se os métodos clássicos, onde a definição dos critérios de geração de soluções ocorre antes da execução dos mesmos.

Com o objetivo de auxiliar os gestores de organizações na definição da melhor localização para instalações, tornando essa decisão mais acertada, são propostos nesse trabalho dois métodos clássicos para a resolução do PLMC formulado como um problema de OM. O PLMC foi abordado tendo como meta a otimização de dois objetivos: a maximização do atendimento da demanda dos clientes e a minimização do custo de instalação das facilidades. Os métodos propostos foram o de ponderação dos objetivos (MPO) e o de critério global (MCG). Para exemplificar a aplicação dos métodos foi utilizada uma instância gerada com base em ReVelle et al. (2008).

O restante desse trabalho está organizado como segue. Na seção 2 são apresentados o PLF e o PLMC, bem como a descrição dos métodos clássicos propostos. Na seção 3 são apresentadas e analisadas as soluções 
obtidas. A seção 4 conclui o trabalho e na seção 5 são feitos os agradecimentos.

\section{REFERENCIAL BIBLIOGRÁFICO}

\subsection{PROBLEMA DE LOCALIZAÇÃO DE FACILIDADES - PLF}

Segundo Daskin (1995), problemas de localização tratam de decisões sobre a obtenção da melhor configuração para a instalação de uma ou mais facilidades.
Existem diversos fatores que influenciam nesse tipo de decisão, tais como: condições de estradas, incentivos fiscais, proximidade com clientes/fornecedores, dentre outros.

O PLF tem como objetivo minimizar os custos de transporte da organização e, sua resolução não é trivial. O número de possíveis soluções para o problema é elevado, sendo calculado pela Equação (1), no qual m repressenta o número de localidades candidatas à instalação de uma facilidade e p o número de facilidades a serem instaladas.

$$
C_{p}^{m}=\frac{m !}{p !(m-p) !}
$$

Como pode ser visto na Equação (1), quanto maior o número de candidatas à localização de uma facilidade e menor o número de facilidades a serem instaladas, maior será o número de soluções possíveis.

Para Arakaki e Lorena (2006), os PLF podem ser classificados em problemas de cobertura e de localização de medianas. Em ambos o objetivo é determinar a localização para facilidades otimizando determinado(s) objetivo(s). As aplicações do PLF encontradas na literatura são as mais variadas, como a localização de serviços de emergência, modelos probabilísticos para localizaçãoalocação, localização de antenas para internet a rádio e telecomunicações, etc.

Dentre as principais variantes do PLF encontradas na literatura, optou-se nesse trabalho pelo PLMC, descrito na seção seguinte.

\subsection{PROBLEMA DE LOCALIZAÇÃO DE MÁXIMA COBERTURA - PLMC}

O PLMC foi introduzido por Church e ReVelle (1974) tendo como objetivo determinar a localização de facilidades de modo a maximizar o atendimento da demanda dos clientes. O atendimento da demanda de um cliente depende de uma distância (raio de cobertura), ou seja, a demanda de um cliente é considerada atendida caso o mesmo encontre-se dentro do raio de cobertura de pelo menos uma facilidade.

De forma genérica, o PLMC pode ser modelado matematicamente conforme proposto por Church e ReVelle (1974) e descrito a seguir.

\section{- Parâmetros do modelo}

$N=\{1,2, \ldots, n\}$ : conjunto de clientes cuja demanda deve ser atendida;

$M=\{1,2, \ldots, m\}$ : conjunto de localidades candidatas à instalação de uma facilidade.

Di: demanda do cliente $i \in N$;

dij: distância entre o cliente i e a facilidade instalada em j.

p: número de facilidades a serem instaladas;

R: raio de cobertura;

Si $=\left\{j \in M \mid d_{i j} \leq R\right\}$ : conjunto de localidades no qual a instalação de uma facilidades atenderá a demanda do cliente i.

- Variáveis de decisão

$x i \in\{0,1\}, \forall i \in N$ tal que:

$$
x_{i}=\left\{\begin{array}{l}
1, \text { se a demanda do cliente } i \text { for atendida } \\
0, \text { casocontrário }
\end{array}\right.
$$


yj $\in\{0,1\}, \forall j \in M$ tal que:

$$
y_{j}=\left\{\begin{array}{l}
1, \text { se uma facilidade for instalada na localidade } j \\
0, \text { casocontrário }
\end{array}\right.
$$

\section{- Modelo matemático}

Max Demanda $=\quad \sum_{i \in N} D_{i} x_{i}$

sujeito a

$$
\begin{array}{ll}
\sum_{j \in S_{i}} y_{j} \geq x_{i} & \forall i \in N \\
\sum_{i \in M} y_{j}=p & \\
x_{i} \in\{0,1\} \quad \forall i \in N \\
y_{j} \in\{0,1\} \quad \forall j \in M
\end{array}
$$

A função objetivo (2) busca a maximização da demanda total atendida. Sendo assim, quanto maior a demanda de um cliente, maior será o interesse em atendê-lo. O conjunto de restrições (3) estabelece que o cliente i só será atendido se existir uma facilidade em j tal que dij $\leq \mathrm{R}$. A restrição (4) determina 0 número de facilidades a serem instaladas em $p$ unidades. As restrições (5) e (6) definem o domínio das variáveis.

Ao resolver o PLMC são determinadas as localizações de $p$ facilidades, sendo os clientes alocados às mesmas, normalmente as mais próximas. Por essa razão, trata-se de um problema de localização-alocação, sendo esse de natureza combinatória. Para grande parte dos problemas com essa caracteristica, sua resolução exige elevado esforço computacional.

No presente trabalho, o PLMC foi abordado como um problema multiobjetivo, sendo considerada uma segunda meta: minimização dos custos de instalação das facilidades. Considerando fj o custo de instalação de uma facilidade na localidade $j \in M$, a Equação (2) ficou da seguinte forma:

$$
\text { Max Demanda/Custo }=\sum_{i \in N} D_{i} x_{i}-\sum_{j \in M} f_{j} y_{j}
$$

A escolha do PLMC deu-se pelo fato de esse ser um problema que apresenta inumeras aplicações reais. Badri et al. (1998) desenvolveram um modelo de programação inteira multiobjetivo para o PLCM visando a definição das melhores localizações para estações do corpo de bombeiros. Hoffmann e Gómez (2003) utilizaram o PLMC vinculado a um sistema de informações geográficas para auxiliar no posicionamento de torres de transmissão. Santos e Müller (2006) utilizaram o PLMC com o objetivo de determinar a localização para esquadrões de aeronaves de interceptação na região amazônica. Para isso inseriram novas restrições ao problema de forma a adaptá-lo à situação proposta. Arroyo e Marques (2006) utilizaram o método GRASP para a resolução do PLMC com o objetivo de determinar a localização de antenas de transmissão em pontos específicos de uma região (cidade). Os autores buscaram atender a maior demanda possível utilizando o mínimo de antenas. Santos et al. (2012) propuseram métodos metaheurísticos para a resolução do 
PLMC visando a implementação de uma rede de malha sem fio em uma Instituição Federal de Ensino, no qual a resolução do problema determinou a localização dos pontos de acesso. Calderín et al. (2017) propuseram uma ferramenta baseada no PLMC e no Sistema de Informação Geográfica (SIG ou GIS - Geographic Information System) para a determinação de localizações para postos policiais.

Para a resolução do MOPLMC foi proposta a utilização de dois métodos clássicos de OM, descritos na seção a seguir.

\subsection{MÉTODOS CLÁSSICOS DE OTIMIZAÇÃO MULTIOBJETIVO}

A resolução de um problema de OM consiste na obtenção de um conjunto de soluções que satisfaça algumas restrições e otimize uma função constituída por diversos termos ou funções-objetivo. Cada solução do conjunto gerado é representada por um ponto em um diagrama de Pareto, conforme a Figura 1, onde são considerados dois objetivos de minimização, f1(x) e f2(x).

Quando são considerados objetivos conflitantes, dificilmente existirá uma solução que seja ótima em relação a todos. Os diferentes conjuntos de soluções para um problema são representados por fronteiras de Pareto, onde a fronteira ótima, evidenciada na Figura 1, representa o melhor conjunto. $\mathrm{Na}$ Figura 1, as soluções são divididas por graus de dominância, levando em consideração a solução x3. Uma solução xi domina outra xj quando apresenta melhores valores para todos os objetivos considerados, como é o caso de $\times 3$ e $\times 4$. Todas as soluções pertencentes à mesma fronteira são consideradas indiferentes entre si.

FIGURA 1 - Diagrama de Pareto

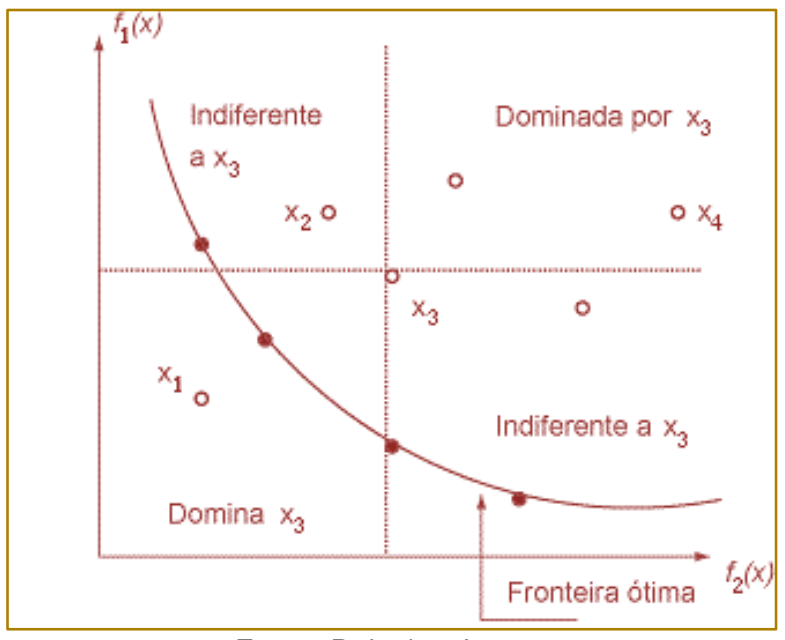

Fonte: Próprios Autores.

Os métodos utilizados para a determinação desses conjuntos de soluções podem ser divididos em três categorias, dependendo de como o tomador de decisão interfere no processo:

- $\quad$ Articulação de preferências antes do início da otimização: informações dadas pelo tomador de decisão levam a um problema de otimização mono-objetivo;

- $\quad$ Articulação de preferências após o fim da otimização: um conjunto de soluções é determinado, só então o tomador de decisão seleciona a solução mais adequada dentro do conjunto;

- $\quad$ Articulação de preferências durante a otimização: o processo é dividido em etapas, onde, após cada uma, um conjunto de soluções é apresentado ao tomador de decisão de modo que essas servirão de guia para a próxima etapa.

Nesse trabalho optou-se pela utilização de métodos clássicos, no qual a definição dos critérios de geração de soluções ocorre antes da execução da mesma. Isso é feito combinando os objetivos do problema em um 
único objetivo, segundo uma determinação de pesos e, como consequência, o problema acaba constituindo-se na otimização de um único objetivo. Entretanto, é recomendável a utilização de mais de um método, de forma a permitir a comparação entre as soluções obtidas e a escolha das mais confiáveis.

Dentre os métodos clássicos encontrados na literatura, destacam-se aqui os métodos de ponderação dos objetivos e do critério global. Porém, para a utilização desses métodos é necessário, primeiramente, definir a solução ideal (fO) para cada um dos $r$ objetivos considerados. Para determinar a solução ideal, deve-se encontrar, separadamente, a solução ótima para cada função-objetivo, conforme a Equação (7):

$$
f_{i}^{0}=\operatorname{Max} / \operatorname{Min} f_{i}(s), i=1, \ldots, r
$$

Dependendo das características do problema abordado e da instância utilizada, a determinação das soluções ideiais pode ser o principal complicador na utilização dos métodos clássicos, uma vez que a obtenção da solução ótima pode ser difícil.

\section{A - Método de ponderação dos objetivos - MPO}

O MPO é um dos mais populares métodos de $\mathrm{OM}$. Nele, ao se atribuir para cada objetivo diferentes coeficientes de ponderação, permite-se que os tomadores de decisão priorizem um determinado objetivo. Isto é, dados r objetivos, é criada uma função monoobjetivo f, dada pela Equação (8).

$$
f(s)=\sum_{i=1}^{r} w_{i} f_{i}(s)
$$

em que wi $\geq 0$ são os coeficientes de ponderação que representam a importância relativa de cada função-objetivo fi. Geralmente assume-se que:

$$
\sum_{i=1}^{r} w_{i}=1
$$

Quando não possuem a mesma unidade de medida, os objetivos precisam ser multiplicados por uma constante di, sendo, assim, expressos de forma adimensional
(Deb, 2001). Portanto, a função-objetivo gerada pelo MPO deve ser escrita como na Equação (10):

$$
f(s)=\sum_{i=1}^{r} w_{i} f_{i}(s) d_{i}
$$

De acordo com Deb (2001), melhores resultados são obtidos quando di $=1 / \mathrm{fiO}$, para $i=1, \ldots, r$. A dificuldade ao utilizar o MPO é encontrar pesos adequados para as funçõesobjetivo, porém é possível encontrar um conjunto de soluções variando os valores de wi.

\section{B - Método do critério global - MCG}

No MCG, a solução ótima é um vetor de variáveis de decisão que minimiza/maximiza algum critério global. Cabe ao tomador de decisão definir a função que melhor descreve esse critério, de forma que se possa obter a solução mais próxima possível da solução ideal. O MCG é indicado nos casos onde deseja-se obter uma solução que atenda a todos os objetivos, considerando-os com o 
mesmo nível de importância. A função que descreve o critério global tem como forma mais comum a Equação (11).

$$
f(s)=\sum_{i=1}^{r}\left(\frac{f_{i}^{0}-f_{i}(s)}{f_{i}^{0}}\right)^{p}
$$

Diversos valores podem ser utilizados para $\mathrm{p}$. Desse modo, a dificuldade é determinar qual valor será mais adequado. De acordo com Osyczaka (1984), os valores mais utilizados são $p=1$ e $p=2$. Boychuk e Ovchimikov (1973) propuseram $p=1$ e Salukvadze (1974) propôs $p=2$ em seus trabalhos, mas outros valores para $\mathrm{p}$ podem também ser usados. A solução do problema diferirá de acordo com o valor escolhido para $\mathrm{p}$.

\section{RESULTADOS E ANÁLISE}

Os métodos propostos nesse trabalho foram implementados computacionalmente no software CPLEX 12.7 e executado em um computador Intel Core i7 3.60GHz e 16GB de RAM, sob sistema operacional Linux Ubuntu 16.04LTS.

Para a realização dos testes computacionais foi utilizada uma instância gerada conforme descrito em ReVelle et al. (2008). Foram determinadas, de forma aleatória e seguindo a distribuição uniforme, a localização de 50 clientes por meio de coordenadas cartesianas com duas dimensões. A localidade de cada cliente foi representada por um ponto $(x, y)$ tal que $x, y \in[0,100]$. As distâncias entre as localidades foram calculadas como Euclidianas (Equação (12)) e a demanda de cada cliente foi determinada aleatoriamente no intervalo $[1,100]$. Da mesma forma, o custo de instalação de uma facilidade em cada uma das localidades foi determinado aleatoriamente no intervalo $[1,100]$. Foi considerada a instalação de 5 facilidades com diferentes raios de cobertura. Os valores dos raios foram determinados entre 10, 15 ou 20.

$$
d_{i j}=\sqrt{\left(x_{i}-x_{j}\right)^{2}+\left(y_{i}-y_{j}\right)^{2}}
$$

Os resultados obtidos para a instância é apresentado na seção a seguir.

\subsection{RESULTADOS OBTIDOS}

Para a aplicação do MPO e do MCG, primeiramente foram determinadas as soluções ideais para os objetivos

$$
f(x)=w_{1} \frac{f_{1}(x)}{887}+w_{2} \frac{f_{2}(x)}{1416}
$$

considerados. Os valores encontrados foram $\mathrm{f} 10=887$ (demanda total atendida) e f20 = 1416 (custo total de instalação das facilidades). As soluções foram obtidas em 10,3 e 12,1 segundos, respectivamente.

No MPO assumiu-se di = 1/fiO, resultando na função objetivo descrita pela Equação (13).
Para a aplicação do método, os valores de w1 e w2 utilizados variam de 0,1 até 0,9. Dessa forma, diferentes soluções foram geradas, determinando o conjunto Pareto-ótimo. Os 
TABELA 1 - Soluções obtidas pelo MPO.

\begin{tabular}{|c|c|c|c|}
\hline w1 & w2 & $f 1(x)$ & $f 2(x)$ \\
\hline 0,9 & 0,1 & 771 & 225 \\
\hline 0,8 & 0,2 & 769 & 131 \\
\hline 0,7 & 0,3 & 734 & 102 \\
\hline 0,6 & 0,4 & 734 & 102 \\
\hline 0,5 & 0,5 & 734 & 102 \\
\hline 0,4 & 0,6 & 661 & 70 \\
\hline 0,3 & 0,7 & 641 & 64 \\
\hline 0,2 & 0,8 & 522 & 43 \\
\hline 0,1 & 0,9 & 407 & 35 \\
\hline
\end{tabular}

Fonte: Próprios Autores.

As soluções soluções descritas na Tabela 1 foram obtidas em um tempo computacional médio de 12,2 segundos.

No MCG foram testados o valores 1 e 2 para o parâmetro $p$, porém a melhor solução foi

$$
f(x)=\left(\frac{887-f_{1}(x)}{887}\right)+\left(\frac{1416-f_{2}(x)}{1416}\right)
$$

Para o MCG, os valores obtidos para os objetivos foram: $f 1(x)=522$ e $f 2(x)=43$. A solução foi obtida em um tempo obtida para $\mathrm{p}=1$, como proposto por Boychuk e Ovchimikov (1973). Sendo assim, considerou-se a função objetivo descrita na Equação

computacional de 11,5 segundos. O diagrama de Pareto com as soluções geradas pelos métodos pode ser visto na Figura 2.

FIGURA 2 - Diagrama de Pareto

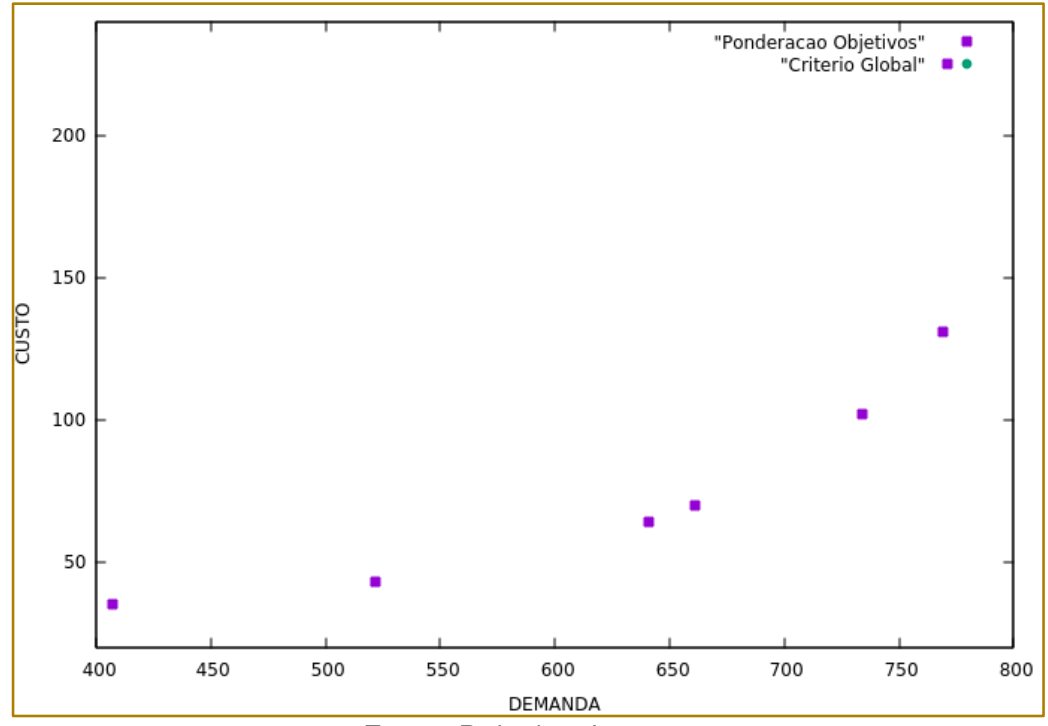

Fonte: Próprios Autores. 
Como pode ser observado na Figura 2, a solução obtida para o MCG é a mesma obtida para uma configuração do MPO.

Os MPO e MCG mostraram-se eficientes, exigindo baixo esforço computacional, na resolução de problema-teste gerado, ou seja, com um número pequeno de localidades. Porém, devido ao fato de o PLMC ser de difícil resolução, é importante ressaltar que, para problemas com dimensões elevadas, os métodos clássicos podem não ser eficientes computacionalmente. Outra importante dificuldade é a determinação das soluções ideais para os objetivos utilizados, que consiste na resolução exata do problema, inviabilizando a utilização dos métodos para a resolução de instâncias com grande número de localidades.

\section{CONCLUSÕES}

O presente trabalho teve como objetivo propor métodos multiobjetivo clássicos para a obtenção de soluções para o PLMC. O PLMC pertence à classe de problemas de otimização combinatória NP-difícil e, é um problema comum a um grande número de situações reais de tomada de decisão, como as que ocorrem dentro do planejamento estratégico de organizações públicas e privadas. O desenvolvimento desses métodos poderá auxiliar os gestores das organizações na determinação da localização de instalações, tornando a tomada de decisão mais acertada, vistos os inúmeros benefícios que isso pode gerar.

Para o desenvolvimento e a aplicação dos métodos, primeiramente, o PLMC foi formulado como um problema de OM. Na formulação proposta foram considerados dois objetivos: a maximização do atendmento da demanda dos clientes e a minimização do

\section{REFERÊNCIAS}

[1] ARAKAKI, R.; LORENA, L. Uma heurística de localização-alocação (HLA) para problemas de localização de facilidades. Produção, n.16, p.319328, 2006.

[2] ARROYO, J.; MARQUES, T. B. Heurística GRASP Aplicada ao Problema de Alocação de Antenas de Transmissão. XXXVIII SBPO, Goiânia, Brasil, 2006.

[3] BADRI, M. A.; MORTAGY, A. K.; ALSAYED, C. A. A Multi-objective Model for custo total de instalação das facilidades. Buscando obter soluções para o problema assim formulado, foram implementados dois métodos clássicos: MPO e MCG. Para testar a aplicação dos métodos foi gerado, conforme a literatura, um problema com 50 clientes (localidades) e 5 facilidades a serem instaladas.

Os métodos obtiveram as soluções para o problema-teste gerado com baixo esforço computacional. As soluções mostraram-se consistentes e, sendo assim, poderão servir de base para os gestores das organizações na determinação da localização de instalações, maximizando a atendimento da demanda de seus clientes e minimizando seu custo de instalação das facilidades.

Entretanto, devido ao PLMC ser de difícil resolução, é importante ressaltar que, para problemas com dimensões mais elevadas, os métodos clássicos podem não ser eficientes computacionalmente. Outra limitação dos métodos é a necessidade da determinação das soluções ideais para os objetivos, que consiste na resolução exata do problema, inviabilizando a utilização dos mesmos para a resolução de instâncias com grande número de clientes.

Como proposta de trabalhos futuros, podem ser considerados outros ou mais objetivos. Em relação a testes, podem ser utilizadas instâncias maiores que a utilizada nesse trabalho, visando verificar até onde os métodos são eficientes.

\section{AGRADECIMENTOS}

Os autores gostariam de agradecer à Universidade Federal de Ouro Preto pelo incentivo e apoio no desenvolvimento desse trabalho.

Location Fire Stations. European Journal of Operational Research, n.110, p.243-260, 1998.

[4] BOYCHUK, L. M. e OVCHINNIKOV, V. O. Principal Methods of Solution Multicriterial Optimization Problems (Survey). Soviet Automatic Control, n.6, p.1-4, 1973.

[5] CALDERÍN, J. F.; NODARSE, C. P.; YERA, L. S.; RODRÍGUEZ, D. E. Software Tool for Model and Solve The Maximum Coverage Location Problem, a Case Study: Locations Police Officers. 
Revista Investigacion Operacional, n.38, p.141-149, 2017.

[6] $\mathrm{CHURCH}, \mathrm{R}$;; REVELLE, C. The maximal covering location problem. Regional Science Association, n.32, p.101-118, 1974.

[7] DASKIN, M. Network and discrete location: models, algorithms and applications. New York: Wiley Interscience, 1995.

[8] DEB, K. Multiobjective Optimization using Evolutionary Algorithms. New York: John Wiley, 2001.

[9] GOMES, H. C.; NEVES, F. A.; SOUZA, M. J. Multi-objective metaheuristic algorithms for the resource-constrained project scheduling problem with precedence relations. Computers \& Operations Research, n.44, p.92-104, 2014.

[10] HOFFMANN, L. T.; GÓMEZ, A. T. Uma Abordagem do Problema de Localização de Torres de Rádio Transmissão Auxiliado por um Sistema De Informação Geográfica. XXXV SBPO, Natal, Brasil, 2003.
[11] OSYCZAKA, A. Multicriterion Optimization in Engineering with FORTRAM Programs. England: Ellis Horwood Ltd., 1984.

[12] REVELLE, C.; SCHOLSSBERG, M.; WILLIAMS, J. Solving the maximal covering location problem with heuristic concentration. Computers \& Operations Research, n.35, p.427-435, 2008.

[13] SALUKVADZE, M. E. On the Existence of Solution in Problems of Optimization under Vector Valued Criteria. Journal of Optimization Theory and Applications, n.12, p.203-217, 1974.

[14] SANTOS, R. P.; MÜLLER, C. Problema de Localização de Máxima Cobertura Aplicado à Localização de Esquadrões de Aeronaves de Interceptação na Região Amazônica. XXXVIII SBPO, Goiânia, Brasil, 2006.

[15] SANTOS, T. A.; VIANNA, D. S.; MEZA, E. B. M.; SILVA, R. M. Heurísticas GRASP+VND e ILS+VND para o Problema de Alocação de Pontos de Acesso em uma Rede em Malha Sem Fio. XXXII ENEGEP, Bento Gonçalves, Brasil, 2012. 


\section{Bapítulo 6}

\section{ANÁLISE DA CONFIABILIDADE NA PONTUALIDADE DE VOOS DE ALGUMAS EMPRESAS BRASILEIRAS UTILIZANDO CADEIAS DE MARKOV}

\section{Elyelton Cesar de Souza Lima}

Amanda Ribeiro Ganske

\section{Christiane Wenck Nogueira Fernandes}

\section{Luisa Mafra de Oliveira}

Silvia Lopes de Sena Taglialenha

Resumo: No atual cenário da aviação civil, para uma empresa tornar-se competitiva no mercado é fundamental a qualidade na prestação de serviços, atrelado à satisfação dos clientes. Assim, o presente trabalho tem como objetivo estimar o grau de confiabilidade na pontualidade de voos de algumas empresas aéreas brasileiras, estimando os percentuais de cancelamentos e atrasos de voos em determinado período para quatro rotas aéreas brasileiras de grande fluxo. Neste sentido, aplicou-se os conceitos de Cadeias de Markov para determinação das estimativas apresentadas no trabalho. Mostra-se um alto grau de confiabilidade na previsão dos percentuais de atraso dos voos.

Palavras chave: Cadeias de Markov. Empresas aéreas. Pontualidade de voos. 


\section{INTRODUÇÃO}

Antes privilégio de poucos, voar hoje se tornou acessível e uma realidade para a grande maioria da população brasileira. Entre os anos de 2004 e 2014, ocorreu um desenvolvimento expressivo do setor de transporte aéreo no país, acarretando em uma redução de cerca de $48 \%$ do custo de passagens aéreas domésticas. Paralelamente, a média anual de crescimento do setor aeroviário foi três vezes o crescimento médio do PIB (Produto Interno Bruto) para o mesmo período (3,4\%). Com base nesta conjuntura, segundo dados apresentados pela Secretaria Nacional de Aviação Civil "o número de passageiros cresceu $170 \%$ alcançando 117 milhões em 2014".

Dentre os vários aspectos analisados pelo cliente para a escolha da empresa aérea que atenda suas expectativas encontra-se o nível de confiabilidade na pontualidade dos voos. Uma empresa que apresentar pontualidade, atrelado à qualidade de seus serviços, assim como um bom serviço de bordo, conforto, segurança, etc., certamente estará entre as mais competitivas.

Neste contexto, o presente artigo pretende estimar o grau de confiabilidade na pontualidade dos voos de três grandes empresas aéreas brasileiras através da estimativa dos percentuais de cancelamentos e atrasos de voos, avaliando estes percentuais para quatro rotas aéreas brasileiras de grande fluxo, que se encontram entre as dez rotas brasileiras de maior fluxo.

O presente artigo apresenta o referencial teórico, um tópico onde será abordada a metodologia utilizada neste artigo e o desenvolvimento da análise realizada, da apresentação dos resultados e, por fim, da conclusão.

\section{REFERENCIAL TEÓRICO}

\subsection{PROCESSOS ESTOCÁSTICOS}

De acordo com Almeida et al. (2015), um processo estocástico é uma família de variáveis aleatórias $\left\{X_{(t)}, t \in T\right\}$ definidas em um espaço de probabilidade, indexado por um parâmetro $t$, onde t varia no conjunto $T$. $O$ conjunto $T$ é chamado de espaço de parâmetro. Os valores assumidos por $X_{(t)}$ são chamados de estados, e o conjunto de todos os possíveis estados é chamado de espaço de estados do processo estocástico e é denotado por $\mathrm{E}$.

Segundo Hillier \& Lieberman (2013), os processos estocásticos são de interesse porque descrevem o comportamento de um sistema que opera ao longo de algum período.

Exemplos de processos estocásticos:

- Variação do tráfego em um cruzamento;

- Variação diária no tamanho do estoque de uma empresa;

- Variação minuto a minuto do índice IBOVESPA;

- Variação no número de chamadas feitas a uma central telefônica;

- A evolução dos níveis de estoque semanais de um Centro de Distribuição, etc.

A estimativa do grau de confiabilidade na pontualidade dos voos trata-se de um processo estocástico, já que trata de um fenômeno que varia de forma imprevisível à medida que o tempo passa. Esta imprevisibilidade implica que as observações foram feitas em diversas ocasiões diferentes, sob condições presumivelmente idênticas.

\subsection{CADEIAS DE MARKOV}

Segundo Almeida (2007), para um processo estocástico ser considerado uma Cadeia de Markov, seu comportamento dinâmico deve respeitar uma característica, chamada propriedade markoviana. Essa característica demonstra a probabilidade condicional que em um evento futuro, dado qualquer evento passado, no estado presente $X_{t}=i$, depende somente do estado presente do processo, não importando como o processo chegou a tal estado.

De acordo com Taha (2008), um processo estocástico é um processo de Markov se a ocorrência de um estado futuro depender somente do estado imediatamente precedente. Processos de Markov: probabilidade de $X t$ assumir um valor futuro depende apenas do estado atual (desconsidera estados passados): 


$$
P\left(X_{n}=x_{n} \mid X_{1}=x_{1}, X_{2}=x_{2}, \ldots, X_{n-1}=x_{x-1}\right)=P\left(X_{n}=x_{n} \mid X_{n-1}=x_{n-1}\right) \text { para } n=0,1,2, \ldots, n
$$

Seja $X_{t}$ um processo de Markov, i e j estados, s e t tempos:

$$
P_{i j}=P\left[X_{(s+t)}=j \mid X_{(s)}=i\right] s \geq 0 \text { e } t \geq 0
$$

Se $P_{i j}$ independe do tempo então o processo de Markov é dito estacionário ou homogêneo.

Para Taha (2008), a notação matricial é uma forma conveniente de resumir as probabilidades de transição. Assim, a matriz $P$ define a cadeia de Markov, sendo todas as probabilidades de transição fixas e independentes ao longo do tempo. Para determinar a matriz de decisão para $N$ fases, eleva-se a matriz P na n-ésima potência.

Considerando que em uma Cadeia de Markov $\left\{X_{n}\right\} n \geq 1$ composta por espaço de estados $S=\{1,2, \ldots, s\}$ existam $s^{2}$ probabilidades de transição, de acordo $\operatorname{com}\left\{p_{i j}\right\}, i=1, \ldots, s e j=$ $1,2, \ldots, s$. A matriz $P$ apresentada na Figura 1, expressa as probabilidades de transição de uma Cadeia de Markov:

Figura 1 - Matriz de transição

$$
\mathrm{Pn}=\left(\begin{array}{ccc}
p 11 & \cdots & p 1 s \\
\vdots & \ddots & \vdots \\
p s 1 & \cdots & p s s
\end{array}\right)
$$

Fonte: Taha (2008)

De acordo com Taha (2008), a partir das probabilidades $a^{(0)}=\left\{a_{j}(0)\right\}$ de iniciar no estado j, e a matriz de transição $P$ de uma Cadeia de Markov, as probabilidades absolutas $a^{(n)}=\left\{a_{j}(n)\right\}$ de estar no estado $j$ após $n$ transições $(n>0)$ são calculadas da seguinte maneira:

$$
\begin{gathered}
a^{(1)}=a^{(0)} * P \\
a^{(2)}=a^{(1)} * P=a^{(0)} * P P=a^{(0)} * P^{2} \\
a^{(3)}=a^{(2)} * P=a^{(0)} * P^{2} P=a^{(0)} * P^{3} \\
a^{(n)}=a^{(0)} * P^{n}, n=1,2, \ldots, n
\end{gathered}
$$

A matriz $P^{n}$ representa a matriz de transição após $n$ etapas:

$$
\begin{gathered}
P^{n}=P^{n} * P \\
P^{n}=P^{n-m} * P^{m}, 0<m<n
\end{gathered}
$$

Estas equações são conhecidas como equações de Chapman-Kolgomorov, e comprovam que a matriz de probabilidades de transição de $n$ estados pode ser obtida elevando a matriz de transição da etapa a nésima potência. (TAHA, 2008)

O grau de confiabilidade da pontualidade de um determinado voo pode ser considerado um processo Markoviano, quando visto de forma que, a análise estocástica de uma ocorrência independe dos eventos anteriores. Deste modo, o estudo de atrasos e cancelamentos de um determinado vôo busca realizar uma previsão de situações futuras, desconsiderando os episódios antecedentes. 


\section{METODOLOGIA}

\subsection{DESCRIÇÃO DO CENÁRIO}

As análises deste trabalho basearam-se na seleção de quatro importantes rotas nacionais, sendo os principais critérios de escolha o volume de passageiros e a abrangência por estado. As rotas selecionadas foram:

- Rota 1: São Paulo - Rio de Janeiro;

- Rota 2: Brasília - São Paulo;

- Rota 3: São Paulo - Salvador;

- Rota 4: Porto Alegre - São Paulo.

A Rota 1 possui o maior fluxo de passageiros, com cerca de 6,7 milhões de pessoas no ano de 2014, segundo dados da ANAC (Agência Nacional de Avião Civil).

Para o estado de São Paulo foram considerados os aeroportos de Congonhas e Guarulhos. Já, a análise para o Rio de Janeiro foi feita com base na movimentação nos aeroportos Santos Dumont e Galeão.

As três empresas aéreas com maior representatividade e participação de mercado no contexto do transporte aeroviário no Brasil foram as escolhidas para englobar este estudo, sendo definidas por:

- Empresa A;

- Empresa B;

- Empresa C.

O período analisado foi $\mathrm{O}$ mês de dezembro, por representar a época de maior movimentação nos aeroportos de todo o Brasil (devido aos feriados importantes e período de férias), foi definido como o tempo de base para o estudo. Foram utilizados dados desde dezembro de 2012 até dezembro de 2016, totalizando 5 anos de observação.
O grau de confiabilidade das empresas A, B e C, juntamente com a previsão de cancelamentos e atrasos para dezembro do ano corrente, foi estimado para cada uma das quatro como será apresentado nos tópicos a seguir.

\subsection{BASE DE DADOS}

A Resolução ANAC n 218, de 28 de fevereiro de 2012, estabelece que os percentuais de atrasos e de cancelamentos de voos do transporte aéreo público regular doméstico e internacional de passageiros no Brasil devem ser divulgados mensalmente na página da ANAC na internet para a consulta do público em geral.

Os percentuais são divulgados de acordo com modelos estabelecidos por meio da Portaria ANAC no 464/SRE, de 13 de março de 2012, publicada no Diário Oficial da União de 19 de março de 2012 e são apresentados conforme segue:

- Individualmente para cada etapa básica de voo;

- Consolidados por empresa e par de aeroportos de origem e de destino.

São publicados dois percentuais de atrasos, um considerando as etapas que atrasam 30 minutos ou mais e outro considerando as etapas que atrasam 60 minutos ou mais.

No contexto da aviação civil, o termo 'etapa básica de voo' corresponde àquelas etapas realizadas pela aeronave desde a sua decolagem até o próximo pouso. Os dados estatísticos das etapas representam o status da aeronave em cada etapa do voo, apresentando a movimentação de cargas e passageiros entre os aeródromos de origem e destino da aeronave. 
Tabela 1 - Exemplo de percentuais para a Rota 3 realizada pela Empresa A

\begin{tabular}{|c|c|c|c|c|c|c|c|c|c|}
\hline \multirow[b]{2}{*}{$\begin{array}{c}\text { Empresa } \\
\text { Aérea }\end{array}$} & \multirow[b]{2}{*}{$\begin{array}{l}\text { No } \\
\text { Voo }\end{array}$} & \multicolumn{2}{|c|}{ Aeroporto de Origem } & \multicolumn{2}{|c|}{ Aeroporto de Destino } & \multirow[b]{2}{*}{$\begin{array}{l}\text { Etapas } \\
\text { Previstas }\end{array}$} & \multirow[b]{2}{*}{$\begin{array}{c}\% \text { de } \\
\text { Cancela } \\
\text { mento }\end{array}$} & \multicolumn{2}{|c|}{$\%$ de Atrasos } \\
\hline & & $\begin{array}{c}\text { Designador } \\
\mathrm{OACl}\end{array}$ & Nome & $\begin{array}{c}\text { Designador } \\
\mathrm{OACl}\end{array}$ & Nome & & & $\begin{array}{c}\text { Superiore } \\
\text { s a } \\
30 \mathrm{~min} .\end{array}$ & $\begin{array}{c}\text { Superiore } \\
\text { s a } 60 \\
\text { min. }\end{array}$ \\
\hline Empresa A & 3154 & SBGR & $\begin{array}{l}\text { São Paulo- } \\
\text { Guarulhos }\end{array}$ & SBSV & Salvador & 31 & 0 & 19 & 10 \\
\hline Empresa A & 3170 & SBGR & $\begin{array}{l}\text { São Paulo- } \\
\text { Guarulhos }\end{array}$ & SBSV & Salvador & 31 & 3 & 40 & 17 \\
\hline Empresa A & 3178 & SBGR & $\begin{array}{l}\text { São Paulo- } \\
\text { Guarulhos }\end{array}$ & SBSV & Salvador & 31 & 0 & 39 & 13 \\
\hline Empresa A & 3600 & SBSP & $\begin{array}{l}\text { São Paulo- } \\
\text { Guarulhos }\end{array}$ & SBSV & Salvador & 27 & 11 & 8 & 4 \\
\hline Empresa A & 3604 & SBSP & $\begin{array}{l}\text { São Paulo- } \\
\text { Guarulhos }\end{array}$ & SBSV & Salvador & 4 & 0 & 0 & 0 \\
\hline Empresa A & 3628 & SBSP & $\begin{array}{l}\text { São Paulo- } \\
\text { Guarulhos }\end{array}$ & SBSV & Salvador & 4 & 0 & 0 & 0 \\
\hline Empresa A & 3662 & SBGR & $\begin{array}{l}\text { São Paulo- } \\
\text { Guarulhos }\end{array}$ & SBSV & Salvador & 31 & 0 & 16 & 10 \\
\hline Empresa A & 3732 & SBSP & $\begin{array}{l}\text { São Paulo- } \\
\text { Guarulhos }\end{array}$ & SBSV & Salvador & 5 & 0 & 0 & 0 \\
\hline Empresa A & 3804 & SBGR & $\begin{array}{l}\text { São Paulo- } \\
\text { Guarulhos }\end{array}$ & SBSV & Salvador & 31 & 0 & 6 & 0 \\
\hline Empresa A & 3816 & SBGR & $\begin{array}{l}\text { São Paulo- } \\
\text { Guarulhos }\end{array}$ & SBSV & Salvador & 31 & 3 & 23 & 20 \\
\hline Empresa A & 3894 & SBGR & $\begin{array}{l}\text { São Paulo- } \\
\text { Guarulhos }\end{array}$ & SBSV & Salvador & 31 & 0 & 3 & 3 \\
\hline Empresa A & 3895 & SBGR & $\begin{array}{l}\text { São Paulo- } \\
\text { Guarulhos }\end{array}$ & SBSV & Salvador & 31 & 0 & 10 & 6 \\
\hline
\end{tabular}

Fonte: ANAC (2014)

\subsection{PLANILHA ELETRÔNICA}

Com base nos dados fornecidos pela ANAC, foram construídas planilhas eletrônicas, como mostra a tabela 2 para os cálculos referentes aos percentuais de cancelamentos e atrasos para cada uma das quatro rotas, tendo como prestadora dos serviços de transporte as três companhias aéreas citadas, num período total de cinco anos. Ao final desta etapa de análise foram obtidas 60 planilhas, e a partir destas foi possível calcular os valores em porcentagem necessários para a construção das Matrizes de Transição de Estado (Matriz P) da Cadeia de Markov.

Tabela 2 - Exemplo de planilha eletrônica

\begin{tabular}{|c|c|c|c|c|}
\hline Etapas previstas & Realizadas & \%C & \%A 30+ & \%A $60+$ \\
\hline 31 & 31 & 0 & 3 & 3 \\
\hline 31 & 31 & 0 & 19 & 3 \\
\hline 31 & 31 & 0 & 13 & 0 \\
\hline 31 & 31 & 0 & 35 & 19 \\
\hline 31 & 31 & 0 & 26 & 13 \\
\hline 31 & 31 & 0 & 15 & 25 \\
\hline 27 & 27 & 0 & 25 & 0 \\
\hline 4 & 4 & 0 & 20 & 0 \\
\hline 5 & 5 & 0 & 0 & 6 \\
\hline 5 & 5 & 0 & 10 & 3 \\
\hline 31 & 31 & 0 & 6 & 19 \\
\hline 289 & 31 & 0 & 43 & 0,0657 \\
\hline
\end{tabular}

Fonte: Autores

O número de voos realizados foi calculado a partir da quantidade de voos previstos, desconsiderando o percentual de etapas canceladas. Desta forma, o número total de cancelamentos foi obtido pela subtração entre as etapas previstas e realizadas.
Os cálculos referentes ao total de atrasos foram feitos através de uma média ponderada entre o número de etapas realizadas e o número de atrasos de 30 (ou mais) e 60 (ou mais) minutos. 
O percentual de cancelamentos foi apurado por meio da divisão da quantidade de etapas canceladas pela quantidade de etapas previstas no mês de referência, de acordo com a seguinte fórmula:

Percentual de Cancelamentos = Etapas Canceladas / Etapas Previstas.

O percentual de atrasos é apurado por meio da divisão da quantidade de etapas atrasadas em cada intervalo de atraso pela quantidade total de etapas realizadas, de acordo com a seguinte fórmula:
Percentual de Atrasos = Etapas Atrasadas $/$ Etapas Realizadas.

\section{RESULTADOS}

No presente trabalho se obteve as Matrizes $\mathrm{P}^{1}$ através das Equações de ChapmanKolgomorov. As matrizes resultantes deste processo correspondem às previsões do grau de confiabilidade das empresas aéreas em relação ao percentual de atrasos e cancelamentos de voos para dezembro de 2017.

Tabela 3 - Rota 1 para dezembro de 2017

\begin{tabular}{|c|c|c|c|}
\multicolumn{5}{|c|}{ São Paulo-Rio de Janeiro } \\
Empresa A & $\%$ C & 0,074 & $\%$ A 60+ \\
\hline Empresa B & 0,087 & 0,115 & 0,024 \\
\hline Empresa C & 0,105 & 0,064 & 0,031 \\
\hline
\end{tabular}

Fonte: Autores

Tabela 4 - Rota 2 para dezembro de 2017

\begin{tabular}{|c|c|c|c|}
\hline \multicolumn{3}{|c|}{} & Brasília - São Paulo \\
\hline Empresa A & $\%$ \%A 30+ & \%A 60+ \\
\hline Empresa B & 0,052 & 0,134 & 0,034 \\
\hline Empresa C & 0,049 & 0,186 & 0,054 \\
\hline & 0,226 & 0,140 & 0,096 \\
\hline
\end{tabular}

Tabela 5 - Rota 3 para dezembro de 2017

\begin{tabular}{|c|c|c|c|}
\hline \multicolumn{3}{|c|}{ São Paulo - Salvador } \\
\%A30+ & $\%$ A 60+ \\
\hline Empresa A & $\%$ C & 0,131 & 0,044 \\
\hline Empresa B & 0,006 & 0,085 & 0,020 \\
\hline Empresa C & 0,045 & 0,073 & 0,033 \\
\hline
\end{tabular}

Tabela 6 - Rota 4 para dezembro de 2017

\begin{tabular}{|c|c|c|c|}
\hline & \multicolumn{3}{c|}{ Porto Alegre - São Paulo } \\
\hline Empresa A & $\% \mathrm{C}$ & $\% \mathrm{~A} 30+$ & \%A 60+ \\
\hline Empresa B & 0,037 & 0,058 & 0,019 \\
\hline Empresa C & 0,036 & 0,095 & 0,024 \\
\hline
\end{tabular}

Fonte: Autores

Para obter uma melhor visualização dos resultados obtidos e assim tornar mais fácil uma análise comparativa dos percentuais de cancelamentos e atrasos de cada uma das três empresas para cada uma das quatro rotas, os dados obtidos foram trabalhados no Excel para gerar os gráficos comparativos, como mostrado na figura 1, figura 2, figura 3 e figura 4: 


\section{0}

Figura 1 - Previsão de percentuais de cancelamentos e atrasos da rota 1 dezembro de 2017

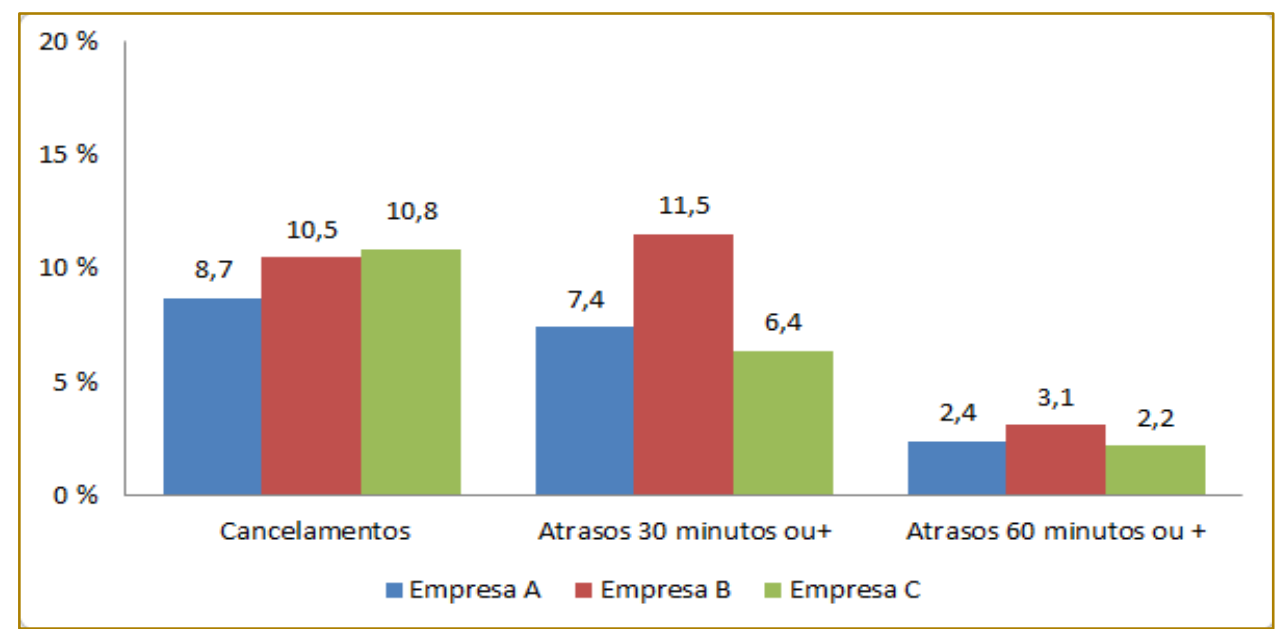

Fonte: Autores

Figura 2 - Previsão de percentuais de cancelamentos e atrasos da rota 2 para dezembro de 2017

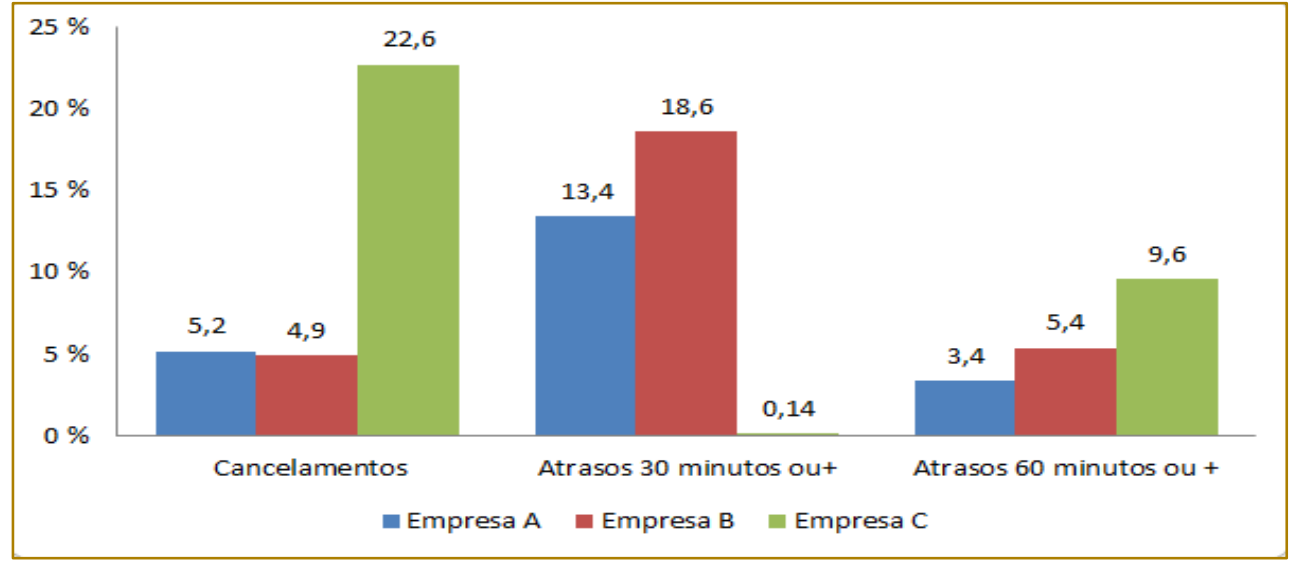

Fonte: Autores

Figura 3 - Previsão de percentuais de cancelamentos e atrasos da rota 3 para dezembro de 2017

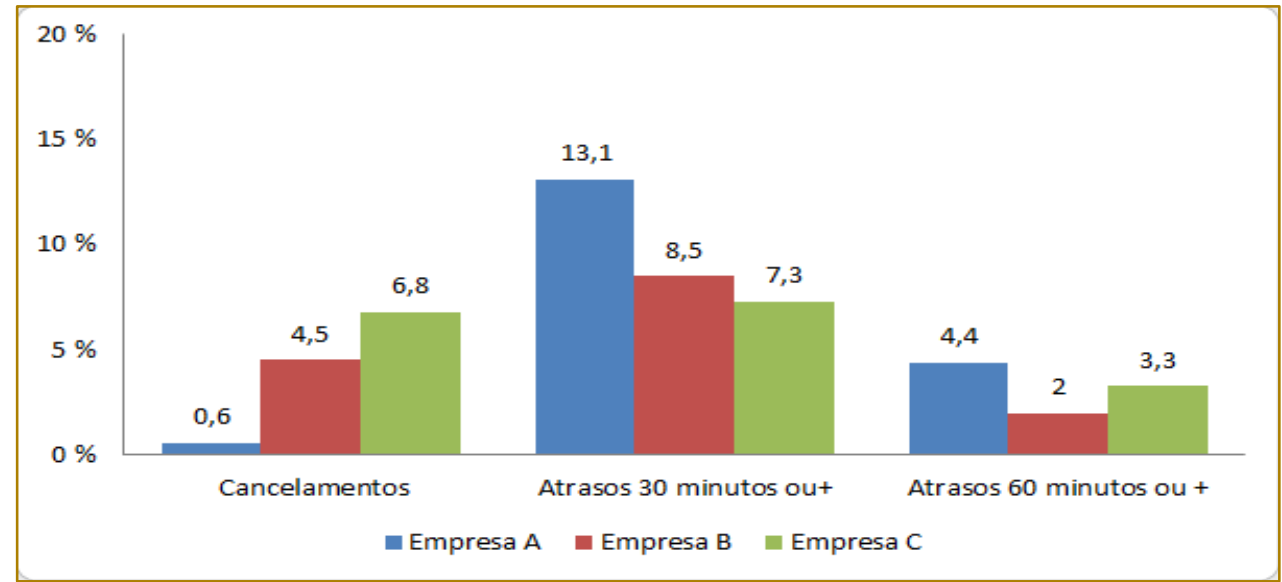

Fonte: Autores 
Figura 4 - Previsão de percentuais de cancelamentos e atrasos da rota 4 para dezembro de 2017

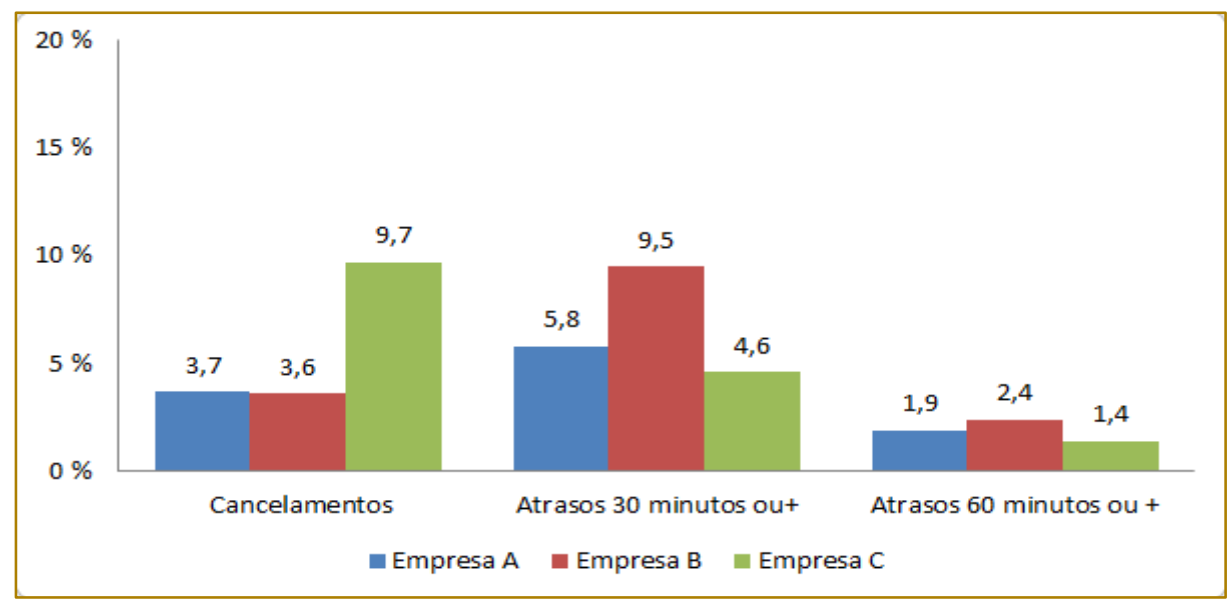

Fonte: Autores

\section{CONCLUSÃO}

A partir da análise dos resultados obtidos, é possível concluir que os percentuais de cancelamentos fornecem dados com menor grau de confiabilidade, isso se justifica pelo fato de que muitos fatores internos e externos, como condições climáticas, greves, manutenção e etc., afetam as operações viárias. Porém, estes fatores não foram levados em consideração no presente estudo.

Desta forma, uma ideia de desenvolvimento de futuros trabalhos na mesma temática seria investigar com maior acurácia os percentuais de cancelamentos, porém, levando em consideração os fatores aqui não abordados e que contribuem muito para a determinação da eficiência e confiabilidade das companhias aéreas.

\section{REFERÊNCIAS}

[1] ANAC. Histórico dos percentuais de atrasos e cancelamentos. Disponível em: $<$ http://www.anac.gov.br/assuntos/dados-eestatisticas/historico-dos-percentuais-de-atrasos-ecancelamentos >. Acesso em: 20 jun. 17.

[2] ALMEIDA, Ígor Lorenzato. Redes neurais recorrentes para inferência de redes de interação gênica utilizando cadeias de Markov. 2007. 108 f. Dissertação (Mestrado) - Curso de Computação Aplicada, Universidade do Vale do Rio dos Sinos, São Leopoldo, 2007. Disponível em: <http://www.repositorio.jesuita.org.br/handle/UNISI NOS/2231>. Acesso em: 20 jun. 17.

[3] ALMEIDA, Marcos André Pereira et al. Cadeias de Markov: aplicações no cotidiano.
A aplicação do método considerando as 3 empresas aéreas, apresenta a empresa A com menor cancelamento de voos e menor número de atrasos com 60 minutos ou mais, a empresa $\mathrm{C}$ possui menor número de atrasos de 30 minutos ou mais, não levando em consideração as rotas.

Com relação as rotas, a decisão pode ser tomada para a empresa com menor avaria, se for considerado a rota 1,2 e 4 a empresa A é a melhor escolha, já a rota 3 a empresa $B$ se comportou melhor.

Para os percentuais de atrasos de voos a aplicação de cadeias de Markov se mostrou uma ferramenta eficiente com um alto grau de confiabilidade dos resultados obtidos.

Cadernos de Graduação: Ciências exatas e tecnológicas, Aracaju, v. 3, n. 1, p.45-54, out. 2015. Disponível em:<periodicos.set.edu.br $>$. Acesso em: 20 jun. 17.

[4] BRASIL. Ministerio dos transportes, Portos e Aviação Civil. Disponivel em: < http://transportes.gov.br/> Acesso em: 09 set. 18.

[5] HILLIER, Frederick S.; LIEBERMAN, Gerald. J. Introdução à Pesquisa Operacional. 9o ed. São Paulo: Editora Bookman, 2013.

[6] TAHA, Hamdy A. Pesquisa Operacional: uma visão geral. 8. ed. São Paulo: Pearson Prentice Hall, 2008. 


\section{Capítulo 7}

\section{A PRODUCÃO CIENTIFFICA MUNDIAL SOBRE CADEIAS DE SUPRIMENTOS ÁGEIS PUBLICADA EM PERIÓDICOS INDEXADOS PELA SCOPUS E WEB OF SCIENCE: UM ESTUDO BIBLIOMÉTRICO}

\section{Thales Botelho de Sousa \\ Carlos Eduardo Pinto \\ Weidy Luana Rocha Gervaz \\ Willian Victor Silva Borba Cordeiro \\ Cássio Germano Lara de Souza \\ Igor Fonseca da Rocha}

Resumo: As cadeias de suprimentos ágeis têm sido amplamente estudadas nos últimos anos, pois mostram-se eficientes para lidar com os distúrbios e turbulências dos atuais mercados competitivos. Este estudo visa avaliar o conjunto de artigos sobre o tema publicado em periódicos indexados nas bases de dados Scopus e/ou Web of Science. A metodologia adotada foi uma análise bibliométrica, visando apresentar os periódicos que constituem o principal fórum de discussão da temática, a distribuição anual das pesquisas, os países mais produtivos e os artigos com maior fator de impacto. Os resultados evidenciam que 159 artigos sobre o tema redigidos na língua inglesa foram publicados em 92 periódicos até junho de 2018. Os periódicos mais produtivos são o International Journal of Production Economics, International Journal of Agile Systems and Management, Supply Chain Management, International Journal of Services and Operations Management, International Journal of Production Research, International Journal of Advanced Manufacturing Technology e International Journal of Logistics Management. O Reino Unido, Índia, Irã, Estados Unidos e China são os países com o maior número de artigos publicados. Com base no fator de impacto dos artigos, o Reino Unido tem contribuído de forma mais acentuada para o desenvolvimento da temática.

Palavras-chave: Cadeias de Suprimentos Ágeis; Gestão da Cadeia de Suprimentos; Bibliometria; Scopus; Web of Science. 


\section{INTRODUÇÃO}

De acordo com Shan e Wang (2018), a gestão da cadeia de suprimentos visa alcançar vantagem competitiva sustentável e abrange diversas atividades, envolvendo o fluxo de informações e de bens (desde a extração de matérias-primas até a disposição final dos produtos). O termo gestão da cadeia de suprimentos surgiu em 1982, caracterizado pelos consultores Oliver e Webber como uma rede de organizações que estão envolvidas nos diversos processos e atividades necessários para a produção de valor na forma de produtos e serviços (ASGARI et al., 2016; HARLAND, 2013).

Devido à sua importância para a prática gerencial, o conceito de agilidade vem ganhando uma atenção cada vez maior nas pesquisas sobre gestão da produção e gestão da cadeia de suprimentos (MARTINEZ-SANCHEZ; LAHOZ-LEO, 2018). Segundo Baramichai et al. (2007), uma Agile Supply Chain (ASC) ou Cadeia de Suprimentos Ágil representa um facilitador essencial para a agilidade de uma empresa. A ASC tem como objetivo fornecer uma resposta rápida e eficaz da cadeia de suprimentos às mudanças nas necessidades dos clientes (TARAFDAR; QRUNFLEH, 2017). As ASCs têm se mostrado eficientes e capazes de lidar com os distúrbios e turbulências dos atuais mercados competitivos e incluem empresas como fornecedores e centros de produção e de distribuição que são legalmente separados, mas cujos termos de operações são interligados por fluxo de dados e informações de feedback (ABBASI; HOSNAVI; BABAZADEH, 2014). O alcance da eficiência em uma ASC representa uma ótima solução para atender às demandas dos clientes por produtos de baixo custo, alta qualidade, curtos prazos de entrega e altos níveis de serviço (MISHRA et al., 2015).

Ao investigar a literatura sobre ASC publicada em periódicos indexados na Scopus e Web of Science, é possível ver que alguns trabalhos apresentaram revisões de literatura sobre o tema (CHIARINI; VAGNONI, 2017; SHAHIN; KHALILI; POURHAMIDI, 2017; HAQ; BODDU, 2015; SALEESHYA; SACHIN, 2015; LEMIEUX et al., 2012; WU; BARNES, 2011; REN; YUSUF; BURNS, 2009), mas que nenhum apresentou índices bibliométricos. Estudos bibliométricos sintetizam o conhecimento existente para encontrar tendências e entender onde a informação pode estar faltando nos vários campos da ciência (BLANK et al., 2013). Assim, visando auxiliar o desenvolvimento da literatura sobre ASC, este trabalho visa apresentar uma visão geral da produção científica sobre o tema publicada em periódicos indexados pelas supracitadas bases de dados.

O restante deste trabalho é estruturado da seguinte maneira: a seção 2 apresenta uma breve revisão compreensiva sobre o tema; a seção 3 descreve os métodos utilizados para pesquisar, organizar e analisar a literatura, bem como os principais tópicos a serem discutidos; a seção 4 apresenta os resultados obtidos; e a última seção aponta as conclusões relacionadas à pesquisa, suas principais limitações e oportunidades para futuros trabalhos, bem como as referências usadas para estruturá-la.

\section{FUNDAMENTAÇÃO TEÓRICA}

A ASC é sensível ao mercado, o que significa que ela é capaz de ler e responder às demandas reais dos clientes (CHRISTOPHER, 2000). Este tipo de estratégia é mais adequado para produtos inovadores, de grande variedade, curto ciclo de vida, alta margem de lucro, e é mais bem representado na indústria da moda (CHRISTOPHER; TOWILL, 2001; SHAHIN; KHALILI; POURHAMIDI, 2017).

Os principais elementos das ASCs são velocidade, flexibilidade, responsividade, robustez, gestão orientada e baseada em eventos, foco na redução de lead times e aumento da visibilidade da cadeia de suprimentos (BARAMICHAl et al., 2007; MASON-JONES; NAYLOR; TOWILL, 2000; OLSSON; ARONSSON, 2015; POOL et al., 2018). De acordo com Christopher, Lowson e Peck (2004), uma ASC é sensível ao mercado, pois está intimamente ligada às tendências do usuário final do produto; é virtual, pois depende de informações compartilhadas entre todos os parceiros da cadeia de suprimentos; é baseada em rede de empresas, visando ganhar flexibilidade ao usar os pontos fortes de parceiros especializados; e tem alinhamento de processos, possibilitando alto grau de interconectividade entre os membros da rede.

Uma ASC pode ser dividida em duas partes: uma em que os produtos são empurrados com base no planejamento e na previsão, e outra em que os produtos são retirados da 
cadeia de suprimentos com base na demanda real do cliente (SHARMA; BHAT, 2014). De acordo com Sharma e Bhat (2014), uma parte do projeto de uma ASC é a decisão de onde colocar o ponto de desacoplamento, o qual pode ser dividido em dois pontos: um para o desacoplamento de informações e outro para a localização do ponto de estoque estratégico.

De acordo com Martinez-Sanchez e LahozLeo (2018), as ASCs têm as seguintes características: sensibilidade ao mercado (resposta à demanda real e melhor antecipação às oportunidades e ameaças), integração de processos (compartilhamento on-line de dados entre compradores e fornecedores), ligação em rede (criação de redes colaborativas entre os membros para responder rápida e efetivamente às mudanças do mercado) e virtualização (desenvolvimento conjunto de produtos, compartilhamento de sistemas e informações). O compartilhamento de informações na cadeia de suprimentos ajuda a diminuir os problemas ocasionados pelo efeito chicote (XU et al., 2016).

Segundo Matawale, Datta e Mahapatra (2016), a gestão de ASCs é apoiada pelo processo efetivo de seleção de fornecedores, entretanto, ao selecionar um fornecedor em uma ASC, além dos critérios tradicionais de seleção de fornecedores (custo, qualidade e desempenho), critérios relacionados à agilidade também devem ser considerados.

Considerando o objetivo da compra e as características do mercado de suprimentos, Baramichai et al. (2007) classificaram as ASCs em 4 categorias, e este portfólio pode ser usado por empresas para analisar e determinar as estratégias apropriadas para sua parceria e função de compras da cadeia. A Tabela 1 apresenta a classificação dos referidos

autores.

Tabela 1 - Categorias das ASCs

\begin{tabular}{|c|c|}
\hline Categoria & Descrição \\
\hline $\begin{array}{l}\text { Agilidade por meio da cadeia } \\
\text { de suprimentos flexível }\end{array}$ & $\begin{array}{l}\text { As empresas dentro da cadeia de suprimentos flexível são integradas com } \\
\text { o mais básico relacionamento entre comprador e vendedor. }\end{array}$ \\
\hline $\begin{array}{l}\text { Agilidade por meio da } \\
\text { empresa virtual ágil }\end{array}$ & $\begin{array}{l}\text { As empresas que participam desse tipo geralmente continuam a } \\
\text { desenvolver suas competências essenciais, mantendo sua independência } \\
\text { e tentando obter acesso a uma ampla gama de recursos e capacidades } \\
\text { oferecidos por outros membros. }\end{array}$ \\
\hline $\begin{array}{l}\text { Agilidade por meio da rede de } \\
\text { parceiros ágeis }\end{array}$ & $\begin{array}{l}\text { O objetivo da função de compras nesse tipo de cadeia de suprimentos é } \\
\text { obter capacidade, reduzir custos e melhorar a flexibilidade da operação } \\
\text { diária. A integração de uma empresa com seus fornecedores é limitada ao } \\
\text { compartilhamento de dados operacionais sobre níveis e políticas de } \\
\text { estoque, bem como das demandas do cliente final. }\end{array}$ \\
\hline $\begin{array}{l}\text { Agilidade por meio da } \\
\text { empresa ágil estendida }\end{array}$ & $\begin{array}{l}\text { As empresas que operam nesse tipo de cadeia de suprimentos devem } \\
\text { decidir (junto com seus fornecedores) como estruturar os relacionamentos } \\
\text { e as operações para acomodar com eficiência vários eventos não } \\
\text { planejados que possam ocorrer. Para isso, visando lidar com as mudanças } \\
\text { imprevisíveis, a empresa pode utilizar recursos e capacidades dos } \\
\text { fornecedores, ainda que eles não os controlem ou possuam diretamente. }\end{array}$ \\
\hline
\end{tabular}

Fonte: Adaptado de Baramichai et al. (2007).

Como o ambiente de uma ASC deve ser altamente flexível, nos últimos tempos tem crescido o uso da manufatura em nuvem nas empresas que adotam este tipo de estratégia, o que as tornam mais acessíveis a recursos e capacidades externas e possibilitam o fornecimento de melhores soluções de personalização dos produtos (YU et al., 2018).

\section{METODOLOGIA}

A metodologia utilizada visa obter resultados capazes de abordar o progresso da produção acadêmica sobre ASCs publicada em periódicos científicos indexados nas bases de dados Scopus e/ou Web of Science. Justificase a escolha de artigos publicados exclusivamente em periódicos devido ao fato de sua seleção e avaliação serem mais 
criteriosas que a seleção de artigos publicados em anais de congressos e simpósios (CARNEVALLI; MIGUEL, 2008), além de serem considerados como as pesquisas de mais alto nível, tanto para coleta de informações, quanto para divulgação de novos resultados e descobertas (NGAl et al., 2008).

Para atingir tais propósitos, um estudo bibliométrico foi conduzido. De acordo com Vanti (2002), a bibliometria tem grande destaque dentre as diversas formas de avaliação do conhecimento científico e de medição de fluxos de informação, estudando aspectos quantitativos da produção com emprego de métodos matemáticos e estatísticos (TAGUE-SUTCLIFFE, 1992). A pesquisa bibliométrica visa analisar se existem padrões na literatura pesquisada, identificar os periódicos que mais publicaram artigos sobre o tema, a evolução destas publicações ao longo dos anos e as áreas mais relacionadas à temática pesquisada (PRASAD; TATA, 2005).

Neste trabalho, a pesquisa bibliométrica foi realizada para apresentar os periódicos que constituem o principal fórum de discussão da temática avaliada, os principais tópicos discutidos nos artigos, os países que mais publicaram artigos relacionados ao tema, e, dentre estes, os artigos que tiveram o maior impacto para a ciência.

Para selecionar as publicações de interesse, nas bases de dados foi pesquisado por meio do título, resumo e palavras-chave (sem restrição ao período de publicação) o termo "Agile Supply Chain*" e foram levantados somente artigos redigidos em inglês, devido ao fato de este ser o idioma oficial da ciência. Após a leitura e análise do resumo e introdução dos artigos encontrados, considerando que alguns artigos apenas mencionam o termo "Agile Supply Chain*" no resumo e palavras-chave e que alguns artigos estão duplicados (ou seja, estão indexados nas duas bases de dados), após o devido refinamento chegou-se ao número final de 159 artigos. É importante ressaltar que os artigos obtidos do ano de 2018 incluem apenas as publicações realizadas até o mês de junho.

\section{RESULTADOS}

Nesta seção, os resultados e a análise do estudo serão apresentados em tabelas e figuras, de acordo com os critérios previamente definidos.

\subsection{PUBLICAÇÕES POR PERIÓDICO}

A Figura 1 representa uma nuvem de palavras que apresenta os periódicos onde os artigos foram publicados. A nuvem de palavras é uma representação gráfica do texto em que as palavras mais frequentes são realçadas por fontes maiores ou cores mais escuras (IEFREMOVA; SAS; KOZAK, 2016).

Figura 1 - Nuvem de palavras dos periódicos onde os artigos foram publicados.

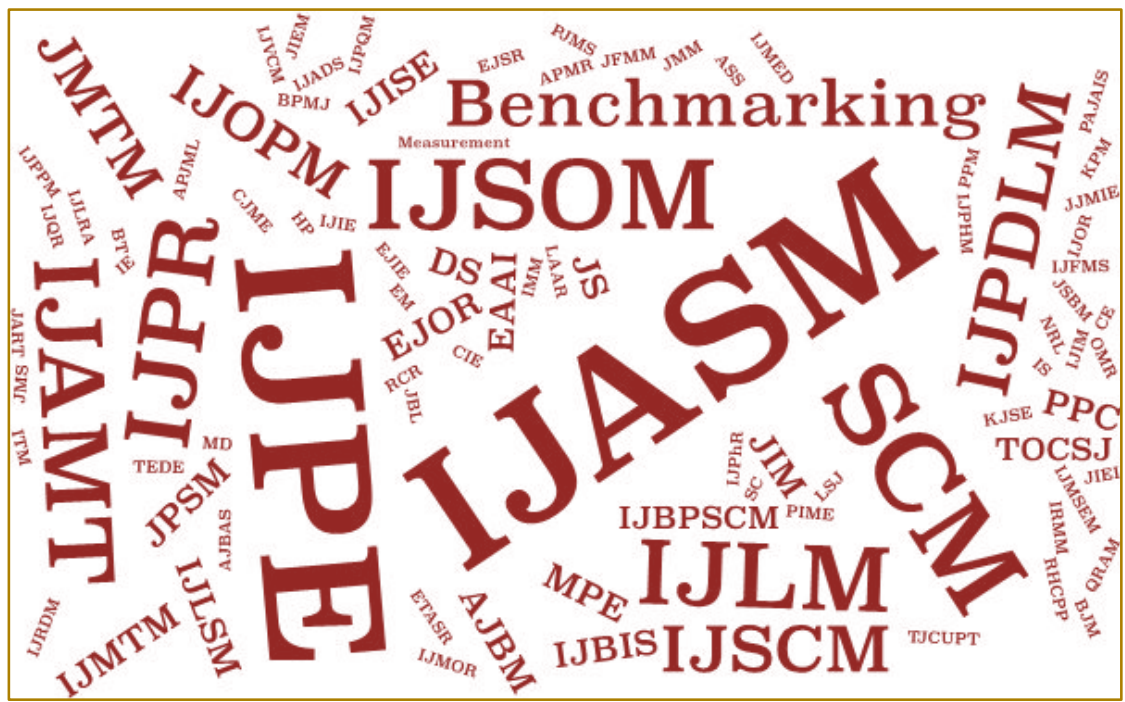


Em relação ao número de trabalhos publicados, os periódicos mais produtivos são o International Journal of Production Economics (IJPE) e International Journal of Agile Systems and Management (IJASM), com 9 artigos; Supply Chain Management (SCM) e International Journal of Services and Operations Management (IJSOM), com 6 artigos; International Journal of Production Research (IJPR), International Journal of Advanced Manufacturing Technology (IJAMT) e International Journal of Logistics Management (IJLM), com 5 artigos.

Além da logística e gestão da cadeia de suprimentos (Supply Chain Management, International Journal of Logistics Management, International Journal of Physical Distribution \& Logistics Management, International Journal of Supply Chain Management), grande parte dos trabalhos sobre o tema têm sido publicados em periódicos das áreas de gestão da produção (International Journal of Production Economics, International Journal of Agile Systems and Management, International Journal of Services and Operations Management, International Journal of Production Research, International Journal of Operations \& Production Management), manufatura avançada (International Journal of Advanced Manufacturing Technology, Journal of Manufacturing Technology Management) e administração (Benchmarking).
Como pode ser visto na Figura 2, o primeiro artigo sobre ASC foi publicado em 1999, em 2002 não foi publicado nenhum artigo sobre o tema em periódicos indexados pela Scopus e/ou Web of Science, e, embora existam algumas flutuações, o número de publicações sobre o tema começou a aumentar substancialmente em 2006.

Dos 159 artigos desenvolvidos sobre o tema, 80 foram publicados em periódicos que estão indexados no Journal Citation Report (JCR). Para Hsieh e Chang (2009), o JCR avalia e classifica os periódicos de acordo com o impacto das citações de suas publicações na Thomson Reuters, resultando no fator de impacto do periódico. O fator de impacto ajuda a avaliar a importância relativa de um periódico, especialmente quando comparado com outros do mesmo campo. A Figura 2 apresenta a quantidade anual de artigos publicados em periódicos com e sem JCR. Pode-se argumentar que a predominância de publicação dos artigos em periódicos de alto impacto indica que a pesquisa acadêmica sobre algum tema tem qualidade e é bastante atrativa para a ciência mundial. Com relação à produção científica sobre ASCs, como a publicação em periódicos com e sem JCR oscila muito, ainda não é possível estabelecer tendências.

Figura 2 - Quantidade anual de artigos publicada em periódicos com e sem JCR.

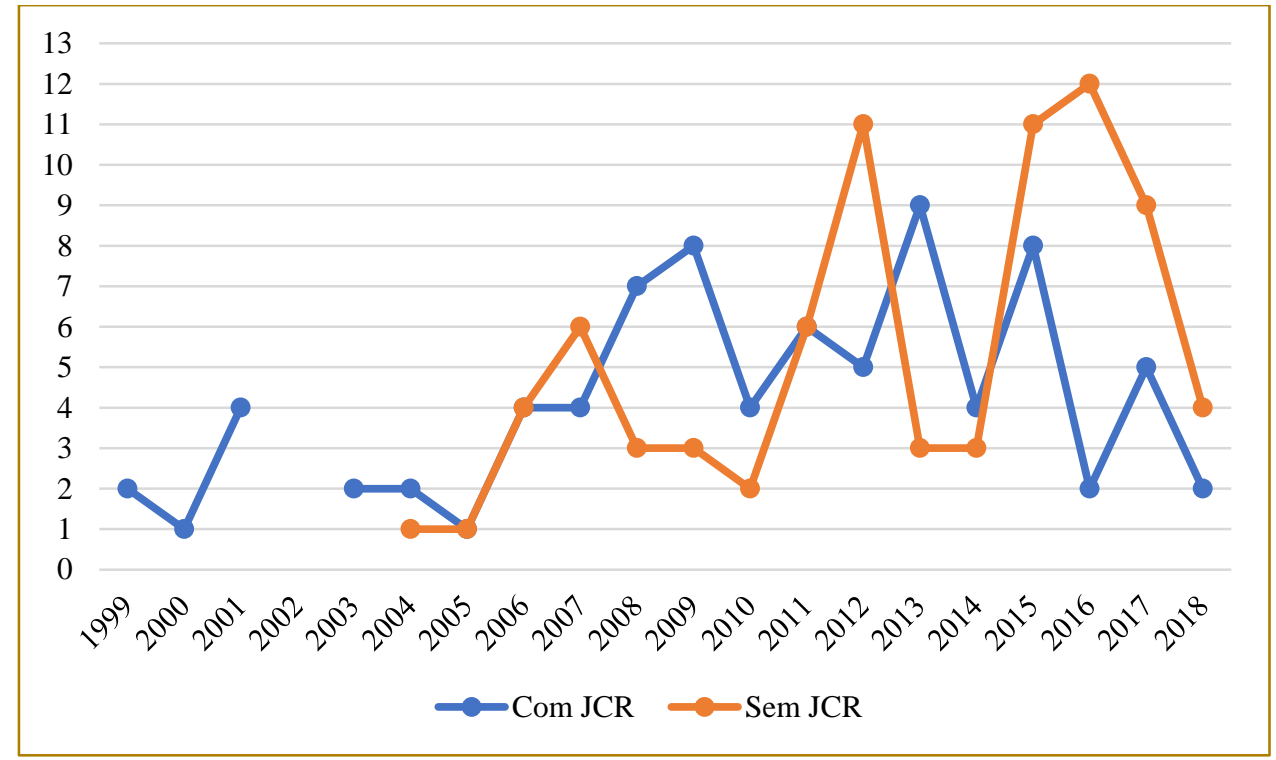




\subsection{TÓPICOS}

A Figura 3 apresenta uma nuvem de palavras sobre as palavras-chave mencionadas nos artigos. Excluindo da análise os termos inerentes ao tema central das pesquisas (agilidade, ágil, gestão, cadeia, suprimentos), pode-se afirmar que temas como desempenho, manufatura, análise, flexibilidade, tecnologia, informação, parceria, integração e estrutura tiveram grande relevância para o seu desenvolvimento. $\mathrm{Na}$ Figura 3, também pode ser notada a presença de termos como enxuta, responsiva, verde e resiliente, pois alguns trabalhos sobre o tema discutem comparações entre a estratégia ágil e outros tipos de cadeias de suprimentos.

Figura 3 - Nuvem de palavras das palavras-chave mencionadas nos artigos.

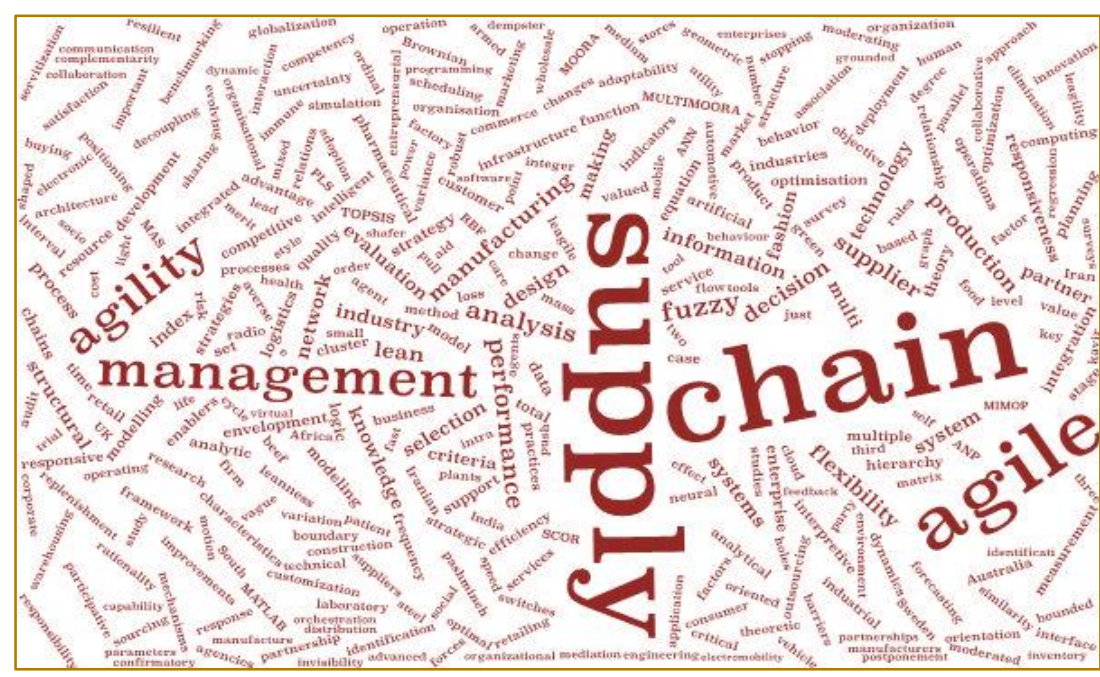

\subsection{PAÍSES}

A Figura 4 apresenta uma nuvem de palavras dos países que desenvolveram pesquisas sobre o tema, segundo a filiação dos autores.

Figura 4 - Nuvem de palavras dos países mais produtivos.

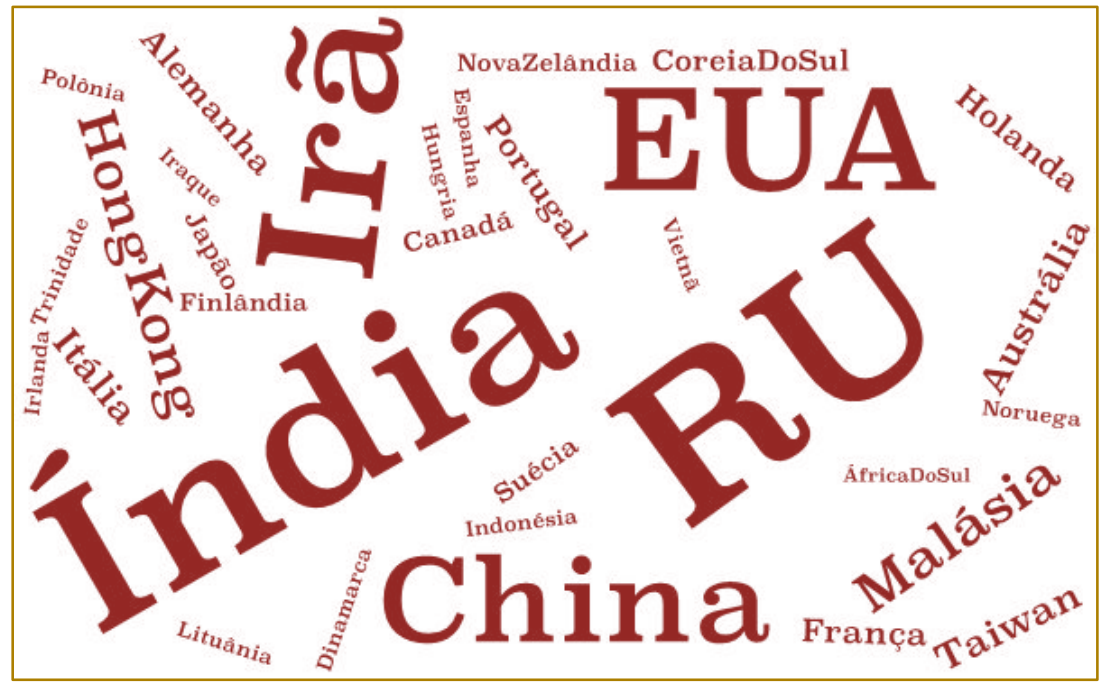


O Reino Unido é o país mais produtivo em termos de artigos publicados, com 35 trabalhos. Índia (33), Irã (27), Estados Unidos (26) e China (21) também são países com quantidade significativa de trabalhos publicados. A Figura 4 também apresenta que a maioria dos países que desenvolveram pesquisas sobre o tema são desenvolvidos. Este resultado corrobora com os dados de Far, Akbari e Clarke (2017), os quais afirmam que como a ASC é bastante importante para a solidez da economia, ela é muito mais comum em países desenvolvidos.

\subsection{FATOR DE IMPACTO DOS ARTIGOS}

A análise do impacto de um artigo para a ciência é um índice de difícil mensuração.
Caso tome-se o número de citações como base, pode-se criar um certo viés temporal, já que os artigos mais antigos têm uma grande vantagem fornecida pelo tempo. Homrich et al. (2018) afirmam que a avaliação do impacto de um artigo para áreas científicas deve considerar tanto a média de citações anuais quanto o fator de impacto do periódico onde o artigo foi publicado, já que o fator de impacto pode mudar a posição de um artigo no ranking de citações e a consideração da média anual de citações é menos sensível às variações anuais das citações. O cálculo do fator de impacto do artigo é apresentado na Equação 1, desenvolvida por Carvalho, Fleury e Lopes (2013).

$$
\text { Fator de impacto do artigo = média anual de citações } \times(1+\mathrm{JCR})
$$

As Tabelas 2 e 3 apresentam os artigos sobre ASCs com maior impacto para a ciência, considerando o número de citações recebidas nas bases de dados Scopus e Web of Science, respectivamente.

Tabela 2 - Artigos com maior fator de impacto na Scopus

\begin{tabular}{|c|c|c|c|c|c|}
\hline Ano & Título do artigo & Periódico & $\begin{array}{l}\text { JCR } \\
(2017)\end{array}$ & $\begin{array}{l}\text { Média } \\
\text { anual de } \\
\text { citações }\end{array}$ & $\begin{array}{l}\text { Fator de } \\
\text { impacto } \\
\text { do artigo }\end{array}$ \\
\hline 2000 & $\begin{array}{l}\text { The agile supply chain: } \\
\text { competing in volatile markets }\end{array}$ & $\begin{array}{l}\text { Industrial Marketing } \\
\text { Management }\end{array}$ & 3,678 & 46,49 & 217,43 \\
\hline 2001 & $\begin{array}{l}\text { An integrated model for the } \\
\text { design of agile supply chains }\end{array}$ & $\begin{array}{l}\text { International Journal of } \\
\text { Physical Distribution \& } \\
\text { Logistics Management }\end{array}$ & 4,215 & 27,06 & 141,11 \\
\hline 2006 & Agility index in the supply chain & $\begin{array}{l}\text { International Journal of } \\
\text { Production Economics }\end{array}$ & 4,407 & 19,07 & 103,11 \\
\hline 2004 & $\begin{array}{l}\text { Agile supply chain capabilities: } \\
\text { determinants of competitive } \\
\text { objectives }\end{array}$ & $\begin{array}{l}\text { European Journal of } \\
\text { Operational Research }\end{array}$ & 3,428 & 18,07 & 80,03 \\
\hline 2001 & $\begin{array}{l}\text { Measuring agile capabilities in } \\
\text { the supply chain }\end{array}$ & $\begin{array}{l}\text { International Journal of } \\
\text { Operations \& Production } \\
\text { Management }\end{array}$ & 2,955 & 16,29 & 64,43 \\
\hline
\end{tabular}


Tabela 3 - Artigos com maior fator de impacto na Web of Science

\begin{tabular}{|c|c|c|c|c|c|}
\hline Ano & Título do artigo & Periódico & $\begin{array}{l}\text { JCR } \\
(2017)\end{array}$ & $\begin{array}{l}\text { Média } \\
\text { anual de } \\
\text { citações }\end{array}$ & $\begin{array}{l}\text { Fator de } \\
\text { impacto } \\
\text { do artigo }\end{array}$ \\
\hline 2000 & $\begin{array}{l}\text { The agile supply chain: } \\
\text { competing in volatile markets }\end{array}$ & $\begin{array}{l}\text { Industrial Marketing } \\
\text { Management }\end{array}$ & 3,678 & 31,57 & 147,67 \\
\hline 2006 & Agility index in the supply chain & $\begin{array}{l}\text { International Journal of } \\
\text { Production Economics }\end{array}$ & 4,407 & 13,15 & 71,11 \\
\hline 2006 & $\begin{array}{l}\text { Humanitarian aid: an agile } \\
\text { supply chain? }\end{array}$ & Supply Chain Management & 3,833 & 11,75 & 56,79 \\
\hline 2004 & $\begin{array}{l}\text { Agile supply chain capabilities: } \\
\text { determinants of competitive } \\
\text { objectives }\end{array}$ & $\begin{array}{l}\text { European Journal of } \\
\text { Operational Research }\end{array}$ & 3,428 & 12,52 & 55,43 \\
\hline 2001 & $\begin{array}{l}\text { Measuring agile capabilities in } \\
\text { the supply chain }\end{array}$ & $\begin{array}{l}\text { International Journal of } \\
\text { Operations \& Production } \\
\text { Management }\end{array}$ & 2,955 & 9,94 & 39,32 \\
\hline
\end{tabular}

A Tabela 4 apresenta o país de origem dos autores que desenvolveram os artigos de maior fator de impacto.

Tabela 4 - País de origem dos autores dos artigos com maior fator de impacto

\begin{tabular}{|l|l|}
\hline \multicolumn{2}{|c|}{ Título do artigo País } \\
\hline The agile supply chain: competing in volatile markets & Reino Unido \\
\hline An integrated model for the design of agile supply chains & Reino Unido \\
\hline Agility index in the supply chain & Taiwan \\
\hline Agile supply chain capabilities: determinants of competitive objectives & Reino Unido, Estados Unidos \\
\hline Measuring agile capabilities in the supply chain & Reino Unido \\
\hline Humanitarian aid: an agile supply chain? & Austrália, Reino Unido \\
\hline
\end{tabular}

Entre os artigos com maior fator de impacto, os temas discutidos foram: concorrência entre empresas, projeto de estruturação de cadeias ágeis, desenvolvimento de modelos de mensuração da agilidade, estratégias para redução de custos, seleção e integração entre parceiros na cadeia de suprimentos e modelagem de sistemas.

\section{CONSIDERAÇÕES FINAIS}

Este trabalho serviu para tecer um panorama geral da produção científica sobre ASCs publicada em periódicos indexados na Scopus e/ou Web of Science. Os 159 artigos relacionados ao tema foram publicados em 92 periódicos. A apresentação dos periódicos mais produtivos em relação às publicações sobre o tema direciona as principais fontes para a divulgação de trabalhos futuros. O estudo bibliométrico revelou que $\mathrm{o}$ International Journal of Production Economics, International Journal of Agile Systems and Management, Supply Chain Management, International Journal of Services and Operations Management, International Journal of Production Research, International Journal of Advanced Manufacturing Technology e International Journal of Logistics Management são os periódicos mais prolíficos em relação à pesquisa publicada. Além de ser o periódico mais produtivo, o International Journal of Production Economics publicou um dos artigos de maior relevância para o desenvolvimento do tema, tomando como base o fator de impacto do artigo na Scopus e Web of Science. Com relação ao fator de impacto do artigo, pode-se afirmar que o periódico Industrial Marketing Management teve a maior contribuição para a divulgação 
do tema, pois teve o maior índice tanto na Scopus quanto na Web of Science.

Pesquisadores de 32 países publicaram estudos sobre o tema. Com relação aos países de filiação dos autores, foi possível verificar que o Reino Unido deu a maior contribuição para o desenvolvimento do tema, pois foi o país com maior número de publicações e desenvolveu pesquisas de grande relevância para a ciência, levando-se em consideração o fator de impacto dos artigos. É possível ver que a pesquisa está fortemente concentrada em países desenvolvidos, o que reflete o sucesso da gestão da cadeia de suprimentos das empresas instaladas neles.

\subsection{LIMITAÇÕES DA PESQUISA E OPORTUNIDADES PARA FUTUROS TRABALHOS}

Como em qualquer estudo bibliométrico, é importante enfatizar que o método utilizado para 0 desenvolvimento deste artigo apresenta algumas limitações. A amostra de artigos analisada foi extraída de apenas duas bases de dados, o que pode ter desconsiderado estudos relevantes publicados em outras fontes. Além disso, o fato de apenas artigos publicados em periódicos terem sido analisados (devido à

\section{REFERÊNCIAS}

[1] ABBASI, M.; HOSNAVI, R.; BABAZADEH, R. Agile and flexible supply chain network design under uncertainty. International Journal of Industrial Engineering, v. 21, n. 4, p. 190-208, 2014

[2] ASGARI, N. et al. Supply chain management 1982-2015: a review. IMA Journal of Management Mathematics, v. 27, n. 3, p. 353-379, 2016 .

[3] BARAMICHAI, M. et al. Agile supply chain transformation matrix: a QFD-based tool for improving enterprise agility. International Journal of Value Chain Management, v. 1, n. 3, p. 281-303, 2007.

[4] BLANK, L. et al. Directions in green roof research: a bibliometric study. Building and Environment, v. 66, p. 23-28, 2013.

[5] CARNEVALLI, J. A.; Miguel, P. A. C. Review, analysis and classification of the literature on QFD - types of research, difficulties and benefits. International Journal of Production Economics, v. 114, n. 2, p. 737-754, 2008.

[6] CARVALHO, M. M.; FLEURY, A. L.; LOPES, A. P. An overview of the literature on sua maior relevância e qualidade) não significa que artigos publicados em anais de congressos não possam ter contribuições importantes para o desenvolvimento do tema. $\mathrm{E}$, finalmente, o estudo bibliométrico desenvolvido baseou-se nas percepções dos autores, o que pode desconsiderar aspectos tidos como importantes a partir de outros pontos de vista.

No entanto, apesar das limitações, este estudo ajuda a iluminar a literatura científica sobre ASCs, uma vez que apresenta a caracterização da produção científica, mostrando os tópicos de maior atratividade para a ciência, bem como os artigos e temas que tiveram o maior impacto. Outros estudos bibliométricos podem ir além dos tópicos discutidos aqui, para que uma visão geral da produção científica seja mais ampla e/ou mais detalhada em relação aos temas analisados. Futuros trabalhos podem examinar as principais abordagens e procedimentos técnicos utilizados para o desenvolvimento dos artigos, redes de colaboração entre pesquisadores e países, lacunas de pesquisa a serem exploradas em futuros trabalhos, artigos publicados em outras bases de dados bibliográficas, bem como outros tipos de produção acadêmica relacionados ao tema.

technology roadmapping (TRM): contributions and trends. Technological Forecasting \& Social Change, v. 80, n. 7, p. 1418-1437, 2013.

[7] CHIARINI, A.; VAGNONI, E. Strategies for modern operations management: Answers from European manufacturing companies. Benchmarking: An International Journal, v. 24, n. 4, p. 1065-1081, 2017.

[8] CHRISTOPHER, M. The agile supply chain: competing in volatile markets. Industrial Marketing Management, v. 29, n. 1, p. 37-44, 2000.

[9] CHRISTOPHER, M.; LOWSON, R.; PECK, $\mathrm{H}$. Creating agile supply chains in the fashion industry. International Journal of Retail \& Distribution Management, v. 32, n. 8, p. 367-376, 2004.

[10] CHRISTOPHER, M.; TOWILL, D. An integrated model for the design of agile supply chains. International Journal of Physical Distribution \& Logistics Management, v. 31, n. 4, p. 235-246, 2001.

[11] FAR, S. M.; AKBARI, M.; CLARKE, S. The effect of IT integration on supply chain agility 
towards market performance (a proposed study). Informing Science: The International Journal of an Emerging Transdiscipline, v. 20, p. 99-117, 2017.

[12] HAQ, A. N.; BODDU, V. Analysis of agile supply chain enablers for Indian food processing industries using analytical hierarchy process. International Journal of Manufacturing Technology and Management, v. 29, n. 1-2, p. 30-47, 2015.

[13] HARLAND, C. M. Supply chain management research impact: an evidence-based perspective. Supply Chain Management: An International Journal, v. 18, n. 5, p. 483-496, 2013.

[14] HOMRICH, A. S. et al. The circular economy umbrella: trends and gaps on integrating pathways. Journal of Cleaner Production, v. 175, p. 525-543, 2018

[15] HSIEH, P-N.; CHANG, P-L. An assessment of world-wide research productivity in production and operations management. International Journal of Production Economics, v. 120, n. 2, p. 540-551, 2009

[16] IEFREMOVA, O.; SAS, D.; KOZAK, M. International collaboration among authors of Current Science. Current Science, v. 110, n. 8, p. 1414-1418, 2016

[17] LEMIEUX, A-A. et al. A new analysis framework for agility in the fashion industry. International Journal of Agile Systems and Management, v. 5, n. 2, p. 175-197, 2012.

[18] MARTINEZ-SANCHEZ, A.; LAHOZ-LEO, F. Supply chain agility: a mediator for absorptive capacity. Baltic Journal of Management, v. 13, n. 2, p. 264-278, 2018.

[19] MASON-JONES, R.; NAYLOR, B.; TOWILL, D. R. Engineering the leagile supply chain. International Journal of Agile Management Systems, v. 2, n. 1, p. 54-61, 2000

[20] MATAWALE, C. R.; DATTA, S.; MAHAPATRA, S. S. Supplier/partner selection in agile supply chain: Application of vague set as a decision making tool. Benchmarking: An International Journal, v. 23, n. 4, p. 866-892, 2016.

[21] MISHRA, S. et al. Application of fuzzy integrated MULTIMOORA method towards supplier/partner selection in agile supply chain. International Journal of Operational Research, v. 22, n. 4, p. 466-514, 2015.

[22] NGAI, E. W.T. et al. RFID research: an academic literature review (1995-2005) and future research directions. International Journal of Production Economics, v. 112, n. 1, p. 510-520, 2008.

[23] OLSSON, O.; ARONSSON, H. Managing a variable acute patient flow - categorising the strategies. Supply Chain Management: An International Journal, v. 20, n. 2, p. 113-127, 2015.

[24] POOL, J. K. et al. The effect of business intelligence adoption on agile supply chain performance. International Journal of Productivity and Quality Management, v. 23, n. 3, p. 289-306, 2018

[25] PRASAD, S.; TATA, J. Publication patterns concerning the role of teams/groups in the information systems literature from 1990 to 1999. Information \& Management, v. 42, n. 8, p. 11371148,2005

[26] REN, J.; YUSUF, Y. Y.; BURNS, N. D. A decision-support framework for agile enterprise partnering. International Journal of Advanced Manufacturing Technology, v. 41, n. 1-2, p. 180192, 2009

[27] SALEESHYA, P.G.; SACHIN, B. Modelling and analysis of an agile supply chain. International Journal of Productivity and Quality Management, v. 15, n. 4, p. 486-510, 2015.

[28] SHAHIN, A.; KHALILI, A.; POURHAMIDI, M. Proposing a new approach for evaluating supply chain agility by data envelopment analysis with a case study in Pashmineh Kavir factory. International Journal of Services and Operations Management, v. 26, n. 3, p. $277-293,2017$

[29] SHAN, W.; WANG, J. Mapping the landscape and evolutions of green supply chain management. Sustainability, v. 10, n. 3, p. 597-629, 2018.

[30] SHARMA, S. K.; BHAT, A. Modelling supply chain agility enablers using ISM. Journal of Modelling in Management, v. 9, n. 2, p. 200-214, 2014

[31] TAGUE-SUTCLIFFE, J. An introduction to informetrics. Information Processing \& Management, v. 28, n. 1, p. 1-3, 1992.

[32] TARAFDAR, M.; QRUNFLEH, S. Agile supply chain strategy and supply chain performance: complementary roles of supply chain practices and information systems capability for agility. International Journal of Production Research, v. 55, n. 4, p. 925-938, 2017.

[33] VANTI, N. A. P. Da bibliometria à webometria: uma exploração conceitual dos mecanismos utilizados para medir o registro da informação e a difusão do conhecimento. Ciência da Informação, v. 31, n. 2, p. 152-162, 2002.

[34] WU, C.; BARNES, D. A literature review of decision-making models and approaches for partner selection in agile supply chains. Journal of Purchasing \& Supply Management, v. 17, n. 4, p. 256-274, 2011.

[35] XU, N-R. et al. Research on evolutionary mechanism of agile supply chain network via complex network theory. Mathematical Problems in Engineering, v. 2016, p. 1-9, 2016.

[36] $\mathrm{YU}, \mathrm{C}$. et al. A delayed product differentiation model for cloud manufacturing. Computers \& Industrial Engineering, v. 117, p. 6070, 2018. 


\section{Papítulo 8}

\section{O RESUltAdO NO PLANEJAMENTO DA PRODUCẼO DEVIDO À ASSOCIACÃO DAS CAMADAS DE CONTROLE AVANÇADO E DE SCHEDULING NA INDÚSTRIA}

\section{Isis Juliane Arantes Granja}

Cássio Valdemar Parra Granja

Resumo: As camadas de Scheduling e de controle avançado atuam de forma independente no processo produtivo na indústria. Algumas análises começam a compreender que a inclusão dessas camadas, oferecem possibilidades de melhoria no processo produtivo, simultaneamente gera melhores resultados operacionais. Em especial, a determinação do seqüenciamento ótimo de produtos e é sensível aos tempos de transição, conseguidos da camada de controle, visto que são vigorosamente dependentes das variáveis de processo. Esse artigo verifica o resultado da inserção dessas camadas, aderindo a estratégia de controle avançado MPC, considerando um modelo não linear de planta química. Resultados de simulação computacional, permitem comprovar a necessidade de se agregar informações procedentes da camada de controle avançado no Scheduling da produção.

Palavras chave: Scheduling, Controle avançado, Processo produtivo. 


\section{INTRODUÇÃO}

$\mathrm{Na}$ realidade industrial, as camadas de decisão sobre Programação da Produção e Controle de processos, tradicionamente estão separadas, entretanto com o objetivo de melhorias na economia do processo produtivo, a inclusão dessas camadas vem acomodando uma atenção sistemática e crescente. Considerando que as decisões de uma dessas camadas consistem necessariamente de informações da outra, a melhoria na integração entre elas acarreta em melhores resultados operacionais. No entanto, essa integração não é um trabalho simples, a sua complexidade é devida, acima de tudo, a ocorrer em diferentes escalas de tempo. Por isso a atenção da comunidade cientifica e industrial tem crescido na busca dessa integração. (BALDEA e HARJUNKOSKI, 2014; GROSSMANN, 2005).

Este artigo apresenta um exemplo simulado de integração dessas camadas que mostra claramente como as informações da camada de controle impactam na camada de programação da produção. Para isso, foi utilizada a estratégia DMC (Dynamic Matrix Control) que pode ser vista em (MACIEJOWSKI, 2002). Para o cálculo do scheduling ótimo são utilizadas informações sobre os tempos de transição que ocorrem na troca da produção de produtos distintos em uma planta química, obtidas por simulação do controle do processo, que impactam diretamente no sequenciamento da produção. Observou-se que uma pequena mudança nas especificações da matéria prima, em apenas uma variável, já é suficiente para mudança no scheduling da produção. Isso mostra que as camadas de scheduling e controle realmente devem ser vistas de forma integrada.

Turrioni e Mello (2012) afirmam que o método de simulação é utilizado quando se deseja experimentar um sistema real a partir de um modelo com a verificação da resposta do sistema a modificações propostas. Nas décadas de 60 e 70 a simulação era excessivamente cara e utilizavam ferramenta que eram disponíveis apenas para grandes corporações. Atualmente, com a evolução dos computadores e de ferramentas de software, o tempo e esforço dispendido em um projeto de simulação foi radicalmente reduzido sendo utilizado principalmente na análise dos resultados. (MARTINS, MELLO E TURRIONI, 2014).
Segundo Azevedo et al. (2010), simulação é uma ferramenta exploratória de apoio a decisão que utiliza modelos que permitem a realização de experimentos para análise de comportamentos futuros de um sistema e também a construção de cenários com base em alterações de parâmetros. De acordo com Perros (2009), um modelo de simulação é, em geral, usado para estudar os sistemas da vida real em condições virtuais. Particularmente o interesse consiste na quantificação do desempenho de um sistema em estudo para diversos valores de seus parâmetros de entrada. Essas medidas quantificadas de desempenho podem ser muito úteis no processo de decisão gerencial. Foi utilizado o método de simulação para apresentar o impacto da integração das camadas de decisão do sequenciamento da produção, scheduling, com o controle avançado em um processo contínuo.

Segundo Du et al. (2015), as funções de Programação e Controle da produção definem metas de produção com base na demanda e buscam cumpri-las, mesmo com a presença de perturbações, por isso essas funções são consideradas essenciais na cadeira de suprimentos na indústria de processos. A construção de modelos dinâmicos com base matemática comum entre as funções de Programação e Controle da Produção é necessária para suportar as incertezas, de modo que sua execução possa ocorrer em tempo real para os mais diversos tipos de sistemas de produção (BALDEA e HARJUNKOSKI, 2014; LINDHOLM e NYTZÉN, 2014; DU et al., 2015). Lindholm e Nytzém (2014) afirmam que para a melhoria na eficiência operacional na indústria de processos é preciso que as funções de programação da produção e de controle do processo sejam otimizadas. Yugma et al. (2014) consideram que as atividades de programação e controle são inevitavelmente confrontadas, devido principalmente ao aumento da complexidade das técnicas e escalas de produção, isto porque cada uma dessas camadas depende de informações da outra.

Para a Programação da Produção, Shobrys e White (2002) consideram as seguintes variáveis-chaves: tempo inicial de uma operação, unidade, local de ocorrência, duração e o volume a ser processado. Consideram como indicadores: demanda do produto e possibilidade de manter as unidades operando continuamente em 
horizontes de tempos que pode ser de dias a meses, e que normalmente estão relacionados com tempos críticos de entrega de matérias- primas e ciclos de operação dos equipamentos e unidades operacionais.

Para a redução de custos e operação mais eficiente da planta, ARC (2015) afirma que é comum utilizar-se de ADP (Advanced Process Control) e ferramentas de otimização em tempo real. Entretanto, as necessidades de requisitos de produção mudam constantemente para adequação às oportunidades de mercado. Com isso as empresas estão buscando a representação de um modelo mais integrado da planta, com a produção colaborativa e a mensuração do seu desempenho em tempo real. Segundo Kozák (2014), o sucesso obtido com os métodos de controle convencionais para automação de processos, tais como PID (Proportional-Integral Derivative), Sistemas Lineares, entre outros, promoveram o desenvolvimento de novos métodos baseados em algoritmos mais elaborados e estratégias de software com uso efetivo de hardware. Esses métodos incluem: MPC-Model Predictive Control, MPC híbrido, MIMOMultiple-Input-Multiple-Output, controle robusto e adaptativo, e mais recentemente, chegando a métodos computacionais baseados em técnicas de inteligência artificial, com uso de algoritmos genéticos, redes neurais, sistemas fuzzy, e outros mais.

DMC (Dynamic Matrix Control) é um tipo real de controle preditivo (MPC) que consiste em um conjunto de esquemas de controles mais avançados que os tradicionais PID (LOPEZGUEDE et al., 2013). Nppert (2002), DMC é um dos métodos de controle preditivo mais populares. É especialmente poderoso para vários sistemas de controle com múltiplas entradas e múltiplas saídas. Por isso é muito utilizado em estudos com simulação. Já para Bagheri e Sedigh (2015) DMC é uma das primeiras implementações comerciais de MPC e é amplamente utilizado em muitos processos químicos, isto devido a estrutura simples do controlador e exigência mínima de informações de planta.

A planta química consiste em um reator CSTR (Continuous Stirred-Tank Reactor) não isotérmico que converte um reagente $A$ em três produtos P1, P2 e P3, diferenciados apenas pelas concentrações. As concentrações do exemplo correspondem a regiões de estabilidade quando a planta, em malha aberta, é perturbada por um sinal do tipo degrau unitário. O modelo matemático do reator consiste de um sistema de equações diferenciais ordinárias de segunda ordem proveniente do balanço de massa do reagente $A$ e do balanço de energia.

$$
\begin{aligned}
& \frac{d C_{A}}{d t}=\frac{q}{V}\left(C_{A O}-C_{A}\right)-k_{0} e^{\frac{-E_{A}}{R T}} C_{A} \\
& \frac{d T}{d t}=\frac{q}{V}\left(T_{0}-T\right)-\frac{1}{\rho C_{p}} k_{0} e^{-\frac{E_{A}}{R T} C_{A} \Delta H-\frac{U A}{V \rho C_{p}}(T-T C)}
\end{aligned}
$$

Sendo que: CA e T são concentração e temperatura, $U$ é o coeficiente de transferência de calor, A é área de transferência de calor, $\rho$ e Cp são densidade e capacidade térmica da mistura de reação, $V$ é o volume do reator, q é a taxa do fluxo de alimentação, CAO é concentração de entrada, EA é a energia de ativação, ko é o fator préexponencial na expressão de taxa de reação, Tc é a temperatura do fluido de refrigeração e T0 a temperatura de alimentação. Os valores dos parâmetros estão dados na Tabela 1.

O modelo do controlador DMC é construído após testes de simulação, tomando como referência a planta química modelada. Em cada ponto de operação, determina-se a matriz dinâmica considerando o horizonte do modelo $\mathrm{N}$, tal que $\mathrm{N}=50$ e período de amostragem $\mathrm{T}=0,05 \mathrm{~min}$.

Os parâmetros $L=5$ e $R=10$ representam os movimentos das ações de controle da variável manipulada Tc e o horizonte de predição das saídas futuras. É usada uma trajetória de referência com o parâmetro $\square=0.8$ que define a taxa de aproximação ao setpoint da variável controlada T (temperatura do corpo do reator) a ser alcançada. Os valores desses parâmetros são definidos por inspeção nos resultados da simulação. Vale ressaltar que não são valores otimizados. A função no 
tempo da variável manipulada definida pela estratégia de controle DMC adotada (maiores detalhes desta função podem ser

$$
\Delta \mathrm{T} \chi=(\mathrm{AT} \mathrm{A})-1 \mathrm{AT} \supseteq
$$

Onde: A é a matriz dinâmica e Ê é a matriz que representa o desvio predito da saída em relação à trajetória desejada. O problema da programação da produção pode ser modelado como um problema de otimização, considerando intervalos de tempos ("slot"), associados a cada produto. Assumem- se, neste caso, três intervalos (slots), um para cada produto. Cada slot contém um período de
encontrados
apresentada
em Maciejowski (2002) é seguir: a

$$
J=\frac{1}{T_{m}}\left[\sum_{i=1}^{3} \pi_{i} \omega_{i}-\sum_{i=1}^{3} C_{e, i} \omega_{i} \sum_{s=1}^{3} z_{i, s}\left(T_{m}-t_{s}^{f}\right)-q C_{r m} T_{m}\right]
$$

em que: $\quad \mathrm{Tm}, \pi \mathrm{\imath}, \omega \mathrm{\imath}, \mathrm{X} \sigma, \imath \varepsilon \zeta \mathrm{l}, \sigma, \quad$ são respectivamente: makespan, preço de venda do produto i, quantidade produzida do produto i, custo de estocagem do produto i transição e um período de produção. 0 período de transição corresponde ao tempo necessário para alcançar as novas condições de operação do reator para a produção de um novo produto, conforme mostra a Figura 1. A programação ótima então objetiva maximizar a seguinte função objetivo de lucro (BALDEA, HARJUNKOSKI, 2014)

Figura 1 - Programação da Produção baseada em intervalos de tempo para processos contínuos.

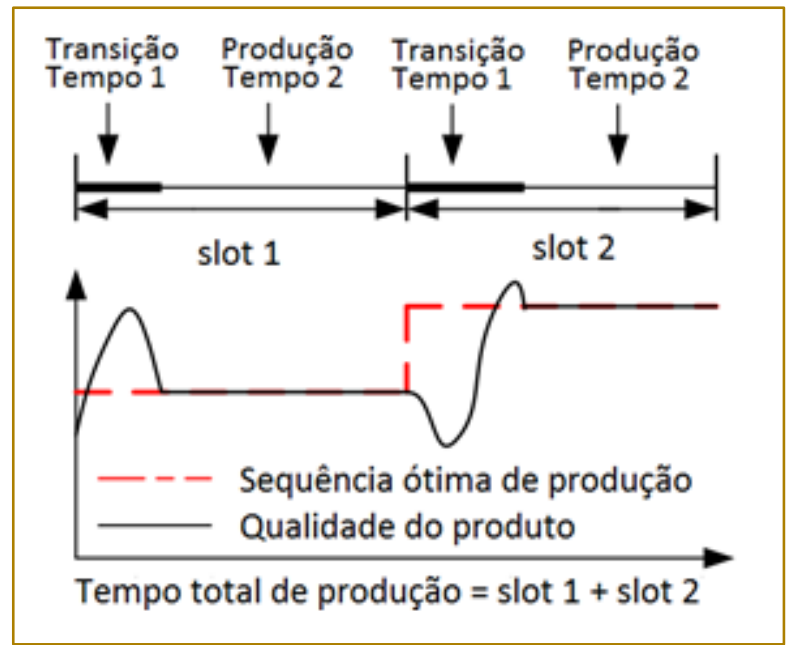

Fonte: adaptado de Flores-Tlacuahuac e Grossmann, 2006. 
A quantidade produzida do produto i é dada por:

$$
\omega_{i}=\sum_{s=1}^{3} \int_{\tau_{s}^{s}+\tau_{i i}}^{f_{s}^{f}} z_{i, s} q d t
$$

Sendo que: $t_{s}^{s}$ é o tempo de início no slots onde o produto i é produzido, $t_{s}^{f}$ é o tempo de finalização para o mesmo slot, $\tau_{\text {If }}$ é o tempo de transição entre 0 produto no slot s-1 e o produto i feito no slot s. Os instantes de tempo devem satisfazer as seguintes relações de precedência:

$$
t_{s}^{f}>t_{s}^{s}+\tau_{i i} \quad \forall_{S}>1 \quad(6) \quad t_{s}^{s}=t_{s-1}^{f} \forall_{s \neq 1}(7) \quad \text { e } \quad t_{3}^{f} \leq T_{m}
$$

as quais: requerem que um intervalo de tempo (slot) seja maior que o correspondente tempo de transição; impõem a coincidência de que o tempo final de um slot com o tempo inicial do slot seguinte; e definem a relação entre o tempo final do último slot com o tempo total de ciclo $(\mathrm{Tm})$.

$$
\sum_{s=1}^{3} Z_{i, s}=1 \quad \forall_{i}
$$

$\sum_{i=1}^{3} Z_{i, s}=1=1 \forall_{S}$

A formulação do problema deve incluir também restrições para a satisfação das demandas:

$$
\omega \mathrm{l}=\delta \mathrm{l}, \forall \mathrm{l}
$$

Para determinar o sequenciamento ótimo é necessário considerar todas as possíveis sequências de produção e os tempos de transição $\tau_{\mathrm{fi}}$ nas equações. Seus valores dependem da dinâmica do sistema, e podem, em princípio, ser computados com a realização de testes para todas as possíveis transições entre produtos. Isto sugere que o problema de controle para este reator deve ser abordado antes do problema de programação.

\section{RESULTADOS}

Os resultados de simulação que ilustram a dependência entre as tomadas de decisão definidas para as camadas de scheduling e de controle. São apresentados dois exemplos do processo produtivo. Para isto, foi utilizado um modelo de CSTR dado por Henson e
As variáveis binárias $Z_{i, s} \in\{0,1\}$ estão associadas cada qual a um produto, assegurando que o produto i é feito apenas uma vez para os três slots disponíveis

Seborg (1993). Os parâmetros do modelo da planta considerada são fornecidos na Tabela 1. O reator transforma $O$ reagente $A$ em produtos distintos pela concentração final: P1 $89,8 \%, C A=0,112 \mathrm{~mol} / \mathrm{l}), \mathrm{P} 2$ (96,1\%, CA = $0,039 \mathrm{~mol} / \mathrm{l})$, e P3 $(98,2 \%, \mathrm{CA}=0.018 \mathrm{~mol} / \mathrm{l})$. Os produtos são obtidos com a manutenção da temperatura em regime no corpo do reator nos seguintes valores: 381,69K, 401,49K e 416,43K para os produtos P1, P2 e P3, respectivamente.

O primeiro exemplo mostra os resultados por simulação dos tempos de transição, com uso dos dados da tabela 1, para as possíveis sequencias de produção de P1, P2 e P3. Enquanto que, o segundo exemplo mostra os resultados da simulação considerando uma perturbação de $1 \%$ na qualidade do reagente A, que alimenta o reator. 
TABELA 1 - Parâmetros de processo CSTR exotérmico

\begin{tabular}{|c|c|}
\hline \multicolumn{1}{|c|}{ Parâmetro } & Valor \\
\hline$C_{A 0}$ & $1 \mathrm{~mol} / \mathrm{l}$ \\
\hline$\Delta \mathrm{H}$ & $-5.104 \mathrm{~J} \mathrm{~mol}-1$ \\
\hline $\boldsymbol{\rho}$ & $103 \mathrm{~g} \mathrm{dm}-3$ \\
\hline $\mathrm{UA}$ & $5.104 \mathrm{~J} \mathrm{~K}-1 \mathrm{~min}-1$ \\
\hline $\mathrm{Cp}$ & $0,239 \mathrm{~J} \mathrm{~g}-1 \mathrm{~K}-1$ \\
\hline$k_{\circ}$ & $7,21010 \mathrm{~min}-1$ \\
\hline
\end{tabular}

Fonte: Henson \& Seborg (1993)

A demanda para cada produto $\mathrm{Pi}, \mathrm{i} \in\{1,2,3\}$ é dada por $\delta=[2040$ 30] dm3, os preços são $\pi=\left[\begin{array}{lll}1000 & 1200 & 2000\end{array}\right] \$ / d m 3, \quad 0$ armazenamento custos de estocagem $\mathrm{CE}=$ [20 50 30] $\$ / \mathrm{dm} 3 / \mathrm{min}$, a taxa de fluxo de alimentação é $q=1 \mathrm{dm} 3 / \mathrm{h}$, o custo de matéria-prima é de $20 \$ / \mathrm{dm} 3$, e a concentração de alimentação CAO $=1 \mathrm{~mol} / \mathrm{l}$. As simulações computacionais da aplicação do scheduling e da atuação do controlador DMC foram desenvolvidas no ambiente MATLAB. De acordo com Mathworks(2016) MATLAB (MATrix LABoratory) consiste em um software interativo de alto desempenho voltado para solução numérica de problemas matemáticos.

O primeiro exemplo, tem-se a temperatura $\mathrm{TO}=350 \mathrm{~K}$ e $\mathrm{CAO}=1 \mathrm{~mol} / \mathrm{l}$. Para esse parâmetro, ilustra-se o comportamento das variáveis manipulada TC e de controle T correspondentes a produção de P2 a partir das condições de operação de produção de P1. A partir da resposta da variável controlada $T$ é identificado o tempo de $\tau_{12}$, em minutos, conforme mostra a Figura 2, onde mostra o comportamento das variáveis manipulada e controlada e o tempo de transição para a passagem da produção:

Figura 2 - Gráfico do comportamento das variáveis manipulada e de controle para T0=350K e CAO $=1 \mathrm{~mol} / \mathrm{l}$.

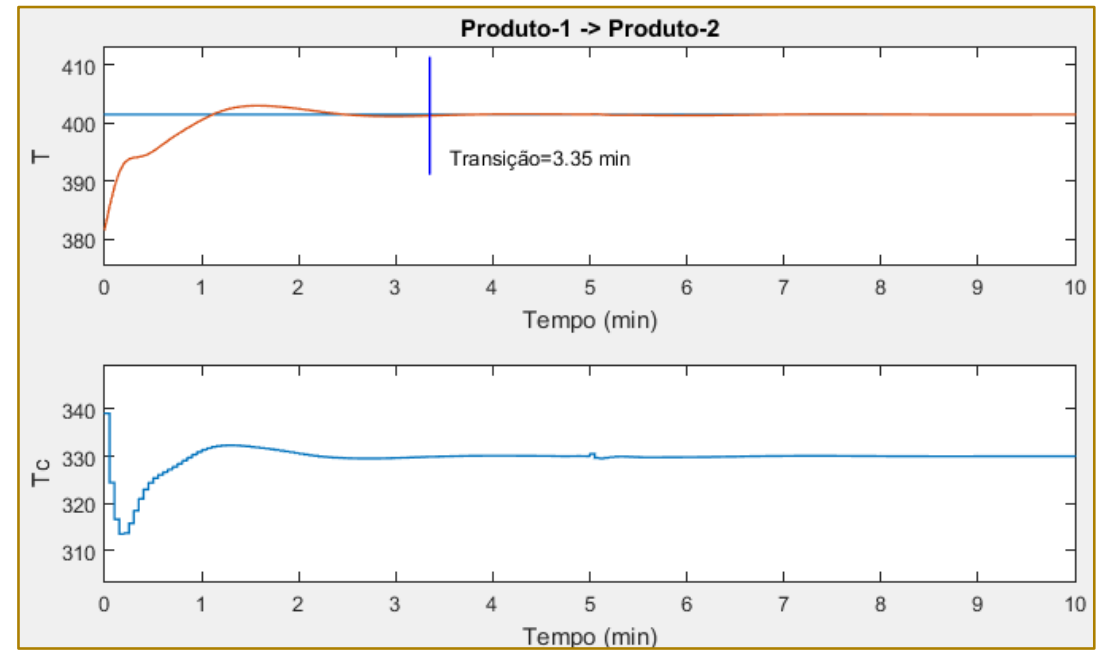

Fonte: Autores (2018)

A solução do problema de otimização considerando os tempos de transição determinados e demais parâmetros do controlador é tal como segue:
Sequência ótima: Produto $2 \rightarrow$ Produto $3 \rightarrow$ Produto 1. $\mathrm{J}=465,41 \mathrm{R} \$ / \mathrm{min} ; \mathrm{Tm}=95,65 \mathrm{~min}$.

Em um segundo exemplo, considerou-se uma variação de $1 \%$ na concentração do reagente A, ficando $\mathrm{CAO}=1,01 \mathrm{~mol} / \mathrm{l}$. Os demais parâmetros foram mantidos iguais aos do 
exemplo 1. A Figura 3 apresenta o gráfico do comportamento das variáveis manipulada e de controle:

Figura 3 - Gráfico do comportamento da variável manipulada e de controle para T0=350K e CA0 = $1,01 \mathrm{~mol} / \mathrm{l}$.

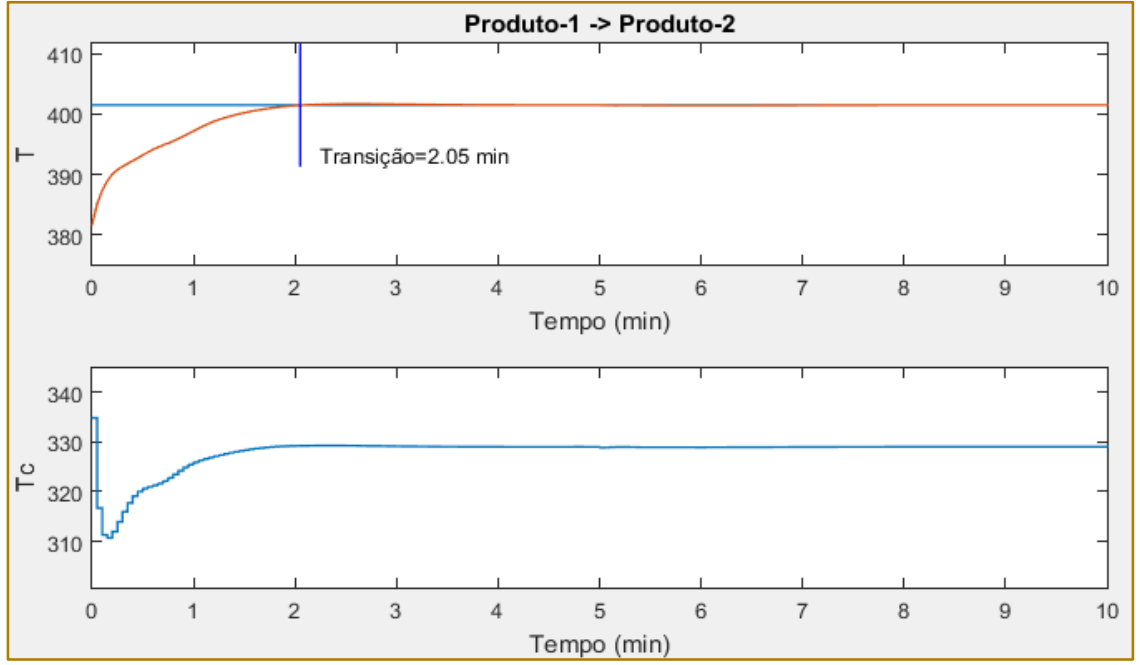

Fonte: Autores (2018)

Neste exemplo, a solução do problema de otimização considerando os tempos de transição determinados e demais parâmetros do controlador é tal como segue:

Sequência ótima: Produto $2 \rightarrow$ Produto $1 \rightarrow$ Produto 3. J=457,5 R\$/min; $T m=99,10 \mathrm{~min}$

Observa-se que uma mínima variação em uma variável de operação do reator, no caso a concentração da matéria prima, modifica os tempos de transição que impactam nos valores de makespan e de lucro, bem como o sequenciamento ótimo da produção.

\section{CONCLUSÃO}

A literatura vem apontando a importância da integração de camadas de decisão na indústria de processos. As informações obtidas a partir da integração entre as camadas permitem que as decisões tomadas levem a um melhor desempenho operacional. (BALDEA e HARJUNKOSKI, 2014; GROSSMANN, 2005)

Para constatar o impacto na programação da produção devido à integração das camadas de controle avançado e de scheduling na indústria de processos, considerou-se a simulação computacional de um modelo de processo químico associado a um reator CSTR controlado pela estratégia de controle DMC, visando a obtenção de três produtos de acordo com a programação da produção resultante da resolução de um problema de otimização.

A partir dos experimentos computacionais, os tempos de transição que ocorrem na mudança de processamento de produtos distintos, bem como na variação de tolerância na especificação de materiais que alimentam o processo, variam significativamente, forçando a camada de scheduling a alterar a programação da produção de forma a alcançar melhorias no desempenho operacional da planta.

Experimentos computacionais indicam que os tempos de transição, decorrentes das trocas de tipos de produtos definidos pela programação da produção, são fortemente dependentes das variáveis envolvidas no processo, em particular de flutuações em parâmetros de matéria prima, mesmo aqueles delimitados pelos limites de tolerância préestabelecidos. A sensibilidade dos tempos de transição observada provoca, no caso em questão, fortes impactos na programação da produção, ou seja, a camada de scheduling deve rever a programação da produção considerando informações da camada de controle de processos a fim de alcançar melhorias no desempenho operacional da planta. Se operam isoladamente, o desempenho do processo produtivo pode ser intensamente degradado. 
Resultados de simulação confirmam a necessidade da integração de informações das duas camadas: scheduling e controle. Constata-se que relativamente reduzidas variações nas especificações da matéria prima geram alterações na programação ótima da produção, com efeitos significativos para o desempenho da planta como um todo.

Considerar uma estratégia integrada para estabelecer as decisões nas diferentes

\section{REFERÊNCIAS}

[1] ARC Advisory Group. Advanced Process Control \& On-line Optimization. Five year market analysis and technology forecast through 2017. (2015) Disponível em: http://www.arcweb.com/services/supplierselection/pages/advanced-process-control.aspx Acesso em: 08/05/2015

\section{[2] AZEVEDO,D.;}

VACCARO,L.R.;LIMA,R.C.;SILVA,D.O. Um Estudo de Simulação Computacional para Análise de Perfis de Aprendizagem Organizacional. Produção, v. 20, n. 4, p. 639-656. 2010 BAGHERI,P.;SEDIGH,A.K. Robust tuning of dynamic matrix controllers for first order plus dead time models. Applied Mathematical Modelling n.39 p.7017-7031, 2015

[3] BALDEA, M.; HARJUNKOSKY, I. Integrated production scheduling and process control: A systematic review. Computers and Chemical Engineering,n. 71, p. 377-390, 2014.

[4] DU, J.; PARK, J.; HARJUNKOSKI,I.; BALDEA, M. I. A time scale-bridging approach for integrating production scheduling and process control. Computers and Chemical Engineering, $\mathrm{n}$. 79, p. 59-69, 2015. FLORES-TLACUAHUAC, A.;GROSSMANN, I. E. Simultaneous Cyclic Scheduling and Control of TubularReactors: Parallel Production Lines. Industrial \& Engineering ChemistryResearch,n. 50, p. 8086-8096, 2011.

[5] GROSSMANN, I.Enterprise-wide Optimization: A New Frontier in Process Systems Engineering Chemical, Wiley InterScience (www.interscience.wiley.com), n. 51, p. 1846-1857, 2005.

[6] HENSON, M.A., SEBORG, D. E. Theoretical analysis of unconstrained nonlinear model-predictive control. Int. J. Control, v. 58, p. 1053-1080, 1993.

[7] KOZÁK, S. State-of-the-art in control engineering. Journal of Electrical Systems and Information Technology,n. 1, p. 1-9 (2014).

[8] LOPEZ-GUEDE,J.M.;FERNANDEZGAUNA,B.;GRANÃ,M.;OTERINO, F. On The Influence of Prediction camadas de um processo produtivo, em especial as camadas de scheduling e controle, se apresenta como uma alternativa de expressivo potencial em face da necessidade vital de manter altos índices de desempenho. Assim, esforços de pesquisa são imprescindíveis para expandir a teoria envolvida e permitir que técnicas possam ser efetivamente aplicadas nos respectivos segmentos produtivos.

[9] Horizon in Dynamic Matrix Control. International Journal of Control Science and Engineering. 2013. MACIEJOWSKI, J. M. Predictive Control with Constraints, Essex, Pearson Education Limited, 2002. MARTINS, R.A.; MELLO, A. H. P.; TURRIONI, J.B. Guia para Elaboração de Monografia e TCC em Engenharia de Produção. Editora Atlas SA. São Paulo, 2014.

[10] PERROS,H. Computer Simulation Techniques: The Definitive Introduciton. Compute Science Department NC State Universitu, Raleigh 2009.

[11] SHOBRYS, D. E.; WHITE, D. C. Planning, scheduling and control systems: why cannot they work together. Computers and Chemical Engineering,n. 26, p. 149-160 (2002).

[12] MATLAB. Disponível em: http://www.mathworks.com/products/matlab/feature s.html\#matlab_speaks_math. Acesso em: 04/06/2016.

[13] NIPPERT,R.C. Simple Models That Illustrate Dynamic Matrix Control. Proceedings of the 2002 American Society for Engineering Education Annual Conference \& Exposition. American Society for Engineering Education, 2002.

[14] TURRIONI, J. B.; MELLO C. H. P. Metodologia de Pesquisa em Engenharia de Produção. Programa de Pós- Graduação em Engenharia de Produção da Universidade Federal de Itajubá. UNIFEl (2012). Disponível em: http://www.carlosmello.unifei.edu.br/Disciplinas/Me strado/PCM-10/Apostila-

Mestrado/Apostila_Metodologia_ Completa_2012.pdf, Acesso em: 08/05/2015.

[15] YUGMA, C.; BLUE, J.; DAUZÈREPÉRÈS,S;VIALLETELLE,P.Integration of Scheduling and Advanced Process Control in Semiconductor Manufacturing: Review and Outlook. IEEE International Conference on Automation Science and Engineering (CASE) Taipei, Taiwan, August 1822 ,

2014. 


\section{Bapítulo 9}

\section{REESTRUTURACÃO DO CONTROLE DE ESTOQUE ATRAVÉS DOS PRINCIIPIOS DO LEAN THINKING}

\section{Pablo Costa}

Andrei Bonamigo

Resumo: A busca pela excelência dos serviços prestados pelas empresas de fabricação de equipamentos médicos-hospitalares no mercado tem se demonstrado como desafio nessas organizações. Nesse sentido, eliminar perdas e entregar maior valor ao cliente consumindo menos é fundamental. Diante do exposto, o presente estudo objetiva estruturar o sistema de gestão de estoque de uma empresa fabricante de equipamentos médicos-hospitalares à luz dos princípios do Lean Thinking. Para alcançar esse objetivo foi conduzido um estudo baseado na pesquisa-ação de modo a solucionar os problemas de não conformidade, os conceitos Lean Thinking foram aplicados por meio das ferramentas Just In Time e Kanban para controle de estoque. A realização dessa reestruturação, deu-se via do reconhecimento do fluxo do processo, levantamento de dados, cálculos estatísticos, fabricação de cartões, painéis, totens e prateleiras para aplicação do Kanban e acompanhamento das atividades no chão de fábrica. A partir deste estudo, foi possível mitigar os problemas de não-conformidades ligadas a gestão de estoques, aumentar a participação da equipe para a tomada de decisão, e melhor organizar o processo de gestão de estoques.

Palavras-Chave: Lean Manufacturing. Expedição. Estoque. Kanban, Equipamentos médicos-hospitalares 


\section{INTRODUÇÃO}

A busca pela excelência é constante em qualquer modelo de organização que procura obter vantagem competitiva em cima de seus concorrentes (BRITO et al., 2017). Essa busca, faz com que a empresa não pare no tempo, de maneira a manter a mesma no mercado (MARCHON et al., 2018).

Segundo Lubben (1989) e Bel (2018), a vantagem competitiva significa explorar ou tirar vantagem de algo que os concorrentes foram incapazes de desenvolver, o que podese considerar uma tarefa árdua. Para os autores, obter uma vantagem competitiva significa ser mais eficiente, oferecer um melhor serviço o ter o melhor produto.

A iniciativa das empresas em melhorar a qualidade com custos menores, vem das exigências dos clientes e competitividade global, forçando a mesma a estar sempre buscando inovar para conseguir um aprimoramento contínuo das vantagens competitivas (PORTER, 1999; BEL, 2018).

Para alcançar resultados significativos, é indispensável que as organizações aprimorem seu processo produtivo, como o seu controle, deixando-o cada vez mais rigoroso, a fim de evitar possíveis imprevistos que possam acarretar em não conformidades ou até mesmo na paralisação da empresa.

Visando atender as necessidades e satisfação do cliente, a empresa deve preocupar-se com a qualidade do processo. Um processo bem elaborado faz com que sejam eliminados desperdícios de tempo e recursos, melhorando assim a qualidade do mesmo, bem como a capacidade produtiva da empresa. Sabendo da importância que um pensamento enxuto tem para empresa, a utilização das ferramentas do Lean Thinking (pensamento enxuto), ou seja por meio de uma filosofia baseada na eliminação de desperdícios, torna-se uma alternativa para obter maior controle e a melhoria da produtividade das empresas.

O Lean Manufacturing, ou seja, o Lean Thinking aplicado na manufatura, apresenta ferramentas voltadas ao aperfeiçoamento dos processos da empresa, trazendo diversos benefícios para organização, contribuindo de maneira direta com a eliminação dos desperdícios, via princípios do pensamento enxuto (MOREIRA, 2012; HOFFMAN et al., 2018).
Segundo Shingo (1996), o pensamento enxuto procura eliminar 0 desperdício que geralmente não é notado, porque se tornou aceito como uma parte natural do trabalho diário, assim como a movimentação de colaboradores. O autor também diz que é classificado como perda, toda atividade que não contribui para operações.

Ligado ao pensamento enxuto, está o Just In Time, o qual representa uma abordagem conceitual para desenvolver e operar um sistema de manufatura na busca da eliminação das perdas nos processos, em especial as perdas de superprodução (LUBBEN 1989; PINTO et al., 2018).

Lubben (1989), fala que o Just In Time permite obter vantagem competitiva através do uso de três ferramentas gerenciais: integrando e otimizando, melhorando continuamente e entendendo o cliente.

Diante do exposto, o presente estudo objetiva reestruturar o sistema de gestão de estoque de uma empresa do setor metal-mecânico à luz dos princípios do Lean Thinking, uma vez que para Pimenta (2018), as empresas do setor metal-mecânico encontram-se em um cenário de incertezas diversas, apresentando dificuldades como comunicação, informações do chão de fábrica, cadastros, programação da produção, maior qualidade com menor desperdício e especialistas competentes.

\section{GESTÃO E CONTROLE DE ESTOQUES}

Estoque é definido como a acumulação armazenada de recursos materiais em um sistema de transformação, porém, também é usado para descrever qualquer recurso armazenado (SLACK et al., 2006). Para Slack et al. (2006) aos olhos do gerente de produção, os estoques são custosos e algumas vezes empatam considerável quantidade de capital, além de serem arriscados devido a deterioração, tornar-se obsoleto ou perder-se e também pelo espaço valioso na produção. Porém, a geração de estoque é uma garantia reconfortante contra o inesperado, no caso de uma alteração de demanda.

Os estoques podem ser divididos em dois tipos, aquele que ocorre naturalmente como resultado de determinadas práticas e 0 estoque necessário (SHINGO, 1996). O autor afirma que existem algumas razões para geração de estoque natural, entre elas estão as previsões incorretas da demanda do 
mercado, superprodução para evitar riscos, produção em lotes e também as diferenças no turno de trabalho. Segundo o autor, o acúmulo de estoque pode ser através da ineficiência no processo ou nas operações.

Slack et al. (2006) afirmam que não importa o que é armazenado como estoque, ou onde o mesmo está posicionado na operação, ele existirá devido a diferença de ritmo ou de taxa entre fornecimento e demanda. Se essa diferença não existisse, nenhum item seria estocado.

Os estoques têm importância fundamental para o desempenho de muitas operações, porém, segundo Slack, Chambers e Johnston (2009), o mesmo pode acarretar em congelamento de dinheiro, na forma de capital de giro, custos de armazenamento, tornar-se obsoleto à medida em que novas alternativas de produtos apareçam, danificarse ou deteriorar-se, perdido ou caro para recuperar, perigoso para armazenar consumir espaço que poderia ser utilizado para produção, custos administrativos e secundários.

Para Peinado e Graeml (2007), os itens a serem mantidos em estoque devem ser classificados pela curva $A B C$, de modo a diferenciar a relevância em relação ao capital investido, ou seja, manter maior quantidade em estoque de produtos de baixo valor unitário, pois seu reflexo financeiro, chega a ser muitas vezes desprezível.

Segundo Peinado e Graeml (2007), mesmo com o mais tecnológico sistema de controle de materiais (softwares e equipamentos), onde toda movimentação é feita automaticamente, sem o contato humano, não haverá garantia de eliminação total das divergências de estoque. Os mesmos também ressaltam que são vários os fatores que contribuem para essas divergências, podendo estar ligados a falha na conferência de recebimento dos materiais recebidos, falha na digitação da nota fiscal, falha na estrutura do produto, ausência de apontamento das perdas não planejadas, ausência de desvios de especificação de material, extravios e furtos.

Para Slack et al. (2006) existem quatro tipos de estoque, sendo eles o estoque isolador, estoque de ciclo, estoque de antecipação e estoque de canal, os quais são gerados através do desequilíbrio entre a taxa de fornecimento e de demanda em diferentes pontos de qualquer operação.
Baseado no controle de estoque zero do Sistema Toyota de Produção, existem três estratégia para que se atinja a produção ideal com estoque igual a zero, sendo elas a redução drástica dos ciclos de produção, a eliminação de quebras e defeitos, através da detecção das causas e solução através da raiz do problema e redução dos tempos de setup para menos de 10 minutos ou para segundos, através da adoção da TRF (SHINGO, 1996).

\subsection{LEAN MANUFACTURING}

Moreira (2012), diz que os conceitos e a metodologia do Lean Manufacturing foram difundidos em meados dos anos 90, através de pesquisas realizadas por professores do MIT (Massachusetts Institute of Technology) e divulgação do livro "A máquina que mudou o mundo: a História da Produção Enxuta", escrito por Womack, Jones e Roos, relatando a transformação da produção de carros considerando à mão, em massa e chegando a produção enxuta.

Segundo Ohno (1997), o Lean Manufacturing, também conhecido como Sistema Toyota de Produção, tem como conceito a eliminação de desperdícios e elementos desnecessários, produzindo somente o necessário, no momento necessário e quantidade requerida, com objetivo de reduzir custos.

Ohno (1997) também comenta sobre os setes desperdícios encontrados na indústria, os quais referem-se a espera, defeito, transporte, movimentação, excesso de estoque, excesso de produção e super processamento. Para Shingo (1996) o sistema mantém o foco na produção enxuta e eliminação de desperdícios, fazendo com que a produção atenda a necessidade do cliente.

Já para Womack e Jones (2004), a eliminação dos desperdícios, torna a empresa mais flexível e capaz de responder às necessidades dos clientes entregando produto ou serviço em menor tempo, com maior qualidade e menor custo.

Womack e Jones (1998) dizem que há cinco princípios do pensamento enxuto que oferecem uma colaboração valiosa para gestão de processos e podem ser citadas como especificação do valor, identificação da cadeia de valor, fluxo de valor, produção puxada e busca da perfeição. 


\subsection{JUST IN TIME}

Surgido em meio a um cenário de características de desaquecimento de mercado, logo após a Segunda Guerra Mundial, o Just In Time é originado do Sistema Toyota de Produção, desenvolvido na década de 60 pela Toyota Motors Company, como meio de resposta ao elevado nível de complexidade e precisão exigido pelo sistema tradicional de abastecimento (PEINADO e GRAEML, 2007).

Segundo Shingo (1996), o Sistema Toyota de Produção, tem como objetivo central, capacitar as organizações para responder com rapidez às constantes mudanças da demanda do mercado. Ohno (1997) diz que em um sistema Just In Time, o processo de fluxo estará em linha de montagem no momento e quantidade necessária, podendo chegar ao estoque zero, caso o fluxo seja estabelecido integralmente. $\mathrm{O}$ autor também fala que o termo "Just In Time" (apenas a tempo) é conhecido por esse nome por indicar a hora e quantidade certa que as peças devem chegar, do contrário, se as peças chegarem antes do que são necessárias, o desperdício não pode ser eliminado. Para Shingo (1996), o Just In Time significa "no momento certo", porém da ênfase que esse sistema, não representa exatamente o momento estabelecido, mas sim um pouco antes, com uma certa folga.

Para Slack et al. (2006) o sistema apresenta como características principais, a produtividade puxada pela demanda, o controle do fluxo entre estágios é conseguido pela utilização de cartões simples, resultando em um sistema de controle simples, visual e transparente, as decisões de planejamento e controle são amplamente descentralizadas, a programação é baseada em taxas de produção em vez de volume produzido, O JIT assume a flexibilidade dos recursos e Lead Time reduzidos e os conceitos de planejamento e controle do JIT são apenas uma parte da filosofia de produção JIT mais ampla e explícita.

Martins e Laugeni (2005) afirmam que o sistema JIT afeta praticamente todos os aspectos da operação de uma fábrica, como tamanho dos lotes, programação, qualidade, layout, fornecedores, relações trabalhistas e muitos outros.

\subsection{KANBAN}

Segundo Ohno (1997), o Kanban é uma ferramenta para conseguir o Just In Time, e para mesma funcionar de maneira correta, todo processo de produção deve ser administrado de forma a fluir tanto quanto possível. Além disso, deve-se nivelar a produção tanto quanto possível e trabalhar com padrões de trabalho.

Já para Martins e Laugeni (2005), o Kanban é conceituado como método de autorização da produção e movimentação de material, usado para controlar a ordem dos trabalhos em um processo sequencial. Os autores também afirmam que o Kanban é um subsistema do JIT.

Para Ohno (1997), o Kanban é uma ferramenta maravilhosa quando usada corretamente, do contrário pode acarretar em problemas sérios. $\mathrm{O}$ autor relata que para que a ferramenta seja utilizada de maneira correta e habilmente, deve-se primeiro entender com clareza seu papel e então estabelecer regras para seu uso.

Ohno (1997) também ressalta que a utilização do Kanban tem como objetivo eliminar desperdícios, mão de obra e estoques, eliminar produtos defeituosos e impedir recorrência de panes. O sistema Kanban apresenta funções como: fornecer informação sobre apanhar ou transportar, fornecer informação sobre a produção, impedir a superprodução e o transporte excessivo, servir como uma ordem de fabricação afixada às mercadorias, impedir produtos defeituosos pela identificação do processo que os produz e revelar problemas existentes e mantém o controle de estoques.

Segundo Ohno (1997), para utilização do sistema, é necessário seguir algumas regras, tais como:

- O processo subsequente apanha o número de itens indicados pelo Kanban no processo pendente;

- O processo inicial produz itens na quantidade e sequência indicadas pelo Kanban;

- Nenhum item é produzido ou transportado sem um Kanban;

- Serve para afixar um Kanban às mercadorias:

- Produtos defeituosos não são enviados para o processo seguinte. O 
resultado é mercadorias $100 \%$ livres de defeitos;

- Reduzir o número de Kanban aumenta sua sensibilidade aos problemas.

\section{MÉTODOS E TÉCNICAS}

O presente estudo objetiva reestruturar o sistema de gestão de estoque de uma empresa do setor metal-mecânico à luz dos princípios do Lean Thinking. A empresa estudada, está localizada na cidade de Luzerna, no meio oeste do estado de Santa Catarina, atuando a mais de trinta anos na fabricação de equipamentos médicoshospitalares, como armários, estantes e carros utilizados para armazenamento de equipamentos de apoio a video cirurgias.

Para atingir o objetivo proposto neste estudo, foram utilizadas as ferramentas oriundas do pensamento enxuto Kanban e Just In Time, que compreenderam quatro etapas. Sendo elas:

$\mathrm{Na}$ primeira etapa, foi conduzido o reconhecimento do fluxo do processo, levantamento de dados, cálculos estatísticos para prestar suporte na tomada de decisão. Nessa etapa adicionalmente foi efetuada a análise documental conforme Lakatos e Marconi (2001) em relatórios fornecidos pela própria empresa. No entanto, para tratar desses dados, foram utilizados cálculos de estoque mínimo, fluxograma, folhas de verificação e 5w2h através da ferramenta Asana para organização das atividades relacionadas à essa pesquisa.

Em seguida, foi analisado os dados coletados e realizadas reuniões com os coordenadores de fábrica, gerente de produção, PCP e alguns colaboradores para auxiliarem na atividade de suporte e acompanhamento da implementação da ferramenta Kanban e Just In Time no chão de fábrica.

Na terceira etapa do estudo, foi conduzida a aplicação da ferramenta Kanban, foi preciso realizar a confecção dos cartões e dos painéis para controle de estoque e também ordens de produção, além de totens e prateleiras para armazenamento dos produtos e suporte dos cartões.

Já a quarta etapa, compreendeu a construção de Procedimentos Operacionais Padrão (POP) para padronizar o controle de estoque e facilitar o entendimento do mesmo aos colaboradores. Nessa etapa concomitante foi monitorado e os resultados obtidos de modo a propor melhorias incrementais em atividade ligadas a gestão de estoque, POPs e operações no que comunga o Kanban e Just In Time.

\section{RESULTADOS E DISCUSSÕES}

Para iniciar a aplicação da metodologia, foram realizadas reuniões com os setores administrativo, PCP, produção, expedição e montagem para definir os estoques do setor da expedição para que aplicação do Kanban.

Como Ohno (1997) relata, para que a ferramenta seja utilizada de maneira correta e habilmente, deve-se primeiro entender com clareza seu papel e então estabelecer regras para seu uso. Sendo assim, começamos com a avaliação dos produtos através do cálculo de estoque mínimo, seguindo alguns conceitos do pensamento enxuto.

Para realização dos cálculos, levamos em consideração o tempo de produção registrado como 15 dias, um fator de segurança de 95\%, o total de vendas em um determinado período, o Lead Time e o desvio padrão.

Através dos dados levantados, contendo a espécie do produto e seu estoque mínimo, foi gerado uma tabela (representada abaixo como tabela 1) para identificação da quantidade de cartões a serem utilizados com o sistema Kanban. 
Tabela 1 - Cálculos para estoque mínimo

\begin{tabular}{|c|c|c|c|c|c|c|c|c|c|c|c|c|c|c|c|c|c|c|c|c|c|}
\hline & Fator de Segurança & & \multicolumn{2}{|c|}{$95 \%$} & \multicolumn{3}{|c|}{1,645} & \multicolumn{4}{|c|}{ Total de Kanbans: } & \multirow[b]{3}{*}{$\begin{array}{l}\text { Est. } \\
\text { Minimo }\end{array}$} & \multirow{3}{*}{\multicolumn{2}{|c|}{$=\begin{array}{l}\text { Ponto } \\
\text { de } \\
\text { pedido }\end{array}$}} & \multirow{3}{*}{$\begin{array}{l}41 \\
\bar{F}\end{array}$} & \multirow{3}{*}{\multicolumn{2}{|c|}{\begin{tabular}{|l} 
\\
Lote de \\
produção
\end{tabular}}} & \multicolumn{4}{|c|}{224} \\
\hline & Atualizado em 18/06/18 & & & & & & & & \multirow{2}{*}{\multicolumn{2}{|c|}{$\begin{array}{l}\text { Lead } \\
\text { Time } \\
\text { (meses) }\end{array}=$}} & & & & & & & & & & \\
\hline Cód. $=$ & Produto & $=$ & \begin{tabular}{|l|} 
Total de \\
Vendas \\
em 12 \\
meses \\
\end{tabular} & $=$ & $\begin{array}{l}\text { Venda } \\
\text { Média = } \\
\text { Mensal }\end{array}$ & $\begin{array}{l}\text { Venda } \\
\text { Desv. } \\
\text { pad }\end{array}$ & 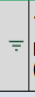 & $\begin{array}{l}\text { Tempo de } \\
\text { produçăo } \\
\text { (dias) }\end{array}$ & & & & & & & & & & $\begin{array}{l}\text { Estoque } \\
\text { Máximo }\end{array}$ & $\bar{F}$ & $\begin{array}{l}\text { Rotatividade } \\
\text { do lote } \\
\text { (meses) }\end{array}$ & $=$ \\
\hline 00001 & Armário - 1 & & & 30 & 2 & & 1 & & 7 & & 0,32 & & 2 & & 3 & & 10 & & 13 & & 4,4 \\
\hline 00002 & Armário - 2 & & & 18 & 1 & & 1 & & 7 & & 0,32 & & 2 & & 3 & & 5 & & 8 & & 8,6 \\
\hline 00003 & Armário - 3 & & & 22 & 5 & & 2 & & 7 & & 0,32 & & 2 & & 4 & & 10 & & 14 & & 2,0 \\
\hline 00004 & Armário - 4 & & & 14 & 10 & & 7 & & 7 & & 0.32 & & 7 & & 11 & & 10 & & 21 & & 1,0 \\
\hline 00005 & Armário - 5 & & & 11 & 15 & & 7 & & 7 & & 0,32 & & 7 & & 12 & & 10 & & 22 & & 0,6 \\
\hline 00006 & Armário - 6 & & & 58 & 18 & & 8 & & 7 & & 0,32 & & 8 & & 14 & & 10 & & 24 & & 0,6 \\
\hline 00007 & Armário - 7 & & & 123 & 4 & & 2 & & 7 & & 0,32 & & 3 & & 5 & & 10 & & 15 & & 2,6 \\
\hline 00008 & Armário - 8 & & & 15 & 1 & & 1 & & 7 & & 0,32 & & 1 & & 2 & & 5 & & 7 & & 3,5 \\
\hline 00009 & Armário - 9 & & & 200 & 14 & & 6 & & 7 & & 0,32 & & 6 & & 11 & & 10 & & 21 & & 0,7 \\
\hline 00010 & Armário - 10 & & & 36 & 3 & & 2 & & 7 & & 0.32 & & 3 & & 4 & & 10 & & 14 & & 3,3 \\
\hline 00011 & Armário - 11 & & & 68 & 6 & & 4 & & 7 & & 0,32 & & 4 & & 6 & & 10 & & 16 & & 1,8 \\
\hline 00012 & Armário - 12 & & & 225 & 19 & & 6 & & 7 & & 0,32 & & 6 & & 12 & & 10 & & 22 & & 0,5 \\
\hline 00013 & Armário - 13 & & & 55 & 5 & & 3 & & 7 & & 0,32 & & 3 & & 5 & & 5 & & 10 & & 1,1 \\
\hline 00014 & Armário - 14 & & & 24 & 2 & & 1 & & 7 & & 0,32 & & 2 & & 3 & & 5 & & 8 & & 2,5 \\
\hline 00015 & Armário - 15 & & & 43 & 4 & & 2 & & 7 & & 0,32 & & 2 & & 4 & & 5 & & 9 & & 1,4 \\
\hline
\end{tabular}

Fonte: A empresa analisada, 2018.

Após a definição dos estoques mínimos, realizamos a aplicação da metodologia Kanban para controle de estoque. Foi utilizado a ferramenta Asana para aplicação do $5 \mathrm{WH}$, definindo o plano estratégico para aplicação do Kanban.

\subsection{CONTROLE DE ESTOQUE}

Slack et al. (2006) afirmam que estoque existe devido a diferença de ritmo ou de taxa entre fornecimento e demanda.

Levando como base a importância de um bom controle de estoque, foi aplicado no setor de expedição, a ferramenta Kanban para tal controle, a qual utiliza cartões com padrões diferentes para identificar produtos ou serviços, dando ênfase na gestão visual.

Como Martins e Laugeni (2005) explicam, o Kanban é conceituado como método de autorização da produção e movimentação de material, usado para controlar a ordem dos trabalhos em um processo sequencial. Os autores também afirmam que o Kanban é um subsistema do JIT.

\subsection{LAYOUT DO CARTÃO - ESTOQUE}

Os cartões para controle de estoque serão impressos pelo PCP, o qual ficará responsável pelo controle dos mesmos. As impressões deverão ser em folhas de cor: verde, amarelo, vermelho, de modo que:

Verde: Representa o nível de estoque máximo ou quase completo, não havendo necessidades de gerar ordens de produção;

Amarelo: Representa uma necessidade de abastecimento de estoque, devendo assim ser emitido uma ordem de produção do produto.

Vermelho: Representa alerta de estoque, mostrando que há poucas unidades disponíveis para entrega. Este nível requer maior atenção na ordem de produção do produto, pois se houver algum atraso, poderá gerar a falta de produtos no estoque.

Nos cartões, deverão aparecer os seguintes dados: Código interno do produto, descrição do produto, quantidade de cartões emitidos naquela cor e número do cartão referente a cor. 
Figura 1 - Cartão de controle de estoque

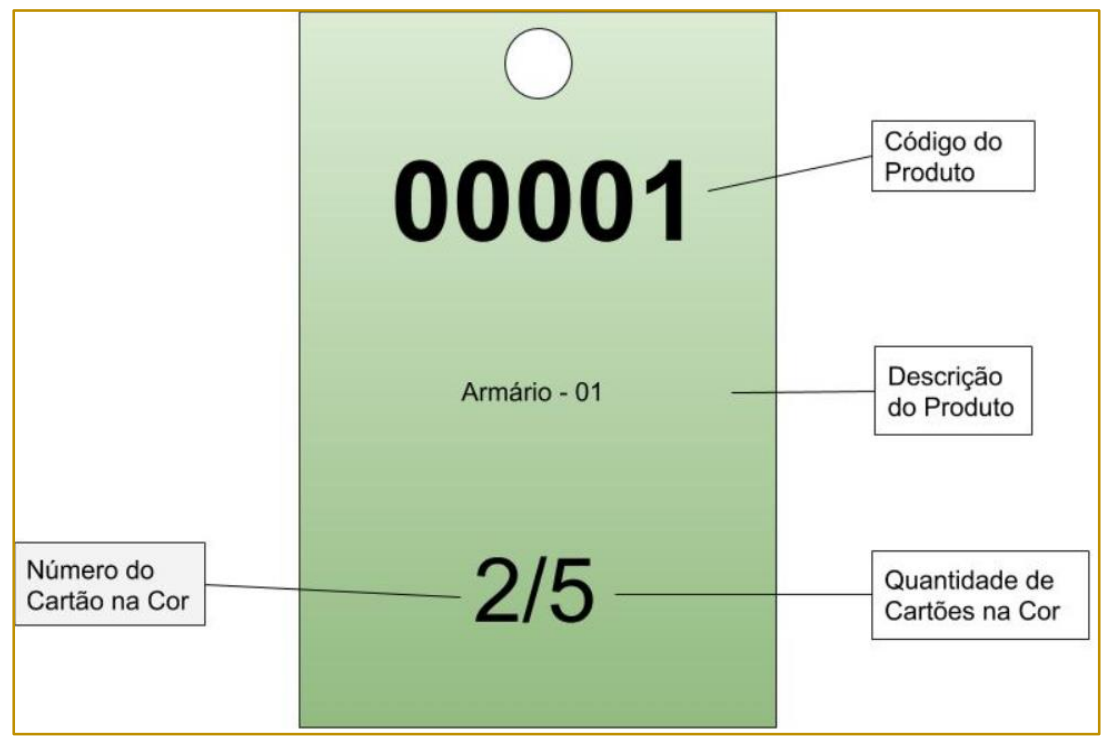

Fonte: A empresa analisada, 2018.

O número de cartões a serem utilizados para cada produto, assim como a quantidade de cartões de cada cor, serão norteados através do cálculo de estoque mínimo, levando em conta o tempo necessário para fabricação do produto.

\subsection{LAYOUT DO CARTÃO - ORDEM DE PRODUÇÃO (OP)}

Os cartões para ordens de produção serão impressos pelo PCP, nas cores: azul e branco, de modo que:
Azul: Cartão de ordem de produção normal, indica qual o produto e qual o lote a ser produzido;

Branco: Cartão de ordem de produção especial, indica uma variação nas vendas, sendo necessário uma mudança no lote de produção do produto.

Figura 2 - Cartão de ordem de produção

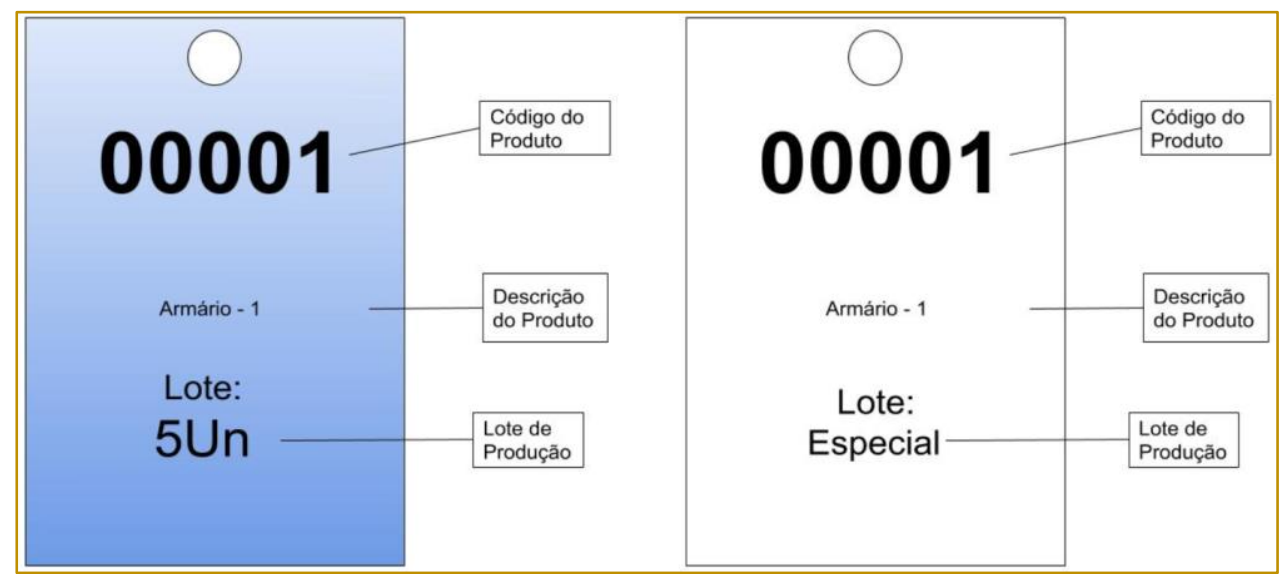

Fonte: A empresa analisada, 2018.

Nos cartões de produção, deverão aparecer os seguintes dados: Código interno do produto, descrição do produto e tamanho do lote de produção. 


\subsection{LAYOUT DO PAINEL - ESTOQUE}

No painel de controle de estoque da expedição, cada cartão terá um lugar definido, de modo a ser anexado sempre no mesmo lugar e na mesma ordem.

O painel encontra-se fixado na lateral da prateleira da expedição, com objetivo de facilitar a visualização de movimento do estoque e as operações necessárias para correção do mesmo.

O modelo de painel está representado na imagem a seguir.

Figura 3 - Painel dos cartões de controle de estoque

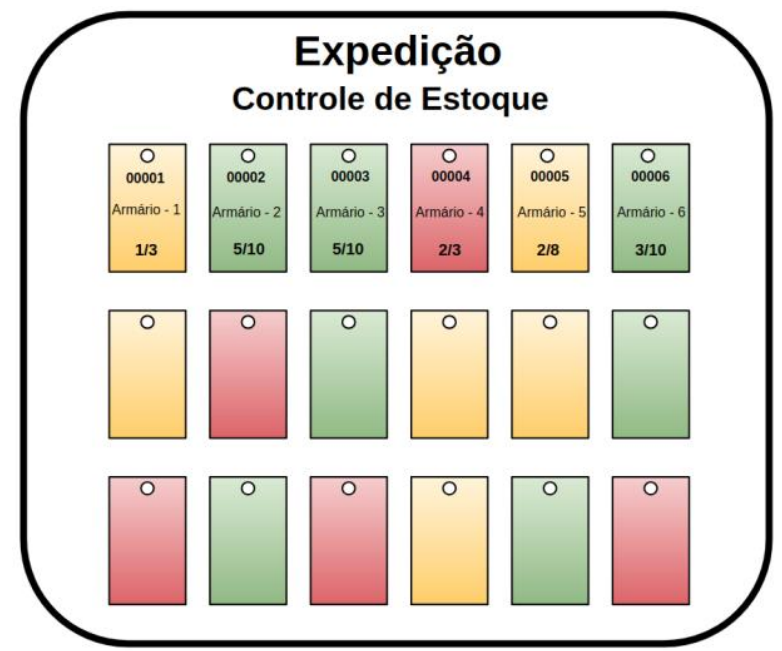

Fonte: A empresa analisada, 2018.

\subsection{LAYOUT DO PAINEL - ORDEM DE PRODUÇÃO}

Neste painel ficarão anexados os cartões para ordens de produção, os quais serão utilizados para solicitação de emissão das mesmas.

A organização dos cartões neste painel, deverá seguir a mesma ordem dos cartões anexados no painel de controle de estoque, mantendo sempre um padrão de localização para melhor identificação do cartão.

O modelo de painel está representado na imagem a seguir.

Figura 4 - Painel dos cartões de ordem de produção

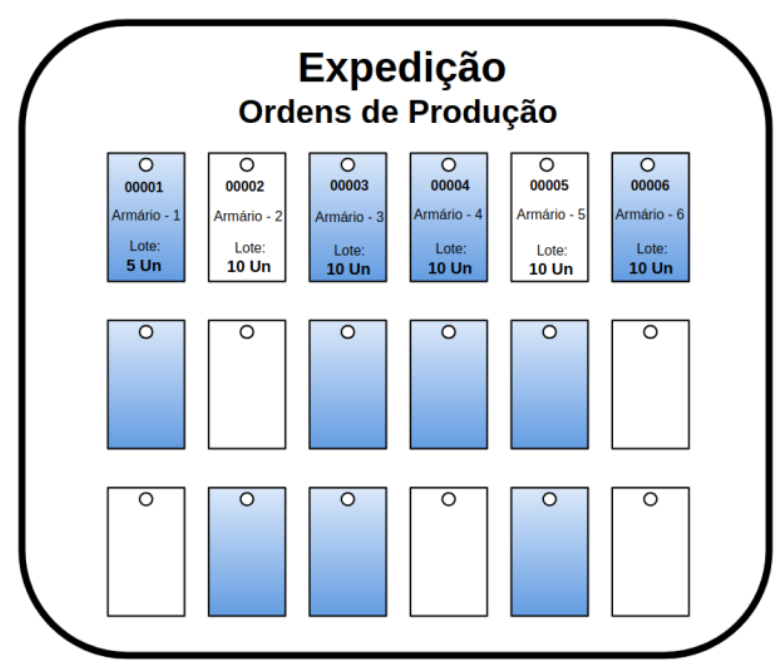

Fonte: A empresa analisada, 2018. 


\subsection{FLUXOGRAMA DOS CARTÕES}

Os cartões de estoque deverão permanecer na frente de cada setor de produto, na ordem: verde, amarelo e vermelho, sendo que cada cartão representa um item no estoque. Cabe destacar que a cada item removido, seja retirado também um cartão, anexando-o ao painel de cartões de estoque, conforme imagem abaixo.

Figura 5 - Ordem dos cartões de controle de estoque

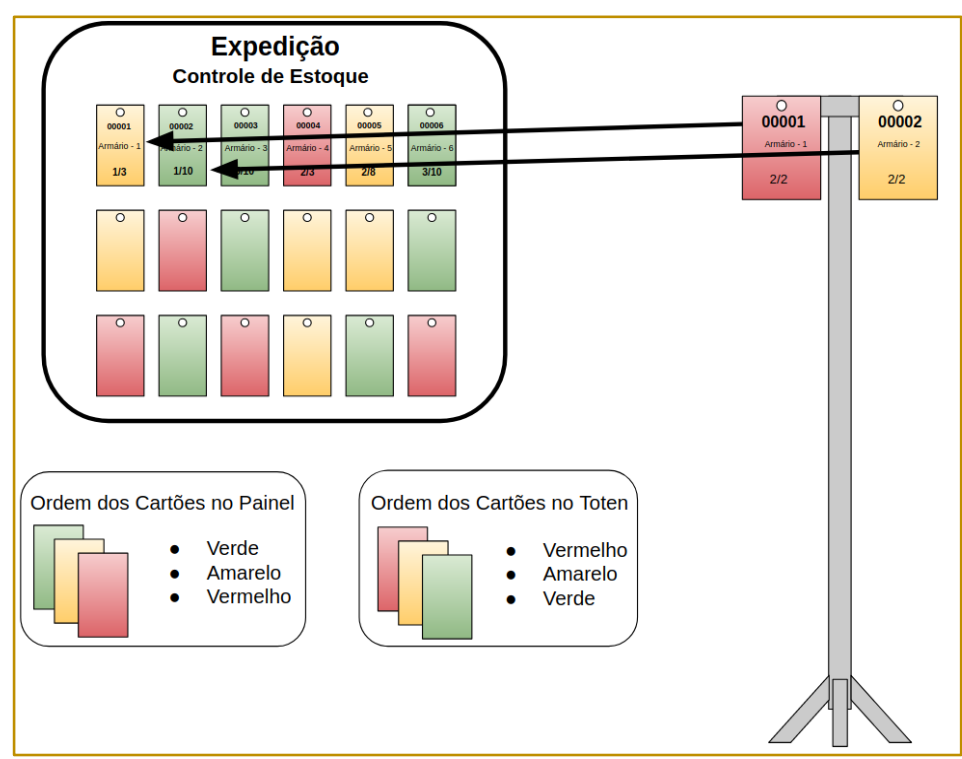

Fonte: A empresa analisada, 2018.

A ordem dos cartões não deve ser alterada, sendo que o cartão retirado do toten deve ser sempre aquele que estiver na frente dos outros. Ao colocar o cartão no painel, a ordem dos cartões ficará invertida, a qual deve ser ajustada quando os cartões voltarem para o estoque.

Os cartões de ordens de produção, permanecerão em um painel específico até o momento em que o cartão amarelo aparece no painel de estoque. A partir do momento em que esse cartão estiver visível, deve ser emitida uma ordem de produção, então o responsável pelo controle de estoque retira o cartão de ordem de produção do painel e o encaminha ao PCP, o qual deve emitir uma ordem de produção e mandar ambos (ordem de produção e cartão de produção) para montagem. O cartão de produção só retorna para o painel quando a ordem de produção for concluída.

O ciclo de todo processo para expedição de um produto, ficará deste modo:

Fluxograma 1 - Fluxograma do processo de expedição

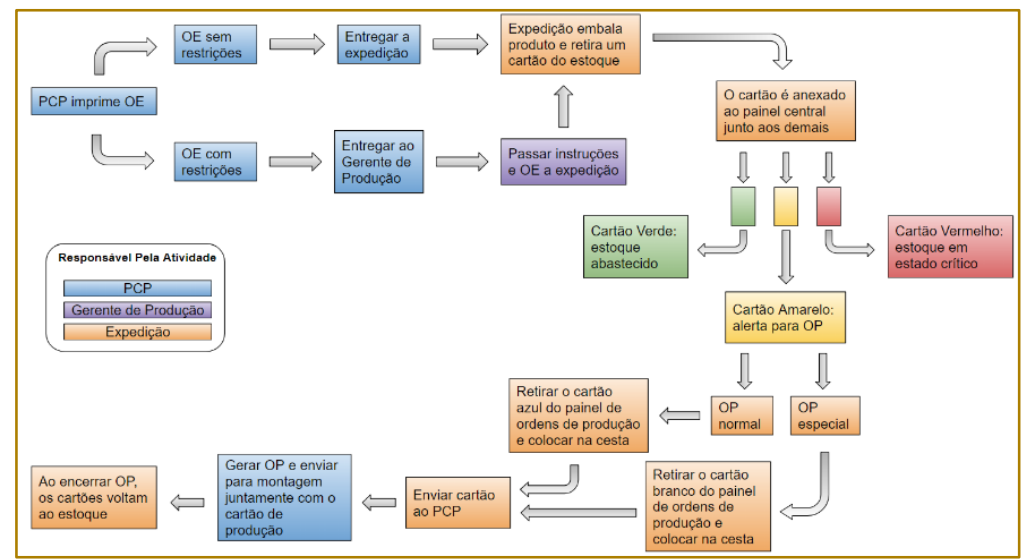

Fonte: A empresa analisada, 2018. 


\section{CONCLUSÃO}

O presente estudo objetiva reestruturar 0 sistema de gestão de estoque de uma empresa do setor metal-mecânico à luz dos princípios do Lean Thinking. Por meio da aplicação das ferramentas do Lean nas organizações pode-se constatar que é possível acarretar em uma produção mais organizada e um melhor controle dos processos.

Seguindo o conceito do pensamento enxuto, o Just In Time faz com que os processos sejam organizados de modo a atender a demanda sem gerar desperdícios. Desse modo, a aplicação do Kanban na empresa analisada, contribuiu com melhorias na gestão de estoque e tempo de entrega, fazendo com que o objetivo de redução de não conformidades do setor de expedição fosse alcançado. Porém, acredita-se que os resultados dessa aplicação fiquem mais evidentes com o passar do tempo, devido a empresa estar se adaptando a essa metodologia.

Além de solucionar o problema com não conformidades, também foi possível observar o melhor aproveitamento de um dos

\section{REFERÊNCIAS}

[1] Associação Brasileira de Normas Técnicas. NBR ISO 10006 - Gestão da qualidade diretrizes para a qualidade no gerenciamento de projetos. Rio de Janeiro: ABNT, 2000. 18 p.

[2] BEL, R. A property rights theory of competitive advantage. Strategic Management Journal, v. 39, n. 6, p. 1678-1703, 2018.

[3] BRITO, L. A. L.; SUAN P. K.. Management practices in medium-sized private hospitals in São Paulo, Brazil. Cadernos de saúde pública, v. 33, n.3, 2017.

[4] HOFFMANN, N.; REIS, L. V.; KIPPER, L. M. Cientometria dos sistemas de produção Lean manufacturing e cLeaner production: um olhar nos periódicos da ABEPRO. Revista Produção Online, v. 18, n. 1, p. 329-349, 2018.

[5] LAKATOS, E. M.; MARCONI, M. A. Fundamentos metodologia científica. 4.ed. São Paulo: Atlas, 2001

[6] LUBBEN, R.T. Just-In-Time. 2 $2^{\underline{a}}$ ed. São Paulo: McGraw-Hill, 1989.

[7] MARCHON, H. P. et al. Logística de armazenamento: Estudo de caso de um colaboradores, o qual estava destinado a conferir o estoque de produtos prontos, ocasionando uma queda de produtividade.

A partir deste estudo, a empresa obteve uma visão diferenciada de seus processos, sendo possível identificar futuras oportunidades de melhorias na gestão de estoque de outros setores. Com isso, a organização decidiu aprofundar o assunto tratado na pesquisa com objetivo de aproveitar ao máximo os benefícios trazidos pela ferramenta.

Desta forma, fica claro que os controles de processos não precisam ser complicados para serem considerados eficazes, mas sim, simplificado e visual, dando melhor transparência sobre a situação real do processo, facilitando o entendimento dos responsáveis.

Porém, para que a empresa possa manter os controles confiáveis, são necessárias verificações e atualizações, visando sempre adaptar a real situação da empresa com a ferramenta, gerando assim um processo de Kaizen (melhoria contínua). A partir do presente estudo, pode-se observar a importância do pensamento enxuto e suas ferramentas na busca pela excelência.

supermercado. Revista Uniabeu, v. 11, n. 27, p. 214-231, 2018.

[8] MARTINS, P.G.; LAUGENI, F.P. Administração da Produção. $2^{\underline{a}}$ ed. São Paulo: Saraiva, 2005.

[9] MOREIRA, D.A. Administração da produção e operações. $2^{\underline{a}}$ ed. Ver. E ampl. São Paulo: Cengage Learning, 2012.

[10] OHNO, T. O Sistema de Produção: além da produção em larga escala. $1^{\underline{a}}$ ed. Porto Alegre: Bookman, 1997.

[11] PEINADO, J.; GRAEML, A.R. Administração da Produção: Operações Industriais e de Serviços. Curitiba: UnicenP, 2007.

[12] PIMENTA, J. As cinco principais dificuldades do setor metal mecânico - Disponível em: $\quad<$ https://www.nomus.com.br/blgindustrial/principais-dificuldades-de-gestao-setormetal-mecanico/>. Acessado em: 23 de set. 2018.

[13] PINTO, J. L. Q. et al. Introduction to Lean and Just-in-Time Manufacturing. In Just in time Factory. Springer, Cham.2018 
[14] PORTER, M. E. Competição: Estratégias Competitivas Essenciais. Harvard School Business Press, 1999.

[15] SLACK, N. et al. Administração da Produção. 1aㅡ Edição. ed. São Paulo: Atlas, 2006.

[16] SLACK, N.; CHAMBERS, S.; JOHNSTON, R. Administração da Produção. 3aㅡ ed. São Paulo: Atlas S.A., 2009.

[17] SHINGO, S. O Sistema Toyota de Produção do Ponto de Vista da Engenharia de
Produção. 2a ed. Porto Alegre. Editora Bookman, 1996.

[18] WOMACK, J.P.; JONES, D.T. A mentalidade enxuta nas empresas: elimine 0 desperdício e crie riqueza. 11. reimpr. Rio de Janeiro: Elsevier, 2004.

[19] WOMACK, J.P.; JONES, D.T. A Mentalidade Enxuta nas Empresas. 4a ed. Rio de Janeiro, Editora Campus Ltda, 1998. 


\section{Bapítulo 10}

\section{PCM - PLANEJAMENTO E CONTROLE DE MANUTENÇÃO, ESTUDO DE MELHORIA EM UMA EMPRESA DO RAMO AGROPECUÁRIO}

\section{Isabela Muckenberger Saddi}

Juliana Pardinho dos Santos

Rogério Francisco de Oliveira

Luiz, Felipe Cougo

Resumo: Esse artigo relata o passo a passo de um estudo de melhoria no PCM Planejamento e Controle de Manutenção dentro de uma fábrica de rações de grande porte, situada no interior do Estado do Paraná. Teve como objetivo auxiliar na elaboração de uma sistemática estruturada para a gestão da manutenção. Foram realizadas visitas técnicas para conhecer as necessidades acerca do assunto, logo após foi feito um levantamento bibliográfico sobre o tema, em livros, artigos científicos, revistas e monografias. Para atingir esses objetivos, fez-se a coleta de dados na empresa através de questionários, entrevistas informais e participações nas paradas de manutenção. Analisados esses dados fez-se a proposta de uma nova rotina no setor de manutenção, onde foi possível mensurar com maior confiabilidade esses dados, afim de gerar indicadores para melhor acompanhamento do setor. Implantados em junho de 2017 foram coletados resultados dos indicadores até o mês de agosto de 2017, dando início a um maior controle e processamento das informações.

Palavras-chave: Planejamento e controle da manutenção, indicadores, Rotina, manutenção 


\section{INTRODUÇÃO}

A incessante procura pelo aumento da disponibilidade dos ativos de uma instalação industrial, requer do setor de manutenção sempre buscar novas práticas que auxilie a alcançar esse objetivo. Deixando de lado ao máximo as manutenções corretivas, pois essas paradas inesperadas ocasionam grandes perdas de produção e podem comprometer o meio ambiente e a saúde ocupacional dos colaboradores. Para Viana (2002), produção engloba operação associada à manutenção, então é necessário planejar esse conjunto, para isso utiliza-se da ferramenta responsável pelas ações preventivas, preditivas, análise e tomadas de decisão, denominada de PCM (Planejamento e Controle da Manutenção).

O estudo em questão foi realizado em uma das plantas de uma cooperativa que é presente em todo o território nacional, fundada em 1925 seu faturamento no ano de 2016 foi de $\mathrm{R} \$ 232$ milhões. A planta estudada fica localizada no interior do Estado do Paraná, onde a unidade produz rações peletizadas e fareladas para animais de grande porte e aves. Essa tem a capacidade de produzir 50 toneladas por hora de ração e tem produção contínua, utilizando-se também da produção puxada, ou seja, não mantém estoques do produto final, sendo assim é de suma importância que o setor de manutenção tente garantir ao máximo a alta disponibilidade dos equipamentos.

Com essas informações e pesquisas relacionadas ao assunto foi feito um levantamento bibliográfico e proposto à empresa uma nova rotina visando o correto preenchimento de documentos relacionados às atividades de manutenção para obter maior confiabilidade dos dados gerados e auxiliar na elaboração de planos e cronogramas do setor.

Para isso foi utilizado a metodologia vista no fluxograma na Figura 1, onde observa-se o passo a passo empregado para se alcançar os resultados.

Figura 1 - Fluxograma da metodologia utilizada

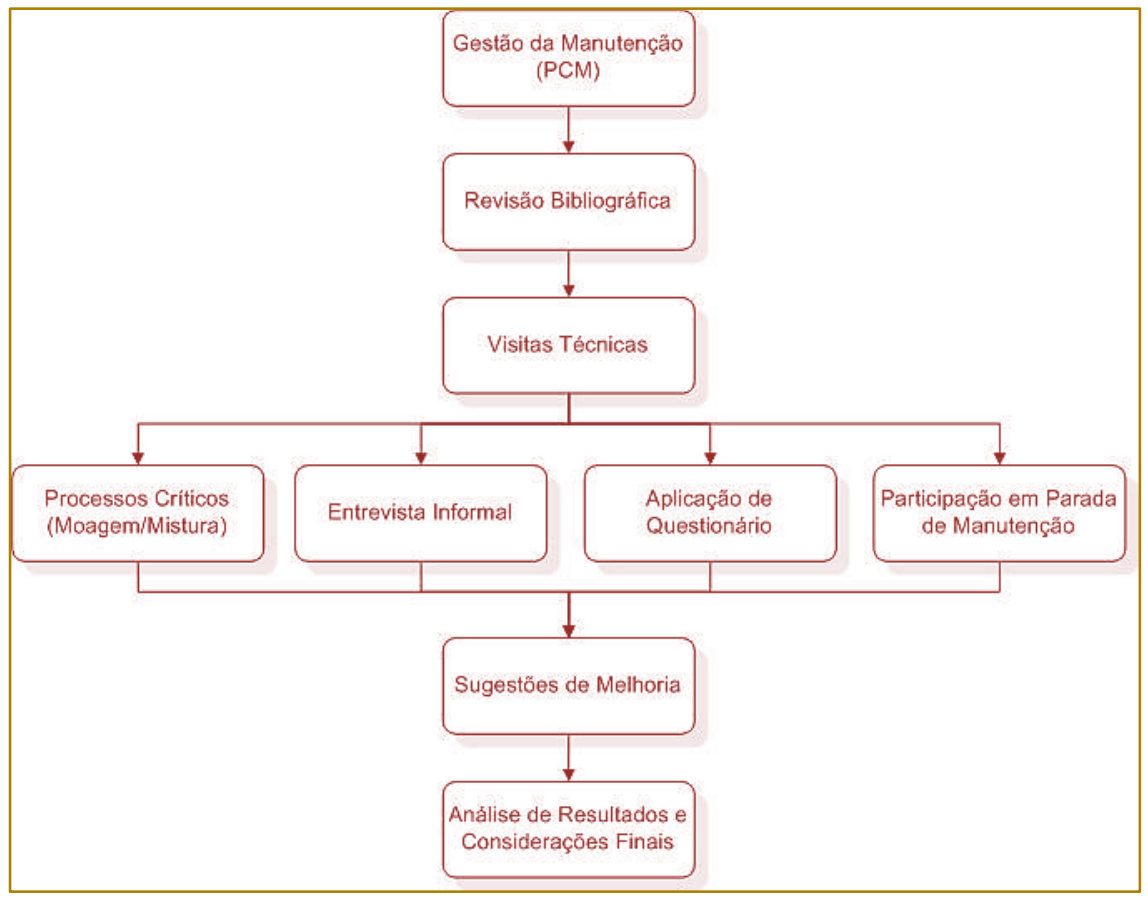

Fonte: Os Autores

\section{REFERENCIAL TEÓRICO}

\subsection{A IMPORTÂNCIA DA MANUTENÇÃO}

Nas últimas décadas a manutenção deixou de ser vista como uma simples atividade de reparo de máquinas e equipamentos, e sim uma oportunidade de se alcançar metas e objetivos dentro de uma empresa, tornandose assim uma função estratégica dentro do 
processo produtivo passando a ser parte fundamental para alcançar tais metas.

Hoje a manutenção é um fator determinante quando se trata de qualidade e produtividade de uma organização, ainda pode trazer vantagens perante empresas concorrentes, pois quanto mais eficaz é a manutenção dentro de uma empresa melhores serão seus resultados.

Como Viana (2002) afirma, a manutenção não pode se limitar a apenas corrigir problemas cotidianos, deve prosseguir com melhorias constantes, tendo como norte o máximo aproveitamento dos materiais de trabalho, ligados ao zero defeito.
Para Slack et al. (1999) é importante saber porque a manutenção se preocupa tanto em examinar de forma sistemática suas instalações, pois acarreta em benefícios para a segurança dos colaboradores, aumenta a confiabilidade e na qualidade, custos com operações mais baixos, tempo de vida útil dos equipamentos se tornam maiores e a depreciação das instalações é menor.

\subsection{TIPOS DE MANUTENÇÃO}

$\mathrm{Na}$ Tabela 1 é explicado os tipos de manutenção utilizado no desenvolver do estudo.

Tabela 1 - Tipos de manutenção

\begin{tabular}{|c|c|}
\hline Tipos de Manutenção & Descrição \\
\hline Manutenção Detectiva & $\begin{array}{l}\text { Vem da palavra (Detectar), começou a ser mencionada a partir da década de 90. Este } \\
\text { método procura atuar em sistemas de proteção detectando falhas ocultas ou não } \\
\text { perceptíveis a equipe de manutenção ou de operação, buscando aumentar a } \\
\text { confiabilidade dos equipamentos. Esta prática busca verificar se um sistema de } \\
\text { proteção ainda está em funcionamento. (Ferreira, 2009) }\end{array}$ \\
\hline \multirow{3}{*}{ Manutenção Corretiva } & $\begin{array}{l}\text { Manutenção realizada quando um equipamento ou componente apresentam falhas, para } \\
\text { que então possam desempenhar sua função especificada novamente. Também são } \\
\text { consideras as correções de qualquer anomalia, podendo ser classificadas como pane, } \\
\text { falha, quebra ou desempenho menor do que o esperado. Dentro deste conceito de } \\
\text { manutenção corretiva esta pode ser dividida em duas classes sendo elas: }\end{array}$ \\
\hline & Manutenção Corretiva Não Planejada; \\
\hline & $\begin{array}{l}\text { Manutenção Corretiva Planejada. A primeira é responsável por corrigir a falha de modo } \\
\text { aleatório, caracterizada pela atuação depois da ocorrência do fato. Quando se tratando } \\
\text { de manutenção corretiva planejada, esta só se realiza com decisão gerencial, tanto com } \\
\text { acompanhamento preditivo ou pela decisão de manter operando até a quebra. (Kardec } \\
\text { e Nassif, 1999) }\end{array}$ \\
\hline \multirow{5}{*}{ Manutenção Preditiva } & $\begin{array}{l}\text { Denomina-se de manutenção preditiva todo o trabalho de acompanhar e monitorar as } \\
\text { condições dos equipamentos, os parâmetros operacionais e a degradação } \\
\text { do mesmo. Segundo Kardec e Nassif (1999) são condições básicas para se empregar } \\
\text { este tipo de manutenção: }\end{array}$ \\
\hline & O equipamento deve permitir algum tipo de monitoramento/ medição; \\
\hline & O equipamento deve merecer este tipo de ação, em função dos custos envolvidos; \\
\hline & As falhas devem ser provenientes de causas que permitam ser monitoradas; \\
\hline & Ser possível estabelecer um programa de monitoramento. \\
\hline \multirow{2}{*}{ Manutenção Preventiva } & $\begin{array}{l}\text { De acordo com Kardec e Nassif (1999), esta é a atuação realizada de forma a reduzir ou } \\
\text { evitar a falha ou quebra no desempenho, obedecendo a um plano previamente } \\
\text { elaborado, tendo como base intervalos predeterminados de tempo. }\end{array}$ \\
\hline & $\begin{array}{l}\text { Toda manutenção realizada em um equipamento que não esteja em falha, se enquadra } \\
\text { neste tipo de manutenção, pois os equipamentos ainda se encontram em condições } \\
\text { operacionais. }\end{array}$ \\
\hline
\end{tabular}




\subsection{PLANEJAMENTO E CONTROLE DA MANUTENÇÃO}

De acordo com Branco Filho (2006) no Dicionário de Termos de Manutenção, PCM é o órgão ou função dentro de uma empresa de qualquer nível que pratica a programação e o controle dos trabalhos executados pelas equipes de manutenção, e pode ser representado também como PPCM (Programação e Planejamento do Controle da Manutenção).

Homens e mulheres buscam constantemente a perfeição na manutenção, Viana (2002) afirma que o PCM é um processo que proporciona e auxilia para chegar cada vez mais próximo do desejado.

Entretanto não é necessário ter um departamento exclusivo na empresa para a realização do PCM, Branco Filho (2008) afirma que esse pode existir em qualquer empresa, mesmo nas de pequeno porte. Nessas empresas esse trabalho pode ser realizado por uma pessoa que tenha ocupações na área de manutenção e que seja treinada para essas funções. A tarefa fica ainda mais fácil com o auxílio da informática, através do uso de um computador ou microcomputador para programar as tarefas necessárias.

\subsection{PLANEJAMENTO E PROGRAMAÇÃO DA MANUTENÇÃO}

O planejamento e a programação são dois processos que andam juntos, Gonçalves (2015) descreve planejamento como sendo a teoria ou detalhes de um projeto, usado para criar os passos para alcançar os objetivos, e programação está ligada ao plano, atribuindo datas, previsões, horários para cada etapa em específico.

O programador da manutenção tem como principal função programar as tarefas da equipe com datas e horários que estão sob seu encargo, e apoiar o supervisor. Branco Filho (2008) menciona algumas qualidades que o programador deve possuir:

- Formação técnica;

- Habilidade de trabalhar em equipe;

- Boa comunicação;

- Ter aptidão para trabalhos em papéis;

- Ter alto conhecimento par trabalhar som softwares de planejamento;
- Entender e cumprir as instruções recebidas;

- Saber programar as tarefas com estimativa de tempo;

- Entender a importância da ligação da manutenção com os demais departamentos;

- Incentivar os demais colaboradores.

\subsection{INDICADORES}

Gonçalves (2015) relata que indicadores significam dados estatísticos relativos a um ou diversos processos que se deseja controlar. São usados para comparar e avaliar situações atuais com situações anteriores, onde servem para medir os desempenhos contra as metas e padrões definidos por alguma organização ou entidade.

O mesmo autor ainda descreve os objetivos dos indicadores nas organizações como sendo:

- Mensurar os resultados e gerir o desempenho;

- Embasar a análise crítica dos resultados obtidos e do processo de tomada de decisão;

- Contribuir para a melhoria contínua dos processos organizacionais;

- Facilitar o planejamento e o controle do desempenho;

- Viabilizar a análise comparativa do desempenho da organização.

A expressão indicador de manutenção no dicionário de termos de manutenção, segundo Branco Filho (2006), são dados estatísticos relativos à situação da manutenção, sua performance e o crescimento de sua qualidade e desempenho de suas funções. São divididos em dois tipos, Indicadores de Capacitação (o que estou capacitado a fazer) e Indicadores de Desempenho (como eu estou fazendo o meu trabalho).

São prerrogativas de uma equipe de manutenção, independentemente do nível, prestar serviços e zelar para que máquinas e equipamentos estejam sempre em condições produtivas satisfatórias, o que se denomina disponibilidade, sendo a base da maior lucratividade da empresa. 
As maiores dificuldades encontradas nos grupos de manutenção são exatamente como medir e avaliar este desempenho. Dentro de um planejamento estratégico, sugere-se que as equipes conduzam os seus trabalhos como se fosse um negócio, medindo resultados e performance, porém se observa que os resultados apontados são em boa parte fictícios, ou seja, estão distantes de um negócio real.

\subsubsection{MTBF - TEMPO MÉDIO ENTRE FALHAS}

De acordo com Tavares (1999), este índice deve ser usado para equipamentos que são reparados após a ocorrência de falhas.

Viana (2002) explica que a serventia deste índice é observar o comportamento da maquinaria, diante das intervenções, ainda afirma que este valor deve aumentar com o passar do tempo, pois é um sinal de que o número de corretivas vem diminuindo.

Pode ser calculado este índice da seguinte maneira, dividindo a soma das horas disponíveis dos equipamentos (HD), pelo número de intervenções corretivas neste equipamento no período (NC).

$$
M T B F=\frac{H D}{N C}
$$

\subsubsection{MTBF - TEMPO MÉDIO ENTRE REPAROS}

Tavares (1999) recomenda o uso deste indicador para itens em que o tempo de reparo é significativo em relação ao tempo de operação.

Pode se concluir que quanto menor o índice de MTTR com o passar do tempo melhor, pois os reparos corretivos demonstram impactar cada vez menos na produção, segundo Viana (2002).

O tempo médio entre reparos pode ser obtido com a divisão da soma de horas de indisponibilidade para operação devido a manutenção (HIM) pelo número de intervenções corretivas no período (NC).

\section{DESENVOLVIMENTO}

\subsection{ENTREVISTAS}

A equipe de manutenção da fábrica é formada por 06 técnicos e um supervisor. A equipe de técnicos divide tarefas de manutenção mecânica, eletroeletrônica, automação e controle, instrumentação, rotinas de inspeção de máquinas e equipamentos, usinagem e conservação, dentre outras. Já o supervisor recebe solicitações de manutenção da produção, analisa e distribui aos técnicos e acompanha a execução das mesmas, registrando e arquivando os documentos inerentes à conclusão dos serviços (O.S.).

$$
M T T R=\frac{H I M}{N C}
$$

Para que fossem colhidas informações quanto à dinâmica de tarefas, conhecimento de normas, nível de treinamento, entre outras questões, questionários foram adaptados, tendo como base estudos realizados pelo SEBRAE e o Programa de Gestão da Manutenção para Micro e Pequenas Empresas como visto na Tabela 2. Assim estes foram aplicados ao grupo, sendo um questionário para o supervisor e outro para cada um dos técnicos. As respostas obtidas relatam como são documentadas e executadas pela equipe as atividades diárias, bem como é o ponto de vista dos manutentores quanto as normas da empresa. 
Tabela 2 - Resultado dos questionários

\begin{tabular}{|c|c|c|}
\hline Questões & $\operatorname{Sim} \%$ & Não \% \\
\hline $\begin{array}{l}1 \text { - Existe na empresa procedimentos escritos de orientação de correta } \\
\text { utilização de máquinas e equipamentos? }\end{array}$ & 0 & 100 \\
\hline $\begin{array}{l}2 \text { - Existem normas para manutenção e conservação de máquinas, } \\
\text { equipamentos e instalações? }\end{array}$ & 50 & 50 \\
\hline $\begin{array}{l}3 \text { - Existem registros que avaliem a normalidade dos equipamentos de } \\
\text { produção? }\end{array}$ & 67 & 33 \\
\hline $\begin{array}{l}4 \text { - As ações de correção e soluções executadas nas falhas/quebras são } \\
\text { registradas após ocorrência? }\end{array}$ & 67 & 33 \\
\hline $\begin{array}{l}5 \text { - Quanto à manutenção dos equipamentos, existe algum tipo de } \\
\text { programação? }\end{array}$ & 83 & 17 \\
\hline $\begin{array}{l}6 \text { - Com a realização prévia de manutenção de algum equipamento } \\
\text { poderia ter sido evitado à perda mesmo? }\end{array}$ & 100 & 0 \\
\hline $\begin{array}{l}7 \text { - Os colaboradores de manutenção possuem treinamento para buscar } \\
\text { qualidade na realização do seu serviço? }\end{array}$ & 0 & 100 \\
\hline $\begin{array}{l}8 \text { - Existe programa de treinamento para colaboradores da área de } \\
\text { manutenção? }\end{array}$ & 0 & 100 \\
\hline $\begin{array}{l}9 \text { - O equipamento apresenta falha repetitiva à manutenção atua } \\
\text { buscando um bloqueio definitivo da causa? }\end{array}$ & 83 & 17 \\
\hline $\begin{array}{l}10 \text { - É de seu conhecimento o Planejamento e Controle da Manutenção } \\
\text { dentro da fábrica? }\end{array}$ & 33 & 67 \\
\hline
\end{tabular}

Fonte: Os Autores

\subsection{PROCESSO DE INFORMAÇÃO DE MANUTENÇÕES}

Para um melhor entendimento acerca do processo de informação na realização das manutenções corretivas e preventivas, foram realizadas entrevistas informais com 0 supervisor da manutenção, sendo relatado o passo a passo de cada situação.

Na manutenção corretiva a parada ou falha no processo é constatada pela produção, que solicita a necessidade de reparo para o supervisor da manutenção. Este analisa a modalidade do serviço podendo ser mecânico, elétrico, hidráulico, civil ou de melhoria. Logo após avalia- se a disponibilidade de recursos, sendo peças ou ferramentas para que aconteça o reparo; caso haja necessidade gera-se uma solicitação de compra. Vencida esta etapa o técnico responsável pela modalidade do reparo executa o serviço. Após a execução é solicitada a O.S. ao supervisor, que a lança no sistema contabilizando as horas do trabalho. As ordens são arquivadas por 5 anos, como visto na Figura 2. 
Figura 2 - Fluxo de manutenção corretiva

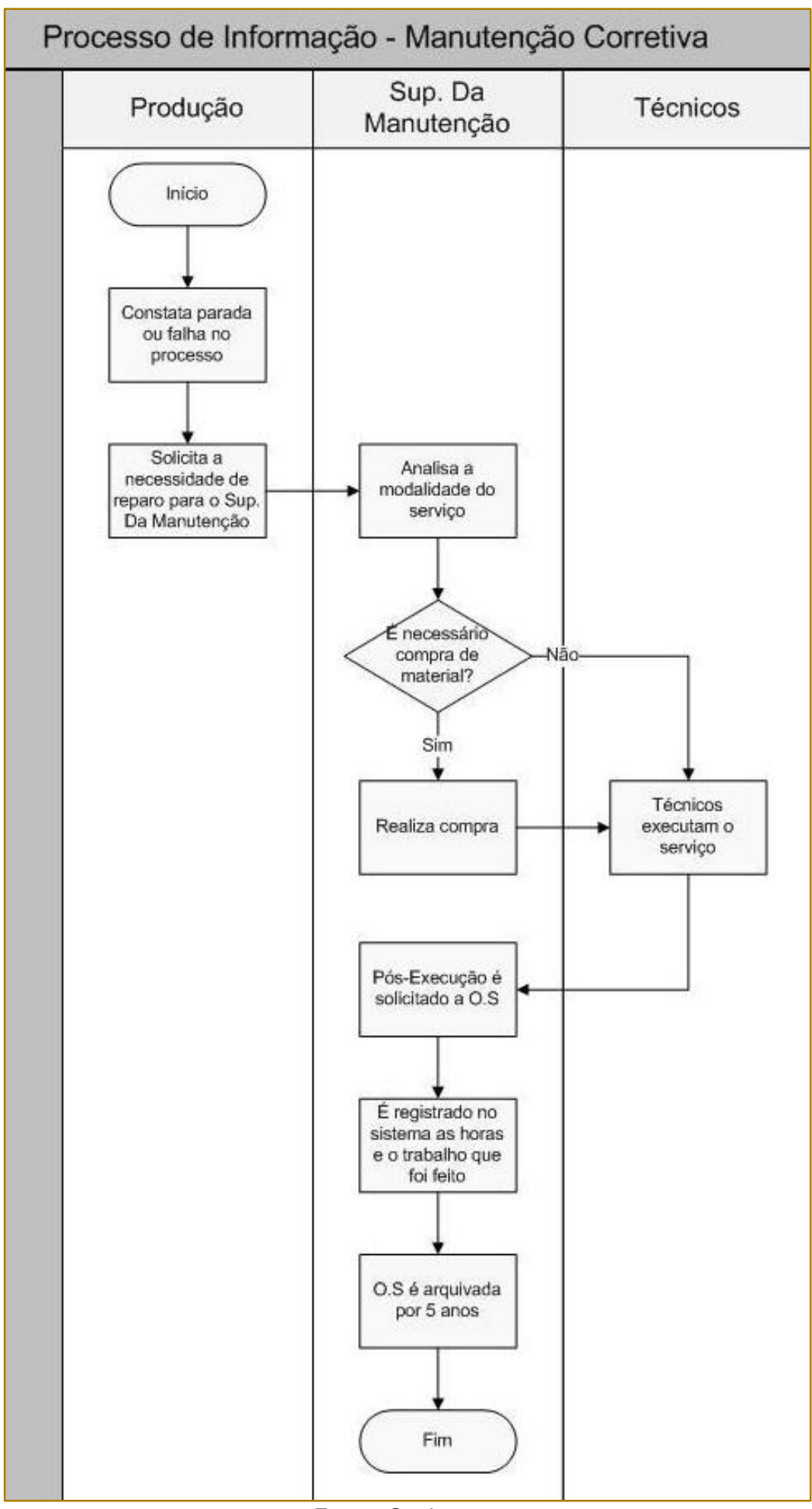

Fonte: Os Autores

No caso da manutenção preventiva a percepção sobre a necessidade da mesma também é feita pela produção. Com essa solicitação o supervisor realiza um estudo de Horas/Homem para a execução das tarefas e lança no plano preventivo, originando o plano de manutenção que é impresso semanalmente, onde também avalia os recursos necessários para a cumprimento da mesma. Os técnicos de manutenção executam as tarefas, e após o trabalho realizado o supervisor verifica se o plano de 
manutenção foi realizado conforme solicitado, as horas são lançadas no sistema e as ordens também arquivadas por 5 anos. Esse processo é observado no fluxo na Figura 3.

Figura 3 - Fluxo da manutenção preventiva

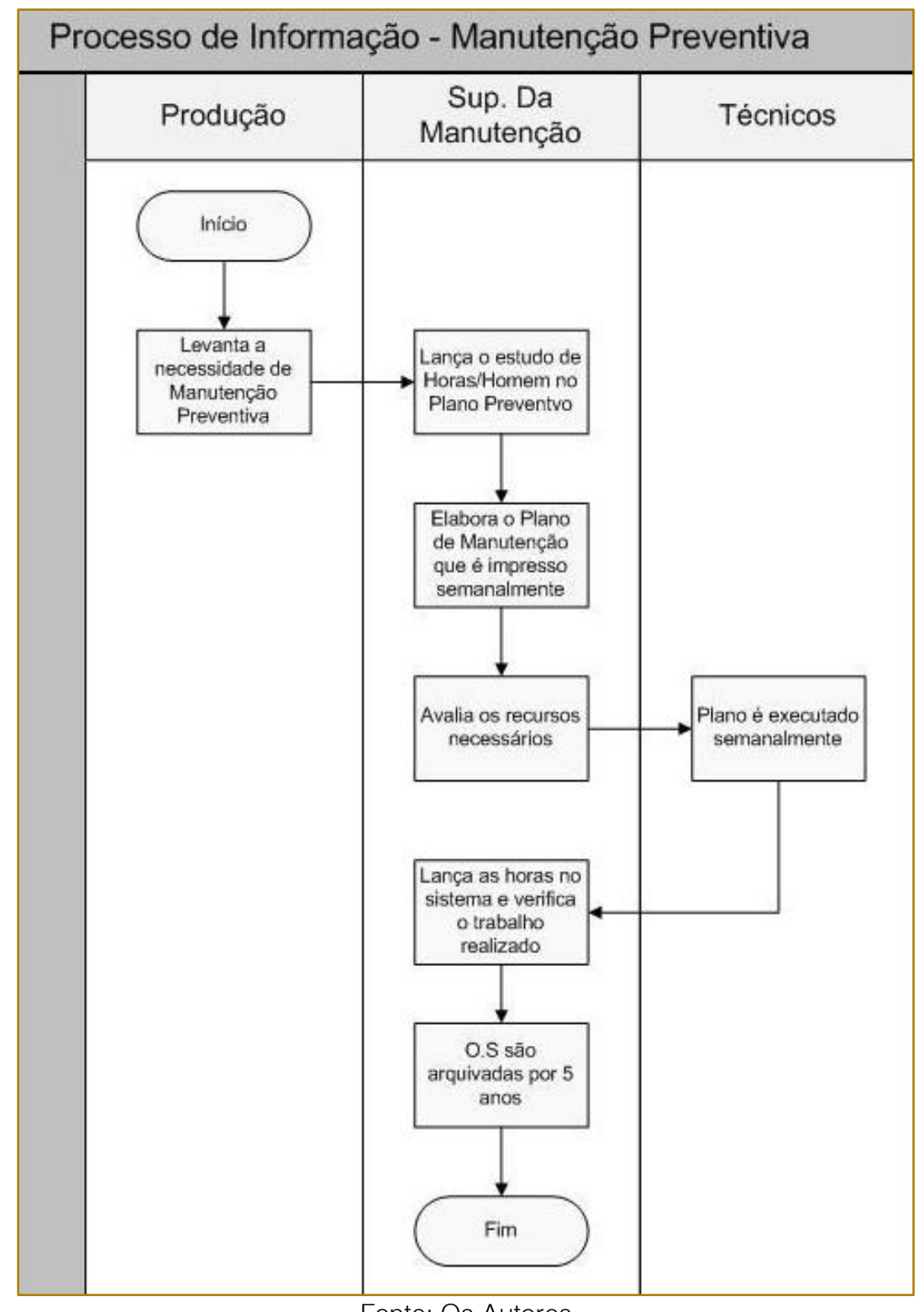

Fonte: Os Autores

\subsection{PREENCHIMENTO DE DOCUMENTOS}

Em uma O.S. seu preenchimento não depende somente de uma pessoa, tão pouco é um trabalho simples, o que demandou uma grande dedicação de tempo para que fosse explicado para os técnicos quais seriam os campos necessários preencher e quais a informações seriam relevantes. Contudo, o adequado preenchimento não se deve somente aos técnicos, grande parte é de responsabilidade do programador, o qual também foi orientado com quais informações eram relevantes e quais campos eram necessários preenchimento e em quais momentos, uma vez que para o programador a O.S. é preenchida duas vezes, uma antes da realização do serviço dos técnicos e uma após a realização das atividades dos mesmos, para que então de entrada no sistema e possa ser gerados dados e gráficos para serem avaliados pelo gestor da área. 


\section{RESULTADOS E DISCUSSÕES}

Dentre as mudanças que ocorreram na empresa, uma delas foi a contratação do programador, o que influenciou na mudança do fluxo das informações dentro do setor da manutenção, melhor distribuição de tarefas aos integrantes do setor, apontamentos de horas advindas das execuções das atividades, interface de manutenção com compras, entre outras.

\subsection{PROCESSO DE INFORMAÇÃO NA MANUTENÇÃO CORRETIVA E PREVENTIVA APÓS INTERVENÇÃO}

Na manutenção corretiva a detecção da falha continua sendo feita pela produção, que solicita a necessidade de reparo para o supervisor da manutenção; esse agora analisa a modalidade e a situação, que pode ser, emergência, urgência e normal. O supervisor pondera a quantidade de horas que a parada vai necessitar e passa para o programador, que por sua vez tem 3 horas para gerar a O.S. A Ordem de serviço é entregue para o técnico responsável pela modalidade, que após executar o trabalho faz o apontamento das horas dentro de um prazo máximo de 24 horas. Ao receber a ordem apontada, o programador tem 2 horas para lança-la no sistema, conforme Figura 4.

Figura 4 - Manutenção corretiva após a intervenção

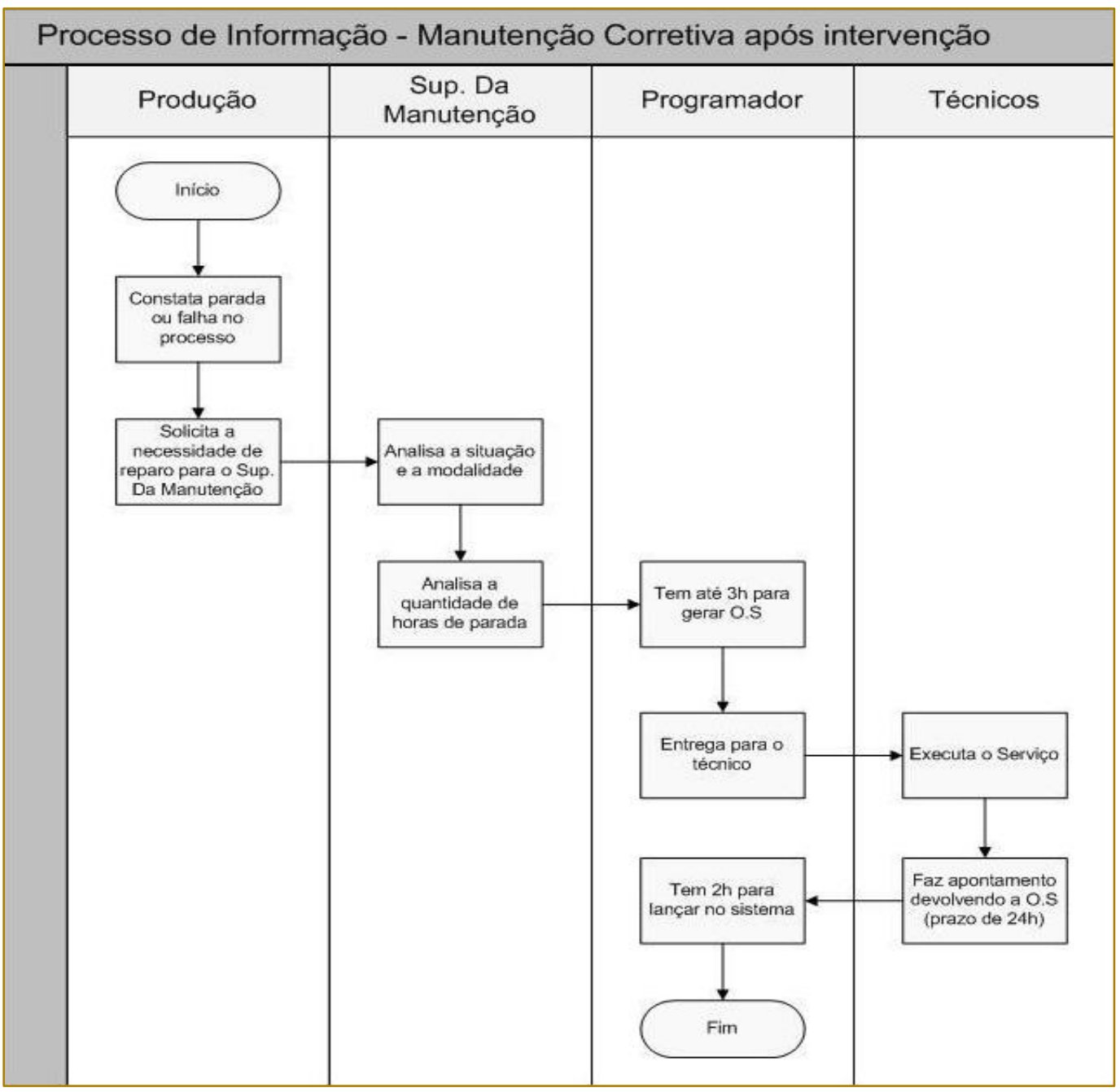

Fonte: Os Autores 
$\mathrm{Na}$ manutenção preventiva a produção levanta a necessidade de reparo e encaminha para o supervisor que transforma essa solicitação em O.S. O programador tem horários determinados para lançar essas ordens no sistema e para colocar em dia as ordens realizadas na semana anterior. No mesmo dia as 15:00 horas é feita a distribuição das tarefas da semana para os técnicos. Após a execução ou não das mesmas, estas retornam para o programador que as destinam ao sistema finalizando-as ou enviando-as novamente para o supervisor que faz uma análise e na próxima programação as lança novamente no plano de manutenção preventiva, este processo pode ser observado na Figura 5.

Figura 5 - Manutenção preventiva após a intervenção

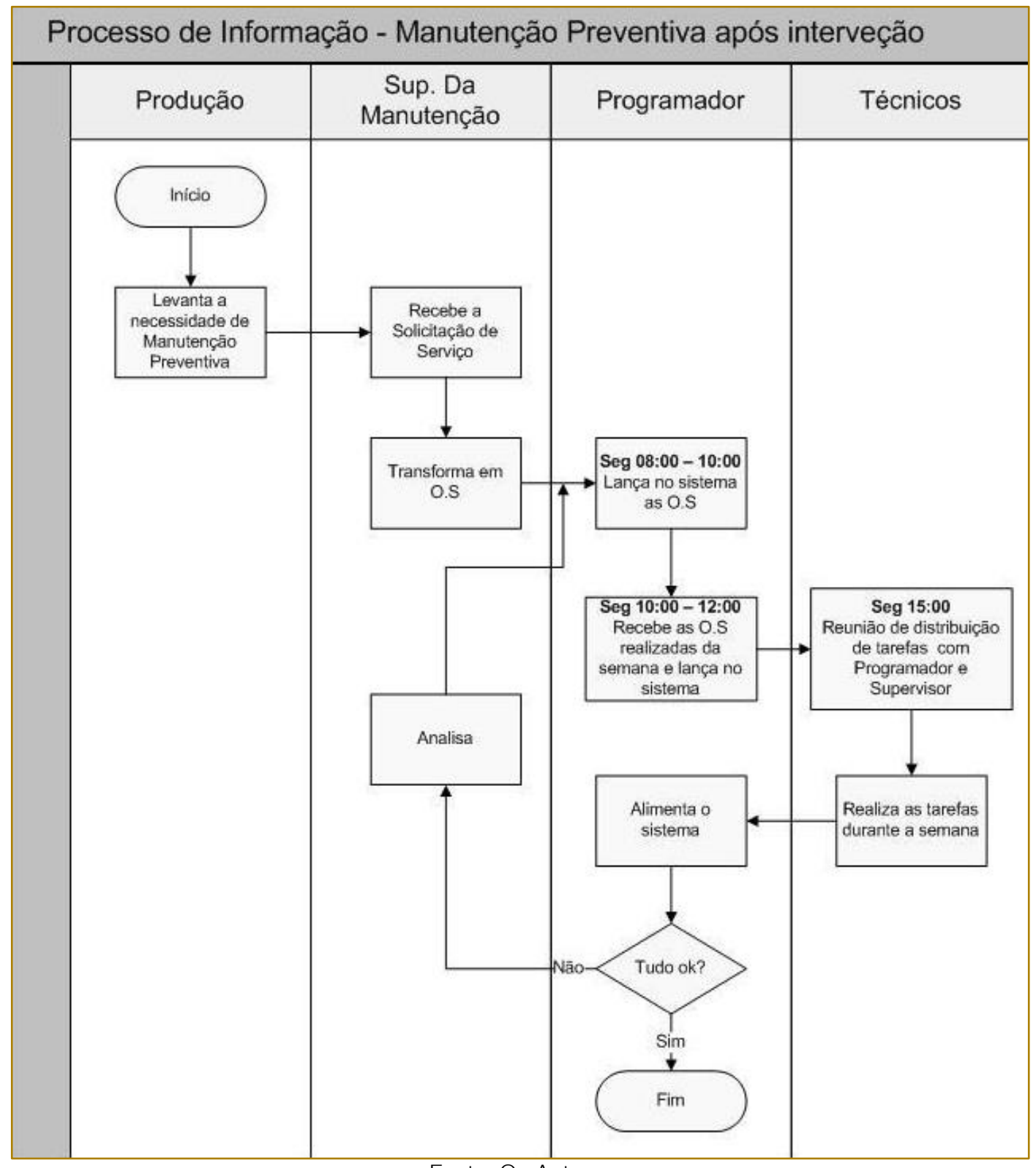

Fonte: Os Autores

\subsection{ANÁLISE DO MTBF}

Outro indicador que começou a ser utilizado pela empresa é o MTBF - tempo médio entre falhas, que pode se dizer mais facilmente quanto tempo a fábrica trabalha sem ter uma falha tanto elétrica quanto mecânica. Como é possível observar no gráfico da Figura 6, a equipe de manutenção tinha uma meta a ser alcançada, que foi estabelecida pelos gerentes da cooperativa no ano corrente de 
75h. Com as informações do gráfico é possível ainda observar que nos meses de junho e julho esta meta não foi alcançada, diferente do mês de agosto que quase dobrou a meta.

Mas é importante explicar como foram obtidos estes resultados nos meses em questão, o tempo de parada da fábrica é dividido pelo número de paradas obtidas no mês. Como em toda divisão o resultado se deve ao divisor, que neste indicador é o número de paradas, nos dois primeiros meses a quantidade de paradas foi alta, já quando se tratando do último mês medido foi baixa, por isso, conseguiu-se este resultado de 144,16h sem paradas na fábrica, o que indica um resultado bom, pois este indicador quanto mais alto melhor, pois significa que a fábrica trabalhou mais tempo sem parar para fazer manutenção.

Figura 6 - Análise do MTBF

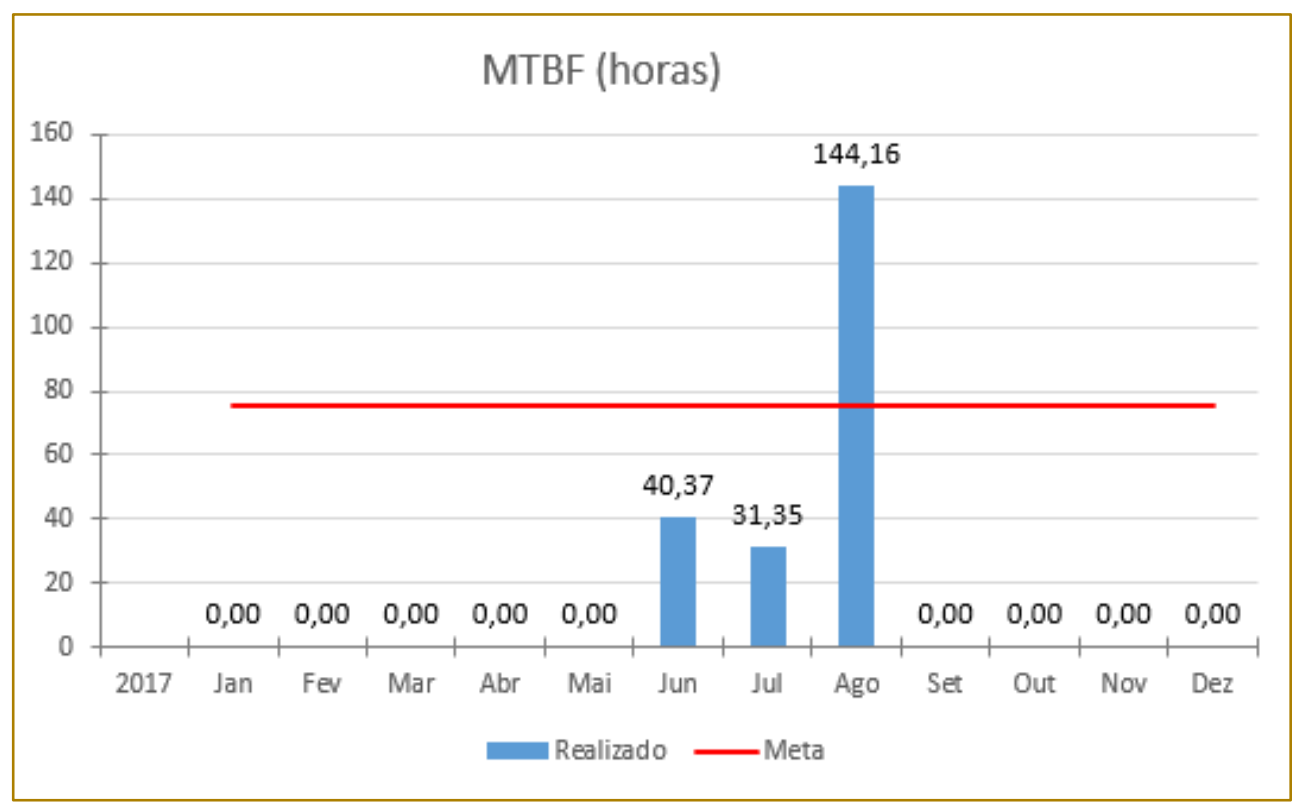

Fonte: Os Autores

\subsection{ANÁLISE DO MTTR}

Para que fosse possível realizar a análise deste indicador foi necessário ter as O.S's preenchidas corretamente e com os dados verídicos dos acontecidos dentro da fábrica. Este índice mede o tempo que a equipe de manutenção está levando em média para fazer os reparos dentro da fábrica, portanto, quanto mais baixo melhor, significa que estão mais qualificados e mais tempo de fábrica funcionando. Este indicador é obtido através da divisão do tempo total de paradas pelo número de paradas.

No mês de agosto onde há a discrepância dos dados, houve duas paradas consecutivas devido a tradição da empresa, onde a produção acreditava ser superior à manutenção, impedindo assim que a manutenção realizasse seu trabalho. Ocorreu que arrebentou uma correia do elevador de caneco de matéria prima, e uma sobressalente da mesma encontrava-se no estoque da manutenção, porém, a produção não permitiu que fosse feita a troca alegando que o reparo seria mais rápido e a fábrica voltaria a funcionar tão logo, a equipe de manutenção por já ter conhecimento do funcionamento da empresa fez somente o reparo, o que acarretou em 450 minutos de fábrica parada. Porém no dia seguinte a correia arrebentou novamente, entretanto a equipe de manutenção se impôs e realizou a troca da correia o que ocasionou em mais 435 minutos de fábrica parada. É possível observar na Figura 7 que no mês de agosto de 2017 o número de falhas foi baixo, o que para este indicador de manutenção é muito bom, porém o tempo parado foi muito alto, o que prejudicou e muito o indicador, portanto neste mês obteve-se 1420 minutos de fábrica parada e somente 5 paradas o que elevou o indicador do MTTR para 284 minutos como ilustrado na 8. 
Figura 7 - Falhas estratificadas de agosto

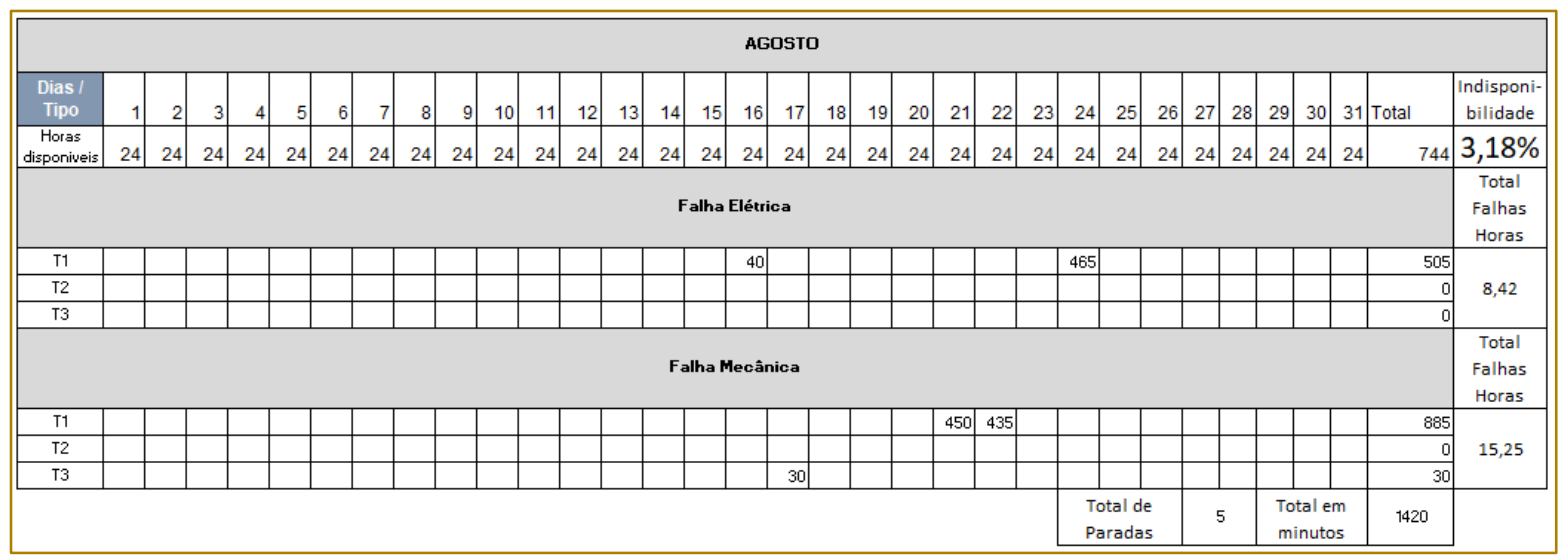

Fonte: Os Autores

Figura 8 - Análise do MTTR

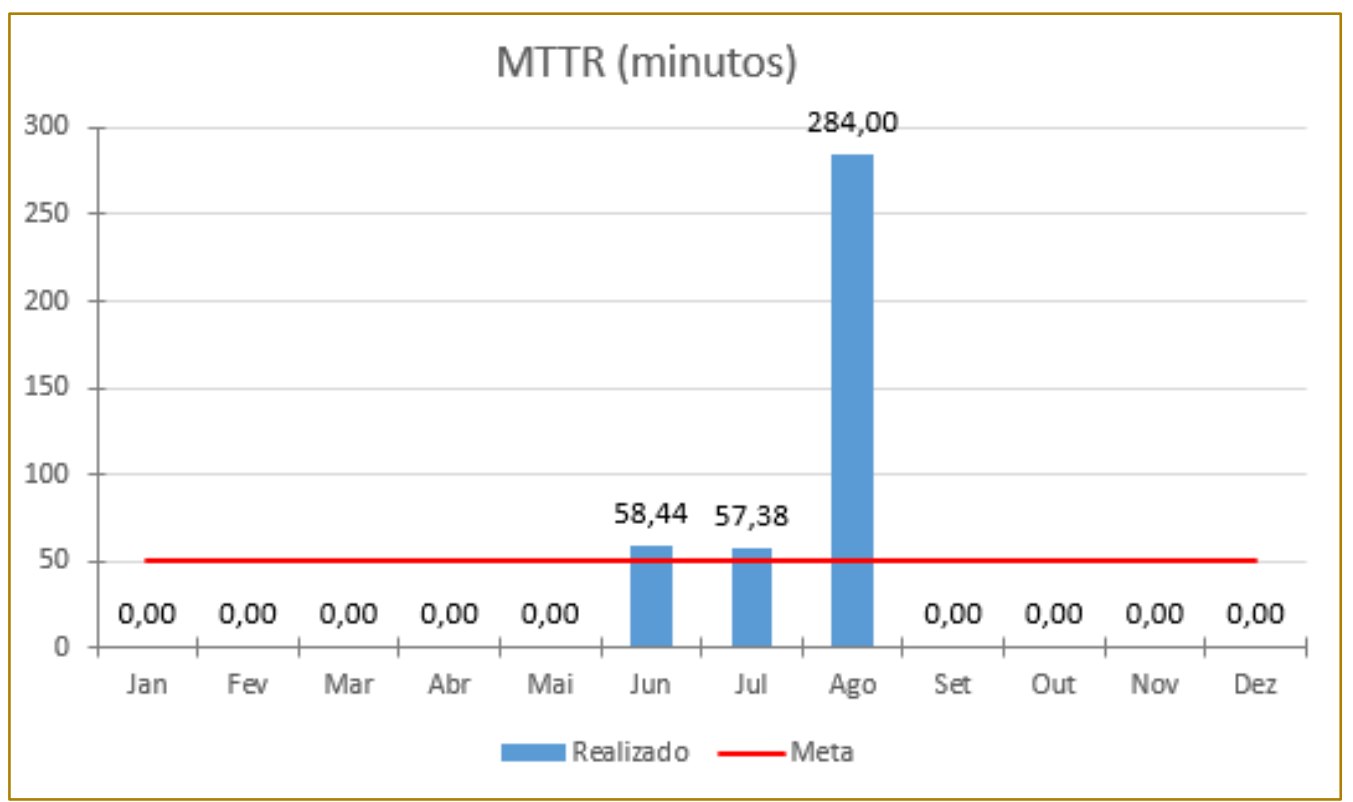

Fonte: Os Autores

\section{CONCLUSÃO}

Por se tratar de uma empresa tradicionalista, onde os colaboradores estavam habituados a ditar suas rotinas, foi encontrado uma divergência nos processos que deveriam ter como resposta a unanimidade, sendo assim foi necessário trabalhar a padronização no setor e mentalidade dos técnicos para que acatassem as tarefas a eles encarregadas a partir da nova estruturação proposta.

Apesar desta dificuldade encontrada no início do desenvolvimento do estudo, após a percepção dos ganhos pelos técnicos, a aceitação da implementação do PCM na rotina se tornou visível.

Em muitas empresas, ainda hoje, o método de planejamento de manutenção é obsoleto, quando não, inexistente, o que torna a organização das atividades um tanto quanto dificultosa, deixando-a ineficiente perante sua devida função. Uma vez que não planejada adequadamente não traz ganhos significativos à organização.

O presente trabalho abre caminho para a expansão de novos indicadores que poderão fazer parte da rotina do PCM, contribuindo com uma gestão mais eficaz. Técnicas de 
análise preditiva podem ser implantadas na manutenção, apresentando resultados

\section{REFERÊNCIAS}

[1] BRANCO FILHO, Gil. Dicionário de Termos de Manutenção, Confiabilidade e Qualidade. 4 ed., Ciência Moderna Ltda, Rio de Janeiro. 2006.

[2] BRANCO FILHO, Gil. A Organização, o Planejamento e o Controle da Manutenção. Ciência Moderna Ltda, Rio de Janeiro. 2008.

[3] FERREIRA, Lívia Lima. Implementação da Central de Ativos para Melhor Desempenho do Setor de Manutenção: um estudo de caso Votorantim Metais. Trabalho de Conclusão de Curso (Graduação em Engenhara de Produção); Universidade Federal de Juiz de Fora, Juiz de Fora. 60f.. 2009.

[4] GONÇALVES, Edson. A Manutenção Industrial - Do Estratégico ao Operacional. Editora Ciência Moderna, Rio de Janeiro. 2015. significativos quanto a durabilidade e segurança dos equipamentos.

[5] KARDEC PINTO, Alan, NASCIF XAVIER, Júlio de Aquino. Manutenção: função estratégica. 1를. Ed., Qualitymark Ed, Rio de Janeiro. 1999.

[6] SEBRAE - PE, Diagnóstico da Gestão da Manutenção em Micro e Pequenas Empresas. Pernambuco. 17p. 2004.

[7] SLACK, Nigel. CHAMBERS, Stuart, HARLAND, Christine, HARRISON, Alan, JOHNSTON, Robert.

[8] Administração da Produção. Editora Atlas S.A., São Paulo. 1999.

[9] VIANA, Herbert Ricardo Garcia. PCM Planejamento e Controle de Manutenção. Qualitymark Ed, Rio de Janeiro. 2002. 


\section{Bapítulo 11}

\section{APLICACÃO DO RCM (REALIBILITY CENTRED IN MAINTENANCE) NA REDUCÃO DE FALHAS: ESTUDO DE CASO EM UMA FÁBRICA DE PREGOS}

\section{Márcio Iscold Dutra}

Resumo: A manutenção precisa deixar de ser apenas eficiente, para se tornar eficaz, quando considerada como função estratégica, responde diretamente a disponibilidade e confiabilidade dos ativos físicos e a qualidade dos produtos finais. Em um cenário cada dia mais competitivo, as empresas estão buscando sempre melhorar seus processos, tratando seus equipamentos como diferencial competitivo. Entender o tipo de manutenção é garantir a otimização do processo, dominar a técnica de análise do tipo e efeito de falha é essencial para empresa, pois saber reconhecer e resolver as falhas e princípios de falhas faz conexão com o crescimento da mesma. Existem várias técnicas de utilização de ferramentas que apoiam a empresa quando se trata de análise das falhas, elas estudam de maneira criteriosa as causas dos problemas afim de diminui-los ou até mesmo eliminá-los, alinhados ao princípio do RCM- Reliability Centered Maintenance-Manutenção Centrada na Confiabilidade, manutenção centrada na confiabilidade. Baseado neste intuito o presente trabalho está relacionado com as atividades de manutenção, especificamente no modelo de redução e prevenção de falhas de um setor industrial, através da ferramenta RCM.

Palavras-chave: manutenção, falhas, RCM, MCC. 


\section{INTRODUÇÃO}

O grande avanço tecnológico tem contribuído para que o mercado atual viva em uma era cada vez mais competitiva. As exigências dos clientes consumidores aliado ao alto índice de concorrentes que se instalam aos mercados fazem com que as empresas invistam em ativos, buscando aumentar seu volume de produção. Com isto as empresas têm tratado seus equipamentos como diferencial competitivo, a gestão da manutenção tem como objetivo a Conservação do equipamento. Por meio da manutenção é possível antecipar a falha que poderia ocasionar paradas imprevistas de seus equipamentos produtivos, programar uma intervenção e atuar sem prejudicar os compromissos da produção.

É pertinente enfatizar que a Revolução Industrial, ocorrida na Inglaterra no século XVIII foi a grande precursora das ações de manutenção. As ferramentas da qualidade decorrentes desde então, são aplicadas para auxiliar as empresas a estabelecer e definir um padrão, transformando, dessa forma, meros fatos em informações concretas. Existem várias metodologias que auxiliam na gestão das atividades, entre as mais utilizadas estão o RCM.

Dominar a técnica de análise do tipo e efeito de falha é essencial para empresa, pois saber reconhecer e resolver as falhas e princípios de falhas faz conexão com o crescimento da mesma. Além da aplicação do RCM o artigo visa incentivar o uso de ferramentas da qualidade, otimizando processos, a partir da eliminação das falhas e a metodologia da melhoria contínua, uma vez que ele oferece subsídios teóricos capazes de facilitar a aplicação da ferramenta.

\subsection{JUSTIFICATIVA}

A produção nos dias atuais tem como o objetivo aumentar a produtividade e por consequência, aumentar o valor agregado do produto. Atualmente, com a grande competitividade entre as indústrias no âmbito mundial, existe a necessidade de se produzir - máximo possível, levando-se em consideração a capacidade da indústria, de modo a ter o mínimo de perdas (de material, recursos financeiros, etc.) possível. (FELíClO, pag. 12)

Uma manutenção gerenciada adequadamente contribuirá para qualidade e produtividade do produto, minimizará custos de produção, terá controle total e será mais ágil nos processos industriais garantindo uma vantagem competitiva para a empresa sobre os concorrentes. Baseado neste intuito o presente trabalho está relacionado com as atividades de manutenção, especificamente no modelo de redução e prevenção de falhas de um setor industrial, através da ferramenta RCM. Desta forma, este artigo irá avaliar e demonstrar como a utilização de ferramentas de qualidade pode auxiliar no processo de melhoria e desempenho em um setor de produção.

\subsection{ESCOPO E DELIMITAÇÃO DO ARTIGO}

O presente trabalho tem como foco específico descrever a aplicação dos modelos de ferramentas de qualidade em um equipamento. Foi elaborado a partir de observações no processo de melhoria contínua no setor de manutenção, de forma que a aplicação pretenda reduzir os níveis de não conformidade de forma eficaz, podendo ser aplicado aos demais equipamentos da empresa.

\subsection{OBJETIVOS}

O objetivo deste artigo é apresentar a elaboração da metodologia RCM, com base nas técnicas de qualidade para a redução e prevenção de falhas em sistemas operacionais. O estudo apresenta um estudo bibliográfico sobre o tema de Manutenção, explica seus métodos e ações com foco na manutenção centrada na confiabilidade, descreve e analisa uma implementação do RCM em um sistema de confecção de pregos na empresa e por fim avaliar os resultados desta implementação como ferramenta de apoio a manutenção.

\subsection{METODOLOGIA}

O artigo utiliza uma abordagem de pesquisa exploratória de natureza aplicada visando maior familiaridade com o problema, de acordo com VERGARA (2005) é uma busca de conhecimentos sobre gestão de manutenção, através de pesquisas, observações análises, qualificações e interpretação de dados. É descritiva, por buscar abordagens com a junção das práticas de manutenção e operação. 
A pesquisa também tem caráter bibliográfico e documental, pois se utiliza de investigação em artigos, livros e redes eletrônicas sobre os principais conceitos e práticas associados ao tema e está delimitado com os seguintes temas: (i) Revolução Industrial (ii) história da manutenção (iii) tipos de manutenção (iv) confiabilidade na manutenção (v) RCM (vi) análise de criticidade (vii) critérios de análise (viii) avaliação do risco (ix) matriz de criticidade( $x$ ) funções significantes(xi) FMEA.

\section{REVISÃO LITERÁRIA}

\subsection{REVOLUÇÃO INDUSTRIAL}

Fomentada pelo espírito capitalista, a Revolução Industrial modificou toda a estrutura capitalista e social da Europa e de todo o mundo. Segundo Miranda (2012), as primeiras fábricas de produção em massa foram desenvolvidas na Grã-Bretanha, logo depois Estados Unidos e América de uma forma tão avassaladora que encerraram de vez o sistema econômico feudal. A revolução também deu origem a uma espécie de "robotização do trabalhador". O operário passou a servir a uma máquina, se transformando num operário que desempenhava atividades cotidianas totalmente cansativas.

O mundo foi mudando e o sistema de produção acompanhando sua evolução, as necessidades dos países por poder culminaram em sangrentas guerras. Após a Guerra civil americana, em 1800, surgem novos mercados e novos postos de trabalho. Em 1880 revelam-se os cargos de engenheiros, técnicos, executivos, pesquisadores e educadores. Frederick Winslow Taylor (1856-1915) destacou-se entre eles e foi considerado pai da Administração Científica, seu objeto de estudo científico eram os problemas fabris ocorrentes em sua época, "...obter o resultado desejado com menor desperdício de tempo, esforço e materiais." (NORMAN, 2001)

No começo do século XX, Henry Ford projeta o modelo $T$ para ser fabricado em linhas de montagem, que reuniu fundamentos como produção em massa, baixo custo de manufatura, produtos padronizados, linha de montagem mecanizada, especialização de mão de obra, a Revolução Industrial estava focada na tarefa e na eficiência de seus processos.
O sistema Toyota foi desenvolvido para contrapor o Fordismo, tinha como objetivo reduzir o desperdício, promovendo a melhoria contínua do processo produtivo. A filosofia do TCQ (Total Quality Control - Qualidade Total) preparou as organizações para trabalhar com as mudanças e busca da melhoria contínua dos resultados. As descobertas na área da informática ocasionaram uma revolução nas informações e suas aplicações, equipamentos e sistemas cada vez mais sofisticados vêm surgindo ao longo dos dias. Os marcos históricos descritos aqui mostraram transformações que ocorreram na história da industrialização.

\subsection{HISTÓRIA DA MANUTENÇÃO}

No fim do século XIX, com a mecanização das indústrias, surgiu a necessidade dos primeiros reparos e até 1914, a Manutenção era renegada a segundo plano sendo executada pelo mesmo efetivo de operação. Com a implantação da produção em série, instituída por Ford, as fábricas passaram a estabelecer programas mínimos de produção e, em consequência, sentiram necessidade de criar equipes que pudessem efetuar reparos em máquinas operatrizes no menor tempo possível. Assim surgiu um órgão subordinado à operação, cujo objetivo básico era de execução da Manutenção. NETO (2017)

Conforme Harilaus (1998), a Manutenção é definida como um conjunto de ações técnicas e administrativas, incluindo a de supervisão, que se destina a preservar, reajustar e colocar um item em um estado no qual possa desempenhar uma função requerida. (NBR 5462-1994).

Ainda segundo Moubray (1997) podemos dividir a história da manutenção, de forma geral, em três períodos distintos.

Primeiro período: anterior a $2^{\mathrm{a}}$ Guerra Mundial, manutenção na primeira geração, não se tinha nas empresas muita preocupação com as falhas/paradas e a disponibilidade de produção apresentadas aos equipamentos.

Segundo período: manutenção da segunda geração, após a Guerra Mundial. Planos de preventivas foram elaborados e a preocupação com os tempos de parada dos equipamentos produtivos começou a existir e os custos de manutenção começaram a ter controle. 
Terceiro período: manutenção da terceira geração, nesta fase busca-se novas maneiras de maximizar a vida útil dos equipamentos, mais acentuada com a longevidade do mesmo, a fim de se ter uma maior disponibilidade e confiabilidade, se preocupando ainda com segurança, custos sob controle, qualidade e meio ambiente.

\subsection{TIPOS DE MANUTENÇÃO}

Manutenção corretiva não planejada: Esse tipo de manutenção é caracterizado pela atuação das equipes de manutenção em fatos que já ocorreram, não existe uma preparação para ela, ocorre devido a falhas ou desempenhos inferiores ao esperado, corrigese a falha a fim de evitar outras consequências (WILLIANS, 1994 apud CASTELLA, 2001).

Manutenção corretiva planejada: A correção para a falha ou condição anormal do equipamento, depende de uma decisão gerencial, ele tem a opção de adotar um acompanhamento preditivo ou deixar que o equipamento opere até sua quebra. Precisam ser avaliados alguns fatores para a tomada de decisão corretiva como: negociação de parada do processo produtivo com a equipe de operação, aspectos ligados à segurança, melhor planejamento dos serviços, garantia de ferramental e peças sobressalentes, necessidade de recursos humanos tais como serviços contratados. Uma vez que se espera a falha trabalha-se com a possibilidade de planejamento dos recursos necessários para a intervenção da manutenção. (PINTO e XAVIER, 2001 apud MUASSAB, 2002).

Manutenção preventiva: Reduz o risco de paradas não planejadas causadas por falhas nos equipamentos, principalmente quando se fala em máquinas ligadas diretamente ao processo. Antes de qualquer ação preventiva, tem que se ter uma pré-análise dos técnicos de manutenção, pois assim torna o serviço mais especializado e reduz de forma significativa o fator de improvisação. Assim, o índice de qualidade no serviço alcança um patamar bem mais elevado do que em um ambiente alicerçado somente por manutenções corretivas, já que há um

conhecimento bem maior sobre o funcionamento das máquinas (VIANA, 2002).

Manutenção preditiva: antes da ação preventiva é necessário uma pré-analise do técnico de manutenção, a manutenção preventiva tem como objetivo a redução do risco de paradas não planejadas causadas por falhas nos equipamentos. Tornando possível assim um considerável aumento no índice de qualidades, visando definir o instante correto da intervenção, com o máximo de aproveitamento do ativo (OTANI e MACHADO, 2008).

Manutenção detectiva: realiza um planejamento para a manutenção do equipamento, busca atuar no instante correto para que não prejudique o aproveitamento do ativo, afirma PINTO e XAVIER (2001). Sua importância cresce a cada dia, em virtude da maior automação das plantas e utilização de microprocessadores.

\subsection{CONFIABILIDADE NA MANUTENÇÃO}

Segundo Pinto e Xavier (2001) confiabilidade é resultante do pleno funcionamento de um determinado item, por um intervalo de tempo estabelecido, sob condições definidas de uso, conforme o mesmo foi programado para executar. Com isto a confiabilidade do equipamento consiste em funcionar corretamente, durante o tempo preestabelecido.

Conforme Tavares (1999), a diminuição das falhas não programadas, com a reedição do estado dos equipamentos, aliado ao uso dos recursos de lubrificação, com o planejamento das intervenções, planejamento, organização, previsão do estado do equipamento, se torna quase obrigatória para um planejamento computadorizado dentro da manutenção centrada na confiabilidade.

\subsection{RCM - MANUTENÇÃO CENTRADA NA CONFIABILIDADE}

O RCM é uma metodologia que identifica quais as práticas mais indicadas, dentro de uma operação, para a preservação das funções nela existentes. Ou seja, identifica e mensura a confiabilidade de um sistema (equipamentos, máquinas e processos) e, de maneira científica, propõe meios para aumentar essa confiabilidade (MARCORIN e LIMA, 2003). O RCM visa à utilização máxima dos recursos disponíveis, desde que viáveis, para garantir a confiabilidade de operação. Além disso, pelo alto nível de informações que gera, permite a empresa melhorar seu desempenho operacional, aumentar a vida útil dos equipamentos, melhorar a tomada de 
decisão a respeito das manutenções (quando, onde, oque e por que fazer). Depois de levantados os riscos de falhas, a empresa poderá dirigir seus esforços para as máquinas que, caso falhem, possam vir a gerar algum agravante para o ambiente e/ou seus próprios colaboradores. Melhora, portanto, a segurança (SOUZA e LIMA,2003).

Segundo a definição de Kroner (1999) apud Souza e Lima (2003), pode-se seguir os sete passos para implantação da metodologia RCM, os quais serão descritos a seguir:

Passo 1 - Seleção de equipamento/área onde será realizada a manutenção: Escolha do setor ou do equipamento que receberá a manutenção, onde forem aceitos os investimentos apresentados, planeja-se então os detalhes da manutenção como análises (quando e onde), auditorias e treinamento;

Passo 2 - Determinação do desempenho desejado e capacidade real tecnológica do ativo: depois de estabelecido o desempenho e a capacidade a manutenção do equipamento deve ser planejada e programada de modo que o mesmo tenha sempre condições de executar o que ele foi projetado para executar e o que se espera que ele execute de maneira correta;

Passo 3 - Análise das falhas do ativo: registrar e analisar as falhas funcionais conforme afetam o desempenho do equipamento, classificando-as em falhas parciais e totais, falhas limites inferiores e superiores e falhas contexto operacional. Isso permitirá à manutenção um maior conhecimento e controle sob seus equipamentos;

Passo 4 - Estudar as causas das falhas, seus efeitos e possíveis consequências: geralmente utiliza-se, o método FMEA Análise de Modos de Falha e seus Efeitos para se obter informações que justifiquem a tomada de decisão afim de amenizar ou mesmo eliminar a causa da falha.

Passo 5 - Selecionar o tipo de manutenção mais adequada, de acordo com a seguinte classificação: tempo (preventiva), condição (preditiva) e teste (detectiva). Resultando em uma maior confiabilidade operacional do equipamento consequentemente uma maior vida útil do mesmo com a manutenção preditiva, gerando um baixo custo de manutenção.

Passo 6 - Formular e Implementar o Plano de Manutenção: deve ser realizado uma análise entre as recomendações já existentes e as do novo plano, afim de entender quais são as alterações necessárias para o sucesso na manutenção.

Passo 7 - Melhoria Contínua: através de uma constante analise e reanalise de ações, encontramos a melhoria continua, muito mais importante é que os setores da organização estejam sempre bem esclarecidos quanto as atividades propostas e as adaptações sugeridas para que possa ocorrer de uma forma geral na empresa apresentando assim o resultado esperado.

\subsection{MÉTODOS DE ANÁLISE DE FALHAS}

Conforme Moubray (1997) define falha como: a incapacidade de um equipamento ou item desempenhar sua função, através de interrupção ou alteração da sua capacidade. Esta identificação permite prever o que acontece e quando, avalia seus impactos e o que pode ser feito para prevenir e antecipar ou até mesmo eliminar esta falha.

Gráfico de Pareto: Esta ferramenta permite indicar os parâmetros que tem influência significativa sobre cada processo. Através deste diagrama consegue-se priorizar a ação que terá melhor resultado, ele consiste em um gráfico de barras que ordena as frequências das ocorrências da maior para a menor, permitindo a localização dos problemas vitais e eliminação de perdas. Seu principal objetivo está em identificar as "poucas causas vitais" dentre as "muitas causas triviais".

Método dos Cinco Porquês: Belohlavek (2006), explica que os "5 porquês são" sustentados por diferentes níveis de fundamentação, de acordo com o nível do problema. Assim, Belohlavek (2006), define cada um dos porquês: primeiro por quê tem como objetivo descrever o seu funcionamento, permitindo resolver os problemas do ponto de vista operacional; segundo por quê - refere-se, de um ponto de vista mais lógico, aonde as partes deste algo permite resolver problemas sem que haja o desajuste funcional entre essas partes: terceiro por quê - explica o problema visto como um sistema, o que permite analisar além das fronteiras do problema e analisar os limites do mesmo; quarto por quê- analisa o problema a partir da sua natureza, das suas essências e do contexto no qual está inserido; quinto por quê - explica a realidade com base nas leis naturais, assim pode-se encontrar soluções para os problemas de nível 
universal, cujas consequências também são universais.

\subsection{ANÁLISE DE CRITICIDADE}

Conforme Wessels e Sautter (2009) a análise de criticidade fornece uma visão final dos efeitos de um modo de falha, podendo ser conduzida a assuntos de relatos qualitativos ou quantitativos. Quantitativa é a obtenção de um número critico através de taxas de falhas, modos de falhas, efeitos com valores conhecidos e confiáveis. Já a abordagem qualitativa é quando não se tem base de dados, sendo necessário qualificar a criticidade pelos membros da equipe. Porém conforme vai ocorrendo o amadurecimento do projeto é aconselhável coletar estes dados e utilizar métodos qualitativos.

\subsection{AVALIAÇÃO DO RISCO}

Uma maneira de se avaliar o criticidade é através do RPN (RiskPriorityNumber), que é a análise dos riscos associados as falhas, com foco nas ações de manutenção. Ela pode ser realizada através das equações mostradas abaixo:

$\mathrm{RPN}=\mathrm{S} \times \mathrm{F}$

$R P N=S \times F \times D$ quando é utilizado o nível de detecção

Onde: S é a Severidade do modo de falha, $\mathrm{F}$ a sua frequência e D o nível de detecção

\subsection{MATRIZ DE CRITICIDADE}

A matriz de criticidade é um meio visual para identificar e comparar os modos de falha para todos os componentes dentro de um determinado sistema ou subsistema, avaliando-os através da relação da probabilidade de ocorrência com a severidade (HEADQUARTERS, 2006; IEC, 2006)

\subsection{FUNÇÕES SIGNIFICATIVAS}

O planejamento deve definir os equipamentos críticos da empresa, estando subdividido da seguinte forma, conforme aborda Filho (2003):

- Classe A: são equipamentos vitais e únicos para o processo, quando sujeitos a falhas, podem ocasionar risco de morte ou danos ao ser humano e ao meio ambiente;
- Classe B: são equipamentos que ocasionam graves perdas de produção quando sujeitos a falhas;

- Classe C: são equipamentos que quando sujeitos a falhas acarretam apenas os custosos reparos, não devendo entrar no plano de manutenção preventiva.

O próximo passo é avaliar é se a falha recorrente neste sistema é evidente ao mantenedor ou não, não sendo necessário inspeções ou testes para sua detecção. Falhas ocultas para Garza (2002) são aquelas que estão associadas a dispositivos de proteção ou "standby" e que não apresentem resultados diretos para a operação, mas são associadas a outros modos de falhas que podem ser graves.

As falhas também podem gerar impactos relacionados ao meio ambiente, com a violação ou infração das leis e padrões da área, ou causar lesões e ameaçar a vida do usuário do sistema em análise. Além dos fatos apresentados, uma falha pode relacionar diretamente a capacidade de produção, a qualidade do produto, eficiência do processo, gerando uma insatisfação do cliente e impactado nos custos da empresa.

\subsection{FMEA}

Stamatis apud Leal et al. (2006) definem o FMEA (FailureModeandEffectAnalysis) como um procedimento de análise de um sistema usado para identificar, definir e eliminar os modos de falhas conhecidos e potenciais. Identificar o problema antes mesmo que ele aconteça, evitando futuras surpresas no decorrer do processo e antes que estes atinjam o cliente.

\section{DESENVOLVIMENTO}

O presente trabalho apresenta a implementação de um modelo de RCM, para a redução de paradas no sistema $X$ de um processo industrial com o auxílio de outras ferramentas de qualidade.

A implementação do RCM deve ser realizada de acordo com o contexto operacional em que se encontra, observando seus processos, produtos, identificando o modelo de gestão, que terá a compreensão de todos. Considerando tais fatos, abaixo é proposto um programa para a implementação do RCM. 
- Seleção do sistema e coleta de informações;

- Identificação das funções e falhas no sistema;

- Seleção das subunidades críticas;

- Análise do FMEA

- Processo de atualização e Melhoria contínua

Primeiro é descrita uma breve apresentação do sistema e todo o seu processo de produção.

\subsection{EXPLICAÇÃO TÉCNICA}

O equipamento alvo deste trabalho (figura 01) é responsável pela fabricação de pregos, que tem como matéria prima fio metálico trefilado de liga de carbono. O conjunto de mordentes que compõe o equipamento puxa o fio metálico trefilado do estocador em direção à máquina, estes também servem para segurar o prego enquanto o processo de estampagem forma a cabeça do mesmo. Enquanto isso acontece, as navalhas cortam seu tamanho fazendo a ponta do prego. Logo após o prego ser cortado ele cai por uma bandeja até a peneira rotativa, onde o prego é separado da limalha antes de cair na caçamba coletora.

O fio metálico trefilado chega até o desenrolador (figura 02) através de pontes rolantes sendo transportado para dentro da máquina com o auxílio do braço, o processo de corte ao qual o fio metálico previamente desempenado é cortado em partes pequenas que variam de acordo com o comprimento do prego a ser produzido. Formado por dois cabeçotes (inferior e superior) que giram no mesmo sentido fazendo coincidir seus pares de navalhas e dessa forma cisalhando o fio metálico este é inserido na máquina. Cada cabeçote de corte é composto em média por seis pares de navalhas com as arestas de corte em forma triangular, as quais além de efetuar o corte também moldam a ponta do prego. Portanto o resultado deste processo é um prego com ponta e sem cabeça, ou seja, a confecção da ponta do prego. Depois do prego cortado, para que nossa matéria prima se transforme realmente em um prego, o que resta é a estampagem da cabeça (figura 03). Para isso a máquina é equipada com dois aros de mordentes, um que é montado em um rolamento no lado da máquina e outro que é fixado no rolamento da porta frontal. Depois da porta frontal fechada, os dois aros são acoplados, e os mordentes de um aro formam par com o de outro. Cada aro possui em média 40 mordentes, cuja finalidade é segurar e servir de molde para fabricação da cabeça do prego. É nessa parte do processo que o movimento até então retilíneo da matéria prima se transforma em giratório (sentido horário), passando por três etapas principais: A alimentação de cada mordente com prego cortado, a estampagem da cabeça pelo rolo estampador e o desprendimento (ejeção) do prego para calha de saída, finalizando desta forma o processo de fabricação do prego. Ou seja, o prego entra na máquina, passa pelos aros do mordente, corta, faz a estampagem e depois libera o processo de fabricação do prego. Ou seja, o prego entra na máquina, passa pelos aros do mordente, corta, faz a estampagem e depois é ejetado.

Figura 01: Máquina enkotec

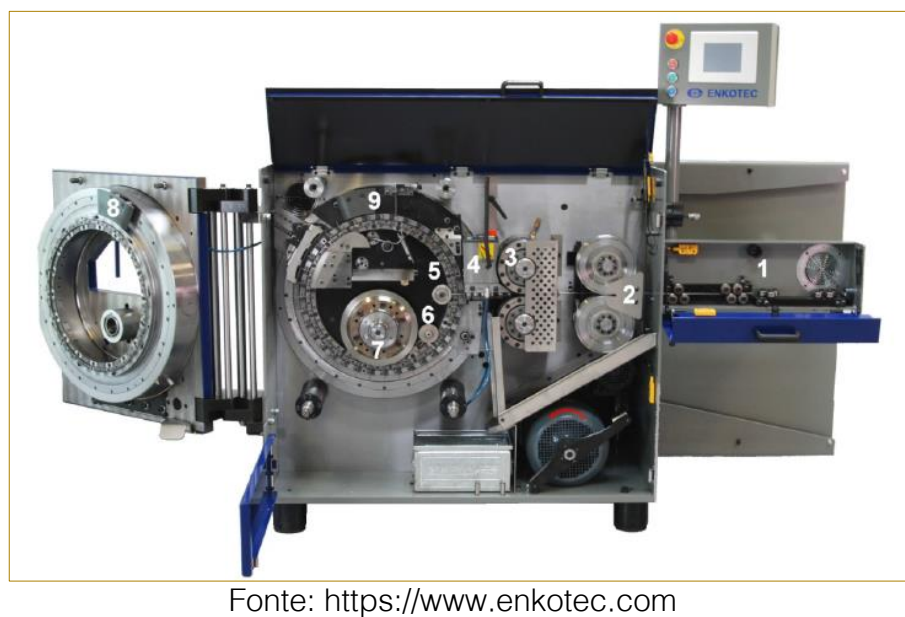




\section{1}

Figura 02: Desenrolador e braço

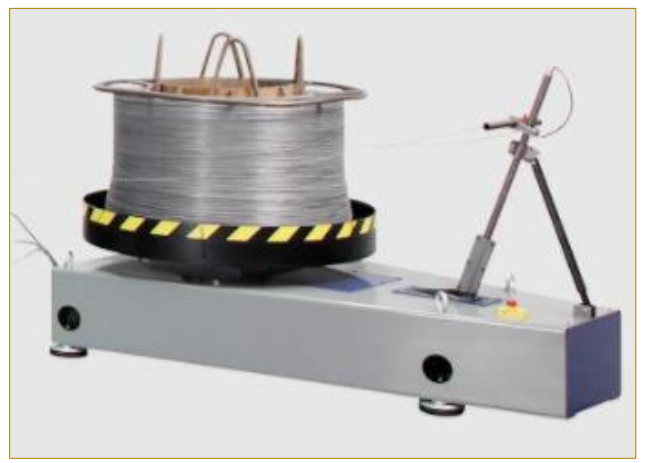

Fonte: https://www.enkotec.com

Figura 03: Processo de estampagem da cabeça do prego

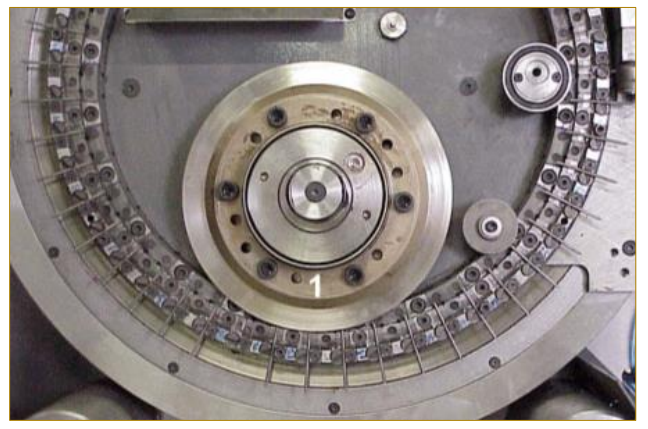

Fonte: https://www.enkotec.com

\subsection{SELEÇÃO DO SISTEMA E COLETA DE INFORMAÇÕES}

A adoção de uma estratégia de manutenção deve vir a partir de uma decisão gerencial, mas para que isto ocorra é necessário quebrar certos paradigmas e mudanças na cultura organizacional. Toda implementação de atividades ou normas geram estresse em toda a organização, por isso, deve-se ter muito cuidado ao sugerir uma alteração nas atividades. As melhorias devem ser entendidas como realmente essenciais e não como ordem da gerência, só assim o êxito da nova rotina será completo.

O fluxo de decisão é baseado em perguntas desenvolvidas pelos membros da equipe, que conduzirão a seleção das atividades de manutenção.
A coleta de informações servirá de base para análises posteriores e poderá ser implementado conforme necessidade das operações. Podem ser utilizados através de manuais de fornecedores, dados de falhas, diagramas de funcionamentos, requisitos de manutenção.

O primeiro passo foi identificar as equipes técnicas responsáveis pela análise, execução e administração da metodologia que foi composta por profissionais da área (mecânicos, elétricos e programação Quadro 1). Os profissionais deveriam ser entendedores do assunto, com um conhecimento técnico adquirido ao longo dos anos de trabalho capazes de transformar seu conhecimento tácito em explícito.

Quadro 01: Planilha e descrição do sistema

\begin{tabular}{|c|c|c|c|}
\hline Unidade & Empresa $\mathrm{x}$ & Equipamento: & X \\
\hline Sub-unidade: & Desenrolador/acionamento/estampagem & Responsáveis: & Equipe de atuação \\
\hline Função & Máquina de fabricar pregos & Data da elaboração: & $02 / 01 / 2018$ \\
\hline
\end{tabular}

Fonte: O autor (2018) 
Através da matriz de criticidade (tabela 01) e utilizando a "Análise ABC" justifica-se aplicação do RCM no sistema $X$ que comprova sua criticidade. Como o foco da implementação está na redução das falhas relacionadas a subunidade do sistema, Estampagem, ficando restrito a análise no mesmo.

\subsection{IDENTIFICAÇÃO DAS FUNÇÕES E FALHAS FUNCIONAIS}

O próximo passo é registrar a descrição do sistema, com sua função e parâmetro dos componentes do subsistema (tabela 01). A parte superior da tabela é composta pela descrição do sistema analisado, onde descreve o nome do mesmo, sua subunidade, a parte do equipamento, e a função primária deste, sendo padrão para todos os demais que equipamentos que utilizarão a metodologia. Para este cálculo deve-se levar em consideração o fator peso (tabela 02) para que a multiplicação resulte em uma definição clara de quais sistemas são realmente críticos.

\subsection{1 - CLASSIFICAÇÃO DOS EFEITOS}

O nível de gravidade deve ser estabelecido ao final da análise dos modos de falha, ainda no FMEA, com objetivo de identificar os modos de falha que não produzem efeito no sistema ou que apresentam efeitos insignificantes (IEC, 2006; HEADQUARTERS, 2006).

\subsubsection{1 - SEVERIDADE}

Índice que reflete a gravidade da ocorrência do modo de falha. E podem ser classificadas conforme o quadro 02.

\subsection{2. - OCORRÊNCIA}

Índice que reflete a estimativa da probabilidade do acontecimento do modo de falha. E podem ser classificadas conforme 0 quadro 03.

\subsection{3. - DETECÇÃO}

Índice que reflete a dificuldade de detecção dos modos de falha. E pode ser classificado conforme quadro 04.

Quadro 02: Classificação dos níveis de severidade das falhas

\begin{tabular}{|c|c|c|c|c|c|c|}
\hline & \multicolumn{6}{|c|}{ SEVERIDADE } \\
\hline & Segurança & $\begin{array}{c}\text { Meio } \\
\text { Ambiente }\end{array}$ & $\begin{array}{l}\text { Parada não } \\
\text { planejada } \\
\text { do } \\
\text { equipamento } \\
\quad(m \text { in) }\end{array}$ & \begin{tabular}{|c|} 
Parada \\
planejada \\
do \\
equipame \\
nto \\
(min)
\end{tabular} & $\begin{array}{l}\text { Custo de } \\
\text { reparo da } \\
\text { falha } \\
\text { (milhares } \\
\text { R\$) }\end{array}$ & \\
\hline $1-2$ & Nenhum & Nenhum & $<10$ & $<30$ & $<5$ & $\begin{array}{l}\text { MARGINAL } \\
\text { Falha não teria efeito real no sistema. } \\
\text { O cliente provavelmente nem notaria a falha. }\end{array}$ \\
\hline 3 & Nenhum & Nenhum & 10 a 30 & 30 a 50 & 7 a 10 & $\begin{array}{l}\text { BAIXA } \\
\text { Provoca redução gradual de performance do produto e } \\
\text { surgimento gradual de ineficiência. } \\
\text { Cliente perceberá leves variações no desempenho do sistema, } \\
\text { mas não ficará insatisfeito com elas. }\end{array}$ \\
\hline 4 & Nenhum & Nenhum & 30 a 50 & 50 a 80 & 8 a 10 & MODERADA \\
\hline 5 & Nenhum & Nenhum & 50 a 80 & 80 a 120 & 11 a 30 & $\begin{array}{l}\text { Produto sofrerá uma degradaçáo progressiva. } \\
\text { Cliente perceberá razoável deterioracão no desempenho do }\end{array}$ \\
\hline 6 & Nenhum & Nenhum & 80 a 120 & 120 a 160 & 30 a 50 & sistema e ficará desconfortável e irritado com a falha. \\
\hline 7 & $\begin{array}{c}\text { Acidente } \\
\text { SPT }\end{array}$ & $\begin{array}{c}\text { Impacto médio } \\
\begin{array}{c}\text { Penalidades } \\
\text { legais }\end{array}\end{array}$ & 120 a 160 & 160 a 200 & 51 aa 70 & $\begin{array}{l}\text { ALTA } \\
\text { O sistema se torna inoperável. }\end{array}$ \\
\hline 8 & $\begin{array}{c}\text { Acidente } \\
\text { SPT }\end{array}$ & $\begin{array}{c}\text { Impacto médio } \\
\begin{array}{c}\text { Penalidades } \\
\text { legais }\end{array}\end{array}$ & 160 a 200 & 200 a 250 & 71 a 100 & $\begin{array}{l}\text { Alto grau de insatısfação do cliente. } \\
\text { A falha envolve riscos à segurança, ao meio ambiente ou à } \\
\text { requisitos legais. }\end{array}$ \\
\hline 9 & $\begin{array}{c}\text { Acidente } \\
\text { CPT }\end{array}$ & \begin{tabular}{|c|} 
Impacto grave \\
Penalidades \\
legais
\end{tabular} & 200 a 250 & 250 a 300 & $>100$ & MUITO ALTA \\
\hline 10 & Fatalidade & $\begin{array}{l}\text { Impacto grave } \\
\text { Penalidades } \\
\text { legais } \\
\text { Perda da } \\
\text { imagem }\end{array}$ & $>250$ & $>300$ & $>100$ & $\begin{array}{l}\text { O sistema se torna inoperável. } \\
\text { Alto grau de insatisfação do cliente. } \\
\text { A falha envolve riscos à segurança, ao meio ambiente ou à } \\
\text { requisitos legais. }\end{array}$ \\
\hline
\end{tabular}

Fonte: Próprio Autor (2018 
Quadro 03: Classificação dos níveis das ocorrências das falhas

\begin{tabular}{|c|c|c|}
\hline & \multicolumn{2}{|r|}{ Ocorrência } \\
\hline \multirow[b]{2}{*}{1 a 2} & 1 falha a cada & \\
\hline & 10 anos & $\begin{array}{c}\text { REMOTA } \\
\text { A falha é improvável, excepcional }\end{array}$ \\
\hline 3 a 4 & 3 anos & $\begin{array}{c}\text { PEQUENA } \\
\text { Relativamente poucas falhas }\end{array}$ \\
\hline 5 a 6 & 1 ano & $\begin{array}{l}\text { MODERADA } \\
\text { Falha ocasional, algumas vezes }\end{array}$ \\
\hline 7 a 8 & 3 meses & $\begin{array}{c}\text { ALTA } \\
\text { Falha frequente, repetitiva }\end{array}$ \\
\hline 9 a 10 & 1 mês & $\begin{array}{l}\text { MUITO ALTA - MENSAL } \\
\text { Inevitável, certamente ocorrerá a falh }\end{array}$ \\
\hline
\end{tabular}

Fonte: Próprio autor (2018)

Quadro 04: Classificação dos níveis de detecção das falhas

\begin{tabular}{|c|c|c|}
\hline & \multicolumn{2}{|r|}{ DETECÇÃO } \\
\hline & $\begin{array}{l}\text { Propabilidade } \\
\text { de detectar a } \\
\text { falha }\end{array}$ & $\begin{array}{l}\text { É possível detectar o defeito antes que vire } \\
\text { falha? } \\
\text { PIMS, inspeção, preditiva, supervisório (nivel } \\
\text { baixo, nivel alto), percepção do operador }\end{array}$ \\
\hline 1 a 2 & $100 \%$ & $\begin{array}{l}\text { MUITO ALTA } \\
\text { A falha será certamente detectada durante o } \\
\text { projeto/fabricação/montagem/operação. }\end{array}$ \\
\hline 3 a 4 & $90 \%$ & $\begin{array}{l}\text { ALTA } \\
\text { Boa chande de determinar a falha. } \\
\text { Em processo, ações corretivas são tomadas } \\
\text { em pelo menos } 90 \% \text { das vezes em que seus } \\
\text { parâmetros saem fora de controle }\end{array}$ \\
\hline 5 a 6 & $50 \%$ & $\begin{array}{l}\text { MODERADA } \\
50 \% \text { de chande de determinar a falha } \\
\text { Somente em } \underline{50 \%} \text { das vezes em que o } \\
\text { processo sai de controle são tomadas ações } \\
\text { corretivas }\end{array}$ \\
\hline 7 a 8 & $10 \%$ & $\begin{array}{l}\text { BAIXA } \\
\text { Não é provável que a falha seja detectável } \\
\text { Nível de controle muito baixo. }\end{array}$ \\
\hline 9 a 10 & $0 \%$ & $\begin{array}{l}\text { ABSOLUTAMENTE INDETECTÁVEL } \\
\text { A falha não será detectável, com certeza. }\end{array}$ \\
\hline
\end{tabular}

Fonte: Próprio autor (2018)

\subsection{SELEÇÃO DAS SUBUNIDADES CRÍTICAS}

O objetivo foi identificar as subunidades críticas que ao apresentarem uma falha terão um impacto maior sobre a função do sistema, os modos de falha que estarão em análise (gráfico 01). Ao decompor o sistema, foram analisados os parâmetros críticos de seus subsistemas, utilizando para critério de seleção o Diagrama de Pareto, descritos no 1.7.7.

Das 14 subunidades do equipamento, foram selecionados apenas um que apresentou um número crítico de falhas (tabela 03). 
Tabela 01: Matriz de criticidade

\begin{tabular}{|c|c|c|c|c|}
\hline \multicolumn{5}{|c|}{ EMPRESA X } \\
\hline \multicolumn{5}{|c|}{ Responsável: Equipe de elaboração Data da revisão: 01/02/2018 } \\
\hline EQUIPAMENTO & & $\mathbf{Y}$ & $\mathrm{x}$ & $\mathbf{z}$ \\
\hline SUB-UNIDADE & & $\begin{array}{l}\text { Desenrolador, } \\
\text { acionamento, } \\
\text { estampagem, corte, } \\
\text { alimentação, ejeção, } \\
\text { endireitamento, } \\
\text { lubrificação } \\
\end{array}$ & $\begin{array}{l}\text { Desenrolador, } \\
\text { acionamento, } \\
\text { estampagem, corte, } \\
\text { alimentação, ejeção, } \\
\text { endireitamento, } \\
\text { lubrificação } \\
\end{array}$ & $\begin{array}{l}\text { Translação ponte, translação } \\
\text { carro, elevação }\end{array}$ \\
\hline FUNÇÃO PRIMÁRIA & & Fabricar pregos & Fabricar pregos & $\begin{array}{l}\text { Movimentação intermediário, } \\
\text { retirada de produção }\end{array}$ \\
\hline & $\mathbf{P}$ & & & \\
\hline Influência na produção $(0,3$ ou 5$)$ & 10 & 5 & 5 & 0 \\
\hline $\begin{array}{c}\text { Influência na qualidade do } \\
\text { produto }(0,3 \text { ou } 5)\end{array}$ & 10 & 5 & 5 & 0 \\
\hline $\begin{array}{c}\text { Influência no meio ambiente } \\
(0,3 \text { ou } 5)\end{array}$ & 10 & 0 & 0 & 0 \\
\hline $\begin{array}{c}\text { Influência na segurança pessoal } \\
(0,3 \text { ou } 5)\end{array}$ & 10 & 0 & 0 & 5 \\
\hline Existência de stand by $(0,3$ ou & 8 & 5 & 5 & 3 \\
\hline $\begin{array}{c}\text { Ocorrência de falhas } \\
\text { (Confiabilidade do Item) }(0,3 \text { ou }\end{array}$ & 10 & 5 & 5 & 3 \\
\hline \begin{tabular}{|c}
$\begin{array}{c}\text { Recupe ração da produção após } \\
\text { reparo }(0,3 \text { ou } 5)\end{array}$ \\
\end{tabular} & 8 & 3 & 3 & 0 \\
\hline $\begin{array}{c}\text { Influência no cus to da produção } \\
\left(\begin{array}{l}0 \text { ou } 5)\end{array}\right.\end{array}$ & 8 & 3 & 5 & 0 \\
\hline Fator de Correção $(0,2$ a 1,0) & & 0,8 & 0,8 & 0,8 \\
\hline $\begin{array}{c}\begin{array}{c}\text { A produção fim é interrompida } \\
\text { por }+24 \mathrm{~h}\end{array} \\
\end{array}$ & & $\mathrm{~N}$ & $\mathrm{~N}$ & $\mathrm{~N}$ \\
\hline Pontuação Final & & 190,4 & 203,2 & 83,2 \\
\hline Criticidade & & B & $\bar{A}$ & C \\
\hline
\end{tabular}

Fonte: Próprio autor (2018)

Tabela 02: Análise de criticidade

\begin{tabular}{|c|c|c|c|}
\hline IIEM & $\begin{array}{l}\text { FATOR DE } \\
\text { DAIHA }\end{array}$ & PASO & CRITÉRIO \\
\hline \multirow{3}{*}{1} & \multirow{3}{*}{$\begin{array}{l}\text { Influênciana } \\
\text { Produção }\end{array}$} & \multirow{3}{*}{10} & Não para a produção da unidade operacional. \\
\hline & & & $\begin{array}{l}\text { A feta a produção da unidade operacional,porém s em afetar a produção da } \\
\text { planta }\end{array}$ \\
\hline & & & $\begin{array}{l}\text { Afeta a produção da unidade operacional, afetando o plano de produção } \\
\text { da planta. }\end{array}$ \\
\hline \multirow{3}{*}{2} & \multirow{3}{*}{\begin{tabular}{|c|} 
Influência na \\
qualidade do \\
produto
\end{tabular}} & \multirow{3}{*}{10} & Não influi na qualidade do produto da Unidade operacional. \\
\hline & & & In flui na qualidade do produto da Unidade operacional. \\
\hline & & & Influ i na qualidade do produto da planta. \\
\hline \multirow{3}{*}{3} & \multirow{3}{*}{$\begin{array}{l}\text { Influência no } \\
\text { meio ambiente }\end{array}$} & \multirow{3}{*}{10} & Não influi no meio ambiente. \\
\hline & & & $\begin{array}{l}\text { A falha provoca impacto médio no meio ambiente, sujeito a penalidades } \\
\text { legais. }\end{array}$ \\
\hline & & & $\begin{array}{l}\text { A falha provoca impacto grave no meio ambiente com penalidade legale/ } \\
\text { ou perda de imagem. }\end{array}$ \\
\hline \multirow{3}{*}{4} & \multirow{3}{*}{$\begin{array}{c}\text { Influência na } \\
\text { segurança } \\
\text { pessoal }\end{array}$} & \multirow{3}{*}{10} & Não influina segurança pessoal. \\
\hline & & & Exis te ris co de acidente pessoal em caso de fallha. \\
\hline & & & Exis te alto potencial de acidente pessoal,em caso de falha. \\
\hline \multirow{3}{*}{5} & \multirow{3}{*}{$\begin{array}{l}\text { Existência de } \\
\text { stand by }\end{array}$} & \multirow{3}{*}{8} & Possui stand by ou não necessita (não afeta a produção). \\
\hline & & & A feta a produção da unidade operacional e não possui stand by. \\
\hline & & & A feta a produção da planta e não possui stand by. \\
\hline \multirow{3}{*}{6} & \multirow{3}{*}{$\begin{array}{c}\text { Ocomência de } \\
\text { falhas } \\
\text { (confiabilidade } \\
\text { do item) }\end{array}$} & \multirow{3}{*}{8} & $\begin{array}{l}\text { Alta confiabilidade, normalmente não há ocorrência de falhas dentro de } \\
75 \text { dias. }\end{array}$ \\
\hline & & & $\begin{array}{l}\text { Média confiabilidade, há ocorrência de falhas esporádicas e /ou aleatórias } \\
\text { entre } 30 \text { e } 75 \text { dias. }\end{array}$ \\
\hline & & & $\begin{array}{l}\text { Baixa confiabilidade, ocorrência freqüente de fallhas. Falas dentro de } 30 \\
\text { dias. }\end{array}$ \\
\hline \multirow{3}{*}{7} & \multirow{3}{*}{$\begin{array}{l}\text { Recuperação } \\
\text { da produção } \\
\text { após reparo }\end{array}$} & \multirow{3}{*}{8} & Imediata. \\
\hline & & & $\begin{array}{l}\text { Recuperação rápida das condições normais de produção após reparo } \\
(<8 \text { horas })\end{array}$ \\
\hline & & & $\begin{array}{l}\text { Recuperação demorada das condições normais de operação após reparo } \\
(>\text { hororas). }\end{array}$ \\
\hline \multirow[b]{2}{*}{8} & \multirow{2}{*}{$\begin{array}{c}\text { Influência no } \\
\text { custo da } \\
\text { produção }\end{array}$} & \multirow[b]{2}{*}{8} & Não afeta o cus to de produção da planta \\
\hline & & & A feta o cus to de produção da planta(tubarão completa- lucro cres cente) \\
\hline
\end{tabular}

Fonte: Próprio autor (2018) 
Gráfico 01: Diagrama de Pareto

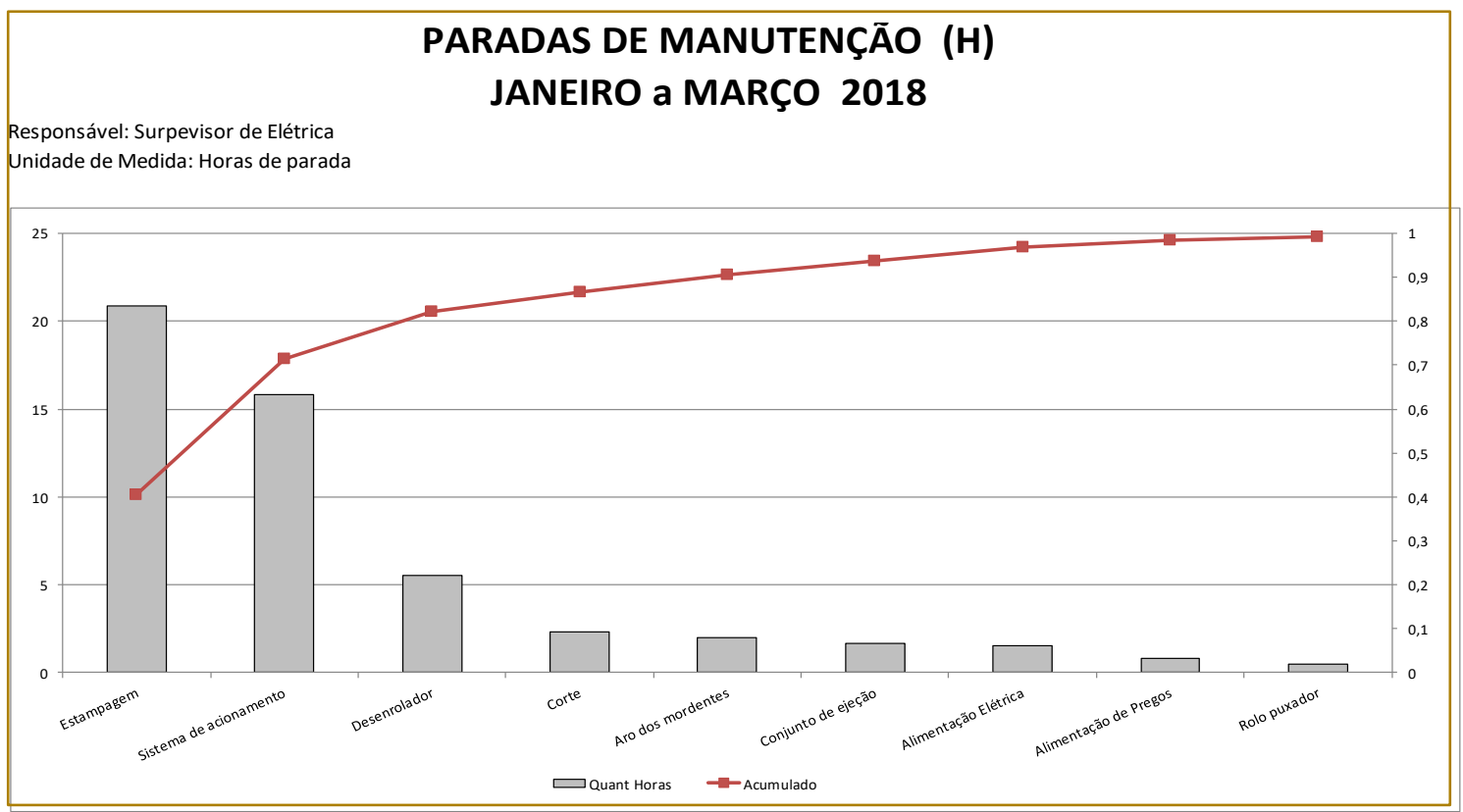

Fonte: Próprio autor (2018)

Tabela 03: Dados encontrados diagrama de Pareto

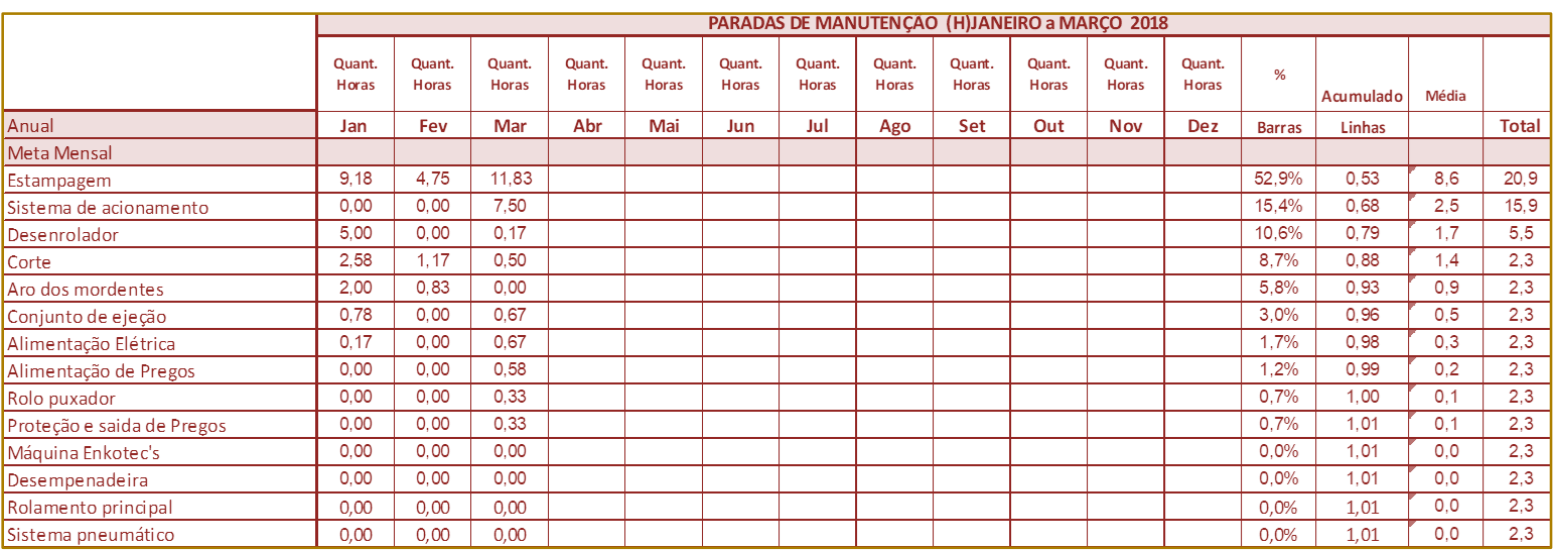

Fonte: Próprio autor (2018)

\section{6 - ANÁLISE DO FMEA}

Com a análise das funções e falhas funcionais com base no contexto operacional, foi identificado uma função principal (quadro 01), e três falhas funcionais (i) Navalha quebrada ou desgastada, (ii) Mordentes quebrados ou desgastados (iii) baixa pressão entre os mordentes (tabela 04). 
Tabela 04: Elaboração do FMEA

\begin{tabular}{|c|c|c|c|c|c|c|c|c|c|c|c|}
\hline \multicolumn{12}{|c|}{$\begin{array}{l}\text { ESTUDO E DESENVOLVIMENTO DE PLANOS DE MANUTENÇĀO } \\
\text { RCM / MCC - MANUTENÇÃO CENTRADA NA CONFIABILIDADE }\end{array}$} \\
\hline UNIDADE & \multicolumn{5}{|c|}{ EMPRESAX } & & EQUIPAMENTO: & \multicolumn{3}{|c|}{$\mathbf{X}$} & \\
\hline $\begin{array}{l}\text { SUB- } \\
\text { UNIDADE: }\end{array}$ & \multicolumn{5}{|c|}{ ESTAMPAGEM } & & RESPONSÁVEIS: & \multicolumn{3}{|c|}{ Equipe de atuação } & \\
\hline FUNÇÃO & \multicolumn{5}{|c|}{ MÁQUINA DE FABRICAR PREGOS } & & TA DA ELABORAÇÃO: & \multicolumn{3}{|c|}{$02 / 01 / 2018$} & \\
\hline Item & Função & Falha Funcional & $\begin{array}{c}\text { Modo de } \\
\text { falha }\end{array}$ & Efeito da falha & RPN & $\phi$ & & SEV & oc & DET & Causa \\
\hline \multirow{7}{*}{1} & \multirow{21}{*}{ 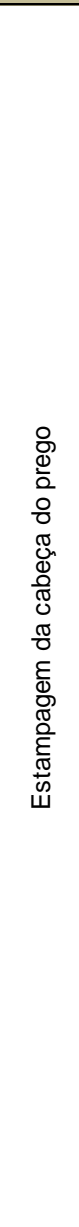 } & \multirow{14}{*}{ 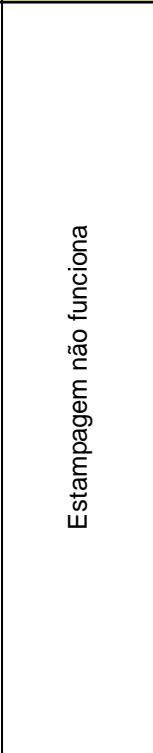 } & \multirow{7}{*}{ 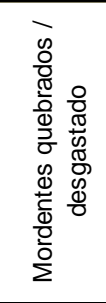 } & \multirow{7}{*}{ 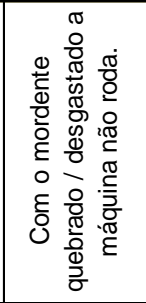 } & \multirow{7}{*}{126} & \multirow{7}{*}{1} & & \multirow{7}{*}{7} & \multirow{7}{*}{6} & \multirow{7}{*}{3} & Falha operacional \\
\hline & & & & & & & & & & & $\begin{array}{l}\text { Falha operacional na } \\
\text { regulagem }\end{array}$ \\
\hline & & & & & & & & & & & Falha operacional \\
\hline & & & & & & & & & & & Falha operacional \\
\hline & & & & & & & & & & & Falha técnica \\
\hline & & & & & & & & & & & Parafuso mal torqueado \\
\hline & & & & & & & & & & & $\begin{array}{l}\text { Cunha dos mordentes do } \\
\text { parafuso mal torqueado }\end{array}$ \\
\hline \multirow{7}{*}{2} & & & & & & & & & & & Falha técnica \\
\hline & & & & o. 들 & & & & & & & \begin{tabular}{|l|} 
Folga na dobradiça \\
\end{tabular} \\
\hline & & & 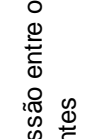 & 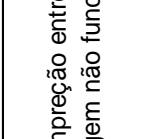 & & & & & & & $\begin{array}{l}\text { Afrouxamento das porcas } \\
\text { de fixação do conjunto de } \\
\text { compressão de fechamento } \\
\text { inferior }\end{array}$ \\
\hline & & & 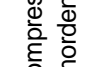 & $\begin{array}{l}\varepsilon \\
0 \\
0 \\
0 \\
0\end{array}$ & 147 & 1 & & 7 & 3 & 7 & $\begin{array}{l}\text { Falha operacional no } \\
\text { fechamento dos aros }\end{array}$ \\
\hline & & & $\begin{array}{l}O \mathcal{O} E \\
0 \\
0\end{array}$ & 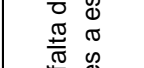 & & & & & & & $\begin{array}{l}\text { Falha operacional na } \\
\text { regulagem }\end{array}$ \\
\hline & & & $\stackrel{\sigma}{ \pm}$ & $\pi \stackrel{0}{ \pm}$ & & & & & & & Parafuso mal torqueado \\
\hline & & & & రิ & & & & & & & $\begin{array}{l}\text { Cunha dos mordentes do } \\
\text { parafuso mal torqueado }\end{array}$ \\
\hline \multirow{7}{*}{3} & & \multirow{7}{*}{ 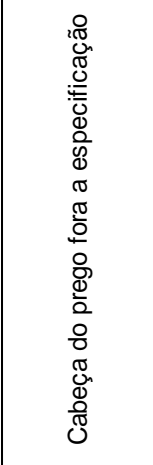 } & \multirow{7}{*}{ 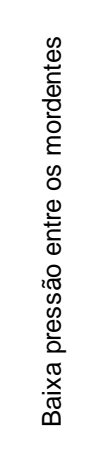 } & \multirow{7}{*}{ 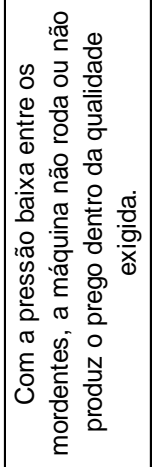 } & \multirow{7}{*}{140} & \multirow{7}{*}{1} & & \multirow{7}{*}{7} & \multirow{7}{*}{5} & \multirow{7}{*}{4} & $\begin{array}{l}\text { Folga na dobradiça da } \\
\text { porta principal }\end{array}$ \\
\hline & & & & & & & & & & & Falha operacional \\
\hline & & & & & & & & & & & $\begin{array}{l}\text { Afrouxamento das porcas } \\
\text { de fixação do conjunto de } \\
\text { compressão de fechamento } \\
\text { inferior }\end{array}$ \\
\hline & & & & & & & & & & & Falha operacional \\
\hline & & & & & & & & & & & $\begin{array}{l}\text { Falha operacional na } \\
\text { regulagem }\end{array}$ \\
\hline & & & & & & & & & & & Parafuso mal torqueado \\
\hline & & & & & & & & & & & $\begin{array}{l}\text { Cunha dos mordentes do } \\
\text { parafuso mal torqueado }\end{array}$ \\
\hline
\end{tabular}

Fonte: Próprio autor (2018) 
Tabela 05: Análise dos Cinco Porquês

\begin{tabular}{|c|c|c|c|c|c|c|}
\hline \multicolumn{7}{|c|}{$\begin{array}{l}\text { ESTUDO E DESENVOLVIMENTO DE PLANOS DE MANUTENÇÃO } \\
\text { RCM / MCC - MANUTENÇÃO CENTRADA NA CONFIABILIDADE }\end{array}$} \\
\hline UNIDADE & \multicolumn{4}{|l|}{ EMPRESAX } & EQUIPAMENTO: & $\mathbf{x}$ \\
\hline $\begin{array}{l}\text { SUB- } \\
\text { UNIDADE: }\end{array}$ & \multicolumn{4}{|c|}{ ESTAMPAGEM } & RESPONSÁVEIS: & Equipe de atuação \\
\hline FUNÇão & \multicolumn{4}{|c|}{ MÁQUINA DE FABRICAR PREGOS } & DATA DA ELABORAÇÃO: & $02 / 01 / 2018$ \\
\hline \multirow{22}{*}{ 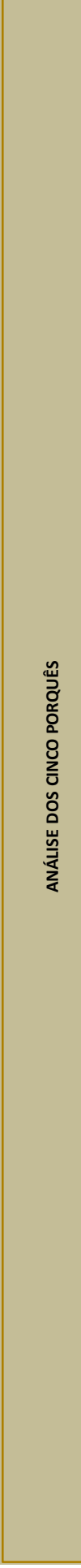 } & $\begin{array}{l}\text { Modo de } \\
\text { falha }\end{array}$ & Efeito da falha & Por que? & Por que? & Por que? & Por que? \\
\hline & \multirow{7}{*}{$\begin{array}{l}0 \\
0 \\
\frac{0}{0} \\
0 \\
0 \\
0 \\
0 \\
0 \\
0 \\
0 \\
0 \\
0 \\
0 \\
0 \\
0 \\
0 \\
0 \\
0 \\
0 \\
0 \\
0 \\
0 \\
0 \\
0 \\
0 \\
\Sigma\end{array}$} & \multirow{7}{*}{ 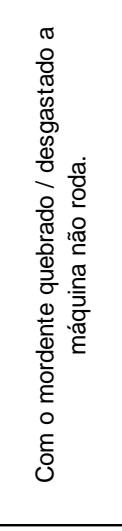 } & $\begin{array}{l}\text { Fechamento do aro dos } \\
\text { mordentes fora do ponto }\end{array}$ & Falha operacional & & \\
\hline & & & $\begin{array}{l}\text { Prego solto entre os } \\
\text { mordentes }\end{array}$ & \begin{tabular}{|c|} 
Prego não foi ejetado e \\
caiu entre os aros
\end{tabular} & $\begin{array}{l}\text { Falha operacional na } \\
\text { regulagem }\end{array}$ & \\
\hline & & & \multirow{3}{*}{$\begin{array}{l}\text { Quebra da presilha } \\
\text { (Bloco carregador) }\end{array}$} & $\begin{array}{l}\text { Fechamento do aro dos } \\
\text { mordentes fora do ponto }\end{array}$ & Falha operacional & \\
\hline & & & & \multirow{2}{*}{$\begin{array}{c}\text { Parafuso de fixação da } \\
\text { presilha quebrado ou } \\
\text { mal fixado }\end{array}$} & $\begin{array}{l}\text { Erro na regulagem de } \\
\text { fechamento da pinça }\end{array}$ & Falha operacional \\
\hline & & & & & Falha técnica & \\
\hline & & & \multirow[b]{2}{*}{ Mordente mal fixado } & $\begin{array}{l}\text { Cunha dos mordentes } \\
\text { com parafuso quebrado }\end{array}$ & Parafuso mal torqueado & \\
\hline & & & & $\begin{array}{c}\text { Cunha dos mordentes } \\
\text { com parafuso mal } \\
\text { torqueado }\end{array}$ & & \\
\hline & \multirow{7}{*}{ 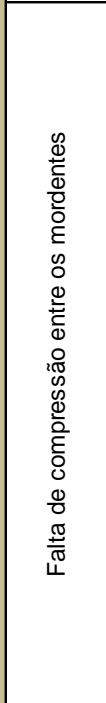 } & \multirow{7}{*}{ 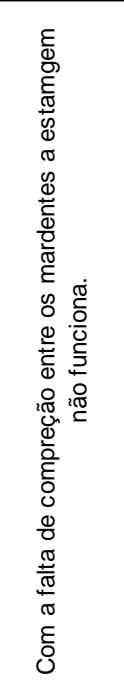 } & $\begin{array}{c}\text { Falha na regulagem de } \\
\text { compressão }\end{array}$ & Falha técnica & & \\
\hline & & & $\begin{array}{c}\text { Rosca do eixo de } \\
\text { fechamento inferior } \\
\text { espanado }\end{array}$ & Folga na dobradiça & & \\
\hline & & & $\begin{array}{c}\text { Afrouxamento das } \\
\text { porcas de fixação do } \\
\text { conjunto de } \\
\text { compressão de } \\
\text { fechamento inferior }\end{array}$ & & & \\
\hline & & & $\begin{array}{l}\text { Fechamento do aro dos } \\
\text { mordentes fora do ponto }\end{array}$ & $\begin{array}{l}\text { Falha operacional no } \\
\text { fechamento dos aros }\end{array}$ & & \\
\hline & & & $\begin{array}{l}\text { Prego solto entre os } \\
\text { mordentes }\end{array}$ & \begin{tabular}{|c|}
$\begin{array}{c}\text { Prego não foi ejetado e } \\
\text { caiu entre os aros }\end{array}$ \\
\end{tabular} & $\begin{array}{l}\text { Falha operacional na } \\
\text { regulagem }\end{array}$ & \\
\hline & & & \multirow{2}{*}{ Mordente mal fixado } & $\begin{array}{l}\text { Cunha dos mordentes } \\
\text { com parafuso quebrado }\end{array}$ & Parafuso mal torqueado & \\
\hline & & & & $\begin{array}{c}\text { Cunha dos mordentes } \\
\text { com parafuso mal } \\
\text { torqueado }\end{array}$ & & \\
\hline & \multirow{7}{*}{ 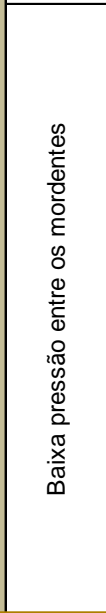 } & \multirow{7}{*}{ 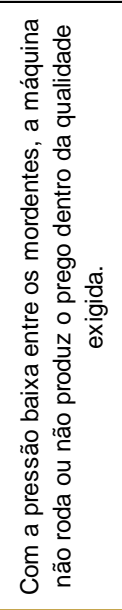 } & \multirow{2}{*}{$\begin{array}{c}\text { Porcas do eixo de } \\
\text { fechamento inferior mal } \\
\text { apertada }\end{array}$} & $\begin{array}{l}\text { Porca / eixo com a } \\
\text { rosca espanada }\end{array}$ & $\begin{array}{c}\text { Folga na dobradiça da } \\
\text { porta principal }\end{array}$ & \\
\hline & & & & Falha operacional & & \\
\hline & & & $\begin{array}{c}\text { Afrouxamento das } \\
\text { porcas de fixação do } \\
\text { conjunto de } \\
\text { compressão de } \\
\text { fechamento inferior }\end{array}$ & & & \\
\hline & & & $\begin{array}{l}\text { Fechamento do aro dos } \\
\text { mordentes fora do ponto }\end{array}$ & Falha operacional & & \\
\hline & & & $\begin{array}{c}\text { Prego solto entre os } \\
\text { mordentes }\end{array}$ & $\begin{array}{c}\text { Prego não foi ejetado e } \\
\text { caiu entre os aros }\end{array}$ & $\begin{array}{c}\text { Falha operacional na } \\
\text { regulagem }\end{array}$ & \\
\hline & & & \multirow[b]{2}{*}{ Mordente mal fixado } & \begin{tabular}{|c|} 
Cunha dos mordentes \\
com parafuso quebrado
\end{tabular} & Parafuso mal torqueado & \\
\hline & & & & $\begin{array}{c}\text { Cunha dos mordentes } \\
\text { com parafuso mal } \\
\text { torqueado }\end{array}$ & & \\
\hline
\end{tabular}

Fonte: A empresa $\mathrm{X}$ 
Tabela 06: Propostas de Melhorias

\begin{tabular}{|c|c|c|c|c|c|c|}
\hline \multicolumn{7}{|c|}{$\begin{array}{l}\text { ESTUDO E DESENVOLVIMENTO DE PLANOS DE MANUTENÇÃO } \\
\text { RCM / MCC - MANUTENÇÃO CENTRADA NA CONFIABILIDADE }\end{array}$} \\
\hline UNIDADE & \multicolumn{4}{|l|}{ EMPRESAX } & EQUIPAMENTO: & $\mathbf{x}$ \\
\hline $\begin{array}{ll}\text { SUB- } \\
\text { UNIDADE: }\end{array}$ & \multicolumn{4}{|c|}{ ESTAMPAGEM } & RESPONSÁVEIS: & Equipe de atuação \\
\hline FUNÇÃo & \multicolumn{4}{|c|}{ MÁQUINA DE FABRICAR PREGOS } & DATA DA ELABORAÇÃO: & $02 / 01 / 2018$ \\
\hline \multirow{22}{*}{ 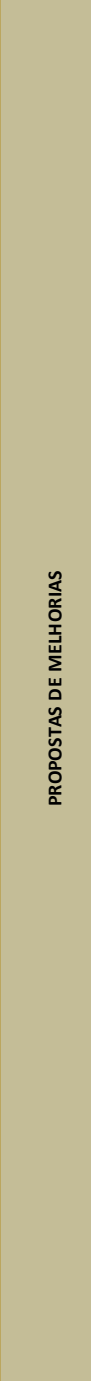 } & $\begin{array}{c}\text { Modo de } \\
\text { falha }\end{array}$ & Efeito da falha & Causa & Tarefa Proposta & & \\
\hline & \multirow{7}{*}{ 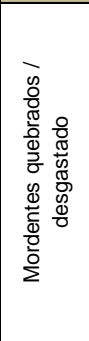 } & \multirow{7}{*}{ 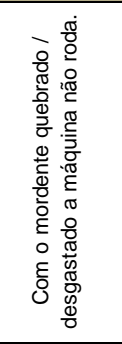 } & Falha operacional & \multicolumn{3}{|c|}{$\begin{array}{l}\text { Procedimentar posicionamentos correto dos aros antes do fechamento. } \\
\text { Garantir mordentes reservas. }\end{array}$} \\
\hline & & & Falha operacional na regulagem & \multicolumn{3}{|c|}{ Procedimentar a regulagem do sistema de ejeção } \\
\hline & & & Falha operacional & \multicolumn{3}{|c|}{$\begin{array}{l}\text { Procedimentar posicionamentos correto dos aros antes do fechamento. } \\
\text { Garantir mordentes reservas. }\end{array}$} \\
\hline & & & Falha operacional & \multicolumn{3}{|c|}{ Procedimentar regulagem da régua de fechamento da pinça. } \\
\hline & & & Falha técnica & \multicolumn{3}{|c|}{ Garantir parafuso e presilhas reservas. } \\
\hline & & & Parafuso mal torqueado & \multicolumn{3}{|c|}{ Procedimetar troca de mordentes } \\
\hline & & & $\begin{array}{l}\text { Cunha dos mordentes com } \\
\text { parafuso mal torqueado }\end{array}$ & \multicolumn{3}{|c|}{$\begin{array}{l}\text { Procedimetar troca de mordentes. } \\
\text { Garantir cunha dos mordentes reserva. }\end{array}$} \\
\hline & \multirow{7}{*}{ 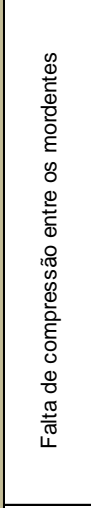 } & \multirow{7}{*}{ 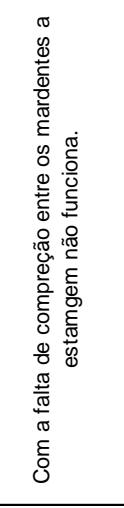 } & Falha técnica & \multicolumn{3}{|c|}{$\begin{array}{l}\text { Comprar aparelho de medição da compressão entre os rolamentos principais. } \\
\text { Procedimentar e treinar regulagem da compressão. }\end{array}$} \\
\hline & & & Folga na dobradiça & \multicolumn{3}{|c|}{$\begin{array}{l}\text { Garantir dobradiça recuperada reserva. } \\
\text { Realiza inspeção nas preventivas }\end{array}$} \\
\hline & & & $\begin{array}{l}\text { Afrouxamento das porcas de } \\
\text { fixação do conjunto de } \\
\text { compressão de fechamento } \\
\text { inferior }\end{array}$ & \multicolumn{3}{|c|}{ Inspecionar preventivamente a fixação do conjunto. } \\
\hline & & & $\begin{array}{c}\text { Falha operacional no fechamento } \\
\text { dos aros }\end{array}$ & \multicolumn{3}{|c|}{$\begin{array}{l}\text { Procedimentar posicionamentos correto dos aros antes do fechamento. } \\
\text { Garantir mordentes reservas. }\end{array}$} \\
\hline & & & Falha operacional na regulagem & \multicolumn{3}{|c|}{ Procedimentar a regulagem do sistema de ejeção } \\
\hline & & & Parafuso mal torqueado & \multicolumn{3}{|c|}{ Procedimetar troca de mordentes } \\
\hline & & & $\begin{array}{l}\text { Cunha dos mordentes com } \\
\text { parafuso mal torqueado }\end{array}$ & \multicolumn{3}{|c|}{$\begin{array}{c}\text { Procedimetar troca de mordentes. } \\
\text { Garantir cunha dos mordentes reserva. } \\
\text { Garantir parafuso reserva. }\end{array}$} \\
\hline & \multirow{7}{*}{ 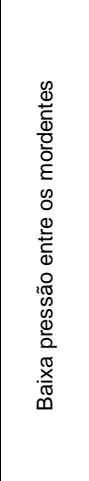 } & \multirow{7}{*}{ 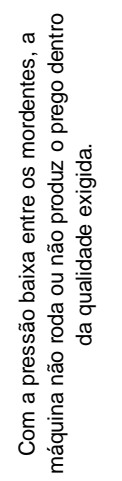 } & $\begin{array}{l}\text { Folga na dobradiça da porta } \\
\text { principal }\end{array}$ & \multicolumn{3}{|c|}{$\begin{array}{l}\text { Garantir dobradiça recuperada reserva. } \\
\text { Realiza inspeção nas preventivas }\end{array}$} \\
\hline & & & Falha operacional & \multicolumn{3}{|c|}{$\begin{array}{l}\text { Procedimentar posicionamentos correto dos aros antes do fechamento. } \\
\text { Garantir mordentes reservas. }\end{array}$} \\
\hline & & & $\begin{array}{l}\text { Afrouxamento das porcas de } \\
\text { fixação do conjunto de } \\
\text { compressão de fechamento } \\
\text { inferior }\end{array}$ & \multicolumn{3}{|c|}{ Inspecionar preventivamente a fixação do conjunto. } \\
\hline & & & Falha operacional & \multicolumn{3}{|c|}{$\begin{array}{l}\text { Procedimentar posicionamentos correto dos aros antes do fechamento. } \\
\text { Garantir mordentes reservas. }\end{array}$} \\
\hline & & & Falha operacional na regulagem & \multicolumn{3}{|c|}{ Procedimentar a regulagem do sistema de ejeção } \\
\hline & & & Parafuso mal torqueado & Procedime & tar troca de mordent & \\
\hline & & & $\begin{array}{l}\text { Cunha dos mordentes com } \\
\text { parafuso mal torqueado }\end{array}$ & $\begin{array}{r}\text { Procedime } \\
\text { Garantir cunt } \\
\text { Garant }\end{array}$ & $\begin{array}{l}\text { tar troca de mordent } \\
\text { a dos mordentes res } \\
\text { ir parafuso reserva. }\end{array}$ & \\
\hline
\end{tabular}

Fonte: Próprio autor (2018)

\section{7 -PROCESSO DE ATUALIZAÇÃO E MELHORIA CONTÍNUA}

Após a implementação das atividades de melhorias que foram realizadas foi possível identificar que os principais problemas encontrados no processo de estampagem do prego a grande parte deles estavam relacionados à falha técnica e operacional. $\mathrm{A}$ capacitação dos mesmos irá permitir uma melhora no processo de fabricação uma vez que os mesmos terão informações sobre quais ações e padrões deverão ser seguidos.
O processo de fabricação de pregos será monitorado para comprovar o resultado da análise e o número de ocorrências das falhas relacionadas ao sistema de estampagem do prego também será monitorado e através destes dados serão realizadas melhorias na análise do RCM.

\section{CONCLUSÃO}

O resultado da pesquisa irá demonstrar que o estudo teórico e as recomendações para um gerenciamento ideal não precisam ser apenas 
um sonho, que podem ser discutidos e implementados dentro da organização. Mesmo sabendo das dificuldades que encontraria no caminho, a empresa decidiu implementar a metodologia do RCM com o intuito de estabelecer pontos chaves, que se seguidos, a levará a uma excelência organizacional, através da melhoraria em seus resultados operacionais e de manutenção.

Durante a implementação desta análise, a revisão bibliográfica ressaltou etapas essenciais para garantir a concretização dos objetivos propostos pela metodologia do RCM, podendo ser consultada em futuras aplicações e servindo de projeto piloto para a implementação em demais equipamentos críticos. Outros itens possuem oportunidades claras de melhoria, e os elaboradores estão cientes disso, e serão sim analisados posteriormente, mas dependem de uma maior criticidade no processo de operação.

No mês em que foi implementado o processo de estampagem apresentava uma média de 8,6 horas de parada por mês, o que representa um turno de perda de produção (31 toneladas de prego por turno). Com base nestes resultados espera-se encontrar, com a implementação do RCM, uma redução nas paradas de 8,6 horas para3,0 horas

\section{REFERÊNCIAS}

[1] BELOHLAVEK, P. Como manejar problemas complexos: Uma abordagem ontológica unicista. Blue EagleGroup, 2006.

[2] CASTELLA, Marco César. Análise crítica da área de manutenção em uma empresa brasileira de geração de energia elétrica. 2001. 152 f. Dissertação (mestrado em Engenharia de Produção) - Universidade Federal de Santa Catarina, 2001

[3] FILHO, G. B. Auditoria em Manutenção. In: VIII Congresso de Manutenção Semapi. 5... 2003. São Paulo. Anais.São Paulo: SEMAPI, 2003.

[4] GAITHER, Norman. FRAZIER. Administração da Produção e Operações. São Paulo. Pioneira,2001.

[5] HEADQUARTERS.Failure Modes, Effects and Criticality Analyses (FMECA) for Command, Control, Communications, Computer, Intelligence, Surveillance, and Reconnaissance (C4ISR) Facilities.Technical Manual (TM 5-698-4). Departmentof the Army. Washington, DC, 2006. média/mês, uma vez que as principais falhas são causadas por falha humana e estes serão capacitados adequadamente e incentivados a propor melhorias.

Em uma análise geral do trabalho, pode-se verificar a consolidação da metodologia do FMEA no quesito de análise das funções, falhas e propostas de melhorias. Todas as etapas de análises da metodologia precisaram ser realizadas por profissional que possuem um alto nível de conhecimento do equipamento X. A utilização do diagrama de Pareto, Matriz de criticidade mostraram-se eficazes na identificação das falhas, sem a necessidade de ferramentas complexas e que com o processo de melhoria contínua será possível propor melhorias futuras.

Os pontos apresentados no decorrer do trabalho nos levam a enxergar que as mudanças no paradigma relacionados à manutenção e operação são necessárias para um aumento nos indicadores de disponibilidade e consequentemente no aumento da produção. É evidente o interesse das empresas em evoluir, buscando desenvolver setores de produção cada vez mais confiantes, em cenários competitivos eles certamente farão grande diferença e determinarão a continuidade da organização.

[6] LEAL, F.; PINHO, A. F.; ALMEIDA, D. A. Análise de Falhas Através da Aplicação do FMEA e da Teoria Grey. Disponível em: <http://revistas.utfpr.edu.br/pg/index.php/revistagi/ article/view/131/128>. Acesso em: 20Mai 2018.

[7] MIRANDA, Fernando Silveira Melo Plentz, A mudança no paradigma econômico, a Revolução Industrial e a Posição do Direito do Trabalho, 2012.

[8] MOUBRAY, J. Reliability-centered maintenance: second edition. 2ª ${ }^{-}$ed. New York: Industrial Press Inc., 1997

[9] MUASSAB, J. R. Gerenciamento da Manutenção na Indústria Automobilística, Taubaté, 2002. Monografia - Universidade de Taubaté.

[10] NETO, Teófilo Cortizo Moreira, A história da evolução do sistema de gestão de manutenção, Disponível em: https://www.webartigos.com/artigos/a-historia-daevolucao-do-sistema-de-gestao-demanutencao/75650/. Acesso em: 20 Mai. 2018

[11] OTANI, M.; MACHADO, W. V. A proposta de desenvolvimento de gestão da manutenção 
industrial na busca da excelência ou classe mundial. Revista Gestão Industrial. Vol.4, n.2, 2008.

[12] PINTO, Alan K., XAVIER, Júlio A. N. Manutenção Função Estratégica, Rio de Janeiro, Qualitymarck Ed., 2001.

[13] SOUZA, S. S.; LIMA, C. R. C. Manutenção Centrada em Confiabilidade como Ferramenta Estratégica. In: XXIII Encontro Nac. de Eng. de Produção, 2003, Ouro Preto - MG.

[14] TAVARES, Lourival A. Administração Moderna da Manutenção, Rio de Janeiro, Novo Pólo Publicações e Assessoria Ltda, 1999.
[15] VERGARA, S. C.; Projetos e relatórios de pesquisa científica em administração. 6 ${ }^{\underline{a}}$ edição. São Paulo: Atlas, 2005. 94 p.

[16] VIANA, H. R. G. PCM, Planejamento e controle de manutenção. Rio de Janeiro: Quallymark, 2002.

[17] XENOS, Harilaus G. Gerenciando a Manutenção Produtiva: O caminho para Eliminar Falhas nos Equipamentos e Aumentar a Produtividade. Belo Horizonte: Editora deDesenvolvimento Gerencial, 1998. 


\section{Gapítulo 12}

\section{ANÁLISE DO DESPERDÍCIO EM UM CANTEIRO DE OBRAS NA CIDADE DE ARAGUAÍNA-TO}

\section{Jhony Carlos Lucena Cardoso}

Denes de Paula Alves Sousa

\section{Mariana Matos Arantes}

Resumo: O objetivo desse estudo tem como foco entender quais os fatores que levam o elevado índice de desperdício de material. Com isso foi feito levantamento de pesquisa teórica para compreender e submeter o estudo a seguir tais informações adquiridas. Foi utilizada a estratégia de pesquisa baseada em 3 (três) obras de uma mesma construtora, onde foi observado alguns desperdícios, tal como o armazenamento de areia, onde não tinha repartição entra ela e a brita causando mistura e retrabalho na hora de separa-las, o deslocamento até o canteiro central para buscar ferramentas que não se encontravam no local na hora da necessidade, mau planejamento no projeto que levou a paralização de uma parte da construção.

Palavras chave: Desperdícios; Estratégia; Armazenamento; Planejamento; Necessidade. 


\section{INTRODUÇÃO}

A construção civil é um dos ramos que está no topo na cadeia econômica do País, com altíssimo grau de empregabilidade, além disso, contribui para o desenvolvimento da produção nacional, entretanto apresentando elevado índice de desperdício, tais como, organização das matérias primas em um canteiro de obras, distribuição no processo produtivo, layout, localização das máquinas, distância entre cada parte do processo. No ramo da construção civil há elevado índice de desperdícios, consequentemente influenciando diretamente no aumento de custo da produção.

\section{REVISÃO BIBLIOGRÁFICA}

\subsection{HISTÓRIA DA CONSTRUÇÃO CIVIL}

Segundo BORGES (2010), a construção civil entrelaça com o contexto histórico dos seres humanos desde os princípios, o homem usa essa atividade como forma de transformações do seu ambiente natural, meio de sobrevivência no planeta, modificando o ambiente através dos tempos. Para HALPIN (2004), muitos desses mecanismos antigos, como as pirâmides de Egito, Roma antiga, Athenas se tornam impressionantes mesmo do ponto de vista dos padrões modernos, seus formatos tridimensionais, com uso de poucas tecnologias, revolucionou toda nossa história, extraordinário monumentos que até os dias atuais são fontes de inspirações.

O STEEL FRAME consiste em um método construtivo formulado em perfis de aço galvanizado estruturado a frio, ele é projetado para suportar as cargas distribuídas na edificação, trabalhando junto aos demais mecanismos de distribuição em um edifício (MORIKAWA 2006).

De acordo com MOLINA (2012), o WOOD FRAME, podemos definir como um sistema construtivo industrializado, resistente e com aspectos estruturais de madeira originária de reflorestamentos, tratada, elaborado de painéis de pisos, paredes e telhados que são combinados ou revestido de outros materiais, possibilitando o aumento do conforto térmico e acústico e protegendo a edificação.

Os métodos construtivos em STEEL FRAME e WOOD FRAME, são processos que são utilizados na construção civil que substituirão os processos mais artesanais. Além disso, os sistemas apresentam um desenvolvimento tecnológico que contribuir para a sustentabilidade e o melhoramento de todo o processo.

Mostra-se de que independente do porte da obra um canteiro de obras possibilita uma organização e produtividade melhor se comparando com as que não possuem. $O$ canteiro tem fundamental importância no processo construtivo, pois se trata do gargalo da construção onde todo material necessário para o andamento da obra necessita passar, com um canteiro de obras bem gerenciado traz agilidade e bom andamento de toda construção.

\subsection{CONSTRUÇÃO CIVIL: CANTEIRO DE OBRAS}

A NBR 12284, (ABNT, 1991), define o canteiro de obras como a "área de trabalho fixa e temporária, onde se desenvolve operações de apoio e execução de uma obra". Segundo a Norma Regulamentadora 18 (NR-18, 1995) ele também pode ser definido como as "áreas destinadas à execução e apoio dos trabalhos da indústria da construção, dividindo-se em áreas operacionais e áreas de vivência".

Segundo BORGES (2010), através dessa organização é possível gerar a maior qualidade, desempenho de vida do colaborador, possibilitando relacionar as premissas de trabalho e a produtividade nos canteiros de obra.

Um canteiro mal planejado e executado pode ocasionar prejuízo na obra, desperdícios desproporcionais de tempo e material, mão de obras correndo o risco de um acidente na obra, podendo ocasionar a paralisação da obra por uma ação judicial de segurança do trabalho. (BORGES, 2010).

Muitas obras são tocadas sem um mínimo de organização e planejamento de execução, colocando em risco o andamento da obra e a segurança dos colaboradores envolvido no processo. (HALPIN, 2004).

De acordo MATTOS (2010), o canteiro de obra é essencial na execução da obra, aonde a obra ganha sua fisionomia, cara, expressão, podendo decretar os desperdícios na obra, definindo sua margem de lucro no empreendimento. 


\subsection{DESPERDÍCIO DE MATERIAIS NA CONSTRUÇÃO CIVIL}

$\mathrm{Na}$ construção civil existe uma demanda muito grande de materiais, entretanto um número que assusta é a quantidade que é desperdiçada. Estudos informam que o material utilizado em 3 obras, seria capaz de fazer outra construção idêntica, ou seja, o mal aproveitamento chega a $1 / 3$ do total (SOARES, 2010).

Segundo SOUZA (2003), pode-se afirmar que as construções podem classificar em dois grandes grupos, os recursos físicos e financeiros. Com o elevado crescimento no uso de técnicas e investimento em maquinário vem possibilitando uma redução nos recursos financeiros, sendo que os dois recursos tendem a andar lado a lado, no funcionário na utilização do material até o responsável pela reposição, preocupado com o valor no mercado de cada material.

Segundo FORMOSO (1999), perdas na construção civil estão além de somente a perca do material, pois se trata de tudo que envolve o processo, se trata de toda ineficiência no uso de maquinários, materiais, mão de obra e capital, ultrapassando a quantidade necessária para a produção, serviços que não agregam valor e eleva assim o custo final da construção.

\subsection{PRODUÇÃO ENXUTA}

Para CORRÊA (2012), a produção enxuta, fortemente conhecida como Sistema Toyota de Produção (STP), teve sua origem no Japão, devido à falta de recursos deixada pela segunda guerra, levou os engenheiros Eiiji Toyoda e Taichi Ohno, a desenvolverem esse método, devido as limitações de recursos enfrentadas, que através deste método é desenvolvido melhoria continua onde diminuiriam os desperdícios na produção.

De modo geral, aplicando-se o Sistema Toyota de Produção (STP), é primordial fazer a nivelação da produção, está sendo uma responsabilidade da produção ou do controle de produção. Este nivelamento de produção poderá exigir antecipações ou atrasos de expedições, que pode levar os clientes há esperar um pouco. Quando a produção se encontra com níveis controlados pode-se aplicar o sistema puxado de produção para equilibra o sistema.
Entretanto, para se pensar em produção enxuta, é essencial compreender o conceito de Just-in-Time (JIT). Conforme Corrêa e Corrêa (2012), sendo a base do JIT flexibilidade e qualidade, sendo que somente com demandas sobre eles, haverá a produção, viabilizando uma produção zero estoque. Tornando-se uma das ferramentas principais do sistema, sendo ele o sistema de produção "puxado", ou seja, só é produzido quando há solicitação, sendo a solicitação por sinais (visuais, sonoros, dentre outros) que faz o envio, assim é disparado, que acarreta no início da produção.

\subsection{SISTEMA 5S}

O $5 S$ é interpretado como uma ferramenta importante com sua metodologia participativa e propulsora da qualidade. Oferecendo conhecimento necessário para todos os trabalhadores, podendo desenvolver um bom desempenho e ajustes em suas funções. De modo que, pelo fato de ser um programa integrado, onde os sensos trabalham interligados, proporcionando assim resultados satisfatórios, não para os colaboradores, mas também para o ambiente organizacional.

Conforme ABRANTES (2007), para que tais melhorias no comportamento dos empregados venham a trazer melhores resultados, deve-se começar pela mudança nos hábitos de todos os trabalhadores para com a organização, limpeza, asseio e ordem do local de trabalho. Por isso o senso de autodisciplina, pois ele tem principal influência sobre os demais.

Para OLIVEIRA (1997), esse sistema tem como principal foco promover a alteração comportamental das pessoas, reorganizando totalmente a empresa através de identificação dos materiais, execução constante de limpeza no local de trabalho, eliminação de materiais obsoletos, elaborando um ambiente que gere saúde física e mental para os colaboradores.

O gerenciamento da construção é muito importante na obra, suas definições de quais métodos ou técnica a ser escolhida na construção é fundamental para o sucesso da obra em questão, visando todo o processo, desde o canteiro de obra até o acabamento final. Um conjunto que trabalha em equilíbrio, utilizando métodos bastante diversificados, continuamente introduzindo pensando nas vantagens da construção definimos a forma 
melhor a ser empregada os recursos disponíveis na obra.

\subsection{CONSTRUÇÃO ENXUTA}

Para AKKARI (2003), a necessidade de um empreendimento bem moderado e programado, incentivou a criação de um novo método de processos "Lean Construction", chamado também de "Construção Enxuta". É importante ressaltar também, com o elevado crescimento das exigências dos clientes externos e internos, deparou-se com a necessidade de upgrade e melhorias nos processos de controle levando em conta as atividades antes não avaliadas como preferencias na construção.

Para COELHO (2009), destaca que a construção enxuta se trata de uma adaptação da produção enxuta; o cumprimento de seus princípios da a possibilidade da identificação que de certo modo geram paralizações no fluxo de trabalho, chamadas de atividades que não agregam valores. Sendo essas que paralizações que causam os desperdícios ou até mesmo retrabalho, onde devemos buscalas para minimiza-las.

\section{METODOLOGIA}

Para o desenvolvimento e análise dos desperdícios que ocorrem em um canteiro de obras da construção civil, foram realizadas vistas in loco, onde se coletou as informações necessárias e analisou-as através de um check-list elaborado através dos parâmetros estabelecidos por SOUZA (2005). Todas as análises foram realizadas baseadas em princípios qualitativos.
Tendo relação nos métodos de produção buscou-se um tratamento direto nas execuções das tarefas e procedimentos através de ferramentas como 5s, Lean Constrution, etc. onde com treinamento e conscientização da equipe pode ocorrer redução no custo final da obra.

\subsection{VISITA IN LOCO}

A empresa escolhida para a avaliação, é uma construtora do ramo da Engenharia Civil, localizada em ARAGUAÍNA-TO e que atua no mercado público e privado. Para o desenvolvimento das atividades foram abordadas obras de caráter público, distribuídas em todo o perímetro urbano do município. As obras em questão possuíam canteiro de dimensões reduzidas e ambas tratam de projetos de ampliação da edificação existente.

Constatou-se que a manutenção desses canteiros de obras de menor porte ocorre através de um canteiro central, onde as atividades de maior complexidade são desenvolvidas. Esse dificulta a manutenção imediata caso necessite, pois o canteiro central fica a uma distância significativa das obras, podendo ocasionar paralização da obra por causa da espera de insumos e o gasto de combustível necessário no deslocamento.

\subsection{CHECK-LIST}

Para a comparação com os parâmetros apresentados por Espinelli (2005) foi elaborado o check List, onde foram abordados os itens,conformeapresentado na Tabela

Tabela 1 - Check-list de análise de desperdício em canteiro de obras

\begin{tabular}{|c|c|c|c|c|}
\hline \multicolumn{5}{|c|}{$\begin{array}{l}\text { Análise em uma construção na cidade de Araguaína-TO } \\
\text { Check list - Canteiro de obras }\end{array}$} \\
\hline 1 & Desperdício em material & SIM & $\mathrm{NÃO}$ & Observações \\
\hline 1.1 & Areia & & & \\
\hline 1.2 & Brita & & & \\
\hline 1.3 & Ferro & & & \\
\hline 1.4 & Cimento & & & \\
\hline 1.5 & Tijolos & & & \\
\hline 2 & Desperdício em mão de obra & & & \\
\hline 2.1 & Pedreiro & & & \\
\hline 2.2 & Servente & & & \\
\hline
\end{tabular}


Tabela 1 - Check-list de análise de desperdício em canteiro de obras (continuação...)

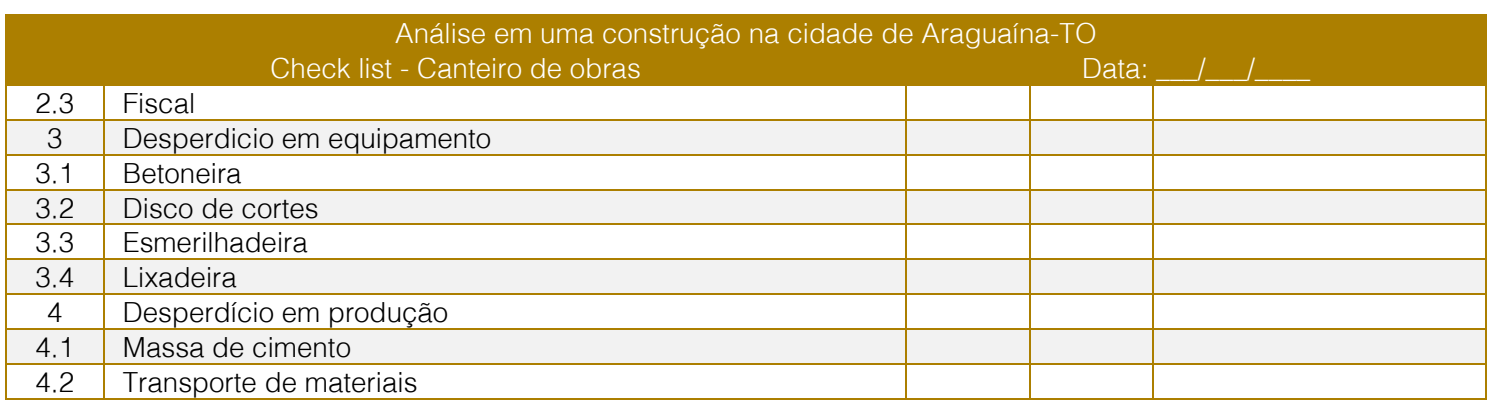

Fonte: Adaptado de Souza, 2005

\section{RESULTADOS E DISCUSSÃO}

Os resultados obtidos através da observação do canteiro de obras e analisados com o auxílio do check-list estão apresentados a seguir. A análise baseia-se em uma forma qualitativa com assistência de imagens para visualização e entendimento dos resultados obtidos.

\subsection{ANÁLISE IN LOCO}

Inicialmente foi realizada uma análise in loco para reconhecimento visual e coleta de dados das obras, deu-se prioridade por insumos de primeira necessidade e que auxiliam diretamente no bom desenvolvimento das atividades.

Na figura 1, pode-se observar que a brita esta acondicionada diretamente no solo, sem nenhum tipo de baia que faça a retenção do material. Esse acondicionamento gera desperdício por espalhamento do material, uma vez que devido ao transporte, chuvas, modo de coleta, etc. pode-se ocorrer uma dispersão da mesma.

Figura 1 - Brita acondicionada sem baia de retenção

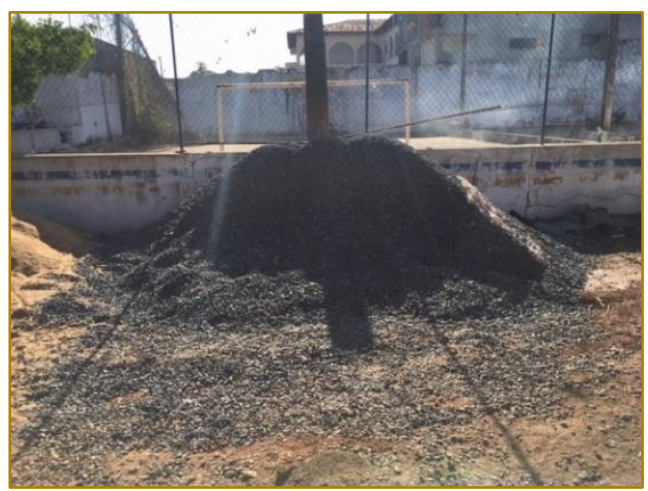

Na figura 2 é mostrado um gabarito de obra que está aguardando a liberação de adequação de projeto, uma vez que o projeto inicial veio em inconformidade com a obra e inexequível. Essa inconformidade tem gerado atraso e empecilhos no bom desenvolvimento das atividades, prejudicando o cronograma estipulado. O não andamento das atividades conforme determinado, gera para a empresa gasto com funcionários parados e atrasos em contrato. 
Figura 2 - Gabarito aguardando liberação de projeto

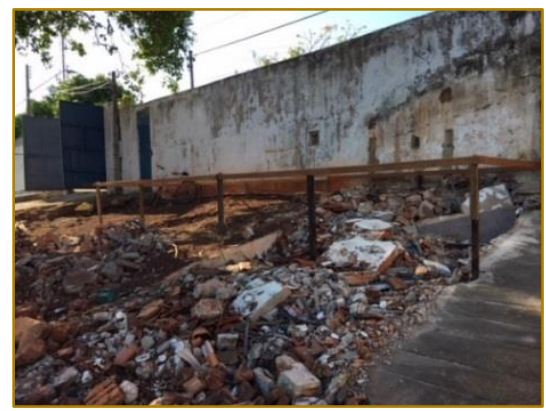

Na figura 3 é exposto como é realizado o acondicionamento da matéria prima, sendo que esta está localizada fora do canteiro de obras, a brita não tem baias para impedir que se espalhe, sem nenhum tipo de proteção contra furtos. E prescindível relatar que calçada é um local para o transito de pedestres não sendo a mesma destinada ao armazenamento de quaisquer tipos de materiais, vale ressaltar que é necessária a rápida realocação do material, uma vez que, sua locação inadequada pode causar mais problemas, tais como autuação por parte da fiscalização municipal pelo uso indevido da calçada.

Figura 3 - Acondicionamento irregular

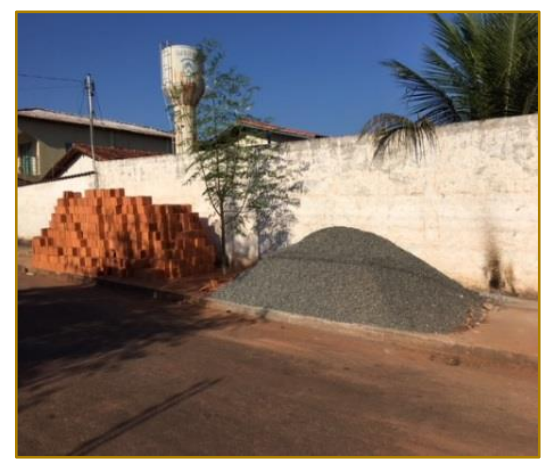

A figura 4 mostra uma caminhonete, veículo de transporte de materiais e ferramentas do canteiro central para as obras. Como o canteiro central esta dando suporte a 3 (três) obras na cidade, precisa-se constantemente do uso da mesma. Devido o maquinário principal se encontrar no canteiro central, a logística para o desempenho das atividades na hora exata da necessidade é necessário o deslocamento constante de insumos.

Figura 4 - Veículo de transporte

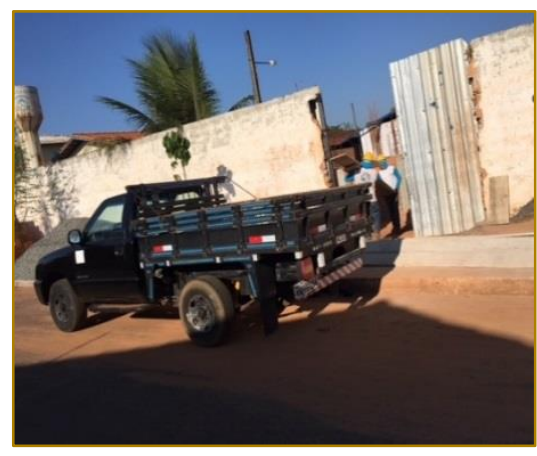


As Figuras 5 e 6 mostram ferragens e marcenaria, que são montados no canteiro de obras central, no momento da visita estavam expostos à intempéries, pois o galpão não dispunha de espaço para acondicionamento do material. Eles eram cortados e moldados

Figura 5 - Ferro para vigas

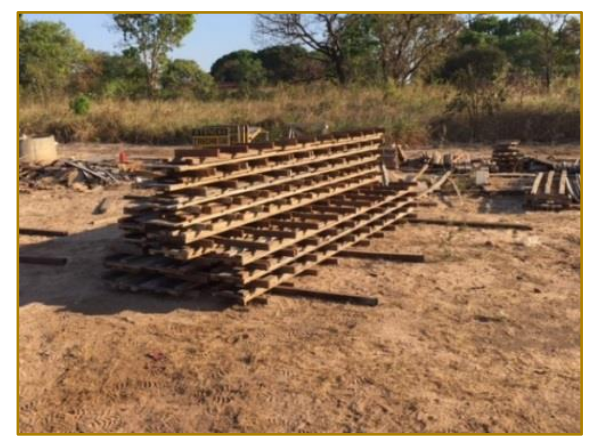

\subsection{VERIFICAÇÃO EM CHECK-LIST}

O check-list foi utilizado como uma referência de mapeamento onde é possível observar na figura 06 o gráfico do desperdício total nos canteiros de obra. Pode-se observar que a maior perda está relacionada a areia, brita e no local, para posteriormente serem destinados às obras conforme solicitação, esse transporte acarreta em uma logística de transporte maior bem como o consumo e combustível.

Figura 6 - Madeira

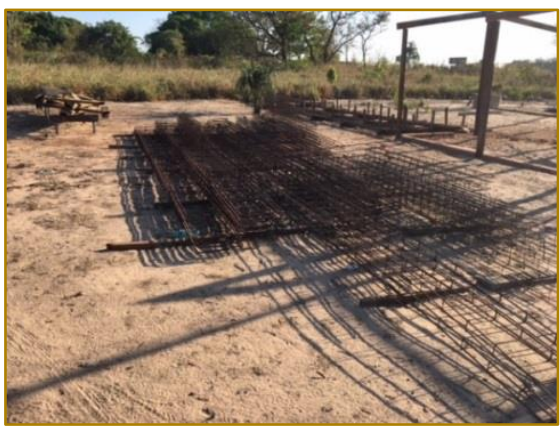

transporte, onde essa aparece nitidamente com os maiores picos, em sequência tem-se o tijolo onde em uma das obras é alocado fora do canteiro, isso ocorreu em 3 obras.

Figura 6 - Tipos de desperdícios apresentados nas obras

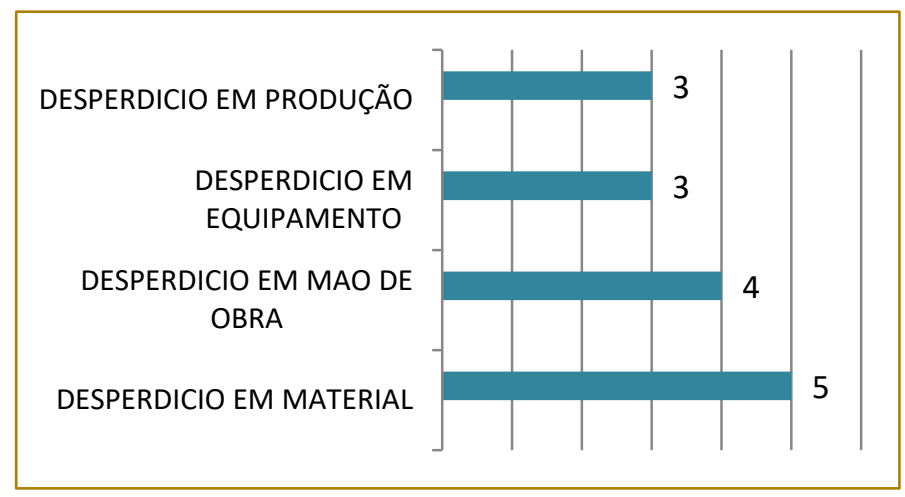

\section{CONSIDERAÇÕES FINAIS}

No contexto deste estudo nota-se uma dificuldade na parte de armazenamento das matérias primas ocasionando desperdício, pois na coleta do material espalhava o mesmo ou até mesmo misturava com a brita que estava logo ao lado. Com isso precisava de mais retrabalho, tendo a necessidade de um funcionário para poder separar esses materiais. Trabalho esse que poderia ser diminuído colocando as baias ao redor desses materiais.
Nota-se também o meio de manutenção sendo ela centralizada, levando em consideração a distancia do canteiro central para os demais isso causa um pouco de espera e ociosidade quando se trata da necessidade de materiais que estão no canteiro central. Deste modo a descentralização deste canteiro central possibilitaria um maior rendimento na manutenção da obra e equipamentos. 


\section{REFERÊNCIAS}

[1] ASSOCIAÇÃO BRASILEIRA DE NORMAS TÉCNICAS (1987). NBR 10.004 - Resíduos Sólidos: Classificação. Rio de Janeiro. 63p.

[2] ASSOCIAÇÃO BRASILEIRA DE NORMAS TÉCNICAS. Norma Brasileira 1367 (NBR 12284) Áreas de vivência em canteiros de obras, 1991.

[3] ASSOCIAÇÃO BRASILEIRA DE NORMAS TÉCNICAS. Norma Brasileira 6122:2010-Projeto e execução de fundações.

[4] BORGES, Alberto de Campos; Praticas das pequenas Construções. 6. Ed. São Paulo: Edgard Blucher LTDA, 2010, pag. 1, 10, 45 a 50.

[5] COELHO, Clara B. T. Antecipações gerenciais para a inserção de atividades facilitadoras na execução de alvenaria de tijolos cerâmicos: análise dos relatos de agentes do processo. 2009. 120 f. Dissertação (Mestrado) Programa de Pós-Graduação em Engenharia Civil. Universidade Federal do Paraná. Ponta Grossa, 2009.

[6] CORRÊA, H. L.; CORRÊA, C. A. Administração de Produção e Operações Manufatura e serviços: uma abordagem estratégica. 3a Ed. São Paulo: Editora Atlas S.A., 2012. 680p.

[7] Formoso, C. T. et al. Perdas na construção civil: conceitos, classificações e seu papel na melhoria do setor. http://www.pedrasul.com.br/artigos/perdas.pdf $<$ Acessado, 07/04/2018

[8] FORMOSO, C. T. Lean Construction: princípios básicos e exemplos. Construção Mercado: custos, suprimentos, planejamento e controle de obras. Porto Alegre, v. 15, p. 50-58, 2002.

[9] HALPIN, Daniel W; WOODHEAD, Ronaldo W; Administração da Construção Civil. 2. Ed. São Paulo: LTC, 2004, pag 10 a 40.

[10] JUNQUEIRA, Luiz Eduardo Lollato. Aplicação da Lean Construction para redução dos custos de produção da casa 1.0. Escola Politécnica da Universidade de São Paulo, Departamento de Engenharia de Produção. Especialização em Engenharia de Produção para Construção Civil. 2006. Disponível em: $<$ http://leanconstruction.wordpress.com/downloads />. Acesso em: 19 abril 2018.
[11] LIKER, Jefrey. O modelo Toyota : 14 Princípios de gestão do maior fabricante do mundo - SP, 2005.

[12] MATTOS, Aldo Dórea; Planejamento e Controle de Obras. São Paulo: Pini LTDA, 2014, pag 21 a 40.

[13] ROCHA NETO Humberto Soares Da. Avaliação dos índices de desperdícios de materiais. 2010 http://civil.uefs.br/DOCUMENTOS/HUMBERTO\%20 SOARES\% 20DA\%2OROCHA\%20NETO.pdf < Acessado, 05/04/2018

[14] SAURIN, T. A. Método para diagnostico e diretrizes para planejamento de canteiros de obras de edifícios. 1997. Dissertação (Mestrado em Engenharia) - Programação de pós-Graduação em Engenharia Civil da Universidade Federal do Rio Grande do Sul (CPGEC/EFRGS), Porto Alegre 1997.

[15] SOUZA, Ubiraci Espinelli Lemes de. Como reduzir perdas nos canteiros. p. 15, 2005.

[16] WOMACK, J. P., JONES, D. T.;ROSS, D. A máquina que mudou o mundo - SP, 1992.

[17] WOMACK, James P.; JONES, Daniel T. A mentalidade enxuta nas empresas - Lea Thinking. 10.ed.Rio de Janeiro: Elsevier, 2004

[18] ABDEL-AAL, R.E.; AL-GARNI, Z. Forecasting Monthly Electric Energy Consumption in eastern Saudi Arabia using Univariate TimeSeries Analysis. Energy Vol. 22, n.11, p.1059-1069, 1997.

[19] ABRAHAM, B.; LEDOLTER, J. Statistical Methods for Forecasting. New York: John Wiley \& Sons, 1983

[20] LIM, C.; McALEER, M. Time Series Forecasts of International Travel Demand for Australia. Tourism Management, artigo aceito em 2001 para publicação, aguarda impressão.

[21] MAKRIDAKIS, S.; WHEELWRIGHT, S.; HYNDMAN, R.J. Forecasting Methods and Applications.. 3. ed. New York: John Wiley \& Sons, 1998.

[22] PELLEGRINI, F.R.; FOGLIATTO, F. Estudo comparativo entre modelos de Winters e de BoxJenkins para a previsão de demanda sazonal. Revista Produto \& Produção. Vol. 4, número especial, p.72-85, 2000. 


\section{Bapítulo 13}

\section{ELABORACÃO DE REATOR AERÓBIO EM ESCALA LABORATORIAL COMO PÓS-TRATAMENTO DE EFLUENTE SANITÁRIO DE RESTAURANTE UNIVERSITÁRIO}

Beatriz Fernanda Crotti

Amanda Silva Nunes

Dioni Fraisoli

Micheli Maria de Oliveira

Isabela Bruna de Tavares Machado Bolonhesi

Resumo: O número de estudantes fazendo uso do restaurante universitário vem aumentando cada ano, principalmente devido a práticidade e rotina corriqueira. Em restaurantes, a quantidade de efluente gerado é diretamente proporcional ao número de refeições realizadas no dia. A carência e precariedade de sistemas tratamento de esgoto são responsáveis por uma série de distúrbios ambientais e de saúde pública, dessa forma viu-se a necessidade do desenvolvimento de alternativas tecnologicamente simples e viáveis para solução dos problemas imediatos. Sendo assim, o presente estudo tem como objetivo o estudo de um reator aeróbio em escala laboratorial como método de pós-tratamento de esgoto sanitário do efluente do restaurante universitário da Universidade Tecnológica Federal do Paraná - Londrina, bem como avaliar os parâmetros temperatura, $\mathrm{pH}$, Demanda Química de Oxigênio (DQO) e sólidos. O reator com capacidade para 2 litros de efluente, constituído de uma bomba compressora de ar foi desenvolvido no laboratório de saneamento. O lodo teve papel fundamental no tratamento, já que nele estão presentes os microrganismos de interesse para metabolização da matéria orgânica do efluente a ser tratado, os mesmos foram obtidos por meiode biobobs. A introdução do esgoto ocorreu por bateladas em intervalos de 3 dias, a cada alimentação eram verificados os parâmetros a serem analisados. $O$ reator mostrou-se eficiente na remoção de DQO, com $80 \%$ de remoção. Em relação aos sólidos a eficiência na remoção foi significativamente baixa, $65 \%$. Por fim, para resultados mais satisfatórios seria necessario maior tempo de adaptação da biomassa e aperfeiçoamento do sistema.

Palavras chave: Saneamento, Tratamento Aeróbio, Pós-Tratamento. 


\section{INTRODUÇÃO}

O número de pessoas que realizam refeições fora do lar aumenta gradativamente acompanhando um cotidiano tumultuado que a população vem enfrentando. Dessa forma a opção de realizar refeições em restaurantes traz uma solução para otimização do tempo disponível em meio as atividades rotineiras. Os estudantes representam grande parte desse número de pessoas que realizam refeições fora do lar, principalmente por passar muito tempo dentro das universidades em função de atividades acadêmicas (SOUZA, 2015).

Em 2016, 1.990.078 de estudantes estavam matriculados em instituições públicas de ensino superior, e esse número aumentou cerca de 56\% entre 2006 e 2016. Este número de estudantes encontram-se matriculados em apenas 298 universidades espalhadas pelo Brasil (INEP, 2016).

Segundo a ANDIFES, em 2014, cerca de $31,21 \%$ dos universitários de instituições federais realizavam pelo menos uma de suas refeições no restaurante universitário, totalizando 302.627 refeições por dia.

O gerenciamento da produção das refeições não se limita apenas ao processo da cozinha à mesa, é necessario um acompanhamento contínuo dos subprodutos gerados ao longo da produção, como o efluente sanitário. Esse gerenciamento é de suma importancia dada à grande quantidade de efluente que é gerado em relação a quantidade de refeição produzida, resultando em uma quantidade subproduto ao qual pede-se uma solução de destinação. Para a realização da destinação do esgoto gerado é fundamental a utilização de um tratamento para redução do impacto negativo que este pode causar para a saúde humana e para o meio ambiente, se descartado de forma inadequada (ARAÚJO, 2013).

A falta de tratamento de esgoto sanitário ou até mesmo a precariedade do mesmo gera graves problemas ambientais como a contaminação de corpos d'água, do lençol freático, contaminação do solo, entre outros, além de vulnerabilidade socioambiental. Em nosso país, principalmente em regiões com índices de menor desenvolvimento e mais carentes, as doenças por falta de saneamento ou má adequação do sistema vem agravando - quadro epidemiológico. Investir em saneamento é uma forma de se reverter a situação atual, dados divulgados pelo
Ministério da Saúde afirmam que para cada $\mathrm{R} \$ 1,00$ investido no setor de saneamento, economiza-se $R \$ 4,00$ na área de medicina curativa (GUIMARÃES e SILVA, 2007).

De acordo com a NBR 9.648 (ABNT, 1986) esgoto sanitário é o despejo líquido constituído de esgoto doméstico e industrial, água de infiltração e a contribuição pluvial parasitária.Em relação a composição do esgoto sanitário, temos que basicamente 99,9\% é água e 0,1\% de sólidos, sendo esses constituídos por partículas em suspensão, dissolvidas, microrganismos e compostos orgânicos e inorgânicos.

$\mathrm{Na}$ Tabela 1 podemos verificar as características típicas do esgoto sanitário bruto. A FUNASA (2004) divide as características do esgoto sanitário em químicas, biológicas e físicas, cujas características são citadas abaixo:

Química: característica relacionada à presença de matéria orgânica e inorgânica.

- Matéria orgânica: cerca de 70\% dos sólidos no esgoto são de origem orgânica, geralmente esses compostos orgânicos são uma combinação de carbono, hidrogênio e oxigênio, e algumas vezes com nitrogênio;

- Matéria inorgânica: é formada principalmente pela presença de areia e de substâncias minerais dissolvidas

Biológica: relacionada com a presença de microrganismos - os principais são as bactérias, os fungos, os protozoários, os vírus e as algas.

Física: característica relacionada ao material particulado, temperatura, odor, cor e turbidez.

- Temperatura: em geral, é pouco superior à das águas de abastecimento. A velocidade de decomposição do esgoto é proporcional ao aumento da temperatura;

- Odores: são causados pelos gases formados no processo de decomposição, assim o odor de mofo, típico de esgoto fresco é razoavelmente suportável e o odor de ovo podre, insuportável, é típico do esgoto velho ou séptico, em virtude da presença de gás sulfídrico;

- Cor e turbidez: indicam de imediato o estado de decomposição do esgoto. A tonalidade acinzentada acompanhada alguma turbidez é típica do esgoto fresco e a cor preta é típica do esgoto velho. 
Tabela 1: Valores de parâmetros encontrados em esgoto sanitário

\begin{tabular}{|c|c|c|c|}
\hline Parâmetros & Esgoto Forte & Esgoto médio & Esgoto Fraco \\
\hline ST & 1.160 & 730 & 370 \\
\hline SST & 360 & 230 & 120 \\
\hline SSV & 280 & 175 & 90 \\
\hline DBO 5,20 & 400 & 200 & 100 \\
\hline DQO & 800 & 400 & 200 \\
\hline O.D. & 0 & 0 & 0 \\
\hline N total & 85 & 40 & 20 \\
\hline N orgânico & 35 & 20 & 10 \\
\hline Amônia livre & 50 & 20 & 10 \\
\hline N-NO2 & 0,10 & 0,05 & 0 \\
\hline N-NO3 & 0,40 & 0,20 & 0,10 \\
\hline P total & 20 & 10 & 5 \\
\hline P orgânico & 7 & 4 & 2 \\
\hline P inorgânico & 13 & 6 & 3 \\
\hline
\end{tabular}

Fonte: Jordão e Pessôa (2005).

Atualmente, os processos para o tratamento de esgoto tendem a ser biológicos.A decisão pelo processo a ser empregado, deve-se levar em consideração, principalmente, as condições do corpo hídricoreceptor (estudo de autodepuração e os limites definidos pela legislação ambiental) e da característica do esgoto bruto gerado (IMHOFF e IMHOFF, 1996).

Eficiência, confiabilidade, sustentabilidade, simplicidade, requisitos de área, custos de implantação são fatores importantes para serem analisados na seleção de sistema para o tratamento de esgoto, sendo que cada sistema deve ser analisado individualmente e adotar a melhor alternativa técnica e econômica. O tratamento biológico de esgoto sanitário é a estabilização da matéria orgânica por mecanismos biológicos por meio de bactérias, protozoários, fungos e algas. Esse tratamento busca reproduzir o que a natureza faz naturalmente nos cursos d'água, em que a matéria orgânica é estabilizada por mecanismos naturais, ocorrendo o fenômeno chamado de autodepuração (VON SPERLING, 1996).

Os processos biológicos podem ser aeróbios, com a presença de oxigênio e anaeróbios, sem a presença de oxigênio. No tratamento aeróbio, os microrganismos degradam a matéria orgânica que é assimilada como alimento e fonte de energia, mediante processos oxidativos. Enquanto estabilizam a matéria orgânica eles consomem o oxigênio dissolvido no meio (SANT'ANNA JR., 2010).

Para a operação de sistemas aeróbios alguns parâmetros devem ser considerados para uma boa eficiência do sistema, tais como: temperatura, $\mathrm{pH}$, e oxigênio dissolvido e concentração de matéria orgânica. A faixa ótima de temperatura para esses sistemas é de 25 a $30^{\circ} \mathrm{C}$, porém podem ser operados com temperaturas entre 10 e $40^{\circ} \mathrm{C}$. A faixa de $\mathrm{pH}$ adequada varia entre 6,0 e 8,0 e o OD até o mínimo de 0,5 mg/L. Uma desvantagem do sistema aeróbio é que necessita de aeração mecânica ou difusa o que acarreta em gasto de energia. Entre os principais sistemas de tratamento aeróbios estão as lagoas aeradas, os lodos ativados e os filtros biológicos (VON SPERLING, 2005). Alguns desses processos podem ser replicados em escala de bancada para avaliação dos parâmetros de monitoramento e otimização do tratamento, o que é o foco do presente artigo. 


\section{OBJETIVO}

\subsection{OBJETIVO GERAL}

Desenvolver um reator aeróbio em escala laboratorial alimentado por batelada com esgoto sanitário pré tratado e analisar sua eficiência e resultados finais do tratamento.

\subsection{OBJETIVO ESPECÍFICO}

Construir um reator aeróbio com capacidade para 2 litros para pós tratamento de efluente sanitário;

Analisar parâmetros em cada troca de batelada nos quesitos:

- Temperatura

- PH (entrada e saída)

- DQO (entrada e saída)

- Sólidos Totais

- Sólidos TotaisVoláteis

- Sólidos Totais Fixos

Comparar os resultados obtidos dos parâmetros de entrada e saída;

Avaliar a eficiência do sistema, apontando possíveis erros e melhorias.

\section{METODOLOGIA}

O projeto foi desenvolvido na Universidade Tecnológica Federal do Paraná campus Londrina, no Laboratório de Saneamento, como complemento e atividade prática da disciplina de Gerenciamento e Tratamento de Esgoto Sanitário, com início no dia 04 de junho de 2018, e término em 25 de junho de 2018.

O efluente em estudo foi gerado no restaurante universitário do campus, que possui um funcionamento de $14 \mathrm{~h}$, sendo das $7 \mathrm{~h}$ as $21 \mathrm{~h}$, todos os dias exceto aos sábados que funciona das $7 \mathrm{~h}$ as $14 \mathrm{~h}$, e aos domingos não abre. O restaurante é responsável pelo preparo das refeições do almoço e jantar que fica a disposição dos alunos das $11 \mathrm{~h}$ as $14 \mathrm{~h}$ no almoço e das 17:30 as 19:30 no jantar. Junto ao restaurante também possui uma cantina de funcionamento continuo. O estabelecimento prepara cerca de 550-600 refeições no almoço e 250-300 no jantar por dia.
Segundo a NBR 7229 da ABNT um estabelecimento do tipo restaurante e/ou similares contribui com cerca de 25L/pessoa/dia. Dessa forma, chegamos a uma produção diária de 22.500L/dia de efluente com a necessidade de ser tratado.

O efluente gerado diariamente era direcionado para um conjunto de reatores anaeróbio-aeróbio que removiam parte de matéria organica e nitrogênio. O efluente de saída desse conjunto foi utilizado para alimentação do reator aeróbio descrito no presente trabalho.

\subsection{PREPARO DO LODO}

No sistema que foi desenvolvido, o lodo tem papel fundamento no tratamento do esgoto, sendo nele presente todos os microrganismos de interesse para metabolizar a matéria orgânica do efluente em estudo.

Portanto para a obtenção de um lodo concentrado em microrganismos foi recolhido uma porção do material de imobilização da biomassa (biobobs) existente no sistema anaeróbio-aeróbio citado anteriormente com uma quantidade pequena de efluente. $O$ material foi agitado por 5 minutos $e$ posteriormente deixou-se sedimentar por 30 minutos, obtendo-se então o lodo para inóculo no reator. O material poroso presente dentro do biobobs é forrado por um biofilme de bactérias, ao passar o efluente pelos poros isso aumenta área de contato, disponibilizando matéria orgânica para ser digerida pelos microrganismos.

\subsection{MONTAGEM DO REATOR}

Trata-se de um reator em escala laboratorial com aeração para desenvolver um sistema aeróbico para tratamento do efluente, com alimentação em batelada. $O$ efluente foi obtido a partir do um conjunto de reatores anaeróbio-aeróbiopreenchido com biobobs conforme citado anteriormente. Segundo Martins (2014), o efluente sanitário do restaurante universitário da Universidade Tecnológica Federal do Paraná, campus Londrina, possui característica de baixa concentração de DQO mesmo no esgoto bruto, quando comparado com valores de outros restaurantes universitários, mesmo variando bastante as concentrações de DQO, os valores nunca ultrapassaram 100mgO2/L. Para o presente trabalho, o efluente que 
alimentou o sistema aeróbio proposto já havia sido tratado anteriormente por um sistema prévio, constituindo, neste caso, um póstratamento.

O reator foi construído em um Erlenmeyer com capacidade para 2 Litros e uma bomba de compressor de ar com pedra porosa para disponibilizar oxigênio homogeneamente em todo o reator para desenvolvimento das bactérias aeróbias de interesse para $\mathrm{O}$ tratamento do efluente.

Para melhor administração do volume do Erlenmeyer foi introduzido $600 \mathrm{ml}$ de lodo e $1200 \mathrm{ml}$ de esgoto pré-tratado, como mostra a Figura

Figura 1: Esquematização do Reator Aeróbio

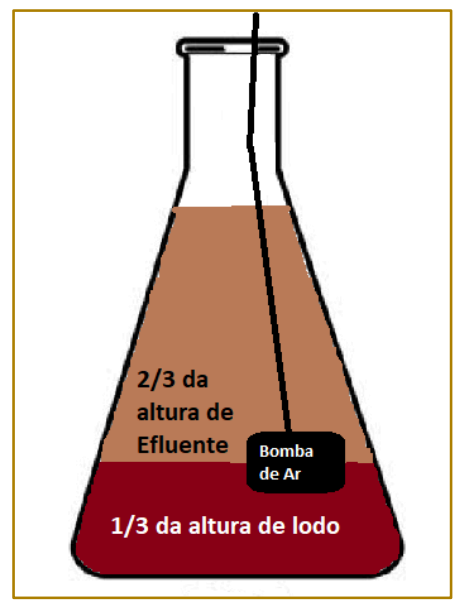

Fonte: Crotti, 2018.

O microrganismo tem alta capacidade de metabolizar matéria orgânica, sendo por esse motivo muito utilizado para o tratamento de esgotos que possuem em sua composição grande concentração de matéria orgânica advindas, por exemplo, de efluentes alimentícios, como restaurantes. Entretanto, para o processo de metabolização acontecer da maneira mais eficiente, alguns fatores são essenciais, como temperatura e $\mathrm{pH}$, necessitando algumas vezes adaptação da biomassa, já que as bactérias presentes podem variar conforme as condições do ambiente, quando o lodo é de baixa idade há predominância de microrganismo flagelados e rizópodes, com lodo de alta idade a predominância é de Trachelophyllum sp., ciliado livre (CORDI, et. al. 2008). Buscando essa adaptação, a primeira troca de batelada foi de quatro dias, ao longo do tratamento o tempo de detenção hidráulica (tdh) foi de apenas três dias.

\subsection{ANÁLISES LABORATORIAIS}

Foram separadas amostras do efluente bruto e entrada e saída de cada batelada, verificando o $\mathrm{pH}$, temperatura e DQO. Já as análises de sólidos foram feitos na primeira e na última alimentação do reator. As análises foram feitas seguindo os seguintes procedimentos:

\subsubsection{TEMPERATURA E PH}

a) Separado $100 \mathrm{ml}$ de escroto bruto em um bécker;

b) Separado $100 \mathrm{ml}$ de esgoto tratado em bécker;

c) Levar as amostras ao pHmetro e introduzir o pHmetro e o termómetro em um bécker de cada vez;

d) Esperar estabilizar;

e) Anotar os valores indicados no visor digital.

\subsubsection{DQO E SÓLIDOS}

As análises de DQO e série de sólidos eram realizadas apenas a cada sete dias, sempre com amostras colhidas na troca de batelada. Para análise de DQO seguiu-se o método do refluxo fechado (DQO - 5220 D) (APHA, AWWA \& WEEF,1998). A diluição utilizada para a análise de DQO foi de $40 \%$ de amostra para $60 \%$ de água para o esgoto bruto e 
tratado. Para a série de sólidos, seguiu-se a metodologia gravimétrica (2540 B e 2540 C, APHA, AWWA \& WEEF,1998). Os parâmetros medidos foram sólidos totais (ST), sólidos totais fixos (STF) e sólidos totais voláteis (STV).

\section{RESULTADOS E DISCUSSÕES}

$\mathrm{O}$ pH é uma variável de extrema importância para bom funcionamento do sistema de tratamento, o controle desta variável auxilia no desenvolvimento dos microrganismos, pois se tivermos um pH muito ácido há redução destes organismos e um $\mathrm{pH}$ muito básico inibe o desenvolvimento dos microrganismos consumidores de matéria orgânica.

As análises $\mathrm{pH}$ foram realizadas para $\mathrm{O}$ esgoto bruto que corresponde ao esgoto que passou por um pré tratamento, ao ser alocado no reator, portanto corresponde a entrada do efluente no reator, logo o esgoto tratado é o que está saindo do reator, na Tabela 2 estão apresentados os valores de $\mathrm{pH}$ e temperatura do efluente durante o período de tratamento. Houve um problema na leitura dos valores de $\mathrm{pH}$ que apresenta-se um pouco discrepantes até mesmo quando se realizava as medições do $\mathrm{pH}$ da água.

Tabela 2: Valores de Temperatura e pH para amostras de entrada (bruto) e saída (tratado) do sistema

\begin{tabular}{|c|l|c|c|}
\hline Data & \multicolumn{2}{|c|}{ Esgoto } & Temperatura $\left(^{\circ} \mathrm{C}\right)$ \\
\hline $04 / 06$ & Tratado & 25 & 5,34 \\
\hline \multirow{2}{*}{$07 / 06$} & Bruto & 28 & 5,18 \\
\cline { 2 - 4 } & Tratado & 23 & 3,66 \\
\hline \multirow{3}{*}{$14 / 06$} & Bruto & 26 & 4,85 \\
\cline { 2 - 4 } & Tratado & 22 & 4,98 \\
\cline { 2 - 4 } & Água & 22 & 5,42 \\
\hline \multirow{3}{*}{$18 / 06$} & Bruto & 23 & 6,86 \\
\cline { 2 - 4 } & Tratado & 22 & 7,25 \\
\cline { 2 - 4 } & Água & 22 & 10 \\
\hline \multirow{3}{*}{$21 / 06$} & Bruto & 22 & 4,26 \\
\cline { 2 - 4 } & Tratado & 22 & - \\
\cline { 2 - 4 } & Água & 22 & 5,25 \\
\hline
\end{tabular}

Dado faltante na leitura do efluente tratado do dia 21/06, não foi feita devido a incoerência dos valores apresentados pelo equipamento, portanto não conferem confiabilidade no valor de $\mathrm{pH}$ neste dia.
A análise de sólidos totais, fixos e voláteis, foram realizadas em dois períodos distintos, os resultados encontrados para cada um dos parâmetros podem ser observados nas Tabelas 3 e 4.

Tabela 3: Sólidos totais, sólidos fixos e sólidos voláteis obtidos na primeira análise

\begin{tabular}{|c|c|c|c|c|c|c|c|}
\hline $\begin{array}{l}\text { Primeira amostra } \\
\text { (bruto 04/06) }\end{array}$ & $\begin{array}{c}\text { Volume de } \\
\text { amostra (mL) }\end{array}$ & Po & P1 & P2 & ST & STF & STV \\
\hline Cadinho III & 25 & 31,761 & 31,772 & 31,767 & 0,44 & 0,24 & 0,20 \\
\hline Cadinho III & 25 & 30,822 & 30,833 & 30,829 & 0,44 & 0,28 & 0,16 \\
\hline
\end{tabular}

Fonte: Crotti et. al. (2018).

Tabela 4: Dados encontrados para sólidos na segunda análise

\begin{tabular}{|c|c|c|c|c|c|c|c|}
$\begin{array}{c}\text { Segunda amostra (Efluente } \\
\text { tratado 21/06) }\end{array}$ & $\begin{array}{c}\text { Volume de } \\
\text { amostra }(\mathrm{mL})\end{array}$ & Po & P1 & P2 & ST & STF & STV \\
\hline Cadinho III & 25 & 67,765 & 67,770 & 67.767 & 0,200 & 0,08 & 0,120 \\
\hline Cadinho III & 25 & 66,751 & 66,757 & 66,753 & 0,240 & 0,08 & 0,160 \\
\hline
\end{tabular}

Fonte: Crotti et. al. (2018) 
Para se avaliar a eficiência de remoção de sólidos, foram feitas médias de cada duplicatas do respectivo período de análise, como apresentado na Tabela 5.

Tabela 5: Eficiência na remoção de sólidos

\begin{tabular}{|l|c|c|c|}
\hline & ST $(\mathrm{g} / \mathrm{L})$ & STF $(\mathrm{g} / \mathrm{L})$ & STV $(\mathrm{g} / \mathrm{L})$ \\
\hline Inicial 04 de Junho & 0,44 & 0,26 & 0,18 \\
\hline Final 21 de Junho & 0,22 & 0,08 & 0,14 \\
\hline Remoção & $50 \%$ & $69,2 \%$ & $22,2 \%$ \\
\hline
\end{tabular}

Fonte: Crotti et. al. (2018).

A remoção de STF foi a que apresentou maior eficiência, cerca de 69\%. Em relação aos sólidos totais e sólidos voláteis, com $50 \%$ e $22,2 \%$ de remoção respectivamente, essa eficiência não se mostrou tão representativo, apesar de visualmente aparentar um aspecto mais claro, como demonstra a Figura 2.

Figura 2: Aspecto do Efluente Após o Tratamento

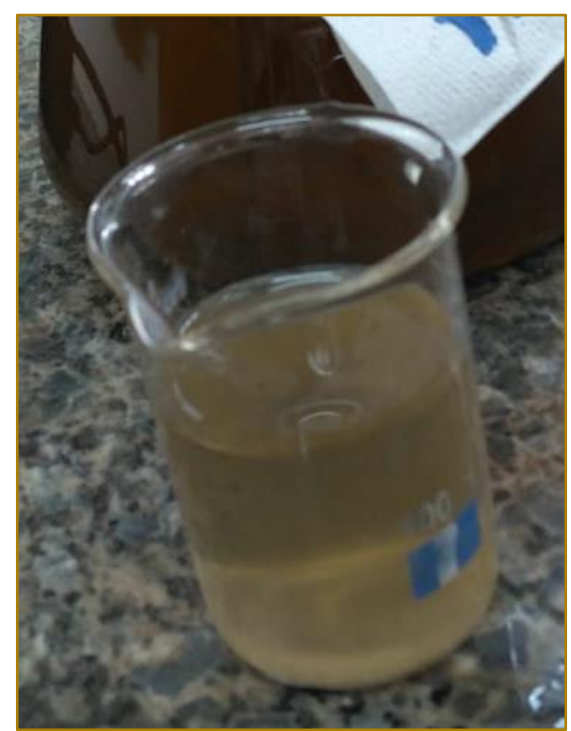

Fonte: Crotti, 2018.

Durante o experimento foram analisados os valores de Demanda Química de Oxigênio (DQO) presentes no efluente de entrada e de saída, uma vez que tal parâmetro mede a quantidade de matéria orgânica presente que pode ser oxidada, os valores obtidos durante o experimento são apresentados na Tabela 6.

Tabela 6: Valores de DQO de entrada e saída do experimento

\begin{tabular}{|c|c|c|}
\hline Data & $\begin{array}{c}\text { DQO Entrada } \\
(\mathrm{mg} . \mathrm{L}-1)\end{array}$ & $\begin{array}{c}\text { DQO Saída } \\
(\mathrm{mg} . \mathrm{L}-1)\end{array}$ \\
\hline $04 / 06$ & 300 & - \\
\hline $07 / 06$ & 223 & 53 \\
\hline $14 / 06$ & 179 & 48 \\
\hline $21 / 06$ & - & 36 \\
\hline Média & 234 & 45.7 \\
\hline Remoção média de DQO (\%) & \multicolumn{2}{|c|}{80.5} \\
\hline
\end{tabular}

Fonte: Crotti et. al. (2018) 
Conforme apresentado na Tabela 2, observase que o tratamento proposto obteve um resultado positivo em relação ao parâmetro de $\mathrm{DQO}$, uma vez que o tratamento conseguiu oxidar a maior parte da matéria orgânica presente no efluente, apresentando uma remoção de 80,5\%.

Mendonça (2002) utilizou um sistema de lodos ativados como pós-tratamento de efluente sanitário em escala laboratorial, em seu experimento o sistema era alimentado de maneira contínua, o tdh no lodos ativados era de 6 h. O sistema apresentou remoção de $64 \%$ de DQO total e $44 \%$ de sólidos totais

Segundo Aisse et. al. (2017) que utilizou um filtro biológico aerado submerso (FBAS) como pós-tratamento de um efluente doméstico que passou por um tratamento em UASB, seus resultados de remoção de DQO foram próximo ao adquiridos neste experimento, de $78,1 \%$ de remoção, podendo então concluir um resultado satisfatório do reator construído em questão por obter uma eficiência de remoção de $\mathrm{DQO}$ de $80,1 \%$. Ainda referente ao FBAS, o resultado obtido de remoção de sólidos foi de $75,9 \%$, sendo o reator aeróbio de bancada desenvolvido apresentou uma remoção de sólidos de 65\%, um pouco a baixo quando comparado, portanto, não tão

\section{REFERÊNCIAS}

[1] ABNT - Associação Brasileira de Normas Técnicas, Norma Brasileira NBR 9648: Estudos de Concepção de Sistemas de Esgoto Sanitário, 1986.

[2] ABNT - Associação Brasileira de Normas Técnicas, Norma Brasileira NBR 7229: Projeto, Construção e Operação Tanques Sépticos, 1997.

[3] APHA, AWWA \& WEEF - American Public Health Association, American Water Works Association, Water Environmet Federation. Standard Methods for the Examination of Water and Wastewater . 1998.

[4] AISSE, M. M. et al. Avaliação do Sistema Reator UASB e Filtro Biológico Aerado Submerso para o Tratamento de Esgoto Sanitário. XXVII Congresso Interamericano de Engenharia Sanitária e Ambiental, Curitiba, PR, 2017

[5] ANDIFES - Associação Nacional dos Dirigentes das Instituições Federais de Ensino Superior. IV Pesquisa do Perfil Sócioeconomico e Cultural do Estudante de Graduação das Instituições Federais de Ensino Superior Brasileiras em 2014. Fórum Nacional de Pró-reitoresde Assuntos Comunitários e Estudantis. Uberlândia MG, Julho de 2016 eficiente quanto o esperado. Por se tratar de um pós-tratamento, e consequentemente o efluente já possuir remoção de carga orgânica, os resultados encontrados no efluente do reator aeróbio apresentar uma baixa remoção de sólidos pode ser justificada.

\section{CONCLUSÃO}

O reator apresentou tempo reduzido de operação (21 dias), e apresentou eficiência na redução dos valores de DQO do efluente, apresentando uma remoção de 80\%. Em relação aos sólidos totais e sólidos voláteis a eficiência de remoção encontrada foi relativamente baixa ao desejável, de apenas $65 \%$ os resultados encontrados estão relacionados, provavelmente ao fato do efluente utilizado já passar por um tratamento prévio, resultando em uma carga orgânica bem reduzida e dessa forma não apresentando resultados muito significativos. Para resultados mais confiáveis cabe maiores tempos de adaptação e aperfeiçoamento do sistema, permitindo dessa forma melhorias significativas na eficiência da redução de sólidos.

[6] ARAÚJO, R. K. Dinâmica da Contaminação por Efluente Sanitário em Área de um Campus Universitário. Dissertação para título de mestrado. Universidade Federal de Santa Maria, Centro de Tecnologia, Programa de PósGraduação em Engenharia Civil. Santa Maria, RS, 2013.

[7] CORDI, L. Montagem, partida e operação de um sistema de lodos ativados para o tratamento de efluentes: parâmetros físico-químicos e biológicos. Engenharia Ambiental: Pesquisa e Tecnologia, vol. 5, no 1., p. 97-115. Espírito Santo do Pinhal - SP, 2008.

[8] Fundação Nacional de Saúde. Manual de Saneamento. 4a ed. Brasília: Fundação Nacional de Saúde, FUNASA. 2006.

[9] GUIMARÃES; SILVA, C. E. Saneamento Básico. Universidade Federal Rural do Rio de Janeiro (UFRRJ). Rio de Janeiro, p. 9. 2007.

[10] IMHOFF, K. R.; IMHOFF, K. Manual de tratamento de águas residuárias. Editora Edgard Blucher. São Paulo, 1996.

[11] INEP - Instituto Nacional de Estudos e Pesquisas Educacionais Anísio Teixeira. Censo da 
Educação Superior. Notas Estatísticas. Ministério da Educação,. Brasil, 2016.

[12] JORDÃO, E. P.; PESSÔA, C. A. Processos anaeróbios reatores UASB. Tratamento de esgoto doméstico. $4^{\circ}$ ed. Rio de Janeiro. 2005

[13] MARTINS, P. M. Biofiltro Aerado Submerso Preenchido com Biobob $₫$ Aplicado ao Tratamento de Efluente de Campus Universitário. Universidade Tecnológica Federal do Paraná (UTFPR), Trabalho de conclusão de curso de Engenharia Ambiental, Londrina, PR, 2014.

[14] MENDONÇA, L. C. Microbiologia e cinética de sistema de lodos ativados como póstratamento de efluente de reator anaeróbio de leito expandido. Tese de doutorado em Engenharia Civil. Escola de Engenharia de São Carlos, Universidade de São Paulo. São Calors, SP, 2002.

[15] SANT'ANNA JR., G. L. Tratamento biológico de efluentes: fundamentos e aplicações. Rio de Janeiro. Interciência, 2010, 418p.
[16] SISTEMA NACIONAL DE INFORMAÇÕES SOBRE SANEAMENTO - SNIS. Diagnóstico dos serviços de água e esgoto, 212p. 2014.

[17] SOUZA, M. S. Avaliação Ambiental e Econômica do Uso de Bioaumento em Caixas de Gordura de Restaurantes da Região de Jacarepaguá - Rio de Janeiro. Dissertação para título de mestrado em Sistemas de Gestão da Universidade Federal Fluminense (UFF). Niterói, 2015.

[18] VON SPERLING, M. Introdução à qualidade das águas e ao tratamento de esgotos. 3. ed. Belo Horizonte: Departamento de Engenharia Sanitária e Ambiental; Universidade Federal de Minas Gerais, 2005.

[19] VON SPERLING, M. Princípios básicos do tratamento de esgoto. Vol. 2. Departamento de Engenharia Sanitária e Ambiental - UFMG. Belo Horizonte: UFMG. 1996. 211p. 


\section{Gapítulo 14}

\section{UTILIZAÇÃO DA SOFT SYSTEMS METHODOLOGY EM UMA INDÚSTRIA DE BEBIDAS NO MARANHÃO}

\section{Eduardo Mendonça Pinheiro}

Ruan Carlos Corrêa Mendes

Herbeth Sandro Malheiros Bezerra

\section{Clemilton Oliveira de Sousa}

Elon Vieira Lima

Ana Célia Silva Vieira

Resumo: O objetivo do trabalho é demonstrar a utilização da Soft Systems Methodology na resolução de problemas pouco estruturados e de alta complexidade, além de ser uma forma de disseminação da metodologia para outras organizações empresariais. Para tal, foi utilizado um caso prático de aplicação numa indústria de bebidas no município de São Luís-MA, onde encontrou-se uma situação problemática. Enfatizou-se a sistematização e a estruturação de tal problema, adotando o SSM para ajustar as problemáticas à situação ideal. Ao final, são propostas soluções com base nesses preceitos com a busca de um modelo de gestão para o alcance de bons resultados para a empresa.

Palavras-Chave: Metodologia SSM, Estruturação de Problemas, Gestão da Qualidade. 


\section{INTRODUÇÃO}

O mercado de refrigerantes no Brasil é um mercado crescente. Segundo relatório do Banco Nacional de Desenvolvimento Sustentável (BNDES, 2006), a tendência nos últimos anos é de aumento do consumo de refrigerantes. Segundo Quintella (2003) os refrigerantes e os refrescos constituem as bebidas não alcoólicas mais consumidas no Brasil, com um consumo estimado em cerca de $70 \mathrm{~L} /$ habitante ano, portanto superior ao de cerveja, ainda na faixa dos 50 L/habitante ano. O Brasil é hoje o terceiro maior consumidor de refrigerantes, perdendo somente para os Estados Unidos e o México.

O crescimento quase que contínuo desde 1990 desse mercado é fruto da maior estabilidade monetária do país aliada à introdução de garrafas de material plástico, que favoreceram o barateamento da produção, e o desenvolvimento de marcas regionais.

O consumo de refrigerante depende de fatores externos, independentes da empresa (férias, datas festivas, calor etc). Apesar dessas variações sazonais, o mercado é estável devido possuir alto poder de substituição dos produtos e alta elasticidade do preço (WETZEL, 2009).

Segundo a Associação Brasileira da Indústria de Refrigerantes (ABIR, 2016) para os próximos anos é esperado um crescimento do mercado e maior diversificação, seguindo uma tendência mundial. A exploração de nichos específicos deverá ser feita de forma mais intensa, com o surgimento de novos sabores e adição de componentes às formulações tais como: vitaminas, fibras e aminoácidos, aumentando valor nutritivo e econômico às bebidas.

O relatório do BNDES aponta a logística de expedição com um ponto crítico para o sucesso dos demais atores no mercado. As mercadorias têm baixo valor agregado (valor unitário) sendo compensadas na sua quantidade distribuída no mercado. Portanto, o volume de mercadoria é o sucesso da empresa, dependendo exclusivamente da boa logística de carregamento na fábrica (SILVEIRA DA ROSA; COSENZA; TEIXEIRA DE SOUZA LEÃO, 2006).

Observando a dinâmica de carregamento de refrigerantes de uma indústria de refrigerantes, localizada em São Luís-MA, percebe-se uma oportunidade de melhoria no seu processo operacional com a aplicação da Soft Systems Methodology (SSM). Portanto, o objetivo do trabalho é mostrar que abordagens interpretativas para resolução de problemas gerenciais precisam ser adaptadas para a produtividade do carregamento de refrigerantes nos caminhões de entrega da empresa aplicando a metodologia da SSM.

\section{REVISÃO DE LITERATURA}

\subsection{SOFT SYSTEMS METHODOLOGY (SSM)}

A Soft Systems Methodology (SSM) foi desenvolvido por Peter Checkland no final dos anos 60 na Universidade de Lancaster, no Reino Unido (RINGER, 2014). Originalmente, ele era visto como uma ferramenta de modelagem, mas anos mais tarde passou a ser visto como uma ferramenta de desenvolvimento de aprendizagem e significado (BELLINI; RECH; BORENSTEIN, 2004). Embora desenvolva modelos, esses, supostamente, não serviriam para representar o "real mundo", mas com a utilização das regras e princípios de sistemas permitem estruturar o seu pensamento sobre o mundo real. Os modelos não são nem descritivo ou normativo, embora possam transportar elementos de ambos. Uma das coisas interessantes sobre o SSM é que ele restringe o seu pensamento, com o intuito de expandir o seu pensamento. Assim, explodindo a idéia de que o pensamento do sistema é sempre expansivo (COTA; FREITAS; CHENG, 2007).

A SSM é um processo organizado e flexível, baseado em ideias de sistema, para lidar com situações que alguém vê como problemáticas, um processo organizado de pensamento na forma de tomar ação para melhoria da situação (CHECKLAND; POULTER, 2006).

Checkland e Poulter (2006) explicam como a dinâmica da metodologia, a partir dessa consideração, se organiza pela ideia de sistemas. Um conjunto de atividades logicamente ligadas constitui um todo, suas propriedades emergentes sendo sua intencionalidade. As atividades, visando atingir um propósito, são monitoradas em relação às medidas de desempenho definidas de forma que ação de controle adaptável pode ser tomada caso necessário (CHECKLAND; POULTER, 2006; COTA JÚNIOR; FREIRAS; CHENG, 2008). 
Ferreira (2008) sugere que SSM tem como principal objetivo identificar e estruturar situações problemáticas e com dificuldades de definição, visando de forma encadeada, relacionar o mundo real e o mundo do pensamento sistêmico, para se chegar às ações que promovam a solução de um problema com o propósito de alcançar um sistema desejável. Apesar de ser uma metodologia pouco utilizada no Brasil, mas que se mostra como uma útil ferramenta sob o enfoque da visão sistêmica para identificação de problemas e geração de soluções (DE JESUS SOARES et al., 2018).

De forma prática a SSM foi projetada para ajudar a formular e resolver situações chamadas de soft, problemas complexos e geralmente com vários componentes humanos (PINHEIRO; SANTOS; REIS, 2016), apresentando, em função desta característica, diferentes percepções do mesmo problema ou objetivo, com diferentes Weltanschauungen (visões de mundo) dos diversos stakeholders envolvidos no sistema (VENTURI et al., 2005). Segundo Checkland (1981), procura-se responder a três perguntas: (1) Quais são as características essenciais deste tipo de sistema? (2) Tais sistemas podem ser projetados, melhorados ou modificados? E (3) Caso possam, de que maneira?
A estrutura de SSM consiste em (CHECKLAND, 1981; CURO; BELDERRAIN, 2010): (1) Identificar a problemática. (2) Estruturá-la relacionando estrutura e processo para montar quadros ou situações (desenhos ricos), com o cuidado de não empregar padrões pré-estabelecidos, considera-se o assunto de preocupação nas pessoas, os papéis que elas desempenham, os tipos e a hierarquia de poder. (3) Utilizando-se uma abordagem sistêmica na busca de definições essenciais e enfatizam-se elementos como clientes, atores, transformação desejada, visão de mundo organizacional, proprietários e restrições ambientais. (4) Formam-se os modelos conceituais que são as realizações ideais que deveriam ser feitas para cada definição essencial. (5) Abandona-se o mundo sistêmico e volta ao mundo real onde há a comparação do segundo e quarto passo para elencar as mudanças que realmente se mostraram ajustadas. E (6) Através do conhecimento cultural da empresa, são aplicados testes para comprovar se elas são ou não factíveis. Em sua última parte (7), a SSM propõe as ações a serem implementadas. Esses estágios permitem seguir uma sequência para a estruturação e definição do problema, e seus passos representados na Figura 1.

Figura 1 - Modelo convencional da SSM em sete passos

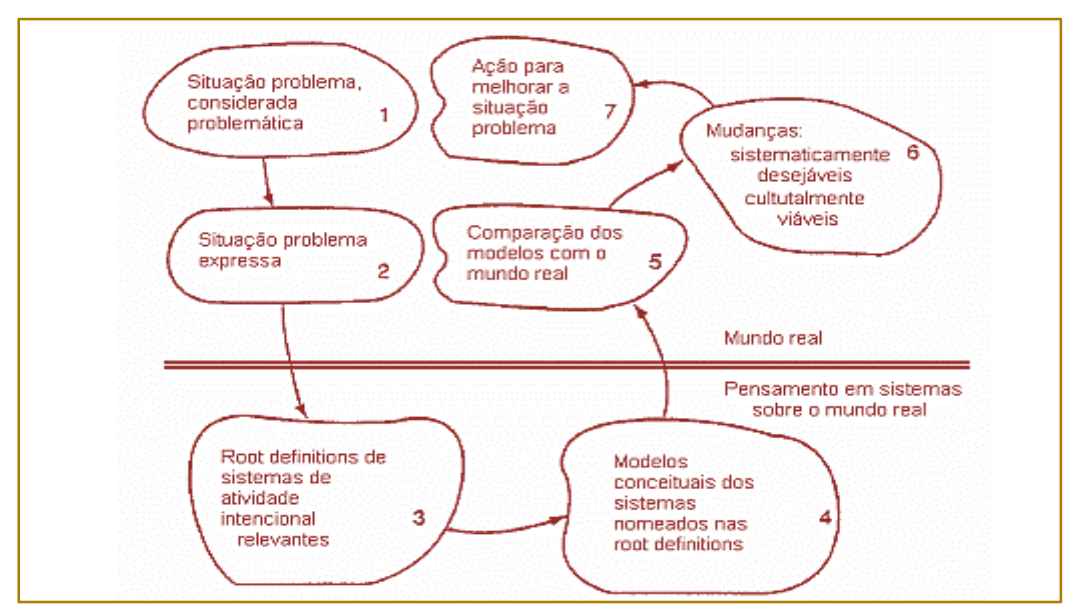

Fonte Checkland (1981)

\section{METODOLOGIA}

O trabalho foi realizado numa indústria de bebidas localizada no município de São LuísMA, empresa genuinamente maranhense com uma atuação ampla pelo estado do
Maranhão. A indústria está situada na zona industrial, próxima da rodoviária federal BR 135, facilitando o escoamento de sua produção. A empresa possui um mix de produtos como refrigerantes, água natural e bebida energética. 
Adaptando o roteiro utilizado por VENTURI et al. (2005), iniciou-se na empresa promovendo reuniões com intuito de discutir problemas que vinham ocorrendo corriqueiramente e de difícil solução. A direção da empresa e mais funcionários responsáveis por setores chegaram a uma problemática comum e que envolvia o carregamento de refrigerantes. Baseado na problemática, o grupo aplicou o SSM.

Nas reuniões seguintes foram momentos de brainstorming para explicar a situação problema e definir soluções ideais.

O grupo desse trabalho apresentou a metodologia à empresa visando à melhoria da área de produção e as conclusões sobre mudanças culturalmente viáveis em busca da melhoria contínua. Conforme Venturi et al. (2005) e Curo e Belderrain (2010), dividiu-se a metodologia em etapas, facilitando a compreensão da aplicação do SSM.

A pesquisa descritiva tem uma abordagem qualitativa. A modelagem do sistema relevante foi realizada pelo programa Bizagi Modeler 3.2.6.094.

\section{RESULTADOS E DISCUSSÃO}

\subsection{ETAPA 1 - SITUAÇÃO PROBLEMÁTICA NÃO-ESTRUTURADA}

No primeiro momento necessitou-se expor todas as informações possíveis dos setores da indústria para a definição do problema. A aplicação da técnica do brainstorming foi utilizada para evidenciar as percepções do grupo.

A definição encontrada sobre a situação problema foi assim determinada: "Demora no carregamento devido falhas operacionais na produção, acarretando falta de produto acabado e não 'batendo' com a nota de expedição".

\subsection{ETAPA 2 - SITUAÇÃO PROBLEMÁTICA EXPLICADA}

Nessa etapa criou-se uma representação dos problemas do "mundo real" identificados pelo grupo e se elaborou uma figura rica (Figura 2) em detalhes contendo os atores, elementos do sistema e suas inter-relações, e a situação problemática a ser resolvida. Nesta etapa é possível ver a inter-dependência das áreas ao setor de expedição da empresa, deixando claro a cadeia de falhas no processo.

Figura 2 - Figura Rica

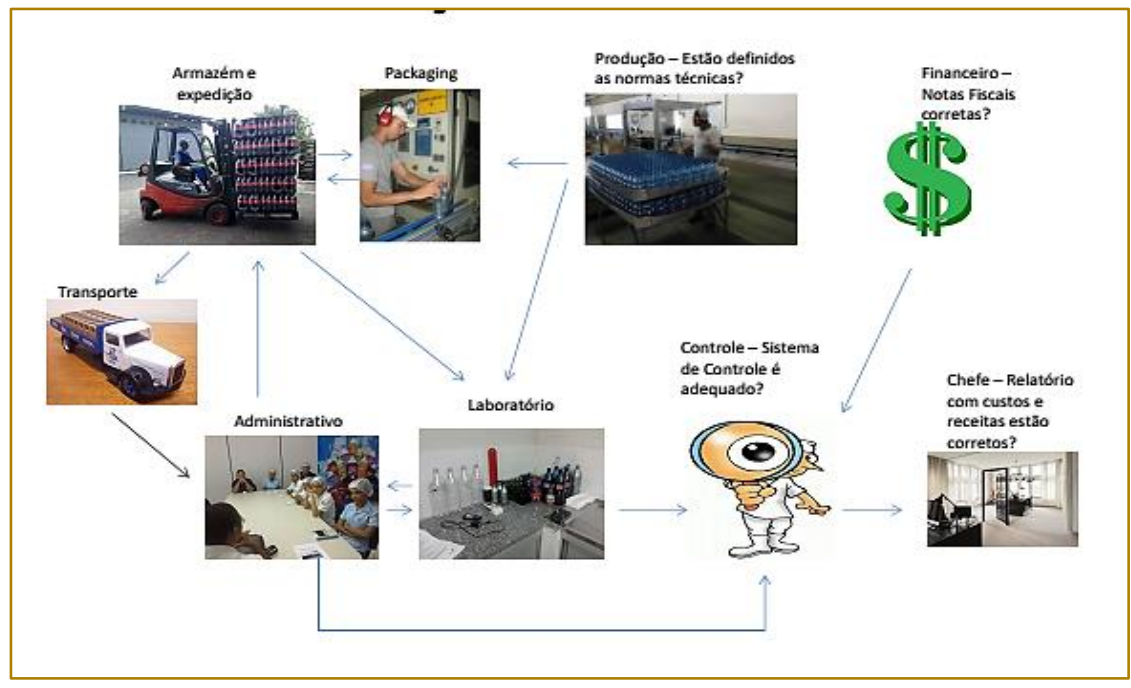

Fonte: Autores (2018)

Observações realizadas na produção contribuíram na formulação da figura 2 representada. Portanto, alguns erros foram detectados nessa observação e que interferem no processo final de expedição dos produtos foram visualizados, tais como: layout fabril não conforme; falta de comunicação interna através de um sistema informatizado; falhas na produção de refrigerantes, principalmente pela demora do setor de 
packaging; e falhas de apontamento do inventário e causando retrabalho.

Baseados na figura rica, os problemas explicados logo acima foram divididos em dois pontos para melhorar a análise:10 Problemática na produção; e $2^{\circ}$ - Falha de comunição entre os setores.

\subsection{ETAPA 3 - DEFINIÇÕES DO SISTEMA RELEVANTE}

Os elementos da palavra mnemônica CATWOE são utilizados para a definição dos sistemas relevantes.

\subsection{1 "CATWOE" \\ C - Clientes: distribuidores, revendedores, funcionários;}

A - Atores internos: funcionários da indústria. Atores externos: motoristas e promotores de vendas:

T - Transformação: integração nas informações de diversos setores que chegam a área de produção e melhoria da comunicação entre elas;

W - Weltanschauung: empresa de refrigerante com mix variado e com forte apelo ao público Classe B/C e com ações de marketing intensas para esse público específico, produção padronização da qualidade do produto, hierarquização do processo, agilidade no processo de packaging, procedimentos revisados e equipe de vendas própria;

O - Donos: diretoria e supervisor industrial;

E - Restrições do ambiente: supremacia nacional da concorrente no segmento (multinacionais), rotas de entregas longas, pessoal de venda limitado e custos operacionais.

Definição raiz:

A área de produção monitora, previne, corrige e avalia as informações sobre produtos acabados que entram e saem da empresa, incluindo análises de qualidade do produto acabado e matéria prima, financeiro e recall. O setor visa garantir que a produção funcione na sua totalidade e garanta a entrega de produtos para o mercado consumidor em dias.

\subsection{ETAPA 4 - MODELOS CONCEITUAIS}

De acordo com a definição sucinta e elementos do CATWOE, o grupo modelou os seguintes sistemas:

I - Otimizar o carregamento de refrigerantes para a expedição e mercado consumidor;

II - Monitorar a rede de comunicação entre os setores e o recebimento destas na área de produção.

III - Viabilizar sistema de informática para integração e transmissão das informações entre os setores.

IV - Reformular as normas industrias obsoletas e atualizar as normas essenciais.

$\mathrm{V}$ - Processo de treinamento de funcionários sob as novas normas e responsabilidades.

VI - Otimização do layout da empresa.

VII - Integrar os setores através da informatização, visando à melhoria contínua da empresa.

Visto o sistema relevante, fez-se o modelo conceitual, conforme a Figura 3. 
Figura 3 - Modelo conceitual do sistema relevante

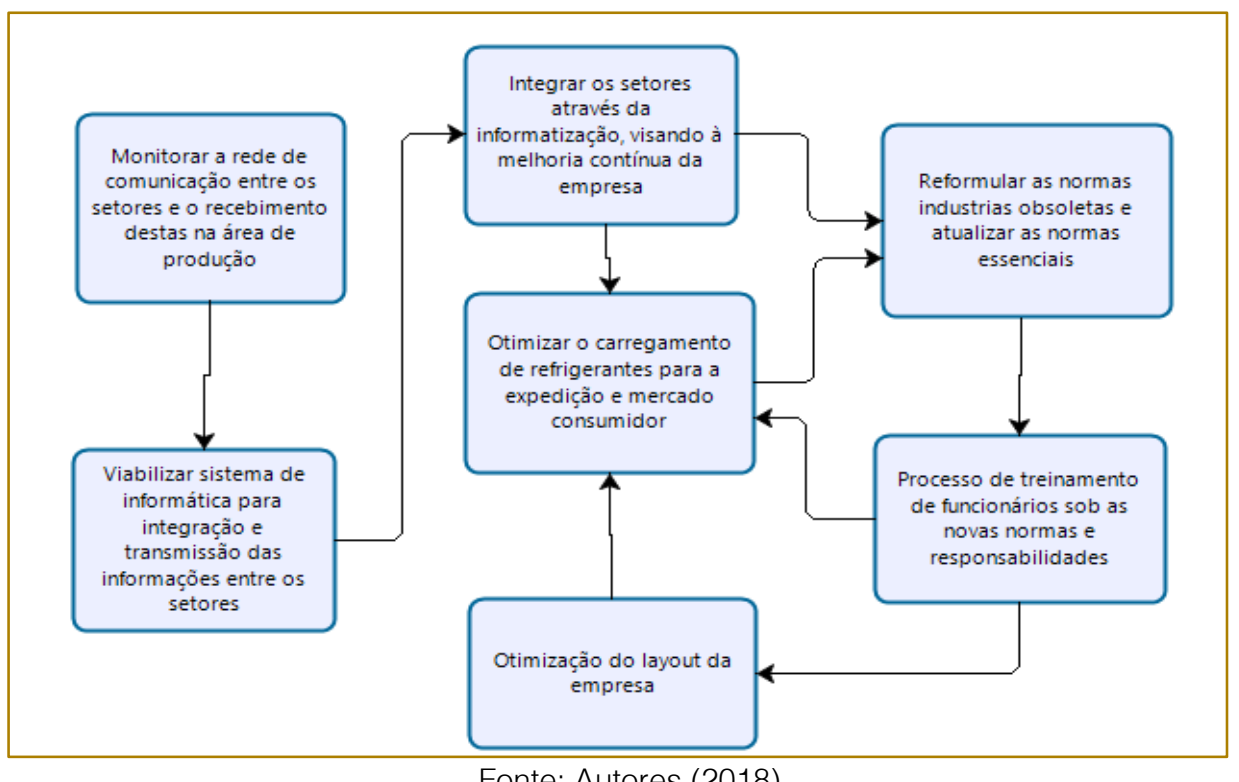

Fonte: Autores (2018)

\subsection{ETAPA 5 - MODELO CONCEITUAL COM A SITUAÇÃO REAL}

O grupo elaborou comparações, comentários e avaliações da realidade do processo de Controle de Produção da empresa, através de analogia e confronto entre os modelos conceituais (etapa 4) e mundo real (etapa 2). Cada parágrafo abaixo está associado, respectivamente, aos itens de I a VII da etapa 4.

A otimização dos processos para agilidade e confiabilidade no carregamento dos produtos para fins de atender a demanda e seus prazos.

O sistema de comunicação utilizado pela empresa não integra todas as áreas pertinentes. A eficiência desse processo é deficiente, pois cria divergência entre as quantidades de refrigerantes apresentadas na Guia de Carga e o real (a carga do caminhão), causando falhas no pedido do dia com a produção real.

O programa atual não integra todas as áreas não podendo controlar efetivamente sua produção e expedição.

A revisão da normatização foi apontada motivada pelas problemáticas identificadas durante este trabalho. A empresa recentemente passou por implantação de Sistema de Gestão da Qualidade, ISO 9.001/2015, Implantação das Boas Práticas de Fabricação e Sistema de Análise de Perigos e Pontos Críticos de Controle, mas antes faltava um padrão e normas não estavam bem definidas.

A empresa realiza os treinamentos para atualização dos funcionários antigos e recepção de novos funcionários, porém as novas normas ainda não tinham sido repassadas e não possui um cronograma de treinamentos definido.

Recentemente, a empresa passou por reforma estrutural melhorando o fluxo das cargas e a disponibilidade de novas linhas de produção, melhorando, consideravelmente, a expedição dos produtos acabados.

O planejamento integrado das atividades falhava por não possuir formulários controlando as atividades de produção causando um mal monitoramente e repasse de informações aos setores, além de não possuir um sistema informatizado para repasse dessas informações.

\subsection{ETAPA 6 - MUDANÇAS SISTEMATICAMENTE DESEJÁVEIS E CULTURALMENTE VIÁVEIS}

Atualmente, a empresa vem buscando novos mercados e o crescimento da produção tem proporcionado uma visão de gestão mais proativa e facilitando as mudanças propostas.

Com tudo, a empresa buscou os Serviços Técnicos Tecnológicos do SENAI-MA para orientação tecnológica; atualizando em novas tecnologias e normalização de processos. 
Modernização do setor de packaging com aquisição de maquinário moderno que otimize os processos.

A busca de um sistema informatizado composto de um programa para auxiliar a área de produção integrado aos demais setores da indústria para a agilidade do carregamento de refrigerantes.

Gerar um cronograma de treinamentos para aperfeiçoamento dos funcionários mais antigos e formação dos novatos às normas da empresa e manter os sistemas de gestão da qualidade devidamente implementados e melhorados.

\subsection{ETAPA 7 - AÇÕES PARA MELHORAR A SITUAÇÃO PROBLEMA.}

A empresa está em fase de planejamento, estudando o orçamento do ano seguinte e a aquisição de software para integração dos setores produtivos e administrativo da empresa.

O SENAI através dos serviços de consultoria e assessoria técnica e tecnológica

\section{REFERÊNCIAS}

[1] ASSOCIAÇÃO BRASILEIRA DA INDÚSTRIA DE REFRIGERANTES E DE BEBIDAS NÃO ALCOÓLICAS. Volume de produção do mercado brasileiro de refrigerantes dos anos de 2010 a 2016. 2016. Disponível em: <https://abir.org.br/o-setor/dados/refrigerantes/>. Acesso em: 01 set. 2018

[2] BELLINI, C. G. P.; RECH, I.; BORENSTEIN, D. Soft Systems Methodology: Uma aplicação no "Pão dos pobres" de Porto Alegre. In: ERA eletrônica, v. 3, n. 1, art. 3, jan/jun 2004. Disponível em:

<http://www.scielo.br/pdf/\%0D/raeel/v3n1/v3n1a06. pdf> Acesso em: 2 Jul. 2018.

[3] CHECKLAND, P. Systems Thinking, Systems Practice. John Wiley \& Sons, 1981. 330p.

[4] CHECKLAND, P., POULTER, J. Learning for Action: A Short Definitive Account of Soft Systems Methodology and its use for Practioners, Teachers and Students. Chichester, West Sussex, England: John Wiley \& Sons, 2006. 200p.

[5] COTA JÚNIOR, M. B. G.; FREITAS, J. S.; CHENG, L. C. Uma análise de soft systems methodology e sua utilização para melhoria do processo de desenvolvimento de cultivares em uma instituição de pesquisa agropecuária. proporcionará a empresa à busca das melhorias de processos e inovação nos seus processos.

E por fim, aplicação imediata dos monitoramentos das normas implantadas e os treinamentos.

\section{CONCLUSÃO}

A metodologia do sistema SSM aplicado na empresa foi capaz de identificar de forma holística as problemáticas dos setores e dos processos da indústria e com clareza, mostrar as modificações a serem implementadas.

A associação do sistema SSM ao sistema de gestão da qualidade e segurança de alimentos compõe uma excelente ferramenta de gestão para identificação e melhoria contínua da empresa.

A implantação do SSM na empresa será um diferencial competitivo devido às melhorias nos processos fabril e administrativo, sendo encarado como uma ferramenta de gestão da qualidade de grande eficiência.

In: Embrapa Milho e Sorgo-Artigo em anais de congresso (ALICE). In: CONGRESSO BRASILEIRO DE SISTEMAS, 3.; CONGRESSO CATARINENSE DE SISTEMAS, 1., 2007, Florianópolis. Pratica sistêmica em situação de complexidade: Anais... Florianópolis: UFSC, 2007., 2008.

[6] CURO, R. S. G; BELDERRAIN, M. C. N. Uma aplicação da Soft Systems Methodology para estruturar o problema da produção científica de um curso de ensino superior. In: Simpósio de Engenharia de Produção, 17, 2010, Bauru. Anais..., Bauru, 2010.

[7] DE JESUS SOARES, J.; FIUZA, C. G. C.; SERRA, M. C.; DE OLIVEIRA, T. S.; PINHEIRO, E. M. Estruturação de problemas em uma escola pública com a aplicação da Soft Systems Methodology (SSM). Desafio Online, v. 6, n. 2, 2018.

[8] FERREIRA, D. D. M.; SILVA, A. R.; REBELLO, T. C. S.; SANTOS, N. Soft System Methodology (SSM) no contexto da educação tecnológica: contribuição aos processos de Gestão do Conhecimento (GC). In: IV Congresso Nacional de Excelência em Gestão, Niterói, 2008. Anais... Niterói: UFF, 2008

[9] LIBONI, L. B.; CEZARINO, L.; MARTINELLI, D.P. Aplicação da Soft System Methodology na Solução de um Problema em uma 
Aliança Estratégica para Desenvolvimento de Novos Produtos. In: Congresso Brasileiro de Sistemas, 3, 2007, Florianópolis. Anais... Florianópolis, 2007.

[10] PINHEIRO, E. M.; SANTOS, SOUSA, S. G.; REIS, E. C. G. Aplicação da metodologia soft systems para estruturar problemas em um curso de graduação. Perspectivas Online: Humanas Sociais \& Aplicadas, v. 6, n. 17, 2016.

[11] QUINTELLA, H. L. M. M. e BOGADO, S. D. C. Tecnologia da Informação e Competitividade na Indústria de Bebidas não Alcoólicas. UFF - RPEP. 2003, v. 3. Disponível em: <www.producao.uff.br/conteudo/rpep/volume3200 3/relpesq_303_09.doc>. Acesso em: 09 nov. 2017.

[12] ROSENHEAD J.; MINGERS J. Rational Analysis for a Problematic World: Problem Structuring Methods for Complexity, Uncertainty and Conflict, 2nd edition. 2001.

[13] RINGER, N. J. Desafios do setor de energia eólica no Brasil: uma abordagem sistêmica. 2014. Dissertação (Mestrado em
Administração). Universidade de São Paulo. Ribeirão Preto, 153 p.

[14] SILVEIRA DA ROSA, S. E.; COSENZA, J. P.; TEIXEIRA DE SOUZA LEÃO, L. Panorama do Setor de Bebidas no Brasil. São Paulo: BNDES Setorial, $2006 . \quad$ Disponível em: $<$ http://www.bndes.gov.br/conhecimento/resposta. asp?setorTema=Bebidas $>$. Acesso em: 13 nov. 2017

[15] VENTURI, M. J.; OLIVEIRA, M. R.; ANDRADE, D. A. C.; MEDEIROS, D. G. Aplicação da Metodologia SSM (Soft Systems Methodology) na dinâmica do fluxo de informações da área de logística em uma cervejaria. In: 1st International Society for the Systems Sciences-Brazilian Chapter Systems Conference, São Paulo, Brazil. 2005. Proceedings... São Paulo: USP, 2005.

[16] WETZEL, A. L. G. Projeto de arranjo físico para melhoria de produtividade no processo de carregamento em uma indústria de bebidas. 2009. 145 p. Trabalho de conclusão - Escola Politécnica da Universidade de São Paulo. São Paulo. 


\section{Gapítulo 15}

\section{EXECUÇÃO DO PROJETO DA CONSTRUÇÃO DE UMA PONTE DE PALITOS DE PICOLÉS UTILIZANDO O GERENCIAMENTO DE PROJETO E O GUIA PMBOK}

\section{Rudson Lourival Oliveira da Silva}

Priscila de Oliveira Serafini

\section{Deborah Deah Assis Carneiro}

Resumo: O objetivo deste artigo é mostrar a aplicação do gerenciamento de projetos na construção de uma ponte de palito de picolé usando o guia PMBOK. Esse projeto foi desenvolvido para que, através de uma competição de teste de carga em pontes de palito de picolé, no Centro Universitário Estácio da Amazônia, fosse possível evidenciar e mensurar como um projeto se inicia, quais as etapas a serem seguidas, como essas etapas devem ser desenvolvidas corretamente e quais os caminhos corretos a serem seguidos para que, não só esse, mas, qualquer tipo de projeto chegue ao fim com sucesso. O protótipo foi desenvolvido baseado em um edital previamente lançado, com as diretrizes a serem seguidas. Durante o plano de projeto, foi escolhido o modelo da ponte, estimado a quantidade de material e o tempo de construção. Após isso, o plano foi colocado em prática, o teste de carga foi executado e, ao fim, foram identificados erros e acertos na elaboração e execução do projeto. Este artigo está dividido de modo que seja mostrado o referencial teórico e metodologia utilizada, bem como a análise de dados. Ao final, encontra-se a conclusão, explorando os erros e acertos e aprendizado para trabalhos futuros.

Palavras-chave: Ponte de palitos de picolé, Gerenciamento de projetos, PMBOK, Estácio da Amazônia. 


\section{INTRODUÇÃO}

O guia Project Management Body of Knowledge (PMBOK) é um manual elaborado pela renomada instituição Project Management Institute (PMI) e considerado a "bíblia" na área de gestão de projetos. Segundo o PMBOk "Projeto é um esforço temporário empreendido para criar um produto, serviço ou resultado único e exclusivo". (DINSMORE, 2009).

Para que o projeto seja bem executado, o mesmo deve conter um plano bem elaborado, e deve conter três fases essenciais: planejamento, execução e controle. Para essas três fases, o gerente de projeto deve ter um conhecimento aguçado, assim como sua equipe, do projeto e das técnicas que serão usadas nesse empreendimento, das restrições de qualidade, de tempo e de custo que afetam ou que possam afetar a realização do projeto. A equipe deve ter ciência que, todos os esforços que serão empreendidos no projeto, devem conter a mesma essência, ou seja, ter êxito na execução do projeto levando em conta o que foi posto no plano inicial. Podemos observar essas fases na Estrutura Analítica do Projeto (EAP) (MOURA,2006).

As pontes de palito de picolé são uma forma de testarmos modelos, formas, técnicas e a melhor escolha de projeto para que a ponte suporte uma carga previamente definida. Essas pontes, levadas as proporções, é a maneira mais próxima à que um aluno do curso de engenharia civil pode chegar a realidade do mercado do mesmo ramo, pois, para o projeto da ponte de palito, deveremos estudar, de maneira similar, as técnicas, cálculos de um projeto real de uma ponte treliçada em aço ou madeira. É levado em conta, os parâmetros reais dos palitos, suas dimensões e capacidades de absorção de carga e com isso possamos desenvolver e escolher um melhor projeto e com isso, sustentar ou superar a carga pré-definida.

Esse artigo tem como objetivo mostrar como a gestão de projetos pode ser aplicada num projeto da construção de uma ponte de treliças utilizando palitos de picolé como parte da avaliação da disciplina Bases de Gestão para Engenharia do curso de Engenharia Civil do Centro Universitário Estácio da Amazônia.

Na metodologia será abordado como foi feito o projeto físico da ponte e a estimativa da quantidade de palitos utilizados, a construção da ponte utilizando as diretrizes do guia PMBOK bem como o teste de carga que pôs a prova todo o desenvolvimento do projeto. Como segunda etapa, a análise e discussão de dados serão apresentadas, confrontando os dados obtidos e os dados do projeto, com o intuito de pôr à prova a gestão de projetos através do guia PMBOK. Ao final, a conclusão do trabalho nos dará a real relação entre a metodologia e a discussão de dados.

\section{REFERENCIAL TEÓRICO}

\subsection{PROJECT MANAGEMENT BODY OF KNOWLEDGE (PMBOK)}

O PMBOK é um guia que revolucionou o tema gestão de projetos, pois, é dele que é baseado todos os planos de novos empreendimentos e projetos. Ele é um padronizador de processos, áreas de conhecimentos, ferramentas e técnicas. Este guia não deve ser considerado uma forma metodológica de abordagem, pois não as difere de acordo com cada projeto e sim o inverso. Ele estipula um padrão a ser seguido por qualquer tipo de projeto e fornece uma visão geral para que todo empreendimento possa segui-lo e não padrões restritos a cada tipo de projeto. (DINSMORE, 2009).

Segundo DINSMORE e CABANIS-BREWIN, 2009, podemos resumir projeto em alguns pontos:

- Tem início, meio e fim;

- É planejado, executado e controlado;

- Desenvolve produtos, serviços ou resultados exclusivos;

- É desenvolvido por etapas e tem evolução progressiva;

- Tem necessidade de uma equipe de profissionais para executá-lo;

- Possui recursos limitados;

Para o guia, gerenciamento de projetos é, basicamente, a utilização de ferramentas e gestão de diversas áreas a fim de influenciar diretamente na execução de projetos, pois, tais ferramentas, foram desenvolvidas para que o gerente de projeto possa, junto com sua equipe, executar de acordo com o projeto base, todos os parâmetros consolidados com proprietário do empreendimento. Para tais processos, gerenciar é definir e alcançar objetivos ao mesmo tempo que é otimizado recursos, como por exemplo, tempo, dinheiro, pessoas, etc. Ainda segundo DINSMORE e CABANIS-BREWIN, 2009, o PMBOK abrange 
diversas áreas em um projeto, num total de 10, que são: gerenciamento de escopo de tempo, de recursos humanos, das partes interessadas (Stakeholders) de aquisições, de risco, de qualidade, de comunicação, de custo, e de integração.

\subsection{PONTES TRELIÇADAS}

Uma treliça, na engenharia de pontes, normalmente é um modelo estrutural reticulado advindo de formas triangulares, normalmente de metal ou madeira para pontes, montadas por barras interligadas umas às outras por uma rótula, ou nó, comumente conhecido dessa maneira. Pontes por sistemas triangulares, é, na engenharia, um sistema perfeito para o cálculo estrutural. Nesses conjuntos, as cargas consideradas atuam diretamente nos nós, cargas designadas como tração (ação de forças em sentidos opostos "saindo" da viga) ou compressão (ação de forças em sentidos opostos "entrando" na viga). É importante salientar que, pontes treliçadas são ótimas absorventes de forças no sentido vertical, mas, péssimas para forças laterais (MARTHA, 2010)

Dentre os diversos tipos de pontes treliçadas, os mais conhecidos são: os de tipo "pratt", "howe", "warren" e "warren modificado". Cada tipo é mostrado na figura 1 e designa uma forma diferente dos sistemas triangulares e com isso, como as cargas serão suportadas e como a estrutura se comportará. Cada estrutura foi desenvolvida para vencer diferentes distância, ter um melhor custo benefício e resistir aos esforços produzidos pelas ações que nelas atuam. (GOMES, 2016).

Figura 1 - Tipos de pontes de treliças

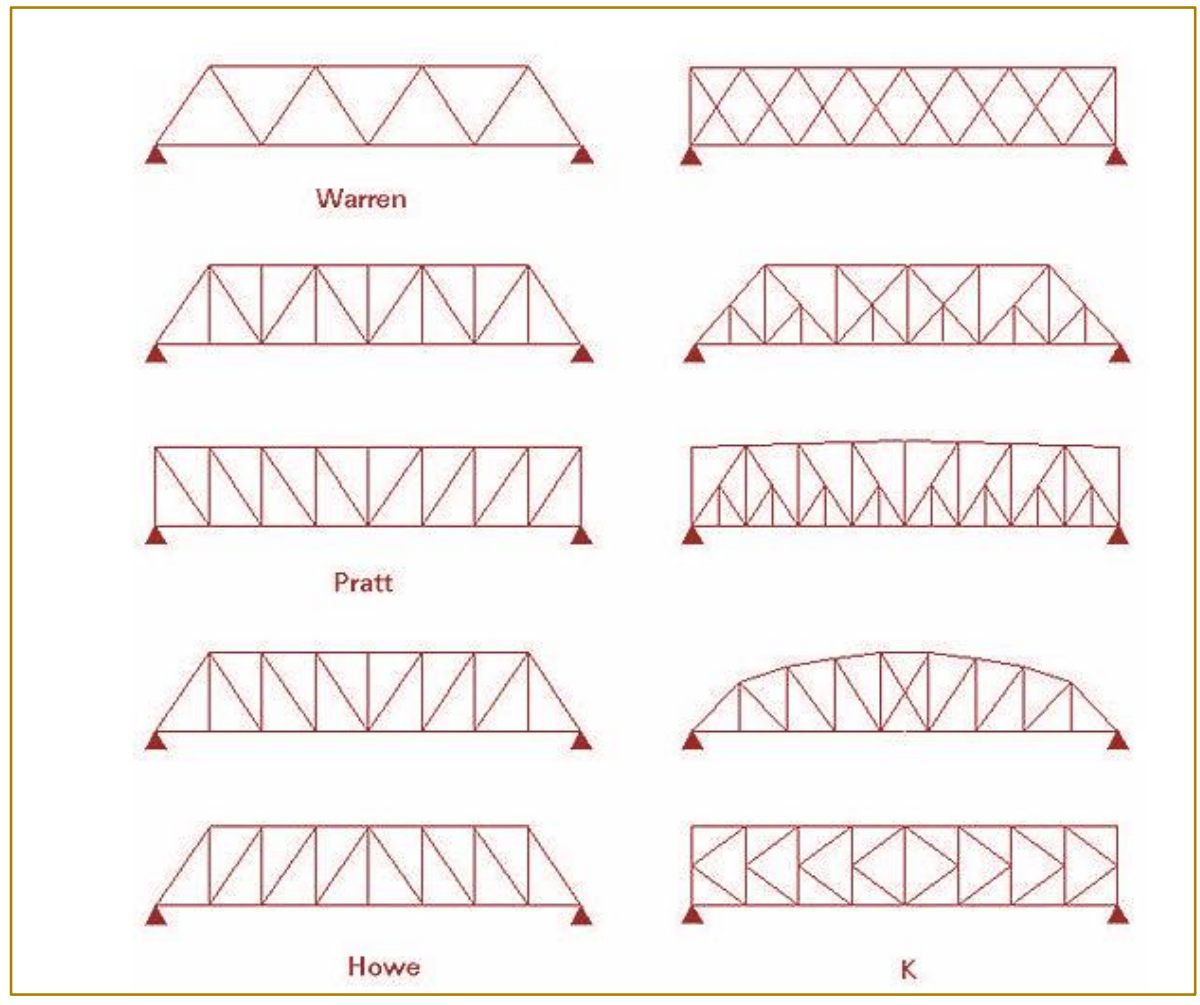

Fonte: DEMGi - 2018

\section{METODOLOGIA}

A metodologia utilizada para a elaboração deste projeto visa à correta utilização das ferramentas e técnicas do guia PMBOK de gerenciamento de projeto e a correta execução do protótipo da ponte de palito de picolé, seguindo as orientações constantes no regulamento de sua competição, visando o melhor aprendizado das técnicas para aplicações posteriores no decorrer da vida acadêmica e profissional.

O projeto para a ponte de palito de picolé foi regido por um edital interno, na disciplina de Bases de Gestão para Engenharia no curso 
de Engenharia Civil do Centro Universitário Estácio da Amazônia. Esse edital estipulou pontuações, limites, mínimos e máximos, de carga, dimensões e peso da ponte e datas.

Para elaboração do projeto foram especificados alguns parâmetros de construção da ponte que estão listados a seguir:

- Deve ser indivisível, de tal forma que não existam partes móveis ou encaixáveis;

- Ser construída utilizando apenas palitos de picolé de madeira e cola para madeira;

- Deve ser capaz de vencer um vão de $70 \mathrm{~cm}$ estando apoiada livremente nas suas extremidades (5 $\mathrm{cm}$ de cada lado), totalizando uma ponte de $80 \mathrm{~cm}$;
-

Ter a largura de 1 palito de picolé (aproximadamente $9 \mathrm{~cm}$ ), ao longo de todo seu comprimento;

- Deve ter um tabuleiro que permitiria a passagem de carros em um projeto real;

- Poderá receber revestimento considerando que os palitos de picolé devam ficar aparentes;

- A altura máxima da ponte, medida verticalmente desde seu ponto mais baixo até o seu ponto mais alto, não deverá ultrapassar $30 \mathrm{~cm}$;

- $\quad$ Não ultrapassar o peso de 400g;

- Não será permitida a utilização das faces verticais da torre de suporte como ponto de apoio horizontal da ponte;

A figura 2 apresenta um esquema genérico de construção da ponte e o critério de admissibilidade da base da ponte.

Figura 2 - Esquema genérico e admissibilidade da base

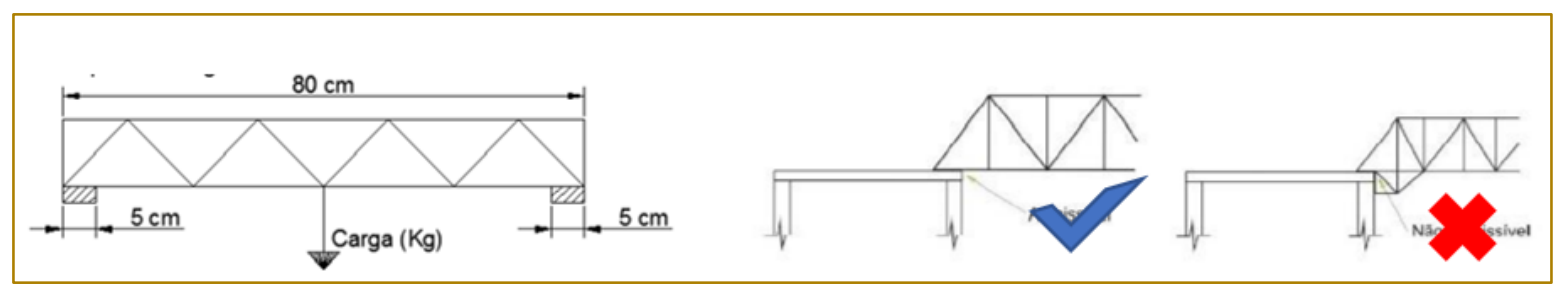

Fonte: UFRR Grupo PET de Engenharia Civil - 2014

Buscando-se o melhor custo benefício sobre pontes treliçadas, foi identificado que os modelos "warren modificado" são os que se destacam, pois, esse modelo suporta cargas consideráveis e necessitam de menos mátria prima para sua confecção, nos chamando atenção, por temos no edital do concurso, tolerância de peso final do protótipo e cargas mínimas e máximas estipuladas pelo mesmo certame. O modelo citado acima, em projetos reais, são os mais usuais, pelo mesmo parâmetro, suporte de carga em relação a massa da ponte. Na figura 3 temos uma imagem de uma ponte real do "warren modificado".

Figura 3 - Ponte do tipo Warren modificada

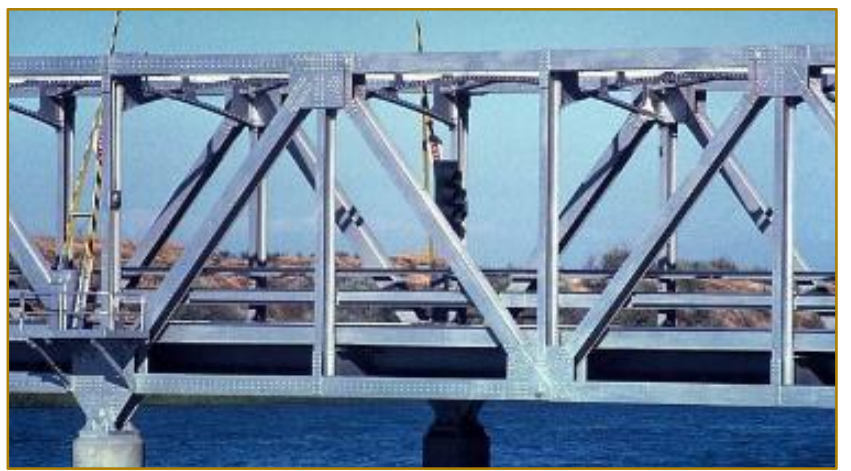

Fonte: ROMÃO - 2003 
Com as especificações e o tipo de ponte definida, o projeto foi elaborado seguindo as diretrizes do guia PMBOK. Como padrão, utilizou-se o modelo da empresa Escritório de Projetos, que disponibiliza gratuitamente conteúdo para gerenciamento de projetos. Dentre as ferramentas constantes no guia PMBOK foram utilizadas:

- Termo de abertura de projeto;

- Plano de gerenciamento de projeto;

- Status Report;

- Lições aprendidas.

O plano de gerenciamento de projeto é o documento mais completo do gerenciamento, nele estão contidas as seguintes informações: escopo, tempo, recursos humanos, aquisições, riscos, qualidade, comunicação e custos do projeto.

Após a fase de elaboração do plano de gerenciamento de projeto, todas as decisões foram tiradas do papel e colocadas em ação. $\mathrm{Na}$ construção da ponte de palitos de picolé foram utilizados palitos cujas dimensões eram $115,0 \mathrm{~mm}$ de comprimento, 2,0 $\mathrm{mm}$ de espessura e $8,4 \mathrm{~mm}$ de largura. Para união dos palitos foi usada uma unidade de cola para madeira, como especificado no edital.
A primeira parte da execução do projeto foi a confecção de um gabarito para que os palitos de picolé fossem fixados mais rapidamente e para que a secagem da cola fosse mais rápida. Nos pilares diagonais foi utilizada uma angulação de 45을 baseando-se em algumas pesquisas de pontes de treliça do tipo warren modificado.

Devido a uma interpretação errônea do regulamento do concurso, o tabuleiro foi feito utilizando os palitos no mesmo sentido do comprimento da ponte. Foram utilizados 7 palitos postos lado a lado repedidos por 7 vezes ao longo do comprimento. As laterais foram reforçadas com 6 palitos de cada lado, no sentido perpendicular aos do tabuleiro. As laterais e o tabuleiro foram unidos com palitos na base. Desse modo, temos $8,28 \mathrm{~cm}$ de largura e $80 \mathrm{~cm}$ de comprimento.

Os pilares verticais e inclinados foram dispostos ao longo da ponte, sempre utilizando dois palitos colados a fim de dar maior resistência. Os verticais foram cortados de modo a ficar com o mesmo valor da largura da ponte $(8,28 \mathrm{~cm})$ e os inclinados de acordo a ficar com a angulação de $45^{\circ}$ do ponto de encontro com o vertical. Para encontrar o valor da inclinação usamos a relação de cosseno, mostrada na figura 4.

Figura 4 - Cálculo dos pilares diagonais

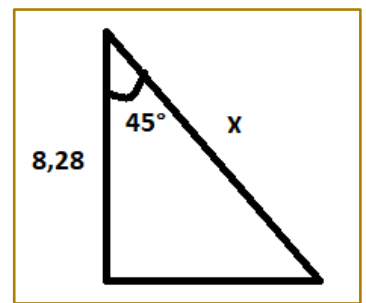

Fonte: O autor - 2018

$$
x=\frac{8,28}{\cos 45^{\circ}}=11,7 \mathrm{~cm}
$$

Na figura 5 temos o esquema do projeto da ponte de palito de picolé utilizando o software Scketchup. 
Figura 5: Projeto da ponte - (1) Perspectiva isométrica; (2) Vista lateral; (3) Vista superior; (4) Vista frontal

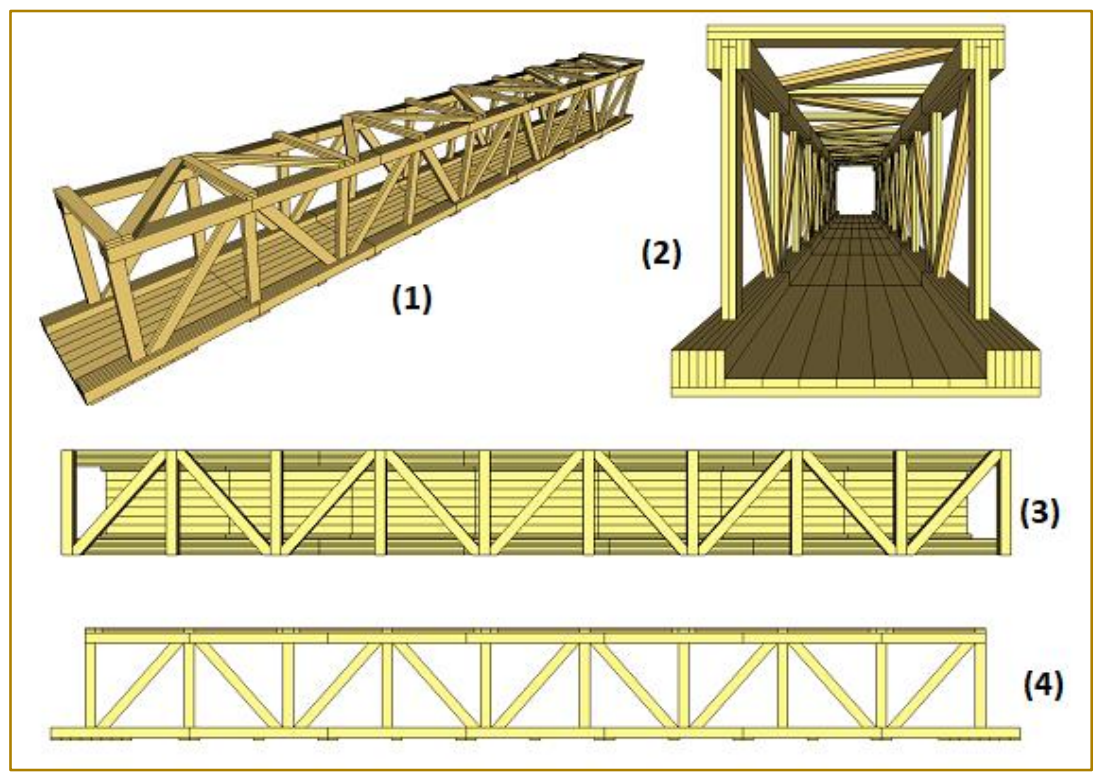

Fonte: O autor - 2018

$\mathrm{Na}$ avaliação geral foram utilizados três critérios: Estética, Eficiência Estrutural e Suporte de Carga Máxima.

Atendendo ao critério de estética, foram utilizadas lixas próprias para madeira em três espessuras diferentes: fina, média e grossa, a fim de dar maior acabamento e beleza ao projeto. Esse critério teve três avaliadores que levaram em conta o acabamento dos filetes e das junções, inovação e criatividade. A média das avaliações compuseram a nota final.

A estimativa do valor da carga de colapso seria obtida pelo grupo através de cálculos específicos de resistência dos materiais e testes carga nos mesmos, bem com a utilização de softwares para auxiliar na correta determinação deste valor. Essa determinação compreendeu $20 \%$ da nota final, para critérios aceitáveis de margem de erro, foram adotados $\pm 10 \%$ para a nota máxima neste critério, e para cada quilo acima ou abaixo haveria decremento de 0,1 pontos da nota parcial, não ultrapassando o total da nota de $20 \%$.

Para o critério de eficiência estrutural deveriam ser observados os seguidos dados: para este critério foi estabelecido o valor de $30 \%$ na nota final. Para calcular a eficiência do protótipo foi estipulado que a eficiência seria determinada pela razão do peso da ponte pela carga de colapso: eficiência $=$ $\frac{\text { carga de colapso }}{\text { peso da ponte }}$ e a nota corresponde seria determinado de acordo com a tabela a seguir:

Tabela 1: Notas Parciais referentes aos valores de eficiência obtidos

\begin{tabular}{|c|c|}
\hline Eficiência & Nota Parcial \\
\hline$\geq 200$ & 3,0 \\
\hline$\geq 150$ e $<200$ & 2,5 \\
\hline$\geq 100$ e $<150$ & 2,0 \\
\hline$\geq 50$ e $<100$ & 1,5 \\
\hline$\geq 25$ e $<50$ & 1,0 \\
\hline$\geq 15 e<25$ & 0,5 \\
\hline$<15$ & 0,0 \\
\hline
\end{tabular}

Fonte: UFMA - 2014. 
O teste de carga inicial foi feito aplicando uma carga correspondente a $10 \mathrm{~kg}$ no centro do vão que se, decorrido 10 segundos da sua aplicação, a ponte não apresentasse danos estruturais, seria considerado que a ponte passou no teste de carga mínima, estando habilitada para participar do teste de carga de colapso). Foram colocadas cargas com pesos determinados pela comissão a fim de especificar a carga máxima que a estrutura foi dimensionada a suportar, sendo que para isso a estrutura devia suportar esta carga por um total de 10 segundos antes de entrar em colapso para que o peso utilizado fosse considerado, caso contrário seria estipulado como peso máximo à carga logo anterior a esta. A pontuação correspondente para a carga máxima foi dada pela tabela a seguir:

Tabela 2: Notas Parciais referentes aos valores obtidos de carga máxima

\begin{tabular}{|c|c|}
\hline Carga Máxima & Nota Parcial \\
\hline$\geq 70 \mathrm{~kg}$ & 3,0 \\
\hline$\geq 60$ e $<70$ & 2,5 \\
\hline$\geq 50$ e $<60$ & 2,0 \\
\hline$\geq 40$ e $<50$ & 1,5 \\
\hline$\geq 30$ e $<40$ & 1,0 \\
\hline 20 e $<30$ & 0,5 \\
\hline$<20$ & 0,0 \\
\hline \multicolumn{2}{|c|}{ Fonte: UFMA -2014} \\
\hline
\end{tabular}

\section{ANÁLISE DE DADOS}

Foram usados entre 250 e 270 palitos de picolé para a confecção da ponte o que é equivalente a quase 3 pacotes contendo 100 unidades cada. Para união e acabamento dos filetes foi utilizado $75 \%$ de um tubo de $90 \mathrm{~g}$ de cola para madeira e duas lixas para madeira. A ponte, pesou um total de $388 \mathrm{~g}$ não ultrapassando o máximo permitido de $400 \mathrm{~g}$. A carga suportada pela estrutura foi de $90 \mathrm{Kg}$.

Figura 6: Ponte finalizada

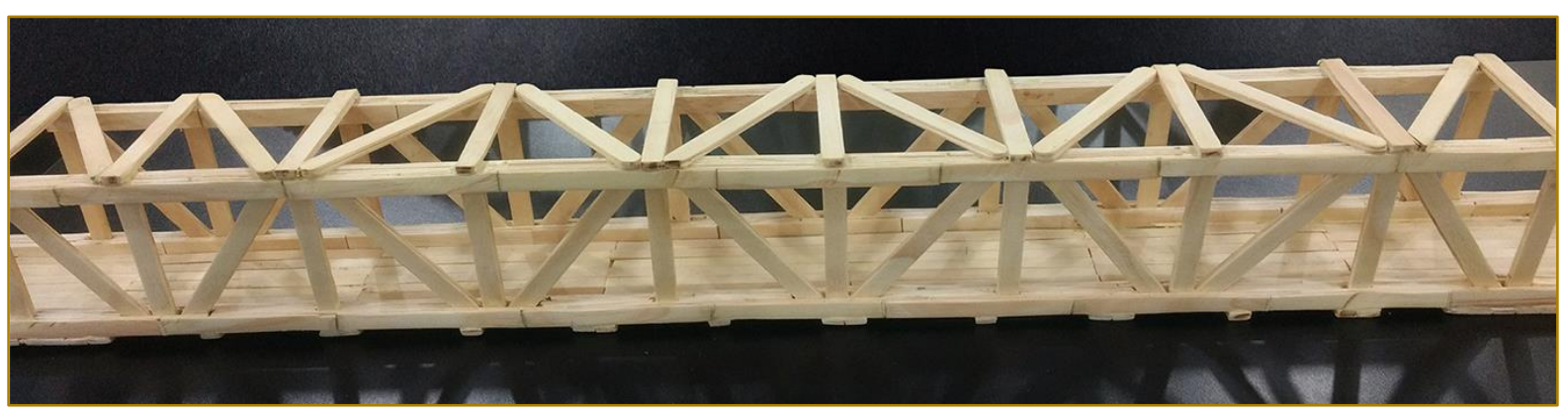

Fonte: O Autor - 2017

Na figura 7 temos algumas imagens do teste de carga. Ao lado esquerdo temos as anilhas utilizadas. Ao centro temos como foram postas as anilhas para realização do teste e, por fim, ao lado direito temos o a ponte após o rompimento da estrutura. 
Figura 7: Teste de carga: (1) Anilhas de teste; (2) Carga aplicada; (3) Ponte após o colapso

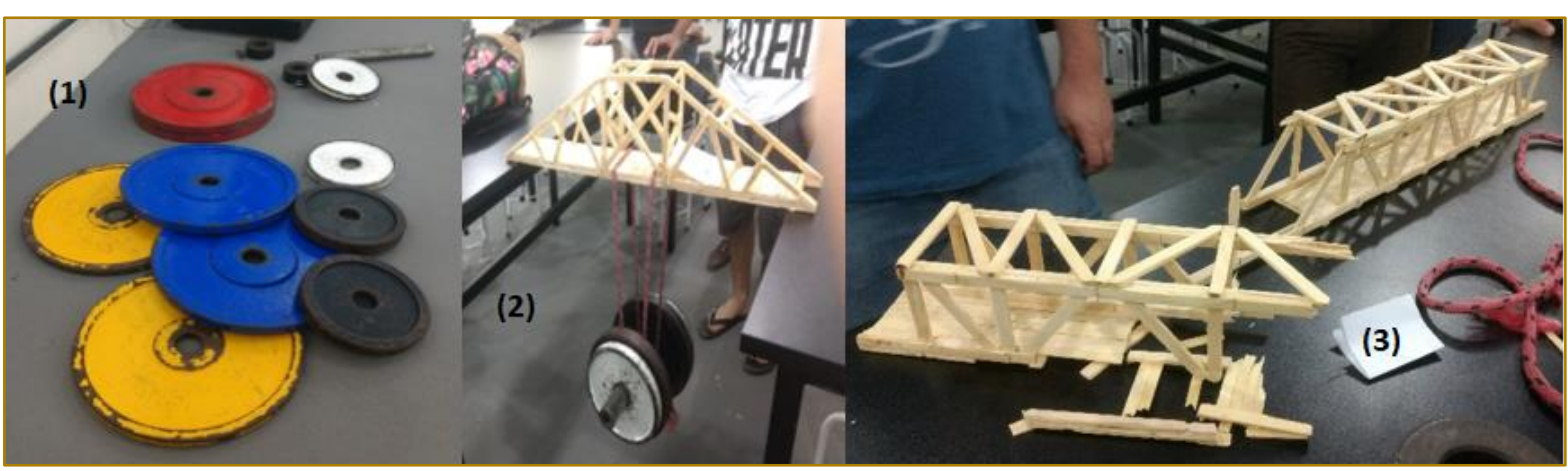

Fonte: O autor - 2017

No processo de confecção, encontramos um problema comum para o material usado, que foi relacionado ao palito de picolé, pois, de cada 10 palitos, 3 viam com avarias graves ou tinham a resistência e elasticidade bem abaixo dos demais, atrasando a fabricação das cessões. Outro empecilho foi não ter os devidos conhecimento teórico sobre cálculo estrutural pois a disciplina Bases de Gestão para Engenharia é uma disciplina do ciclo básico de engenharia e disciplinas mais específicas são ministradas em semestres posteriores. Porém, com um pouco de pesquisa, conseguiu-se chegar a um resultado aceitável. De maneira oposta, a confecção da treliça foi feita de maneira rápida devido ao desenvolvimento do gabarito, o que facilitou o processo.

Com o pouco conhecimento teórico o grupo estimou uma carga de colapso de $70 \mathrm{~kg}, 20 \mathrm{~kg}$ a menos que a carga de colapso no teste de carga. Com isso, o grupo ficou com nota no quesito estimativa igual a 0 . Porém a relação entre peso da ponte e carga de colapso foi de 231,95, um valor muito satisfatório. As especificações e pontuações final do grupo é apresentada na tabela 3.

Tabela 3: Notas Parciais referentes aos valores obtidos de carga máxima

\begin{tabular}{|l|l|}
\multicolumn{1}{|c|}{ Especificações } & \multicolumn{1}{c|}{ Notas } \\
\hline Estimativa: $70 \mathrm{~kg}$ & Estética: 1,4 \\
\hline Peso da Ponte: $388 \mathrm{~g}$ & Estimativa: 0 \\
\hline Comprimento: $80 \mathrm{~cm}$ & Eficiência: 3,0 \\
\hline Largura: $8 \mathrm{~cm}$ & Carga Máxima: 3,0 \\
\hline Altura: $8,5 \mathrm{~cm}$ & \\
\hline Carga Máxima: $90 \mathrm{~kg}$ & Total: 7,4 \\
\hline
\end{tabular}

Fonte: O autor -2018

\section{CONCLUSÃO}

O desenvolvimento deste artigo possibilitou uma análise apurada sobre a aplicação do guia PMBOK, sobre estruturas treliçadas e a aplicação dos dois quesitos anteriores no desenvolvimento da ponte de palito de picolé.

De um modo geral, os resultados foram satisfatórios, pois, o guia PMBOK ajudou identificar as etapas da construção da ponte, a prever os possíveis erros que podiam atrapalhar o andamento do projeto. Desse modo, o desenvolvimento do projeto fluiu de maneira alinhada com os planos inicias, pontos esses, sendo o carro chefe do guia de gerenciamento de projetos.

O tipo de treliça escolhida, Warren Modificada, foi de suma importância, pois, é um modelo que agrega resistências as cargas axiais e um custo benefício eficiente para o projeto. $\mathrm{O}$ projeto atendeu aos requisitos e 
objetivo determinados ficando apenas a ressalva que para um melhor dimensionamento do mesmo é necessária uma maior compreensão das técnicas e cálculos que envolvem sua construção. Para projetos futuros, com mais conhecimento adquirido no decorrer da vida acadêmica, haverá uma maior facilidade de elaboração de projetos relacionados e minimização dos erros cometidos tendo maior chance de sucesso.

Dada a importância do tema, é de suma importância agregarmos conhecimento teórico para podermos ter um melhor

\section{REFERÊNCIAS}

[1] DEMGI (DEPARTAMENTO DE ENGENHARIA MECÂNICA E GESTÃO INDUSTRIAL DA ESCOLA SUPERIOR DE TECNOLOGIA DE GESTÃO DE VISEU (ESTGV)) - Resistência dos materiais, Capítulo 3 - Esforços internos e Métodos das Seções, 2018. Disponível em: <http://slideplayer.com.br/slide/43676/> Acesso em 19/04/2018

[2] DINSMORE, PAUL C.; CABANIS-BREWIN, JEANNETTE. Manual de gerenciamento de projetos. Estados Unidos da América: Brasport, 2009. p. 1-5.

[3] GOMES, MARIA IDÁLIA. Estudo e Análise de Treliças. Área Departamental de

[4] Engenharia Civil. Instituto Politécnico de Lisboa. Isel, Lisboa, Portugal. p. 5-9; p. 18-23, abril 2016. desempenho em projetos futuros e para que os resultados sejam mais satisfatórios. Nesse sentido, os objetivos computados nesse artigo, foram alcançados, pois, foi constatado que o guia PMBOK e suas ferramentas possui um intuito único e certo, que é conferir ao gerente de projetos, medidas e maneiras com que ele possa levar ao êxito a conclusão do projeto que the foi dado. O guia tem ferramentas simples e fáceis, porém, necessitam de uma pessoa que possa entende-las e expô-las a sua equipe, fazendo que a mesma trabalhe de forma fluída, levando o projeto ao seu intuito principal, a satisfação do cliente.

[5] MARTHA, LUIZ FERNANDO. Análise de Estruturas: Conceito e métodos básicos. Rio de Janeiro: 2010. p. 30-32.

[6] MOURA, DÁCIO G.; BARBOSA, EDUARDO F. Trabalhando com projetos. Rio de Janeiro: Vozes, 2006.

[7] ROMÃO, XAVIER. Sistemas Articulados Planos - Mecânica I - 2002/2003

[8] UFMA - CENTRO DE CIÊNCIAS SOCIAIS, SAÚDE E TECNOLOGIA. Edital Competição de Pontes Treliçadas de Palito de Picolé. Imperatriz, MA - 2014

[9] UFRR - GRUPO PET DE ENGENHARIA CIVIL. Regulamento do segundo concurso de pontes de palito de picolé da UFRR. Boa Vista $\mathrm{RR}$,

2014. 


\section{Gapítulo 16}

\section{ANÁLISE PRELIMINAR DE RISCO - APR - NO AMBIENTE LABORAL DO SETOR DE MARMORARIA: ESTUDO DE CASO NO MUNICÍPIO DE JOÃO PESSOA - PB}

\section{Marcella Renata Silva de Araújo de Sales}

\section{Denise Dantas Muniz}

\section{Eduardo Braga Costa Santos}

Renata Dantas Muniz de Queiroz

Resumo: O setor de marmoraria é um dos mais proeminentes dentro do mercado de rochas ornamentais, dos quais existem diversas problemáticas que são contempladas em legislação e que demandam maior atenção no tocante à manutenção preventiva sobre o uso dos Equipamentos de Proteção Individual - EPI - disponibilizados pela empregadora, assim como a percepção dos trabalhadores referente aos processos de prevenção e segurança no ambiente laboral. Contudo, uma quantidade considerável de riscos ainda é verificável dentro das empresas do setor e estes podem trazer prejuízos significativos para a qualidade de vida do trabalhador. Para a realização deste trabalho, foi realizada uma análise do ambiente laboral de uma marmoraria localizada em João Pessoa - PB e aplicada a Análise Preliminar de Riscos - APR - para escalonar o nível de risco dos perigos decorrentes das ações executadas neste local de trabalho. Os resultados obtidos implicam em um risco elevado nas instalações e no processo de acabamento do mármore, implicando na proposição de soluções, uma vez que itens analisados apresentaram níveis de risco considerados catastróficos, assim como nível de perigo crítico, que precisam serem solucionados.

Palavras-chave: APR, Marmoraria, EPIs, SST. 


\section{INTRODUÇÃO}

Todo e qualquer agente dentro do setor produtivo é impulsionado a atualizar preceitos básicos em relação à missão, visão e valores que o norteiam devido às intensas mudanças e transformações ocorridas no mercado quanto aos âmbitos sociocultural, econômico e ambiental. Esta conjuntura exige das empresas um posicionamento eficiente e eficaz na gestão de seus negócios, de forma a não ter em sua competência limitada à eficiência técnico-econômica, mas que analise os custos e as oportunidades em áreas distintas e correlatas ao processo produtivo que utiliza na agregação de valor ao produto (PORTER, 2005).

Os impactos provocados pelas empresas, na tentativa de estabelecer suas relações com o meio ambiente e sobre as comunidades nos quais estão inseridas, provocam grandes e progressivas mudanças ao espaço onde estão localizadas. Tal fato se mostra evidente nas atividades de mineração e beneficiamento de rochas ornamentais, onde apesar dos efeitos socioeconômicos positivos nas localidades, provocam acentuadamente um impacto no ambiente e, consequentemente, sobre a população que reside em seu entorno.

Nos últimos anos, mudanças nas práticas de gestão dos recursos destas empresas, das quais estão inclusas a implantação de medidas de segurança no ambiente laboral, visam minimizar os acidentes de trabalho, doenças ocupacionais, bem como proteger a integridade e a capacidade de trabalho das pessoas envolvidas no processo produtivo.

\section{REFERENCIAL TEÓRICO}

\subsection{SAÚDE E SEGURANÇA DO TRABALHO}

O trabalho, de acordo com Centurion (2003), "é a transformação de matéria prima em bens necessários à sobrevivência humana, é energia humana física e mental, [...] e devido à pressão e o estresse, [...] surgem o risco e o cansaço". Desta forma, as probabilidades de ocorrência de acidentes se tornam reais e contramedidas para minimizar os riscos, no qual se adotam metodologias contempladas pela Saúde e Segurança do Trabalho - SST.

A SST é fundamentada como sendo a promoção e a manutenção de elevados níveis de qualidade de vida e bem-estar social, físico e mental de todos os trabalhadores em seu ambiente laboral, atuando inclusive na prevenção de doenças e acidentes relacionados ao trabalho, através do controle dos riscos resultantes das condições de trabalho em que os trabalhadores são expostos (MUNIZ, 2016).

No Brasil, a SST é regulamentada pela portaria 3214/78 do Ministério do Trabalho e Emprego - MTE, que publicou a Lei 6514/77, habilitando a execução e devida regulamentação das Normas Regulamentadoras - NR, que estabelecem os parâmetros e todos os critérios a serem observados e adotados na questão da SST, sendo a obrigação do cumprimento por parte das empresas de caráter privado e/ou público, inclusos órgãos e autarquias de todas as esferas de atuação (CAMISASSA, 2015).

\subsection{ACIDENTE DE TRABALHO}

Santana et al (2006) descrevem o acidente de trabalho como sendo as lesões decorrentes de causas externas, aos traumas e envenenamentos ocorridos no ambiente de trabalho durante a execução de atividades ocupacionais e/ou durante o período in itinere e às doenças ocupacionais.

Segundo informações da Organização Internacional do Trabalho - OIT (2011), 2,34 milhões de trabalhadores morrem a cada ano de doenças ocupacionais e acidentes ocorridos no ambiente de trabalho, sendo deste número 2,02 milhões advindos das enfermidades relacionadas com 0 desempenhar da atividade profissional e 321 mil por questão de acidente do tipo físico. No caso do Brasil, o total de acidentes estipulados aproxima-se do quantitativo de 5 milhões, valor seis vezes superior ao total de registros notificados no Comunicado de Acidente de Trabalho - CAT - entre 2012 e 2013 (ALMEIDA, 2016). Estima-se que 4\% do Produto Interno Bruto - PIB - dos países desenvolvidos sejam gastos por doenças e agravos ocupacionais, podendo aumentar esta taxa para $10 \%$ quando se trata do assunto em países emergentes (SANTANA et al, 2006)

A legislação trabalhista brasileira, em seu artigo 19 na Lei ำ 8.213/91, define o acidente de trabalho como sendo "aquele que ocorre pelo exercício do trabalho, a serviço da empresa, provocando lesão corporal ou perturbação funcional que cause a morte, ou 
a perda, ou a redução permanente ou temporária da capacidade para o trabalho" (BRASIL, 1991). A norma NBR 14280 (ABNT, 2001) define o acidente de trabalho como uma ocorrência imprevista e indesejável, instantânea ou não em função do tempo, relacionada com o exercício do trabalho, que resulte ou possa resultar em lesão pessoal, sendo estes classificados como:

- Acidente do trabalho grave;

- Acidente do trabalho fatal;

- Acidente típico;

- Acidente de trajeto;

- Acidente devido à doença do trabalho.

Esta classificação introduziu a possibilidade de identificar os riscos no ambiente de trabalho, tornando 0 ambiente mais susceptível ao trabalhador estar sujeito ao dano laboral. A NR 9 (FUNDACENTRO, 2008) considera como riscos ambientais os agentes físicos, químicos e/ou biológicos existentes nos ambientes de trabalho que, em função de sua natureza, concentração ou intensidade e tempo de exposição, são capazes de causar danos à saúde do trabalhador.

Para o caso dos trabalhadores do setor de rochas ornamentais, especificando a transformação de rochas brutas em rochas polidas. De maneira geral, estes estão expostos a diversos riscos que comprometem a integridade física e mental dos mesmos (BARBOSA FILHO, 2010). Existe um elevado risco de acidentes previstos na atividade, que incluem manuseio de aditivos químicos, altos níveis de ruído e inalação de particulados, que podem levar ao afastamento do trabalhador por períodos de tempo consideráveis, provocando danos de nível financeiro e de saúde ao trabalhador, agravando até o óbito.

\subsection{ANÁLISE PRELIMINAR DE RISCOS}

A Análise Preliminar de Riscos - APR - é uma ferramenta que, segundo Chaves (2016), se faz eficaz para a identificação de potenciais riscos no ambiente de trabalho, no qual Barbosa Filho (2010) afirma que "é uma técnica qualitativa realizada previamente à execução das tarefas que [...] estabelece meios e medidas a serem cumpridas". Ao partir da identificação antecipada de elementos e fatores ambientais que representem perigo elevado, analisa-se de maneira detalhada cada uma das etapas do processo, possibilitando assim a escolha das ações mais adequadas para minimizar a possibilidade de acidentes. De acordo com Seiffert (2010), a elaboração de um APR é realizada através de algumas etapas como:

- Revisão de problemas conhecidos: busca por analogias e similaridades com outros sistemas;

- Revisão da missão a que se destina: atenção aos objetivos, exigências de desempenho, funções e procedimentos, estabelecer limites de atuação e delimitar o sistema;

- Determinação dos principais riscos: apontar riscos com potencialidade para lesões diretas imediatas, perdas de função, materiais e danos aos equipamentos;

- Revisão dos meios de eliminação ou Risk Controlling: investigar os meios de eliminação e controle dos riscos, estabelecer as melhores opções compatíveis com as exigências do sistema;

De acordo com Benite (2004), a elaboração da APR é feita por meio de um processo indutivo, sendo estes dados comumente registrados em formulário, conforme tabela 1 que exibe os perigos identificados, assim como as causas e os danos causados, levando em consideração na avaliação dos riscos a probabilidade para acontecer o acidente e a gravidade do acidente, obtendo o valor considerável. Soma-se que as escalas podem ser quantificadas e modificadas, conforme a tabela 2 seguinte. 
TABELA 1 - Modelo de formulário APR.

\begin{tabular}{|c|c|c|c|c|c|}
\hline \multicolumn{6}{|c|}{ Análise Preliminar de Risco (APR) } \\
\hline \multicolumn{6}{|c|}{ Origem: } \\
\hline \multicolumn{3}{|c|}{ Identificação dos Perigos } & \multicolumn{3}{|c|}{ Avaliação de Risco } \\
\hline Perigo & Situação & Danos & Probabilidade & Gravidade & Risco \\
\hline \multicolumn{2}{|c|}{ P - Probabilidade } & \multicolumn{2}{|c|}{ G-Gravidade } & \multicolumn{2}{|c|}{$P \times G=$ Riscos } \\
\hline
\end{tabular}

TABELA 2 - Escala de probabilidade e gravidade.

\begin{tabular}{|c|c|c|c|}
\multicolumn{2}{|c|}{ Escala de Probabilidade } & Escala de Gravidade \\
\hline Alta (3) & Esperado que ocorra & Alta (3) & Morte e lesões incapacitantes \\
\hline Média (2) & Provável de ocorrer & Média (2) & $\begin{array}{c}\text { Doenças ocupacionais e lesões } \\
\text { menores }\end{array}$ \\
\hline Baixa (1) & Improvável de ocorrer & Baixa(1) & Danos materiais e prejuízos ao processo \\
\hline
\end{tabular}

Fonte: Adaptado de Benite (2004).

Conforme tabela 3, quanto à gradação dos riscos, estes podem ser classificados quanto ao potencial danoso ao sistema produtivo e aos recursos humanos, observando o grau, a severidade e as características.

TABELA 3 - Gradação de riscos pela Análise Preliminar de Riscos.

\begin{tabular}{|c|c|c|}
\hline Grau & Severidade & Características \\
\hline I & Desprezível & $\begin{array}{c}\text { Não causa degradação impeditiva de funcionamento ao sistema produtivo (processo } \\
\text { ou instalações) ou ameaças os recursos humanos. }\end{array}$ \\
\hline II & $\begin{array}{l}\text { Marginal/ } \\
\text { Limítrofe }\end{array}$ & $\begin{array}{c}\text { Degradação moderada com danos menores, sem causar lesões. Compensável ou } \\
\text { controlável. }\end{array}$ \\
\hline III & Crítica & Degradação crítica. Dano substancial, com lesões, impondo ações imediatas. \\
\hline IV & Catastrófica & $\begin{array}{c}\text { Causador de séria degradação ou perda do sistema produtivo, bem como lesões } \\
\text { graves ou mortes. }\end{array}$ \\
\hline
\end{tabular}

Fonte: Barbosa Filho, 2010.

Considerando-se conjuntamente a frequência esperada para a sua ocorrência, é possível estimar qualitativamente o risco de um empreendimento ou de uma atividade produtiva qualquer, conforme tabela 4 . De posse das avaliações quanto à frequência esperada e à gravidade das ocorrências, é possível estabelecer uma priorização relativa entre os casos possíveis, suas potenciais consequências, bem como no tocante às medidas decorrentes a serem tomadas, conforme determinada pela matriz de classificação de riscos na figura 1. 
TABELA 4 - Análise Preliminar de Risco de um empreendimento qualquer.

\begin{tabular}{|c|c|c|}
\hline Categoria & Frequência anual & Descrição \\
\hline A - Extremamente remota & $f<10-4$ & $\begin{array}{l}\text { Conceitualmente possível, mas de ocorrência improvável } \\
\text { durante toda a vida útil do sistema produtivo. }\end{array}$ \\
\hline B - Remota & $10-4<f<10-3$ & $\begin{array}{c}\text { Ocorrência não esperada durante a vida útil do sistema } \\
\text { produtivo. }\end{array}$ \\
\hline C - Pouco Provável & $10-3<f<10-2$ & $\begin{array}{l}\text { Pouco provável de ocorrer durante toda a vida útil do } \\
\text { sistema produtivo. }\end{array}$ \\
\hline D - Provável & $10-2<f<10-1$ & $\begin{array}{c}\text { Esperado ocorrer até uma vez durante a vida útil do sistema } \\
\text { produtivo. }\end{array}$ \\
\hline E - Frequente & $f>10-1$ & $\begin{array}{c}\text { Ocorrência esperada por várias vezes durante a vida útil do } \\
\text { sistema produtivo. }\end{array}$ \\
\hline
\end{tabular}

Fonte: Barbosa Filho, 2010.

FIGURA 1 - Matriz de classificação de riscos.

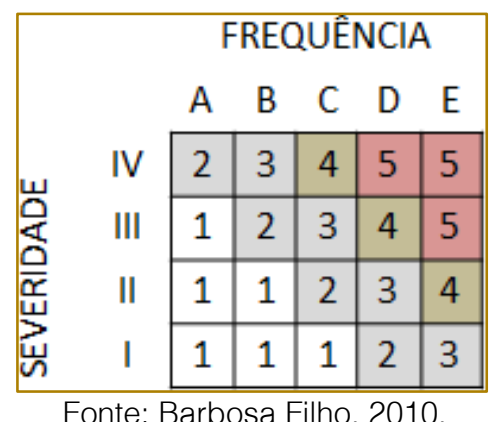

Nesta linha de condição, para os riscos do tipo 5, considerados como não toleráveis, as medidas e os controles existentes (salvaguardas) devem ser reforçados e ampliados de imediato com o intuito de reduzir a probabilidade de sua ocorrência ou de seus impactos, posto que, no estado atual em que se encontram, estes podem ser insuficientes.
Para os riscos do tipo 1 e 2, considerados toleráveis, será suficiente o cumprimento dos procedimentos planejados, observando-se o comportamento dos indivíduos e do próprio sistema produtivo ao longo de sua vida útil. Por sua vez, os riscos do tipo 3 e 4 devem igualmente ter medidas visando a redução do seu potencial danoso e a sua probabilidade de ocorrer, conforme tabela 5.

TABELA 5 - Relação Severidade-Frequência-Risco.

\begin{tabular}{|c|c|c|}
\hline \multicolumn{2}{|c}{ Severidade } & \multicolumn{2}{c}{ Frequência } & Risco \\
\hline I- Desprezível & A - Extremamente Remota & $1-$ Desprezível \\
\hline II - Marginal & B - Remota & $2-$ Menor \\
\hline III - Crítica & C - Improvável & $3-$ Moderado \\
\hline IV - Catastrófica & D - Provável & 4 - Sério \\
\hline & E - Frequente & 5 - Crítico \\
\hline
\end{tabular}

Fonte: Barbosa Filho, 2010. 


\subsection{MARMORARIA}

A marmoraria é um ramo da atividade industrial regulamentada pelas leis federais $\mathrm{n}^{\circ}$ 6567/78, no 6938/81 e ำ 9605/98, além da NBR 10004 (classificação ambiental do resíduo). Seu produto base, o mármore, descreve todas as rochas carbonáticas capazes de receber algum tipo de polimento
(FUNDACENTRO, 2008; SEBRAE, 2018), sendo a composição mineralógica dependente da composição química do sedimento e do grau metamórfico das rochas. O processo produtivo se divide em sete etapas distintas como observado na figura 2.

FIGURA 2 - Fluxograma do processo de produção dos mármores.

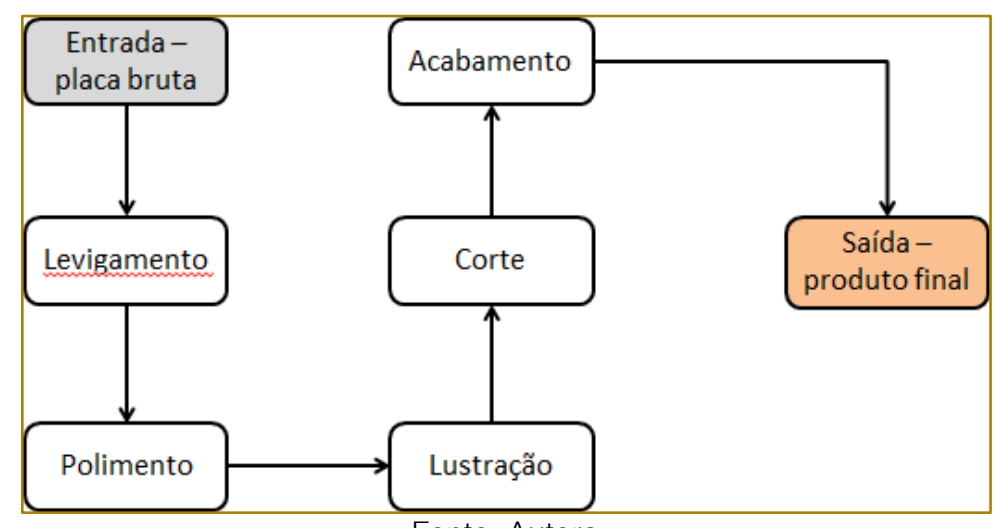

Os insumos necessários para a produção dos mármores comerciais são a granalha, lâminas, a cal, a borra de carbureto, água e energia. Estes insumos serão usados para a produção de uma mistura abrasiva para realizar o polimento das rochas, e são disponibilizados os processos de polimento, dos quais destacam-se:

- Processo flameado: mármore e granito queimados utilizando oxigênio, água e fogo. Resulta em material áspero e com acabamento especial;

- Processo levigado: polimento não concluído, usando apenas os grãos iniciais do polimento. Resulta em material não áspero e opaco;

- Processo jateado: uso de forte jato de areia e granalha, resultando em rocha antiderrapante;

- Processo apicoado: as rochas são picotadas por pícolas, resultando em material áspero, com acabamento peculiar e menos áspero que o flameado.

As maiores concentrações de mármore no Brasil estão localizados no Espírito Santo, sendo este também o maior produtor de rochas ornamentais do país, movimentando um mercado de US\$2,1 bilhões anuais, destacando a comercialização interna e externa, além das transações de máquinas, equipamentos, insumos e materiais de consumo e serviços.

\subsection{RELAÇÃO ENTRE SST E MARMORARIA}

Um dos maiores problemas referentes à SST no setor de marmoraria são os riscos ocupacionais provocados pelo contato direto com o maquinário e com os agentes químicos gerados no processo de tratamento superficial das rochas, como o polimento. Risco é definido como sendo tudo o que possuir o potencial de causar doenças ou acidentes (SCHETTINI, 2014).

Destaca-se entre os riscos possíveis do setor - referente aos resíduos particulados, conforme a descrição feita por Fundacentro (2008) sobre as sobras de produção das marmorarias, descrevendo a poeira suspensa constituída de mármores, granitos e ardósias. Granitos e ardósias possuem em sua composição sílica, elemento comum na natureza e que varia conforme a condição geológica do local onde a rocha foi extraída, podendo possuir até 65\% (granito) e 30\% (ardósia) de percentual de concentração. Mármores não possuem sílica, com rara exceção do mármore travertino (até 15\%). 
Outros pontos estão referentes ao processo produtivo do setor marmoreiro, nos quais são elencados o transporte interno dos insumos, armazenamento, leiaute e equipamentos de agregação de valor ao produto, os riscos referentes aos acidentes se intensificam quando realizados de forma incorreta ou perigosa.

\section{METODOLOGIA}

A pesquisa realizada se caracteriza como descritiva devido às observações e descrições com o intuito de conhecer de forma detalhada 0 ambiente $e$ as características da atividade (YIN, 2001; GIL, 2002), que auxiliaram na construção de tabelas e na aplicação da APR na marmoraria objeto de estudo, facilitando a enumeração das possíveis causas que culminou para o problema com maior fator de risco mediante a APR, utilizando as variáveis frequência e severidade para obter uma matriz de classificação de riscos.

Levantou-se com a APR problemas sobre processo de produção, acidentes de trabalho, o uso de EPIs e condições de trabalho, usando um checklist baseado no Manual de Referência para Marmorarias do Fundacentro
(2008) e observando as seguintes NR: NR 6 Equipamentos de Proteção Individual, NR 10 Segurança em Instalações e Serviços em Eletricidade, NR 11 - Anexo I - Transporte, movimentação, armazenagem e manuseio de materiais de chapas de mármore, granito e outras rochas, NR 12 - Segurança no Trabalho em Máquinas e Equipamentos (CAMISASSA, 2015).

\section{RESULTADOS E DISCUSSÕES}

\subsection{DESCRIÇÃO DO PROCESSO PRODUTIVO}

Conforme figura 3 , o processo se inicia no descarregamento das chapas do caminhão transportador de forma manual, onde as chapas de mármore e de granito possuem um peso específico médio de $60 \mathrm{~kg} / \mathrm{m}^{2}$, dimensões de 3,00×2,00 metros e espessura variando de 2 (dois) a 3 (três) $\mathrm{cm}$. Há a necessidade de 3 funcionários para a execução da atividade, onde 1 realiza a manobra da placa e 2 outros ficam no nível inferior ao piso do caminhão para receberem estas placas. Destaca-se que não há uso de luvas ou outros equipamentos de segurança por parte dos empregados por julgarem desnecessários ou incômodos.

FIGURA 3 - Ciclo de produção do mármore comercial.

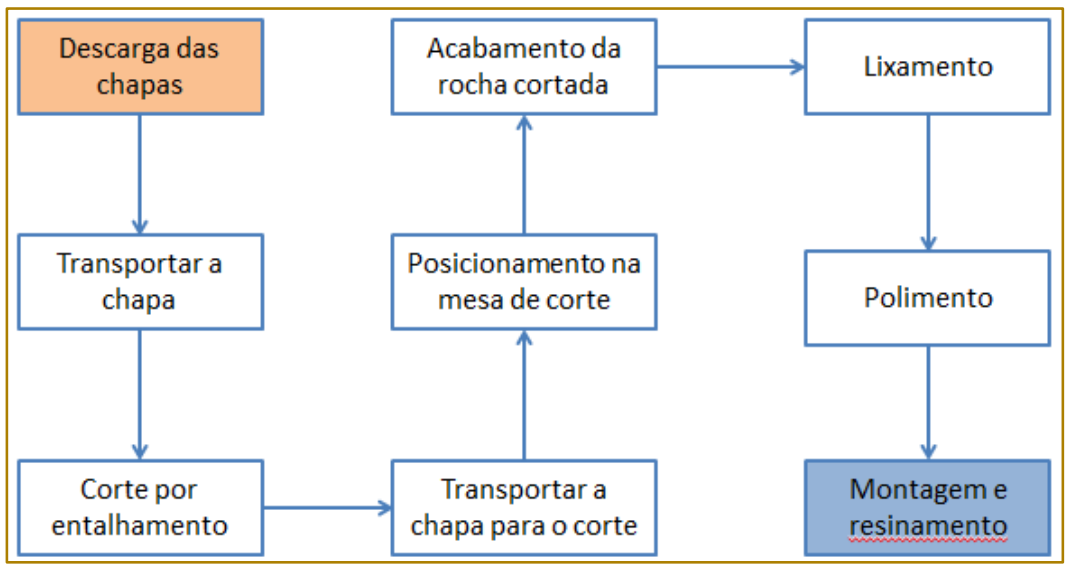

Fonte: Autora.

Após o descarregamento, é necessário transportar as chapas até o estoque usando um dispositivo de transporte adaptado, porém não funcional, de $20 \mathrm{~cm}$ de altura e com duas rodas, no qual dois funcionários empurravam a chapa apoiada em um solo irregular e não pavimentado, precisando segurar as pedras para que não tombassem. Desta forma, os funcionários sujeitam-se aos acidentes de trabalho como lesões cortantes e esmagamento.

Quanto ao processo de produção para beneficiar a rocha bruta, ocorre a preparação da chapa no estoque, realizada por 2 funcionários do corte: um serrador e um ajudante. Estes usam uma talhadeira e uma marreta para quebrar a rocha nas dimensões 
desejadas, sendo que estes não usavam óculos de proteção e luvas de raspa. Desta forma, os mesmos estavam submetidos ao

FIGURA 4 - Processo de corte realizado na marmoraria estudada.

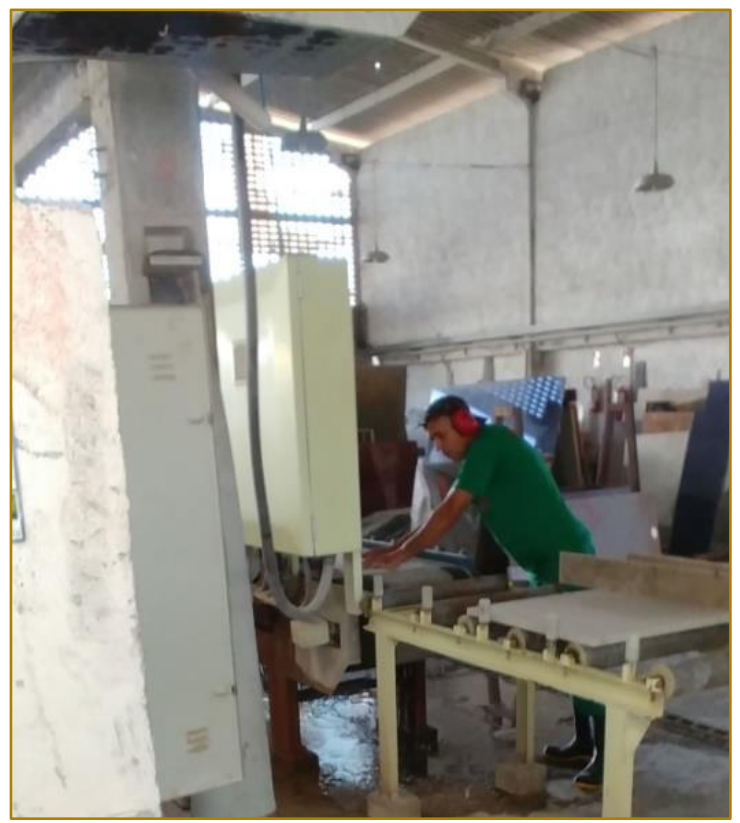

risco de lesões nas mãos e de lesões nos olhos com estilhaços gerados pela quebra da placa.

FIGURA 5 - Setor de montagem final e resinamento do mármore.

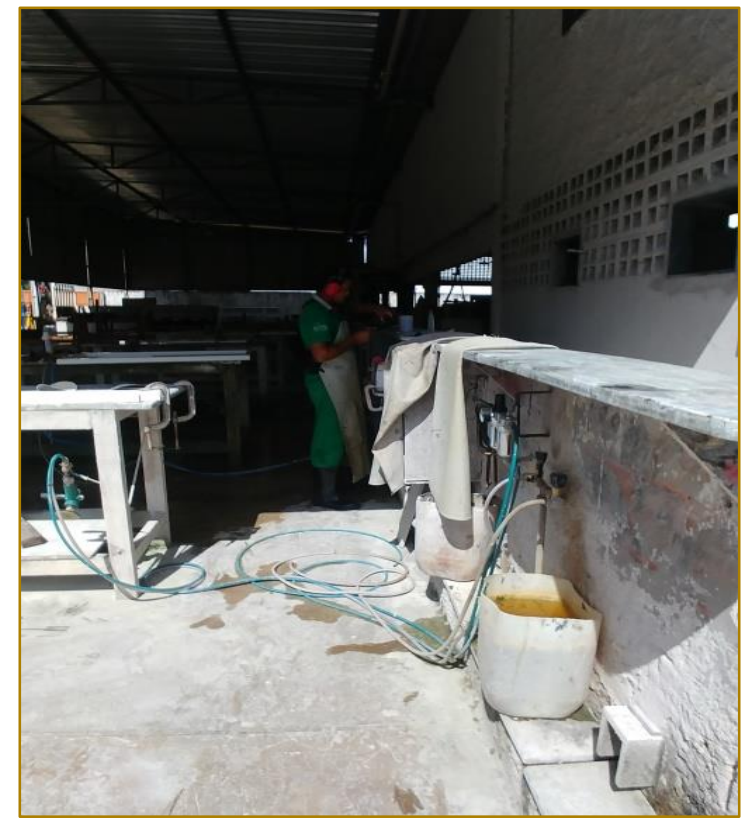

Fonte: Autora

De acordo com a figura 4, para executar 0 corte da peça nas especificações pedidas pelo cliente, o operador posiciona a chapa na mesa de corte, realiza os ajustes da altura do disco de serragem, liga a máquina e então liga uma válvula de acionamento da água. Com a mão direita gira a manivela e com a mão esquerda apoia e empurra a chapa, se aproximando perigosamente ao disco de serragem, mantida de forma desprotegida, podendo acarretar em grave lesão no menor descuido. Ressalta-se que as máquinas e os equipamentos possuem isolamento elétrico.

O acabamento final da peça é realizado com lixamento, polimento, montagem e resinamento. $\mathrm{O}$ lixamento consiste no operador usar uma lixadeira angular de $5 \mathrm{~kg} \mathrm{e}$ 3 discos de desbaste para retirar as quinas e dar forma as bordas do produto. Nenhum dos equipamentos contém dispositivos de proteção, deixando o disco da lixadeira totalmente exposto e aumentando a probabilidade de ocorrerem acidentes. Há o agravante dos equipamentos serem ligados em tomadas distantes das bancadas de acabamento, fazendo com que toda a fiação fique espalhada pela área de produção das marmorarias. No polimento, a atividade é executada utilizando politrizes e média de 06 lixas de diferentes granulometrias, objetivando um produto com superfície lisa e brilhosa. Nestas operações, os funcionários estão expostos aos mesmos riscos que o lixamento.

Como observado na figura 5, a última etapa do processo de acabamento é a montagem e resinamento das peças, onde os funcionários colam as partes do produto utilizando silicone ou massa plástica e finalizam o processo aplicando uma resina sob o produto. Os perigos observados na atividade estão no manuseio de peças pesadas de granito, mármore ou ardósia que podem cair da bancada e lesionar gravemente os membros inferiores.

\subsection{RESULTADOS DA APR NO OBJETO DE ESTUDO}

Neste ponto, analisou-se os riscos provenientes das 03 fases de produção: descarregamento, corte e acabamento, além das instalações e organização da empresa. 
Desta forma, as tabelas 6 a 9 trazem, a partir da correlação entre as variáveis frequência e severidade, o nível de risco e as recomendações para cada risco de acidente identificado.

TABELA 6 - APR: descarregamento e transporte de chapas

\begin{tabular}{|c|c|}
\hline Riscos & Acidente \\
\hline Causas & Transporte manual de cargas pesadas e sem proteção \\
\hline Efeito & Lesões nos membros superiores e inferiores; Possibilidade de fatalidade. \\
\hline Frequência & E - frequente \\
\hline Severidade & IV - catastrófico \\
\hline Nível de risco & 5 - Crítico \\
\hline Observações & $\begin{array}{l}\text { Uso de EPI com bico de aço e luvas de raspa; Uso de meios mecânicos para } \\
\text { transporte das chapas. }\end{array}$ \\
\hline
\end{tabular}

Fonte: Autora.

TABELA 7 - APR: serragem

\begin{tabular}{|c|c|}
\hline Riscos & Acidente \\
\hline Causas & Ausência de proteção no disco de corte da serra \\
\hline Efeito & Lesões nos membros superiores; Corte grave e/ou amputação dos dedos da mão. \\
\hline Frequência & $E$ - frequente \\
\hline Severidade & III - Crítico \\
\hline Nível de risco & 5 - crítico \\
\hline Observações & Aquisição e uso de dispositivo de proteção \\
\hline
\end{tabular}

Fonte: Autora.

\section{TABELA 8 - APR: Acabamento}

\begin{tabular}{|l|l|}
\hline \multicolumn{1}{|c|}{ Riscos } & $\begin{array}{l}\text { Ausência dos dispositivos de proteção nas lixadeiras; Ausência de EPIs e/ou uso } \\
\text { inadequado dos EPIs; Armazenamento e manuseio inadequados de materiais } \\
\text { inflamáveis; }\end{array}$ \\
\hline Efeitos & $\begin{array}{l}\text { Corte grave nos membros superiores e tronco; Lesão nos membros superiores, } \\
\text { inferiores, tronco e olhos; Queimaduras nos membros superiores; }\end{array}$ \\
\hline Frequências & E- frequente; E - frequente; D - provável \\
\hline Severidade & II - Marginal; II - Marginal; II - Marginal \\
\hline Nível de risco & 4 - sério; 4 - sério; 3 - moderado \\
\hline Observações & $\begin{array}{l}\text { Aquisição e uso de dispositivos de proteção para lixadeiras; Aquisição de EPIs, definir } \\
\text { procedimentos para uso de máquinas; Sinalização de produtos inflamáveis. }\end{array}$ \\
\hline
\end{tabular}

Fonte: Autora. 
TABELA 9 - APR: instalações

\begin{tabular}{|l|l|}
\multicolumn{2}{|c|}{ Riscos } \\
\hline Causas & $\begin{array}{l}\text { Fiação desprotegida com presença de água; Solo irregular e não pavimentado; } \\
\text { Obstrução das áreas de trânsito por estoques e produtos finalizados. }\end{array}$ \\
\hline Efeitos & Choques Elétricos; Corte grave ou amputação de mão e dedos; Queda e/ou fraturas. \\
\hline Frequência & D - provável; D - provável; E - frequente. \\
\hline Severidade & IV - catastrófica; II - marginal; II - marginal. \\
\hline Nível de risco & 5 - crítico; 3 - moderado; 4 - sério. \\
\hline Observações & $\begin{array}{l}\text { Construção e manutenção de canaletas, proteção da fiação elétrica e instalação de } \\
\text { tomadas próximas a bancada e atendendo a NR10; Pavimentação e nivelamento do } \\
\text { solo; Adequação do leiaute da marmoraria, definir área de estocagem de insumo e de } \\
\text { produto acabado, destinar adequadamente os refugos. }\end{array}$ \\
\hline
\end{tabular}

Fonte: Autora.

\section{CONCLUSÕES}

Após obtenção de resultados da APR, identificaram-se quais riscos de acidentes que os trabalhadores da empresa do setor marmoreiro estão expostos, classificando-os conforme seu nível de risco e prioridade de intervenção. Ressalta-se que a exposição a agentes químicos como a poeira mineral (sílica, coríndon), o ruído, os riscos ergonômicos e de acidentes aumentam a probabilidade da saúde do trabalhador ser mais afetada de forma negativa. Com os riscos levantados, foi possível sugerir ações preventivas para eliminação e minimização dos riscos existentes, assim como tomou-se ciência da necessidade urgente em se modificar os procedimentos de SST no objeto de estudo.

\section{REFERÊNCIAS}

[1] ABNT - ASSOCIAÇÃO BRASILEIRA DE NORMAS TÉCNICAS. NBR 14280: cadastro de acidentes de trabalho procedimento e classificação. Rio de Janeiro: ABNT, 2001.

[2] ALMEIDA, C. Atividade de risco: 5 milhões de trabalhadores se acidentaram em um ano, diz IBGE. Publicado no O Globo, atualizado em 2016. Disponível em https://oglobo.globo.com/ Acesso em 14/12/2017.

[3] BARBOSA FILHO, A. N. Segurança do trabalho \& gestão ambiental. $3^{\underline{a}}$ edição. São Paulo: Atlas, 2010.
Contudo, tais modificações devem estar fortemente acompanhadas da capacitação dos recursos humanos para a execução segura das tarefas, além da melhoria de insumos e ferramentas para minimizar a produção de poeira e reduzir as probabilidades da ocorrência de acidentes e doenças. Considerando que os problemas ocupacionais gerados pela inalação de sílica cristalina particulada não foi observado neste estudo, demandam-se estudos estatísticos referentes aos efeitos das doenças respiratórias, cutâneas e ocupacionais referentes, assim como os efeitos diretos e indiretos que podem provocar ao trabalhador, às empresas e ao sistema previdenciário.

[4] BENITE, A. G. Sistema de gestão de segurança e saúde do trabalho para empresas construtoras. Dissertação. (Mestrado em Construção Civil). Universidade de São Paulo, 2004.

[5] BRASIL. Lei no 8.213, de 21 de Julho de 1991. Dispõe sobre os planos de Benefícios da Previdência Social e dá outras providências. Brasília: Diário Oficial da União, 14/08/1991.

[6] CAMISASSA, M. Q. Segurança e saúde no trabalho: NRs 1 a 36 comentadas e descomplicadas. São Paulo: Método, 2015.

[7] CENTURION, J. M. R. Segurança do trabalho na distribuição do acetileno. 
Dissertação. 168f. (Mestrado em Engenharia de Produção). Universidade Federal de Santa Catarina, 2016.

[8] CHAVES, A. Análise preliminar de risco. Disponível em https://areasst.com Acesso em 30/05/2018.

[9] FUNDACENTRO. Marmorarias manual de referência: recomendações de segurança e saúde no trabalho. São Paulo: Fundacentro, 2008.

[10] GIL, A. C. Como elaborar projetos de pesquisa. 4aㅡ edição. São Paulo: Atlas, 2002.

[11] MUNIZ, D. D. Influência da gestão da segurança e saúde ocupacional e dos resíduos de construção e demolição na responsabilidade social: um estudo de caso. Dissertação. 184 fls. (Mestrado em Engenharia de Produção). Universidade Federal da Paraíba, 2016.

[12] PORTER, M. E. Estratégia competitiva: técnicas para análise de indústrias e da concorrência. $1^{a \underline{a}}$ edição. Rio de Janeiro: Elsevier/Campus, 2005.

[13] ORGANIZAÇÃO INTERNACIONAL DO TRABALHO. Tendências mundiais e desafios da segurança e saúde no trabalho. ILO introductory report: global trends and challenges on occupational safety and health. XIX World Congress on Safety and Health at Work. Genebra: International Labour Office, 2011.

[14] SANTANA, V. S. et al. Acidentes de trabalho: custos previdenciários e dias de trabalho perdidos. Revista da Saúde Pública, 40(6):1004-12, 2006.

[15] SCHETTINI, C. F. L. Avaliação da exposição ao ruído ocupacional em galpões de triagem de resíduos recicláveis. Monografia. 69 f. (Especialização em Engenharia de Segurança do Trabalho). Universidade Tecnológica Federal do Paraná, 2014.

[16] SEBRAE - SERVIÇO DE APOIO A MICROEMPRESA BRASILEIRA. Marmoraria. Disponível em https://www.es.sebrae.com.br Acesso em 01/06/2018.

[17] SEIFFERT, M. E. B. Sistemas de gestão ambiental (ISO 14001) e saúde e segurança operacional (OHSAS 18001): vantagens da implantação integrada. $2^{2}$ edição. São Paulo: Atlas, 2010.

[18] YIN, R. K. Estudo de caso: planejamento e métodos. $2^{\mathrm{a}}$ edição. Porto Alegre: Bookman, 2001. 


\section{Bapítulo 17}

\section{PROJETO DO TRABALHO EM UM TORNO CNC: DA ANÁLISE À SUGESTÃO DE ADEQUAÇÕES DAS CONDIÇÕES DE SAÚDE E SEGURANÇA}

Joele Marques

Antônio Felipe Machado

Juliana Machion Gonçalves

Fábio Morais Borges

Resumo: A indústria de máquinas e equipamentos contribui para desenvolvimento econômico do país, e vem evoluindo nas últimas décadas. A fabricação de peças em um menor tempo possível, como é o caso do torno de Comando Numérico Computadorizado (CNC) acompanha essa evolução, produzindo peças complexas em um curto espaço de tempo. A atividade de operação do torno CNC envolve riscos ergonômicos e de acidentes. Esse trabalho teve como objetivo a realização do o projeto de trabalho em um torno CNC, de forma a avaliar a situação de trabalho e propor soluções para minimizar os riscos ocupacionais existentes, de forma a buscar o equilíbrio saúde - produtividade. Foi adotado como pressuposto teórico metodológico a Análise Ergonômica do Trabalho, a fim e compreender a forma como o trabalho era realizado, identificando o problema, os riscos envolvidos com prováveis causas, compreendendo o trabalho prescrito e real e chegando a um diagnóstico da situação de trabalho. Foram verificados os seguintes problemas: adoção de postura inadequada durante o período de programação do torno CNC, onde o trabalhador permanece com os membros superiores levantados, risco de aprisionamento de membros entre partes rotativas e choque elétrico. Além disso, foi verificado a existência de alta carga cognitiva na atividade na etapa de programação da máquina, onde é exigido do trabalhador, concentração, memória e poder de decisão, aliados à necessidade de agilidade para atender às demandas das empresas. Por fim, foi realizada a proposta de soluções através da utilização de software de CAM (Manufatura Assistida por Computador) via wifi ou cartão de armazenamento, instalação de dispositivos de segurança e diversificação de tarefas.

Palavras-chave: Torno CNC, AET - Analise Ergonômica do Trabalho, segurança do trabalho, Projeto do Trabalho 


\section{INTRODUÇÃO}

As condições de trabalho, a saúde e os acidentes são foco de estudos e pesquisas desde o início da industrialização até as mudanças na forma de organização do trabalho, com a introdução da microeletrônica. Os modernos projetos de máquinas-ferramenta, em sintonia com os desejos e as necessidades do mercado, vêm desenvolvendo equipamentos versáteis e flexíveis que proporcionam, cada vez mais, melhores resultados e desempenho (FERRARI, 2015).

De acordo com o Anuário Estatístico da Previdência Social - Brasil (2015), a indústria de transformação apresentou um total de 152 mil acidentes de trabalho, onde o subsetor de Fabricação de produtos de metal, contribui com 11 mil acidentes. Nos serviços de usinagem, tornearia e solda, foram registrados 1.152 acidentes de trabalho. Só na Paraíba em 2015, ocorreram 4.184 acidentes (BRASIL, 2015).

Os modernos tornos automáticos a comando numérico permitem a produção econômica de pequenas séries, face ao rápido tempo de preparação da máquina. Possuem vantagens em economia de mão de obra, realização da produção de forma constante, qualidade constante das peças usinadas, e o desgaste uniforme das ferramentas de corte (FERRARI, 2002).

Nos processos tecnológicos mais avançados, onde ocorre a introdução da robótica, são os trabalhadores de manutenção os mais expostos aos riscos mecânicos. Neste contexto, estes riscos estão ficando menos visíveis e menos óbvios, reforçando a necessidade de maior atenção e uma melhor identificação (VILELA, 2000).

Um ambiente de trabalho seguro contribui para a proteção da integridade física e mental do trabalhador por meio da redução do número de acidentes e doenças ocupacionais, assim como, reduziu os números e tempos de afastamentos por motivo de doenças e/ou acidentes, proporcionando maior tempo de trabalho e produtividade para a empresa (IIDA, 2005).

Por fim, o objetivo desse artigo foi o de realizar o análise e projeto de trabalho em um torno CNC, de forma a avaliar a situação de trabalho e propor soluções para minimizar os riscos ocupacionais existentes, de forma a buscar o equilíbrio saúde - produtividade.
Dessa forma, foi caracterizada a atividade estudada, com identificação dos riscos, prováveis causas e controles existentes para cada etapa da atividade, resolução dos riscos identificados, propondo soluções para adequação das condições de saúde e segurança do posto de trabalho analisado.

\section{REFERENCIAL TEÓRICO}

A análise de um posto de trabalho é um modelo metodológico que possibilita 0 entendimento das situações encontradas nos postos, "investigando os fatores que influenciam na eficiência e desempenho da situação estudada, com a finalidade de melhorar o conforto e segurança na execução do trabalho e aumentar a produtividade[...]" (CAMAROTTO, 2007).

Projeto de trabalho é o dimensionamento dos recursos materiais e organizacionais necessários à melhor interação entre todos os fatores técnicos, organizacionais e humanos para a realização de tarefas de trabalho, sem sobrecargas e com a maior eficiência possível (BORGES, 2016).

O estudo do trabalho, possui a característica comum das técnicas organizativas de ser um procedimento sistemático usado como ferramenta de investigação e de aperfeiçoamento com a finalidade de aumentar o rendimento de uma unidade produtiva mediante a reorganização do trabalho (CAMAROTTO, 2007).

Para isso, faz-se necessário observar as formas que o trabalho é realizado e não como deve ser realizado. Ainda citando CAMAROTTO (2007), atualmente o estudo do trabalho não se restringe ao estudo dos tempos e movimentos, mas, incorpora também conceitos de ergonomia, segurança do trabalho, qualidade e organização do trabalho.

A Segurança do Trabalho engloba conhecimentos em torno dos perigos e riscos na atividade executada. Ao analisar os riscos, é possível identificar os potenciais perigos decorrentes da instalação de novas unidades e sistemas ou da própria operação da planta que opera com materiais perigosos. Com uma avaliação qualitativa dos riscos associados, identifica-se, desta forma, aqueles que requerem priorização, através de uma matriz de risco. Além disso, são sugeridas ações preventivas ou mitigadoras dos riscos a fim de eliminar as causas ou reduzir os efeitos 
decorrentes de acidentes de trabalho (CESARO, 2013).

A Ergonomia parte do pressuposto de compreender o trabalho para transformá-lo em sua interface com o trabalhador, as condições, a atividade real e os resultados (GUERIN et al, 2011). Para ela é importante identificar o problema, através de uma demanda e posteriormente, fazer uma análise detalhada da tarefa, compreendendo os processos e as operações (IIDA, 2005).

Por fim, a Engenharia de Métodos busca um melhor sequenciamento das ações desenvolvidas nas condições de trabalho, buscando melhorias na produtividade (MOTTA, 2009). De acordo com Robbins (2005) apud Motta (2009), por exemplo, os experimentos feitos por Gilbreth tiveram como propósito a otimização no que diz respeito ao desempenho do trabalho, uma vez que estudou acerca dos efeitos da fadiga do operário quanto à produtividade do mesmo. Pelo seu estudo, foi possível verificar que a fadiga faz com que o operário reduza a produtividade, rotatividade de mão-de-obra, como também o predispõe acidentes ou doenças oriundas do trabalho. Dessa forma, considerou a fadiga como redutora da eficiência do trabalho.

\section{METODOLOGIA}

O presente estudo foi desenvolvido a partir de uma pesquisa qualitativa, com base em estudo de caso, que segundo Yin (2015), analisa condições contextuais, analisando uma situação de trabalho de forma situada.

Para possibilitar a realização deste estudo, foi preciso haver uma base teórica detalhada, de forma fosse possível a elaboração de uma pesquisa bibliográfica. Além disso, como pressuposto teórico-metodológico, a Análise Ergonômica do Trabalho - AET (GUERIN et al, 2011)

Foram realizadas observações semiestruturadas em campo (VIANNA, 2003) e entrevistas com as partes interessadas (BONI \& QUARESMA, 2005). Após a escolha do posto de trabalho, começaram as visitas e acompanhamento das ações do trabalhador. Dessa forma, foi verificada a demanda inicial ligada à queixas no torno $\mathrm{CNC}$, situado no laboratório de metal mecânica. A caracterização da demanda pôde ser verificada por meio da aplicação do questionário nórdico.
A caracterização da empresa foi realizada por meio de observações diretas, visitas, registros fotográficos e coleta de dados que possibilitaram a elaboração do arranjo físico do posto de trabalho, avaliação de fluxos, mapofluxograma e fluxograma. O aplicativo da web para criar plantas chamado Floorplanner foi utilizado nessa elaboração do mapofluxograma e esquema de movimentação do trabalhador.

Em relação à análise de risco, foi realizada inspeção de segurança, levantamento de riscos, análise preliminar de riscos (APR) e construção de tabela com os dados desse levantamento.

No que se refere à tarefa e atividade, a partir do observado in loco, foram coletadas informações, elaborado gráfico homem $x$ máquina. Os principais aspectos analisados foram: manuseio de cargas, posturas corporais adotadas pelo colaborador, riscos ocupacionais presentes na atividade, arranjo físico do local, e avaliações de tempos e movimentos. Assim, foi possível realizar a construção de uma tabela que relacionasse a descrição do processo, os perigos e riscos envolvidos em cada etapa da atividade, e as observações quanto ao modo operatório da atividade.

Posteriormente, foi traçado o diagnóstico do posto de trabalho que confirmaram a existência da demanda. Posteriormente, foi elaborada uma tabela para a validação do diagnóstico com os operadores. Por meio de uma reunião de construção social, as soluções pré-definidas foram apresentadas à empresa para validação. Foi feito a priorização dos riscos existentes por meio da matriz GUT, ferramenta que permite priorizar os riscos identificados, considerando para isso a gravidade do risco, urgência e tendência. Após a validação foi construído o projeto, com propostas de soluções com especificação, para possível implementação.

\section{RESULTADOS}

Essa etapa tem o objetivo de apresentar a pesquisa realizada e caracterização da atividade estudada por meio das etapas da análise ergonômica do trabalho. 


\subsection{ANÁLISE DA DEMANDA E DA EMPRESA}

Foi aplicado o questionário nórdico, identificando dores em pescoço, membros superiores e costas.

O posto de trabalho analisado, pertence à uma instituição privada, de aprendizagem industrial, nacional e de grande porte, localizada na cidade de João Pessoa, Paraíba. Realiza qualificação de trabalhadores e presta serviços técnicos e tecnológicos a outras empresas, como consultoria e assistência ao setor produtivo, laboratoriais, pesquisa aplicada e informação tecnológica.
Apresenta arranjo físico do tipo funcional ou por processo, uma vez que: o setor de metal mecânica encontra-se organizado de acordo com as funções de seus recursos, onde a peça se desloca de acordo com a necessidade de suas operações, e a máquina CNC tem capacidade de usinar inúmeras variedades de peças.

As observações do posto do trabalho também propiciaram o registro do seu processo produtivo, mediante a realização do gráfico de fluxo de processo ou fluxograma (Figura 1):

Figura 1: Gráfico de fluxo do processo

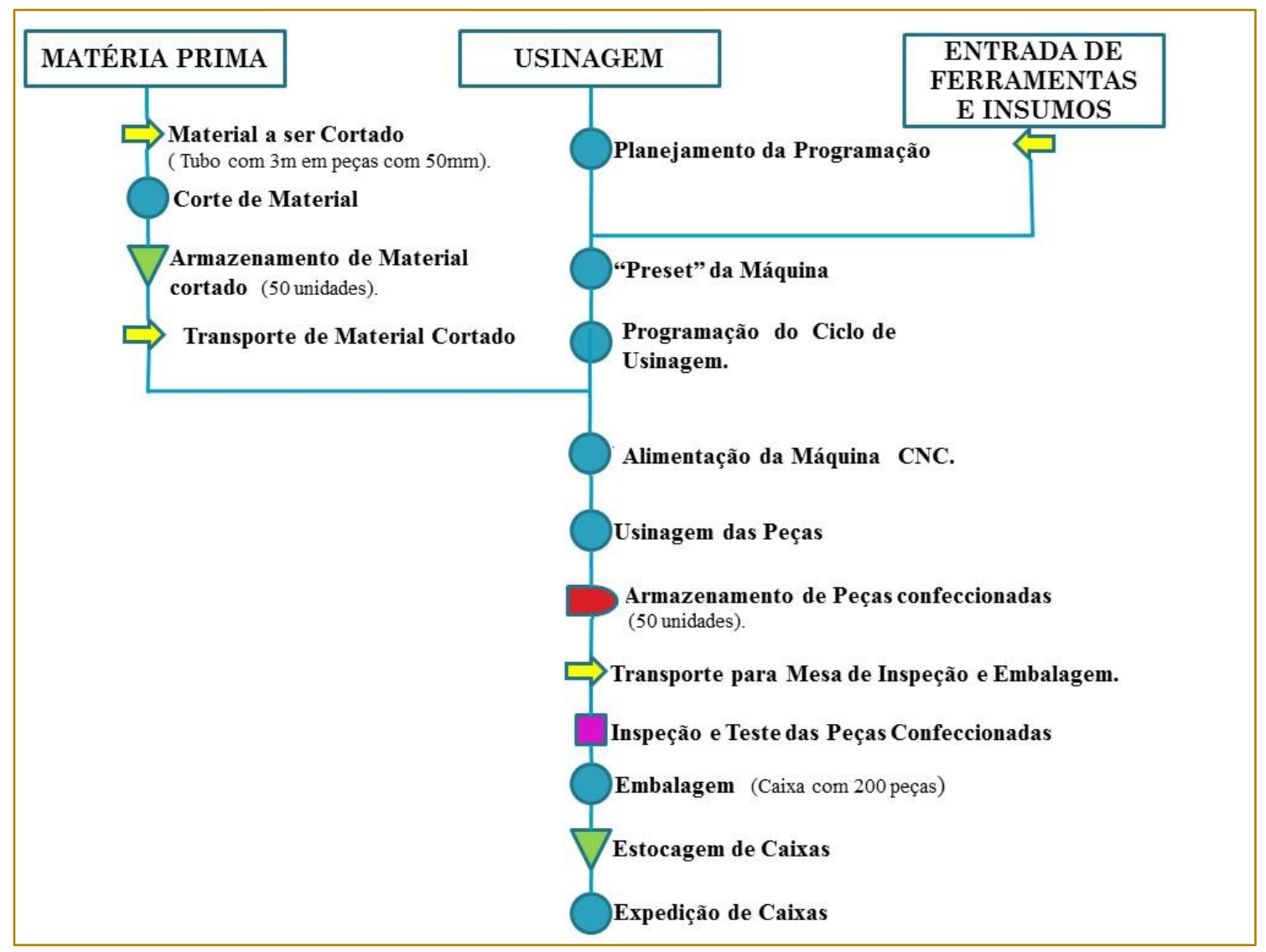

Fonte: Elaborado pelo autor (2017)

O layout e a movimentação realizada pelo operador do torno em seu posto de trabalho, podem ser verificados por meio do mapofluxograma do processo elaborado em conformidade com as observações diretas realizadas (Figura 2). Em complemento, destacou-se a movimentação do operador do torno CNC (Figura 3). 
Figura 2: Mapofluxograma do processo

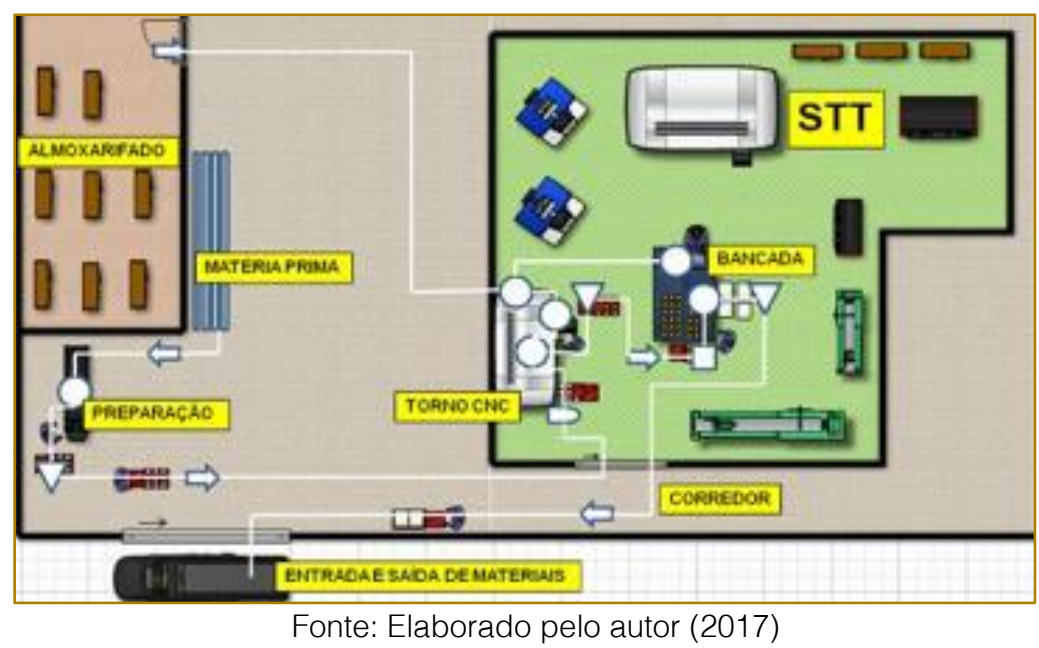

Figura 3: Mapofluxograma do processo - Movimentação do trabalhador

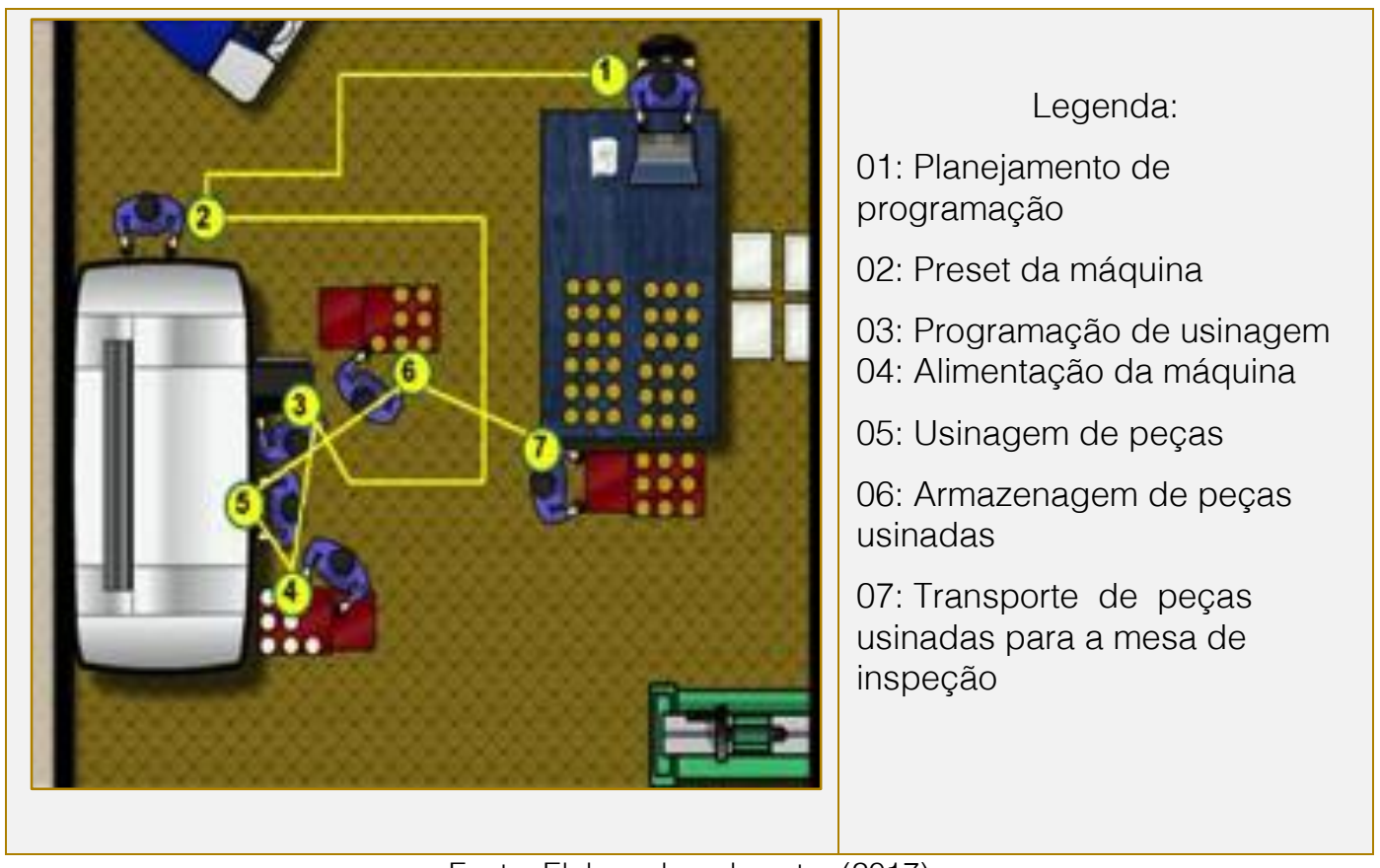

Fonte: Elaborado pelo autor (2017)

A partir dos mapofluxogramas elaborados, constatou-se a sobreposição de movimentações em algumas áreas, referentes aos cruzamentos que o colaborador realiza durante toda sua jornada de trabalho.

\subsection{ANÁLISE DE RISCOS}

Para verificar os riscos, realizou-se a construção de uma Análise Preliminar de risco (APR), ilustrada no Quadro 1, onde os riscos encontrados são classificados em ordem de probabilidade e gravidade, que vão de 1 a 3 , sendo o índice 3 o de maior criticidade. Esses índices foram atribuídos em conjunto com o trabalhador e supervisor, considerando-se a experiência e histórico de possíveis ocorrências. 
Quadro 1: Análise Preliminar de Risco

\begin{tabular}{|c|c|c|c|c|c|}
\hline \multicolumn{6}{|c|}{ ANÁLISE PRELIMINAR DE RISCO } \\
\hline \multicolumn{6}{|c|}{ Origem: Serviço- Usinagem } \\
\hline \multicolumn{3}{|c|}{ Identificação dos Perigos } & \multicolumn{3}{|c|}{ Avaliação de Risco } \\
\hline Perigo & Situação & Danos & $\mathbf{P}$ & G & Risco \\
\hline Ruído & Ruído da máquina & Perda de audição & 1 & 2 & 2 \\
\hline Vapores químicos & Proveniente do fluído de corte & Doenças respiratórias & 1 & 2 & 2 \\
\hline $\begin{array}{l}\text { Levantamento e } \\
\text { transporte manual de } \\
\text { carga }\end{array}$ & $\begin{array}{c}\text { Retirada da peça até a o carrinho } \\
\text { de transporte e depois para } \\
\text { bancada }\end{array}$ & $\begin{array}{c}\text { Dores musculares e } \\
\text { problemas na coluna } \\
\text { vertebral }\end{array}$ & 1 & 2 & 2 \\
\hline $\begin{array}{l}\text { Exigência de postura } \\
\text { inadequada }\end{array}$ & $\begin{array}{c}\text { Mobiliário não ergonômico / } \\
\text { braço suspenso durante digitação }\end{array}$ & $\begin{array}{c}\text { Lombalgias } \\
\text { Doenças ocupacionais } \\
\end{array}$ & 3 & 2 & 6 \\
\hline Alta carga cognitiva & $\begin{array}{l}\text { Exigência de precisão, } \\
\text { cumprimento de prazos e } \\
\text { programações bastante extensas. }\end{array}$ & Sobrecarga cognitiva & 2 & 2 & 4 \\
\hline Choque elétrico & Sistema elétrico da máquina & $\begin{array}{c}\text { Choque elétrico ou } \\
\text { morte }\end{array}$ & 1 & 3 & 3 \\
\hline $\begin{array}{l}\text { Aprisionamento de } \\
\text { membros entre partes } \\
\text { rotativas }\end{array}$ & $\begin{array}{l}\text { Sistema de aprisionamento da } \\
\text { peça }\end{array}$ & $\begin{array}{c}\text { Esmagamento e cortes } \\
\text { de membros } \\
\text { superiores mãos e } \\
\text { dedos }\end{array}$ & 1 & 3 & 3 \\
\hline Queda em mesmo nível & $\begin{array}{c}\text { Desorganização do local de } \\
\text { trabalho }\end{array}$ & Cortes, ferimentos & 1 & 2 & 2 \\
\hline $\begin{array}{c}\text { Queda de material em } \\
\text { partes do corpo }\end{array}$ & $\begin{array}{l}\text { Durante o transporte da matéria } \\
\text { prima ao interior da máquina }\end{array}$ & $\begin{array}{l}\text { Cortes, ferimentos, } \\
\text { Contusões }\end{array}$ & 2 & 1 & 2 \\
\hline $\begin{array}{c}\text { Projeção de partículas } \\
\text { volantes } \\
\end{array}$ & Partículas liberadas na usinagem & Cortes, ferimentos & 1 & 3 & 3 \\
\hline P-PROB & BILIDADE & IDADE & & & \\
\hline
\end{tabular}

Fonte: Elaborado pelo autor, baseado em Borges (2017)

Desta forma, pode-se observar que os riscos identificados com maior pontuação são: exigência de postura inadequada, a alta carga cognitiva e aprisionamento de membros entre partes rotativas.

\subsection{ANÁLISE DA TAREFA}

O nível de tecnologia empregado pela empresa no posto de trabalho em estudo caracteriza-se como automatizado, uma vez que o operador alimenta a máquina com o material pré-usinado (cortado nas dimensões necessárias). Ao final do processo, retira a peça pronta de acordo com os dados (parâmetros, coordenadas numéricas, e processo de execução correto para a usinagem requerida), vigia, controla o processo, e se necessário realiza intervenções.

A tarefa em estudo consiste em usinar peças cilíndricas, composta das seguintes etapas: planejamento, "preset" da máquina, programação da máquina, alimentação da matéria prima, fixação da peça pré-usinada na máquina, usinagem, retirada e transporte de peças.

O gráfico homem máquina foi construído e há tempo de ociosidade do homem enquanto a máquina trabalha. Resumindo, o tempo total do homem foi de 207 horas, 13 minutos e 40 segundos, enquanto que o tempo da máquina foi um total de 200 horas.

Assim, pôde-se realizar o balanceamento do trabalho, onde sugeriu-se a adoção do enriquecimento do trabalho, de forma a otimizar os resultados do trabalhador, proporcionando maior variedade de atividades ao trabalhador, contribuindo para a redução da monotonia atribuída à tarefa.

\subsection{ANÁLISE DA ATIVIDADE}

Com o objetivo de visualizar com melhor precisão as etapas de trabalho realizadas pelo trabalhador, realizou-se uma análise de sua atividade (Quadro 2). 
Quadro 2: Análise tarefa e da atividade

\begin{tabular}{|c|c|c|c|}
\hline REGISTRO FOTOFRÁFICO & $\begin{array}{l}\text { BREVE DESCRIÇÃO } \\
\text { DO PROCESSO }\end{array}$ & $\begin{array}{l}\text { PERIGO / } \\
\text { RISCO }\end{array}$ & OBSERVAÇÒES \\
\hline & $\begin{array}{l}\text { Planejamento: O operador, } \\
\text { juntamente com o supervisor } \\
\text { de STT, planejam todo o } \\
\text { desenvolvimento da execuçä } \\
\text { do produto, verificando e } \\
\text { analisando as variaziveis } \\
\text { necessírias. }\end{array}$ & $\begin{array}{l}\text { Postura } \\
\text { inadequada; } \\
\text { exigència de } \\
\text { carga cognitiva }\end{array}$ & $\begin{array}{l}\text { Exigência de precisio, } \\
\text { cumprimento de prazos e } \\
\text { programaçōes bastante } \\
\text { extensas. }\end{array}$ \\
\hline & $\begin{array}{l}\text { "Preser" da máquina: o } \\
\text { operador realiza o "preset" } \\
\text { (preparaçao) da maquina para a } \\
\text { usinagem da peca, fixando } \\
\text { ferramentas, acessonios, } \\
\text { alimentando-a com insumos, e } \\
\text { referenciando-a. }\end{array}$ & $\begin{array}{l}\text { Exigéncia de } \\
\text { postura } \\
\text { inadequada } \\
\text { (braço } \\
\text { suspenso): e } \\
\text { digitaçia. }\end{array}$ & $\begin{array}{l}\text { Inexisténcia de dispositivo } \\
\text { que mantenha o braço do } \\
\text { colaborador, seristència de } \\
\text { apoiado; Expras. } \\
\text { periodo para pausas. }\end{array}$ \\
\hline & $\begin{array}{l}\text { Programaçào da mảquina: } \\
\text { Colaborador realiza a } \\
\text { programaçào de execução do } \\
\text { produto, alimentando o } \\
\text { computador da maquina com } \\
\text { as informaçöes necessárias. }\end{array}$ & $\begin{array}{l}\text { Exigència de } \\
\text { postura } \\
\text { inadequada } \\
\text { (braço } \\
\text { suspenso); e } \\
\text { digitação }\end{array}$ & $\begin{array}{l}\text { Existéncia de periodo para } \\
\text { pausas. As pausas sấ } \\
\text { concedidas a cada } 02 \text { boras } \\
\text { de programaço, sendo de } 15 \\
\text { minutos cada; } \\
\text { Inexistência de dispositivo } \\
\text { que mantenha o braço do } \\
\text { colaborador, sempre apoiado }\end{array}$ \\
\hline & $\begin{array}{l}\text { Alimentaçầo da matéria } \\
\text { prima: o operador } \\
\text { manualmente alimenta a } \\
\text { máquina com o material pré- } \\
\text { usinado. }\end{array}$ & $\begin{array}{l}\text { Quedarre de } \\
\text { material sobre } \\
\text { parte do corpo }\end{array}$ & $\begin{array}{l}\text { Necessidade de transporte } \\
\text { da materia prima ao interior } \\
\text { da máquina; Utilização de } \\
\text { calçado de segurança; Peso } \\
\text { da peça: } 220 \mathrm{~g}\end{array}$ \\
\hline & $\begin{array}{l}\text { Fixasào da peça pré usinada } \\
\text { na maquina: o colaborador } \\
\text { fixa a pesa por meio de } \\
\text { cilindros pneumiticos, tambeem } \\
\text { acionados por meio de pedais } \\
\text { inferiores. }\end{array}$ & $\mid \begin{array}{l}\text { Sistemar de } \\
\text { aprisionamento } \\
\text { da pesar e } \\
\text { elétrico } \\
\text { máquina: } \\
\text { Prensamento } \\
\text { de partes do } \\
\text { corpo entre } \\
\text { partes } \\
\text { rotativas: } \\
\text { Choque } \\
\text { elétrico }\end{array}$ & 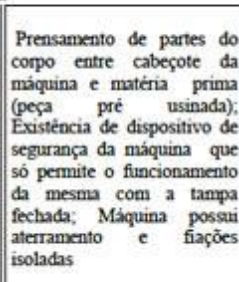 \\
\hline & $\begin{array}{l}\text { Inicio da usinagem: o } \\
\text { operador fecha a tampa de } \\
\text { segurança da máquina e aciona } \\
\text { o botäo "Start", para inicio da } \\
\text { execuçio da programaçăo } \\
\text { (usinagem) da peça. }\end{array}$ & $\begin{array}{l}\text { Aprisionament } \\
\text { o de partes do } \\
\text { corpo } \\
\text { colaborador } \\
\text { entre partes } \\
\text { rotativas; } \\
\text { Projeclio de } \\
\text { particulas } \\
\text { volantes } \\
\text { Perda auditiva }\end{array}$ & 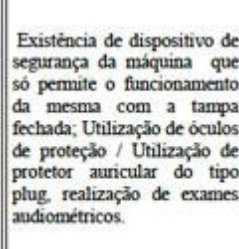 \\
\hline$=$ & 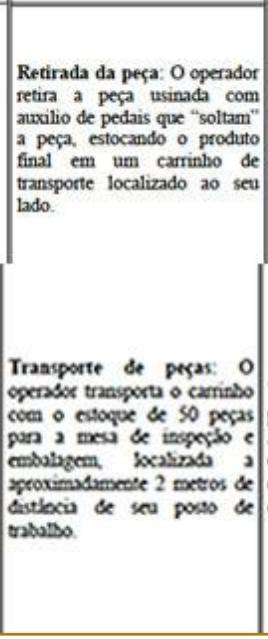 & 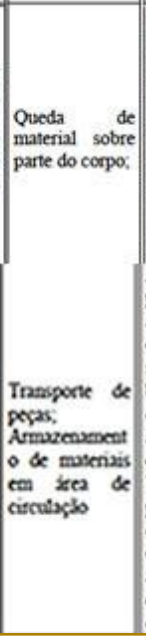 & 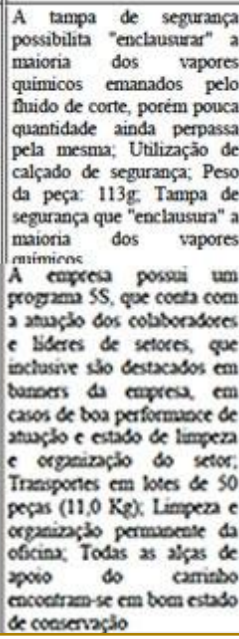 \\
\hline
\end{tabular}

Fonte: Elaborado pelo autor (2017) 


\subsection{DIAGNÓSTICO}

Partindo-se das situações analisadas em detalhe, foi possível formular o diagnóstico do posto de trabalho analisado. Na etapa de programação da máquina foi possível identificar a situação de monotonia em virtude de períodos prolongados de programação, bem como adoção de postura inadequada, com posicionamento (sem apoio) dos membros superiores.
Elaborou-se a Matriz GUT (Quadro 3), na qual os riscos são avaliados levando-se em consideração os critérios de gravidade, urgência e tendência, por meio de pontuações que vão de 1 a 5 , onde a 5 represente o índice de maior criticidade. Em seguida foi realizada uma comparação entre os métodos (Quadro 4).

Quadro 3: Matriz GUT

\begin{tabular}{|c|c|c|c|c|c|}
\hline Risco & Gravidade & Urgência & Tendência & GxUxT & Prioridade \\
\hline Ruído & 3 & 1 & 1 & 3 & 6 \\
\hline Vapores químicos & 3 & 2 & 1 & 6 & 4 \\
\hline $\begin{array}{l}\text { Levantamento e transporte } \\
\text { manual de carga }\end{array}$ & 2 & 1 & 2 & 4 & 5 \\
\hline $\begin{array}{l}\text { Exigência de postura } \\
\text { inadequada }\end{array}$ & 3 & 3 & 2 & 18 & 2 \\
\hline Alta carga cognitiva & 3 & 4 & 1 & 12 & 3 \\
\hline Choque elétrico & 5 & 4 & 1 & 20 & 1 \\
\hline $\begin{array}{l}\text { Aprisionamento de membros } \\
\text { entre partes rotativas }\end{array}$ & 5 & 4 & 1 & 20 & 1 \\
\hline Queda de mesmo nível & 2 & 1 & 2 & 4 & 5 \\
\hline $\begin{array}{l}\text { Projeção de partículas } \\
\text { volantes }\end{array}$ & 3 & 1 & 1 & 3 & 6 \\
\hline $\begin{array}{l}\text { Queda de material em partes } \\
\text { do corpo }\end{array}$ & 2 & 1 & 1 & 2 & 7 \\
\hline
\end{tabular}

Fonte: Elaborado pelo autor, baseado em Borges (2017)

Quadro 4: Comparação APR x GUT

\begin{tabular}{|l|c|c|c|}
\multicolumn{1}{c|}{$\begin{array}{c}\text { APR } \\
\text { Risco }\end{array}$} & Prioridade & Risco & GUT \\
\hline $\begin{array}{l}\text { Exigência de postura } \\
\text { inadequada }\end{array}$ & 1 & Choque elétrico & 1 \\
\hline Alta carga cognitiva & 2 & $\begin{array}{c}\text { Aprisionamento de membros } \\
\text { entre partes rotativas }\end{array}$ & 1 \\
\hline $\begin{array}{l}\text { Aprisionamento de membros } \\
\text { entre partes rotativas }\end{array}$ & 3 & Alta carga cognitiva & 3 \\
\hline
\end{tabular}

Fonte: Elaborado pelo autor (2017)

Quando comparado à matriz GUT, a APR apresentou pouca divergência no que diz respeito à caracterização da priorização dos riscos. O resultado obtido mostrou os mesmos riscos em posições diferentes de classificação, tendo em vista que a matriz GUT analisa a gravidade, urgência e tendência, a APR tem como critérios apenas: probabilidade e Gravidade.

A partir da observação sistemática da atividade, foi possível perceber que a etapa de programação exige atenção do trabalhador. Esse tempo de programação depende da geometria da peça a ser usinada, que pode demorar de duas a oito horas de programação.

Os riscos identificados no posto de trabalho foram:

- Exigência de postura inadequada durante o período de programação do torno $\mathrm{CNC}$, onde o trabalhador permanece com os membros superiores elevados;

- Existência de carga cognitiva, mas especificamente na etapa de programação da máquina, onde é exigido do trabalhador, concentração, memória e decisão, aliados à 
necessidade de agilidade para atender às demandas das empresas;

- Choque elétrico:

- Aprisionamento de membros entre partes rotativas.

\subsection{VALIDAÇÃO DO DIAGNÓSTICO}

A etapa de construção social do projeto foi realizada por meio de reuniões com a presença do operador do torno CNC, supervisor do laboratório de Metal Mecânica, com o objetivo de apresentar as ações de melhoria formuladas, discuti-las e verificar suas aplicabilidades e viabilidades. Alguns pontos foram verificados posteriormente à reunião, traduzidos facilmente como restrições do projeto. São eles: aceitação das ideias ou alternativas pelos stakeholders; verba direcionada para investimentos nas adequações propostas; e verba direcionada para investimentos em ferramental e peças para as adequações internas que serão necessárias.

\subsection{PROJETO DAS MODIFICAÇÕES}

A partir do presente estudo, foi possível conhecer melhor o posto de trabalho estudado, de forma a analisar e propor oportunidades de melhoria, conforme o Quadro

Quadro 5: Projeto das modificações

\begin{tabular}{|c|c|c|}
\hline Risco & Soluções finais & Detalhamento da solução \\
\hline $\begin{array}{l}\text { Exigência de } \\
\text { postura } \\
\text { inadequada }\end{array}$ & $\begin{array}{l}\text { Realização da programação } \\
\text { de peças complexas no } \\
\text { computador convencional, } \\
\text { com transmissão de dados } \\
\text { via wifi ou cartão de } \\
\text { armazenamento }\end{array}$ & $\begin{array}{l}\text { Realização da programação no computador convencional, } \\
\text { com transmissão de dados por meio de softwares de CAM } \\
\text { (Manufatura Assistida por Computador) }\end{array}$ \\
\hline $\begin{array}{l}\text { Aprisionamento } \\
\text { de membros } \\
\text { entre partes } \\
\text { rotativas }\end{array}$ & $\begin{array}{l}\text { Instalação de dispositivo de } \\
\text { segurança }\end{array}$ & $\begin{array}{l}\text { Instalação de dispositivo de segurança auxiliar, de modo que } \\
\text { o mesmo não possa ser neutralizado ou burlado (Item } 12.39 \\
\text { da NR 12, alínea "d"). Sugestão: Cortina de luz. }\end{array}$ \\
\hline \multirow[b]{2}{*}{$\begin{array}{l}\text { Melhoria: } \\
\text { Avaliação de } \\
\quad \text { fluxos }\end{array}$} & \multirow[b]{2}{*}{$\begin{array}{l}\text { Adequação do layout } \\
\text { existente, de forma a evitar } \\
\text { cruzamentos, reduzindo o } \\
\text { risco de queda de mesmo } \\
\text { nível e deslocamentos } \\
\text { desnecessários }\end{array}$} & $\begin{array}{l}\text { A partir da elaboração de um novo template, foi possível } \\
\text { sugerir melhorias de fluxo no posto de trabalho conforme } \\
\text { figura abaixo. Pôde-se melhorar com mudanças na redução } \\
\text { das distâncias percorridas, realocação das mesas de } \\
\text { recebimento de material, e da mesa utilizada para realização } \\
\text { do planejamento da atividade. Desta forma foi possível } \\
\text { otimizar o fluxo de operações, eliminando cruzamentos de } \\
\text { fluxo, e retrocessos durante a realização da atividade. }\end{array}$ \\
\hline & & 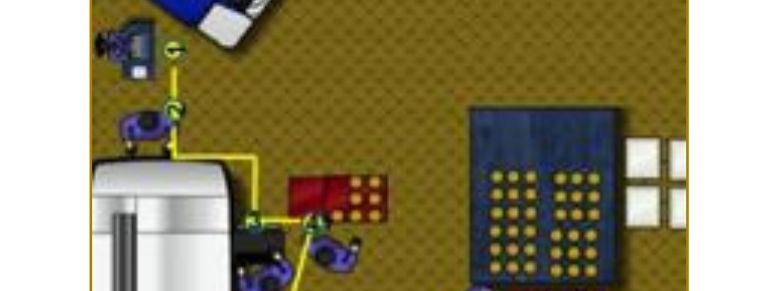 \\
\hline $\begin{array}{l}\text { Alta carga } \\
\text { cognitiva }\end{array}$ & $\begin{array}{l}\text { Adoção de uma estratégia } \\
\text { de enriquecimento do } \\
\text { trabalho, de forma a } \\
\text { aumentar a variedade de } \\
\text { tarefas realizadas pelo } \\
\text { trabalhador }\end{array}$ & $\begin{array}{l}\text { Realização da atividade de operação do torno CNC por } \\
\text { demais trabalhadores qualificados, e diversificação das } \\
\text { atividades do trabalhador da atividade estudada }\end{array}$ \\
\hline
\end{tabular}

Fonte: Elaborado pelo autor (2017) 


\section{CONCLUSÕES}

O presente estudo se propôs a realizar um projeto de trabalho na atividade de operação de um torno CNC, de forma a avaliar a situação de trabalho e propor soluções para minimizar os riscos ocupacionais existentes, buscando o equilíbrio saúde - produtividade.

Foi verificado que a tarefa consistia na usinagem de peças cilíndricas, que neste caso foi a luva roscada para ajuste de andaime, seguindo uma determinada programação. Em seguida, por meio da aplicação de uma Análise Preliminar de Riscos, os riscos identificados com maior pontuação foram: exigência de postura inadequada com a maior pontuação, em seguida, a alta carga cognitiva exigida na atividade, que apresentou a segunda maior pontuação. Também foram considerados 0 risco de aprisionamento de membros entre partes rotativas, tendo em vista atender a temática de adequação da NR 12. De posse dos riscos priorizados, foi elaborada as soluções para o diagnóstico, que foram validadas em uma reunião de construção social junto à empresa. Essas soluções foram adequadas em virtude da realidade da organização, com suas respectivas facilidades e dificuldades,

Em função de possuírem o software de CAD CAM, foi possível a Realização da

\section{REFERÊNCIAS}

[1] BORGES, Fábio Morais. Análise e Projeto de Trabalho III. 2016. Slides de aulas.

[2] BRASIL. Constituição. Ministério da Previdência Social. Anuário estatístico da previdência social. 2015. BONI, Valdete; QUARESMA, Sílvia Jurema. Aprendendo a entrevistar: como fazer entrevistas em Ciências Sociais. Em Tese, v. 2, n. 1, p. 68-80, 2005.

[3] CAMAROTTO, J. A. Projeto do trabalho: métodos, tempos, modelos, posto de trabalho. Apostila elaborada pelo Prof. Dr. João Alberto Camarotto na disciplina Engenharia de Métodos do Programa de Pós-graduação em Engenharia de Produção da UFSCar - Universidade Federal São Carlos, 2007

[4] CESARO, Lenice Raquel de. Adaptação das técnicas APR e HAZOP ao sistema de gestão de segurança do trabalho e meio ambiente. 2013.

[5] FERRARI, Alfredo Vergílio Fuentes. Manufatura avançada com máquinas multitarefa. Usinagem Brasil, nov. 2015. Disponível em programação de peças complexas no computador convencional, com transmissão de dados via wifi ou cartão de armazenamento. Ao propor melhora no fluxo do processo, não houve impedimento pelo Baixo grau de complexidade de realização.

De posse das soluções encontradas e validadas junto à organização, foi possível elaborar o plano de ação que apresentou o motivo da modificação, quando realizar e quem é o responsável pela realização da modificação. Dessa forma, a empresa recebeu o relatório para realizar as adequações, apesar de não estarem abertos a resolução desses problemas, principalmente ligados a NR 12 (cortina de luz), em função de custo.

Portanto, foi possível verificar que pesquisas futuras são necessárias para compreender melhor o passo a passo da realização da atividade de operação de um torno CNC, visto que o estudo foi realizado em determinado tipo de empresa, que tem como atividade principal a aprendizagem industrial. Logo, a análise em diferentes tipos de empresas com rotinas de trabalho diferentes, permitiria um maior conhecimento das situações de trabalho vivenciadas pelos trabalhadores do referido posto de trabalho.

http://www.usinagem-brasil.com.br/10434manufatura-avancada-com-maquinasmultitarefa/pa-1/.Acesso em: 22 fev. 2017.

[6] FERRARI, Alfredo Vergílio Fuentes. A evolução dos tornos automáticos: do came ao CNC. In: II CONGRESSO USINAGEM, 2002, São Paulo. Disponível em: < https://edisciplinas.usp.br/pluginfile.php/1806759/ mod_resource/content/1/M\%C3\%A1quinas\%20mult itarefa\%2

Ona\%20produ\%C3\%A7\%C3\%A30\%20seriada\%20I I. pdf >. Acesso em: 16 de abr. 2017.

[7] GUÉRIN, F., et al. Compreender o trabalho para transformá-lo. São Paulo: Edgar Blücher, 2004. IIDA, Itiro. Ergonomia: projeto e produção. São Paulo: Editora Edgard Blucher, 2005

[8] MOTTA, Fabrício V. Avaliação ergonômica de postos de trabalho no setor de pré-impressão de uma indústria gráfica. 2009. Monografia (Graduação) - Universidade Federal de Juiz de Fora, Juiz de Fora, 2009. 
[9] VILELA, Rodolfo Andrade Gouveia. Acidentes do trabalho com máquinas: identificação de riscos e prevenção. São Paulo: Central Única dos Trabalhadores, 2000.
[10] YIN, R.K. Estudo de caso: Planejamento e métodos. 5. ed. Porto Alegre: Bookman, 2015. 


\section{Gapítulo 18}

\section{GERENCIAMENTO COMPACTO DE RISCOS EM PROJETOS: PRIORIZAÇÃO DO GERENCIAMENTO DE RISCOS CENTRADO NAS ATIVIDADES CRITTICAS}

\section{Luciano Azevedo de Souza}

\section{Celso Souza de Moraes Junior}

Resumo: Este artigo tem por objetivo apresentar uma proposição de gerenciamento dos riscos de projeto centrado na aplicação do Método do Caminho Crítico Critical Path Method (CPM) - e Cadeia Crítica - Critical Chain Path Method (CCPM), como critérios otimizadores, a partir da avaliação de um projeto da indústria automobilística, com o propósito de intensificar a aplicação dos esforços no gerenciamento de riscos sobre as atividades que, ao atrasarem, representem atraso na conclusão do projeto. A metodologia predominante do trabalho é a pesquisa exploratória, apoiada por Estudo de Caso como método qualitativo mais apropriado e sustentada por revisão bibliográfica para a fundamentação teórica dos critérios otimizadores propostos e para posterior análise dos dados. A unidade de análise trata-se de projeto de baixa complexidade, observado entre maio e outubro de 2013. Os resultados obtidos demonstraram uma redução de $60 \%$ das atividades, atendendo o objetivo de otimização de recursos a partir do critério assumido.

Palavras-chave: Gerenciamento de riscos, Projetos, CPM. 


\section{INTRODUÇÃO}

A disseminação das metodologias de gerenciamento de projetos tem ritmo crescente nos últimos anos. Um sinal deste crescimento do número de membros ativos do $\mathrm{PMI}$ (Project Management Institute), reconhecida organização que congrega gerentes de projetos num âmbito Global, pode ser observado na figura 1 a seguir.

Figura 1 - Evolução mundial dos membros do PMI

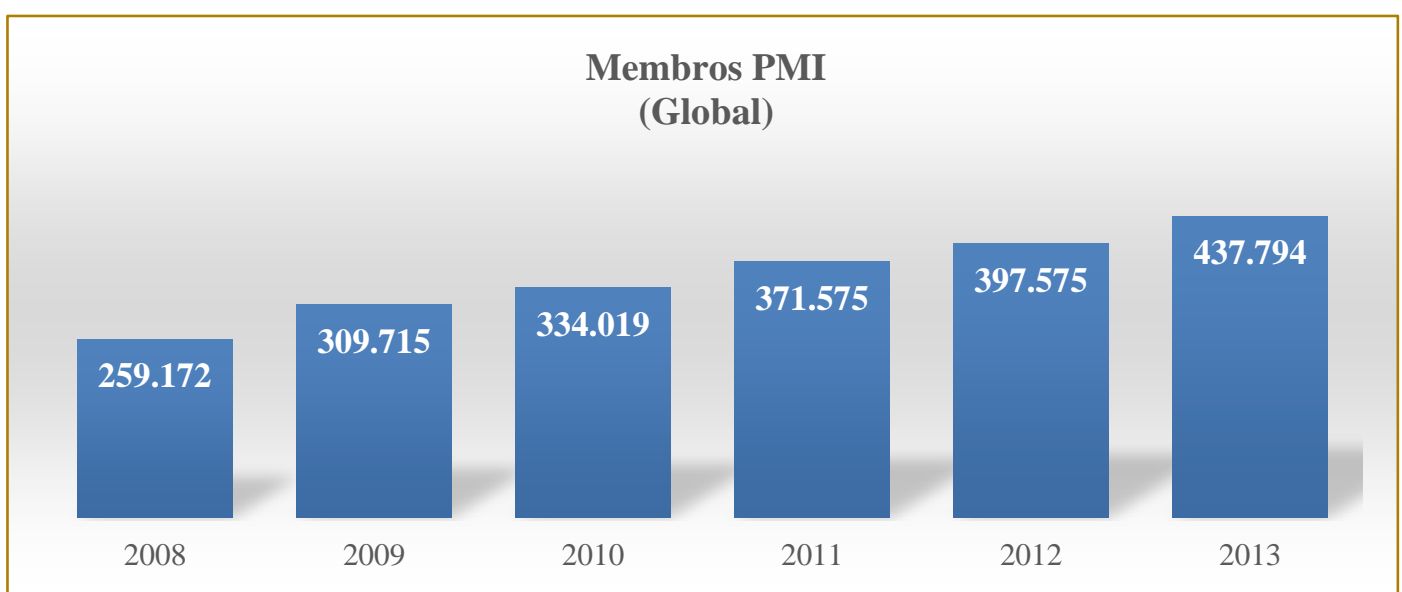

FONTE: Adaptado de PMI Fact Sheet - Project management Institute, (2014)

O objetivo deste trabalho é apresentar uma proposição de gerenciamento otimizado dos riscos de projeto, através da aplicação do Método do Caminho Crítico - Critical Path Method (CPM) e Cadeia Crítica, Critical Chain Path Method (CCPM), com o propósito de intensificar a aplicação dos esforços no gerenciamento de riscos sobre as atividades.

A motivação inicial para este trabalho dá-se após a experiência com um projeto no setor automobilístico, em que não fora aplicado um método de gerenciamento de riscos proposto pelo PMI, e ao final, o projeto apresentou um atraso em torno de 30\% sobre o prazo estimado. Cabe colocar que atrasos afetam sensivelmente a percepção de sucesso ou fracasso de um projeto, seja pela potencialidade em trazer custos adicionais na utilização mais prolongada de recursos, seja pela postergação do início do cumprimento da função econômica do objetivo do projeto, e principalmente, pela possibilidade de se perder a oportunidade ideal para a introdução de medidas vislumbradas no plano estratégico, tendo em vista oportunidades e ameaças mapeadas.

O atraso deste projeto, teve por consequência a postergação de importantes etapas planejadas e algumas delas foram canceladas, em função da dinâmica estratégica.
A reflexão sobre as lições aprendidas desta empreitada fez surgir a proposta de uma exploração analítica com a intenção de identificar um procedimento para a implementação da análise de riscos em projetos futuros, com aplicação de recursos compatíveis com a disponibilidade em tempos de projeto.

O projeto em recorte, de alta complexidade, possui cronograma com 3270 linhas e envolveu fornecedores internacionais, entre outras dificuldades técnicas relacionadas ao reuso de equipamentos, estratégia de desmobilização e mobilização de mão de obra, entre outras. Ainda que um projeto similar ocorresse em curto prazo, a abertura para inovar em gerenciamento de projetos de grande porte só é bem recebida pela organização se as propostas tenham sida experimentadas satisfatoriamente em projetos similares de menor porte, cujo risco seja mais controlável e desvios representem menos impacto ao funcionamento rotineiro da empresa. Desta forma, a técnica sugerida foi testada em um projeto de baixa complexidade com poucas interfaces com o sistema produtivo.

O conteúdo está dividido em cinco seções: inicia-se, em primeiro lugar, com esta Introdução; na segunda seção, abordam-se os principais conceitos disponíveis na literatura consultada sobre gerenciamento de 
riscos e gerenciamento do tempo em projetos; na terceira seção apresenta-se a metodologia de pesquisa adotada e em seguida, na seção quatro, os resultados obtidos no desenvolvimento do trabalho; finalmente, na conclusão, são discutidos os resultados e, por fim, apresentadas as referências bibliográficas utilizadas.

A partir desta abordagem, espera-se que novos trabalhos possam ser produzidos, a fim de possibilitar o aprofundamento das pesquisas, bem como o desenvolvimento de ferramental para aplicação nos softwares de gerenciamento de projetos.

\section{REVISÃO DA LITERATURA}

\subsection{GERENCIAMENTO DE PROJETOS}

Para Vargas (2008), o gerenciamento de projetos é um conjunto de ferramentas gerenciais para o desenvolvimento de habilidades para o controle de eventos não repetitivos, únicos e complexos, para atender requisitos de tempo, custo e qualidade predeterminados. Segundo Kerzner (2011), é um conjunto de atividades e tarefas que possuem um objetivo específico, especificações determinadas, data de início e término definidas, limites de financiamento, consomem recursos humanos e nãohumanos, são multifuncionais.

No contexto que trata as diversas facetas do gerenciamento de projetos, o Project Management Institute (PMI), consolida as melhores práticas na área numa publicação denominada PMBOK® (Project Management Body of Knowledge), em português denominado Guia do Conjunto de Conhecimentos em Gerenciamento de Projetos. O PMBOK (2013, p. 11) apresenta projetos como: "um esforço temporário empreendido para criar um produto, serviço ou resultado exclusivo."

O Gerenciamento de Projetos é descrito no Guia PMBOK@ através de referências de boas práticas, organizadas em 47 processos e 5 Grupos de Processos: Iniciação, Planejamento, Execução, Monitoramento e Controle e Encerramento.

Figura 2 - Áreas do Conhecimento em Gerenciamento de Projetos

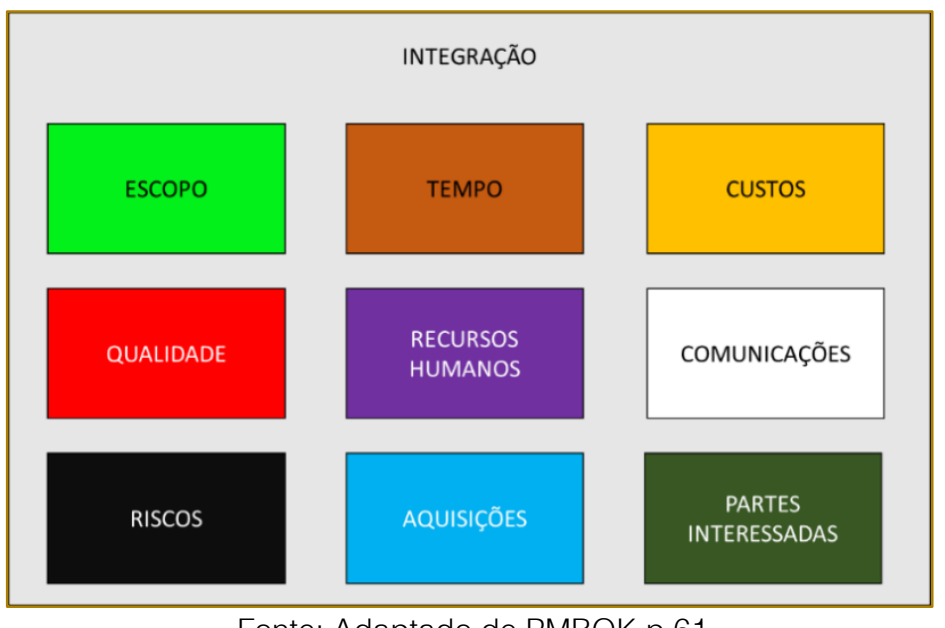

Fonte: Adaptado de PMBOK p.61

O sucesso de um projeto está ligado à capacidade de equilibrar as restrições conflitantes. São apontadas no PMBOK® as principais restrições: Escopo, Qualidade, Cronograma, Orçamento, Recursos e Risco. Para Kerzner (2011, p.40), "[...] a definição de sucesso tem sido atender às expectativas do cliente [...] e acrescenta que "sucesso também inclui realizar o trabalho dentro das restrições da grade de tempo, custos e qualidade/desempenho."

\subsection{GERENCIAMENTO DE RISCOS}

O gerenciamento dos riscos tem por finalidade a identificação de incertezas e a avaliação de probabilidade e consequência de sua ocorrência; contempla também a 
elaboração de medidas de prevenção e reação aos riscos.

Salles Junior et al. (2010, p.25) adota uma abordagem sintética e não-ferramental e apresenta riscos como incertezas e gerenciamento de riscos como um processo para "identificar as possíveis incertezas e tentar controla-las".

Risco é assim definido por Kerzner (2011, p.457): "[...] uma medida da probabilidade e consequência de não se atingir uma meta definida do projeto". E ainda, em uma representação de função matemática onde: "Risco = f(ameaça, proteção) em que o risco aumenta a com a ameaça, mas diminui com a proteção." Esta abordagem, limita-se aos riscos com impacto negativos, mas há que se considerar as incertezas que, ao se confirmarem, poderiam influenciar favoravelmente o projeto.

O PMBOK (2013, p.226) descreve risco como sendo: "[...] um evento ou uma condição incerta que, se ocorrer, tem um efeito em pelo menos um objetivo do projeto", sem definir se a natureza do impacto do risco traz resultados negativos ou positivos, obviamente por existir tais possibilidades.

Observa-se, então, uma variação nos conceitos, ampliando a abrangência para a ocorrência de incertezas favoráveis ao projeto.

O gerenciamento de riscos do projeto inclui os processos relacionados com 0 planejamento, identificação, análise, elaboração de respostas, monitoramento e controle dos riscos em um projeto (PMBOK, 2013). A esse recorte, as respostas aos riscos são tratadas pela prioridade, inserindo recursos e atividades no orçamento, no cronograma e no plano de gerenciamento do projeto (PMBOK, 2013).

Pelo benefício da redução de incertezas e preparação de medidas de prevenção e controle, é necessária a considerável aplicação de recursos, tais como mão de obra especializada, tempo e financiamento.

Para boa compreensão das propostas deste trabalho, é necessário apresentar as ferramentas de gerenciamento do tempo para, por fim, integra-las ao gerenciamento dos riscos e trabalhar a otimização esperada.

\subsection{GERENCIAMENTO DO TEMPO}

Gerenciamento do tempo, é uma das áreas mais visíveis do gerenciamento de projetos, tendo por principal objetivo garantir que o projeto seja finalizado dentro do prazo determinado, pois quando um projeto atrasa, na maioria das vezes ele irá consumir um capital que não era previsto comprometendo custo, podendo acarretar consequências mercadológicas do produto do projeto (VARGAS, 2009).

Para tratar a restrição Cronograma, o gerenciamento do tempo se apresenta (PMBOK, 2008, p.129) como "um conjunto de processos para gerenciar o término pontual do projeto, incluindo definição das atividades, sequenciamento, estimativa dos recursos necessários e durações, desenvolvimento e controle de cronograma."

Em busca das melhores ferramentas para o gerenciamento do tempo, as técnicas de programação de redes são amplamente discutidas na literatura especializada e ganha destaque sobre as demais técnicas.

\subsubsection{PROGRAMAÇÃO DE REDES}

A principal diferença da programação de redes para demais métodos é a representação gráfica capaz de identificar facilmente as relações de interdependência entre atividades.

Para Kerzner (2011, p,315) "O objetivo principal do planejamento de rede é eliminar a necessidade do gerenciamento de crises, fornecendo uma representação pictórica do programa total. "

Neste trabalho, são utilizados dois métodos: Método do Caminho Crítico CPM e Método da Cadeia Crítica ou Corrente Crítica, os quais encontram-se descritos a seguir.

\subsubsection{MÉTODO DO CAMINHO CRÍTICO (CPM)}

O método do Caminho Crítico é um método frequentemente adotado para priorização do planejamento e ciclo de revisão e monitoramento. Visa estabelecer as atividades que determinarão a duração mínima do projeto e identifica a cadeia de atividades relacionadas a fim de propor medidas de compressão, adicionando recursos para abreviar a conclusão do projeto. 
Segundo Kerzner (2011, p.315), o caminho crítico é "[...] estabelecido pelo caminho mais longo através da rede e determina a duração do projeto. É também o caminho mais curto necessário para se concluir o projeto."

Método do Caminho Crítico ou CPM (Critical Path Method) é descrito no PMBOK (2008) como:

"[...] calcula as datas teóricas de início e término mais cedo e início e término mais tarde, para todas as atividades, sem se considerar quaisquer limitações de recursos, executando uma análise dos caminhos de ida e de volta através da rede do cronograma. As datas resultantes de início e término mais cedo e início e término mais tarde [...]" p. 135

Os caminhos críticos têm uma folga total, (diferença entre as datas de início e termino mais cedo e início e termino mais tarde) igual a zero ou negativa e as atividades do cronograma que estão no caminho crítico são chamadas "atividades críticas".

Redes podem possuir múltiplos caminhos quase críticos, ou caminhos k-críticos, onde $\mathrm{k}$ é o késimo caminho crítico, por exemplo, para $\mathrm{k}=1$, temos o caminho mais crítico, para $\mathrm{k}=2 \mathrm{o}$ segundo caminho crítico, em ordem crescente de folgas totais (CONTADOR, 2006). Ou seja, além do caminho crítico, que os softwares de gerenciamento de projetos já representam em seus diagramas de redes, este autor apresenta o conceito de caminhos subcríticos, onde o caminho k1-crítico é o caminho crítico do projeto, o caminho k2crítico seria a sequência que representaria a segunda maior duração do projeto, seria assim 0 primeiro entre os caminhos subcríticos, o caminho k3-crítico o que virá logo em seguida no ranking de maiores durações, e assim por diante. A importância em reconhecer estes caminhos está ligada à maior probabilidade de que se tornem caminho críticos, apresentando assim, menor admissibilidade de atrasos, sendo seu gerenciamento prioritário sobre os menos críticos.

Kerzner (2011, p. 317) apresenta uma característica importante do Método CPM:

"[...] é utilizado em projetos como os de construção, em que o percentual concluído pode ser determinado com precisão razoável e o faturamento do cliente pode ser realizado com base no percentual concluído."

Ou seja, é adequado a projetos tais como de construção civil, pavimentação de estradas e similares cuja medição do avanço físico pode ser obtida em qualquer instante do projeto e é admissível uma boa linearidade entre aplicação de recursos e aceleração do projeto, no entanto não é adequado a projetos cuja medição se dá por eventos, como na área de Pesquisa e Desenvolvimento.

Há, em termos conceituais, uma tênue diferença entre o método CPM e o método da cadeia crítica, porém a consequência prática da não aplicação deste segundo método pode afetar severamente o projeto, pois considera-se as restrições referentes à programação de recursos.

\subsubsection{CADEIA CRÍTICA (CCPM)}

O caminho crítico restrito por recursos é conhecido como a cadeia crítica (PMBOK, 2013, p.132), ou seja, é verificada a disponibilidade dos recursos com utilização simultânea e uma nova avaliação do planejamento das atividades deve ser realizado, priorizando certas tarefas e acrescentando folgas para as tarefas preteridas, afetadas pela indisponibilidade do recurso em restrição. É, portanto, provável que o prazo total do projeto seja aumentado, podendo haver caminhos mais críticos que o inicialmente identificado.

Mesmo que daí obtenha-se uma cadeia crítica, ou corrente crítica, é comum manter a nomenclatura de caminho crítico para aquele que resultará na duração total do projeto e que que em sofrendo atraso, implicará imediatamente um atraso no projeto como um todo.

Os tópicos são distribuídos e indexados pelas áreas de conhecimento em gerenciamento de projetos: integração, escopo, tempo, custos, qualidade, recursos humanos, comunicações, riscos, aquisições e partes interessadas, demonstrados esquematicamente na figura 2.As margens devem ser: esquerda e superior de $3 \mathrm{~cm}$ e direita e inferior de $2 \mathrm{~cm}$. $O$ tamanho de página deve ser A4, impreterivelmente. Por favor, verifique esse aspecto com especial cuidado.

O artigo deve ser escrito no formato do programa Microsoft Word 2003, ou superior. Se você está lendo este documento, significa que você possui a versão adequada do programa.

$\mathrm{Na}$ sequência, passo a passo, serão especificados os detalhes da formatação. 


\section{ASPECTOS METODOLÓGICOS}

A metodologia predominante do trabalho, do ponto de vista do propósito, é denominada por Gil (2002) como Pesquisa Exploratória, e sua finalidade descrita como: "[...] proporcionar maior familiaridade com 0 problema, com vistas a torná-lo mais explícito ou a construir hipóteses. ". São, de acordo com Gray (2012), especialmente úteis quando não se sabe o suficiente sobre um fenômeno.

Do ponto de vista do método, a partir da definição por uma pesquisa qualitativa - que aproxima o pesquisador do contexto pesquisado e busca compreender os fenômenos a ele relacionados - foi escolhido para esta pesquisa o Estudo de Caso, método que é válido para uma ampla diversidade de questões, incluindo desempenho organizacional, desenho e implementação de projetos. Trata-se de uma investigação empírica que, além de explorar temas nos quais as relações podem ser ambíguas, também tenta atribuir relações causais. (GRAY, 2012).

Um dos principais pontos do desenho de pesquisa nos estudos de caso é a definição da unidade de análise (GRAY, 2012); nesta pesquisa, procedeu-se um estudo de caso único, holístico, no período compreendido entre maio e outubro de 2013.

A fundamentação teórica dos critérios otimizadores propostos nesta pesquisa foi reunida a partir de revisão bibliográfica. Segundo Gray (2012), algumas das razões para se pesquisar a bibliografia são identificar lacunas no conhecimento que merecem mais investigação, questionar ideias atuais ou partir de uma teoria aceita, aplicando-a a um novo campo. Em outras palavras, buscar aquilo de que não se conhece ainda a existência (ECO, 2016).

Assim como o planejamento das atividades, que envolve a estimativa de duração, as avaliações qualitativas de riscos, foram realizadas por uma equipe multidisciplinar envolvida do andamento do projeto, com base em experiências em projetos equivalentes.

A avaliação qualitativa foi realizada antes do início das atividades e não houve revisão no decorrer do projeto.

A Obtenção das notas foi realizada por meio de discussão aberta em busca de scores consensuais, não sendo possível o consenso, procede-se a argumentação e decide-se por votação.

Para a construção da tabela dos riscos reduzidos, foram excluídas as tarefas não pertencentes ao caminho crítico, pelo mesmo grupo.

\section{DESENVOLVIMENTO}

$\mathrm{Na}$ fase de projetos, os recursos são muito escassos, seja em termos de finanças, tempo, e principalmente, mão de obra competente e detentora de histórico em projetos semelhantes. Por este motivo, realizar o gerenciamento completo dos riscos torna-se uma tarefa incompatível com as disponibilidades, portanto, inviável. Daí, apresenta-se a proposta de reduzir o campo de aplicação de gestão de riscos, adequando necessidade $x$ disponibilidade, $e$ possibilitando que gerenciamento de riscos reduza as probabilidades de fracasso. Adotamos como critério para esta aplicação compacta de gerenciamento de riscos a criticidade das atividades, ou seja, aquelas que pertençam ao caminho crítico do projeto.

\subsection{APRESENTAÇÃO DO MODELO RESUMIDO:}

Para verificar a aplicação da compactação do gerenciamento de riscos, centrado no caminho crítico, foi adotado um projeto de complexidade reduzida, para que seja realizado o estudo de caso com vistas às possibilidades de generalização futuras.

A figura 3 apresenta o escopo abordado pelo projeto em estudo. 
Figura 3 - Escopo de adaptação do elevador embutido

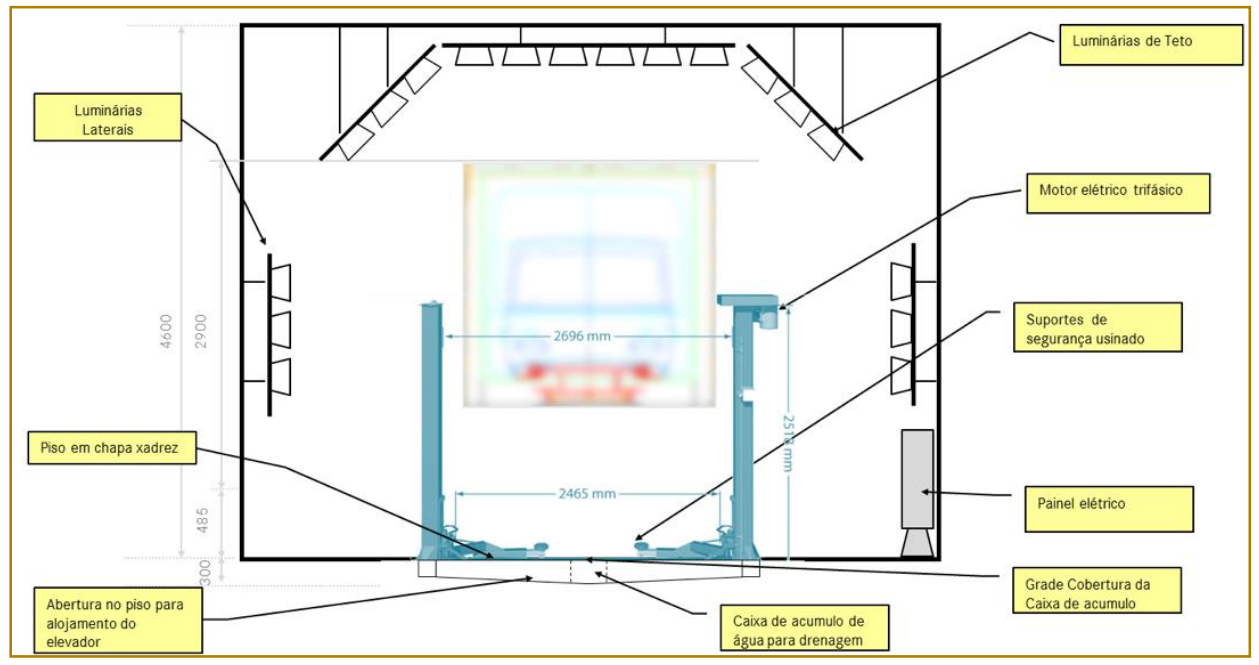

Fonte: Elaborado pelo autor, 2013

O conteúdo do trabalho contempla, portanto, a abertura no piso para alojamento do elevador, cobertura em chapa xadrez, caixa de acúmulo de água para drenagem, grade para cobertura da caixa de acúmulo, elevador automotivo de duas colunas, motor elétrico trifásico, suporte de segurança usinado, painel elétrico, luminárias laterais e de teto.

As atividades de implementação do escopo estão organizadas no cronograma da figura 4 a seguir:

Figura 4 - Cronograma de adaptação do elevador embutido

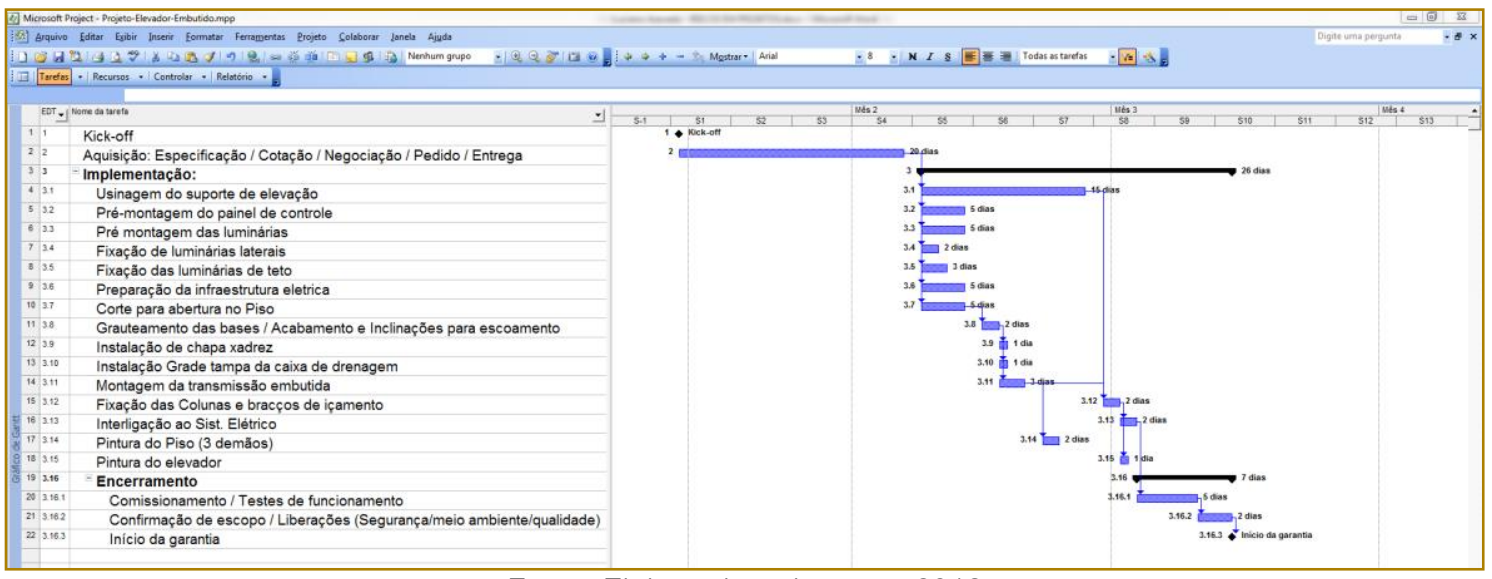

Fonte: Elaborado pelo autor, 2013

\subsection{GERENCIAMENTO DOS RISCOS:}

Adotou-se o método do Brainstorming, no qual um grupo formado por representantes de áreas envolvidas no projeto identificam riscos sobre a estrutura do projeto e apresentam seus argumentos sobre as probabilidades e os impactos de suas ocorrências, conforme tabela 1: 
Tabela 1 - Planilha para Avaliação Qualitativa dos Riscos

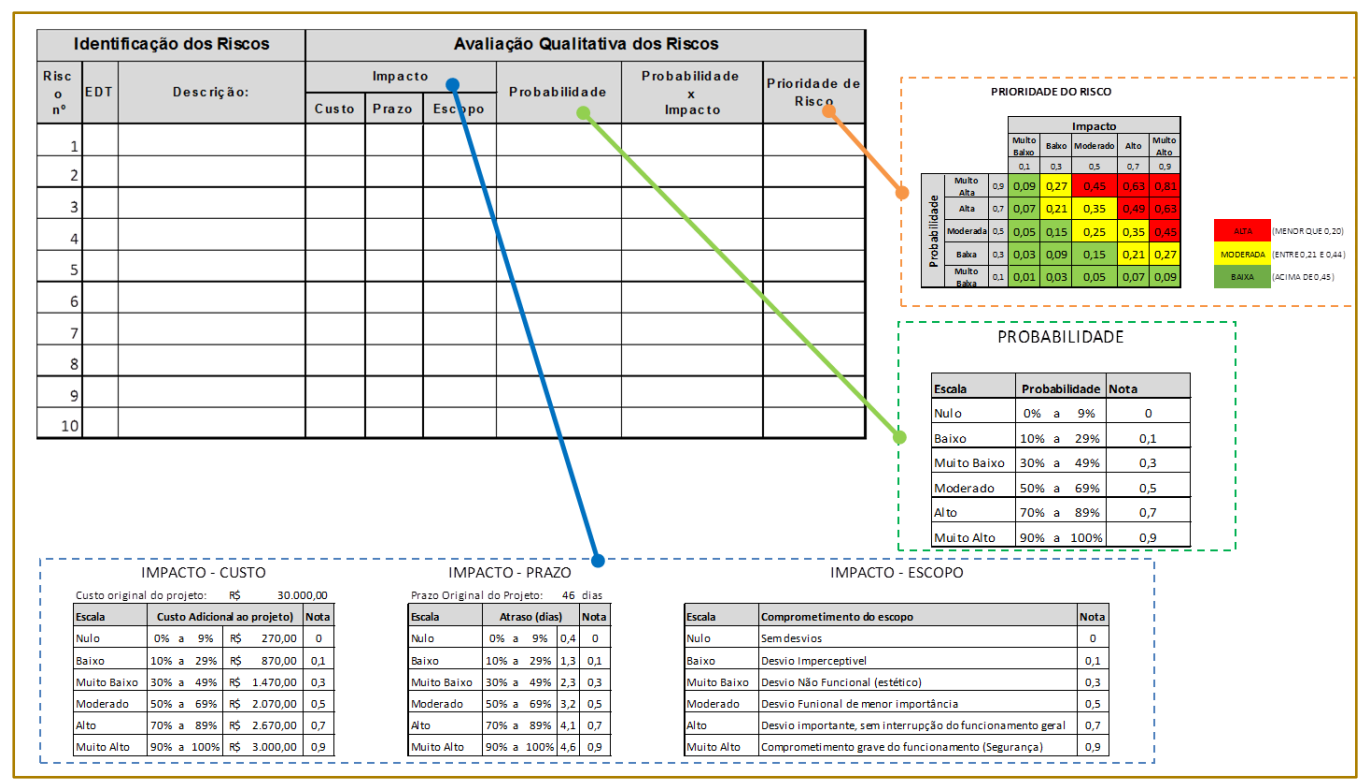

Fonte: Elaborado pelo autor, 2013

A coluna "Risco no" estabelece um indexador para o risco identificado, a "WBS" identifica o código da tarefa na EAP (Estrutura analítica do Projeto, o "nome da tarefa" corresponde ao descritivo etapa, a coluna "Descrição" referese aos riscos associados à tarefa em questão. A Coluna "Impacto" abrange as notas referentes à possíveis implicações da ocorrência do risco nos aspectos de Custo, Prazo e Escopo. Os critérios para preenchimento estão descritos no quadro pontilhado de azul. A Coluna "Probabilidade" refere-se à expectativa de ocorrência do risco e o critério para preenchimento está descrito no quando pontilhado em verde. A Coluna "Probabilidade x Impacto" aplica uma multiplicação do maior valor observado nas colunas de impacto pela probabilidade. Finalmente, a coluna "prioridade do risco" é preenchida conforme critério descrito no quadro pontilhado em laranja.

O preenchimento desta planilha é fruto da aplicação do método Brainstorming, no qual especialistas de diferentes setores opinam livremente e ao final do debate ocorre a consolidação com o auxílio de um moderador. Não atingido o consenso, novamente apresenta-se os argumentos antagônicos, e decide-se por maioria simples obtida em votação. Os resultados podem ser observados na tabela 2 a seguir. 
Tabela 2 - Planilha para Avaliação Qualitativa dos Riscos - Projeto Completo

\begin{tabular}{|c|c|c|c|c|c|c|c|c|c|}
\hline \multicolumn{4}{|c|}{ Identificação dos Riscos } & \multicolumn{6}{|c|}{ Avaliação Qualitativa dos Riscos } \\
\hline \multirow{2}{*}{\begin{tabular}{c|} 
Risc \\
0 \\
$n^{\circ}$
\end{tabular}} & \multirow{2}{*}{ WBS } & \multirow{2}{*}{ Nome da tarefa } & \multirow{2}{*}{ Descrição: } & \multicolumn{3}{|c|}{ Impacto } & \multirow{2}{*}{\begin{tabular}{|l} 
Probabil \\
idade
\end{tabular}} & \multirow{2}{*}{$\begin{array}{c}\text { Probabilidade } \\
\mathbf{x} \\
\text { Impacto }\end{array}$} & \multirow{2}{*}{$\begin{array}{l}\text { Prioridade } \\
\text { de Risco }\end{array}$} \\
\hline & & & & Custo & Prazo & Escopo & & & \\
\hline 1 & & 1 Kick-off & Atraso na autorização do lançamento do projeto & 0 & 0,9 & 0 & 0,1 & 0,09 & BAIXA \\
\hline 2 & & $\begin{array}{l}2 \\
2 \begin{array}{l}\text { Aquisição: Especificação / Cotação / } \\
\text { Negociação / Pedido / Entrega }\end{array}\end{array}$ & Falhas no processo de aquisição & 0,3 & 0,5 & 0,3 & 0,3 & 0,15 & BAIXA \\
\hline & 3 & 3 Implementação: & & 0 & 0 & 0 & 0 & 0 & \\
\hline 3 & 3.1 & Usinagem do suporte de elevação & Falhas durante a fase de usinagem & 0 & 0,1 & 0,9 & 0,1 & 0,09 & BAIXA \\
\hline 4 & 3.2 & Pré-montagem do painel de controle & Montagem incorreta, falta de peças & 0,1 & 0,3 & 0,9 & 0,3 & 0,27 & MODERADA \\
\hline 5 & 3.3 & Pré montagem das luminárias & Atraso na preparação, erro de montagem & 0 & 0,1 & 0,3 & 0,1 & 0,03 & BAIXA \\
\hline 6 & 3.4 & Fixação de luminárias laterais & Danific ação durante a tarefa & 0,1 & 0,3 & 0,3 & 0,1 & 0,03 & BAIXA \\
\hline 7 & 3.5 & Fixação das luminárias de teto & Danific ação durante a tarefa & 0,1 & 0,3 & 0,3 & 0,1 & 0,03 & BAIXA \\
\hline 8 & 3.6 & Preparação da infraestrutura eletrica & $\begin{array}{l}\begin{array}{l}\text { Falhas na conexão com a rede existente, } \\
\text { incompatibilidade entre sistemas }\end{array} \\
\end{array}$ & 0,1 & 0,9 & 0,9 & 0,3 & 0,27 & MODERADA \\
\hline 9 & 3.7 & Corte para abertura no Piso & Atraso, Supresas na obra civil, (pedras, etc). & 0,1 & 0,9 & 0,9 & 0,3 & 0,27 & MODERADA \\
\hline 10 & 3.8 & $\begin{array}{l}\text { Grauteamento das bases/Acabamento e } \\
\text { Inclinaçōes para escoamento }\end{array}$ & Falha no acabamento com interferencia para a fixaçă & 0,1 & 0,5 & 0,9 & 0,3 & 0,27 & MODERADA \\
\hline 11 & 3.9 & Instalação de chapa xadrez & $\begin{array}{l}\begin{array}{l}\text { Problemas de dimensionamento, instalação } \\
\text { inadequada. }\end{array} \\
\end{array}$ & 0,1 & 0,5 & 0,9 & 0,3 & 0,27 & MODERADA \\
\hline 12 & 3.10 & $\begin{array}{l}\text { Instalação Grade tampa da caixa de } \\
\text { drenagem }\end{array}$ & $\begin{array}{l}\text { Problemas de dimensionamento, instalação } \\
\text { inadequada. }\end{array}$ & 0,1 & 0,5 & 0,9 & 0,3 & 0,27 & MODERADA \\
\hline 13 & 3.11 & Montagem da transmissão embutida & $\begin{array}{l}\text { Erro de montagem, fornecimento inadequado, } \\
\text { imcompatibilidade com as obras civis }\end{array}$ & 0,3 & 0,9 & 0,9 & 0,5 & 0,45 & ALTA \\
\hline 14 & 3.12 & $\begin{array}{l}\text { Fixação das Colunas e bracços de } \\
\text { içamento }\end{array}$ & Erro de montagem, fornecimento inadequado. & 0,3 & 0,9 & 0,9 & 0,3 & 0,27 & MODERADA \\
\hline 15 & 3.13 & Interligação ao Sist. Elétrico & $\begin{array}{l}\text { Falhas na conexão com a rede existente, } \\
\text { incompatibilidade entre sistemas }\end{array}$ & 0,9 & 0,9 & 0,9 & 0,3 & 0,27 & MODERADA \\
\hline 16 & 3.14 & Pintura do Piso (3 demãos) & $\begin{array}{l}\text { Falta de material de pintura, material incorreto, } \\
\text { serviço mal executado }\end{array}$ & 0,1 & 0,3 & 0,3 & 0,3 & 0,09 & BAIXA \\
\hline 17 & 3.15 & Pintura do elevador & $\begin{array}{l}\text { Falta de material de pintura, material incorreto, } \\
\text { serviço mal executado }\end{array}$ & 0,1 & 0,3 & 0,3 & 0,3 & 0,09 & BAIXA \\
\hline & 3.16 & Encerramento & & & & & & \#NÚM! & \\
\hline 18 & 3.16 .1 & $\begin{array}{l}\text { Comissionamento / Testes de } \\
\text { funcionamento }\end{array}$ & Falhas nos testes funcionais & 0,3 & 0,3 & 0,5 & 0,5 & 0,25 & MODERADA \\
\hline 19 & 3.16 .2 & $\begin{array}{l}\text { Confirmaçāo de escopo / Liberaçōes } \\
\text { (Segurança/meio ambiente/qualidade) }\end{array}$ & Não conformidades frente às exigências legais & 0,5 & 0,9 & 0,9 & 0,3 & 0,27 & MODERADA \\
\hline 20 & 3.16 .3 & Início da garantia & $\begin{array}{l}\text { Cliente não ac eitar o equipamento por questões de } \\
\text { escopo mal executado }\end{array}$ & 0,5 & 0,9 & 0,9 & 0,1 & 0,09 & BAIXA \\
\hline
\end{tabular}

Fonte: elaborado pelo autor, 2013

\subsection{IDENTIFICAÇÃO DO CAMINHO CRÍTICO}

Para aplicação do gerenciamento de riscos sobre um conjunto mais seleto de atividades, adotou-se como critério a aplicação sobre as tarefas críticas do projeto, ou seja, aquelas que compõem o Caminho Crítico do projeto.

Com o auxílio do MS-Project@, está identificado na figura 5 o caminho crítico, sendo as tarefas críticas destacadas em vermelho. 
Figura 5 - Escopo de adaptação do elevador embutido

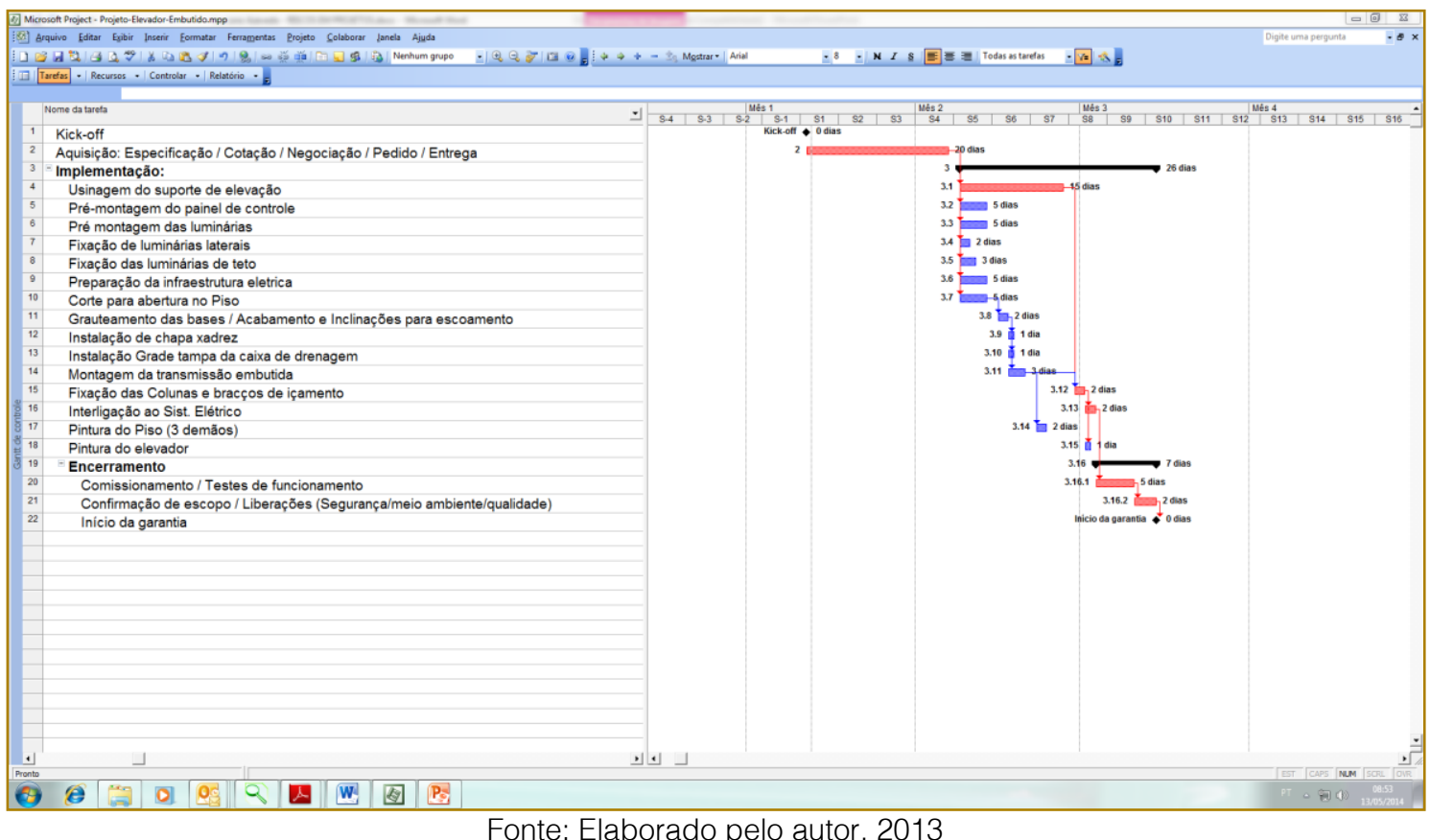

Extrai-se, então, o Caminho Crítico e constituise das tarefas da EAP 2; 3.1; 3.12; 3.13; 3.16.1; 3.16.2. Que correspondem às linhas 2 , $4,15,16,20$ e 21, respectivamente. O Diagrama de Rede, representado na figura 6 a seguir, destaca também em vermelho o caminho crítico, identificando a linha.
As linhas 3 e 19 são agrupamentos, ou resumos, foram tratadas as tarefas críticas específicas contidas nestes resumos. A tarefa 22 é um marco de projeto, referente à recepção do projeto pelo cliente e início do período de garantia.

Figura 6 - Escopo de adaptação do elevador embutido

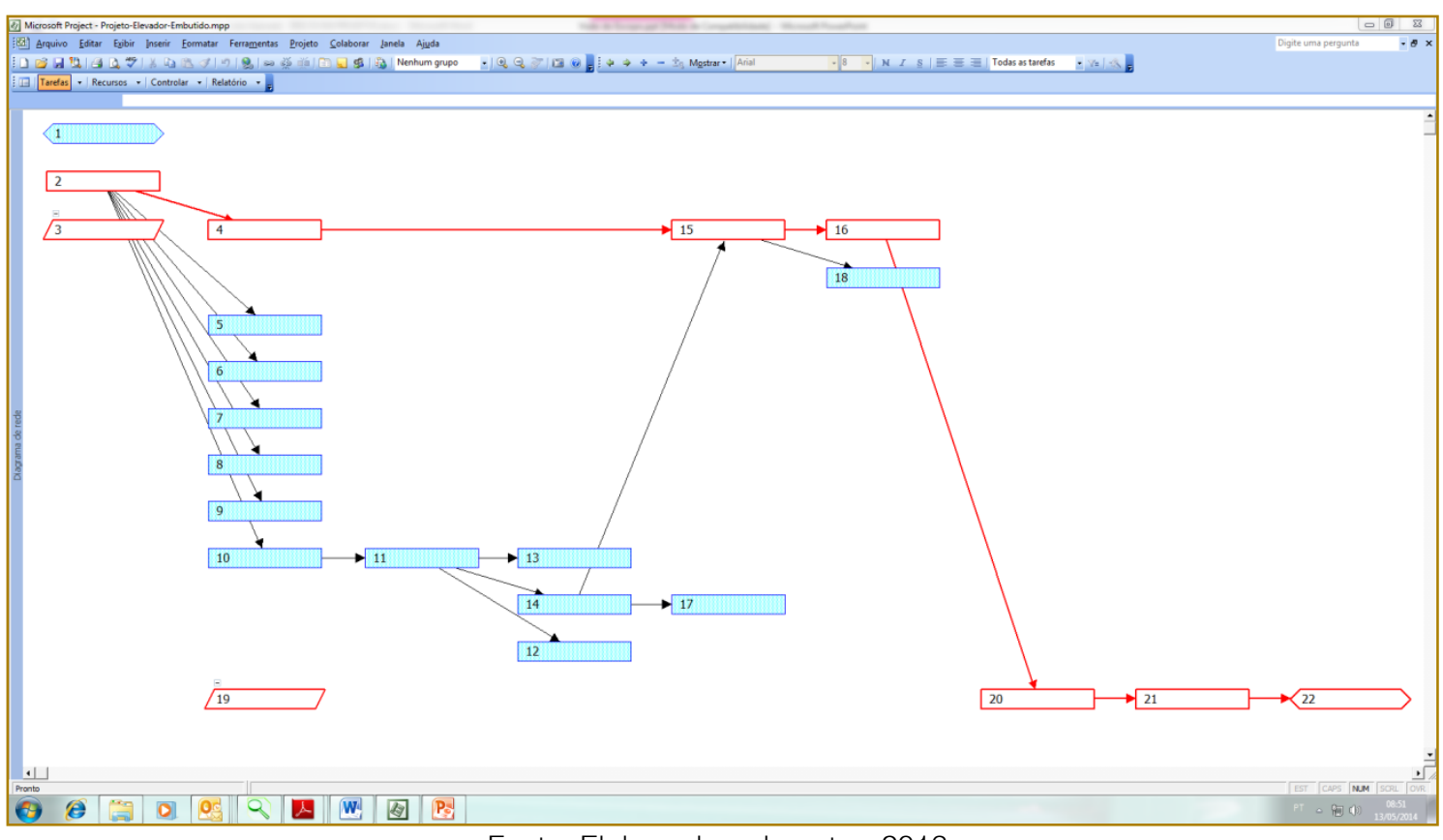

Fonte: Elaborado pelo autor, 2013. 
No relatório da figura 7 extraído do MSProject $®$, estão listadas as tarefas críticas, sendo na coluna id o número da linha, na coluna EDT o código na EAP (Estrutura Analítica do Projeto), e a seguir informações das tarefas sucessoras, com as características respectivamente Número da linha, descrição da tarefa, tipo de relacionamento, sendo todas TI (TérminoInício) e Latência, referente à folga livre entre tarefas.

Figura 7 - Escopo de adaptação do elevador embutido

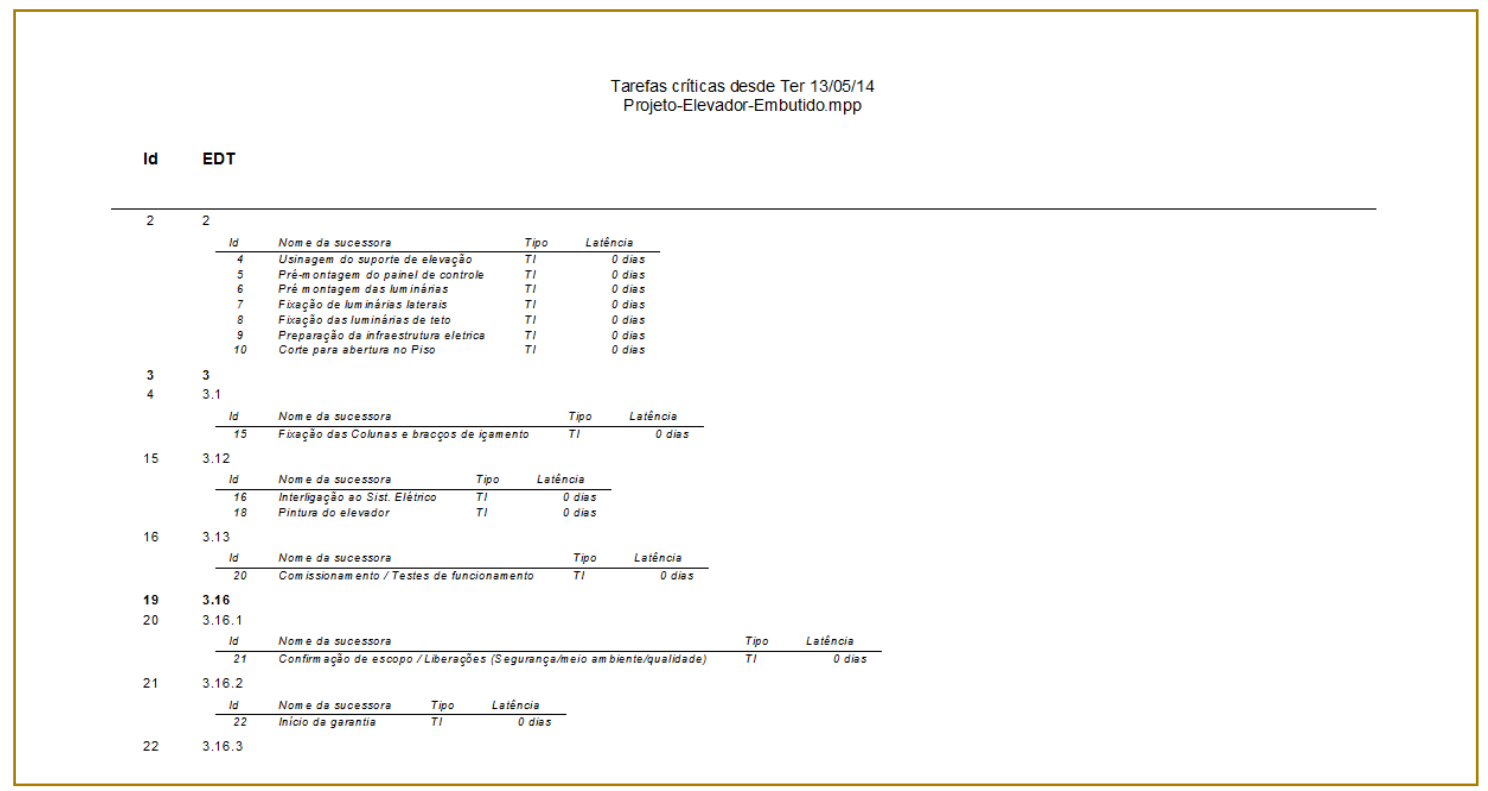

Fonte: Elaborado pelo autor, 2013.

\subsection{GERENCIAMENTO DOS RISCOS SOBRE AS TAREFAS CRÍTICAS}

Baseado na aplicação do estudo do Caminho Crítico apresenta-se na tabela 3 uma revisão da planilha de identificação dos riscos, após a restrição da abrangência às tarefas críticas, aquelas que compõem o caminho crítico do projeto.

Tabela 3 - Gerenciamento compacto dos riscos - Atividades Críticas

\begin{tabular}{|c|c|c|c|c|c|c|c|c|c|c|}
\hline & & & Identificação do: & Riscos & & & Avalie & lação Qu & litativa dos Risc & \\
\hline Risc & WBS & Caminho & Nome da tarefa & Descricão: & & Impacto & & Probabil & Probabilidade & Prioridade de Risco \\
\hline & & Critico & Nome oa tarera & Descriçao: & Custo & Prazo & Escopo & idade & & Priorica ae de fisco \\
\hline & 1 & s & Kick-off & Atraso na autorizaçăo do lançamento do projeto & 0 & 0,9 & 0 & 0,1 & 0,09 & BAIXA \\
\hline 2 & 2 & s & $\begin{array}{l}\text { Aquisiçăo: Especificaçāa / Cotaçăo / } \\
\text { Negociação/ Pedido / Entrega }\end{array}$ & Falhas no processo de aquisiçāo & 0,3 & 0,5 & 0,3 & 0,3 & 0,15 & BAIXA \\
\hline 3 & 3.1 & s & Usinagem do suporte de elevaçāo & Falhas durante a fase de usinagem & 0 & 0,1 & 0,9 & 0,1 & 0,09 & BAIXA \\
\hline 4 & 3.12 & s & $\begin{array}{l}\text { Fixação das Colunas e bracços de } \\
\text { içamento }\end{array}$ & Erro de montagem, formecimento inadequado. & 0,3 & 0,9 & 0,9 & 0,3 & 0,27 & MODERADA \\
\hline 5 & 3.13 & s & Interligação ao Sist. Elétrico & $\begin{array}{l}\text { Fallhas na conexão com a rede existente, } \\
\text { incompatibilidade entre sistemas }\end{array}$ & 0,9 & 0,9 & 0,9 & 0,3 & 0,27 & MODERADA \\
\hline 6 & 3.16 .1 & s & $\begin{array}{l}\text { Comissionamento / Testes de } \\
\text { funcionamento }\end{array}$ & Falhas nos testes funcionais & 0,3 & 0,3 & 0,5 & 0,5 & 0,25 & MODERADA \\
\hline 7 & 3.16 .2 & s & $\begin{array}{l}\text { Confirmação de escopo / Liberaçōes } \\
\text { (Segurança/meio ambiente/qualidade) }\end{array}$ & Não conformidades frente às exigências legais & 0,5 & 0,9 & 0,9 & 0,3 & 0,27 & MODERADA \\
\hline 8 & 3.16 .3 & s & Início da garantia & $\begin{array}{l}\text { Cliente não aceitaro equipamento por questôes de } \\
\text { escopo malexecutado }\end{array}$ & 0,5 & 0,9 & 0,9 & 0,1 & 0,09 & BAIXA \\
\hline
\end{tabular}

Fonte: Elaborado pelo autor, 2013

\subsection{ANÁLISE COMPARATIVA}

Pode-se perceber que o gerenciamento completo do risco trabalha sobre 20 tarefas, já o gerenciamento compacto, somente avaliou
8 tarefas, alcançando uma redução de $60 \%$. Ao prospectar a redução para projetos maiores e semelhantes em escopo, como o projeto inicialmente observado, pode-se 
esperar um ganho ainda maior, pois há tarefas que existem em qualquer tamanho de projeto e fazem parte do caminho crítico, principalmente tarefas de Inicialização e Encerramento dos projetos. Desta forma, é possível que as tarefas do caminho crítico possam representar um percentual ainda menor do conjunto total de tarefas, potencializando a redução obtida.

\section{CONSIDERAÇÕES FINAIS}

Como o estudo foi realizado em um projeto de baixa complexidade, residem limitações que devem ser observadas no projeto completo.

A análise das redes possui métodos matemáticos rebuscados para avaliar uma base construída por estimativas carregadas de incertezas, assim, pode-se aplicar um esforço em vão na melhoria do gerenciamento, $\mathrm{o}$ que justifica $\mathrm{O}$ aprimoramento na estimativa dos prazos, baseando-se em dados históricos de atividades semelhantes.

Como o projeto teve um andamento rigorosamente dentro do prazo estipulado, há oportunidade de investigação para a hipótese de que a duração das atividades tenha sido superestimada, com potencial de otimização na aplicação de recursos para projetos similares futuros.

O gerenciamento qualitativo dos riscos limitou-se aos riscos negativos para o projeto; riscos positivos, ao serem mapeados, podem

\section{REFERÊNCIAS}

[1] CONTADOR, José Luiz; SENNE, Edson Luiz França. Determinação de caminhos k-críticos em redes PERT. Gest. Prod., São Carlos , v. 14, n. 3, dez. 2007.Disponível em <http://www.scielo.br/scielo.php?script=sci_arttext \&pid=S0104-530X20070003

$00004 \& \operatorname{lng}=p t \& n r m=i s o>$. acessos em $25 \mathrm{abr}$. $2014 . \quad$ http://dx.doi.org/10.1590/S0104530X2007000300004.

[2] ECO, Umberto. Como se faz uma tese em Ciências Humanas. 26a Edição, Lisboa: Editorial Presença, 2016

[3] GIL, Antonio Carlos. Como elaborar projetos de pesquisa. 4aㅡ Edição, São Paulo: Atlas, 2002.

[4] GRAY, David. Pesquisa no Mundo Real. $2^{2}$ Edição, Porto alegre: Penso, 2012. resultar em uma compressão de atividades em replanejamento, o que traz o benefício de antecipação da entrega do produto e consequente cumprimento da função econômica objetivada pelo projeto.

O Gerenciamento compacto dos riscos centrado em caminhos k-críticos e folga mínima arbitrada demonstra-se capaz de reduzir a aplicação de recursos no gerenciamento do projeto e impactos no cronograma do projeto. Como resultado de uma minimização da análise, permanece o risco de que alguma atividade fora do corte adotado sofra desvio e represente impacto no projeto que estará influenciado pelo tamanho da seleção de tarefas priorizado.

Há espaço para pesquisas futuras em projetos reais, para a identificação dos cortes da priorização de gerenciamento. No caso dos caminhos k-críticos qual seria o número de k-caminhos recomendado em relação ao número de caminhos existentes nos projetos? $\mathrm{Na}$ abordagem da folga mínima, qual seria a folga mínima razoável a ser adotada? É conveniente adotar uma referência percentual de folga em relação ao o prazo total do projeto?

A identificação dos caminhos k-críticos / folga mínima, para um projeto com maior número de atividades, aproximando-se do cotidiano, irá requerer ferramentas para a o processamento das informações.

[5] KERZNER, Harold. Gerenciamento de Projetos: uma abordagem sistêmica para planejamento, programação e controle. 10ª ed. São Paulo: Editora Blucher, 2011

[6] PMI. PMBOK - Um Guia do conhecimento em Gerenciamento de Projetos (PMBOK®), $5^{\text {a }}$ Edição. Pennsylvania: Project Management Institute - PMI®, 2013

[7] $\mathrm{PMI}$ - Project <management Institute. Disponível em http://brasil.pmi.org/brazil/AboutUS/WhatlsProjectM anagement.aspx acessos em 22 abr. 2014

[8] SALLES JUNIOR, Carlos Alberto Corrêa. Gerenciamento de riscos em projetos. $2^{\underline{a}}$ Ed. Rio de Janeiro: Editora FGV, 2010.

[9] VARGAS, Ricardo Viana. Gerenciamento de Projetos: estabelecendo diferenciais competitivos. $7^{\underline{a}}$ ed. Rio de Janeiro, Brasport, 2009. 


\section{Capítulo 19}

\section{UMA VISÃO GERAL DA INTERNET DE VEÍCULOS}

\section{Thales Botelho de Sousa}

Ernani José Fortunato Lisbôa Enke

Daiane Ferreira Kogiski

Larissa Carvalho Ferreira Reverte

Raphany Cordeiro Hahn

Marcos Vinícius de Freitas Santos

Resumo: A Internet of Vehicles (loV) ou Internet de Veículos engloba comunicação entre veículos, proteção ambiental, conservação de energia e segurança no trânsito. Com o rápido desenvolvimento das tecnologias de informação e comunicação, a loV vem obtendo um enorme interesse comercial e acadêmico, atraindo grande número de empresas e pesquisadores interessados no seu desenvolvimento. Por meio de uma revisão integrativa da literatura, este artigo apresenta uma visão geral da loV, discutindo suas implicações sociais, ambientais e econômicas, seus benefícios e os principais desafios para sua consolidação. Para o desenvolvimento do trabalho, foram analisados 137 artigos publicados em periódicos indexados nas bases de dados Scopus e/ou Web of Science. A análise é baseada nos artigos redigidos na língua inglesa e publicados até junho de 2018. Os resultados evidenciam que a loV é uma das principais aplicações da Internet of Things (IoT); com o uso da tecnologia, vários benefícios relacionados à segurança no tráfego, economia de custos e preservação ambiental podem ser alcançados; e, muitas questões relacionadas à segurança e transmissão das informações representam grandes desafios para o desenvolvimento do tema. As contribuições de vários pesquisadores são apresentadas em um aspecto que servirá ao leitor como um referencial conceitual abrangente e consolidado.

Palavras-chave: Internet de Veículos; Tecnologia da Informação e Comunicação; Revisão Integrativa da Literatura; Scopus; Web of Science. 


\section{INTRODUÇÃO}

Introduzida por Ashton em 1991, a Internet of Things (IoT) ou Internet das Coisas engloba uma variedade de tecnologias e áreas de pesquisa e é referida como a ligação entre a internet e os objetos do mundo real (coisas) identificáveis de forma única (LI; LI, 2012). Por meio de esquemas de endereçamento, a loT permite que coisas e objetos tais como RadioFrequency IDentification (RFID), sensores, atuadores e telefones celulares interajam entre si e cooperem com seus componentes inteligentes ao seu redor para alcançarem metas comuns (LASI et al., 2014). Projetos industriais envolvendo IoT têm sido desenvolvidos em áreas como agricultura, indústria de processamento de alimentos, monitoramento ambiental, vigilância de segurança, transportes, dentre outros (UDEN; HE, 2017).

Como um membro indispensável da loT, a Internet of Vehicles (loV) ou Internet de Veículos desempenha um papel importante no sistema de transporte inteligente e pode promover o desenvolvimento das tão almejadas cidades inteligentes, pois esperase que ela ofereça uma ampla variedade de aplicações para melhorar a segurança nas estradas, a eficiência do tráfego e a entrega de informações sobre entretenimento (ZHU et al., 2018). A loV oferece vários serviços, incluindo aplicativos de segurança (detecção de colisão, aviso de alteração de faixa e fusão cooperativa), gerenciamento inteligente e sustentável do transporte (controle de sinal de tráfego, programação inteligente de tráfego e gerenciamento de frota), serviços dependentes de localização (ponto de interesse e otimização de rotas) e acesso à Internet (YANG et al., 2016). A próxima geração de loV é um campo emergente que atravessa várias disciplinas, incluindo os setores de automação, transporte inteligente, tecnologia da informação, comunicações, energia, etc. (HSU; WANG; YUAN, 2018).

Considerando que tanto a academia quanto a indústria têm desencadeado estudos avançados sobre loV (CHITI et al., 2017; IGLESIA et al., 2017; RUAN; LI; LI, 2017; ZHAO et al., 2018) e que existem muitos desafios e questões críticas para a sua consolidação (DARWISH; BAKAR, 2018; FU et al., 2018; ISLAM; HOSSAN; JANG, 2018), este artigo visa apresentar uma revisão integrativa da literatura sobre o tema, a fim de fornecer ao leitor uma compreensão ampla do termo, embasada em fontes de pesquisa confiáveis.
O restante deste trabalho é estruturado da seguinte maneira: a seção 2 apresenta os métodos utilizados para o levantamento bibliográfico dos artigos relacionados à loV; a seção 3, uma visão geral sobre o tema; a seção 4, a integração de aspectos sociais em seu desenvolvimento; a seção 5 , seus beneficios; a seção 6, os desafios para a sua consolidação; e por fim, a última seção apresenta as conclusões relacionadas ao estudo, apontando as principais limitações da pesquisa.

\section{METODOLOGIA}

A metodologia utilizada para o desenvolvimento deste artigo tem como objetivo obter resultados capazes de apoiar a construção de um melhor conhecimento sobre a loV. A revisão integrativa da literatura, como um tipo específico de revisão de literatura, é apropriada para o desenvolvimento deste artigo. Este método de pesquisa caracterizase pela apresentação de uma abordagem metodológica extensiva em relação às revisões da literatura, pois, para a compreensão completa do fenômeno estudado, permite a inclusão de estudos desenvolvidos com diferentes métodos de pesquisa (KAKUSHI; ÉVORA, 2016). A revisão integrativa da literatura é útil para a definição de conceitos, geração de novos conhecimentos sobre o tópico revisado, revisão de teorias e evidências, e análise de problemas metodológicos de determinado campo de pesquisa (ANDERSEN; BATOVA, 2015; KAKUSHI; ÉVORA, 2016).

Considerando que é difícil ter uma clara distinção entre as publicações que têm alto nível de qualidade e as que não têm, e que nem todas as publicações têm o mesmo valor para os cientistas, este trabalho restringiu suas fontes às bases de dados bibliográficas Scopus e Web of Science. Elas foram selecionadas devido à sua ampla utilização e impacto na comunidade acadêmica internacional (ROMO-FERNÁNDEZ et al., 2011). Foram selecionados apenas artigos publicados em periódicos científicos, devido ao fato de sua seleção e avaliação serem mais criteriosas que a seleção de artigos de congressos e simpósios (CARNEVALLI; MIGUEL, 2008), além de serem considerados como as pesquisas de mais alto nível, tanto para coleta de informações, quanto para divulgação de novos resultados e descobertas (NGAl et al., 2008). 
Para selecionar as publicações de interesse, nas bases de dados foi pesquisado por meio do título, resumo e palavras-chave (sem restrição ao período de publicação) o termo "Internet of Vehicle*" e foram levantados somente artigos redigidos em inglês, devido ao fato de este ser o idioma oficial da ciência. Subsequentemente, procedeu-se à leitura e análise do resumo e introdução dos artigos encontrados, selecionando-se os que apresentavam relevância para os objetivos deste trabalho. A seleção de novos documentos identifica nas referências bibliográficas dos artigos selecionados novas fontes bibliográficas úteis para o desenvolvimento desta pesquisa, visando inseri-los no contexto do artigo, tornando a revisão mais abrangente. A estrutura da metodologia utilizada para a orientação do levantamento bibliográfico dos artigos é apresentada na Figura 1.

Figura 1 - Procedimentos para o levantamento bibliográfico utilizado neste artigo.

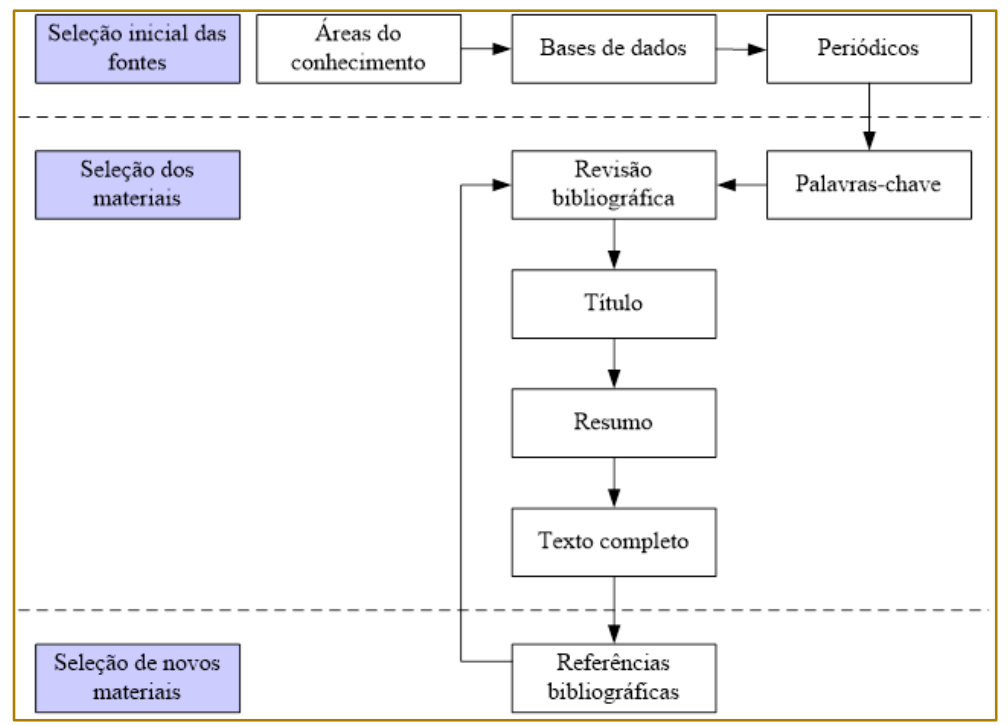

Fonte: Adaptado de Villas, Soares e Russo (2008).

Considerando que alguns artigos estão duplicados (ou seja, estão indexados nas duas bases de dados) e que alguns artigos apenas mencionam o termo "Internet of Vehicle*" no resumo e palavra-chaves, após o devido refinamento, chegou-se ao número final de 137 artigos. É importante ressaltar que os artigos de 2018 incluem apenas as publicações realizadas até o mês de junho.

\section{UMA VISÃO GERAL DA IOV}

De acordo com Singh et al. (2017), a loV representa a combinação da loT com as redes Vehicular Ad hoc NETworks (VANET). A loV é um conjunto de tecnologias e aplicativos que usa comunicação sem fio para fornecer conectividade entre veículos de todos os tipos, entre veículos e infraestrutura rodoviária, e entre veículos, infraestrutura e dispositivos sem fio, visando melhorar a segurança, a mobilidade e o meio ambiente (ZHENG; RAN; HUANG, 2017). Essa arquitetura de rede heterogênea pode ser categorizada em cinco tipos de comunicação veicular: vehicle-to-vehicle (V2V) ou veículo a veículo, vehicle-to-infrastructure (V2I) ou veículo a infraestrutura, vehicle-to-roadside unit (V2R) ou veículo a unidade de estrada, vehicle-to-sensors (V2S) ou veículo a sensores e vehicle-to-pedestrians (V2P) ou veículo a pedestres (ISLAM; HOSSAN; JANG, 2018).

Para Cui et al. (2018), a loV consiste de uma third-party trusted authority (TA) ou autoridade confiável de terceiros, algumas roadside units (RSUs) ou unidades de rota e vários veiculos distribuídos na rota. A TA possui suficientes armazenamento e poder de computação, e é considerada impossível de ser comprometida por um adversário, pois quando um invasor simula que um veículo envia uma mensagem falsa, a TA pode retomar a verdadeira identidade da mensagem enviada. A RSU é uma infraestrutura que é distribuída na rota, comunicando com a TA por meio de uma conexão com fio e com os veículos por meio 
de uma conexão sem fio, a fim de verificar a validade da mensagem recebida. E por fim, cada veículo é equipado com tamper proof device (TPD) ou dispositivo à prova de adulteração, e se comunica com outros veículos e RSUs através de conexões sem fio, transmitindo periodicamente mensagens relacionadas à segurança para veículos próximos e RSUs através do protocolo dedicated short range communications (DSRC) ou de comunicações dedicadas de curto alcance.

A loV representa uma instanciação proeminente da loT em um intelligent transport system (ITS) ou sistema de transporte inteligente, sendo destinada a suportar uma ampla gama de aplicações seguras e não seguras para gerenciamento inteligente, eficiente e sustentável do tráfego, monitoramento ambiental, controle inteligente de veículos, e experiências de condução e viagem seguras, confortáveis e agradáveis (AMADEO; CAMPOLO; MOLINARO, 2016). A tecnologia de posicionamento e reconhecimento de localização é a principal tecnologia da IOV, e, por meio da implantação adequada de dispositivos tais como leitores RFID, semáforos, câmeras de vídeo e tecnologias de alcance sem fio, algoritmos correspondentes de reconhecimento de localização podem ser usados nos veículos em operação (TING; BIN; QI, 2016).

A loV visa construir um sistema inteligente para melhorar a qualidade de vida ou de direção, e formalmente visa aumentar a qualidade da experiência ou do serviço fornecido ao usuário (ZHANG et al., 2016). Segundo Xu et al. (2018), as informações da IoV geradas pelos veículos podem ser categorizadas em duas partes: informações a bordo e informações da rota. Informações a bordo que monitoram o status do veículo, como velocidade, parâmetros do motor, status do freio, etc., podem ser obtidas diretamente dos sensores no veículo. Informações da rota referem-se às informações dos eventos que acontecem na estrada, que podem ser tanto de sensores a bordo (por exemplo, distância entre veículos, objetivos do ponto oculto, vídeo da câmera piloto, etc.) ou de outros via conexões da loV (status do semáforo, notificação de freio do veículo vizinho, mapa, etc.).

O desenvolvimento das cidades inteligentes é um forte impulsionador da loV, pois por meio dela edifícios, casas, dispositivos e pessoas são capazes de se comunicarem por meio de acesso via redes com ou sem fio (ZHANG et al., 2016). Dado que o transporte representa um sétimo da economia mundial, a loV desempenhará um papel importante nas futuras cidades inteligentes (HSU; WANG; YUAN, 2017).

Para implementar uma plataforma de loV, os requisitos funcionais básicos devem incluir coleta, armazenamento, análise e serviços relacionados aos dados dos veículos; os veículos devem carregar dados de condução, incluindo localizações instantâneas e estados de motores de veículos; e estes dados podem ser usados em aplicativos de gerenciamento de veículos em tempo real e off-line (ZHANG et al., 2017).

De acordo com Islam, Hossan e Jang (2018), muitos países já implementaram ou propuseram alguns serviços básicos de loV. Os Estados Unidos instalaram chips de segurança em veículos para armazenar informações de identificação sobre cada veículo em seu centro de dados. O governo da Índia também trouxe seus veículos para uma única rede através de global position system (GPS) ou sistema de posicionamento global e redes sem fio. Um novo sistema de transporte da próxima geração, o cooperative intelligent transportation system (C-ITS) ou sistema cooperativo de transporte inteligente, foi iniciado pela Comissão Europeia. A Coreia do Sul e a Austrália também estão interessados em implementar esses sistemas veiculares automotivos. E, além destas iniciativas nacionais, tanto o Google quanto a Apple estão desenvolvendo um sistema conectado de direcionamento baseado em smartphone, sendo que a Apple já deu a largada ao desenvolver um sistema chamado "CarPlay", o qual contém um recurso de suporte à voz para permitir que o motorista use os serviços do iPhone através da exibição de seu carro.

\section{INTEGRAÇÃO DE ASPECTOS SOCIAIS NA loV}

Um relatório de investigação publicado pelo Eno Center for Transportation revela que se a tecnologia de condução autônoma e cooperação de comunicação veicular pudessem ser adotadas, os acidentes de trânsito causados por erros de direção seriam significativamente reduzidos e o engarrafamento urbano seria bastante aliviado (CHEN et al., 2018). Priscilla, Mathan e Ananthamoorthy (2018) afirmam que 
anualmente, os Estados Unidos perdem mais de 75 bilhões de dólares em produtividade de trabalhadores e 8,4 bilhões de galões de gasolina devido ao congestionamento de estradas ocasionado por acidentes de trânsito. Philip e Ra.K (2018) apontam que mundialmente em média 1,25 milhões de mortes são relatadas devido a acidentes rodoviários.

Segundo Singh et al. (2017), a integração de aspectos sociais na loV permite que os veículos sejam capazes de estabelecer relações sociais uns com os outros de maneira autônoma, considerando as restrições do proprietário. Essas relações podem ser estáticas (entre veículos da mesma empresa automobilística) ou dinâmicas (desenvolvidas através de comunicações veículo a veículo).

A integração de aspectos sociais na loV resolve muitos problemas enfrentados por ela, tais como: conectividade limitada entre veículos, conectividade limitada entre veículos e infraestrutura viária, distribuição eficaz de conteúdo, heterogeneidade e privacidade (SINGH et al., 2017).

Com o surgimento da loV social, poderosos aplicativos como transporte e gerenciamento de logística, serviços de multimídia, localizadores de amigos, compartilhamento de conteúdo, dentre outros, podem ser amplamente aplicados (LAl et al., 2018).

\section{BENEFÍCIOS DA IoV}

A loV não realiza apenas a comunicação sem fio entre veículos, estradas, pedestres e internet, mas também o gerenciamento inteligente de tráfego, o serviço inteligente de informações dinâmicas e a integração inteligente de redes de controle de veículos (HE et al., 2016). Espera-se que por meio da loV vários serviços como avisos de colisão, detecção de congestionamento de tráfego, planejamento de rotas e entretenimento informativo sejam fornecidos, tornando as viagens de tráfego humano mais convenientes.

$\mathrm{Na}$ IoV, os aplicativos relacionados à segurança envolvem mensagens periódicas de status e mensagens de emergência orientadas por eventos. Uma mensagem de emergência é acionada quando um evento imprevisto como um acidente, condições terríveis da estrada, engarrafamento ou um veículo anormal aparece, e assim, os motoristas podem ajustar a velocidade do veículo ou alterar as rotas de acordo com as informações recebidas (ZHU et al., 2017).

De acordo com Zhao et al. (2018), por meio da IoV a velocidade de um veículo é aumentada, ao passo que a distância em relação ao carro seguinte é reduzida; conflitos nos cruzamentos são mitigados mais rapidamente; o controle de sinal é mais flexível; a taxa de utilização de luz verde aumenta; e a zona do dilema (área onde o veículo não pode passar pela linha de parada, nem parar com segurança dentro da linha de parada durante a luz amarela) desaparece.

De acordo com Chen et al. (2018), os principais benefícios da loV são inteligência cognitiva, tomada de decisão confiável, utilização eficiente dos recursos e grande potencial de mercado. $\mathrm{Na}$ inteligência cognitiva, por meio da cognição na rede intraveículo (motoristas, passageiros, dispositivos inteligentes, etc.), rede interveículo (veículos inteligentes adjacentes) e rede externa ao veículo (ambiente rodoviário, rede celular, nós de borda, nuvem remota, etc.), a loV possibilita uma capacidade perceptiva mais precisa, o fornecimento de informações macrocósmicas e estratégias de programação para todo o sistema de transporte. Ao introduzir a computação cognitiva em sistemas de direção autônoma, por meio do ciclo cognitivo de percepção, treinamento, aprendizado e feedback, a capacidade de aprendizagem de veículos autônomos pode ser efetivamente melhorada, e o processo de tomada de decisão dos veículos autônomos será mais completo e confiável. Com a percepção do status do tráfego da rede e das circunstâncias da estrada em tempo real, as decisões derivadas de tecnologias analíticas como aprendizado de máquina e aprendizado profundo podem ajudar o mecanismo cognitivo de recursos a conduzir um controle mais efetivo sobre os veículos e aumentar a eficiência do compartilhamento de informações dentro das redes veiculares. Em termos de oportunidades de mercado, os benefícios trazidos pela loV não se limitam ao mercado de veículos, e estão intimamente ligados a muitos outros aspectos da vida das pessoas, como entretenimento, saúde, agendamento e assim por diante.

A loV não traz apenas benefícios relacionados à segurança no trânsito. Significativos ganhos ambientais e econômicos podem ser obtidos com esta tecnologia. Segundo Amer et al. 
(2016), em torno de 30\% das emissões de dióxido de carbono (CO2) são ocasionadas pela gestão ineficiente de veículos. Estudos da empresa Gartner preveem que mais de 250 milhões de veículos conectados por loV estarão em uso em todo o mundo até 2020, e a União Europeia estima que o valor de mercado global para tecnologias e serviços de loV chegará a 115,26 bilhões de euros no mesmo ano (DARWISH; BAKAR, 2018). As práticas do Cisco IBSG Automotive and Economics preveem que para cada veículo, 1.400 dólares podem ser economizados anualmente com a utilização de loV (DARWISH; BAKAR, 2018).

\section{DESAFIOS PARA A CONSOLIDAÇÃO DA loV}

De acordo com Zhang et al. (2017), como a loV representa uma tendência cada vez mais importante para o transporte futuro, o projeto em larga escala de sistemas relacionados a ela tornou-se uma tarefa crítica, pois as informações correlatas aos status dos veículos de alta frequência (por exemplo, localização, parâmetros do motor) são caracterizados como grande volume com baixa densidade de valor e baixa qualidade de dados.

A implementação bem-sucedida da loV depende de vários fatores, indo desde a colaboração adequada e interconexão entre diferentes setores (energia, meio ambiente, manufatura automotiva, transporte, etc.) até evoluções sustentadas de tecnologia na camada inferior e superior da pilha de protocolos de comunicação (AMADEO; CAMPOLO; MOLINARO, 2016).

Semelhante a outros aplicativos de IoT, na loV os dados do veículo geralmente são organizados em fluxos, e embora cada veículo carregue um pequeno fluxo de dados, um grande fluxo é mesclado na nuvem devido à alta frequência e à grande escala de frota, o que requer o processamento do fluxo de dados dos veículos em tempo hábil (ZHANG et al., 2017). Entretanto, para satisfazer este requisito, existem três principais desafios para o projeto de um sistema industrial de loV de grande escala: (1) o sistema precisa ser altamente escalável para lidar com a grande escala dos dados, (2) o sistema precisa fazer uma boa troca entre os requisitos de tempo real e a precisão dos serviços centrados em dados ao processar dados com baixa qualidade e baixa densidade de valor em grande escala, (3) o sistema precisa ser altamente confiável para suportar serviços críticos de segurança tais como assistência de emergência (ZHANG et al., 2017).

A questão da sustentabilidade na loV é um constante desafio, pois neste ramo a sustentabilidade pode ser alcançada não apenas pelo uso de sistemas veiculares livres de poluição, mas também pela manutenção da segurança no trânsito ou pela prevenção de acidentes ou colisões (BALASUBRAMANIAM et al., 2017).

Erros na transmissão de dados representam outro grande desafio para a consolidação da IoV (SADIQ et al., 2018). O erro de transmissão ocorre quando uma mensagem de emergência é divulgada para fornecer reconhecimento de tráfego, e os veículos precisam aumentar sua capacidade de transmissão de canal para garantir cobertura adicional e mitigar possíveis acidentes. Isso pode causar congestionamento de canal e consumo de energia desnecessário devido a uma configuração imprecisa da energia de transmissão.

De acordo com Chen et al. (2018), as seguintes questões necessitam ser resolvidas para a consolidação da loV: mobilidade em alta velocidade, sensibilidade de atraso (o atraso na comunicação precisa ser medido em milissegundos, pois se houver um congestionamento, muitos acidentes podem ocorrer), perfeita conectividade, privacidade das informações e restrições de recursos.

Diversos autores que publicaram trabalhos sobre o tema afirmam que a segurança na coleta de informações é o principal desafio para a consolidação da loV. Segundo Sun et al. (2017), os sistemas de loV enfrentam vários tipos de ataques, como ataques de autenticação e identificação, de disponibilidade, de confidencialidade, de roteamento, de autenticidade de dados, etc., os quais resultam em vários desafios para os requisitos de segurança e privacidade. Para Guo et al. (2017), com relação à adequada coleta de informações, o sistema deve ter requisitos de segurança com funções operacionais e funções de gerenciamento que incluam: (1) autenticação para identificar o nó do veículo, o nó coletor e o centro de big data, (2) integridade para proteger mensagens contra modificação ou destruição, (3) confidencialidade para proteger as informações enviadas à entidade apropriada, 
e (4) autorização para garantir que apenas os nós autorizados acessem o recurso.

\section{CONSIDERAÇÕES FINAIS}

Como uma parte importante das cidades inteligentes, a loV está emergindo como uma proposta em desenvolvimento em todo o mundo. A loV é um complexo sistema de rede integrado que conecta pessoas (dentro e ao redor de veículos), sistemas inteligentes a bordo de veículos e vários sistemas ciberfísicos em ambientes urbanos. A loV vai além da telemática, redes de veículos e do transporte inteligente integrando veículos, sensores e dispositivos móveis em uma rede global para permitir que vários serviços sejam entregues a sistemas veiculares e de transporte e a pessoas a bordo e ao redor de veículos. Com a consolidação da loV os níveis de poluição atmosférica serão drasticamente reduzidos.

Por meio da revisão integrativa da literatura, foi possível verificar que o escopo de aplicação da loV é bastante amplo, e esta tecnologia tem grande importância no desenvolvimento das cidades inteligentes, permitindo que veículos, dispositivos, construções e indivíduos permaneçam conectados entre si. No entanto, foi possível verificar que a implementação da loV ainda enfrenta muitos desafios tais como conexões flexíveis e eficientes, garantia de qualidade de serviço, várias solicitações de suporte simultâneas, segurança das informações e envio adequado de informações.

\section{REFERÊNCIAS}

[1] AMADEO, M.; CAMPOLO, C.; MOLINARO, A. Priority-based content delivery in the Internet of Vehicles through named data networking. Journal of Sensor and Actuator Networks, v. 5, n. 4, 2016.

[2] AMER, H. et al. An improved simulated annealing technique for enhanced mobility in smart cities. Sensors, v. 16, n. 7, 2016.

[3] ANDERSEN, R.; BATOVA, T. The current state of component content management: an integrative literature review. IEEE Transactions on Professional Communication, v. 58, n. 3, p. 247270, 2015.

[4] BALASUBRAMANIAM, A. et al. Comparative analysis of intelligent transportation systems for sustainable environment in smart cities. Sustainability, v. 9, n. 7, 2017.
Este artigo representa uma importante contribuição teórica para o desenvolvimento de temáticas de pesquisa no campo da loV. Fornecendo uma definição abrangente, este estudo ajuda a esclarecer algumas questões importantes relacionadas ao desenvolvimento e consolidação do tema.

As limitações do artigo resultam de seu escopo e do método de pesquisa aplicado. Como a busca bibliográfica restringiu as publicações às compiladas em língua inglesa, contribuições relevantes em outros idiomas podem ter sido negligenciadas. Além disso, é possível que durante a identificação inicial dos termos de pesquisa importantes tópicos relacionados à loV possam ter sido ignorados, pois foram utilizadas palavras-chave específicas definidas pelos autores, o que pode ter levado a uma lista incompleta de tópicos, e, consequentemente, a uma definição não tão bem consistente sobre o tema.

Apesar das limitações acima mencionadas, acredita-se que este trabalho oferecerá motivação para realizar pesquisas para o avanço do tema e projetos para solução dos desafios da loV. Como pesquisas de cunho teórico representam um passo inicial para o desenvolvimento de uma temática de pesquisa, futuros trabalhos podem fornecer informações mais sistemáticas sobre os tópicos de pesquisa aqui abordados, examinando um conjunto mais amplo de fontes bibliográficas para análise.

[5] CARneVAlLI, J. A.; Miguel, P. A. C. Review, analysis and classification of the literature on QFD - types of research, difficulties and benefits. International Journal of Production Economics, v. 114, n. 2, p. 737-754, 2008.

[6] CHEN, M. et al. Cognitive Internet of Vehicles. Computer Communications, v. 120, p. 5870, 2018.

[7] CHITI, F. et al. Content sharing in Internet of Vehicles: two matching-based user-association approaches. Vehicular Communications, v. 8, p. 35-44, 2017.

[8] CUI, J. et al. Privacy-preserving authentication using a double pseudonym for Internet of Vehicles. Sensors, v. 18, n. 5, 2018. 
[9] DARWISH, T. S. J.; BAKAR, K. A. Fog based intelligent transportation big data analytics in the Internet of Vehicles environment: motivations, architecture, challenges, and critical issues. IEEE Access, v. 6, p. 15679-15701, 2018.

[10] FU, W. et al. A practical intrusion detection system for Internet of Vehicles. China Communications, v. 13, n. 10, p. 263-275, 2016.

[11] GUO, L. et al. A secure mechanism for big data collection in large scale Internet of Vehicle. IEEE Internet of Things Journal, v. 4, n. 2, p. 601610,2017

[12] HE, $X$. et al. A novel load balancing strategy of software-defined cloud/fog networking in the Internet of Vehicles. China Communications, v. 13, n. 2, p. 140-149, 2016

[13] HSU, C-H.; WANG, S.; YUAN, Y. Guest editorial special issue on hybrid intelligence for Internet of Vehicles. IEEE Systems Journal, v. 11, n. 3, p. 1225-1227, 2017.

[14] IGLESIA, I. D. L. et al. Smart bandwidth assignation in an underlay cellular network for Internet of Vehicles. Sensors, v. 17, n. 10, 2017.

[15] ISLAM, A.; HOSSAN, M. T.; JANG, Y. M. Convolutional neural network scheme-based optical camera communication system for intelligent Internet of vehicles. International Journal of Distributed Sensor Networks, v. 14, n. 4, p. 1-19, 2018.

[16] KAKUSHI, L. E.; ÉVORA, Y. D. M. Social networking in nursing education: integrative literature review. Revista Latino-Americana de Enfermagem, v. 24, n. 1, p. 1-12, 2016.

[17] LAI, C. et al. SEGM: A secure group management framework in integrated VANETcellular networks. Vehicular Communications, v. 11, p. 33-45, 2018

[18] LASI, $H$. et al. Industry 4.0. Business \& Information Systems Engineering, v. 6, n. 4, p. 239242, 2014

[19] LI, B.; LI, Y. A bi-directional security authentication architecture for the Internet of Vehicles. Applied Mathematics \& Information Sciences: An International Journal, v. 6, n. 6-3s, p. 821-827, 2012

[20] NGAI, E. W. T. et al. RFID research: an academic literature review (1995-2005) and future research directions. International Journal of Production Economics, v. 112, n. 1, p. 510-520, 2008

[21] PHILIP, A. O.; RA.K, S. A vision of connected and intelligent transportation systems. International Journal of Civil Engineering and Technology, v. 9, n. 2, p. 873-882, 2018.

[22] PRISCILLA, E. J.; MATHAN, K.; ANANTHAMOORTHY, N. P. Performance improvement of a secure mechanism for big data collection in large scale Internet of Vehicle using
MATLAB. International Journal of Pure and Applied Mathematics, v. 118, n. 10, p. 9-15, 2018.

[23] ROMO-FERNÁNDEZ, L. M. et al. Analysis of Europe's scientific production on renewable energies. Renewable Energy, v. 36, n. 9, p. 25292537, 2011.

[24] RUAN, N.; LI, M.; LI, J. A novel broadcast authentication protocol for internet of vehicles. Peer-to-Peer Networking and Applications, v. 10, n. 6, p. 1331-1343, 2017.

[25] SADIQ, A. S. et al. Transmission power adaption scheme for improving loV awareness exploiting: evaluation weighted matrix based on piggybacked information. Computer Networks, v. 137, p. 147-159, 2018.

[26] SINGH, S. et al. A Survey on 5G network technologies from social perspective. IETE Technical Review, v. 34, n. 1, p. 30-39, 2017

[27] SUN, Y. et al. Attacks and countermeasures in the Internet of Vehicles. Annals of Telecommunications, v. 72, n. 5-6, p. 283-295, 2017.

[28] TING, Z.; BIN, W.; QI, G. Congestion warning method based on the Internet of vehicles and community discovery of complex networks. The Journal of China Universities of Posts and Telecommunications, v. 23, n. 4, p. 37-45, 2016.

[29] UDEN, L.; HE, W. How the Internet of Things can help knowledge management: a case study from the automotive domain. Journal of Knowledge Management, v. 21, n. 1, p. 57-70, 2017.

[30] VILLAS, M. V.; SOARES, T. D. L. V. A. M.; RUSSO, G. M. Bibliographical research method for business administration studies: a model based on scientific journal ranking. Brazilian Administration Review, v. 5, n. 2, p. 139-159, 2008.

[31] XU, W. et al. Internet of Vehicles in big data era. IEEE/CAA Journal of Automatica Sinica, v. 5, n. 1, p. 19-35, 2018.

[32] YANG, F. et al. A multi-channel cooperative clustering-based MAC protocol for V2V communications. Wireless Communications and Mobile Computing, v. 16, n. 18, p. 3295-3306, 2016.

[33] ZHANG, Y. et al. Social vehicle swarms: a novel perspective on socially aware vehicular communication architecture. IEEE Wireless Communications, v. 23, n. 4, p. 82-89, 2016.

[34] ZHANG, M. et al. CarStream: an industrial system of big data processing for internet-ofvehicles. Proceedings of the VLDB Endowment, v. 10, n. 12, p. 1766-1777, 2017

[35] ZHAO, H-T. et al. Cellular automata model for traffic flow at intersections in internet of vehicles. Physica A, v. 494, p. 40-51, 2018. 
[36] ZHENG, L.; RAN, B.; HUANG, H. Safety evaluation for driving behaviors under bidirectional looking context. Journal of Intelligent Transportation Systems: Technology, Planning, and Operations, v. 21, n. 4, p. 255-270, 2017.

[37] ZHU, W. et al. Reliable emergency message dissemination protocol for urban internet of vehicles. IET Communications, v. 11, n. 8, p. 1275-1281, 2017.

[38] ZHU, W. et al. SDN-enabled hybrid emergency message transmission architecture in internet-of-vehicles. Enterprise Information Systems, v. 12, n. 4, p. 471-491, 2018. 


\section{Gapítulo 20}

\section{ANÁLISE DA GAMIFICACÃO NO ENSINO EM ENGENHARIA DE PRODUÇÃO: UM ESTUDO SOBRE A APLICAÇÃO DO LEAN BOARD GAME.}

\section{Luís Henrique Rodrigues}

Carlos Roberto Franzini Filho

\section{Thays Aparecida Vendramin Delecrodio \\ Alexandre Tavares Soares \\ Jane Luchtenberg Vieira}

Resumo: A gamificação é um fenômeno recente oriundo da popularização dos games e potencializa a aprendizagem nas mais diversas áreas do conhecimento e da vida das pessoas. Os objetivos em motivar os alunos à ação, auxilio na solução de problemas e promover auto-aprendizagem a partir da aplicação de jogos no processo de ensino-aprendizagem representa um desafio para as instituições de ensino superior e contribuem para que a gamificação seja explorada como uma estratégia de ensino- aprendizagem dirigida a um público-alvo inserido na chamada geração gamer. A aplicação da dinâmica lean board game busca complementar os ensinamentos sobre produção enxuta transmitidos aos alunos do curso de engenharia de produção ao longo do semestre por meio das aulas expositivas. Diante deste cenário, este trabalho propõe-se a analisar os principais aspectos relacionados a gamificação no ensino em engenharia de produção com a aplicação do lean board game. Para atingir ao objetivo proposto, aplicou-se uma survey exploratória onde os dados foram coletados com a aplicação de um questionário disponibilizado aos alunos participantes do jogo lean board game. Espera-se que os resultados obtidos a partir desta experiência possam contribuir e motivar a realização de novas pesquisadas relacionadas ao tema gameficiação no ensino em engenharia de produção.

Palavras-chaves: gamificação, ensino em engenharia de produção, jogo de tabuleiro enxuto. 


\section{INTRODUÇÃO}

A gamificação é um fenômeno recente oriundo da popularização dos games e suas capacidades intrínsecas em motivar a ação, solucionar problemas e potencializar as aprendizagens nas mais diversas áreas do conhecimento e da vida das pessoas. Não se adequar a este cenário pode significar uma defasagem no processo de ensino aprendizagem. Atualmente 0 ensino acadêmico enfrenta o desafio para a mudança de paradigma na forma de ensinar e aprender sendo que o potencial apresentado pelos os games já havia sido percebido há pouco mais de três décadas (PAPERT, 2008).

Prover as competências necessárias para a formação de um Engenheiro de Produção têm sido motivo de preocupação tanto para as empresas quanto as universidades que são responsáveis por suprir as necessidades de um mercado de trabalho onde busca-se cada vez mais por diferenciais competitivos de qualidade e produtividade. Para Goldberg (2012) é notório que os estudantes de Engenharia estão tendo dificuldades em: 1 fazer boas perguntas; 2 - nomear objetos tecnológicos; 3 - modelar processos e sistemas; 4 - decompor problemas complexos em problemas menores; 5 coletar dados para análise; 6 - visualizar soluções e gerar novas ideias; e 7 comunicar soluções de forma oral e por escrito. Diante destas habilidades ausentes na formação do Engenheiro, surge a questão: qual deve ser a estratégia metodológica mais adequada para preencher essa necessidade de formação profissional? Os autores Roth et al (2015), Seixas et al. (2016) e Dichev e Dicheva (2017) sugerem a aplicação de jogos como forma de melhorar o processo de ensino-aprendizado nas instituições de ensino.

Os jogos são considerados ferramentas pedagógicas eficientes para o processo de ensino-aprendizagem em razão de permitirem a exploração de estratégias alternativas em um ambiente seguro e próximo do real, com a vantagem em simplificar os elementos vivenciados no cotidiano e disponibilizá-los em um ambiente de ensino-aprendizagem (SCHRAMM; FORMOSO, 2007). Para lecionar sobre Lean Manufacturing, alguns temas temas interligados que compõem a denominada filosofia lean devem ser levados em consideração: o Kaizen como ferramenta de melhoria contínua, discernimento de uma cultura de aprendizagem, desenvolvimento de liderança e equipes multifuncionais para implantação, aplicação de fluxo continuo para identificação de problemas, utilização de produção puxada, padronização de operações, controle visual, entre outros (LIKER; MEIER, 2004).

A partir da necessidade de inovação que as universidades têm com a sociedade, a coordenação do curso de Engenharia de Produção da Universidade Anhembi Morumbi (UAM) viabilizou a utilização do Lean Board Game nas aulas das disciplinas Gestão da Produção, Gestão de Operações e Tempos e Métodos, com o objetivo de ensinar aos seus alunos os conceitos de Lean Manufacturing. $O$ Lean Board Game é uma ferramenta de ensino de Lean, Gestão Industrial, Manufatura e Engenharia de Produção, baseada na metodologia PBL - Problem Based Learning Aprendizado por meio de Problemas. Os alunos participantes foram desafiados a melhorar o desempenho de uma fábrica, identificando gargalos, restrições e desperdícios, propondo e implementantando melhorias nos processos. A dinâmica ocorreu em um tabuleiro disposto no laboratório de Engenharia de Produção, onde os alunos tinham a sua disposição: o chão de fábrica, as informações necessárias e os indicadores de desempenho. No decorrer do jogo, foram introduzidos os conceitos e ferramentas da Produção Enxuta (Lean Manufacturing), permitindo aos alunos jogadores melhorarem os processos e medirem os resultados obtidos. Esta iniciativa visou o aperfeiçoamento e aquisição de conhecimentos pelos alunos sobre o tema Lean Manufacturing. Diante das considerações inciais, este trabalho propõese a analisar os principais aspectos relacionados a gamificação no ensino em Engenharia de Produção com a aplicação do jogo Lean Board Game.

\section{REFERENCIAL TEÓRICO}

\subsection{GAMIFICAÇÃO NO ENSINO}

O termo gamificação surgiu na indústria de mídia digital, tendo seu primeiro uso documentado em 2008 (DETERDING et al., 2011). Embora se caracterize-se como um fenômeno recente, as ideias que compõem a gamificação são antigas, pois considera-se que a ideia de que o jogo é inerente ao homem e precedente à cultura (HUIZINGA, 1999), dessa forma, os elementos presentes nos jogos constituem a forma de viver e de se 
relacionar do ser humano desde o início da civilização. A gamificação prevê a utilização de elementos tradicionalmente encontrados nos games: narrativa, sistema de feedback, sistema de recompensas, conflito, cooperação, competição, objetivos e regras claras, níveis, tentativa e erro, diversão, interação, interatividade, entre outros (ZICHERMANN e CUNNINGHAM, 2012). Para Werbach e Hunter (2012) este novo fenômeno chamado gamificação consiste na utilização de elementos dos games (mecânicas, estratégias, pensamentos) fora do contexto dos games. A estruturação dos jogos simulados estão apoiados na simulação e visam propiciar ambientes cada vez mais próximos da realidade. Os jogos são pautados em sete elementos/caracteristicas de acordo com Riis, Johansen e Mikkelsen (1995) que estão detalhados no Quadro 1 apresentado a seguir:

QUADRO 1 - Características para desenvolvimento de jogos simuladas e abordagem utilizada.

\begin{tabular}{|l|l|}
\hline \multicolumn{1}{|c|}{$\begin{array}{c}\text { Elemento/característica do } \\
\text { desenvolvimento } \\
\text { de jogos simulados }\end{array}$} & \multicolumn{1}{|c|}{ Abordagem utilizada } \\
\hline $\begin{array}{l}\text { Possuir foco claro e restrito a } \\
\text { poucos temas }\end{array}$ & $\begin{array}{l}\text { A simulação apresenta-se focada em conceitos relativos ao sistema } \\
\text { Lean Production e suas ferramentas. }\end{array}$ \\
\hline $\begin{array}{l}\text { Nivel do jogo adequado aos } \\
\text { participantes }\end{array}$ & $\begin{array}{l}\text { O nivel do jogo concentra-se para alunos a partir do quinto semestre, os } \\
\text { quais já possuem conceitos mais bem definidos, podendo-se obter } \\
\text { resultados mais positivos da dinâmica. }\end{array}$ \\
\hline $\begin{array}{l}\text { Conhecimento do tema pelos } \\
\text { participantes }\end{array}$ & $\begin{array}{l}\text { A aplicação da dinâmica é aconselhada no final do semestre, de forma } \\
\text { que o aluno possa utilizar e correlacionar os assuntos desenvolvidos. }\end{array}$ \\
\hline $\begin{array}{l}\text { Representação de um ambiente real, } \\
\text { para que os participantes possam } \\
\text { fazer analogia com a realidade }\end{array}$ & $\begin{array}{l}\text { A simulação apresenta-se em torno de uma empresa fictícia, que, no } \\
\text { entanto, possui características e desafios a serem alcançados por } \\
\text { empresas reais. }\end{array}$ \\
\hline $\begin{array}{l}\text { Nivel de abstração de acordo com } \\
\text { as limitações dos participantes, não } \\
\text { contendo, se possivel, pontos } \\
\text { ambiguos }\end{array}$ & $\begin{array}{l}\text { Os objetivos e os desafios a serem solucionados pelos alunos são } \\
\text { destacados no inicio da dinâmica, delimitando o tema abordado e } \\
\text { focando o assunto a ser trabalhado. }\end{array}$ \\
\hline $\begin{array}{l}\text { Resultado mensurável, } \\
\text { preferência quantitativamente de }\end{array}$ & $\begin{array}{l}\text { Os resultados obtidos nas diversas fases da simulação são representados } \\
\text { quantitativamente por meio do auxilio de planilhas eletrônicas, as quais } \\
\text { permitem a comparação entre os resultados obtidos durante as fases. }\end{array}$ \\
\hline $\begin{array}{l}\text { Conter direcionadores, tais como, } \\
\text { desafios, competicão e pressão }\end{array}$ & $\begin{array}{l}\text { São apresentados no inicio da dinâmica, com o intuito de direcionar e } \\
\text { focalizar os esforcos desenvolvido }\end{array}$ \\
\hline
\end{tabular}

Fonte: Satolo (2011). Adaptado pelos autores.

Para Cronk (2012), é possível observar melhorias no aprendizado com a participação dos alunos ao aplicar elementos de jogos na construção de sistema baseado em recompensas que agem como um incentivo para o engajamento de estudantes nas discussões em sala de aula. Os objetivos em motivar os alunos à ação, auxilio na solução de problemas e promover auto-aprendizagem a partir da aplicação de jogos no processo de ensino-aprendizagem (KAPP, 2012), contribuem para que a gamificação seja explorada como uma estratégia de ensinoaprendizagem dirigida a um público-alvo inserido na chamada geração gamer. Há resultados relevantes e comprovados por meio das experiências da aplicação de jogos no processo de ensino aprendizagem segundo Sheldon (2012).

\subsection{O ENSINO DE MANUFATURA ENXUTA EM ENGENHARIA DE PRODUÇÃO}

O curso em Engenharia de Produção foi criado em resposta às necessidades das empresas em aumentar o nível de operacionalização dos sistemas de produção, após a Revolução Industrial. Com o aumento significativo na competitividade entre empresas, a Engenharia de Produção mostrou sua importância na melhoria da qualidade de processos, (CUNHA, 2007). Considerando o atual panorama do mercado de trabalho do Brasil, o engenheiro de produção é o que desfruta da melhor situação, principalmente porque sua formação permite que esse profissional tenha uma visão global e formação científica, se adaptando facilmente a diversos ambientes. Estima-se que até 2020, o crescimento anual médio para os setores de engenharia chegue até 13\% (IPEA, 2011). 
Feld (2000) destaca os temas associados à aprendizagem do sistema de produção puxado por meio de uma classificação em cinco categorias das técnicas e ferramentas que devem ser ensinadas aos alunos para a implantação do sistema lean conforme demonstrado no Quadro 2:

QUADRO 2 - Aspectos considerados para a análise da gamificação no ensino em Engenharia de Produção

\begin{tabular}{|c|l|l|}
\hline Categoria & \multicolumn{1}{|c|}{ Descrição } & \multicolumn{1}{|c|}{ Técnicas \& Métodos } \\
\hline Fluxo & $\begin{array}{l}\text { Abrange técnicas relacionadas com trocas } \\
\text { fisicas, procedimentos de desenvolvimento de } \\
\text { produtos e definição de padrões que se fazem } \\
\text { necessários. }\end{array}$ & $\begin{array}{l}\text { Mapeamento do Fluxo de Valor (MFV); } \\
\text { maior grau de customização de processos, } \\
\text { produtos e/ou serviços; conceito de takt } \\
\text { time; organização de layout celular, dentre } \\
\text { outros. }\end{array}$ \\
\hline $\begin{array}{c}\text { Organização } \\
\text { e cultura }\end{array}$ & $\begin{array}{l}\text { São agrupadas neste conjunto de técnicas as } \\
\text { questões relacionadas com a definição de } \\
\text { papéis de individuos, aprendizado, } \\
\text { comunicação e valores partillados. }\end{array}$ & $\begin{array}{l}\text { Organização de equipes multifuncionais, } \\
\text { empowerment, definição de missão e } \\
\text { valores da organização, dentre outros. }\end{array}$ \\
\hline de Processos & $\begin{array}{l}\text { Aborda técnicas relacionadas com } \\
\text { acompanhamento/ monitoramento, controle, } \\
\text { estabilização e melhoria do processo de } \\
\text { produção }\end{array}$ & $\begin{array}{l}\text { CEP (Controle Estatístico de Processo), } \\
\text { SMED (Single Minute Exchange of Die), } \\
\text { Programa 5S, TPM (Total Productive } \\
\text { Maintenance), Poka Yoke, dentre outros. }\end{array}$ \\
\hline Métricas & $\begin{array}{l}\text { Engloba técnicas que medem o desempenho, } \\
\text { objetivos de melhora emedidas de recompensa } \\
\text { para os times de trabalho e colaboradores }\end{array}$ & $\begin{array}{l}\text { Tempo de ciclo, giro de inventário, valor } \\
\text { agregado por trabalhador, dentre outros. }\end{array}$ \\
\hline Logística & $\begin{array}{l}\text { Relaciona as regras de funcionamento, } \\
\text { técnicas e métodos de planificação e controle } \\
\text { de fluxos de materiais internos externos }\end{array}$ & $\begin{array}{l}\text { JT (Just in Time), dimensionamento de } \\
\text { supermercado (Kanban), sistema puxado de } \\
\text { produção, classificação ABC, dentre outros. }\end{array}$ \\
\hline
\end{tabular}

Fonte: Satolo (2011). Adaptado pelos autores.

O planejamento é considerado sob o ponto de vista acadêmico como um ato político pedagógico em razão de revelar intenções e intencionalidade, expor o que se deseja realizar e o que se pretende alcançar (LEAL, 2005). Para Soares (2011), fica claro que as mudanças na metodologia de ensino e nas estratégias de ensino-aprendizagem, devem ser amplamente almejadas, seja por modelos educacionais convencionais ou por modelos baseados em metodologias ativas. Entretanto, fica cada vez mais difícil conciliar o volume tão crescente de conhecimentos técnicos científicos utilizando-se de modelos educacionais convencionais e/ou rígidos (RIBEIRO, 2005). A aplicação da dinâmica com Lean Board Game busca complementar os ensinamentos sobre lean transmitidos aos alunos do curso de Engenharia de Produção ao longo do semestre por meio das aulas expositivas. Embora o Lean Board Game envolva a maior parte dos elementos relacionados as práticas de Manufatura Enxuta, não é possível aplicar uma dinâmica que envolva $100 \%$ de todas as técnicas e ferramentas apresentadas no Quadro 2 (SATOLO, 2011).

Benko e McFarlan (2003) destacam que outros aspectos deveriam ser levados em consideração dentro do Sistema de Produção Enxuto: preocupação com aspectos e impactos ambientais; maior interação do cliente final na customização do produto; fidelização à marca; montagem modular de componentes e rápidas alterações de configuração do chão-de-fábrica das empresas.

\section{METODOLOGIA}

A partir da aplicação de uma survey exploratória para atingir ao objetivo proposto, os dados foram coletados com a aplicação de um questionário disponibilizado aos alunos do curso de Engenharia de Produção participantes das aulas onde o jogo Lean Board Game foi aplicado. O questionário foi estruturado com respostas de multiplas escolhas, de forma a permitir a mensuração dos resultados. De acordo com Forza (2002), uma survey exploratória constitui-se pela coleta de informações por meio de indivíduos sobre eles mesmos ou sobre as organizações às quais eles pertencem. $\mathrm{O}$ tamanho amostral foi estimado em um mínimo de 21 respondentes com um erro máximo de 3\% e confiabilidade de $95 \%$ para um desvio padrão amostral de 0,9798 a partir da fórmula (1): 


$$
n=\left(\frac{Z_{c} S}{E}\right)^{2}(1)
$$

Sendo:

$\mathrm{n}=$ tamanho amostral

Zc = nível de confiança

$\mathrm{s}=$ desvio padrão amostral

$\mathrm{E}=$ erro amostral

Os aspectos considerados para a análise da gamificação no ensino em Engenharia de Produção estão descritos no Quadro 3:

QUADRO 3 - Aspectos considerados para a análise da gamificação no ensino em Engenharia de Produção.

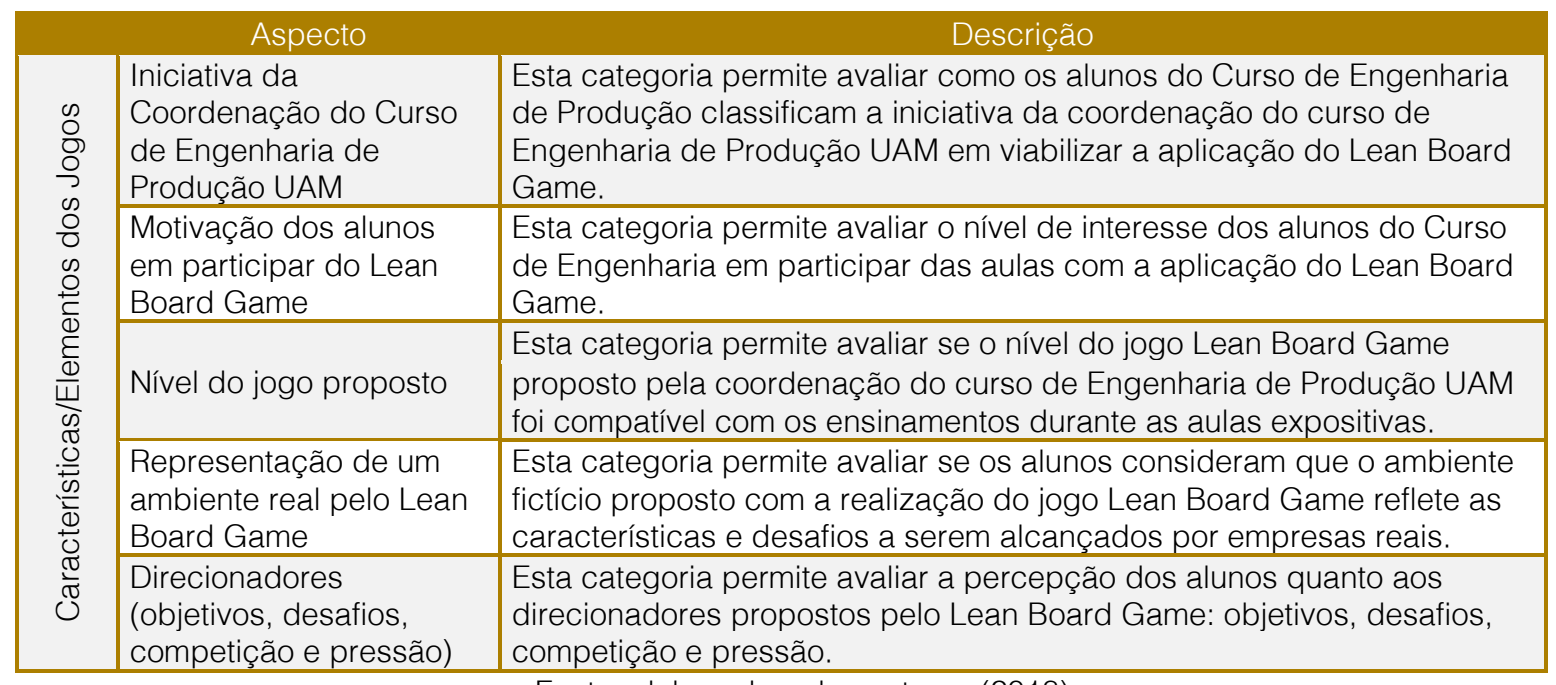

Fonte: elaborado pelos autores (2018).

Os aspectos considerados para a análise da retenção do conhecimento pelos alunos sobre o tema Lean Manufacturing a partir da aplicação do jogo Lean Board Game estão descritos no Quadro 4: 
QUADRO 4 - Aspectos considerados para a análise da retenção do conhecimento pelos alunos sobre o tema

\begin{tabular}{|c|c|c|}
\hline & \multicolumn{2}{|r|}{ Descrição } \\
\hline \multirow{5}{*}{ 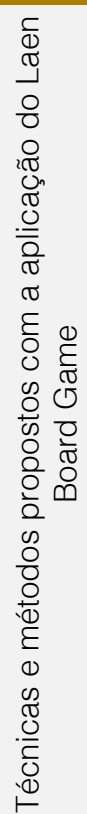 } & $\begin{array}{l}\text { Fluxo de } \\
\text { Produção }\end{array}$ & $\begin{array}{l}\text { Esta categoria permite avaliar o nível de retenção de conhecimento dos alunos sobre } \\
\text { as técnicas e ferramentas previstos no Lean Board Game para o aspecto fluxo de } \\
\text { produção: Mapeamento do Fluxo de Valor (MFV), customização de processos, } \\
\text { produtos e/ou serviços, conceito de takt time e organização de layout celular. }\end{array}$ \\
\hline & $\begin{array}{l}\text { Organização } \\
\text { e cultura }\end{array}$ & $\begin{array}{l}\text { Esta categoria permite avaliar o nível de retenção de conhecimento dos alunos sobre } \\
\text { as técnicas e ferramentas previstos no Lean Board Game para o aspecto } \\
\text { organização e cultura: organização de equipes multifuncionais, empowerment, } \\
\text { definição de missão e valores da organização. }\end{array}$ \\
\hline & $\begin{array}{l}\text { Controle de } \\
\text { Processos }\end{array}$ & $\begin{array}{l}\text { Esta categoria permite avaliar o nível de retenção de conhecimento dos alunos sobre } \\
\text { as técnicas e ferramentas previstos no Lean Board Game para o aspecto controle de } \\
\text { processos: CEP (Controle Estatístico de Processo), SMED (Single Minute Exchange of } \\
\text { Die), Programa 5S, TPM (Total Productive Maintenance) e Poka Yoke. }\end{array}$ \\
\hline & Métricas & $\begin{array}{l}\text { Esta categoria permite avaliar o nível de retenção de conhecimento dos alunos sobre } \\
\text { as técnicas e ferramentas previstos no Lean Board Game para o aspecto métricas: } \\
\text { tempo de ciclo, giro de inventário e valor agregado por trabalhador. }\end{array}$ \\
\hline & Logística & $\begin{array}{l}\text { Esta categoria permite avaliar o nível de retenção de conhecimento dos alunos sobre } \\
\text { as técnicas e ferramentas previstos no Lean Board Game para o aspecto logística: } \\
\text { JIT (Just in Time), dimensionamento de supermercado (Kanban), sistema puxado de } \\
\text { produção e classificação ABC. }\end{array}$ \\
\hline
\end{tabular}

Lean Manufacturing. Fonte: elaborado pelos autores (2018).

Para a análise dos dados elaborou-se um gráfico radar a partir das respostas obtidas com a aplicação do questionário. Utilizou-se da escala Likert para a classificação das respostas das questões, sendo: (1) discordo totalmente, (2) discordo parcialmente, (3) indiferente, (4) concordo parcialmente e (5) concordo totalmente (CUNHA, 2007). O gráfico radar exibe observações multivariáveis de forma a apresentar os pontos fortes e fracos referentes aos aspectos voltados a aplicação do Lean Board Game no processo de ensino- aprendizagem no curso de Engenharia de Produção. A moda amostral de um conjunto de dados trata do valor que ocorre com maior frequência ou o valor mais comum em um conjunto de dados e é especialmente útil quando os valores ou observações não são numéricos, casos em que a média ou mediana não podem ser definidas.

\section{ANÁLISE E DISCUSSÃO DOS RESULTADOS}

As aulas com a aplicação do jogo Lean Board Game aconteceram durante o ano de 2017 e o primeiro semestre de 2018, com a participação de alunos atualmente matriculados no curso de Engenharia de Produção da Universidade Anhembi Morumbi. Esta iniciativa propôs o engajamento e a interação dos alunos do curso de Engenharia de Produção na busca pela maior produtividade no aprendizado. 0 desempenho nesta atividade foi amplamente discutido entre os docentes e os alunos a partir do ranking estabelecido, com os resultados apurados na ocasião da aplicação do jogo Lean Board Game.

Colaboraram com a pesquisa uma amostra de 25 alunos que participaram da aplicação do jogo Lean Board Game. Para cada aspecto proposto na análise da "gamificação" no ensino em Engenharia de Produção e na análise quanto à retenção do conhecimento, pelos alunos, sobre o tema lean manufacturing, a metodologia adotou a moda das respostas dadas pelos respondentes (alunos). A moda obtida para cada aspecto foi postada em um gráfico radar (Figura 1). 
FIGURA 1: Aspectos do ensino de engenharia de produção e do conhecimento em lean manufaturing com a gameficação. Aplicação do Lean Board Game.

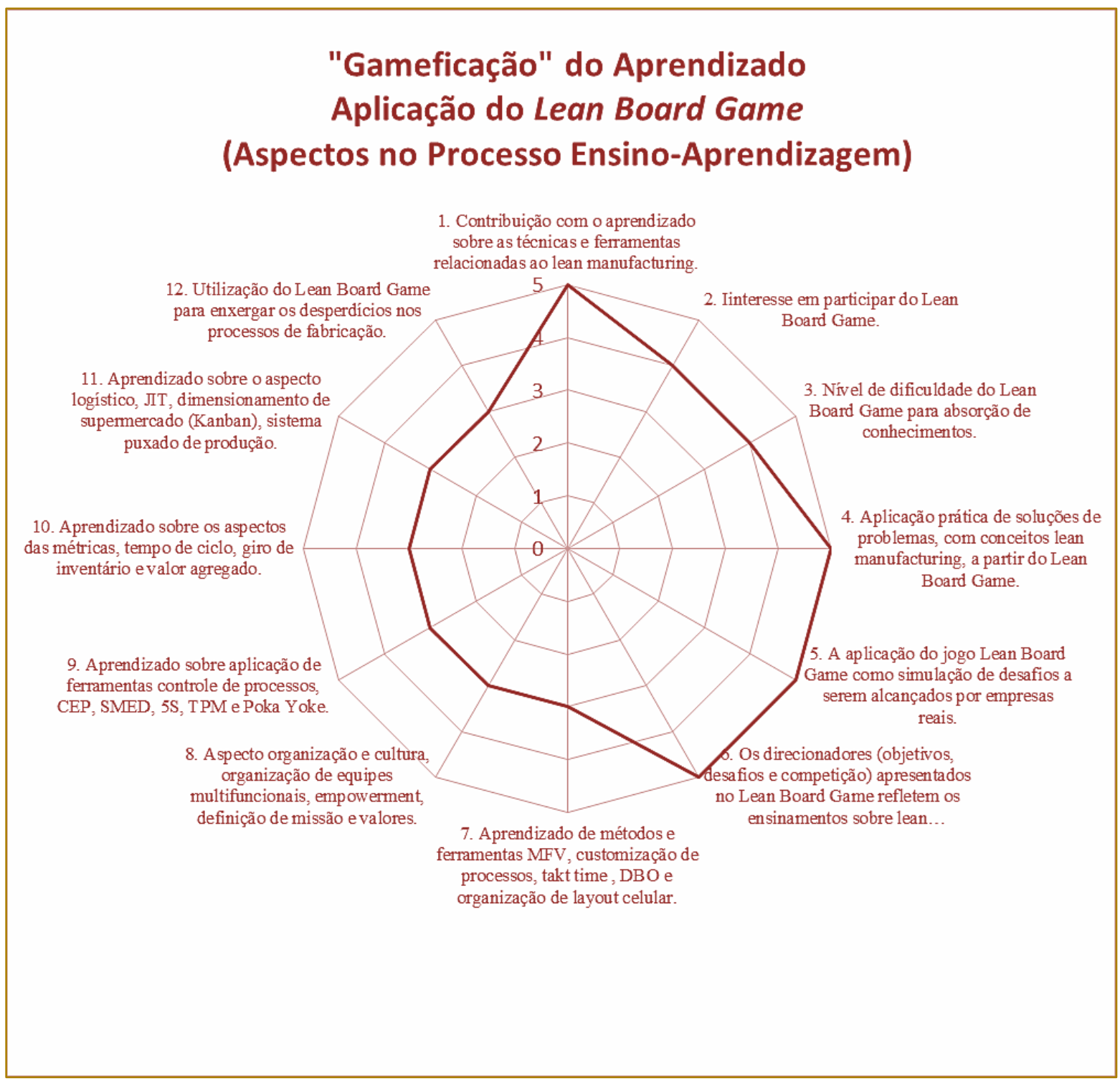

Fonte: elaborado pelos autores (2018)

Os resultados da análise exploratória dos dados coletados demonstraram que a utilização do Lean Board Game contribui significativamente para o aprendizado sobre as técnicas e ferramentas utilizadas no lean manuufacturing. A maioria dos entrevistados demonstraram um forte interesse em participar das práticas com o Lean Board Game, apesar das dificuldades na aplicação do game para absorção dos conhecimentos lean. Os entrevistados concordam totalmente que o Lean Board Game possibilita a aplicação prática dos conceitos de lean manufacturing, para a solução de problemas que envolvam custos causados por desperdícios de superprodução, espera, qualidade, movimentação, estoque, processos desnecessários e transporte. É satisfatório o aprendizado sobre os métodos e ferramentas lean, tais como a aplicação do mapeamento do fluxo de valor (MFV), customização de processos, produtos e/ou serviços, conceito de takt time, diagrama de balanceamento de operações (DBO), organização de layout, fluxo de materiais nos processos de manufatura, poka yoke, $5 \mathrm{~S}$ e TPM. A aplicação dos métodos e ferramentas do lean manufacturing visam o estabelecimento de metas através das métricas de gestão do processo de fabricação. Tais métricas compreendem os conceitos para o cálculo do tempo de ciclo, o acompanhamento do giro de inventário, tempo de valor agregado no fluxo de 
materiais e lead time do processo. $O$ aprendizado sobre as métricas foi identificado na pesquisa como sendo satisfatório.

Sobre a gestão logística dos materiais, a pesquisa avaliou que a aplicação do Lean Board Game facilita de forma satisfatória o aprendizado sobre os métodos e ferramentas do JIT (just in time), tais como o dimensionamento de supermercado (kanban), sistema puxado e o nivelamento da produção.

Os objetivos, desafios, competição e pressão, apresentados na dinâmica prática do Lean Board Game refletem os ensinamentos adquiridos sobre lean manufacturing, a partir da participação nas aulas expositivas.

Há tambem uma total concordância de que o ambiente fictício proposto pelo game reflete características e desafios a serem alcançados por empresas em seus problemas reais e cotidianos.

A experiência com a aplicação do jogo Lean Board Game proporcionou aos alunos atuar em equipes multidisciplinares onde observouse uma relevante oportunidade de exercer competências requeridas pelo mercado de trabalho, bem como, liderança, gestão de conflitos, gestão de tempo e recursos, assunção de responsabilidades e a habilidade de comunicação.

\section{CONSIDERAÇÕES FINAIS}

O objetivo do presente artigo foi analisar os principais aspectos relacionados a gamificação no ensino em Engenharia de Produção com a aplicação do jogo Lean Board Game. Como resultado desta análise, conclui-se que os objetivos, desafios, competição e pressão, apresentados na dinâmica prática do Lean Board Game refletem os ensinamentos adquiridos sobre lean manufacturing a partir da participação nas aulas expositivas e contribui como uma relevante e inovadora estratégia de ensinoaprendizagem em Engenharia de Produção. Os resultados apontam como positiva a

\section{REFERÊNCIAS}

[1] BENKO, C.; MC FARLAN, W. Methamorphosis in the auto industry. Strategy \& Leadership, v.31, n.4, p. 4-8, 2003.

[2] CRONK, Marguerite. Using gamification to increase student engagement and participation in iniciativa da Coordenação do curso do Engenharia em propor a gamificação no ensino em Engenharia de Produção, o que motiva a extensão desta prática para outras disciplinas do curso.

As limitações para a realização desta pesquisa apresentam-se com relação ao baixo número de publicações a respeito gamificação no ensino em Engenharia de Produção. Outra limitação relevante refere-se à população definida para o estudo, pois não foi feita uma triagem dos respondentes quanto a suas experiências prévias sobre a gamificação no ensino. Espera-se que as informações obtidas a partir da realização desta pesquisa contribuam com 0 aprimoramento e extensão das práticas de gameficação no ensino em Engenharia de Produção. Por se tratar de um tema relevante para o ensino em Engenharia de Produção, espera-se que os dados apurados possam motivar novos pesquisadores a prosseguirem com a realização de novas pesquisadas relacionadas ao tema gameficiação e a criação de novos jogos a serem aplicados nas demais disciplinas do curso. Sugere-se aprofundar a pesquisa para os fatores relacionados a retenção do conhecimento de forma a analisar as notas atribuídas pelos docentes como medidor de desempenho dos alunos participantes da dinâmica do Lean Board Game. Acrescenta-se ainda às sugestões, apurar os conhecimentos prévios dos alunos sobre o tema gameficação no ensino. Dessa forma, seria possível realizar uma comparação "antes e depois" da participação do aluno em aulas das disciplinas do curso de Engenharia de Produção com a aplicação do Lean Board Game e contribuir de forma relevante para a análise proposta com a realização deste trabalho. É importante mencionar que após a análise da aplicação do Lean Board Game de forma bem sucedida no ensino em Engenharia de Produção, a mesma poderá ser extendida e aperfeiçoada para as demais disciplinas do curso.

class discussion. In: EdMedia: World Conference on Educational Media and Technology. Association for the Advancement of Computing in Education (AACE), 2012. p. 311-315. 
[3] CUNHA, Luísa Margarida Antunes da et al. Modelos Rasch e Escalas de Likert e Thurstone na medição de atitudes. 2007

[4] DICHEV, C.; DICHEVA, D. Gamifying education: what is known, what is believed and what remains uncertain: a critical review. International Journal of Educational Technology in Higher Education, v. 14, n.9, 2017. DETERDING, Sebastian et al. From game design elements to gamefulness: defining gamification. In: Proceedings of the 15th international academic MindTrek conference: Envisioning future media environments. ACM, 2011. p. 9-15.

[5] FELD, W.M. Lean manufacturing: tools, techniques, and how to use them. CRC Ed. 248 p, 2000 .

[6] FORZA, Cipriano. Survey research in operations management: a process-based perspective. International journal of operations \& production management, v. 22, n. 2, p. 152-194, 2002.

[7] GOLDBERG, David E. The missing basics and other philosophical reflections for the transformation of engineering education. In: Holistic Engineering Education. Springer, New York, NY, 2010. p. 145-158. HUIZINGA, Johan. Homo ludens: Versuch einer bestimmung des spielelements der kultur.1938. Publicado originalmente em 1944. Tradução para língua portuguesa: Homo Ludens: O Jogo Como Elemento da Cultura. São Paulo, SP. Perspectiva, 1999

[8] INSTITUTO NACIONAL DE ESTUDOS E PESQUISAS EDUCACIONAIS ANISIO TEIXEIRA, 2005. Disponível em: <http://portal.inep.gov.br/>. Acesso em: 23 Nov 2017.

[9] KAPP, Karl. The Gamification of Learning and Instruction: Game-based Methods and Strategies for Training and Education. Pfeiffer, 2012.

[10] LEAL, Regina Barros. Planejamento de ensino: peculiaridades significativas. Revista Iberoamericana de Educación, v. 37, n. 3, p. 1-6, 2005

[11] LIKER, J. K. MEIER, D. O modelo Toyota: manual de aplicação, Porto Alegre: Bookman, 2007
[12] PAPERT, Seymour. A Máquina das Crianças: Repensando a Escola na Era da Informática. Trad. Sandra Costa. Porto Alegre: Artmed, 2008.

[13] RIBEIRO, Luis Roberto de Camargo et al. A aprendizagem baseada em problemas ( $\mathrm{PBL}$ ): uma implementação na educação em engenharia na voz dos atores. 2005

[14] RIIS; J. O.; JOHANSEN; J.; MIKKELSEN; $\mathrm{H}$. Design of simulation games: simulation games and learning in production management. Denmak. Chapman \& Hall, 1995

[15] ROTH S., SCHNECKENBERG D., TSAI C. The Ludic Drive as Innovation Driver: Introduction to the Gamification of Innovation. Creativity and Innovation Management, v.24, n.2, p. 300-306, 2015.

[16] SATOLO, Eduardo Guilherme. Modelo de simulação aplicado ao conceito da produção enxuta no ensino de engenharia de produção. Revista Gestão Industrial, v. 7, n. 2, 2011.

[17] SCHRAMM, F.K.; FORMOSO, C.T. Uso de simulação interativa visual no projeto de sistemas de produção de empreendimentos da construção civil. In: ENCONTRO DE TECNOLOGIA DE INFORMAÇÃO E COMUNICAÇÃO NA CONTRUÇÃO CIVIL, 3, Porto Alegre. Anais... Porto Alegre, 2007.

[18] SEIXAS L.R., GOMES A.S., MELO FILHO I.J. Effectiveness of gamification in the engagement of students. Computers in Human Behavior, v. 58, p. 48-63, 2016.

[19] SHELDON, Lee. The Multiplayer Classroom: Designing Coursework as a Game. Boston, MA: Cengage Learning, 2012.

[20] SOARES, Daniel Aldo; TERNES, José. Epistemologia e Educação. Goiânia: Editora da PUC-Goiás, 2011. 140f.

[21] ZICHERMANN, Gabe; CUNNINGHAM, Christopher. Gamification by Design. Implementing Game Mechanics in Web and Mobile Apps. Canada: O'Reilly Media, 2011.

[22] WERBACH, Kevin; HUNTER, Dan. For the win: How game thinking can revolutionize your business. Wharton Digital Press, 2012. 


$$
\text { Alutary }
$$




\section{ALEXANDRE TAVARES SOARES}

Possui graduação em Engenharia Mecânica pela Universidade Federal do Rio Grande (1995), Mestrado em Matemática Aplicada pela Universidade Federal do Rio Grande do Sul (1999) e MBA em Gestão Empresarial pela Escola Superior de Propaganda e Marketing (2005). Atualmente é sócio diretor de vendas e projetos - Reciclapac e professor na Universidade Anhembi Morumbi. Tem experiência na área de Engenharia Mecânica, com ênfase em Processos de Fabricação, Seleção Econômica.

\section{AMANDA SILVA NUNES}

Graduação em andamento em Engenharia Ambiental.

\section{AMANDA RIBEIRO GANSKE}

Graduanda em Engenharia de Transportes e Logística pela Universidade Federal de Santa Catarina. Possui interesse na área de Engenharia de Transportes, Pesquisa Operacional, Otimização e Logística.

\section{ANA CÉLIA SILVA VIEIRA}

Possui especialização em Nutrição e Controle de Qualidade pela Faculdade INTA de Sobral (2012). Tem graduação em Tecnologia de Alimentos pelo Instituto Centro de Ensino Tecnológico (2006) e experiência com Análises Microbiológicas e Físico - Química de Alimentos e Bebidas. Trabalha no SENAI-MA como Analista prestando assessoria e consultoria em empresas da área de Alimentos e Bebidas, implantando Boas Práticas de Fabricação de Alimentos e APPC e ministrando aulas nos cursos técnicos na área de Alimentos. Consultora pelo Programa Alimentos Seguros (PAS).

\section{ANDRÉ CRISTIANO SILVA MELO}

Professor Titular da área de Suprimentos e Coordenador dos Programas de Pós-Graduação Stricto Sensu do CCNT/UEPA. Engenheiro Mecânico pela UFPA, Mestre e Doutor em Engenharia de Produção pela COPPE/UFRJ. Atualmente professor de disciplinas da área de logística em cursos de graduação e pós-graduação da UEPA. Atuou, em Belém, como Coordenador do curso de graduação em Engenharia de Produção da UNAMA e como Coordenador na Secretaria de Estado de Ciência, Tecnologia e Inovação (SECTI) e, no Rio de Janeiro, como Consultor pela Fundação COPPETEC em projetos junto às empresas Bunge Alimentos - Divisão Santista e Furnas Centrais Elétricas S. A.

\section{ANDREI BONAMIGO}

Doutor em Engenharia de Produção pela Universidade Federal de Santa Catarina (2017) possui Mestrado em Administração pela Universidade do Oeste de Santa Catarina, Mestrado Sanduíche no IPS - Polytechnic Institute of Setúbal - Portugal (2014). Especialista em Engenharia de Produção pelo Instituto Superior Tupy - Joinville/SC (2012).

\section{ANTÔNIO FELIPE MACHADO}

Cursa Engenharia de Produção na Universidade Federal da Paraíba - UFPB. Apresenta formação Técnica em Mecânica e Eletromecânica pelo SENAI-CEP-ORC. Possui 14 anos de experiência como docente de qualificação profissional em mecânica industrial, projetos industriais, usinagem convencional e CNC, modelagem e simulação virtual 3D, manutenção e automação industrial. Atualmente atua como supervisor de Manutenção Mecânica na SERCOL - Serviços e Construções LTDA. Interessa-se por educação profissional, projetos industriais, modelagem 3D, programação $\mathrm{CNC}$, manutenção mecânica e automação industrial. 


\section{BEATRIZ FERNANDA CROTTI}

Graduação em Engenharia Ambiental pela Universidade Tecnológica Federal do Paraná, campus Londrina.

\section{BERNARDO MOREIRA VERGARA}

Engenheiro de Produção formado pela Universidade do Estado do Pará. Foi intercambista pelo Ciência sem Fronteiras na Universidad Politécnica de Valencia. Atuou como estagiário nas Centrais Elétricas do Pará, no setor de Suprimentos e Logística. Atualmente é Analista Comercial nas Centrais Elétricas do Pará na área Corporativa de Cobrança. Possui experiência em controle de estoque, análises de processos, análises financeiras e criação de relatórios gerenciais.

\section{BRUNO CEZAR DE FARIAS}

Graduado em tecnologia de Gestão em Logística pela UPE, Técnico em Administração pela Escola Técnica Estadual Miguel Arraes de Alencar.Já atuou como estudante bolsista na monitoria das cadeiras de contabilidade empresarial e custos e auditoria logística pelo PROGRAD e também como participante do projeto de extensão intitulado Logística no dia a dia ao qual tinha como objetivo a divulgação do curso para os alunos concluintes do ensino médio.

\section{BRUNO RABBI}

MESTRANDO EM PESQUISA OPERACIONAL E INTELIGÊNCIA COMPUTACIONAL (UCAM Campos dos Goytacazes- RJ). Especialista em INFORMÁTICA NA EDUCAÇÃO - Faculdade da Serra (FASE). Possui graduação em: BACHARELADO EM CIÊNCIA DA COMPUTAÇÃO Instituto de Ensino Superior do ES - (UNES). Coordenador do Curso Técnico em Informática da SEDU/Escola Presidente Getúlio Vargas. Sócio Administrador e Desenvolvedor de Sistemas e gestor de Tecnologia da Informação da Empresa: BRI - Soluções e Softwares. Tem experiência nas áreas de Educação, programação, banco de dados,computação gráfica, hardware, redes e SO.

\section{CARLOS EDUARDO PINTO}

Professor de Ensino Básico, Técnico e Tecnológico do Instituto Federal de Educação, Ciência e Tecnologia de São Paulo (IFSP), Campus Registro. Mestre em Administração pela Universidade de Extremadura, com reconhecimento pela Universidade Federal de Santa Catarina (UFSC). Especialista em Administração de Marketing pela Fundação de Estudos Sociais do Paraná (FESP). Bacharel em Administração pela Universidade Federal do Paraná (UFPR).

\section{CARLOS ROBERTO FRANZINI FILHO}

Formação Técnica em Mecânica (ETE "Júlio de Mesquita"), graduado Engenheiro de Produção Mecânica pela Universidade do /Grande ABC (2005) e MBA em Gestão da Qualidade \& Produtividade (2010) nesta mesma Instituição de Ensino. Mestrado em Engenharia de Produção na Universidade Nove de Julho (2015). Atuação como Engenheiro de Qualidade de Fornecedores nas empresas: MWM International Motores, Mitsubishi Motors e Ford. Experiência comprovada trabalhando desde 1997 em Fornecedores de Auto-Peças como TRW, Metagal, Saint-Gobain e Kostal . Participação em lançamentos de novos produtos e atuação em diferentes "commodities" nos fornecedores de auto-peças. Conhecimentos em importantes Ferramentas da Qualidade utilizadas pela industria automotiva: APQP, PPAP, FMEA, MSA, CEP, 8D entre outras. Atualmente Docente na Universidade Anhembi Morumbi, lecionando as seguintes disciplinas: Gestão de Contratos \& Projetos, Sistemas de Informação e Tecnologia da Informação e Engenharia Econômica e Engenharia de Tempos \& Métodos. 


\section{CÁSSIA CRISTINA DO CARMO}

Graduação em andamento em Engenharia de Produção.

\section{CÁSSIO GERMANO LARA DE SOUZA}

Graduando em Engenharia de Produção pelo Instituto Federal de Educação, Ciência e Tecnologia de São Paulo (IFSP), Campus Registro. Técnico em Administração pelo Centro Estadual de Educação Tecnológica Paula Souza (CEETEPS), Campus Registro.

\section{CÁSSIO VALDEMAR PARRA GRANJA}

Advogado, Contador, Químico e CEO do Grupo 3Á, Indústria de Saneantes do Estado de Goiás, atuando na administração geral do empreendimento.

\section{CELSO SOUZA DE MORAES JUNIOR}

Graduação em administração pela Faculdade Metodista Granbery (FMG, 2006), especialização em Finanças pela Universidade Federal de Juiz de Fora (UFJF, 2007) e, atualmente, é doutorando do Programa de Pós-graduação em Saúde Brasileira na mesma Universidade. É dirigente da Fundação de Apoio ao Desenvolvimento do Ensino, Pesquisa e Extensão da UFJF. Desenvolveu trabalhos e pesquisas no campo da Avaliação Econômica em Saúde no recorte da Saúde Pública Brasileira, mais especificamente nos modelos de custeios das atenções às condições crônicas de saúde e nas avaliações de eficiências de gastos públicos. Mantem-se envolvido em linhas de pesquisa no Núcleo Interdisciplinar de Estudos e Pesquisas em Nefrologia (NIEPEN/ UFJF) em Avaliação de Custos e Tecnologias em Saúde. Sua experiência, portanto, reside na área de Custos e modelos de simulação de Monte Carlo, desenvolvendo também trabalhos com Análise Envoltória de Dados com o foco na avaliação do orçamento público da Atenção Básica de Saúde em municípios do Estado de Minas Gerais, Brasil.

\section{CHRISTIANE WENCK NOGUEIRA FERNANDES}

Possui Graduação em Matemática pela Universidade Federal de Santa Catarina (1999), Mestrado em Engenharia de Produção pela Universidade Federal de Santa Catarina (2002), Doutorado em Engenharia de Produção pela Universidade Federal de Santa Catarina(2010). Atualmente é Professora Adjunto IV do Departamento de Engenharias da Mobilidade da Universidade Federal de Santa Catarina. Tem experiência na área de Engenharia de Transportes, Pesquisa Operacional e Logística.

\section{CLEMILTON OLIVEIRA DE SOUSA}

Mestre em Engenharia de Produção pelo ITA (2017). Possui graduação em Licenciatura Plena pela Universidade do Sul de Santa Catarina (2010) e graduação em Engenharia Mecânica pela Universidade Estadual do Maranhão (2005). Tem experiência na área educação profissional com ênfase na área técnica atuando no SENAI-MA e IEMA-MA.

\section{CRISTIANO LUÍS TURBINO DE FRANÇA E SILVA}

Cursou o ensino médio técnico em Informática Industrial na Escola Técnica Federal de Ouro Preto (ETFOP) entre 1998 e 2000. Formou-se em Engenharia de Produção pela Universidade Federal de Ouro Preto (UFOP) em 2006. Concluiu o Mestrado em Ciência da Computação pela Universidade Federal de Ouro Preto (UFOP) em 2014. Atualmente é professor do departamento de Engenharia de Produção da Universidade Federal de Ouro Preto (UFOP). 


\section{DAIANE FERREIRA KOGISKI}

Graduanda em Engenharia de Produção pelo Instituto Federal de Educação, Ciência e Tecnologia de São Paulo (IFSP), Campus Registro. Técnica em Logística pela Escola Superior de Administração, Marketing e Comunicação de Campinas (ESAMC).

\section{DEBORAH DEAH CARNEIRO}

Professora Universitária dos cursos de Engenharia Civil e Elétrica nos Centros Universitários Estácio e Claretiano. Especialista em Engenharia de Produção e em Engenharia de Elétrica pela Universidade Cândido Mendes. Mestranda em Física pela Universidade Federal de Roraima (UFRR). Graduada em Engenharia Eletrônica pela Universidade Tecnológica Federal do Paraná,Campus Ponta Grossa . Graduação sanduiche na Anglia Ruskin University, em Cambridge- UK, Beng Electronics.

\section{DEBORAH PORTO CARDOSO}

Graduação em andamento em Engenharia de Produção

\section{DENES DE PAULA ALVES SOUSA}

Graduação em Engenharia de Produção pelo Centro Universitário Tocantinense Presidente Antônio Carlos (UNITPAC). Atualmente trabalha no ramo de turismo, empresa da família buscando meios de minimizar os gastos e melhor investimentos.

\section{DENISE CRISTINA DE OLIVEIRA NASCIMENTO}

Possui graduação em Administração de Empresas pela Universidade Federal Fluminense (2002), mestrado em Engenharia de Produção (2006) e Doutorado em Engenharia e Ciência dos Materiais (2009) pela Universidade Estadual do Norte Fluminense Darcy Ribeiro. Tem experiência na área de Engenharia de Produção e Administração, com ênfase em Processos de Trabalho, atuando principalmente nos seguintes temas: Planejamento e Controle da Produção, Gestão da Cadeia Produtiva, Introdução a Engenharia de Produção, Organização e Métodos, Planejamento Estratégico, Projeto de Produto, Administração Geral, liderança, Empreendedorismo e Sistemas de Informação Gerencial. Professora do Departamento de Administração da Universidade Federal Fluminense em Macaé/RJ.

\section{DENISE DANTAS MUNIZ}

Doutoranda em Ciência e Engenharia de Materiais na Universidade Federal da Paraíba UFPB. Mestre em Engenharia de Produção pela Universidade Federal da Paraíba - UFPB. Professora Emérita do curso de Especialização em Engenharia de Segurança do Trabalho da UNIPE

\section{DIONI FRAISOLI}

Graduação em Engenharia Ambiental e Sanitária.

\section{EDUARDO BRAGA COSTA SANTOS}

Doutorando em Ciência e Engenharia de Materiais pela Universidade Federal da Paraíba UFPB. Mestre em Ciência, Inovação e Modelagem em Materiais pela Universidade Estadual de Santa Cruz - UESC. Graduado em Engenharia: Habilitação em Produção e Sistemas pela Universidade Estadual de Santa Cruz - UESC. Professor Efetivo na Faculdade SENAI da Paraíba - Unidade João Pessoa - no CST em Automação Industrial nas disciplinas de Manutenção Industrial e Gestão e Controle da Qualidade. 


\section{EDUARDO MENDONÇA PINHEIRO}

Doutorando em Agroecologia pela Universidade Estadual do Maranhão (UEMA), Mestre em Agroecologia pela Universidade Estadual do Maranhão (UEMA, 2017). Especialista em Gestão Agroindustrial pela Universidade Federal de Lavras-MG (UFLA, 2006), Especialista em Engenharia de Produção pelo Centro Universitário Internacional (UNINTER, 2017). Graduado em Agronomia pela Universidade Estadual do Maranhão (UEMA, 2004), Licenciatura Plena pela Universidade do Sul de Santa Catarina (UNISUL, 2008). Mestrado em Engenharia pelo Instituto Tecnológico de Aeronáutica (ITA, interrompido em 2014). Coordenador Municipal de Inspeção Sanitária de Produtos de Origem Vegetal pela Secretaria Municipal de Agricultura, Pesca e Abastecimento de São Luís-MA (SEMAPA). Professor substituto dos cursos de Engenharia de Produção e Agronomia na Universidade Estadual do Maranhão. Professor dos cursos de Engenharia pela Faculdade Pitágoras/FAMA. Professor Conteudista e Pesquisador do Curso de Tecnologia de Alimentos pela UEMANET. Consultor pelo Programa Alimentos Seguros (PAS) pelo SENAI-MA.

\section{ELON VIEIRA LIMA}

Graduado em Engenharia Química pela Universidade Federal do Pará (2003). Possui mestrado em Engenharia Química pela Universidade Federal do Pará (2006). Possui experiência no magistério superior para cursos de Engenharia e na gestão de ensino como coordenador de cursos de Engenharia de Produção e Engenharia de Petróleo. Desenvolveu pesquisas na área de Corrosão, Gestão da Qualidade, Gestão de Projetos e Sustentabilidade. Atualmente, atua como professor na Faculdade Pitágoras nos cursos de Administração, Engenharia Ambiental e Engenharia Química.

\section{ELYELTON CESAR DE SOUZA LIMA}

Graduando em Engenharia de Transportes e Logística pela Universidade Federal de Santa Catarina. Trabalhou como estagiário na Associação dos Municípios do Nordeste de Santa Catarina em Joinville - SC, atuando na condução metodológica de elaboração de Planos de Mobilidade Urbana de oito municípios do nordeste catarinense. Tem experiência na área operacional de logística/ transportes, tendo prestado serviços à empresa JadLog - Grupo NBL. Atualmente é estagiário de Logística Corporativa e Transportes na Tigre S/A. Possui interesse na área de Engenharia de Transportes, Pesquisa Operacional, Otimização e Logística.

\section{ERNANI JOSÉ FORTUNATO LISBÔA ENKE}

Administrador do Instituto Federal de Educação, Ciência e Tecnologia de São Paulo (IFSP), Campus Registro. Mestre em Administração Universitária pela Universidade Federal de Santa Catarina (UFSC). Especialista em Comércio Exterior e Gestão Portuária pela Universidade Federal do Rio Grande (FURG). Bacharel em Administração pela Universidade Federal do Rio Grande (FURG).

\section{FABIANA NUNES CABRAL MONTEIRO}

Possui graduação em Sistemas de Informação e Pós-Graduação em Análise e Gestão de Sistemas de Informação pelo Instituto Federal Fluminense. Mestranda do programa de mestrado profissional em Pesquisa Operacional e Inteligência Computacional, atuando principalmente nos seguintes temas: mineração de dados, evasão, planejamento estratégico, matriz SWOT, gestão estratégica, marketing digital e redes sociais. 


\section{FÁBIO MORAIS BORGES}

Professor adjunto do Departamento de Engenharia de Produção. Graduado em Engenharia de Produção Mecânica, com mestrado e doutorado em Engenharia de Produção. Engenheiro de Segurança do Trabalho. Experiência em Projeto Ergonômico de postos de Trabalho na Refinaria Presidente Bernardes de Cubatão (RPBC). Membro do grupo de pesquisa: Laboratório de Projeto do Trabalho, Ergonomia e de Unidades Produtivas - Ergo\&Ação SIMUCAD - UFSCar de 2008 a 2011. Coordenador do Laboratório de Desenvolvimento de Produtos e Inovação (LADEPI) de 2014 a 2017.

\section{FERNANDO CERUTTI AGUIAR}

Especialização em Pós Graduação em Administração Pública pela Universidade Candido Mendes, Brasil(2015). Diretor Administrativo do Instituto Federal Fluminense, Brasil.

\section{GEÓRGIA REGINA RODRIGUES GOMES}

Possui graduação em Licenciatura em Ciências com habilitação em Matemática pela Faculdade de Filosofia de Itaperuna (1989), Análise de Sistemas pela PUC-Rio (1991), mestrado em Informática pela Pontifícia Universidade Católica do Rio de Janeiro (1999) e doutorado em Informática pela Pontifícia Universidade Católica do Rio de Janeiro(2006). Atuou como Analista de Sistemas de 1992 a 2003 na PUC-Rio, trabalhando em desenvolvimento e na manutenção de sistemas de informação corporativos e como coordenadora de desenvolvimento de sistemas. Atua no magistério desde 2000 e no superior desde 2006. Trabalhou como professora Adjunta da Universidade Candido Mendes e como Professora/Diretora de Ensino do IFF-Itaperuna. Atualmente é vice_diretora e professora adjunta da Universidade Federal Fluminense/INFES e professora colaboradora do mestrado da Universidade Candido Mendes. Tem experiência na área de Ciência da Computação, com ênfase em Sistemas de Computação, atuando principalmente nos seguintes temas: Mineração de Dados, Mineração de Texto, Integração de Banco de Dados, Bibliotecas Digitais, Metadados, Recuperação da Informação, Educação a Distância, Sistemas de Informação.

\section{HELTON CRISTIANO GOMES}

Possui graduação em Engenharia de Produção pela Universidade Federal de Ouro Preto UFOP (2005), mestrado em Engenharia de Produção pela Universidade Federal de Minas Gerais - UFMG (2008) e doutorado em Engenharia Civil pela UFOP (2013). Atualmente é Professor Adjunto, nível III, do Departamento de Engenharia de Produção, Administração e Economia da Universidade Federal de Ouro Preto. Tem experiência na área de Engenharia de Produção, com ênfase em Programação Linear, Programação Inteira e Inteira Mista, Otimização Combinatória, Inteligência Computacional, Otimização Multiobjetivo e Planejamento e Programação da Produção.

\section{HERBETH SANDRO MALHEIROS BEZERRA}

Graduado em analise e desenvolvimento de sistemas (UNICEUMA), MBA em Gerenciamento de projetos (ISAN FGV), Pós-graduação em redes Lan e Wan (SENAI / UEMA). Professor do Senai - MA no período de 2012 - 2016 - na área de Tecnologia da informação e redes de computadores. Professor do curso de Tecnologia em Redes de computadores (Pitágoras KROTON - MA). Gestor de STI - Serviço de Tecnologia e Inovação (SENAI - MA) 2014 2016. Superintendente de redes e recursos tecnológicos (SEMIT - Prefeitura de São Luís MA) 2012 - 2014. Coordenador de redes e infraestrutura (EBSERH - DF) - 2017. Atualmente, Coordenador de sistemas de gestão e regulação (SEMUS - Prefeitura de São Luís) . Com grande experiência em gestão de equipes, projetos, elaboração de termos de referência, NOC e SOC, prospecção de clientes e com carteira de clientes consolidada, além de habilidade em negociações. 


\section{IGOR FONSECA DA ROCHA}

Graduando em Engenharia de Produção pelo Instituto Federal de Educação, Ciência e Tecnologia de São Paulo (IFSP), Campus Registro.

\section{ISABELA BRUNA DE TAVARES MACHADO BOLONHESI}

Doutoranda em Engenharia Civil e mestre em Engenharia de Edificações e Saneamento pela Universidade Estadual de Londrina. Formada em Engenharia Ambiental pela Universidade Tecnológica Federal do Paraná. Pós-graduada em Engenharia de Segurança do Trabalho. Atualmente é professora do Magistério Superior do curso de Engenharia Ambiental na Universidade Tecnológica Federal do Paraná (UTFPR) e do curso de Engenharia Civil do Instituto Filadélfia de Londrina (UNIFIL). Tem experiência na área de Engenharia Ambiental, com ênfase em Engenharia Sanitária e Gestão Ambiental, atuando principalmente nos seguintes temas: saneamento, recursos hídricos, tratamento de águas e águas residuárias, gestão de resíduos industriais.

\section{ISABELA MUCKENBERGER SADDI}

Engenheira de produção desde 2017. Negociadora na empresa BRF

\section{ISIS JULIANE ARANTES GRANJA}

Química, responsável técnica pelo Grupo 3Á no Estado de Goiás, indústria de saneantes, Mestre em Engenharia de Produção e Doutoranda em Psicologia, atua diretamente no processo produtivo e na garantia da qualidade.

\section{JANE LUCHTENBERG VIEIRA}

Possui graduação em Engenharia Civil pela Fundação Armando Álvares Penteado (1986) e Mestrado em Habitação: Planejamento, Gestão e Projeto no IPT ? Instituto de Pesquisas Tecnológicas (2005). Atualmente é docente de ensino superior nos cursos de engenharia da Universidade Anhembi Morumbi, nas disciplinas de Desenho Técnico e Expressão Gráfica de Projetos, e também atua como Coordenadora Adjunta do Curso de Engenharia de Produção. Tem experiência na área técnica, em projetos e construção de residências, e na área administrativa empresarial.

\section{JHONY CARLOS LUCENA CARDOSO}

Graduação em Engenharia de Produção pelo Centro Universitário Tocantinense Presidente Antônio Carlos (UNITPAC). Já atuou como Analista de Estoque em uma empresa de peças automotivas na cidade de Araguaína-TO. Atualmente trabalha no ramo de energia solar.

\section{JOELE DOS SANTOS MARQUES}

Possui graduação em Engenharia de Produção pela Universidade Federal da Paraíba (2017), Pós graduação em Logística e Supply Chain pelo Centro Universitário de João Pessoa (2019), e curso técnico em Segurança do Trabalho pela Fundação de Apoio ao IFPB (2009). Possui experiência na área de segurança do trabalho e logística, e atualmente atua como analista de PCP na Elizabeth Porcelanato Ltda. Interessa-se por Segurança do Trabalho, Logística, PCP e Custos. 


\section{JULIANA MACHION GONÇALVES}

Professora Adjunta do Departamento de Engenharia de Produção da Universidade Federal da Paraíba na área de Engenharia do Trabalho (ergonomia, segurança do trabalho, análise e projeto do trabalho). Graduada em Fisioterapia pela Pontifícia Universidade Católica de Campinas (2001). Especialista em Ergonomia pela Universidade Federal de Minas Gerais (2007). Mestre em Engenharia de Produção pela Universidade Federal de São Carlos (2010). Doutora em Engenharia de Produção pela Universidade Federal de São Carlos (2014). Membro do grupo de pesquisa: Laboratório de Projeto do Trabalho, Ergonomia e de Unidades Produtivas - Ergo\&Ação - SIMUCAD - UFSCar de 2008 a 2010. Foco em ensino, pesquisa e extensão dentro do curso de Engenharia de Produção, atuando principalmente nos seguintes temas: Ergonomia e Saúde do trabalhador, Saúde e Trabalho, Segurança do trabalho, Ergonomia, Análise e Projeto do Trabalho.

\section{JULIANA PARDINHO DOS SANTOS}

Engenheira de Produção

\section{KAUÊ JUCÁ JARDIM DE OLIVEIRA}

Graduação em Engenharia de Produção

\section{LARISSA CARVALHO FERREIRA REVERTE}

Graduanda em Engenharia de Produção pelo Instituto Federal de Educação, Ciência e Tecnologia de São Paulo (IFSP), Campus Registro.

\section{LUCIANO AZEVEDO DE SOUZA}

Mestrando em Sistemas de Gestão (UFF-Universidade Federal Fluminense), Especialista em Gestão de Projetos (MBA- Universidade Federal de Juiz de Fora - UFJF - 2015), Engenheiro de Segurança do Trabalho (UFJF-2012) e Engenheiro de Produção (Universidade Salgado de Oliveira-2010). Atua desde 2015 em gerenciamento de projetos públicos no Ministério da Saúde. Possui ampla vivência na indústria automobilística, onde atuou por 18 anos em planejamento de processos, manufatura enxuta, sistemas de gestão (qualidade, meio ambiente e saúde e segurança Ocupacional) e gerenciamento de projetos.

\section{LUÍS HENRIQUE RODRIGUES}

Doutor em Engenharia Mecânica pela UNICAMP na área de Engenharia de Manufatura e Materiais. Mestre em Engenharia Mecânica pela UNICAMP na área de Engenharia de Manufatura e Materiais. Especialista em Administração Industrial pela USP. Graduado em Engenharia Mecânica pelo Centro Universitário da FEl. Há 32 anos atua como professor em Instituições de Ensino Superior, gerente de manufatura e consultor em empresas de vários segmentos. Coordenador de curso na Universidade Anhembi Morumbi. Atualmente é sócio/consultor da Leancell Consultoria em Processos de Manufatura e Serviços, professor da Universidade Anhembi Morumbi e pesquisador no Núcleo de Estudos em Produção Mais Limpa (NEPmaisL). Professor da FEI e FMU.Tem experiência na área de Engenharia de Produção, com ênfase em Planejamento, Projeto e Controle de Sistemas de Produção, implantação de sistema Lean Manufacturing, atuando principalmente nos seguintes projetos: ganho de produtividade, melhoria contínua (kaizen), cadeia de suprimentos. Atuação há mais de 26 anos em projetos de melhorias em empresas dos segmentos têxtil, automobilístico, autopeças, metal mecânica e linha branca. 


\section{LUISA MAFRA DE OLIVEIRA}

Graduanda em engenharia de transportes e logística pela universidade federal de Santa Catarina. Atualmente realiza projeto de pesquisa na área de indicadores de desempenho logístico. Tem interesse na área de engenharia de transportes, logística e gerenciamento de projetos.

\section{LUIZ FELIPE COUGO}

Mestre em Gestão Ambiental, pós-graduado em Gestão da Qualidade SIX SIGMA, Farmacêutico e Bioquímico industrial, Professor de mais de quinze disciplinas de Gestão de QSMS (Qualidade, Segurança, Meio Ambiente e Saúde) para pós-graduação e MBAs, Gestor de Sistemas de QSMSRS, Auditor Líder nos Sistemas Integrados de Gestão (ISO 9001:2008, ISO 14001:2004, OHSAS 18001:2007). Responsável por implantação e manutenção de sistemas integrados de gestão em diversas organizações com obtenção de certificação. Amplo conhecimento em sistemas de gestão, Ferramentas de qualidade, leis e normas. Realizou Atuação como Coordenador de Meio Ambiente - Consórcio Conenge-SC/Elco para PETROBRAS; Atuação na Coordenação do Meio Ambiente e no departamento de QSMS(Qualidade, Segurança, Meio Ambiente e Saúde) - Elco Engenharia de Montagens Ltda; Atuação como supervisor de Garantia da qualidade para empresa de produtos médicos. Atua como Docente no Grupo Educacional UNINTER em todo o território nacional e na Universidade TUIUTI do Paraná. Atua como profissional Analista Sênior de Qualidade na Metso Paper South America.

\section{MARCELLA RENATA SILVA ARAÚJO DE SALES}

Especialista lato sensu em Engenharia de Segurança do Trabalho pelo Centro Universitário de João Pessoa - UNIPÊ.

\section{MÁRCIO ISCOLD DUTRA}

Economista pela Universidade Federal de Juiz de Fora (UFJF), especialista em Gestão da Produção Industrial pela UFJF, MBA em Gestão Empresarial pela Fundação Getúlio Vargas e pós-graduado em Organizações e Métodos pela Universidade Federal Fluminense (UFF). Mestrado em Sistemas de Gestão pela faculdade de Engenharia de Produção da UFF. Professor de graduação e pós-graduação na área de gestão desde 2009. Professor conteudista e tutor de disciplinas semi-presenciais. Atuante na produção e publicação científica em congressos e periódicos nacionais. Orientador de trabalhos de conclusão de curso na graduação e pós-graduação. Gerente operacional na antiga Siderúrgica Mendes Júnior, hoje ArcelorMittal, participando ativamente na condução de projetos de normatização em sistemas de gestão da qualidade - SGQ (certificação: ISO série 9000, OSHAS 18001, BS8800, ISO14000, SA8000). Gerente geral na empresa GEMACON, no ramo de alimentação, conduzindo a ampliação da planta de insumos para a indústria de laticínios e na construção de uma planta para produção de amido modificado. Gerente administrativo em projetos na Companhia Siderúrgica Nacional (CSN), MRS Logística e Votorantim Metais.

\section{MARCOS VINÍCIUS DE FREITAS SANTOS}

Graduando em Engenharia de Produção pelo Instituto Federal de Educação, Ciência e Tecnologia de São Paulo (IFSP), Campus Registro. Técnico em Mecatrônica pelo Instituto Federal de Educação, Ciência e Tecnologia de São Paulo (IFSP), Campus Registro.

\section{MARIANA MATOS ARANTES}

Graduação em Arquitetura e Urbanismo pela Universidade Federal do Tocantins. Especialista em docência universitária pelo Centro Universitário Tocantinense Presidente Antônio Carlos (UNITPAC). Atualmente leciona no (UNITPAC) 


\section{MICHELE BEZERRA SAITO}

Mestre em Engenharia de Produção pela Universidade Federal de Pernambuco (UFPE), Especialista em Gestão da Produção pela Universidade Federal de Pernambuco (UFPE), Graduada em Ciências Econômicas pela Universidade Federal da Paraíba (UFPB). Professora Assistente da Universidade de Pernambuco (UPE) e do MBA de Gestão da Produção da FCAP - UPE. Sócia-majoritária da M\&S Consultoria Empresarial.

\section{MICHELE MARIA DE OLIVEIRA}

Graduação em Engenharia Ambiental

\section{PABLO COSTA}

Estudante do curso de Engenharia de Produção (Conclusão em 2018).

\section{PRISCILA DE OLIVEIRA SERAFINI}

graduada em Engenharia Civil pelo Centro Universitário Estácio da Amazônia (2014-2018). Interessa-se pela área de gestão de projetos. Têm nível de inglês intermediário.

\section{RAFAELA FRANCISCA MOREIRA BARBOSA}

Engenheira de Produção, Graduada na área pela Universidade da Amazônia (UNAMA). Atuou como estagiária na Natura - Indústria e Comércio de Cosméticos LTDA, na área de Gestão de Projetos do NINA (Núcleo Integrado Natura Amazônia) coordenado pela Diretoria de Inovação. Atuou como estagiária na NexGlobal - Consultoría en Proyectos de Inversión, no setor de desenvolvimento de projetos do INADEM (Instituto Nacional del Empreendedor). Possui experiência no processo de extração de óleos essenciais e fixos em plantas piloto e no gerenciamento de resíduos provenientes dessas cadeias e atuou como auxiliar no desenvolvimento de microempresas, realizando planos financeiros, executivos e treinamentos.

\section{RAPHANY CORDEIRO HAHN}

Graduanda em Engenharia de Produção pelo Instituto Federal de Educação, Ciência e Tecnologia de São Paulo (IFSP), Campus Registro. Técnica em Mecatrônica pelo Instituto Federal de Educação, Ciência e Tecnologia de São Paulo (IFSP), Campus Registro.

\section{RENATA DANTAS MUNIZ DE QUEIROZ}

Especialista em Saúde Pública pela Universidade Estadual Vale do Acaraú - UVA. Licenciada em Ciências Biológicas pela Universidade Estadual Vale do Acaraú - UVA

\section{ROGÉRIO FRANCISCO DE OLIVEIRA}

Engenheiro de produção desde 2017. Empresário do comércio de peças para máquinas e equipamentos (vedações). Consultor na área de manutenção desde 1994

\section{RUAN CARLOS CORRÊA MENDES}

Graduação em Engenharia Mecânica - UEMA (2007); MBA em Gerenciamento de Projetos FGV (2010), Graduado em Licenciatura Plena pelo Programa Especial de Formação Pedagógica para Formadores da Educação Profissional - UNISUL (2010). Pós - Graduado em Metodologia do Ensino na Educação Superior - UNINTER (2016). O Mestrando em Engenharia de Produção pelo ITA foi interrompido em 2017. Atualmente esta Cursando a PósGraduação Lato Sensu em Engenharia de Segurança do Trabalho na Universidade Estadual 
do Maranhão. Foi Professor Substituto da Universidade Estadual do Maranhão nos cursos de Engenharia de Pesca e Engenharia de Produção. Foi Instrutor de Aprendizagem Industrial pelo SENAI-MA na Área de Metal Mecânica e Consultor Serviços Tecnológicos e de Inovação entre os anos de 2007 à 2018.

\section{RUAN CARLOS SILVA MENZES OINHEIRO}

Atualmente é bolsista de iniciação científica da Universidade Federal de Ouro Preto. Tem experiência na área de Engenharia de Produção, com ênfase em Pesquisa Operacional.

\section{RUDSON LOURIVAL OLIVEIRA DA SILVA}

graduando em Engenharia Civil pelo Centro Universitário Estácio da Amazônia (2015-2020). Tem inglês como segunda língua.

\section{RUY GOMES DA SILVA}

Possui 15 anos de experiência na área industrial em empresa do ramo de mineração. Graduado em Engenharia de Produção pelo Centro Universitário do Estado do Pará (2011). Mestrado em Engenharia de Produção e Sistemas pela PUCPR (2014). Pesquisador integrante do grupo de pesquisa em Gestão Estratégica de Decisões pela PUCPR. Professor responsável pelo grupo de iniciação cientifica da Faculdade FACEAR_polo Sítio Cercado_Curitiba em 2015/2016. Atuou como professor universitário seguintes centros de ensino superior: ENSITEC; POSITIVO e FACEAR, ambos em Curitiba-PR, no período de 2012 à 2016 e no CESUPA (02/2016 à 12/2017. Atualmente professor na FAMAZ (BELÉM-PA), nos curso de Engenharia de Produção e Eng, Civil, Tem experiência na área de Engenharia de Produção, atuando principalmente nos seguintes temas: alumina, tomada de decisão, redes neurais artificiais, análise hierárquica de processo e multicritério. Interesse nas seguintes áreas do conhecimento: Apoio Multicritério à Decisão (AMD), Métodos Matemáticos para estoque de baixo giro, Planejamento e Controle da Produção, Formulação Matemática, Simulação, Métodos estatísticos, Pesquisa Operacional e desenhos informatizado em Autocad e Solid Works.

\section{SILVIA LOPES DE SENA TAGLIALENHA}

Professora da Universidade Federal de Santa Catarina, Centro Tecnológico de Joinville. Possui Licenciatura em Matemática, com habilitação em Física - UNESP - Faculdade de Ciências e Tecnologia - Júlio de Mesquita Filho, Mestrado em Matemática Pura (Análise) ICMC-USP Universidade de São Paulo - São Carlos e Doutorado em Engenharia Elétrica (Automação) - UNESP - Faculdade de Engenharia de Ilha Solteira. Atua principalmente nos seguintes temas: programação linear inteira, problemas de transporte e logística, meta heurísticas e planejamento da expansão de sistemas de transmissão de energia elétrica.

\section{STEFANIE BRABO DANTAS}

Graduação em andamento em Engenharia de Produção

\section{THALES BOTELHO DE SOUSA}

Professor de Ensino Básico, Técnico e Tecnológico do Instituto Federal de Educação, Ciência e Tecnologia de São Paulo (IFSP), Campus Registro. Doutorando em Engenharia de Produção pela Escola de Engenharia de São Carlos, Universidade de São Paulo (EESC-USP). Mestre em Engenharia de Produção pela Escola de Engenharia de São Carlos, Universidade de São Paulo (EESC-USP). Bacharel em Engenharia de Produção pelo Centro Universitário Eurípides de Marília (UNIVEM). 


\section{THAYANE NASCIMENTO DE AZEVEDO}

Graduanda em Engenharia de Produção

\section{THAYS APARECIDA VENDRAMIN DELECRODIO}

Graduada em Engenharia de Produção pela Universidade Anhembi Morumbi (2016), atualmente cursa especialização lato sensu em Docência do Ensino Superior no Centro de Pós-graduação do Complexo Educacional FMU com conclusão para 2019. Possui artigos publicados em Congressos de Engenharia de Produção, tendo maior interesse em linhas de pesquisa sobre a Educação na Engenharia de Produção.

\section{WEIDY LUANA ROCHA GERVAZ}

Graduanda em Engenharia de Produção pelo Instituto Federal de Educação, Ciência e Tecnologia de São Paulo (IFSP), Campus Registro.

\section{WILLIAN VICTOR SILVA BORBA CORDEIRO}

Graduando em Engenharia de Produção pelo Instituto Federal de Educação, Ciência e Tecnologia de São Paulo (IFSP), Campus Registro. Técnico em Administração pelo Centro Estadual de Educação Tecnológica Paula Souza (CEETEPS), Campus Registro. 


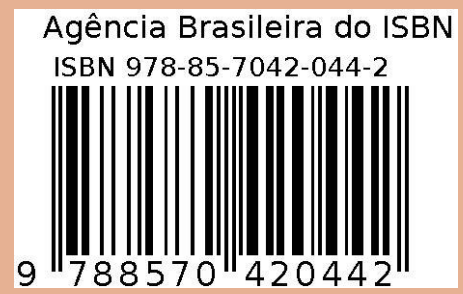

